DEVELOPMENT AND EVALUATION OF A WORKPIECE TEMPERATURE ANALYZER (WPTA) FOR INDUSTRIAL FURNACES

Phase 1

October 1991

Work Performed Under Contract No. FC07-89ID12874

For

U.S. Department of Energy Office of Industrial Technologies Washington, D.C.

By Acurex Corporation Mountain View, California 


\section{DISCLAIMER}

Thro report was prepared as an account of work sponsored by an agency of the Linted States Goversment Veither the Lnited States Government nor ans agency thereot. nor ans of their emplovecs. makes ant warram. express or mpled or ascumes ans legal liability or respomsinility for the accuracy completeness, or usefulness of any information, apparatus. product, or proces disciosed. or represents that its use would not infringe privatels owned rights. Reference herein to any sperific commercial product process, or service by trade name. trademark. manufacturer or otherwise does not necessarily constitute or imply its endorsement. Fecommendaton. or favoring

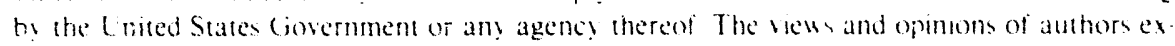
pressed herem do no! necessarily state or reflect those of the Lnted States Government or ans agenc: thereot

This report has been reproduced directly from the best available cony.

Available to DOE and DOE contractors from the ("ice of Scientific and Technical Information. P.O. Box 62. Oak Ridge. TN 37831 : prices available from $16 ! 51576.8401$. FTS 626-8401.

Avalable to the public from the National Technical Information Service. L. S. Department of Commerce. 5285 Port Royal Rd.. Springfield. VA 22161. 


\title{
DEVELOPMENT AND EVALUATION OF A WORKPIECE TEMPERATURE ANALYZER (WPTA) FOR INDUSTRIAL FURNACES (PHASE 1)
}

Final Report

October 1991

Work Performed Under Contract DE-FCO7-89ID12874

Final Report FR-91-104/ESD

\section{Prepared for}

U. S. Department of Energy

Idaho Operations Office, Idaho Falls, ID

Sponsored by the Office of the Assistant Secretary

for Conservation and Renewable Energy

office of Industrial Technologies

Washington D.C.

\author{
Prepared by \\ Acurex Corportion \\ Environmental Systems Division \\ 555 Clyde Avenue \\ P.0. Box 7044 \\ Mountain View, California 94039
}




\section{EXECUTIVE SUMMARY}

This project is directed toward the research, development, and evaluation of a viable commercial product-a workpiece temperature measurement analyzer (WPTA) for fired furnaces based on unique radiation properties of surfaces. This WPTA will provide for more uniform, higher quality products and reduce product rejects as well as permit the optimum use of energy. The WPTA may also be utilized in control system applications including metal heat treating, forging furnaces, and ceramic firing furnaces. A large market also exists in the chemical process and refining industry. WPTA applications include the verification of product temperature/time cycles, and use as a front-end sensor for automatic feedback control systems.

This project is a cooperative agreement between the U.S. Department of Energy (DOE) and the contract members: Acurex Corporation, Environmental Systems Division, the prime contractor; and Pyrometer Instrument Company (PIC) and Ogiso, the subcontractors. Acurex has overall responsibility for the WPTA system product development, and primary responsibility for the application evaluation, the field testing of the Pyrolaser ${ }^{\mathrm{TM}}$, and the conceptual development of the Raman Spectroscopy WPTA. PIC provides expertise in non-contact temperature measurement techniques, instrument development expertise, and equipment for state-of-the-art measurement evaluation. Ogiso provides expertise in laser physics applications research, particularly in Raman Spectroscopy.

This report summarizes the work performed in Phase I of this three-phase project. The work in Phase I included the application evaluation; the evaluation of present technologies and limitations; and the development of a preliminary conceptual WPTA design, including identification of technical and economic benefits. Jpon successful completion of the development of the WPTA, 
commercialization will be carried out by PIC, which will market, manufacture/assemble, distribute, and service the WPTAs.

The application evaluation confirmed that a large market exists for high-accuracy, hightemperature remote instrumentation. It identified the following industries as having the most promising applications for immediate benefit from the technology: petroleum refining and petrochemical production, metal heat treating, flat glass annealing and heat treatment; and the manufacture of brick, clay tile, and vitreous plumbing fixtures. Metal heat treatment was selected for initial field evaluation because of its immediate need and intcrest in a WPTA.

Most temperature measurement devices today measure the environmental temperatidre rather than the actual product temperature, with the exception of surface-mounted thermocouples and a relatively new instrument, the Pyrolaser, from PIC. The Pyrolaser is unique in that it direcily measures the surface emissivity as well as radiation of the surface, at the same time, at a selecied spot on the surface of a workpiece or part at elevated temperature. Typical pyrometers can only be used as reference instruments and do not provide absolute measurements. Thermocouples and RTDs must be attached to the workpiece in order to measure workpiece temperature, which is often prohibitively time-consuming, expensive, or damaging to the workpiece. Acoustic pyrometry, another relatively new technology, provides accurate, detailed, and instantaneous data on gas temperature distribution, but requires thermal modeling to calculate actual workpiece temperature.

Recommendations based on the findings of this report include near-term enhancement of the capabilities of the Pyrolaser, and long-term development of an instrument based on Raman Spectroscopy. Nevelopment of the Pyrofiber, a fiberoptics version of the Pyrolaser, will be a key to solving present problems involving specularity, measurement angle, and costs of multipoint measurement. Extending the instrument's measurement range to include temperatures below $600^{\circ} \mathrm{C}$ will make the product useful for a wider range of applications.

The development of Raman Spectroscopy would result in an instrument that could easily be adapted to incorporate a wealth of additional nondestructive analytical capabilities, including 
stress/strain indication, crystallography, species concentrations, corrosion studies, and catalysis studies, in addition to temperature measurement.

The Pyrolaser presently being marketed sells for approximately $\$ 20,000$. The instrument contains some expensive optics that make it difficult to reduce the costs. The proposed enhancements incorporating fiberoptics and multipoint measurement capability will eliminate the optics in large part, and, therefore, provide an opportunity for lower costs/measurement point, i.e., the Pyrofiber system is expected to sell for approximately the same price, but will have much greater capabilitics of great interest to the user, particularly in temperature control applications of furnaces. The instrument will be able to characterize the entire time/temperature history of parts in continuous furnaces. This information can then be used for feed-forward and feedback temperature cuntrol, making closer control of the furnace, and, hence, higher quality products possible. The Pyrolaser comparison tests reflected in this report show accuracies of $\pm 12^{\circ} \mathrm{F}$ when compared to thermucouples on the surface of the product. This is a very good result considering that the furnace ports presented viewing difficulties, and that it was difficult to adjust the Pyrolaser to part distance accurately. Under more controlled industrial conditions, greater accuracies would be expected. Permanent Pyrofiber installations, once calibrated, would also be expected to yield greater accuracies.

The Raman Spectroscopy instrument was estimated to sell for approximately $\$ 30,000$ in small quantities. Although the laboratory components for the test system would be far more expensive, they have not been optimized for use in an industrial instrument and have many features that would not be required. Very significant cost reductions are expected for an industrial system as a result.

The above cost projections were used in the economic analysis performed that showed systems at these costs would yield high returns on capital when installed. 
EXECUTIVE SUMMARY $\ldots \ldots \ldots \ldots \ldots \ldots \ldots \ldots \ldots \ldots \ldots \ldots \ldots \ldots \ldots$

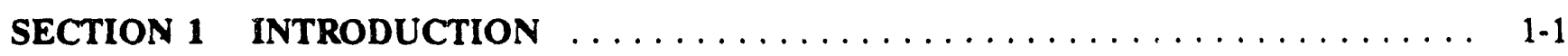

SECTION 2 APPLICATION SELECTION $\ldots \ldots \ldots \ldots \ldots \ldots \ldots \ldots \ldots \ldots \ldots \ldots$

2.1 MARKET ASSESSMENT AND EVALUATION OF

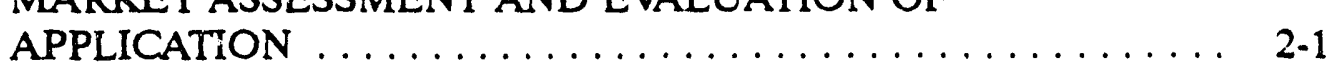

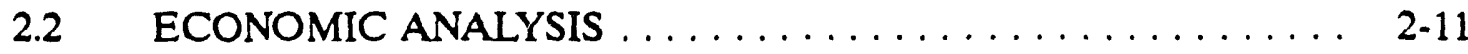

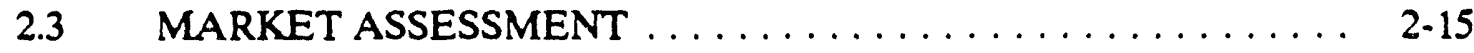

2.4 EXPECTED END PRODUCT AND

SECTION $3 \quad$ TEST SITE SELECTION $\ldots \ldots \ldots \ldots \ldots \ldots \ldots \ldots \ldots \ldots \ldots \ldots \ldots$

3.1 TEST SITE AGREEMENTS . . . . . . . . . . . $3-1$

3.2 PRECISION SPECIALTY METALS (PSM), LOS

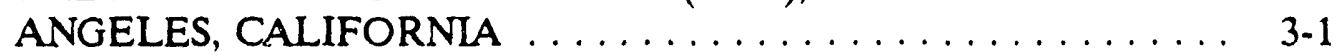

3.3 PINOLE STEEL-TREATING FURNACE, PINOLE,

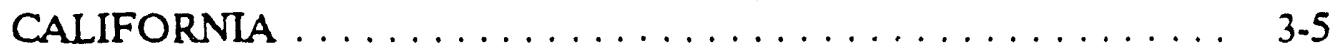

3.4 TELEDYNE WAH CHANG, ALBANY, OREGON . . . . . . . 3.5

3.5 SUMMARY-METALLURGICAL FURNACES $\ldots \ldots \ldots \ldots \ldots 3-7$

SECTION 4 PRESENT TECHNOLOGY ASSESSMENT $\ldots \ldots \ldots \ldots \ldots \ldots \ldots \ldots$

4.1 OVERVIEW $\ldots \ldots \ldots \ldots \ldots \ldots \ldots \ldots \ldots \ldots \ldots \ldots$ 4-1

4.2 COMPARISON OF RAMAN THERMOMETRY AND

PYROLASER PYROMETRY $\ldots \ldots \ldots \ldots \ldots \ldots \ldots \ldots . \ldots . \ldots$

4.2.1 Comparison of Operating Principles . . . . . . . . . . . . . . 4-4

4.2.2 Comparison of Capabilities and Limitations . . . . . . . . . . . . . 4. 4

4.2.3 Comparison of Applicability to Non-Thermometric

Measurements . . . . . . . . . . . . . . . . . . . . . . . . . 4-9

4.2.4 Measurement Regimes for Each Instrument . . . . . . . . . . . . 4-10

4.3 MARKET FOR APPLICATION OF PYROLASER OR

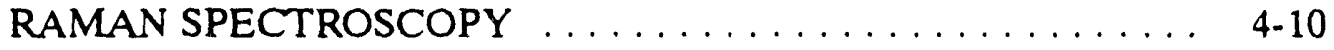

4.4 ADVANCED MEASUREMENT CAPABILITIES OF

RAMAN SPECTROSCOPY $\ldots \ldots \ldots \ldots \ldots \ldots \ldots \ldots \ldots$ 4-11

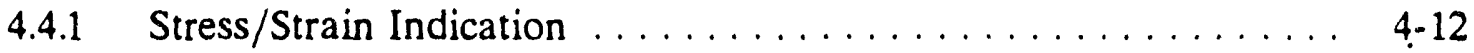

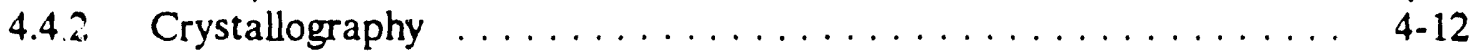

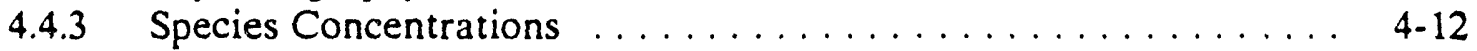

4.4 .4 Corrosion Studies . . . . . . . . . . . . . . . . . . . 4-13

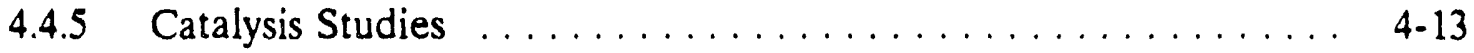

4.5 POTENTIAL PYROLASER ENHANCEMENTS . . . . . . . 4-14 
TABLE OF CONTENTS (concluded)

SECTION 5 PYROLASER-PYROFIBER INDUSTRIAL TESTS $\ldots \ldots \ldots \ldots \ldots \ldots$

$5.1 \quad$ INTRODUCTION $\ldots \ldots \ldots \ldots \ldots \ldots \ldots \ldots \ldots \ldots \ldots \ldots$

5.2 PYROLASER TESTS AT PRECISION SPECLALTY

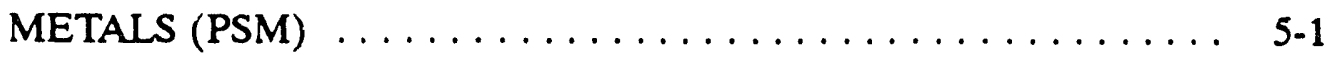

5.2.1 Furnace Details $\ldots \ldots \ldots \ldots \ldots \ldots \ldots \ldots \ldots \ldots \ldots \ldots \ldots$

5.2 .2 Test Measurements $\ldots \ldots \ldots \ldots \ldots \ldots \ldots \ldots \ldots \ldots \ldots \ldots \ldots$

5.2 .3 Discussion of Test Measurements $\ldots \ldots \ldots \ldots \ldots \ldots$

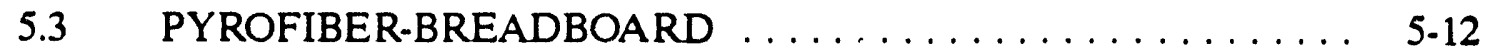

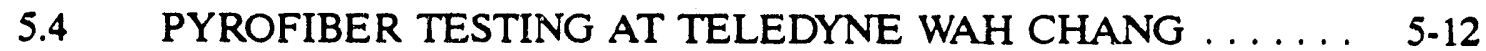

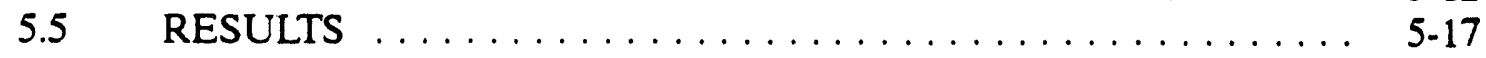

SECTION 6 RAMAN SPECTROSCOPY-FEASIBILITY $\ldots \ldots \ldots \ldots \ldots \ldots \ldots \ldots$

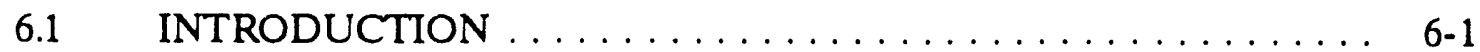

6.2 LITERATURE REVIEW $\ldots \ldots \ldots \ldots \ldots \ldots \ldots \ldots \ldots \ldots \ldots$

6.2.1 Carbon Monoxide Spectrum in a Flame . . . . . . . . . . . . . 6.3

6.2 .2 Temperature Profiles in a Sealed Lamp . . . . . . . . . . . . . . . . $6-4$

6.2.3 Temperature Measurements in Operating Diesel Engine . . . . . . . . 6-4

6.2 .4 Conclusion $\ldots \ldots \ldots \ldots \ldots \ldots \ldots \ldots \ldots \ldots \ldots \ldots \ldots$

6.3 LABORATORY-SCALE RAMAN WPTA SYSTEM . . . . . . . $6-6$

6.3 .1 Introduction $\ldots \ldots \ldots \ldots \ldots \ldots \ldots \ldots \ldots \ldots$

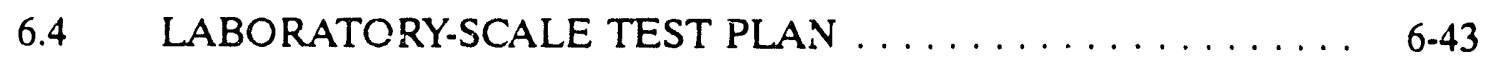

6.4 .1 Introduction $\ldots \ldots \ldots \ldots \ldots \ldots \ldots \ldots \ldots \ldots \ldots \ldots$

SECTION 7 RECOMMENDED LABORATORY-SCALE TESTS AND SENSOR

DEVELOPMENT-PHASE II $\ldots \ldots \ldots \ldots \ldots \ldots \ldots \ldots \ldots \ldots \ldots \ldots$

7.1 INTRODUCTION $\ldots \ldots \ldots \ldots \ldots \ldots \ldots \ldots \ldots \ldots \ldots$ 7-1

7.2 RECOMMENDED WPTA DEVELOPMENT
PROGRAM-PHASE II $\ldots \ldots \ldots \ldots \ldots \ldots \ldots \ldots \ldots \ldots \ldots \ldots, 7-3$

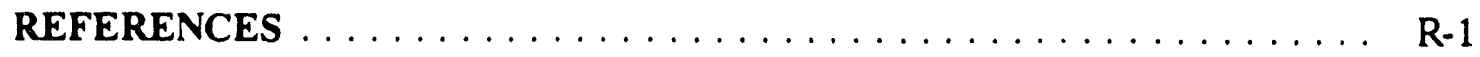

APPENDIX A $\quad \cdots \quad$ ECONOMIC ANALYSIS $\ldots \ldots \ldots \ldots \ldots \ldots \ldots \ldots$ A-1

APPENDIX B -- IMPROVED INFRARED TEMPERATURE MEASUREMENT BY UTILIZATION OF LASER

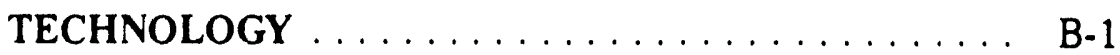

APPENDIX $\mathrm{C} \quad \ldots \quad$ EQUIPMENT SPECIFICATIONS $\ldots \ldots \ldots \ldots \ldots \ldots \ldots$ C-1 


\section{LIST OF ILLUSTRATIONS}

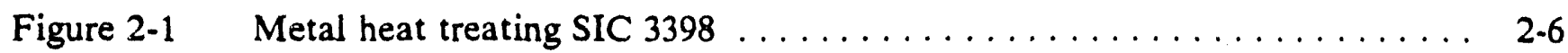

Figure $2-2 \quad$ Heat rate versus throughput $(\mathrm{PSM}) \ldots \ldots \ldots \ldots \ldots \ldots \ldots \ldots$

Figure 2-3 Increased profit versus increased throughput (PSM) $\ldots \ldots \ldots \ldots \ldots$

Figure $3-1 \quad$ PSM furnace cross section $\ldots \ldots \ldots \ldots \ldots \ldots \ldots \ldots \ldots \ldots \ldots \ldots$

Figure $3-2 \quad$ The PSM furnace $\ldots \ldots \ldots \ldots \ldots \ldots \ldots \ldots \ldots \ldots \ldots \ldots \ldots \ldots$

Figure $3-3 \quad$ Pinole Steel heat-treating furnace $\ldots \ldots \ldots \ldots \ldots \ldots \ldots \ldots$

Figure 4-1 Temperature measurements by Raman Spectroscopy . . . . . . . . . . 4-7

Figure $4.2 \quad$ Temperature measurement by Raman Spectroscopy $\ldots \ldots \ldots \ldots \ldots$. . . 4.8

Figure $5-1 \quad$ PSM sintering furnace and burner operation schematic $\ldots \ldots \ldots \ldots$

Figure $5-2 \quad$ Sample data-Pyrolaser $\ldots \ldots \ldots \ldots \ldots \ldots \ldots \ldots \ldots \ldots \ldots$

Figure $5-3 \quad$ Composite plot of PSM test data $\ldots \ldots \ldots \ldots \ldots \ldots \ldots \ldots$

Figure $5-4 \quad$ System schematic $\ldots \ldots \ldots \ldots \ldots \ldots \ldots \ldots \ldots \ldots \ldots \ldots \ldots$

Figure $6-1 \quad$ CARS spectrum of $\mathrm{CO}$ in a flame $\ldots \ldots \ldots \ldots \ldots \ldots \ldots \ldots$

Figure $6-2 \quad$ CARS temperature profile in sealed filament lamp $\ldots \ldots \ldots \ldots \ldots . \ldots$

Figure 6-3 CARS temperature measurement in an operating diesel engine $\ldots \ldots \ldots 6-6$

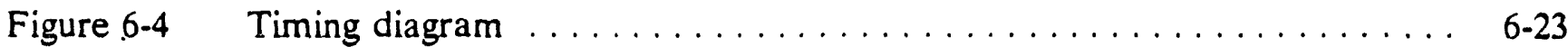

Figure $6-5 \quad$ Laboratory-scale syster: layout-laser beam delivery system $\ldots \ldots \ldots \ldots$. $\ldots$.28

Figure 6-6 Laboratory-scale system layout-Raman signal retrieval and processing camera lens system . . . . . . . . . . . . . . . . 6-29

Figure 6-7 Laboratory-scale system layout-Raman signal retrieval and processing fiberoptic system $\ldots \ldots \ldots \ldots \ldots \ldots \ldots \ldots \ldots . \ldots \ldots$ 6-30

Figure 6-8 Experimental test configuration for studying effects of luminosity, workpiece radiation, laser-modulated incandescence, and window

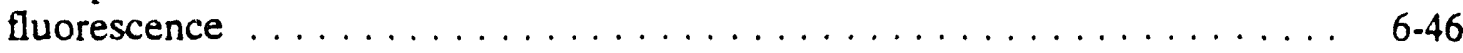




\section{LIST OF TABLES}

Table 2-1 DOE workpiece temperature-applications overview $\ldots \ldots \ldots \ldots . \ldots 2-3$

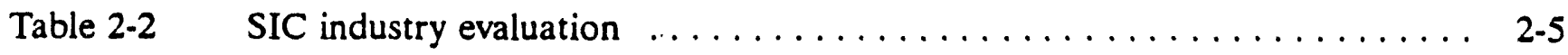

Table $2-3 \quad$ Metal Heat Treating SIC $3398 \ldots \ldots \ldots \ldots \ldots \ldots \ldots \ldots \ldots$

Table 2-4 DOE workpiece temperature analyzer - SIC evaluation-\$20K

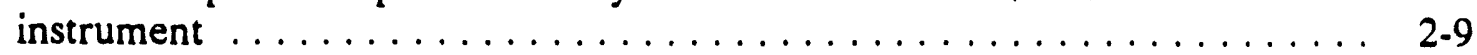

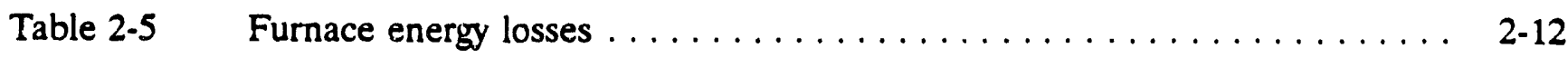

Table 2-6 Project data required for threshold analysis $\ldots \ldots \ldots \ldots \ldots \ldots$

Table $2-7 \quad$ Pyrolaser (threshold input data) $\ldots \ldots \ldots \ldots \ldots \ldots \ldots \ldots \ldots$

Table 2-8 Raman Spectroscopy (threshold analysis input data) . . . . . . . . 2-18

Table $4-1 \quad$ Pyrolaser specifications $\ldots \ldots \ldots \ldots \ldots \ldots \ldots \ldots \ldots \ldots \ldots$

Table $5-1 \quad$ Summary of measurements $\ldots \ldots \ldots \ldots \ldots \ldots \ldots \ldots$

Table 5-2 Test parameters for second set of tests at PSM $\ldots \ldots \ldots \ldots \ldots \ldots$

Table $6-1 \quad$ Documents reviewed $\ldots \ldots \ldots \ldots \ldots \ldots \ldots \ldots \ldots \ldots \ldots \ldots$

Table $6-2 \quad$ Itemization of system components and costs $\ldots \ldots \ldots \ldots \ldots \ldots .32$

Table 6-3 Miscellaneous experimental apparatus and costs $\ldots \ldots \ldots \ldots \ldots 6.36$

Table $6-4 \quad$ Yates' Algorithm $\ldots \ldots \ldots \ldots \ldots \ldots \ldots \ldots \ldots \ldots \ldots$

Table 6-5 Variable levels for test matrix (Yates' Algorithm) thermometry 


\section{SECTION 1}

\section{INTRODUCTION}

This project is directed toward the research, development, and evaluation of a viable commercial product-a workpiece temperature measurement analyzer (WPTA) for fired furnaces based on unique radiation properties of surfaces. This WPTA will provide for more uniform, higher quality products and reduce product rejects as well as permit the optimum use of energy. The WPTA may also be utilized in control system applications including metal hea: treating, forging furnaces, and ceramic firing furnaces. A large market also exists in the chemical process and refining industry.

The project places emphasis in three areas to determine the economic and technical viability of the product. They are: (1) market assessment of the product, (2) the evaluation of currently available products, and (3) the technical feasibility of the WPTA.

WPTA applications include the verification of product temperature/time cycles and use a front-end sensor for automatic feedback control systems. Most systems today measure the environmental temperature rather than the actuai product temperature, with the exception of surface-mounted thermocouples and a relatively new instrument, the Pyrolaser ${ }^{\mathrm{TM}}$, from Pyrometer Instrument Company (PIC). The Pyrolaser is unique in that it measures the surface emissivity as well as radiation of the surface, at the same time, at a selected spot on the surface of a workpiece

or part at elevated temperature. Typical pyrometers can only be used as reference instruments and do not provide absolute measurements. 
The project is being performed in three phases:

Phase I Application Evaluation, Evaluation of Present Technologies and Limitations, and Development of a Preliminary Conceptual WPTA Design Identifying Technical and Economic Benefits.

Phase II WPTA Laboratory-Scale Tests and Evaluations, Full-Scale Design, and Economic Analysis Verification.

Phase III Fabrication of a Prototype WPTA, Field Testing at an Industrial Site, and Preparation of a Commercialization Plan.

The Phase I application evaluation confirmed and quantified the applications and the technical and economic viability of the concepts in addition to the evaluation of presently available technology-the Pyrolaser at an industrial field evaluation site.

Several key decisions were made at the end of Phase I. These decisions provided recommendations for the direction of Phase II.

In Phase II, the enhancements of the Pyrolaser-Pyrofiber or the Raman Spectroscopy WPTA will be verified in laboratory-scale tests and further evaluated. A full-scale design and economic analysis will be conducted to provide sufficient data to make the necessary go/no go decision for Phase III.

In Phase III, a prototype WPTA will be constructed and evaluated at an industrial test site. Acurex has overall responsibiiity for the WPTA system product development, and primary responsibility for the application evaluation, field testing of the Pyrolaser and concept development of the Rarnan Spectroscopy WPTA. PIC provides expertise in non-contact temperature measurement techniques, instrument development expertise, and equipment for state-of-the-art measurement evaluation. Much of the technology and expertise which PIC gained in developing the Pyrolaser is directly transferable to the Raman Spectroscopy WPTA instrument. Raman Spectroscopy requires longer-term development. 
Upon successful completion of the development of the WPTA, commercialization will be carried out by PIC, which will market, manufacture/assemble, distribute, and service the WPTAs. This report summarizes the work performed in Phase I. 


\section{SECTION 2}

\section{APPLICATION SELECTION}

\subsection{MARKET ASSESSMENT AND EVALUATION OF APPLICATION}

The evaluation of potential applications of laser pyrometry serves two purposes. The most important and immediate is to identify markets for early commercialization and other markets suitable for subsequent commercialization or worthy of further investigation at a later date. The second purpose is to identify industries suitable for a test site for Beta-testing of this technology.

The criteria for a suitable market include the economic viability of such a product, applicability of the technology to the processes involved, relative size of the industry and whether or not the industry has a need for precise measurement and control of workpiece or process temperatures.

Although laser pyrometry is technically suited to a wide range of temperatures, most processes involving relatively low temperatures are already instrumented with thermocouples, bimetallic strips, or other conventional technologies, and do not require more sophisticated means of measurement. In contrast, such conventional technologies are often not applicable to hightemperature environments because of the interaction between radiation and convection and their influence on the measurements. Als ?, industries using high temperatures generally produce large volumes or expensive products and have more capital invested in process equipment than do lowtemperature process industries. Thus, they can more easily justify the expense of upgraded measurement and control equipment. Therefore, relatively high-temperature processing is a rough criterion for initial market evaluation. 
The first step in evaluating potential market was to compile a comprehensive list of industries requiring process heat in the form of gas or electrical energy. It was felt that large energy users would likely operate facilities at high temperatures. The GRI report "U.S. Industrial Process Heating Energy Consumption-1985" (Reference 1) provided this list. The industries comprising the list make up the "Process Heat Category" column in Table 2-1.

Initial review of these industries narrowed the list to four candidates: ferrous metal heat treating, glass annealing and forming, petroleum refining and chemical production, and clean clay firing. The reasons for rejecting the other industries are listed in Table 2-1. Note that many of the industries rejected for "instrumentation difficulties" are suitable for later investigation as markets but are not suited to providing initial sales or a test site because of the likelihood of special application engineering requirements and the associated high costs.

The next step in evaluating potential applications was to find Standard Industrial Code (SIC) classifications corresponding to these candidate industries. The SIC codes are a key to a wealth of data on various industries contained in the U.S. Department of Commerce Census of Manufactures (Reference 2) and Annual Survey of Manufactures (Reference 3). For each of the selected SIC codes, a set of statistics was collected. The "STATISTIC" section at the top of Table 2-2 shows an example of the data collected.

The Census of Manufactures also provided the histograph distribution of the number of firms per number of employees, depicted in Figure 2-1. This distribution was the basis for scaling the other statistics, as tabulated in the lower portion of Figure 2-1. The scaled data give an approximate idea of the number of firms with, for example, given levels of capital expenditure or fuel cost. Some of the statistics are distributed linearly; others exponentially, to reflect the rule of thumb assumption that each doubling of employment reflects a 10 percent increase in productivity.

Two rough criteria were establishe to facilitate comparison of the SIC data. Both assume a $\$ 20 \mathrm{~K}$ price tag for the workpiece temperature analyzer instrument. 
Table 2-1. DOE workpiece temperature-applications overview

\section{Selected for Initial Study/Reason for Rejection}

No need for control benefits

Ferrous

Nonferrous

Smelting

Ferrous

Nonferrous

Metal Melting

Steel making

Steel melting

Iron melting

Nonferrous melting

Metal heating

Steel soaking pits

Steel reheat

Ferrous forging

Nonferrous forging

Nonferrous heating

Metal heat treating

Ferrous

Nonferrous

Atmosphere generation

Nonmetallic melting

Glass melting

Curing and forming

Nonmetallic curing

Glass annealing/forming

Rubber

Bonding

Powdered metals

Brazing

Adhesives

Fluid heating

Petroleum refining
No need for control benefits, small industry

Blast furnace (instrumentation difficulties)

Instrumentation difficulties

Melting furnace (instrumentation difficulties)

Melting furnace (instrumentation difficulties)

Melting furnace (instrumentation difficulties)

Melting furnace (instrumentation difficulties, relatively small industry)

Furnace is entirely full of product (instrumentation difficulties)

Furnace is entirely full of product

(instrumentation difficulties)

Relatively small industry

Relatively small industry

Small and diverse industry

* Selected for initial study

Low temperature

Nonapplicable, item of interest is combustion products themselves

Furnace is entirely full of product (instrumentation difficulties)

Low temperature

* Selected for initial study

Steam process

Small market

Furnace brazing is small market

Small market, low temperature

* Selected for initial study. Very large market. Sensor detects tube temperature 
Table 2-1. DOE workpiece temperature-applications overview (concluded)

Process Heat Category

Selected for Initial Study/Reason for Rejection

Petroleum extraction

Chemical production

Drying

Surface film

Continuous sheet

Dirty

Clean

Calcining

Dirty

Clean

Clay firing

Dirty

Clean

Other heating

Dirty

Baking and frying

Singeing and finishing
Very low temperature

* Selected for initial study. Very large market.

Sensor detects tube temperature.

Low temperature

Low temperature

Low temperature and dirty

Low temperature

Cheap and dirty

Gypsum is low temperature. Area of future interest: Alumina (rotary kiln)

Cheap and dirty

* Selected for initial study. For large dense batches, sensor sees outer product only

Cheap and dirty

Complex and fragmented market, low temperature

Low temperature 
Table 2-2. SIC industry evaluation

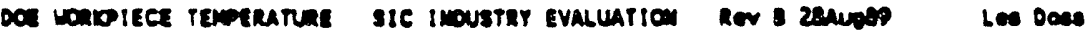

ste: 3390 Induery: Hotal Hoot iroating

staristic

mear of esedblichentes:

Totel ol opment:

Perrall:

Volue edod by nunfectures

cast of neterlates

Volue of ahipuants

wen cepital upandituress

intofopear immerertee:

Men expleal expendl tureas

eso-of-y machinary sasets:

new meninary eap exp:

now cemperter esp exp:

Murehased funls and eleetr:

mrehesed fuls and eleetr:

orr units

78 eseablithments

$17.7 \mathrm{~K}$ pareare

324.2 :

69.5

$416.0 \mathrm{~m}$

$1126.2 \mathrm{~m}$

$42.5 \mathrm{~m}$

$9.1 \mathrm{~m}$

$30.7 \mathrm{~m}$

$622.6 \mathrm{sin}$

$28.2 \mathrm{gm}$

$0.3 \mathrm{sm}$

$80.9 \mathrm{sm}$

17.0 eplltion stu
Yen

1992

192

$19 \%$

192

192

19?

192

192

1928

1802

1998

1902

9930

1980 arr cuits

$1.620 \mathrm{sm} / \mathrm{su}$ 0.057 sa/m

$0.001 \mathrm{~m} m / \mathrm{m}$

energy expandliture / velue 0.118

sune:

cencus of mentectures. Induery serfes 1902, isble 6

cence of hentectures- Indestry series 19a2, rable 4

cencus of henufecturee. Indetry saries 1902, icble 6

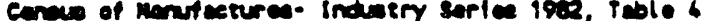

conces of Merufcetures. Industry serles 1992, Table 6

cances of nenuferures. Indentry serles 1992, Toble 4

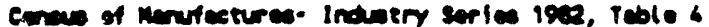

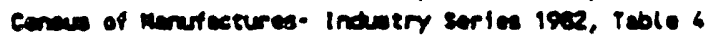

Conas of mentectures- Induetry serifes 1982, Teble 30

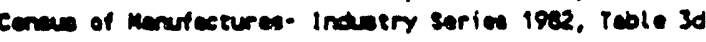
cencen of menutcetures. Indeery saries 1982, Pable 30 Conase of Menufectures- Inderery sapies 1962, Table 3d

Amial surver of Menufecturee 1980-81, Table 3

Amual survery of Menufectures 1980-81, Table 3

Hew center expend tures / meh asears

\begin{tabular}{|c|c|c|c|c|c|c|c|c|c|c|c|}
\hline staristies se & 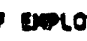 & & & & $x^{2}$ & & & & & & \\
\hline Avorese & $1-6$ & $5-9$ & $10-19$ & $20-69$ & $50-\infty$ & $100 \cdot 269$ & $230-699$ & $500-990$ & $1000 \cdot 2690$ & .2500 & Lin \\
\hline mor of reccbl I shanes: & 109 & 154 & 206 & 210 & 60 & 18 & 0 & 1 & 0 & 0 & $\operatorname{Exp}$ \\
\hline nespen & 2.5 & 7 & 16.5 & 34.5 & 76.5 & 174.5 & 376.5 & 769,5 & 1749.5 & 3250 & $\iota$ \\
\hline Perroll: & 40.64 & 113.79 & 235.72 & 560.84 & 1211.10 & 2036.73 & 600.00 & 1218.12 & 28460.65 & 52233.07 & $b$ \\
\hline velue aded by wan & S4.81 & 183.27 & 619.65 & 1126.97 & 2700.7 & 712.05 & 16954.81 & 37231.84 & 97922.90 & 198092.68 & $\varepsilon$ \\
\hline cost of meroriols: & 34.32 & 111.38 & 255.06 & 63.69 & 1441.37 & 6322.30 & 10304.16 & 22698.16 & 59511.95 & 120309.42 & E \\
\hline velue of shipente: & D.63 & 302.07 & 621.6 & $1 \times+4.11$ & 6431.63 & 1170.16 & $27 \% 4,09$ & 61530.72 & 161397,56 & 326490.41 & $\varepsilon$ \\
\hline Mew eepitel expenditureas: & 5.53 & 16.92 & 30.90 & 73.52 & 138.76 & 371.87 & $7 \times 3.09$ & 1597.26 & 3728.31 & 6025.99 & $b$ \\
\hline $\begin{array}{l}\text { End-of-year immertor: } \\
\text { new eninery eep exp: }\end{array}$ & $\begin{array}{l}8.16 \\
3.56\end{array}$ & $\begin{array}{r}26.27 \\
9.90 \\
\end{array}$ & $\begin{array}{l}60.16 \\
20.50\end{array}$ & $\begin{array}{r}161.23 \\
4.7 \\
\end{array}$ & $\begin{array}{l}387.06 \\
105.35\end{array}$ & $\begin{array}{r}1019.27 \\
26.6 .72 \\
\end{array}$ & $\begin{array}{r}2629.90 \\
520.53 \\
\end{array}$ & $\begin{array}{l}5350.26 \\
1059 . .2\end{array}$ & $\begin{array}{r}16033.95 \\
267.85\end{array}$ & $\begin{array}{r}28389.91 \\
6598.60 \\
\end{array}$ & $\varepsilon$ \\
\hline Hen comperer cep exp: & 0.04 & 0.11 & 0.22 & 0.52 & 1.12 & 2.62 & 3.63 & 11.27 & 26.32 & 68.89 & $b$ \\
\hline 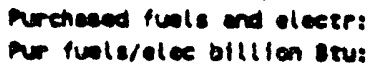 & 6.71 & $\begin{array}{r}21.65 \\
4.53\end{array}$ & $\begin{array}{l}69.60 \\
10.42\end{array}$ & $\begin{array}{r}132.96 \\
27.86\end{array}$ & $\begin{array}{r}399.20 \\
67.08\end{array}$ & $\begin{array}{l}240.56 \\
176.43\end{array}$ & $\begin{array}{r}2003.88 \\
621.08\end{array}$ & $\begin{array}{r}412.19 \\
927.16\end{array}$ & $\begin{array}{r}11573.36 \\
2631.98\end{array}$ & $\begin{array}{r}23612.27 \\
6919.76\end{array}$ & E \\
\hline
\end{tabular}

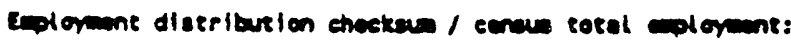

1.13 


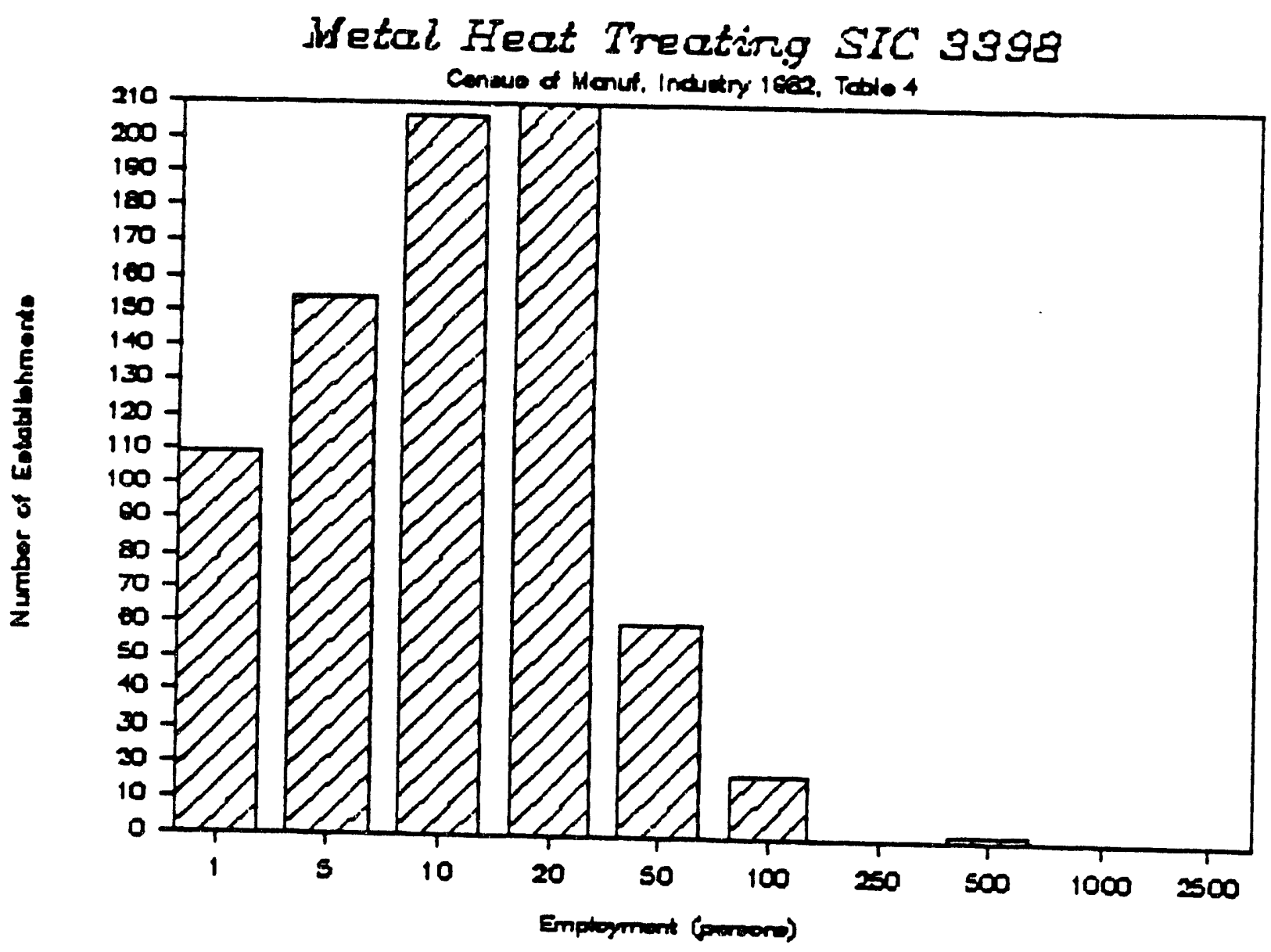

Figure 2-1. N'etal heat treating SIC 3398 
One criterion is the number of potential customers for the instrument. The assumption underiying its estimation is that a customer would not spend more than half of his annual new machinery capital expenditures, nor more than 2 percent of his value of shipments, to buy such a device. A company filling both these requirements would have at least $\$ 40 \mathrm{~K}$ new machinery capital expenditures and $\$ 1 \mathrm{M}$ value of shipments. Table 2-3 shows an example of the application of this criterion to the data of Table $2-2$.

The other criterion is the number of potential unit sales. The assumption underlying its estimation is that larger companies could and would possibly buy multiple units. Table $2 \cdot 3$ shows the method of estimating the number of potential unit sales based on level of new machinery capital expenditure. Table 2-4 tabulates the results of applying these two yardstick criteria on applicable SIC data, in the "Census: Customers/Units" columns. A major problem with this method of organizing the SIC data is that it masks captive facilities, i.e., those owned by larger businesses with a different SIC classification. Examples would be metal heat treating or glass annealing facilities owned by a manufacturer of automobiles or airplanes. Telephone conversations with industry representatives indicate that at least half of the metal and glass heat-treating facilities in the United Stat's are captive. The "Corrected: Customers/Units" columns of Table 2.4 present figures for these two industries doubled to include captive facilities. Table 2.4 also shows the value of sales corresponding to the estimates of unit sales for a $\$ 20 \mathrm{~K}$ instrument. Even the corrected figures present the fluid heating (petroleum and chemicals) applications in an order of magnitude greater than other industries of interest.

At this point, it is important to emphasize that although the SIC evaluation is useful as a rough tool for sizing up potential markets, it is not the last word to use as a base for decisions. Subsequent telephone investigation of the fluid heating industry revealed a low level of interest in relatively high-cost temperature instrumentation.

The principal concern of process heater users is the tube wall temperature. If this temperature becomes too high, coking of the petroleum liquids can occur. This can lead to deposits 
Table 2-3. Metal Heat Treating SIC 3398

DOE Workpiece Temperature: SIC Evaluation

Unweighted-Number of potential customers 289

Number established with $2 \$ 40 \mathrm{~K}$ new machinery capital expense $=210+60+18+1$ and $2 \$ 1 M$ value of shipments

Weighted-Number of potential unit sales

\begin{tabular}{lccc}
\hline $\begin{array}{c}\text { New Machine } \\
\text { Cap Exp. }\end{array}$ & $\begin{array}{c}\text { Weight } \\
\text { Factor }\end{array}$ & $\begin{array}{c}\text { Number } \\
\text { Established }\end{array}$ & $\begin{array}{c}\text { Weight * Number } \\
\text { Established }\end{array}$ \\
\hline 2\$40K, 21M & & & \\
value shipping & 1 & $210+60$ & 270 \\
$>\$ 200 \mathrm{~K}$ & 2 & 18 & 36 \\
$>\$ 400 \mathrm{~K}$ & 3 & 0 & 0 \\
$>\$ 800 \mathrm{~K}$ & 4 & 1 & 4 \\
$>\$ 1.6 \mathrm{M}$ & 5 & & \\
$>\$ 3.2 \mathrm{M}$ & 6 & & \\
$>\$ 6.5 \mathrm{M}$ & 7 & & \\
$>\$ 13 \mathrm{M}$ & 8 & & \\
$>\$ 25 \mathrm{M}$ & 9 & & \\
$>\$ 50 \mathrm{M}$ & 10 & & \\
$>\$ 100 \mathrm{M}$ & 11 & & \\
Total & & & \\
\hline
\end{tabular}

Figures do not include captive facilities. 
Table 2-4. DOE workpiece temperature analyzer-SIC evaluation-\$20K instrument

\begin{tabular}{|c|c|c|c|c|c|c|c|}
\hline \multirow[b]{2}{*}{ SIC Code } & \multirow[b]{2}{*}{ Description } & \multicolumn{2}{|c|}{ Census } & \multicolumn{2}{|c|}{ Corrected } & \multicolumn{2}{|c|}{ Value \$M } \\
\hline & & Customers & Units & Customers & Units & Census & Corrected \\
\hline 3398 & Metal heat treating & 289 & 310 & 578 & 620 & 6.2 & 12.4 \\
\hline 3211 & Flat glass & 33 & 140 & 66 & 280 & 2.8 & 5.6 \\
\hline 3251 & Brick and structural & 185 & 214 & & & & \\
\hline 3255 & $\begin{array}{l}\text { Clay tile } \\
\text { clay refractories }\end{array}$ & 103 & 126 & & & & \\
\hline \multirow[t]{2}{*}{3261} & $\begin{array}{l}\text { Vitreous plumbing } \\
\text { fixtures }\end{array}$ & 35 & 75 & & & & \\
\hline & Clay firing total & 323 & 415 & 323 & 415 & 8.3 & 8.3 \\
\hline 2911 & Petroleum refining & 433 & 2149 & & & & \\
\hline 2865 & $\begin{array}{l}\text { Cyclic crudes and } \\
\text { intermediates }\end{array}$ & 153 & 634 & & & & \\
\hline \multirow[t]{2}{*}{2869} & $\begin{array}{l}\text { Industrial organic } \\
\text { chemicals }\end{array}$ & 465 & 2198 & - & & & \\
\hline & Fluid heating total & 1051 & 4981 & 1051 & 4981 & 99.6 & 99.6 \\
\hline
\end{tabular}

"Corrected" figures assume that roughly half of the metal and glass treating facilities are "captive," i.e., owned by a larger business such as ar automobile manufacturer. Such captive facilities are not reflected in the SIC census data. 
and eventual tube blockage or burnout. Excessive temperatures are usually a result of excessive radiant heat transfer which may be due to faulty design, changes in the fuel compositions. or changes in the process fluid flow or composition. From several users (Shell, Chevron), it was determined that outages often occur every six months or so due to tube failures (usually not on the same unit, though). However, they attribute the primary cause of failure to momentary or full interruptions of process fluid flow. This may be caused by an upset in the refinery or chemical process, or by some instability within the fluid manifolding. At this time, they do not attribute the problems to temperature maldistributions on the combustion sir's Both the manufacturers and the users feel that: (a) there is sufficient tolerance in the design to account for minor changes, (b) these changes occur rarely, and (c) the current use of thermocouples and conventional optical pyrometry to monitor temperature is adequate to detect gross upset conditions. Thus, it is not clear that highly accurate tube wall temperature instrumentation measurement provides any real benefits to justify its cost. Therefore, in the fluid heating sector, laser pyrometry and other advanced workpiece temperature analyzers seem to have their most immediate application in new R\&D. Discussions with process operators tended to indicate no additional accuracy in temperature measurements where required, whereas process engineers tended to have differing opinions. Process engineers seemed to have a better understanding of the optimizaiion of the processes and how small changes in the operation could significantly influence the output of the facility and improve efficiency. For large processors the implications are enormous.

The difficulty of penetrating such a market with a new product should not be underestimated, however, when customers do not fully understand what the new instrumentation can provide. For a small company the required resources are simply too large, and it is wiser to look for markets where receptivity to the concept is good.

This conclusion prompted further investigation of the remaining three industry candidates. Visits to facilities for firing brick showed that brick-firing kilns are densely packed with product, obscuring any view of product while insulated by the outside layer of bricks and thus interfering with 
measurement. Furthermore, the value of the product is relatively low, and bricks that do not meet specifications can be easily recycled. Therefore, the brick industry could expect little real economic benefit from the proposed instrumentation. Vitreous plumbing fixtures and other relatively expensive ceramics are a more likely application in terms of both viewability/measurability and value of product. However, by themselves, they constitute a relatively small market for instruments.

The remaining market candidates are flat glass annealing and heat treatment, quite similar processes. Metal heat treating has the advantage of a relatively larger market and size. It is not surprising that this market was also perceived by DOE to have the greatest need.

The crite:ia for a test site industry also included relative ease of instrumentation. For example, as a noricuntact measurement technology, laser pyrometry has the potential of overcoming the difficulties, of instrumenting a rotary kiln or blast furnace but these difficulties would unnecessarily complicate initial testing of the technology.

\subsection{ECONOMIC ANALYSIS}

An estimate was made as to the cost of the user of a WPTA. The cost of a Pyrolaser is soniewhat lower than the cost of a Raman Spectroscopy system. The latter has greater capabilities, however, too. Specific data were collected for the Precision Specialty Metals (PSM) site for which information was more readily available than for other sites.

Further heat balance and economic analysis of the PSM site was made. A summary of the heat transfer analysis is shown in Table 2-5. This analysis shows that at current maximum throughput of $15,000 \mathrm{lb} / \mathrm{hr}$ only $4 \times 10^{6} \mathrm{Btu} / \mathrm{hr}$ of the $5 \times 10^{6}$ available is utilized. At $5 \times 10^{6} \mathrm{Btu} / \mathrm{hr}$ the maximum throughput could possibly be increased to $19,000 \mathrm{lb} / \mathrm{hr}$ or a 27 percent increase. Using this same approach also shows that at low throughput ( $7000 \mathrm{lb} / \mathrm{hr}$ ), energy savings by turning off burners after the material has reached temperature do not result in significant fuel savings (only about $5-1 / 2$ percent) and the product cools less than $200^{\circ} \mathrm{F}$ due to the well-insulated furnace. 
Table 2-5. Furnace energy losses

\begin{tabular}{|l|l|}
\hline \multicolumn{1}{|c|}{ Location } & \multicolumn{1}{c|}{ Btu/hr } \\
\hline Walls & 147,960 \\
Burner exhaust & 228,150 (Maximum firing rate, 50\% excess air) \\
Furnace ends & $335,980\left(5 \%\right.$ through each end at $\left.2000^{\circ} \mathrm{F}\right)$ \\
Auxiliary stack & $129,195\left(5 \%\right.$ through stack at $\left.2000^{\circ} \mathrm{F}\right)$ \\
Metal exiting & $\mathrm{M}\left(0.10573 \mathrm{Btu} / \mathrm{lbm}^{\circ} \mathrm{F}\right)(2050-70)$ \\
\hline $\mathrm{q}_{\mathrm{T}}=217.8 \mathrm{M}+841,285 \mathrm{Btu} / \mathrm{hr}$ \\
$\mathrm{M}=\mathrm{lbm} / \mathrm{hr}$
\end{tabular}

Figure 2-2 shows the calculated heat rate versus throughput for two different assumptions on losses form the ends and the auxiliary stack. This shows there is considerable room for improvement over the reported heat of 400 to $600 \mathrm{Btu} / \mathrm{lbm}$. However, more precise data need to be collected to determine what other equipment contributes to the reported heat rate and how the duty cycle of the furnace influences the number (periods of down time).

From the results of the heat transfer analysis, the economics of the process were examined from a number of perspectives. Fuel savings at low throughput by shutting down burners after the product has reached temperature was shown to yield only about $130,000 \mathrm{Btu} / \mathrm{hr}$ savings from wall losses. This is only worth about $\$ 5000 / \mathrm{hr}$ at $\$ 5 / 10^{6} \mathrm{Btu}$ and $8000 \mathrm{hr} /$ year of operation. Similarly, if at the high throughput rates the product is overheated by $200^{\circ} \mathrm{F}$, this will result in $330,000 \mathrm{Btu} / \mathrm{hr}$ extra heat loss. If this can be reduced, it will result in a savings of $\$ 13,200 / y r$. So it is seen that fuel savings is not a strong motivation for implementing the technology.

On the other hand, if increased :hroughput can be realized by having a better knowledge of the temperature, a significant increase in profits can be realized. This relationship is shown in Figure 2-3 for a variety of product values. The conclusions from this economic evaluation are that fuel savings probably cannot justify the expense of the pyrometer, but that even if a small increase 


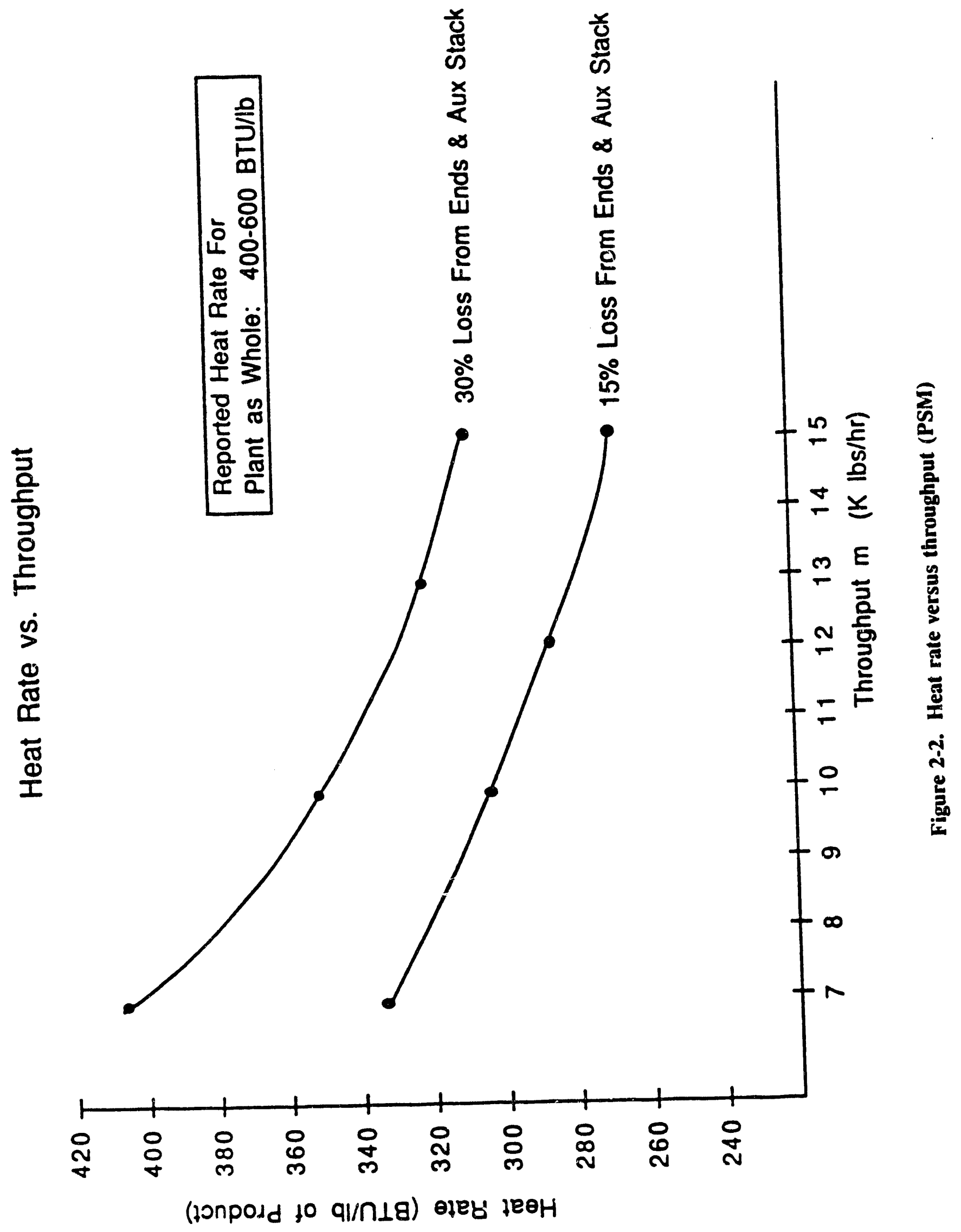




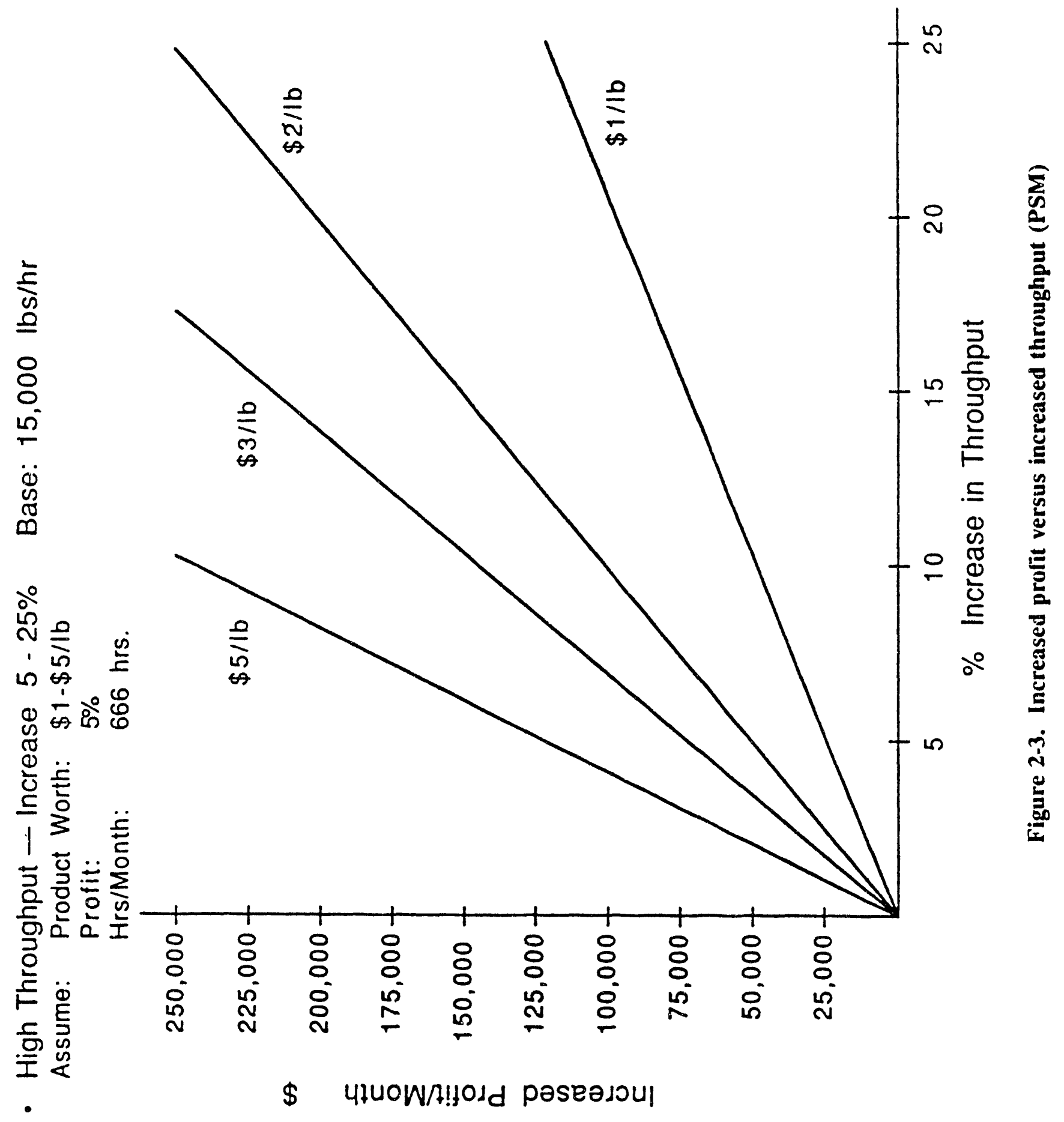


in product throughput is possible while maintaining quality control, the pyrometry can pay for itself in less than a year. On the whole, the PSM site is looking like an excellent candidate.

In addition to the above analysis, the Department of Energy performed a threshold analysis to determine the best use of funds. The analysis was performed for several cases which showed that at a unit cost of $\$ 20,000$ to $\$ 30,000$ significant payback could be realized in a very short time due to either fuel savings or quality improvements. The input parameters required are shown in Table 2-6, and specific values that were used in the analysis for Pyrolaser and the Raman Spectroscopy WPTA as shown in Tables 2-7 and 2-8. The actual results of the study can be reviewed in Appendix A.

The conclusion is that at the above projected cost, significant markets exist based on economic factors. Significant resistance to new technologies by operating personne. nay slow the acceptance of these new systems, however.

\subsection{MARKET ASSESSMENT}

The market assessment and applications evaluation has determined that a large market for advanced, remote sensing, highly accurate thermometry instrumentation exists that will provide the opportunity for improved product quality, reduced reject rates, and lower energy consumption. This market exists at the relatively high-instrument cost of $\$ 20,000 /$ unit. As the unit cost decreases, the market is increased in volume of units sold, but does not necessarily increase in total dollar value. The main benefit of this project accrues at that time to the users in terms of reduced production costs of product due to lower reject rates and lower energy use.

The most attractive entry market is the heat-treating industry, which has a recognized need for this type of instrumentation. The chemical process industry attributes process-related problems to other factors, and only the process engineers appear to understand the enormous benefits that can be derived from closer operating controls. Exxon Corporation invested heavily in development of the present state-of-the-art instrumentation, since they recognized the benefit that could be derived. Exxon owns the patents for Pyrolaser. 
Table 2-6. Project data required for threshold analysis

A. Select typical production unit at one specific size.

B. Estimate the following quantitative parameters:

1. Differential Capital Cost for First Sale

- relative to alternative scenario

-- in "year of first sale" dollars

a. Year first production unit is sold

b. End user purchase price of equipment

c. Installation cost to user -- if in addition to above

d. Profit $(t,-)$ expected by developer

e. Salvage value $(t,-)$ to user

f. Learning curve factor expected by developer over product 1 ife

2. End User Annual Savings for Eirst Sale

- relative to alternative scenario

-- in "year of first sale" dollars

a. Non-fuel operating and maintenance costs $(t,-), \$ /$ unit/y

b. Other non-fuel savings $(t,-), \$ /$ unit/y

c. Per unit energy impact (Btu/y) by type of direct energy: oil, gas, coal, other, and electricity (e $10,000 \mathrm{Btu} / \mathrm{kWh}$ )

d. Production unit useful life

3. Market Penetration

a. Production units sold during first year

b. Production unit sales opportunities over product life

c. Equivalent size unit sales opportunities over product life

d. Equivalent size units sold by year 2010

e. Market penetration of possible sales opportunities

f. Year by which $10 \%, 50 \%$, and $90 \%$ of expected sales are achieved

4. Project R\&D Funding Data -- in "that-year" dollars

a. Sought federal investment in technology by year

b. Sought private investment.in technology by year

5. Private Post-Project Expenses to Commercialize

-- assumed to occur one year prior to first commercial sale

- - in "that-year" dollars

a. All front end costs including "tooling" to start production

6. Federal Acceleration of Market Introduction

a. Years appearance of project technology advanced in marketplace 
Table 2-7. Pyrolaser (threshold input data)

Petroleum Refining Industry

A. The unit size is the same in all cases.

B.1a. 1990 (4 Q)

1b. $\$ 20,000$

1c. $\$ 10,000$

1d. $15 \%$

1e. 0

1f. .9

2a. $\$ 2,000$

2b. $\$ 464,000$

2c. $\$ 17,600$

Based on $\$ 92,767 \mathrm{~K}$ in shipments and $.5 \%$ benefit (2149 units)

2d. 10 years

Based on $1 \%$ improvement in efficiency (2149 units)

3a. 7

3b. 10,000

3c. 10,000

3d. 500

3e. 500 by 2010

3f. 1992, 1995, 2010

4a. $\$ 150,000$

4b. $\$ 100,000$

5a. $\$ 25,000$

6a. 2 - 3 yrs.

Metal Heat Treating Industry (all inputs the same except those noted)

2b. $\$ 182,000$ (quality and throughput improvements)

2c. \$ 13,000 (10\% fuel reduction)

Specific Case

2b. $\$ 150,000$ (improvement in quality and throughput)

2c. $\$ 13,000$

Specific Case

2b. $\$ 3,200,000$ (quality improvement $2 \%$, throughput $2 \%$ )

2c. $\$$. 
Table 2-8. Raman Spectroscopy (threshold analysis input data)

The market for the Raman Spectroscopy System is the same in part as for the Pyrolaser. Pyrolaser can not be used in dirty atmospheric environments and for remote analysis of the surface other than for temperature. The market is therefore substantially larger. The data reflected here is evaluating the semiconductor area where the return on investment appears to be very similar as for the average heat treating facility. There are some other markets such as the petroleum refining market (if fired with dirty fuels) where the payback would be higher.

A. Unit size the same in all cases.

B.1a. 1992 (4 Q)

1b. $\$ 30,000$

1c. $\$ 10,000$

1d. $15 \%$

1e. 0

1f. .9

2a. $\$ 3,000$

2b. $\$ 193,000$ (based on $\$ 9,650 \mathrm{~K}$ shipments of semiconductors and 2029 units)

2c. $\$ 4,000$

2d. 10 years

3a. 7

3b. 22,000

3c. 22,000

3d. 1,100

3e. 1,100 by 2010

3f. 1994, 1997, 2010

4a. $\$ 390,000$

4b. $\$ 100,000$

$5 a . \$ 100,000$

6a. 5 years 
Teledyne Wah Chang, a processor of specialty metals, is a very attractive candidate for a Beta-test site for the new instrumentation expected to be developed on this program. Teledyne has a strong interest in improving control strategies on their Zirconium solution annealing furnace.

Raman Spectroscopy offers exciting additional measurement capabilities in addition to thermometry. Development of this technology is a long term project, whereas the Pyrolaser offers high-quality measurement capabilities at this time.

Pyrolaser enhancements under consideration for implementation are improvements in the determination of the specularity and associated sources of measurements errors and a fiberoptics multiplexing adapter to reduce the cost per measurement point.

\subsection{EXPECTED END PRODUCT AND COMMERCLALIZATION}

The technologies examined both offer an opportunity to improve the measurement capabilities in difficult environments. The specific instruments are not going to be able to address all markets and all situations, however. The investment required in terms of time and research funds is lower for the enhancements to the Pyrolaser system whereas the Raman Spectroscopy WPTA will require substantial development as well as iime.

The Pyrolaser offers an opportunity in the short term whereas Raman Spectroscopy has

much to offer in the long term. Both technologies are similar in that they share common elements such as optics as an example. PIC is therefore in a strong position to commercialize the technology after feasibility has been firmly established and all important design parameters have been determined.

For this reason, the proposed program to proceed incorporates an enhancement program for Pyrolaser and a technology development program for Raman Spectroscopy. Both systems should have fiber optics capability to reduce cost/measurement point and to remove most of the electronics from sensitive environmental areas.

The recommended program is further discussed in Section 7.2. 


\section{SECTION 3}

\section{TEST SITE SELECTION}

\subsection{TEST SITE AGREEMENTS}

Conclusions reached in the market assessment phase of the program confirmed that a large market exists for high accuracy, high temperature remote instrumentation. Some markets will be relatively easy to penetrate whereas others will require substantial demonstration of the benefits that can be derived from this technology.

Efforts have been made to contact companies in the heat treating business to solicit interest in working with a product development team, permitting product testing at their facilities, and developing relationships that will lead to greater understanding of the customer's perceived needs for this type of instrumentation. Response to these efforts has been quite favorable and much has already been learned, particularly about continuous sheet heat treating furnaces.

Agreements have been reached with Precision Specialty Metals (PSM), a stainless steel processor, to conduct testing at their facility and Teledyne Wah Chang.

\subsection{PRECISION SPECLALTY METALS (PSM), LOS ANGELES, CALIFORNIA}

PSM has a new, modern 50 -ft heat-treating furnace that processes $0.006-$ to 0.080 -inch thick by 36- to 50-inch-wide continuous stainless sheet steel. This furnace, as shown in Figures 3-1 and 3-2, has been in operation for less than a year, and utilizes 32 (16 pairs of) new North American Twin Bed Regenerative Burners distributed along the length of the furnace. Temperature control is relatively simple, however, with a single thermocouple in each zone controlling 16 burners ( 8 sets) per zone. The fuel/air ratio for the group of burners in each zone is fixed, and temperature is controlled by modulating the overall firing rate of the complete set of burners for that zone. 


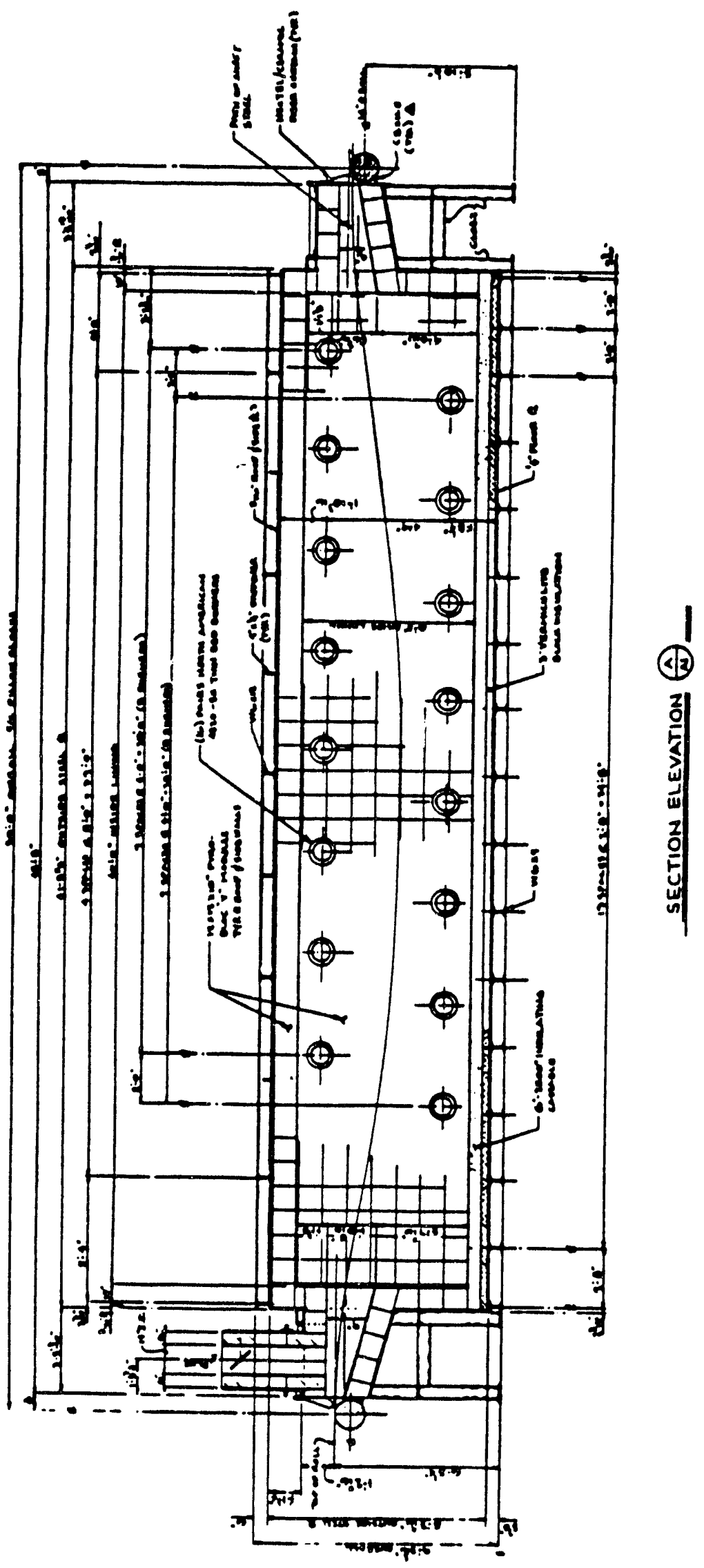

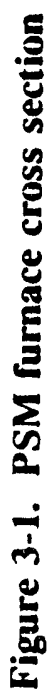




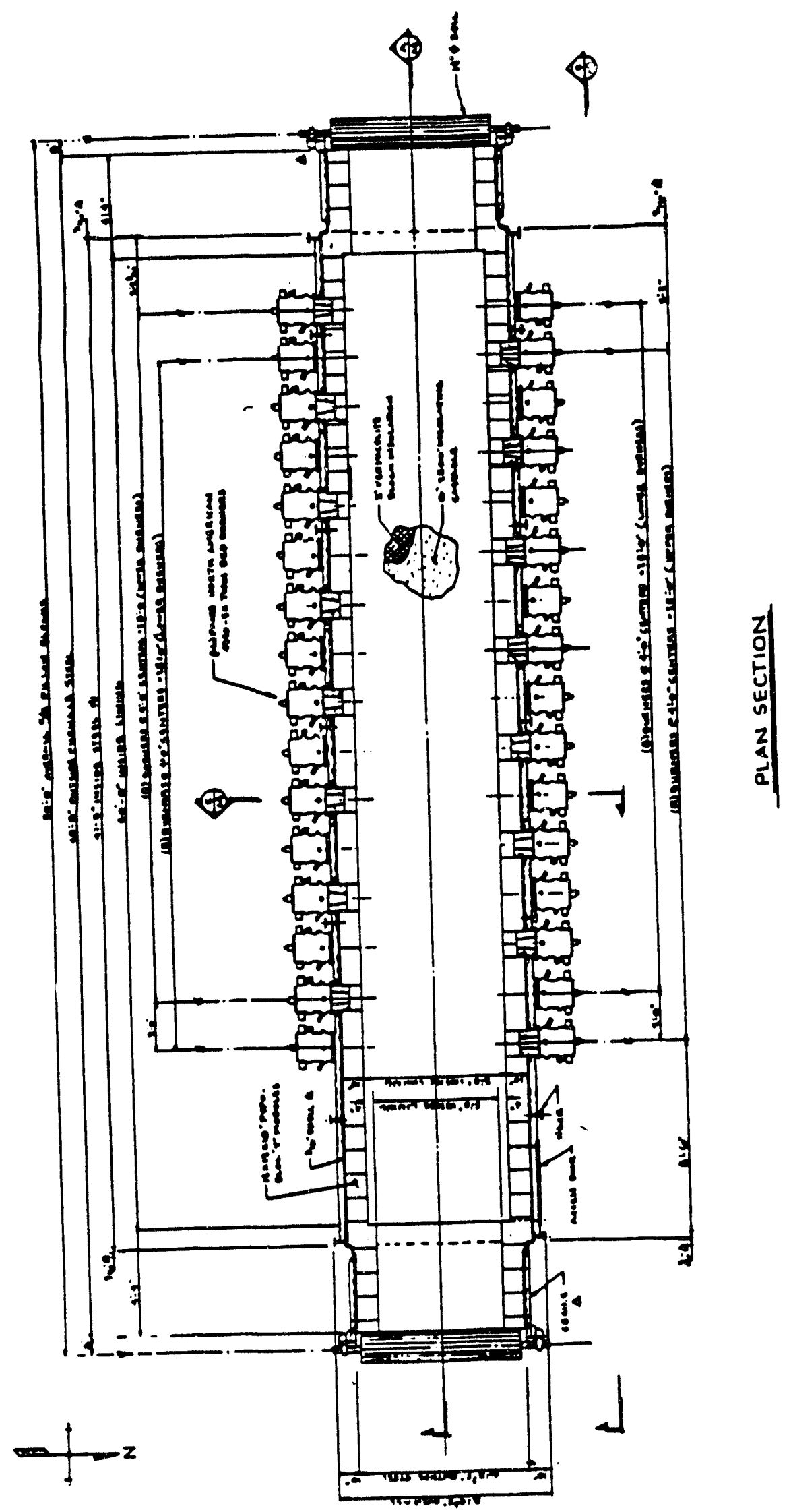

苞 
Localized manual adjustment of each burner for trimming purposes is also possible. For example, at low loads PSM has had some difficulty in achieving sufficient turndown to the extent that they have had to shut down some burner sets and place restrictor orifices in the fuel lines of others.

Metallurgically, the only requirement is that the material reach $2050^{\circ} \mathrm{F}$. In this process the internal microscopic structure of the material begins in a random work-hardened state. When raised to the critical temperature, the material's internal structure becomes uniform, and when cooled to room temperature, the crystalline structure then becomes organized in a regular pattern. The goal is to heat the entire cross-section up to the critical temperature; no significant time is required at temperature.

The present method of operation is based on the experience of running different metals and metal thicknesses. A table has been developed indicating the linear speed of the strip, dependent on width and thickness. Needless to say, this is an empirical process. The maximum throughput on thin material is limited not by the heat capacity of the furnace but by the maximum speed of downstream equipment $(50 \mathrm{ft} / \mathrm{min})$. Maximum throughput of thicker material is perceived to be limited by maximum firing rate of the burners and the time it takes to heat the product to temperature. However, because the instrumentation is so limited, the true maximum firing rate is not known. Currently, PSM litrits maximum throughput of the thicker material to $15,000 \mathrm{lb} / \mathrm{hr}$.

Quality control has not been a problem in that PSM has been able to achieve the critical temperature for all the current throughputs. In addition, because the furnace is so well-insulated, and because of the use of the North American regenerative burners, thermal efficiency and temperature uniformity across the furrace is perceived to be excellent. The benefit of being able to determine the product temperature accurately would be the increased throughput possible with thicker materials, and the potential for lower energy consumption when thinner materials are processed and the minimum number of burners are operated. The return on investment would be substantial, and the equipment could be paid for in a few months of improved operation. 
PSM has expressed strong interest in improved temperature measuring capabilities of its product to improve productivity, quality and ease of operation of its facilities.

\subsection{PINOLE STEEL-TREATING FURNACE, PINOLE, CALIFORNIA}

Pinole Steel has a modern continuous heat-treating furnace that prepares sheet steel for zinc plating or prepainting. The facility, shown in Figure 3-3, consists of three sections: the direct-fired cleaner, a radiant tube annealing section, and a cooling section. The direct-fired heater takes the material to $1050^{\circ} \mathrm{F}$ in an oxidizing atmosphere, utilizing 60 small burners in 4 zones. The zone temperature, measured by a single thermocouple, is controlled by the firing rate to the entire zone. Adjustment of individual burr ers for trimming is done manually. If more temperature information was available, the number of control zones could be increased. However, this would necessitate modifying the piping, increasing the number of control valves, and increasing the number of controllers.

The second section of the furnace takes the temperature of the product to $1350^{\circ} \mathrm{F}$ in a controlled $\mathrm{H}_{2} / \mathrm{N}_{2}$ atmosphere, using radiant tube burners. Again, the number of zones could be increased if a more precise knowledge of the temperature was available. However, considerable hardware and control modifications would be required.

The final section of the furnace is the cooling section, in which no active burners are employed. The main problem is quality control. The instrumentation is limited to a few thermocouples, and, thus, a thorough knowledge of the temperature distribution in each zone is unavailable. Knowledge of the temperature distribution would allow Pinole Steel to adjust the burners to improve quality control.

\subsection{TELEDYNE WAH CHANG, ALBANY, OREGON}

Teledyne Wah Chang is a large rare earth specialty metal producer producing such exotic metals as Zirconium, Hafnium, and Columbium from Australian sand. Teledyne also processes large quantities of Titanium. Zirconium is produced for the nuclear industry to house fuel pellets in fuel elements in nuclear reactors. Hafnium is used as an additive to nickel-base superalloys 


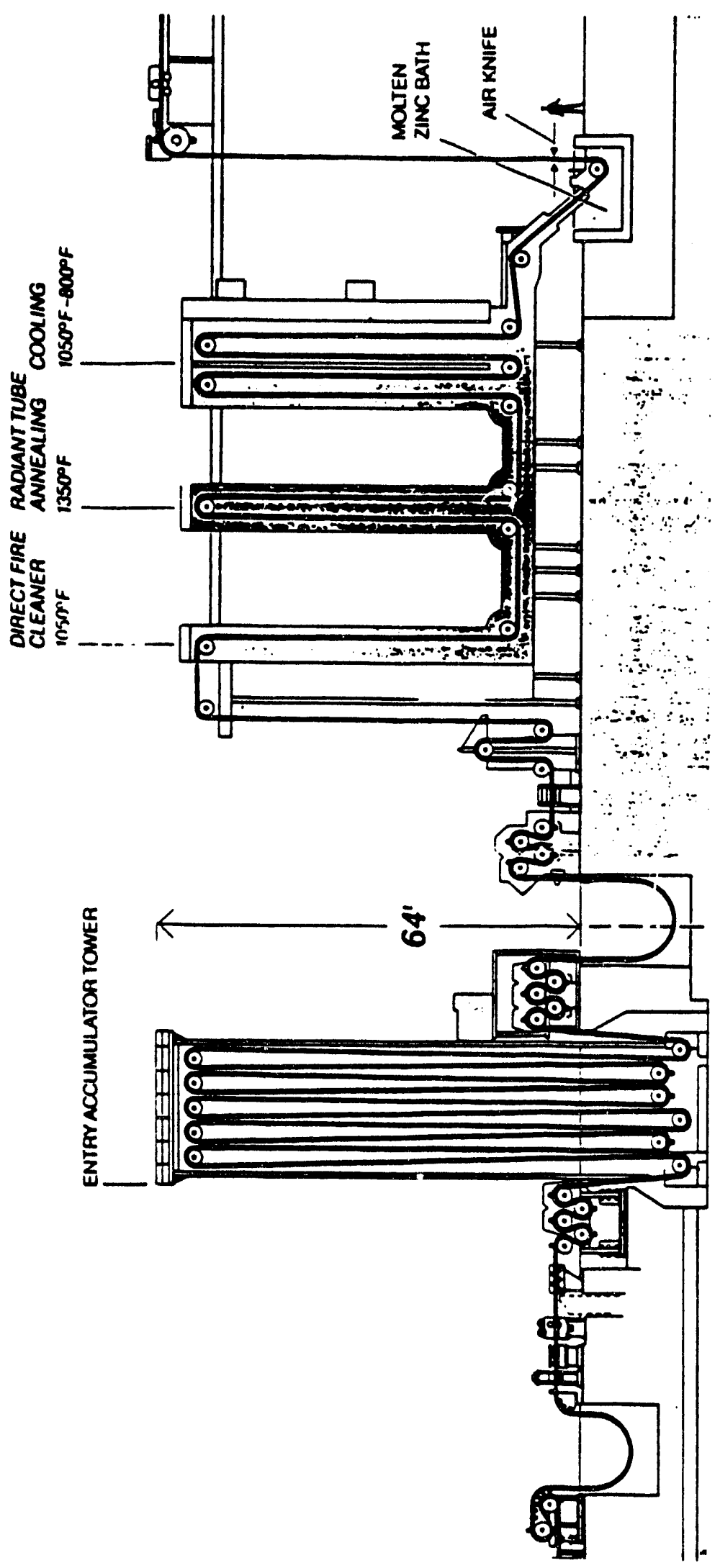

造 
which are used in gas turbines. Columbium finds application in superconductors. What these products have in common is that they are exotic and very high in value. In order to provide the strict requirements of quality and certification, accurate processing procedures and process temperatures must be maintained. Teledyne owns many facilities that process these materials where these requirements apply.

Of particular interest among the many facilities is an electrically heated inert atmosphere solution annealing furnace to continuously treat zirconium alloy sheet. The accuracy requirements are extreme and require that thermocouples be attached to the material and travel through the furnace with the material, because no other method meets the requirements of Bureau of Standards traceability. The temperatures are high requiring very expensive Platinum-Rhodium thermocouples equal to the length of the sheet. This method of monitoring is very expensive, time consuming, and inefficient.

Teledyne Wah Chang expressed a strong interest in working with the development team to test the new products and improve the operation of the facility. Teledyne is also interested in installing active closed loop controls to improve the reliability and predictability of its processes.

An agreement with Teledyne Wah Change to become a Beta-test site was needed, and preliminary tests were performed at this site.

\subsection{SUMMARY-METALLURGICAL FURNACES}

Of the three metallurgical furnace sites evaluated, the Teledyne Wah Chang continuous solution zirconium heat-treating furnace appears to offer the greatest potential for this program for Phase II and Phase III. The Teledyne facility has a sufficient number of view ports to permit observation of the material in process and measure actual process temperatures. Since Teledyne already measures the material temperature for certification purposes with travelling thermocouples that have been calibrated to Bureau of Standards requirements, it offers an ideal comparison of the new measurement technique with proven methods. 
The requirements that PSM have are much less stringent, and PSM does not typically conduct calibration runs, which, if conducted by the development team, would unnecessarily increase the cost of testing of the new product.

Similar comments to those made regarding the PSM facility apply to the Pinole Steel HeatTreating Furnace. The operation can be significantly improved with high-accuracy instrumentation, but the need is not as pressing as for Teledyne, who was willing as of these discussions to make substantial investments in time and equipment to improve the operation.

In summary, the heat-treating industry appears to have the most pressing needs for improved remote workpiece temperature measurement capability, and the need is recognized. Substantial improvements in quality and/or certixication capability can be achieved with new proposed thermometry. With higher confidence in their temperature monitoring capabilities, processors can reduce energy consumption, since the conservative method of supplying more than enough will be tempered. 


\section{SECTION 4}

\section{PRESENT TECHNOLOGY ASSESSMENT}

\subsection{OVERVIEW}

Temperature measurement devices can be broadly classified into two major categories: electronic and mechanical. Electronic devices include resistance temperature detectors (RTD), thermocouples, and noncontact techniques such as optical or radiation pyrometers, and acoustic pyrometers. Mechanical devices include bimetallic and mercury thermometers, etc. A review of the classic temperature measurement technologies needed to cover the various temperature ranges monitored in utility powerplant operations may be found in a recent paper by Gile (1986) (Reference 4). The limitations of optical pyrometers for use in measuring gas temperatures may be found in the reference book Steam/Its Generation and Use (Reference 5). Optical pyrometers, for example, have been used for several years as a way to make spot readings, primarily in combustion zones. To be reliably used, however, optical pyrometers must be responsive io a number of optical wavelengths, and they require some preliminary knowledge of thermal gradients through the gas medium to the point where the temperature measurement is to be made. Other limitations are in the inability of optical pyrometers to track temperatures throughout the furnace depth, and during furnace shutdown and startup cycles or during changes of load. Optical pyrometers are therefore not suitable to measure gas temperatures. For surface measurements the emissivity of the surface must be known. The Pyrolaser overcomes these problems as discussed later.

For gas temperature measurements in furnaces, mechanical temperature measurement systems are used that are typically configured to minimize errors due to radiation effects. An 
excellent review of the measurement of gas temperature in boiler furnaces may be found in a paper by Ely (1969) (Reference 6). These types of temperature probes require that cooling water be circulated in order to keep the probe support from melting. Such water-cooled high-velocity thermocouple (HVT) probes are used to measure temperatures above $1000^{\circ} \mathrm{F}\left(538^{\circ} \mathrm{C}\right)$. They have been successfully 'sed for many years, but become impractical when boiler widths exceed 40 to $50 \mathrm{ft}$ (12 to $27 \mathrm{~m}$ ) since the maximum working length of a probe is $24 \mathrm{ft}(7.3 \mathrm{~m})$. There is often insufficient access to ports or external clearance to permit a complete traverse. Surface temperatures are usually made with contact measurement devices which only read the temperature at one spot.

To utilize HVT to determine average temperatures requires that many point-by-point temperature measurements be taken in a very short time span within a measurement plane. Individual measurements are then averaged to obtain a final temperature. The water-cooled probes are difficult to maneuver and support, and the test procedure is quite labor-intensive. Extreme care must be taken to protect thermocouple junctions, extension wire splices, ceramic shields, and insulators from mechanical damage. This temperature measurement method is suitable only for periodic test measurements. Acurex has extensive experience in the design of high-temperature probes, and has conducted many measurement programs for the EPA and other regula'.ury and government agencies to characterize combustion facility operating conditions and environmental emissions.

Acoustic pyrometry is applied to gas measurements. It is not a new concept as it was first suggested by A. M. Mayer in 1973 (Reference 7). A recent paper by Green and Woodham (Reference 8) discusses acoustic pyrometry applied to a large utility boiler.

Acoustic waves propagate through a gas, or gas mixture, as a primary function of absolute temperature, and to a lesser extent as a function of the specific heat ratio and gas composition. These gas-specific variables can be predetermined (or separately determined) leaving gas temperature as the variable measured by acoustic techniques. 
Green and Woodham's tests were performed under ambient conditions on a out-of-service boiler by comparing acoustically measured temperatures to thermocouples and mercury-in-glass thermometers. They repeated the experiment while the boiler was in service and compared calculated values, based on boiler operating data. They did not conduct high-temperature validation tests with HVTs.

Another approach for measuring gas temperatures based on the propagation velocity of sound has been recently reported. This non-invasive method permits continuous real-time gas temperature measurements in the hostile operating environments existing in utility, commercial, and industrial boilers and furnaces. This method, best described as an acoustic pyrometer, has several advantages over optical pyrometers and thermocouple-type probes.

In large furnaces, water-cooled HVTs can provide bulk furnace temperatures. Temperature distributions, however, can only be measured using these devices provided a means is provided to traverse the furnace to be measured. Such a method is labor-intensive, not practical for large furnaces, and is intrusive to the heating process being measured.

An acoustic pyrometer, when combined with proper signal processing methods, can provide real-time temperature measurements and isothermal contouring within a furnace.

A relatively new instrument allowing the non-contact measurement of surface temperatures is made possible with the Pyrolaser. This instrument has been available for approximately 3 years and relatively few results have been published.

The Pyrolaser differs from an optical pyrometer in that it measures the surface emissivity of the object at the same time and location as the surface radiation. The guesswork has thereby been taken out of estimating the emissivity, which has been the primary source of errors when using an optical pyrometer. Reflections from walls and other surfaces also contributed to these errors.

The Pyrolaser offers a significant advancement over standard optical pyrometers but is still saddled with limitations that would argue for a new technology development such as Raman Spectroscopy. 


\subsection{COMPARISON OF RAMAN THERMOMETRY AND PYROLASER PYROMETRY}

This section compares the Raman thermometry approach to another method currently available for remote thermometry-the Pyrolaser pyrometer.

\subsubsection{Comparison of Operating Principles}

The Pyrolaser pyrometer combines a radiometer with a laser reflectometer for temperature measurements. A GaAlAs laser beam in the wavelength range of 0.8 to $0.9 \mu \mathrm{m}$ is emitted at the target solid and part of the beam gets diffusely reflected into the collection optics. By measuring the laser power diffusely reflected into the known solid angle of the collection optics and comparing it with the incident laser power, the surface reflectively, $R$, may be determined. The emissivity is then determined as $E=1-R$. Knowing the solid spectral emissivity, in the wavelength range of the GaAlAs laser, the solid temperature may be determined by measuring the continuum gray/blackbody radiation in the same wavelength range and using the Planck relationship:

$$
e_{\lambda b}(\lambda)=\frac{2 \pi C_{1} \lambda^{-5}}{\left(e^{C_{2} / \lambda T}-1\right)}
$$

A more detailed discussion is presented Reference 9.

By contrast, the Raman Spectroscopy technique interrogates the workpiece with a laser beam of any frequency and collects the Stokes and Anti-Stokes radiation for ratioing. The ratio of these two signals can then be used to determine the temperature.

\subsubsection{Comparison of Capabilities and Limitations}

Advertised specifications for the Pyrolaser are listed in Table 4-1. The device is lightweight and quite versatile, and the temperature window can be moved up or down. The main limitations of the Pyrolaser are:

- It is inaccurate at low reflectivities $(\sim 0.1)$

- It is not suited to specular surfaces 
Table 4-1. Pyrolaser specifications

\section{PYROLASER - SPECIFICAIIONS}

Temperature Range:

Resolution:

Accuracy:

Repeatability:

Distance Range:

Emissivicy Range:

LED Display in ViewEinder:

LCD Display:

Operaring Wavelengrh:

Visual Field of View:

I.R. Measuring Field:

Acquisition Time:

Sample Rate:

Scorage Capacicy:

Outpue/digical:

Ouepue/analog:

Power Supply:

Operating Time with Fully

Charged Bacreries:

Operaring Ambient Temp:

Scorage Temperature:

Dimensions:

Weight with Bacteries: $600^{\circ} \mathrm{C}-1500^{\circ} \mathrm{C}\left(1100^{\circ} \mathrm{F}-2730^{\circ} \mathrm{F}\right)$

$1^{\circ} \mathrm{C}\left(1^{\circ} \mathrm{F}\right)$

$3^{\circ} \mathrm{C}\left(5^{\circ} \mathrm{F}\right)$ at $1500^{\circ} \mathrm{C}\left(2730^{\circ} \mathrm{F}\right)$, emissivity 0.80

$1^{\bullet} \mathrm{C}\left(1^{\bullet} \mathrm{F}\right)$

$20 \mathrm{~cm}-10 \mathrm{~m}(8 \mathrm{in} .-33 \mathrm{EE}$.

$0.1-1.00$ (all temperacures below $1500^{\circ} \mathrm{C}$ )

4 digit LED corrected temperature

40 character readout of distance, emissivicy,

uncorrected remperature \& corrected remperacure

0.865 microns \pm 0.015

$7^{\circ}$

$1 / 3^{\circ}$ (1 $1 \mathrm{mom}$ e $20 \mathrm{~cm} ; .04^{\prime \prime}$ e 8 in.)

10 ms to 1000 ms selectable

$35 / \mathrm{sec} ; 700$ record dara logger filled in 20 seconds.

700 sers of measurements (rime, location, distance,

emissivicy, uncorrected remperacure \& correcred cemperature) Max number of extraneous temperacure readings (99).

RS 232C 110-19200 baud selectable

$0-5$ vole (resolution $1.25 \mathrm{mV}$ )

$3 \times 9 v$ rechargeable $N i C d$ batreries

2 hours

0 to $+50^{\circ} \mathrm{C}\left(32^{\circ} \mathrm{F}-125^{\circ} \mathrm{F}\right)$

$-20^{\circ} \mathrm{C}-+70^{\circ} \mathrm{C}\left(0-160^{\circ} \mathrm{F}\right)$

$318 \times 211 \times 74 \mathrm{mon}\left(121 / 2 \times 8 \times 3^{\prime \prime}\right)$

$3.5 \mathrm{~kg}$ (7 lbs.) 
- It is only suited to clean environments-no soot

- It is limited to wavelengths not absorbed by gaseous medium

- Laser wavelength must be within target's blackbody emission band

- Temperature range is high: $>600^{\circ} \mathrm{C}$ (with standard optics)

By comparison, the Raman thermometer has a temperature range from near absolute zero to over $4000^{\circ} \mathrm{K}$ (Figures $4-1$ and 4-2). The resolution and accuracy are similar to the Pyrolaser value given in Table 4-1, and just like the Pyrolaser, the range (focusing distance) can be changed by changing the optics. The Raman thermometer is unaffected by emissivity and works equally well with spectral and diffuse surfaces. Actually, spectral surfaces offer the advantage that the elastically scattered signal may be largely avoided by viewing or aiming the laser at an angle. This would relax the requirements for ultra-high rejection in the collection optics. Other advantages of the Raman Spectroscope include:

- No particular laser wavelength is required

- Laser frequency does not have to be outside gas absorption windows or within emission band of solid

- Can be used for non-thermometric measurements as discussed below

- Can be used in dirty environments and combustors

- Can be used to determine both gas and solid temperatures and thus determine heat transfer effectiveness

As discussed in the previous section, Raman thermometry is resistant to interference from:

- Particulate continuum radiation and fluorescence

- Particulate (Mie) scattering

- Laser-modulated incandescence

- Gas radiation, scattering and absorption

- Stray reflections of outside light

- Surface inhomogeneities in absorption and scattering of light 


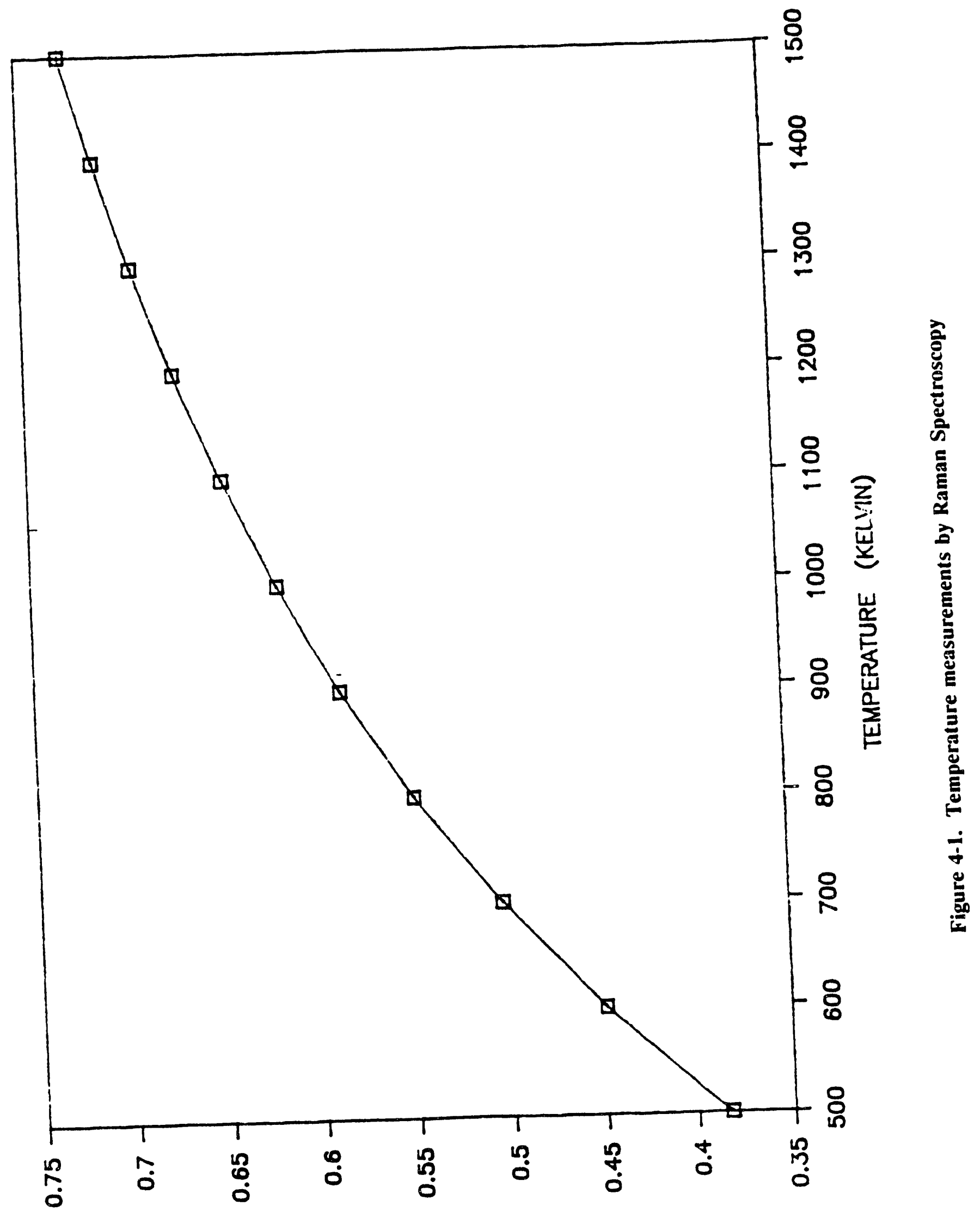

OUFy NUSZUNI 


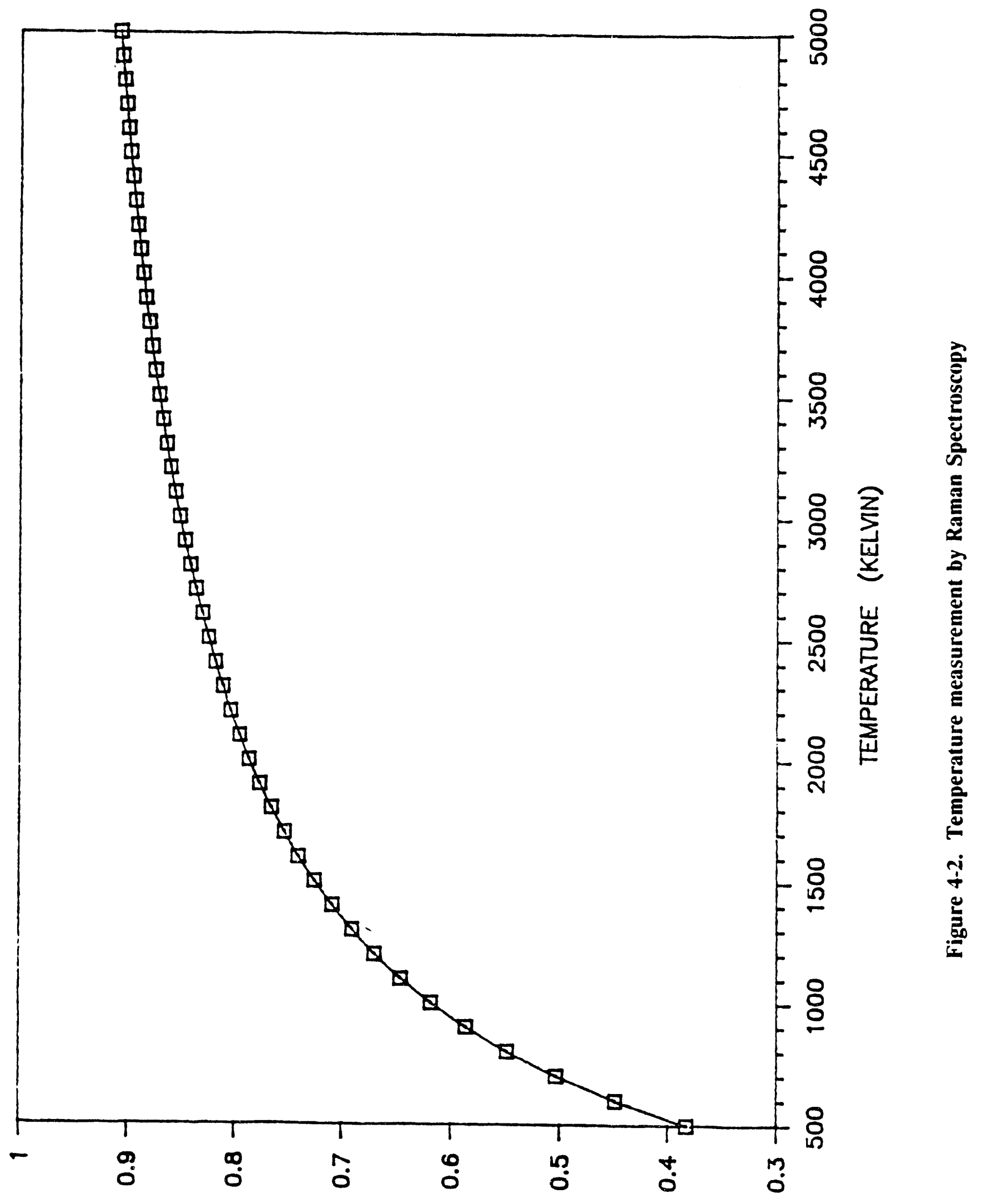

OUVA ULSILNI 
- Window dirt and fluorescence

- Dirty environs within or outside combustors

Although the Pyrolaser pyrometer is a very versatile instrument, it is not resistant to any of these interferences except fluorescence outside the laser emission band. If these fluorescence signals are strong enough, they could make the radiometer measurements erroneous and destroy the accuracy of the measurement.

\subsubsection{Comparison of Applicability to Non-Thermometric Measurements}

Both the Pyrolaser pyrometer and the Raman Spectroscope can be used for other measurements besides temperature.

The Pyrolaser incorporates a reflectometer and can be used for real-time determination of surface reflectivity (in clean environments). It can therefore be applied in materials science to observe surface phenomena such as grain boundary, grain structure, and composition changes. The reflectometer itself will not yield the species on the surface but will indicate if and when changes are taking place. For example, by measuring changes in reflectivity, the device can be used to observe changes during annealing or to infer whether an oxide coating has developed.

The Raman Spectroscope can also be used for several non-thermometric measurements. It can be used for:

- Remote detection and quantification of gaseous species (number density)

- Remote detection of liquid species

- Remote detection of particulate species and subsequent quantification via fluorescence

- Remote measurement of surface properties such as composition and adsorbed species, corrosion, strain/stress, grain properties

- Remote, in situ measurement of catalyst structure, composition and poisoning

- Remote study of processes such as annealing, smelting and heat treating for material composition, properties and temperature 
- Remote study and quantification of rust/oxide formation, soot and other particulate deposition and corrosion

\subsubsection{Measurement Regimes for Each Instrument}

From the above discussion, it can be concluded that the Pyrolaser pyrometer is best suited to measurements in particulate-free environments, at temperatures above several hundred ${ }^{\circ} \mathrm{C}$ ( $>500$ to $600^{\circ} \mathrm{C}$ ) and with non-specular solids having emissivities over 0.10 .

The Raman Spectroscope is suitable for measurements in clean or dirty environments with or without particulate luminosity. There are no requirements on workpiece emissivity ranges and specular reflection does not constitute a problem. The quantity of particulates and solid temperature determine the laser power required. Lasers in the commonly available visible wavelengths can be applied. At solid temperatures below about $1000^{\circ} \mathrm{C}$, low-power (10 to $100 \mathrm{~mW}$ ) $\mathrm{CW}$-lasers can be applied. At temperatures above about $2000^{\circ} \mathrm{C}$ in very sooty liquid- and solid-fueled flames, pulsed lasers are needed with about 0.1 to $1.0 \mathrm{~J} /$ pulse and power output, $P>10^{4} \cdot 10^{6}$ Watts.

\subsection{MARKET FOR APPLICATION OF PYROLASER OR RAMAN SPECTROSCOPY}

The objectives of Phase I were to determine whether Pyrolaser or Raman Spectroscopy is technically and economically feasible for industrial furnaces and to identify the best specific applications. Subobjectives included:

- Identifying the features and benefits of new instrumentation systems needed for improved furnace productivity, with an emphasis on new pyrometry methods

- Characterizing the technical and cost aspects of furnaces and furnace operation, with an emphasis on temperature-related quality control and productivity issues

- Determining the best contribution for new pyrometry and quantifying the benefits

- Assessing the costs and economic attractiveness of new pyrometry

- Estimating the number of furnaces and the energy use impacted by a successful new pyrometry system 
- Helping to identify and qualify candidate field evaluation sites

The application study was to cover furnaces used for metals forming, metals heat treating, the fabrication of ceramic parts, and process and refining furnaces.

The market assessment identified those applications and furnace types for which the new instrumentation will provide the greatest benefits. The market assessment covered:

- The importance of the data to the process

- The ability of current and possible future control systems and burners to utilize the new information provided by the instrumentation system

- The improvements in product quality and yield implied by the improvements

- The improvements in furnace operation implied

- The economic benefits of the improvements

In addition, the market assessment identified the relative size and importance of the various submarkets in the industry, concentrating on submarkets with high premiums on product quality (especially dimensional accuracy and uniformity of bulk properties and surface quality), and a variety of product shapes or sizes being handled in the same facility. This is discussed in Section 2.

\subsection{ADVANCED MEASUREMENT CAPABILITIES OF RAMAN SPECTROSCOPY}

Raman scattering is the inelastic scattering of light from material media. In the Raman effect, the incident light undergoes a wavelength change while the scattering medium experiences an energy change in the process. This effect and its intensity can be used to determine the material or surface temperature. If a laser is directed at a target, the colliding photons can either lose energy to or gain energy from the target medium. The resulting Stokes scattering is monitored, and it can provide a wealth of information besides temperature about the surface condition. Raman scattering in solids has been extensively investigated. Much of the current effort in Raman Spectroscopy is devoted to this technology due to its versatility. In addition to workpiece temperature, Raman scattering yields information about stress/strain, composition, crystal orientation, impurity concentrations, charge carrier concentrations, and several other properties 
simultaneously. Instrumentation to date has been primarily for laboratory purposes except for atmospheric studies, but has not been adapted to the industrial world.

Several advanced additional measurement capabilities are summarized below. The development of Raman thermometry would result in an instrument that could be easily adapted to incorporate these additional capabilities of analysis.

\subsubsection{Stress/Strain Indication}

The Raman effect is made possible by the strain dependence of the electronic polarizability. Raman Spectroscopy can (and has) therefore been used to indicate the effects of uniaxial and hydrostatic stresses. Some development is required before this method is applicable to general in. situ stress/strain measurements. Shear stresses and strains can also be indicated, although it is questionable whether compound stresses can be resolved in any meaningful way.

\subsubsection{Crystallography}

Due to the lattice-specificity, high time-resolution (order of nanoseconds), and high-spatial resolution (order of microns) of a Raman probe, the method is uniquely suited to nondestructive crystallography. Applications include the study of:

- Changes in crystal structure (e.g., $\mathrm{FCC} / \mathrm{BCC} / \mathrm{HCP}$ )

- Changes in the solid phase, ranging from diffusion through such reactions as oxidation/passivation

- Changes in grain property during heating or working

- Elastic and/or plastic deformation of crystals

- Characterication and study of point and line defects

\subsubsection{Species Concentrations}

Raman Spectroscopy can be used to study species concentrations in gases, liquids, and solids. This is especially useful in the solid phase for determining impurity concentrations. The concentration of solute elements affects such properties as strength, hardness, and charge-carrier 
concentration. In the case of semiconductors, the type and conceniration of impurity atoms is crucial, and may be studied during the deposition or diffusion process.

Gases and liquids can be examined via nonlinear Raman effects such as CARS and stimulated Raman, to improve the signal/noise ratio. In combustion gases, for example, transient reaction species and radicals may be studied to elucidate the combustion process.

\subsubsection{Corrosion Studies}

Raman Spectroscopy is well suited to the study of oxide formation and corrosion. Chemical profiles can be obtained of the oxide films on iron, steel, and other metals. In polluted atmospheres, Raman Spectroscopy may also be used to analyze metallic salts formed on piping elements and reaction vessels. Raman analysis can thus be used as an in-place. nondestructive indicator of reaction vessel condition.

\subsubsection{Catalysis Studies}

Raman Spectroscopy is well suited to in-situ studies of catalysts. This nondestructive method can be used to detect and characterize adsorbed species and poisons in-site. The structure. reactivity and phase transitions of the catalyst and substrate can be observed during operation. The potential market for nondestructive, in-situ catalytic study is large and includes the inorganic chemical, petroleum and petro-chemical industries as well as biochemical industries. In-situ observation will allow catalyst performance to be optimized, saving energy and improving product quality. A brief sampling of catalysts is presented below.

- Hydrosulfurization catalysts such as cobalt and nickel molybdates have been studied for rictivity employing Raman spectroscopy

- Methanation catalysts- $\mathrm{NiO} / \mathrm{Cr}_{2} \mathrm{O}_{3} / \mathrm{MgSiO}_{3}$-have also been studied in-situ to determine catalyst structure and the effects of reduction and sulfiding

- Petroleum refining catalysts are numerous and include:

- Naphtha reforming catalysts such as $\mathrm{Pt} / \mathrm{ReCl}$, where $\mathrm{Re}$ denotes a rare earth metal

- Dimerization catalysts such as $\mathrm{Ni}$ or $\mathrm{Al}_{2} \mathrm{O}_{3}$ 
- Polymerization catalysts such as $\mathrm{TiCl}_{4}$ and other Ziegler catalysts

- Isomerization catalysts such as $\mathrm{Pt}$ or $\mathrm{PtCl}$

- Fluid cracking catalysts such as zeolites

- Hydrocracking catalysts such as $\mathrm{CoMo}$ and $\mathrm{NiMo}, \mathrm{NiO}, \mathrm{CoO}, \mathrm{MoO}_{3}$

- Hydrogeneration catalysts such as $\mathrm{NiO}, \mathrm{CoO}$ and $\mathrm{MoO}_{3}, \mathrm{Pt}, \mathrm{Pd}$

- Elemental sulfur recovery catalysts such as $\mathrm{Al}, \mathrm{Ti}, \mathrm{Fe}$ oxides

- Steam hydrocarbon reforming cataiysts such as $\mathrm{Al}_{2} \mathrm{O}_{3}, \mathrm{ZnO}, \mathrm{Fe}, \mathrm{Cr}$ oxides.

Other catalysts that can be studied include Friedel-Crafts catalysts such as $\mathrm{AlCl}_{3}$ and $\mathrm{FeCl}$, Quinone production catalysts such as $\mathrm{V}_{2} \mathrm{O}_{5}$ and $\mathrm{MnO}_{2}$ and Amino-synthetic catalysts such as Pd.

The Raman process is undeterred by the wide variety of processes and catalysts and applies equally to all.

\subsection{POTENTIAL PYROLASER ENHANCEMENTS}

The Pyrolaser represents the latest state-of-the-art remote surface temperature measurement technology. Optical pyrometers measure the energy emitted from a radiating surface. This temperature is dependent on the emissivity of the surface, which is a function of the maturial, temperature and surface condition such as roughness. Pyrolaser not only measures the energy emitted from the radiating surface, but also measures the reflected light from a GaAs laser beam to determine the surface emissivity at the same location where the temperature reading is taken and at the same time. A detailed discussion of the principles of the Pyrolaser can be found in Appendix B: Improved Infrared Temperature Measurement by Utilization of Laser Technology.

Measurements performed on this program at the PSM facility and many previous other facilities have shown that the Pyrolaser is sensitive to surface reflectivity. The instrument performs best when the surface condition comes closest to that of an ideal black body. When the surface of the measured body exhibits a degree of specularity, small errors in the temperature measurement persist. New approaches are being developed to address this question to implement correction factors in the measurement routines. 
A second enhancement that has been identified to make the instrument substantially more attractive to the marketplace is multipoint measuring capability while the unit is located in a fixed location. A multiplexing fiberoptics capability is being investigated.

Additionally, a substantially lower temperature capability is being sought. 


\section{SECTION 5}

\section{PYROLASER-PYROFIBER INDUSTRIAL TESTS}

\subsection{INTRODUCTION}

To gain a better understanding of the Pyrolaser temperature measurement capability, two tests were performed at PSM and one at Teledyne Wah Chang. The tests performed at PSM were conducted in conjunction with another test program to evaluate acoustic pyrometry. The test conducted at Teledyne was performed with a standard Pyrolaser and additionally with an advanced Pyrofiber-breadboard system. The Pyrofiber system utilizes two fiberoptics cables to route the signal to a remote sensor housing. The breadboard system was built as a result of observations made during earlier testing at PSM on this project. The breadboard was to demonstrate the feasibility of this concept. Efficiencies gained on the project allowed for this advanced work showing feasibility. Instrument development would be further carried out in Phase II of this project. Feasibility was demonstrated for the Pyrofiber unit although several specific problems have to be addressed in the future.

\subsection{PYROLASER TESTS AT PRECISION SPECIALTY METALS (PSM)}

Two tests were performed at PSM. The first test was primarily a survey test to determine what the best settings and the best system configuration would be at the site. The following objectives were set for this part of the project.

The exact furnace geometry was to be determined, the access to view the material in process, the thermodynamics and heating cycle, dynamic timing effects, the temperature irradiance conditions and other pertinent ancillary factors. During the course of the inspection several measurements of temperature were made. Expanded tests were performed at a later date in which 
trailing thermocouples were passed through the furnace at the same time Pyrolaser measurements were made.

\subsubsection{Furnace Details}

The metal heat treating operation at PSM uses a continuous strip annealing furnace designed and constructed onsite by J. T. Thorpe in 1988 . It measures $50 \mathrm{ft}$ in length by approximately $8 \mathrm{ft}$ in width. It is fed by a roll of sheetmetal, usually 301 Stainless Steel, which enters at ambient temperature. Furnace temperature setpoints are approximately $1950^{\circ} \mathrm{F}$ and $2050^{\circ} \mathrm{F}$ in the first and second halves (zones) of the furnace, respectively. Different materials and thicknesses require somewhat different temperatures and feedrates.

The furnace is followed by a caustic quench and a set of acid baths for posttreatment according to customer order. The treated metal then winds onto a roll at the end of the process.

A roll of metal takes about 20 to $25 \mathrm{~min}$ for complete processing. Before the end of a roll enters the furnace, the beginning of a new roll is welded to it, for continuity. After passing through the process, the small weld section is discarded and a new roll started.

The furnace has 16 pairs of natural-gas-fired twin bed burners. North American developed the twin bed concept to take advantage of regenerative furnace principles for fuel conservation. One burner fires while its twin serves as a flue, in which heat-storing material extracts heat from the flue gas. After $20 \mathrm{~s}$, they reverse roles, and the heat reclamation bed pre-heats the cold combustion air, without additional fuel expenditure.

A schematic of the PSM sintering furnace and burner operation and description is shown in Figure 5-1.

For utilization of the Pyrolaser there was only one useable access port. This port is situated on the top of the furnace and approximately $6 \mathrm{ft}$ from the steel exit. At this position the steel was in an ascending geometry from its catenary path, and the estimated distance of the steel from the viewing port ranged from 28 to 32 in. The viewing port itself was a glass window having a diameter 


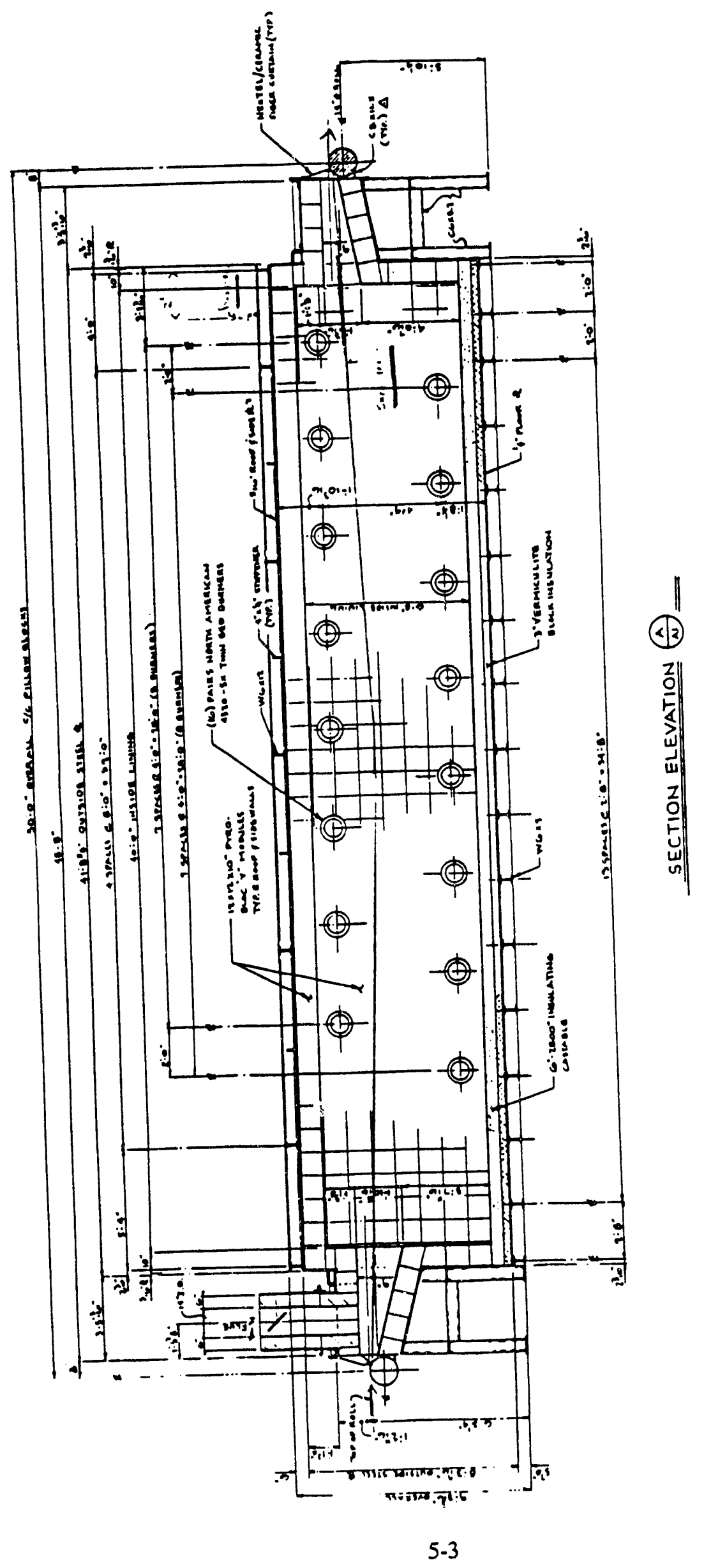

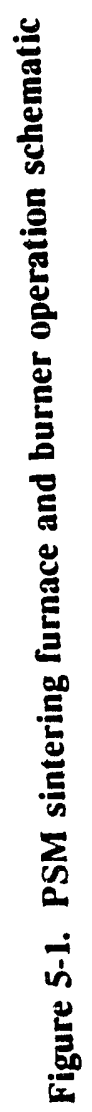


of $1-1 / 2$ in, and sub-tending below the viewing port was a sighting tube with a length of approximately 10 in and an inside diameter of $1-1 / 2$ in.

The burner installation incorporated state-of-the-art technology which recycled expended energy to preheat incoming air mixtures by alternately cycling each burner as a heat source and as an exhaust flue. Cycle time was approximately 20 to $30 \mathrm{~s}$, and as such the field of view of the Pyrolaser, when positioned on the target steel, was intermittently exposed to the natural gas flame approximately $30 \mathrm{~s} / \mathrm{min}$.

The glass viewing port was visually dirty upon first investigation, and it was very difficult to see the surface of the target steel, and essentially impossible to use the Pyrolaser's split image focusing system to input the distance to the instrument. There was no other practical access to the steel target from any other position on the furnace. A possible surrogate measurement of the exiting steel could be made and correlation to the steel temperature at the viewing port location might be inferred.

\section{2 .2 Test Measurements}

The readings of the steel were made through the apparently radiance-obscured window by mounting the instrument on a floor tripod and placing the positioning head in a vertical orientation. The first reading was made with the instrument approximately 12 in from the viewing port; and the minimum distance was set with the objective lens, which for this particular instrument, $\mathrm{S} / \mathrm{N} \# 005$, was $6.35 \mathrm{ft}$. The results yielded an emissivity of 1.0 and a corrected temperature reading of $1247^{\circ} \mathrm{F}$. Five min later a second reading was made of the steel, having increased the height of the tripod so that the instrument was approximately 51 in from the viewing port; and res'lts were an emissivity of 1.0 and corrected temperature reading of $1495^{\circ} \mathrm{F}$. A final reading in the initial series of measurements was made in a hand-held position estimating actual distance from the viewing port to be 53 in, again with minimum distance set into the Pyrolaser; and the results were an emissivity of 0.99 and corrected temperature of $1209^{\circ} \mathrm{F}$. 
Simultaneously, a reading was made on the exiting steel to assess temperature correlation. At an actual and focused distance of $8.58 \mathrm{ft}$ and an inputted target angle of $45^{\circ}$, an emissivity of 0.96 was measured and a corrected temperature of $1702^{\circ} \mathrm{F}$. The time period encompassing all of the above measurements was $13 \mathrm{~min}$, and during this interval the same steel product roll was being processed and the same hoped-for thermodynamic conditions within the furnace were set and controlled. These conditions were to achieve an ambient temperature of approximately $2000^{\circ} \mathrm{F}$ in the area or zone of the furnace where the viewing port and temperature measurements were being made.

In order to obtain access to the viewing port for measurements by the Pyrolaser, a Williamson infrared online pyrometer had to be removed, and it was noted that at that time its indicated reading on the control panel was $2030^{\circ} \mathrm{F}$.

The viewing glass window was changed upon our request, and subsequent readings with the Pyrolaser were made. The first reading with the clean window in the second series of measurements was with the instrument mounted on the tripod at a distance from the viewing port of approximately $51 \mathrm{in}$, and with the viewing port approximately 30 in from the steel, or a total actual distance of $81 \mathrm{in}$, or $6.75 \mathrm{ft}$, and a set-in distance of $6.35 \mathrm{ft}$. The measured emissivity was 0.93 with a corrected temperature of $1860^{\circ} \mathrm{F}$. The next reading in the series, made with the tripod extended to its maximum height, was taken approximately 61 in from the viewing port, the minimum distance set in; and the measured values were an emissivity of 0.63 and a corrected temperature of $1947^{\circ} \mathrm{F}$. The final reading in the second series, with the tripod maintained in its maximum elevated position, but with an inputted distance of $6.75 \mathrm{ft}$, the computed estimated distance, yielded an emissivity of 0.85 and a corrected temperature of $1899^{\circ} \mathrm{F}$.

A third series of readings was made on the target steel from the same viewing port approximately $4 \mathrm{hr}$ later, and this time the automatic mode of operation was selected. It was noted that even in this relatively short time period from the second series of measurements, the visual condition of the sighting port had darkened markedly. During this approximately 2-min time 
measuring period it was necessary to make some fine sighting adjustments on the instrument to assure that it continued to measure the steel through the viewing port.

A second automatic mode set of measurements was then made on the steel sheeting exiting from the furnace, with the Pyrolaser mounted on a tripod and having an angle of incidence of approximately $45^{\circ}$ to the sheeting and having this same target angle set into the instrument.

\section{Discussion of Test Measurements}

The conditions of the viewport glass affected the measured parameters. The first series of readings yielded emissivities of 0.99 to 1.0 and corrected temperatures from $1209^{\circ} \mathrm{F}$ to $1495^{\circ} \mathrm{F}$, indicative of low radiance signals and large laser reflectance radiance measurements. At the same time, the measured temperature values of the steel exiting from the furnace were approximately $1700^{\circ} \mathrm{F}$ and the temperature in the same hot zone as the steel measured was approximately $2000^{\circ} \mathrm{F}$.

There was variation in temperature measurements as a function of actual and set-in focal distance as temperature values varied from $1868^{\circ}$ to $1947^{\circ} \mathrm{F}$ (through a clean, newly replaced viewing port) and emissivity varied from 0.63 to 0.93 . These differences occurred during the second series of readings. The readings were taken through a sight tube which might offer radiance interruption depending upon the target size/focal distance utilized. The measurement of both temperature and reflectance is accomplished by measuring the intensity of a cone of radiation that is defined by the optics of the instrument and the focal distance to the target. Should there be any encroachment of this radiation cone, such as might be caused by the inside diameter of the sighting tube, the amount of radiance measured will be reduced and a lower radiance temperature and reflectance value will be indicated.

The intermittent gas flames had no effect on Pyrolaser measured values.

Further tests of the Pyrolaser on the furnace were needed in view of the variations measured during initial testing and as described above. The condition of the viewing port glass seemed to be a vital component and there should be some means undertaken to maintain the glass. 
Measurements of the exact distance between the steel target material and the Pyrolaser had to be made and this exact information incorporated into the instrument. An average value of focal distance had to be utilized to approximate the catenary variations of the steel sheeting as it passes below the viewport.

Measurements of the steel material by the Pyrolaser should be made with and without the presence of the sighting tube to determine experimentally what effect this tubular system has on both the temperature radiance signal from the target steel and the laser reflectance radiance signal from the Pyrolaser.

Temperature measuring tests of the sheeting utilizing a shorter focal length lens on the instrument should be made to see what effect this change of the measuring cone of radiance, vis-avis the sighting tube, might have on the recorded values of temperature and emissivity.

If possible, sighting of the Pyrolaser through a furnace opening of greater than 2 in is suggested to see if this larger furnace aperture (greater than the aperture of the objective lens system of the instrument) affects the measured values.

Results of the measurements made are tabulated in Table 5-1. Additionally, a sample printout of data from the Pyrolaser test is shown in Figure 5.2.

The second set of data collected at PSM during the second test yielded significantly better results compared to the first, but it also pointed the way toward possible improvements that should be made to the Pyrolaser system.

This set of tests took place from March 27 to 30, 1990. In addition to the Pyrolaser measurements, thermocouples and an acoustic pyrometry system provided data for the tests. Some of the thermocouples were welded to the metal being processed, and were covered with small radiation shields. Other thermocouples were incorporated into custom-designed ring probes, which rode through the furnace on top of the metal being heat treated. Thermocouple signals were coldjunction compensated and linearized before recording. 
Table 5-1. Summary of measurements

\section{SERIES 1:}

WITH THE SIGHTING WINDOW IN A VISUALLY 'DIRTY' CONDITION:

\begin{tabular}{|c|c|c|c|c|}
\hline ACTUAL & DIST. & & & \\
\hline DIST.FROM & SET-IN & MEASURED & CORR. & \\
\hline VI EWPORT* & IO PL & EMISSIVITY & TEMP. & COMMENTS \\
\hline & MINIMUM & & & \\
\hline $12^{\prime \prime}$ & DI STANCE** & 1.0 & 1247 & TRIPOD MOUNTED \\
\hline $51^{\prime \prime}$ & MINIMUM & 1.0 & 1495 & TRIPOD MOUNTED \\
\hline $50 "$ & MI NIMUM & 0.99 & 1209 & HAND-HELD \\
\hline
\end{tabular}

MEASUREMENT OF STEEL EXITING THE FURNACE:
$8.35^{\prime}$
$8.35^{\prime}$
0.96
1702
ACTUAL AND SET-IN ANGLE
OF INCIDENCE $45^{\circ}$

* Distance from vi ewport to steel estimated at 30" (average of catenary POSITION)

* UNABLE TO FOCUS ON TARGET 
Table 5-1. Summary of measurements (concluded)

SERIES 2:

THE VIEWING PORT GLASS WAS CHANGED AND WAS VISIBLY CLEAR:

\begin{tabular}{|c|c|c|c|c|}
\hline ACTUAL & DI ST. & & & \\
\hline DIST.FROM & SET-IN & MEASURED & CORR. & \\
\hline VIEWPORT* & IO $P / L$ & EMISSIVITY & TEMP. & COMMENTS \\
\hline $6.34^{\prime}$ & $6.34^{\prime}$ & 0.93 & 1868 & TRIPOD MOUNTED \\
\hline $6.35^{\prime}$ & $6.35^{\prime}$ & 0.63 & 1947 & TRIPOD MOUNTED \\
\hline $6.75^{\prime}$ & $6.75^{\prime}$ & 0.85 & 1899 & TRIPOD MOUNTE \\
\hline
\end{tabular}

SERIES 3:

A) MEASUREMENT OF STEEL IN THE FURNACE THROUGH THE VIEWPORT IN THE AUTOMATIC MODE: SEE BELOW READINGS 10 THROUGH 63. 
B) STEEL EXITING THE I IACE: SEE ATTACHED READINGS $f$ iHROUGH 107

NOTEBOOK PRINT

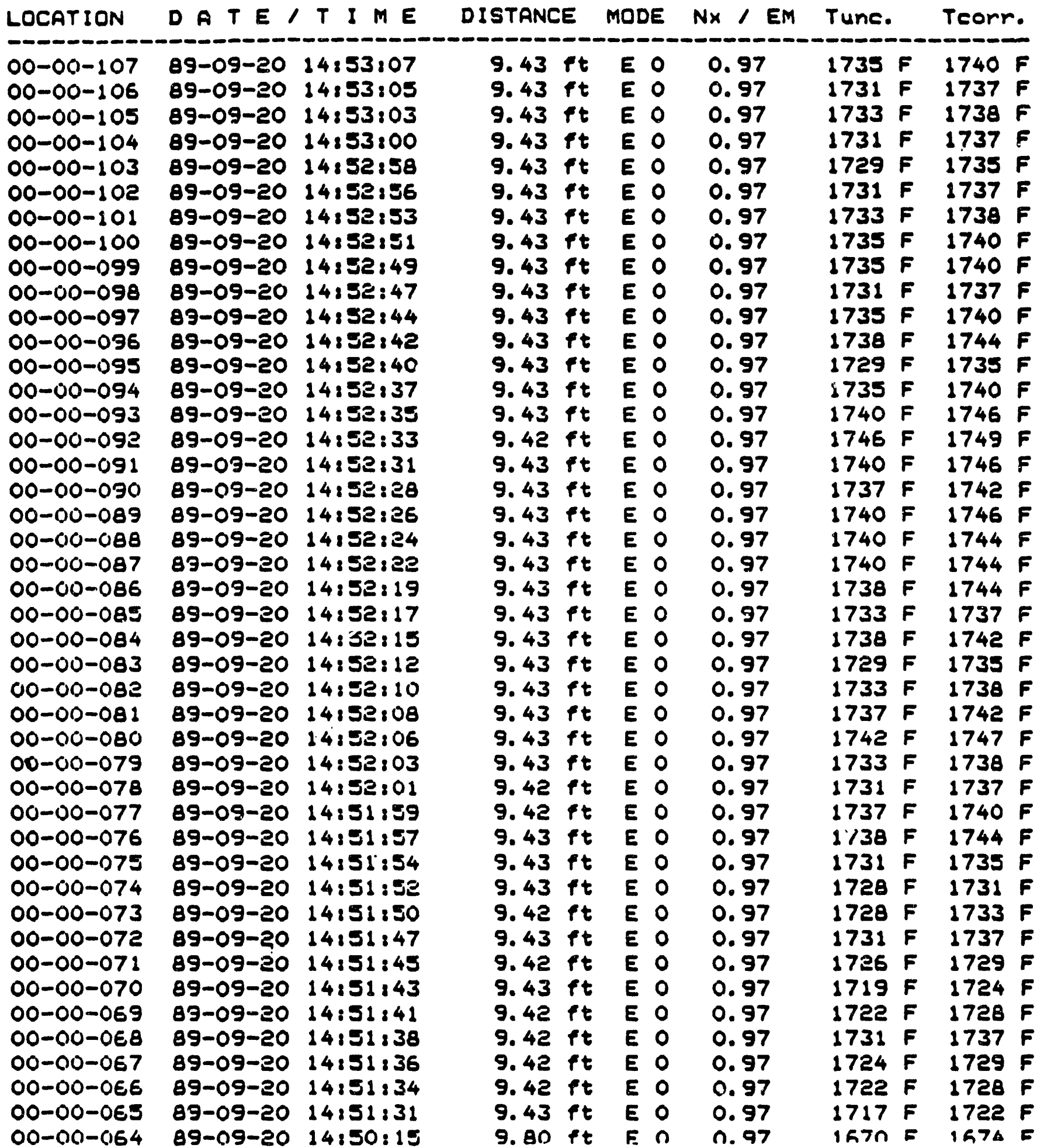

Figure 5-2. Sample data-Pyrolaser 


\begin{tabular}{|c|c|c|}
\hline $\begin{array}{ll}00-00-0 E 3 & 89 \\
00-00-062 & 89 \\
00-00-051 & 85 \\
00-00-060 & 85 \\
00-00-059 & 85 \\
00-00-058 & 85 \\
00-00-057 & 85 \\
00-00-056 & 8 \\
00-00-055 & 8 \\
00-00-054 & 8 \\
00-00-053 & 8 \\
00-00-052 & 8 \\
00-00-051 & 8 \\
00-00-050 & 8 \\
00-00-049 & 8 \\
00-00-048 \\
00-00-047 \\
00-00-046 \\
00-00-045 \\
00-00-044 \\
00-00-043 \\
00-00-042 \\
00-00-041 \\
00-00-040 \\
00-00-039 \\
00-00-038 \\
00-00-037 \\
00-00-036 \\
00-00-035 \\
00-00-034 \\
00-00-033 \\
00-00-032 \\
00-00-031 \\
00-00-030 \\
00-00-029 \\
00-00-028 \\
00-00-027 \\
00-00-026 \\
00-00-025 \\
00-00-0 \Xi 4 \\
00-00-023 \\
00-00-022 \\
00-00-021 \\
00-00-020 \\
00-00-0119 \\
00-00-018 \\
00-00-017 \\
00-00-016 \\
00-00-015 \\
00-00-014 \\
00-00-013 \\
00-00-012 \\
00-00-011 \\
00-00-010\end{array}$ & 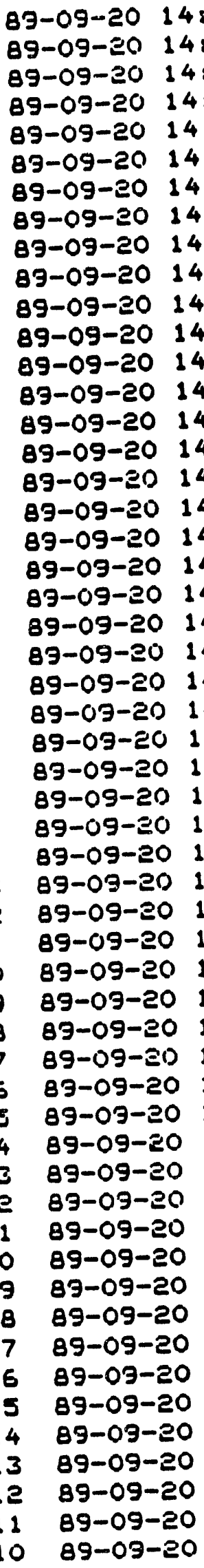 & 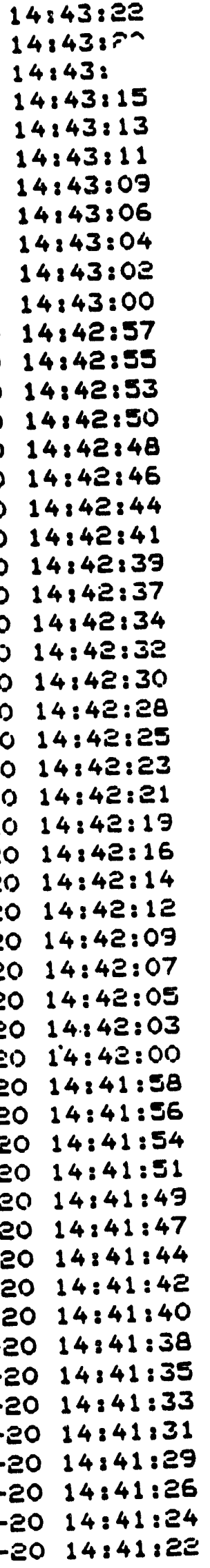 \\
\hline
\end{tabular}

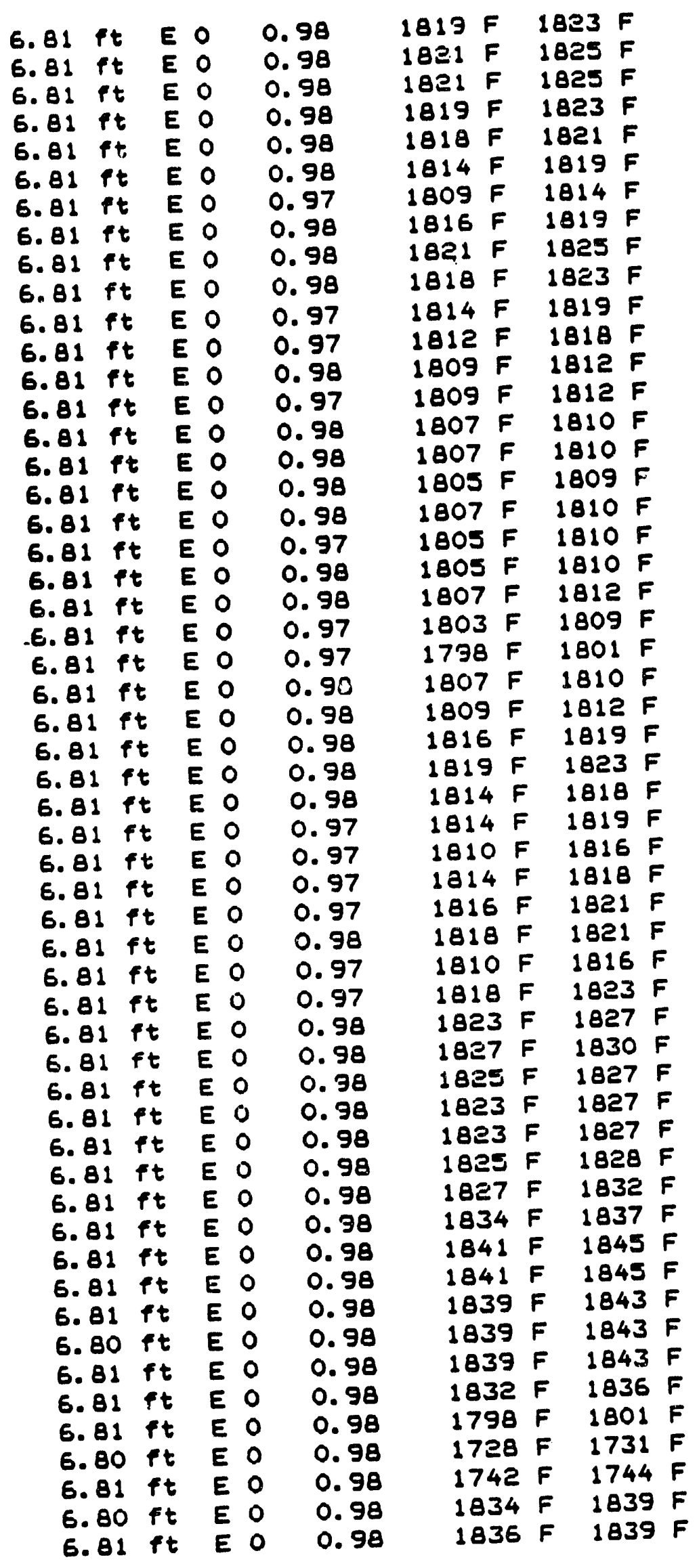

Figure 5-2. Sample data-Pyrolaser (concluded) 
A total of 13 test runs was conducted. Seven included thermocouple and Pyrolaser data, and the other six compared readings from two thermocouple probes. Of the 13 runs, eight included acoustic pyrometry data (see Table 5-2).

Comparison of data from probes located side-by-side on the metal coil shows that the temperature across the width of the sheet is consistent over the sum of the run, but shows minor variations due to the fact that some burners are on while others are off (manually shut off, in addition to the twin bed cycling). The ring versus weld thermocouple data show similar results. An example of a composite plot of data from a test run is shown in Figure 5-3.

The Pyrolaser and thermocouple readings matched to within $23^{\circ} \mathrm{F}$ for the test series, and were usually within approximately $12^{\circ} \mathrm{F}$. Possible sources of error include specularity/view angle effects on the Pyrolaser, and effects of radiation and thermal lag on the thermocouples. Overcoming sensitivity to specularity and view angle is a possible improvement suggested by this set of tests.

A key to the economical implementation of this goal is the development of the Pyrofiber system to eliminate the expensive optics needed for multiple imaging, whether in specularity correction or in multipoint monitoring. The testing described in the next section incorporated a prototype Pyrofiber unit.

\subsection{PYROFIBER-BREADBOARD}

Efficiencies gained on the originally planned program during execution allowed ior expanded feasibility assessments to be performed. PIC prepared a breadboard version of the Pyrolaser. The main optics of the system were replaced with fiberoptics elements. Two fiberoptics cables were mounted on the system. One carried the laser light and directed it onto the target, while the other was used to collect the return signal.

\subsection{PYROFIBER TESTING AT TELEDYNE WAH CHANG}

An agreement had been reached with Teledyne Wah Chang to test Pyrolaser and Pyrofiber technology at the company's facility. Teledyne operates many heat treating facilities processing 


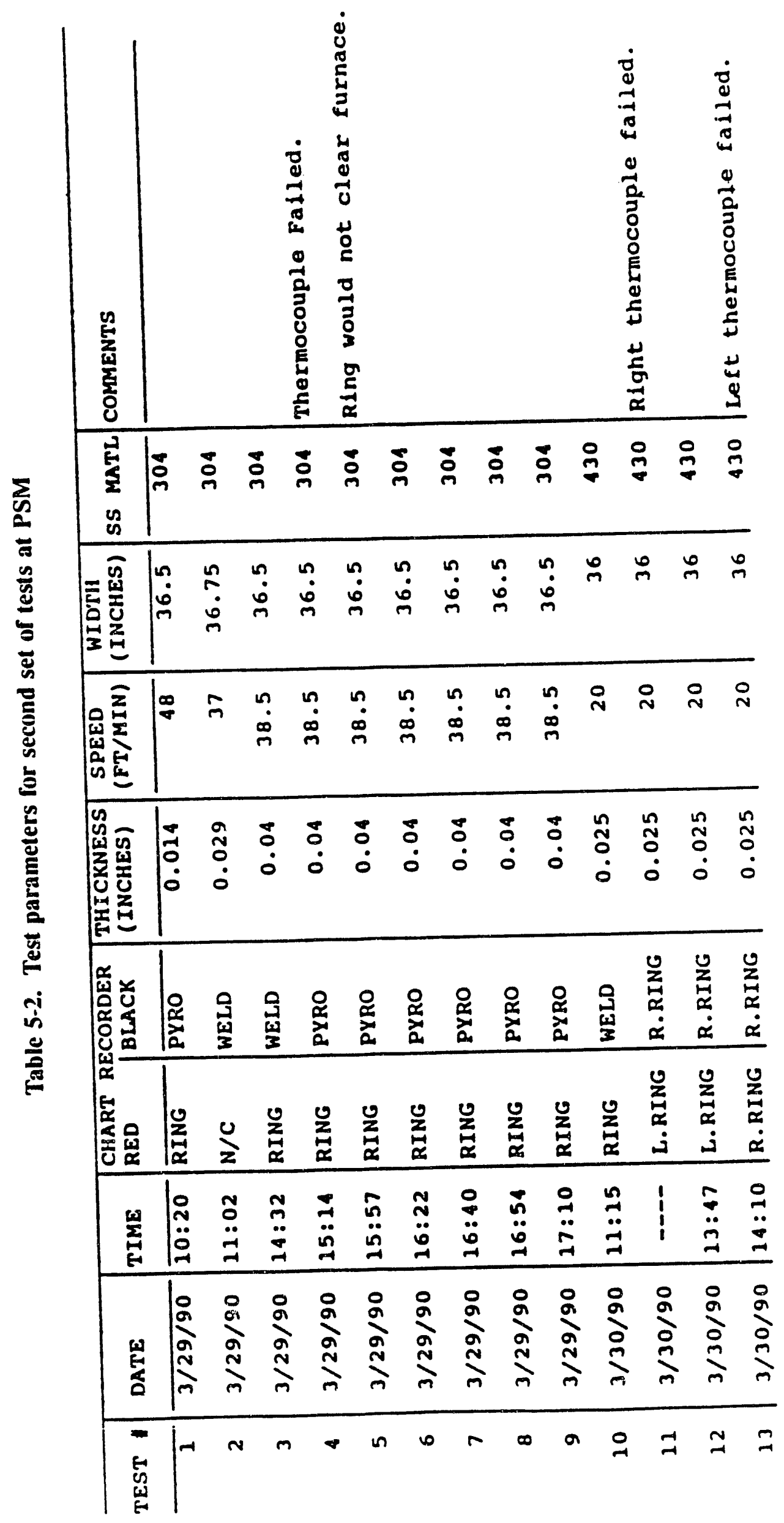




\section{AXIAL TEMPERATURE MAPPING}

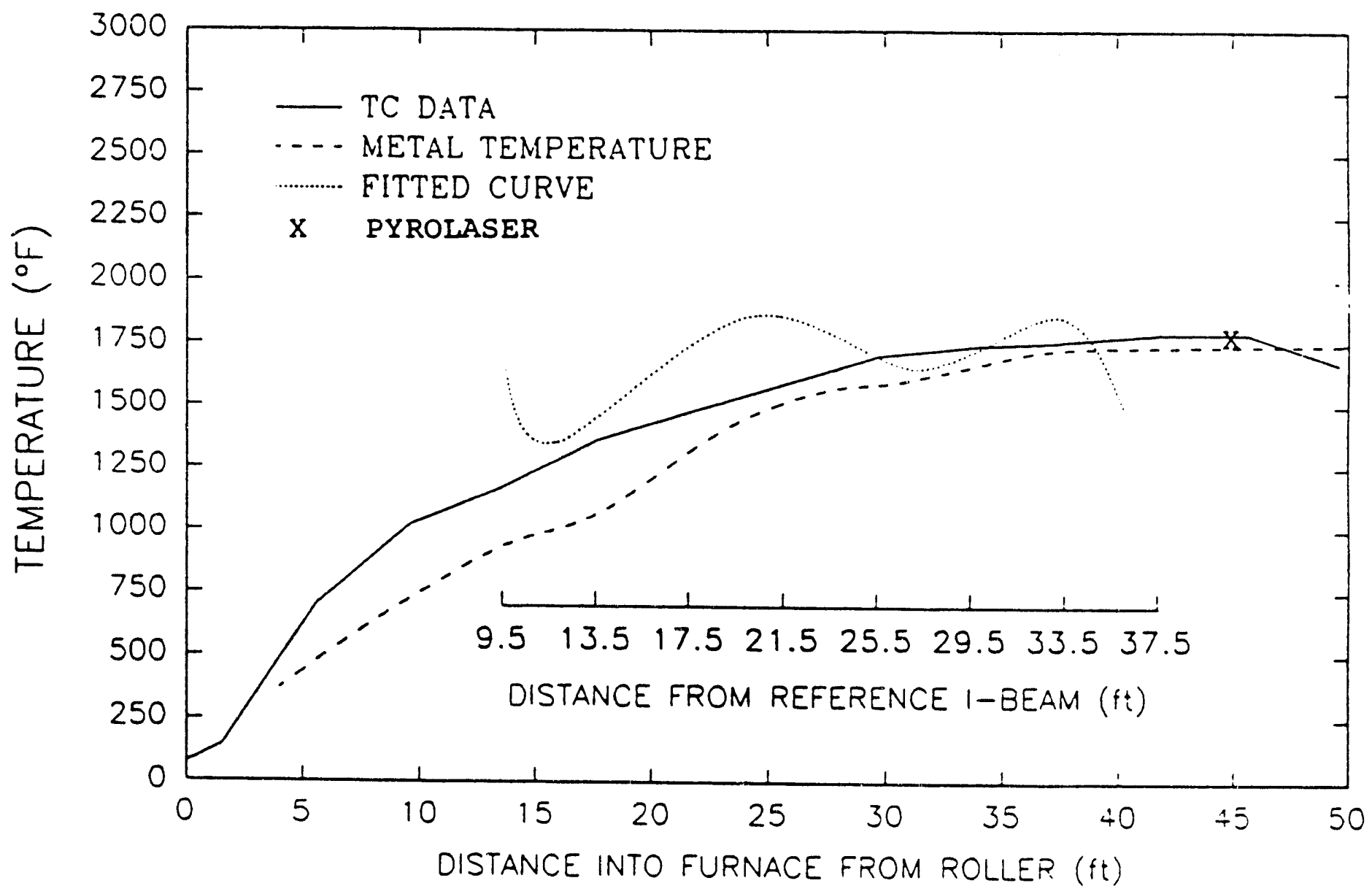

Figure 5-3. Composite plot of PSM test data 
exotic materials used in the nuclear industry. Temperature measuring accuracy requirements are stringent, demanding carefully controlled processes. A continuous sheet annealing furnace similar to that tested at PSM was of particular interest, because it was electrically heated and had an inert nitrogen atmosphere. This minimized the potential problems with combustion products encountered with the PSM furnace.

The primary product heat treated is zirconium of varying thickness and width. To determine the actual temperature in the furnace and of the product as it passes through the furnace, trailing thermocouples are installed on the zirconium sheet. Teledyne installed two additional viewports near the end of the furnace to permit the mounting of a Pyrolaser and Pyrofiber unit. Teledyne also permitted the installation of a data recording PC that monitored all process parameters. These data would be invaluable in assessing the performance of the two systems, and allow comparison with the process parameters.

To accomplish control and data acquisition for a test, it was necessary to write a control program to retrieve data from the various devices. The system schematic is shown in Figure 5-4. An IMC Data Manager was used to connect the various devices via an RS 232 interface. The PC acted in the capacity of controller, directing the flow of data at specific times and also initiating data recording by the temperature measuring devices.

The facility was equipped witlı a Kaye Digistrip Datalogger that recorded all process parameters. These data were also routc $d$ to the PC and included in a data base for evaluation in Lotus $1-2-3$ or other suitable spreadsheet program.

The Pyrolaser unit was installed on the furnace behind a sight glass and valve arrangement to protect the unit from excess heat and also to provide a seal for the furnace. The Pyrofiber unit was installed viewing the material directly since this unit was less sensitive to the heat of the process.

The system was installed and fully checked out. Initial data showed the temperature in the region where the units were installed to be much lower than expected. This meant that data could 


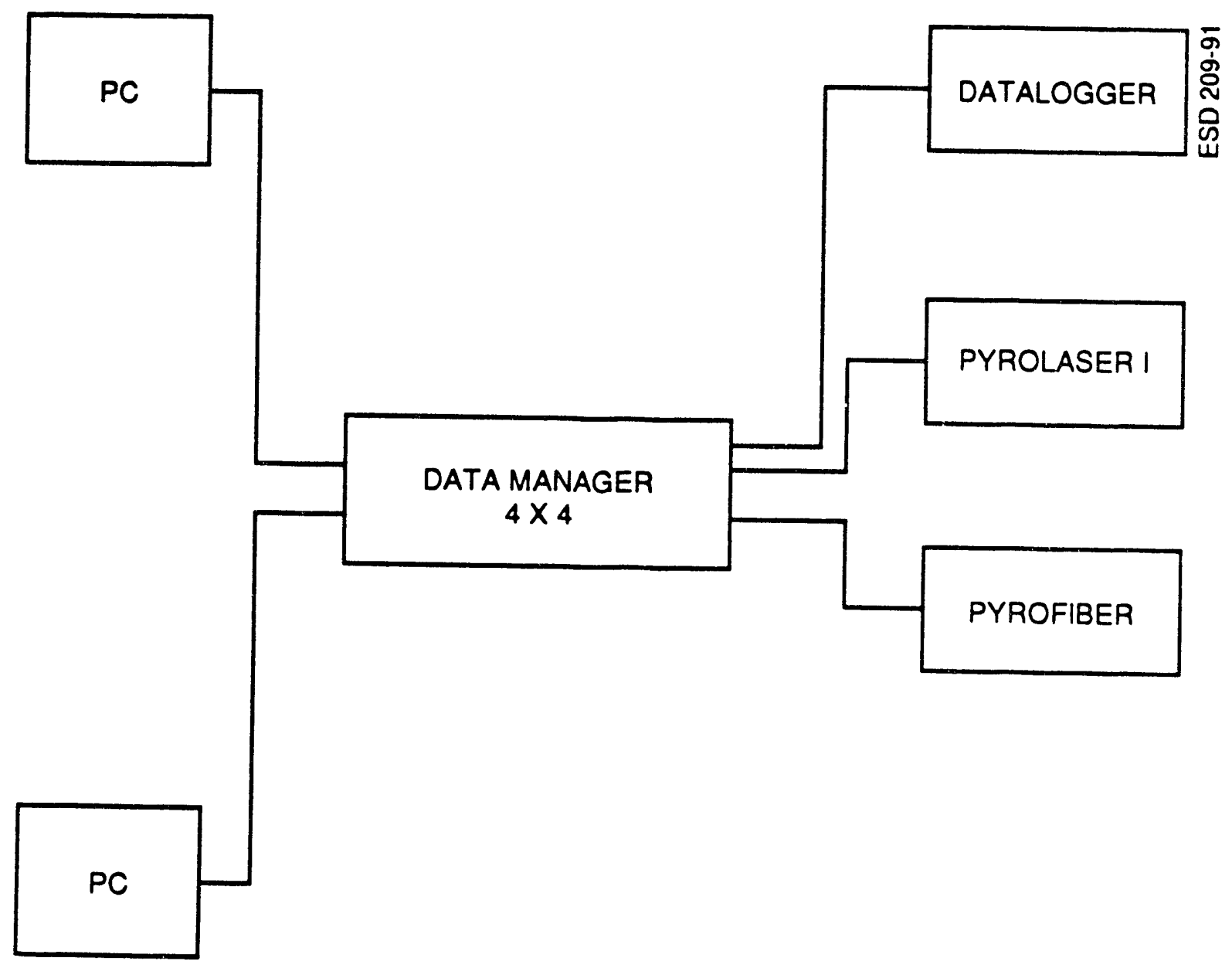

Figure 5-4. System schematic 
only be taken on special high-temperature runs of material. The section where the units were installed apparently experienced significant cooling from the end of the furnace. This was unexpected and new data for Teledyne as well. The problem experienced in this case was the low temperature measuring capability of the Pyrolaser systems, which is near $600^{\circ} \mathrm{C}$.

\section{$5.5 \quad$ RESULTS}

Some initial test results were obtained from the system installed at Teledyne. The data were only partially available since the Pyrolaser system shuts down recording of the data when the temperature is too low. In any case, the system was functional when the temperature was sufficiently high for the material to be processed. A complete analysis of the data, however, was not possible. The results indicated several factors, however.

- To be most versatile, the design of a system musi allow for the monitoring of temperatures below $600^{\circ} \mathrm{C}$

- Reflectivity of the material can be a serious problem when the material is processed at low temperatures where the material does not yet behave as a black body radiator

- Fiberoptics sensors can be installed in areas that are much more restricted than the room required for a Pyrolaser system

Based on the results to date, a work program was developed that would include enhancements to the Pyrolaser. The initial results support the finding that Pyrofiber enhancements to the Pyrolaser system are economical to implement and would advance the state of the art in temperature measurements much faster that other proposed systems. 


\section{SECTION 6}

\section{RAMAN SPECTROSCOPY-FEASIBILITY}

\subsection{INTRODUCTION}

The feasibility of a Raman Spectroscopy surface temperature measurement instrument has been discussed in Section 4.3. It has been shown that the two primary technologies investigated in this project are the Pyrolaser and possible enhancement of Raman Spectroscopy. Pyrolaser technology would offer a quicker entry into the market with an instrument that could perform quite well. This instrument would have to be carefully applied to yield good results. Raman Spectroscopy, on the other hand, offers capabilities beyond temperature measurements and could address a larger market. This technology would require significantly more research and development and would, as a result, become available only at a later date. To determine what the most recent developments have been in Raman Spectroscopy, a literature review was conducted to include any new findings in a laboratory-scale system and test program. Results of the literature review are discussed in Section 6.2 and the laboratory Raman Spectroscopy system is presented in Section 6.4. The test program planned is presented in Section 6.4.

\subsection{LITERATURE REVIEW}

The objective of this task was to review current literature on Raman Spectroscopy as it would apply to the DOE Workpiece Temperature Analyzer project, and to summarize relevant findings.

An extensive number of publications were reviewed, spanning the period of 1986 through 1989. These publications are listed in Table 6-1. 
1. Optics Letters, all issues in 1988, 1989

2. SPIE Optical Engineering, Volumes 27 and 28; 1988, 1989

3. Combustion Science and Technology, 1988 and 1989

4. Combustion and Flame, 1988 and 1989

5. Journal of Quantitative Spectroscopy and Radiative Transfer, 1987-1989

6. Journal of the Optical Society of America, A, 1988, 1989

7. Journal of the Optical Society of America, B, 1988, 1989

8. Optics and Lasers in Engineering, 1988, 1989

9. ASM Journal of Heat Treating

10. Optical and Quantum Electronics, 1989

11. Optics and Spectroscopy, 1988, 1989

12. Reviews on Solid State Science, 1988, 1989

13. Solid State Communications, 1988, 1989

14. Surface Science, 1989

15. Soviet Physics-Solid State, 1988, 1989

16. Spectroscopy Letters, 1988, 1989

17. Journal of Physics C: Condensed Matter, 1989

18. Journal of Physics B: Atomic, Molecular and Optical Physics, 1989

19. Soviet Journal of Optical Technology, 1988, 1989

20. Journal of Vacuum Science and Technology, 1988, 1989

21. Journal of Mat. Research, 1989

22. Advances in Laser Spectroscopy, 1986, 1987

23. Journal of Raman Spectroscopy 
The publications reviewed reported no instances of solid state thermometry applying Raman Spectroscopy. In particular, there was no report on backscatter-spontaneous-Raman Spectroscopy.

The only findings related to the WPTA project involved application of Coherent Anti-Stokes Raman Spectroscopy (CARS). The details may be found in the Journal of Quantitative Spectroscopy and Radiative Transfer, Vol. 40, No. 3, September 1988. The three important results are summarized below in Sections 6.2.1 through 6.2.3.

\subsubsection{Carbon Monoxide Spectrum in a Flame}

In this study, a single mode pulsed laster system was developed to measure linewidths of important gas-phase Raman lines. A spectral resolution of $0.003 \mathrm{~cm}^{-1}$ was achieved. CARS measurements were carried out at Sandia Laboratories on the CO spectrum in a flame. Theoretical predictions were also made and corrected for line broadening effects such as collision and Stark broadening, and for saturation from high laster intensities. The corrected predictions are in good agreement with experiments, as shown in Figure 6-1.

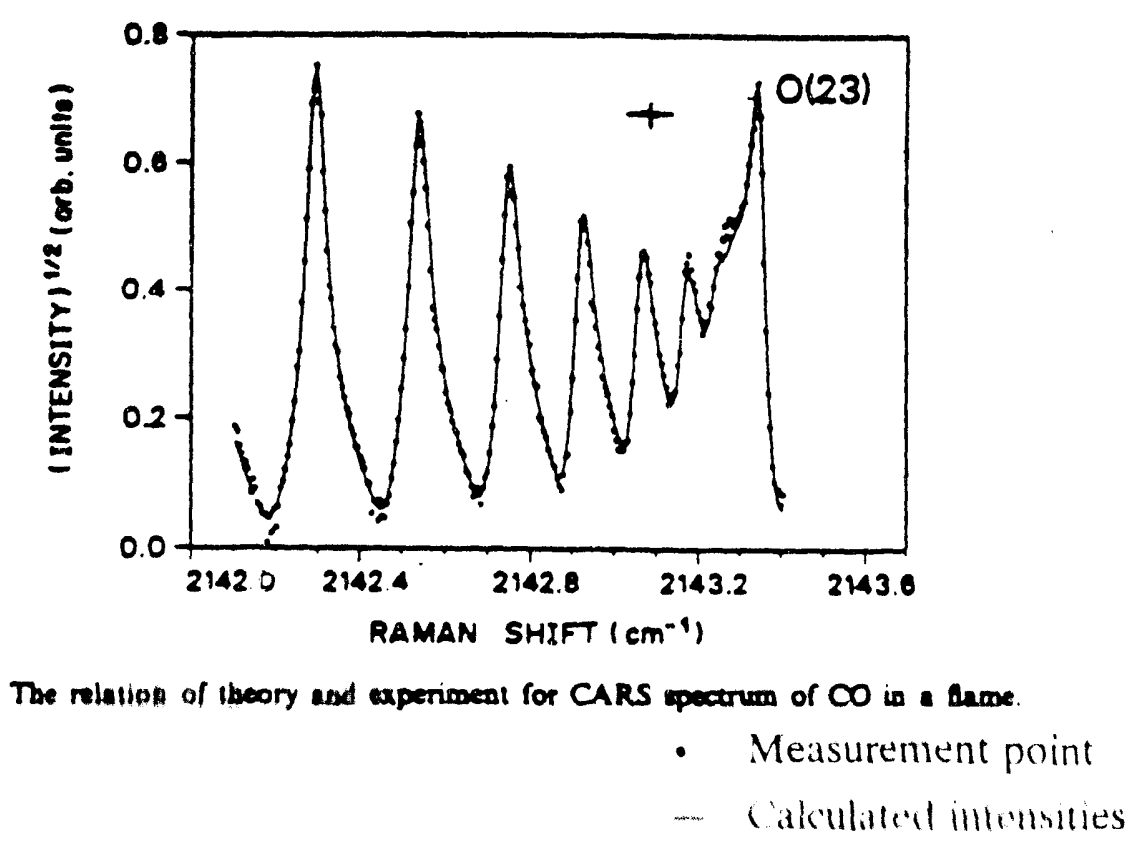

Figure 6-1. CARS spectrum of $r O$ in a flame 
One of the most relevant aspects of this study is the high optical resolution $0.003 \mathrm{~cm}^{-1}$. By comparison, the estimates of Signal/Noise in the WPTA proposal of December 1988 were obtained with a conservative resolution of $0.1 \mathrm{~cm}^{-1}$. The higher resolution $(0.003 \mathrm{~cm})$ makes it easier to filter out noise from spectrally broad interference sources such as particulate luminosity and workpiece gray/blackbody radiation.

\subsubsection{Temperature Profiles in a Sealed Lamp}

CARS was also used to obtain temperature profiles inside a 1,000-W lamp at General Electric Co. The CARS beam geometry and temperature profile are presented in Figure 6-2. It is noteworthy that no special provisions were made for optical access in conducting these measuremerits.

\subsubsection{Temperature Measurements in Operating Diesel Engine}

Finally, CARS was applied to measure temperature as a function of crank angle in a sooty, operating diesel engine. The results are presented in Figure 6-3, where the Raman measurements are compared to a theoretical modei for the engine process. The good agreement is evident.

\subsubsection{Conclusion}

CARS is not applicable to the opaque objects to be probed in the WPTA project. Therefore, the main result of interest in this literature review is the improved spectral resolution of the optics. The 30 -fold improvement from $0.1 \mathrm{~cm}$ to $0.003 \mathrm{~cm}$ is a very important determinant of device accuracy. Also, the calculations of December 1988 assumed a 20 percent detector quantum efficiency. This is conservative, and currently available detectors can improve the Signal to Noise Ratio $(\mathrm{S} / \mathrm{N})$ by as much as 1.5 to 2 over the $\mathrm{S} / \mathrm{N}$ calculated with 20 percent quantum efficiency. 


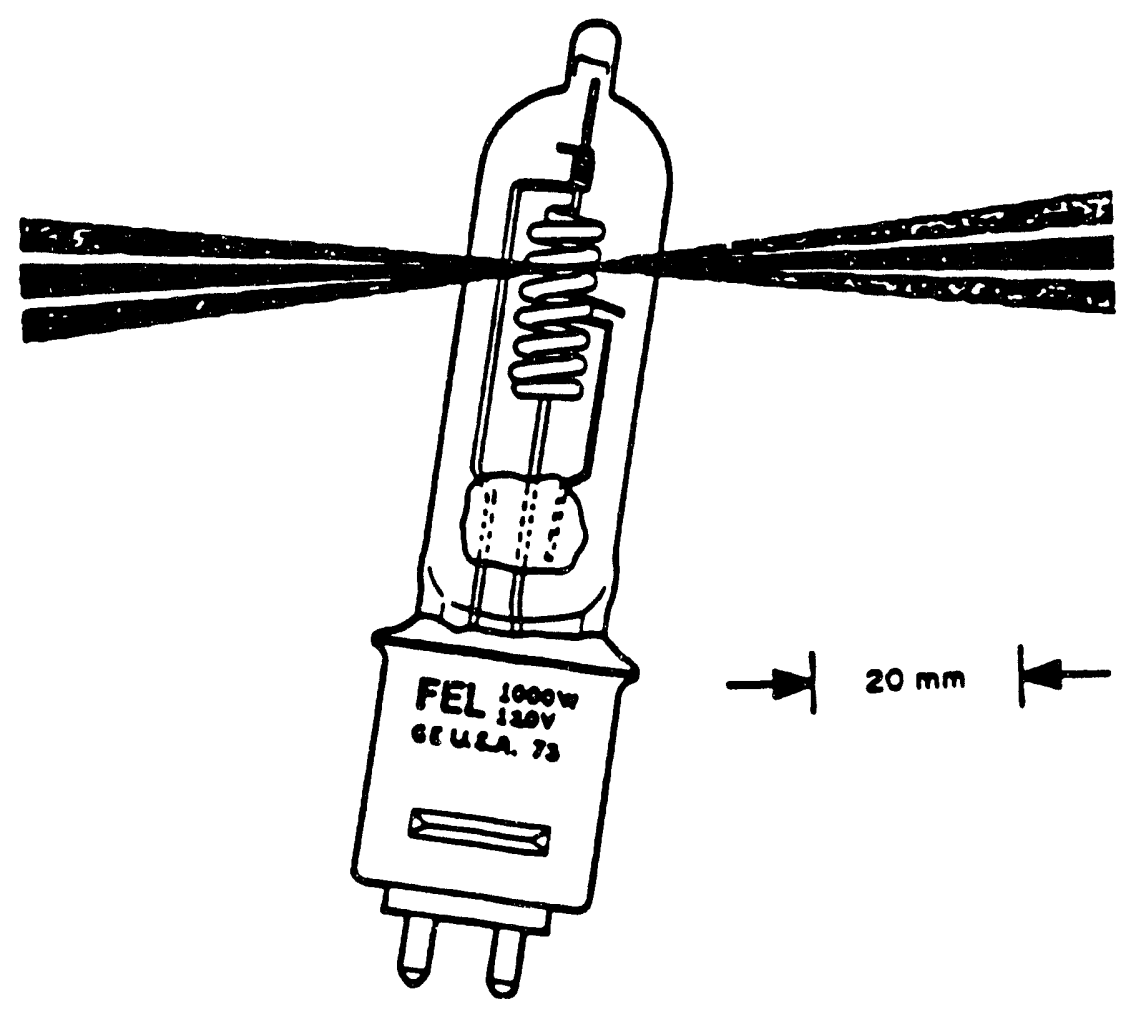

Figure 6-2a. CARS beam geometry

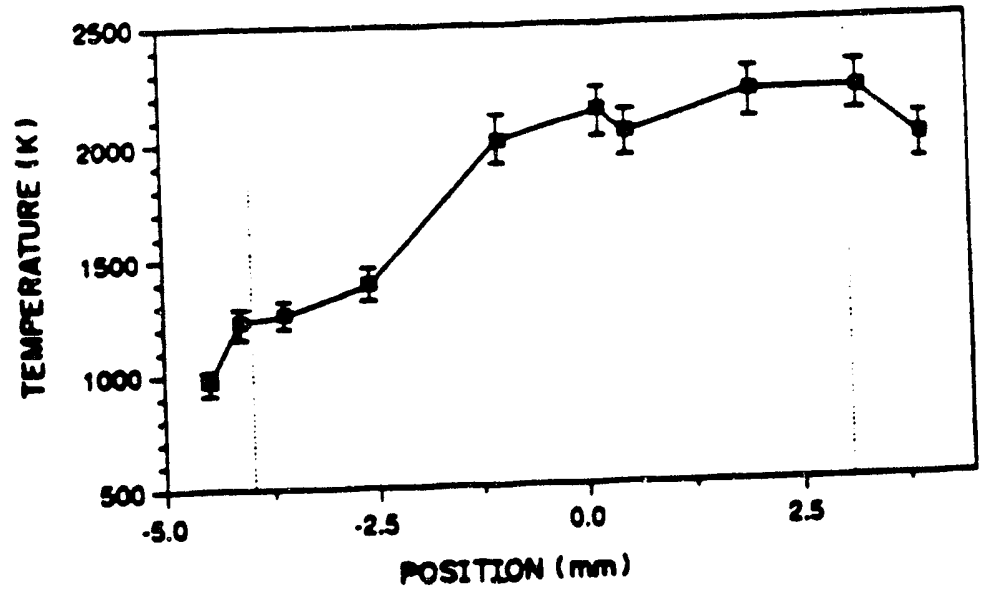

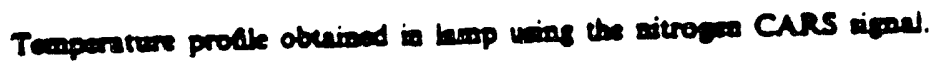

Figure 6-2b. CARS temperature profile

Figure 6-2. CARS temperature profile in sealed filament lamp 


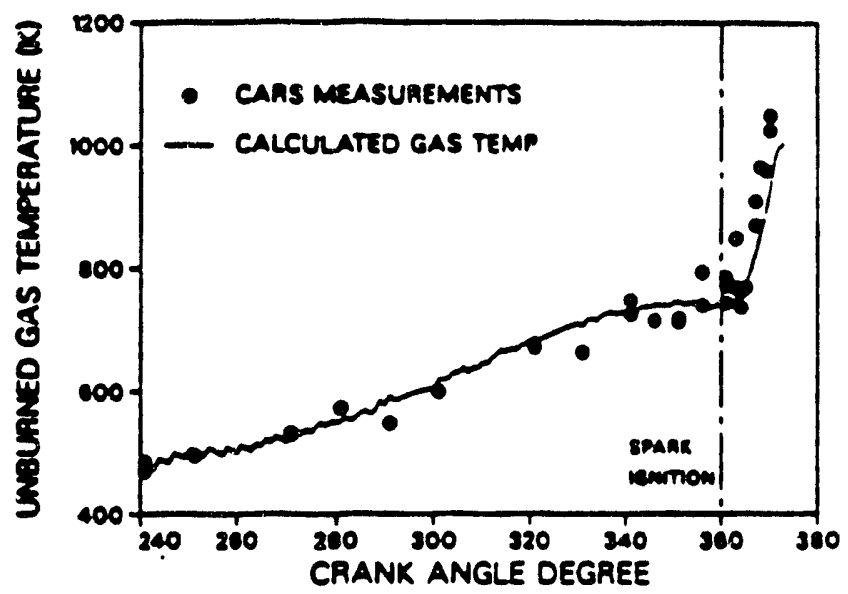

CARS comperature monurements as a hucctios of crabk ande compared to a theoretical model for the envine process.

Figure 6-3. CARS temperature measurement in an operating diesel engine

\subsection{LABORATORY-SCALE RAMAN WPTA SYSTEM}

\subsubsection{Introduction}

This section discusses the laboratory-scale system for investigating Raman Spectroscopy as a Workpiece Temperature Analyzer Technology. The discussion covers basic system components, system tradeoffs and vendor information, system, layout, and system costs.

\subsubsection{Basic System Components}

The Raman WPTA involves six functional subsystems:

- Light Generation

- Light Delivery to workpiece

- Light Retrieval from workpiece

- Spectral Resolution of Retrieved Light 
- Conversion of Resolved Spectra into Computer-Processible Signals

- Computer-Processing of Spectra and Generation of Control Signals

Each subsystem is summarized below.

\section{Light Generation}

The light source is a laser. The required laser characteristics such as power and pulsed/cw (pulsed/centiwatt) depend on the applications environment. Pulsed lasers with higher energies are required for the dirtier/sootier environments and high workpiece temperature, to overcome workpiece and background luminosity. The laser frequency, mode, repeatability and linewidths are also variables, and tradeoffs are discussed in Section 6.3.1.2.

\section{Light Delivery to Workpiece}

The delivery of laser light to the workpiece can be dccomplished via a lens system or via fiberoptics. The factors to consider include safety, flexibility in beam delivery, cost per measurement for multiple simultaneous measurements, signal strengths and losses, space utilization, and operation and maintenance. Each choice has its advantages and disadvantages. These factors are discussed in Section 6.3.1.2. Although a lens delivery system will work well for a laboratory test, fiberoptics are preferable for the ultimate industrial system. They have therefore been chosen for the laboratory tests. This choice permits the evaluation of most important beam-delivery issues during the laboratory phas a and reduces the number of important new variables for the full-scale evaluation.

\section{Light Retrieval from Workpiece}

Retrieval of scattered light from the workpiece can be done via fiberoptics or via a lens system. In solid Raman Spectroscopy, the scattered light signal is very weak (about 10 to 12 orders of magnitude less than the outgoing signal). For fiber collection, this means a relay lens must be attached to the fiber for increased light collection and signal, as well as reduced ambient stray light. Standard relay lenses for fibers are available from vendors such as Oriel. A fiber system with a single fiber will also require a positioner assembly to match the fiber to the spectrograph ( $F$ number 
matching). The positioner is an $\mathrm{X}-\mathrm{Y}-\mathrm{Z}$ adjustable lens-filter assembly. The filter is a notch rejection filter for removal of the Rayleigh signal, which exceeds the Raman signal by about 6 orders of magnitude. Again, fiber systems introduce flexibility in system configuration during industrial use, and should be evaluated in the laboratory-scale design.

A lens recovery system is equally capable for laboratory-scale evaluations. The configuration would involve an off-the-shelf camera zoom lens with F-number set to match the spectrograph $(F / 4.4)$. The positioner discussed above could be used to recollimate/refocus the beam behind the zoom lens for better F-nur.ıber matching and to save money. The zoom-lens would be preceded by a hot mirror (I.R. reflector) to reduce heating of the optical components during industrial use. Again, the hot mirror should be evaluated now, to reduce the number of new variables introduced in the transition from laboratory design to full scale. The zoom lens is followed by the Rayleigh rejection filter, which could be mounted in the positioner.

The choice of lens versus fiberoptics is important enough to warrant evaluation of both during the laboratory stage.

\section{Spectral Resolution of the Retrieved Light}

A spectrograph is used to resolve the incoming light within a very narrow spectral band (of order $50 \mathrm{~nm}$ ). The spectrograph rejects stray light to as low as $10^{-7}$ of the input signal. Within its narrow bandpass, the spectrograph separates the light into a spectrum with resolution of about $0.02 \mathrm{~nm}$. The spectrum is physically displayed against a plane, where different frequency bands ("each color") can be read by separate elements of a detector array.

\section{Conversion of Resolved Spectra into Computer-Proressable Signals}

Spectra from the spectrograph are typically read by a diode array of 512 or 1024 separate elements, or a CCD array (typically $576 \times 384$ ). The output of this array is then A/D converted and made available for computer processing. The proposed design applies a 1024-element diode array, and the data are read via a $50-\mathrm{kHz}, 12 \cdot \mathrm{bit} \mathrm{A} / \mathrm{D}$ board. The Instaspec program controls the diode array and retrieves data from the A/D board after the detector "ON" time has expired. The diode 
array can be read out and digitized at a rate of $20 \mu \mathrm{s} /$ pixel. More program details are presented in the next section, and in Appendix B.

The timing and sequencing of events are greatly simplified by the choice of lasers and by the Instaspec software. The cycle basically consists of three steps:

- The Instaspec program generates an output TTL pulse and sends it via the Instaspec interface card to the "Lamp input" of the DCR-11 laser. This starts the laser firing cycle.

- In response, the DCR-11 laser sends a TTL pulse back to the Instaspec Interface card. The laser pulse can be monitored from either the "Q-Switch Sync Out" or the "Q-Switch Advance Sync Out" BNC connectors. 50 to $100 \mathrm{~ns}$ later, the laser fires its optical pulse, lasting about $10 \mathrm{~ns}$. (An earlier output pulse from the firing of the laser lamp could be monitored instead of the Q-switch pulses. This lamp pulse precedes the optical pulse by a few hundred ns.)

- In response to the Q-switch TTL pulse, the Instaspec program waits a set time (software determined), and turns on the detectors. The detecturs remain on for a period of time determined by the software.

The detector array is then read by the Instaspec software, and the cycle can repeat after about $30 \mathrm{~ms}$. A signal delay line could be installed between the computer and the laser "lamp input" terminal. This option would allow fine tuning of the detector "ON" window relative to the laser optical pulse. The positioning and gating of this window is very important for DC rejection (e.g., of blackbody radiation). When an intensified detector array is used, the intensifier can be gated so that it turns on just before the scattered laser-Raman pulse arrives and turns off just after the Raman pulse finishes. The intensifier "ON" time is only about $10 \mathrm{~ns}$, allowing rejection of the blackbody DC signal. 
The Noise-Equivalent-Power (radiant flux at which Signal/Noise $=1.0$ ) for the selected detector is about $10^{-14} \mathrm{~W}$, while signal levels are conservatively about $10^{-7} \mathrm{~W}$ to $10^{-6} \mathrm{~W}$. Thus, the Raman signals are easily detectable.

\section{Computer-Processing of Spectra and Generation of Control Signals}

The Instaspec program reads diode array data from the $A / D$ converter into standard microcomputers such as IBM-PC/XT/AT and their clones and compatibles, as well as IBM PS/2 and Apple II systems. The proposed design employs an IBM-PC/AT, or compatible, computer.

Instaspec has many other capabilities, including graphics and data manipulation. For example, the scan data can be graphed immediately on screen. The plots are "splayed in 3 dimensions: $x$-pixel position, or wavelength; $y$-intensity; $z$-time, or scan number. A picture of a screen plot is presented in the appendices.

The plots can also be dumped onto printers, laser printers or H-P plotters. Instaspec also allows calculations to be performed on the scanned data. For example, spectra can be ratioed, subtracted, smoothed, differentiated and multiplied by a normalizing factor. Peak search, band integration and calculation of peak width are also useful capabilities. Furthermore, Instaspec can be set up to automatically take a series of scans, save them to disk and/or plot them on a printer or plotter. Different files of operating parameters can be loaded for taking different types of scans. The Instaspec data are stored in ASCII format, and can be accessed by Lotus, Fortran, Basic or other data handling programs. Finally, Instaspec can be control'? ad from an outside program. Subprograms, interfacing specifications and handbooks are provided $i$, the same package. The subprograms are written in Microsoft QuickBasic.

The next section discusses the system tradeoffs for each of the subsystems discussed above in more depth.

\subsubsection{System Tradeoffs}

The proposed design involves tradeoffs in the six areas discussed above. The important design issues are discussed. 


\section{Lasers}

The laser characteristics considered included cost, frequency, beam profile, linewidth, power, pulsewidth, pulse rate, versatility, size and maintenance requirements. Given the following constraints:

- The lowest laser budget consistent with laboratory evaluation of the most important experimental variables and (industrial) noise sources

- Energy requirements of $\sim 100 \mathrm{~mJ} /$ pulse

- Power requirements of $2100 \mathrm{~kW} /$ pulse

- OMA/Computer Data acquisition rates of about $30 \mathrm{~ms} /$ pulse from a 1024-diode array $(=30$ pulses $/ \mathrm{s})$

- Pulsewidth requirements of $<<1 \mu \mathrm{m}$

- Multiwavelength capability desired

- The fourth power dependence of Raman cross-section on frequency (higher cross-section at higher frequency)

- Laser linewidths of $<0.1 \mathrm{~nm}$

- A Gaussian or flat spatial beam profile

- Small size

- Ease of maintenance

the chosen light source is a Nd:YAG laser. Two specific models, Spectra Physics DCR-11 and Continuum's (formerly Quantel) YG-660, are contenders. Sperifications are presented in the appendices.

\section{ND:YAG Lasers}

Nd:YAG lasers satisfy the requirements outlined above. Nd:YAG lasers are capable of multiwavelength operation at $1064 \mathrm{~nm}$ (IR), $532 \mathrm{~nm}$ (green), $355 \mathrm{~nm}$ (UV), and $266 \mathrm{~nm}$ (UV), and each line can be isolated with a harmonic converter. The proposed laboratory test program will be cairied out at $532 \mathrm{~nm}$, and laser specifications are provided in the appendices. The visible beam 
is chosen because of safety and cost concerns. The UV and IR beams are both invisible, and at the very high pulse energies and high pulse rates teing considered, stray beams (e.g., from a breached, misaligned or disconnected component) pose a significant safety problem for an experimenter busy repairing other system components. Also, in the final industrial system, the laser and optics will be out of general view, and a visible bean will provide the best warning and protection of workers. In addition, visible optics are cheaper than UV or UV-enhanced optics, and more readily available off-the-shelf. Finally, visible beams are preferable to IR laser beams because Raman cross-sections increase with the fourth power of frequency, and because IR analysi; will experience more blackbody noise problems from furnaces and hot workpieces.

The laser cost with harmonic converter to isolate the second harmonic is about $\$ 32,200$ for the Spectra Physics DCR-11, and $\$ 31,800$ for the Continuum YG-660. The peak pulsc energies and pulse widths are $135 \mathrm{~mJ}, 6$ to $7 \mathrm{~ns}$, and $65 \mathrm{~mJ}, 6$ to $8 \mathrm{~ns}$, for the DCR-11 and the YG-660, respectively. The pulse power requirements $(2100 \mathrm{~kW})$ are also well satisfied. Both lasers can provide a flat or near-gaussian beam profile at no additional cost.

Both the DCR-11 and the YG-660 are quite compact. The DCR-11 has the added advantage of having been ruggedized for several OEM applications in the past. These applications involve installation in helicopters and operation in the harsh environs of the Mohave desert. The laser was configured as a turnkey, turn-on-and-forget blackbox, requiring no attention from the operator. The main maintenance item is the flashlamp, which needs replacement every 30 million flashes at $\$ 250$. The DCR-11 was also recently configured for an OEM that required an interface card for complete computer control. The interface card costs an additional $\$ 2, n \supset 0$ in single quantities.

The two laser vendors being considered are both local. Spectra Physics of Mountain View, California, promises a 4-week delivery, and Continuum (formerly Quantel) promises 30 to 45 days. Both laser systems are almost identical, but the Spectra Physics model (DCR-11-2) has higher output pulse energy ( $135 \mathrm{~mJ}$ versus $65 \mathrm{~mJ}$ ), and better average power stability $( \pm 5$ percent at $10 \mathrm{hr}$ 
versus \pm 6 percent at $8 \mathrm{hr}$ ). On the other hand, the Continuum model has a higher pulse rate ( $30 \mathrm{~Hz}$ versus $14 \mathrm{~Hz}$ ), better spatial beam characteristics, and better shot-to-shot energy stability ( \pm 4.5 percent versus \pm 7 percent). Both companies have excellent reputations for quality and service.

\section{Nitrogen Lasers}

Nitrogen lasers were also considered, but they only operate in the UV at $337 \mathrm{~nm}$. Nitrogen lasers are much less powerfil than Nd:YAG lasers, emitting about $s 10 \mathrm{~mJ}$ per pulse. They also have relatively broad emission linewidths, and require filtration of the laver pulse. Further, the UV Raman optics are more expensive than visible optics. On the positive side, the Nitrogen lasers are cheaper (abnut $\$ 21,000$ to $\$ 24,000$ ), require low maintenance, and have no flashlamps to replace. One major problem with using them in an experimental setting is the invisibility of the beam. Errant beams could pose a safety problem for an experimenter busy repairing other system components, and for employees in industry.

\section{Dye Lasers}

Dye lasers were also considered. These have all the advantages of Nd:YAG lasers, and, in addition, are far more tunable. The major disadvantage with dye laser systems is cost. Comparable dye laser systems cost about $\$ 20,000$ more that the $\mathrm{Nd}$ :YAGs. Indeed, $\mathrm{Nd}$ :YAGs are used as pump sources for dye laser systems.

\section{Beam Delivery}

The delivery of laser light to the workpiece can be accomplished via a lens system or via fiberoptics. The factors to consider include safety, flexibility in beam delivery, cost per measurement for multiple simultaneous measurements, signal strengths and losses, space utilization, and operation and maintenance. Each choice has its advantages and disadvantages. These factors, which are discussed here, are all interrelated. The choice of method is highly influenced by the fact that the device must ultimately be usable in industry. Thus, experimental conveniences are avoided if the resulting design is useless or dangerous in an industrial setting. 


\section{Beam Delivery: Safety, Space Utilization, Multiple Measurements, Flexibility}

As mentioned above, the laser beams are very powerful, and capable of inflicting severe injury. In industrial settings, fires may also be started by an errant laser beam. As a result, the beams need to be confined for as much of their flight path as possible. Furthermore, any space that is criss-crossed by these beams is essentially dead space in an industrial setting. At up to $\$ 0.5$ per month per square foot per floor, this is an unnecessary expense.

If multiple measurements are needed simultaneously, e.g., in different parts of a long furnace or a long workpiece, fiberoptics allow for flexible beam delivery from a single laser to several measurement points, with confined beams and frugal space utilization. This removes the need for multiple lasers, lowering system overall cost, and improves measurement synchronization. Beam distribution from a laser can be achieved by a lens system, but would be unsuitable for industrial settings due to exposed beams as well as maintenance of optical elements.

\section{Beam Delivery: Operation and Maintenance}

The objective is to design a system that requires little attention, i.e., a fireup-and-forget system. In the final industrial design, the laser will be a blackbox positioned in a remote room with its power supply, and interfaced to a computer. The operators should not even know it exists except to the extent that they can take data, or when it comes time to replace the flashlamp. The laser end of the beam-delivery optics should be sealed to reduce dust/dirt related problems such as reduced damage thresholds and cleaning. The workpiece end of the beam-delivery optics should have a minimum of surfaces, and should be simple to clean. Fiberoptics are preferable to lens systems for heam delivery because:

- They allow remote laser location with long, sealed beam paths

- They aliow an easily sealed optics/laser interface 
- Lens systems require multiple components for bending the beam from the remote laser location to the workpiece. This introduces several maintenance concerns and increases the number of issues about which the user or technician must be knowledgeable (increases O\&M costs).

\section{Beam Delivery: Signal Strengths and Losses}

Lenses have high transmission (typically 96 percent), and the lenses of interest have been coated to reduce Fresnel reflections which could be Jamaging if coupled back into the laser cavity. Lenses also collect signal from a much larger area than the beam cross section, and can acquire stray light in the process. At the workpiece-end of the equipment, however, stray signals are not a problem.

Single fibers also have very high transmissions ( $~ 96$ percent), but need collection lenses to couple onto the laser signal. In addition, fibers can be used to divide the sealed laser beam for simultaneous measurements at several parts of the workpiece. Fiber bundles are less expensive than signal fibers, and are easier for signal coupling and beam division, but have lower transmissions ( $T$ ) due to packing fractions of about $(P=0.8-0.9)$, and reflection loss of about $(R=0.4)$, where

$$
T=P(l-R)^{2} e^{-k l}
$$

and $\mathrm{k}$ is a very small $\left(<0.25 \mathrm{~m}^{-1}\right)$ absorptance coefficient. Transmissions of about 0.55 may be experienced over $10 \mathrm{~m}$, making bundles less attractive than single fibers.

Although a lens delivery system will work well for a laboratory test, fiberoptics are preferable for the ultimate industrial system. They have therefore been chosen for the laboratory tests. This choice allows us to evaluate all important byam-delivery issues during the laboratory phase, and reduces the number of important new variables for the full-scale evaluation.

The maximum working temperature for the glass fibers is about $350^{\circ} \mathrm{F}$. The damage threshold is listed at $10 \mathrm{~J} / \mathrm{cm}^{2}$ for the single fibers, requiring $1000-\mu \mathrm{m}$ fibers to carry $100-\mathrm{mJ}$ pulses. 


\section{Retrieval of Scattered Light from Workpiece}

Retrieval of scattered light from the workpiece can also be done via fiberoptics or via a lens system, and both are discussed here.

\section{Light Retrieval: Fiberoptic Collection}

Single fibers are preferred over fiber bundles because of their higher transmission ( $\sim 96$ percent versus 50 to 70 percent). In solid Raman Spectroscopy, the scattered light signal is very weak (about 10 to 12 orders of magnitude less than the outgoing signal). It is also much weaker (by about 6 orders) than the elastically scattered or Rayieigh signal. For fiber collection, this means a relay lens must be attached to the fiber for increased light collection and increased signal, as well as reduced ambient stray light. Standard relay lenses for fibers are available from vendors such as Oriel. Adding a relay lens to the fiber input increases the sensitivity to viewing angle. This may be helped by defocusing the relay lens a little to spread the input beam over a larger part of the fiber aperture. On the positive side, a relay lens will reduce the amount of ambient stray light collected by the fiber, and will reduce signal dependence on the separation between the fiber and the workpiece.

A fiber system with a single fiber will also require a positioner assembly to match the fiber to the spectrograph (F-number matching) and place the fiber image exactly on the spectrograph slit. The positioner is an $\mathrm{X}-\mathrm{Y} \cdot \mathrm{Z}$ adjustable lens-filter assembly with a notch rejection filter for removal of the Rayleigh signal. Without the F-number matching by the lens assembly, there will be stray light in the spectrograph as the fiber image overfills the grating. Again, fiber systems introduce flexibility in system configurstion during industrial use, and should be evaluated in the laboratory-scale design. The cost of the fiber light retrieval system with relay lens, $2 \mathrm{~m}$ of fiber, $\mathrm{X}-\mathrm{Y}-\mathrm{Z}$ positioner, and associated couplings is $\$ 1,625$. Additional fiber is $\$ 257 / \mathrm{m}$.

\section{Light Retrieval: Camera Lens Collection}

A camera lens is also applicable for Raman signal collection for laboratory-scale evaluations. The configuration would involve an off-the-shelf camera zoom lens with F-number set to match the 
spectrograph $(F / 4.4)$. The positioner discussed above could be usec to recollimate/refocus the beam behind the zoom lens for better F-number matching. The positioner zould also save money since the zoom lenses with closest matching F-number are expensive: ( F/4.5 zoom lens carries a suggested list price of \$3,145, while the pritioner (\$722) Fus 100 to $300 \mathrm{~mm}$ F/5.6 Nikon lens ( $\$ 64 \$$ cost $\$ 1,367$ ). The zoom lens would be preceded by a hot minror (IR reflector) to reduce heating of the optical components during industrial use. Again. the ho: mirror should be evaluated now, to reduce the number of new variables introduced in the transition from laboratory design to full scale. The zoom lens is followed by the Rayleigh rejection filter, which will be mounted in the positioner.

It should be remarked here that many experimenters have used camera lenses (e.g., F/5.6) for their laboratory Raman systems. These lenses have the advantage of having benefitted from significant engineering, and are generally achromatic, non-aberrant, non-reflecting, and highly transmissive ( $~ 96$ percent). Finally, and as mentioned earlier, lenses can collect more signal than fibers, but they are also prone to collecting more stray light.

The choice of lens versus fiberoptics is important enough to warrant evaluation of both during the lab stage.

\section{Spectral Resolution of the Retrieved Light}

Spectrographs were evaluated from three major manufacturers, including Oriel's $1 / 4-\mathrm{m}$ (250-mm) 77200 spectrograph, EG\&G Princeton Applied Research Co.'s 275-mm model 1234 unit, and SPEX's $340-\mathrm{mm} 340 \mathrm{~S}$ and $600-\mathrm{mm} 1877 \mathrm{C}$ triple spectrographs. The major objectives of the spectrographs and associated lenses and filters include:

- Elimination of the Rayleigh line

- Provision of both Stokes and Anti-Stokes Signals

- Resolution of $0.1 \mathrm{~nm}$ or better at $532 \mathrm{~nm}$

- Less than 0.1 percent stray light

- Minimum consumption of photons 
- Small size

- Low cost

The proposed design uses an Oriel 77200 1/4-m spectrograph with a 1200 lines/mm grating and a $10 \mu \mathrm{m}$ slit. A smaller slit will be tried if available, as it improves the resolution. The spectrograph will carry a special Melles-Griot notch rejection filter system up front, to help eliminate the Rayleigh line. This special filter will preferentially reflect elastically scattered light with rejection of over $10^{4}$ per stage, and with a narrow $\left(<7 \mathrm{~nm}\right.$ or $<250 \mathrm{~cm}^{-1}$ ) bandwidth at $532 \mathrm{~nm}$. Two or more Rayleigh filter stages will be required. Although each filter stage decreases the signal level by about 50 percent, the stages are far more cost-effective and more photon-conserving than $60-\mathrm{cm}$ triple spectrographs, which cost over $\$ 20,000$ and can attenuate the photon count by several orders of magnitude.

Double Spectrograph. If the single 77200 spectrograph is insufficient to meet the resolution stray light and Signal/Noise requirements, a second 77200 spectrograph will be added in tandem to create the 77225 double spectrograph. (Two 77200 units in tandem with a center connecting slit are called a 77225). The input slit to this second spectrograph will be the 77207 center slit unit. The double spectrograph costs $\$ 7,262$, while the single spectrograph system costs $\$ 3,310$. Specifications are presented in the appendices. The Rayleigh signals will be about 6 orders of magnitude higher than the Raman signals. If the Notch filters work as advertised, two stages will yield Raman/Rayleigh of about 100, but will attenuate the incoming signal by about 60 to 75 percent.

Spectrographs and Data Resolution. As mentioned before, the spectrograph is used to resolve the incoming light within a very narrow spectral band (of order $50 \mathrm{~nm}$ ). The spectrograph also reject stray light to as low as $10^{-7}$ of the input signal. Within its narrow bandpass, the spectrograph separates the light into a spectrum with resolution of $0.05 \mathrm{~nm}$ or better. The spectrum is physically displayed against a plane, where different frequency bands (each color) can be read by separate elements of a detector array. 
The linear dispersion of the 77200 signal spectrograph is $3.2 \mathrm{~nm} / \mathrm{mm}$ at a wavelength of $500 \mathrm{~nm}$ and using a 1200 lines/mm grating. With a 1-in $(25-\mathrm{mm})$ long diode array, the bandpass is $3.2 \mathrm{~nm} / \mathrm{mm} * 25 \mathrm{~mm}$ or $80 \mathrm{~nm}$. The linear dispersion of the two 77200 spectrographs in series is half that of a single spectrograph, or $1.6 \mathrm{~nm} / \mathrm{mm}$. Combined with a $25-\mathrm{mm}-$ long diode array, this gives a bandpass of $40 \mathrm{~nm}$. The spectrograph resolution is controlled by the slit width rather than the grating. With a $10 \mu \mathrm{m}$ slit, the product of slit width and linear dispersion for the 77200 spectrograph gives a resolution of $10^{-2} \mathrm{~mm} * 3.2 \mathrm{~nm} / \mathrm{mm}=0.032 \mathrm{~nm}\left(1.12 \mathrm{~cm}^{-1}\right)$ at a wavelength of $500 \mathrm{~nm}$. Likewise, the calculated resolution for the two 77200 spectrographs in series is half this value, or about $0.016 \mathrm{~nm}\left(0.56 \mathrm{~cm}^{-1}\right)$ at $500 \mathrm{~nm}$.

The final resolution in the data depends on the width of each diode element or pixel. The diodes or pixels being employed are $25 \mu \mathrm{m}$ wide. As a result, the final data resolution is what can be resolved by two neighboring diodes/pixels (i.e., the linear dispersion multiplied by diode width). Without any curvefitting correction, this pixel resolution amounts to 2.5 (pixel-width/slit width = $25 \mu \mathrm{m} / 10 \mu \mathrm{m}=2.5$ ) times the numbers given in the preceding paragraph. For example, pixel resolution is $2.5 * 0.56 \mathrm{~cm}^{-1}=1.4 \mathrm{~cm}^{-1}$ for the two 77200 spectrographs in series. Sub-pixel resolution can be obtained by curvefitting as discussed in Section 6.4.2.3.

By comparison with the single Oriel spectrograph, the SPEX 340 S spectrograph with a $1800 \mathrm{l} / \mathrm{mm}$ grating and a slit costs $\$ 4,740$, and the EG\&G-PARC 1234 system with $1200 \mathrm{l} / \mathrm{mm}$ grating and $25-\mu \mathrm{m}$ slit costs $\$ 5,170$. These spectrographs are difficult to compare exactly, as they are not clones, but the costs are representative.

The most precise spectrograph evaluated is SPEX's triplemate $1877 \mathrm{C}$ triple spectrograph. This unit also has the highest light rejection, and will reveal structures as close as $15 \mathrm{~cm}^{-1}$ to the laser line. However, the unit costs about $\$ 33,000$ with gratings, and attenuates the photon count significantly.

Triple Spectrometry. Finally, on the subject of signal resolution, we note that another effective method for reducing stray light and the Rayleigh signal is to use a double spectrometer 
in a subtractive mode. The output is then fed to a spectrograph for analysis. This triple spectrometry also greatly attenuates the photon count and further reduces the linear dispersion. This method will be the final contingency if the combination of notch filters and doublespectrographs are unable to extinguish the elastic signal. The equipment is essentially 3 monochrometers/spectrographs, each one similar to the 77200. The least expensive configuration employing $0.22 \mathrm{~m} \mathrm{~F} / 3.9$ spectrometers combines a SPEX 1680A Spectramate Double Spectrometer $(\$ 4,350)$ with a SPEX 1681C Minimate-2 Spectrograph $(\$ 2,050)$, and includes three SPEX-12006500A gratings (\$600*3) and a set of SPEX 1679 F fixed slits $(\$ 150)$ for a total of $\$ 8,350$. Evidently, two notch filters and one spectrograph (at \$5,700) will be much preferred if the elastic signal and stray light are attenuated sufficiently relative to the useful signal.

Oriel representatives are located in Southern California, while PARC is in Fremont, and SPEX is in Milpitas.

\section{Optoelectronic Conversion of Resolved Spectra}

\section{Optical Multichannel Analysis}

OMAs with Unintensified Arrays. The spectrograph output is projected onto a 1024 element diode array, which is read with a $50 \mathrm{kHz}$ 12-bit A/D board specifically packaged for the purpose. Software for acquiring the data and downloading into a computer also comes with the package. The Oriel Instaspec AT system costs $\$ 10,276$, for use with PC/AT compatibles, and comes with a $\$ 150$ programmer's kit. The system interfaces to any AT computer as may be found in a typical laboratory (i.e., computer is extra). The Oriel Intraspex XT system, for use with PC/XT compatibles, is slow:r, and costs $\$ 9,335$. By comparison, the EG\&G-PARC system costs $\$ 11,475$ without a computer. The Instaspec program controls the diode array and retrieves data from the A/D board after the detector "ON" time has expired. The diode array can be read out and digitized at a rate of $20 \mu \mathrm{s}$ per pixel. More program details are presented in the appendices and below.

QMAs with Intensified Arrays. Intensifiers add about $\$ 11,500$ to the detection system cost. The EG\&G PARC system with a gated intensifier costs $\$ 21,695$. The Oriel system with intensifier 
is relatively new, and the PC/AT version is expected to cost about $\$ 22,000$. The importance of intensifiers and gating is discussed below.

Raman Flux Detectability. Using a conservative laser power of $10 \mathrm{~mJ}$ per pulse and a pulse width of $8 \mathrm{~ns}$, together with a conservative scattering and collection efficiency of $10^{.12}$ Raman photons collected per laser photon, gives a Raman flux of

$$
\left(\frac{10 \times 10^{-3} \mathrm{~J}}{8 \times 10^{-9} \mathrm{~s}}\right) \times\left(1 \times 10^{-12}\right)=1.25 \times 10^{-6} \mathrm{~W}
$$

Accounting for attenuation by the Notch filters and collection systems will decrease this flux to about $10^{-7} \mathrm{~W}$ during the laser pulse. The Raman scattering efficiency is estimated from values of scattering efficiencies typical in solids, of about $10^{-7} \mathrm{~cm}^{-1} \mathrm{sterad}^{-1}$, as well as assumed penetrations of about $10^{-5} \mathrm{~cm}$ and collection angles of 1 sterad. The Noise-Equivalent-Power (rad: $\mathrm{Ai}^{\mathrm{t}}$ flux at which $($ Signal/Detector Noise $)=1.0$ ) for the selected detector is about $10^{-14} \mathrm{~W}$, which is 7 orders less than the Raman signal levels. Thus, the Raman signals are sasily detectable.

DC Noise Blocking. At high workpiece temperatures and high laser pulse energy, blackbody radiation from the workpiece, laser-induced particulate incandescence, and radiation from furnace background become important. These DC noise sources can be effectively blocked by a combination of gating and signal subtraction. (Subtraction was discussed in the December 1988 proposal.) Consider workpiece radiation for example. At $2,000 \mathrm{~K}$ and $0.5 \mu \mathrm{m}$ wavelength, the blackbody intensity, $\mathrm{I}$, is about $5 \times 10^{3} \mathrm{~W} / \mathrm{m}^{2} \mu \mathrm{m} . \mathrm{sr}$. Using an imaging beam probe (unit 77653 of diameter $D_{2}=16 \mathrm{~mm}$ as the fiber input and imaging a $1-\mathrm{mm}$ point $\left(A_{1}=10^{-6} \mathrm{M}^{2}\right)$ on the workpiece surface from a distance of $10 \mathrm{~cm}$ gives a view factor of $F_{12}=2.5 \times 10^{-4}$. Here, the subscript 2 refers to the fiberoptic imaging probe of area $A_{2}=3.14 * D_{2}{ }^{2} / 4$. Assuming a Raman linewidth of $\mathrm{D} \lambda=10 \mathrm{~nm}=10^{-2} \mu \mathrm{m}$, the blackbody power incident on the collection system is: 


$$
\begin{aligned}
& \quad 3.1416 \times I \times D \lambda \times A_{1} \times F_{12} \\
& =3.1416 \times\left(5 \times 10^{3}\right) \times\left(1 \times 10^{-2}\right) \times\left(1 \times 10^{-9}\right) \times\left(2.5 \times 10^{-4}\right) \mathrm{W} \\
& =3.9 \times 10^{-8} \mathrm{~W}
\end{aligned}
$$

(The radiant power is lower for lower emissivity materials as are likely to be encountered in industrial workpieces.)

This blackbody radiation is to be compared with the Raman power of $1.5 \times 10^{-6} \mathrm{~W}$. Even if the Raman linewidth increases to about $30 \mathrm{~nm}$ as the temperature increases, the blackbody noise only goes to about $10^{-7} \mathrm{~W}$, still a factor of 10 smaller than the Raman signal. It is important to note that gating is crucial for the rejection of the blackbody signal. Without gating, the Raman signal is only present for $10^{-8} \mathrm{~s}$, while the DC blackbody noise is present for the entire detector "ON" cycle $\left(10^{-2} \mathrm{~s}\right)$. As a result, when the diode signal is sampled in the absence of gating, there is $10^{4}$ to $10^{-}$ as much integrated noise as there is integrated Raman signal (in this example).

Finally, unintensified arrays give about 3,000 photons per count. The Raman power after the notch filter is about $1.5 \times 10^{-7} \mathrm{~W}=4 \times 10^{11}$ photons $/ \mathrm{s}$ at $532 \mathrm{~nm}$ wavelength. If gating is done for $10 \mathrm{~ns}=1 \times 10^{-8} \mathrm{~s}$, this amounts to a total Raman count of $4 \times 10^{11} \times\left(1 \times 10^{-8} / 3,000\right)=1.3$ counts per gate. This is insufficient and must be intensified for data analysis. The intensifier provides a gain of about 500 to 1000 in the count rate. Thus, at high temperatures (above about 1,000 K), gated intensified arrays are needed.

The timing and sequencing of events (Figure 6-4) is greatly simplified by the choice of lasers and by the Instaspec software. The cycle basically consists of 3 steps:

- The Instaspec program generates an output TTL pulse and sends it via the Instaspec interface card to the "lamp inpu:" of the DCR-11 laser. This starts the laser firing cycle

- In response, the DCR-11 laser sends a TTL pulse back to the Instaspec Interface card. The laser pulse (pulse 2a in Figure 6-4) can be monitored from either the "Q-Switch 


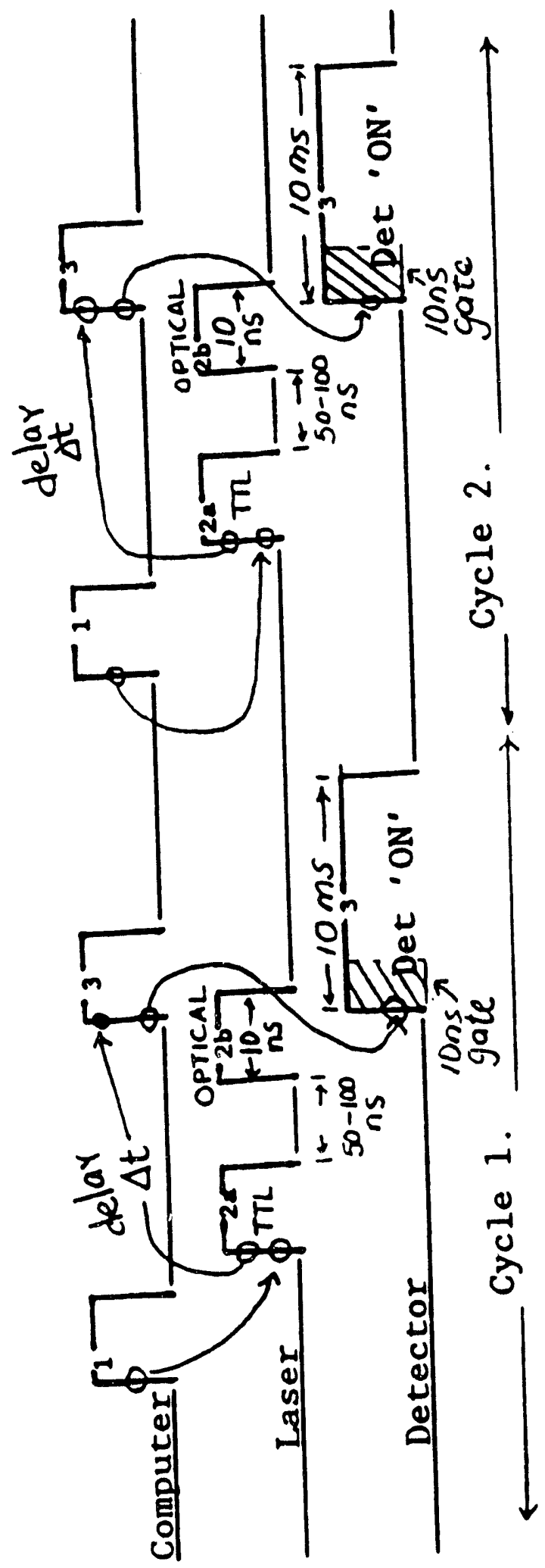

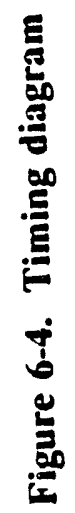


Cync Out" or the "Q-Switch Advance Sync Out" BNC connectors. 50 to 100 ns later, the laser fires its optical pulse (pulse $2 \mathrm{~b}$ in Figure 6-4), lasting about $10 \mathrm{ns.} \mathrm{(An} \mathrm{earlier}$ output pulse from the firing of the laser lamp could be monitored instead of the Q. switch pulses. This lamp pulse precedes the optical pulse by a few hundred ns.)

- In response to the Q-switch TTL pulse, the Instaspec program waits a set time (software determined), and turns on the detectors (pulse 3 in Figure 6-4). The detectors remain on for a period of time which is determined by the software.

The detector array is then read by the Instaspec software, and the cycle can repeat after about $30 \mathrm{~ms}$. A signal delay line could be installed between the computer and the laser "lamp input" terminal. This option would allow fine tuning of the counting gate and the detector "ON" window relative to the laser optical pulse. The positioning and gating of this window is very important for DC rejection (e.g., of blackbody radiation) as discussed earlier. The timing diagram is shown in Figure 6-4.

When an intensified detector array is used, the intensifier can be gated so that it turns on just before the laser-Raman pulse arrives and turns off just after the laser pulse finishes. The intensifier "ON" time is several ns, allowing rejection of the blackbody DC signal. The intensifier increases detector sensitivity and boosts the weak Raman signals by about three orders of magnitude (noise signals are also boosted in the same time window). Intensifiers are employed in practically all Research and Development Raman configurations, but increase detector cost by about $\$ 11,500$.

CCDs are also available for use in detectors. A CCD's resolut $\mathrm{\lambda}$ is excellent zompared with an intensified diode array. With no photocathode, microchannel plate or phosphor, the CCD is not troubled by photocathode dark signal or phosphor persistence. However, the lack of an intensifier means that the $C C D$ cannot be gated. The $C C D$ units available are more expensive than the unintensified diode arrays, and similar in cost to intensified arrays. Since the intensified diode arrays can be gated, the data acquisition system design employs diode arrays rather than CCDs. 
This way, if intensifiers are unnecessary, the cheaper detectors (diodes) will be in use. Similarly, if intensifiers are required with gating to reject DC noise, the gatable detectors (again diodes) will be in use. Finally, using diodes allows the option of starting out unintensified and ungated, and later retrofitting intensification and gating as needed-flexibility in upfront commitment of funds.

\section{Computer-Processing of Spectral Data}

The Optical Multichannel Analyzers (OMA) and related Instaspec software are fully compatible with regular microcomputers such as PC/XT/AT clones. These OMA systems acquire the spectral data for delivery to a computer. The Instaspec program can feed diode array data from the A/D converter into standard microcomputers such as IBM-PC/XT/AT and their clones and compatibles, as well as IBM PS/2 and Apple II systems. The proposed design employs an IBM-PC/AT, or compatible, computer.

Instaspec has many capabilities including graphics and data manipu'ation. For example, the scan data can be graphed immediately on screen. The plots ar $=$ displayed in 3 dimensions: $x=$ pixel position, or wavelength; $y=$ intensity; $z=t i m e$, or scan number. A picture ofi a screen plot is shown in the appendices. The plots can also be dumped onto printers, laser printers or H-P plotters. Instaspec also allows calculations to be performed on the scanned data. For example, spectra can be ratioed, subtracted, smoothed, differentiated and multiplied by a normalizing factor. Peak search, band integration and calculation of peak width are also useful capabilities. Furthermore, Instaspec can be set up to automatically take a series of scans, save them to disk and/or plot them on a printer or plotter. Different files of operating parameters can be loaded for taking different types of scans. The program uses dispersion formulas and information sivout the spectrograph being used (e.g., focal length, gating, center wavelength) to calculate and display the proper wavelength and wavenumber for each diode element. The A/D converter readings can also be converted into other units other than counts, such as percent transmittance, irradiance, absorbance or reflectance.

The Instaspec data are stored in ASCII format, and can be accessed by Lotus, Foriran, Basic or other data handling programs. Finally, Instaspec can be controlled from an outside program. 
Subprograms, interfacing specifications and handbooks are provided with the Instaspec Package. The subprograms are written in Microsoft QuickBasic. Further software in Basic, Fortran or Lotus may be required to deconvolve the spectra and separate out the useful parts for temperature calculation. These subroutines are expected to be relatively simple curvefits, and their outputs will go to $\mathrm{I} / \mathrm{O}$ ports as control signals (e.g., for furnace firing rates.)

The data handling capabilities and ASCII output of Instaspec make it a very powerful program. For temperature calculations, anharmonic effects such as line broadening can be treated by Lorentzian curvefits to yield corrected peak intensities and peak frequencies for both Stokes and Anti-Stokes signals. Subsequently, the peak-ratioing capability of the program can be used to obtain temperatures. The Instaspec program package is also useful for detector calibrations as discussed in Section 6.3.2.7.

System Optimization. Optimization of the Raman thermometry system involves a number of issues. These issues are summarized below and further discussed in the sections indicated.

- The laser must be coupled to the workpiece without optical feedback and with minimal losses. This will be achieved with a dedicated coupler, unit 77597.

- Optimization of the beam delivery system involves configuration to account for the demands of an industrial system. This is discussed above, under the heading, "Optoelectronic Conversion of Resolved Spectra."

- Optimization of the beam retrieval system involves F\# matching, blocking of stray light and maximization of $S / N$. These issues are discussed above, under the heading, "Computer-Processing of Spectral Data."

- Optimization of the optoelectronic conversion involves proper calibration, as discussed in Section 6.3.2.7, and the gating for DC rejection, as discussed above, under the heading, "Optoelectronic Conversion of Resolved Spectra."

- Optimization of the overall system involves proper choice of calibration lines to bracket the spectra chosen for thermometry, as discussed in Section 6.3.2, combined with the 
equipment calibration described in Section 6.3.2.7 and the anharmonicity corrections described in Section 6.3.2.8. The overall design aims at optimizing the system for ultimate industrial use, with such measures as beam confinement, beam division capability, and choice of a non-gray temperature calibration source with temperature dependent emissivity.

\subsubsection{Laboratory-Scale System Layout}

The Laboratory system layout is presented in Figures 6-5, 6-6, and 6-7. Figure 6-5 presents the laser and beam delivery systems, while Figure 6-6 contains the beam retrieval, spectrograph, Optical Multichannel Analyzer and computer.

\section{Beam Output}

Figure 6-5 presents the beam delivery system. This consists of a Nd:YAG laser, coupled to a beamsplitter assembly (78150). The transmitted beam is coupled to a fiberoptic guide and collimated (77645) before passing out to the workpiece.

The reflected beam from the beamsplitter is used for sampling output energy, and is coupled to a photomultiplier tube assembly (77344). The PMT assembly and the other components shown in the dashed box of Figure 6-5 are used to monitor the laser pulse power. This helps prevent damage to the glass fiber from the intense laser beam, and provides a more accurate measurement of laser output than the gauges on the laser panel. Accurate knowledge of outgoing intensity will help determine scattering efficiencies more accurately, but is not crucial for thermometry via Stokes/Anti-Stokes ratioing. Also, optical damage can be prevented by simply turning the laser to a lower power (10 mJ instead of $100 \mathrm{~mJ}$ per pulse). As a result, the PMT assembly is being treated as an option in this design.

\section{Signal Retrieval and Processing}

As discussed earlier, signal retrieval can be achieved by camera lens or by fiberoptics. 


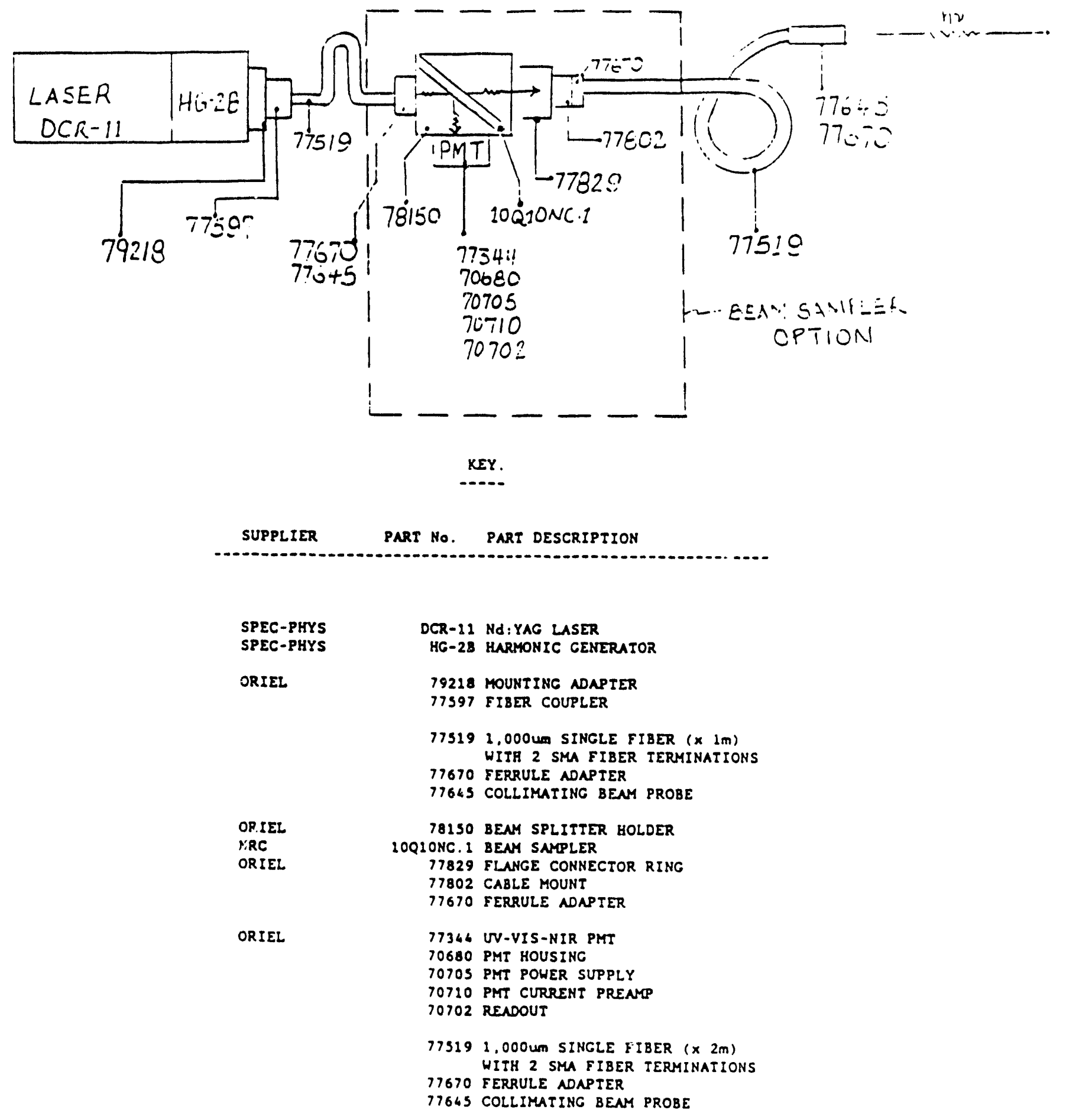

Figure 6-5. Laboratory-scale system layout-laser beam delivery system 
77225

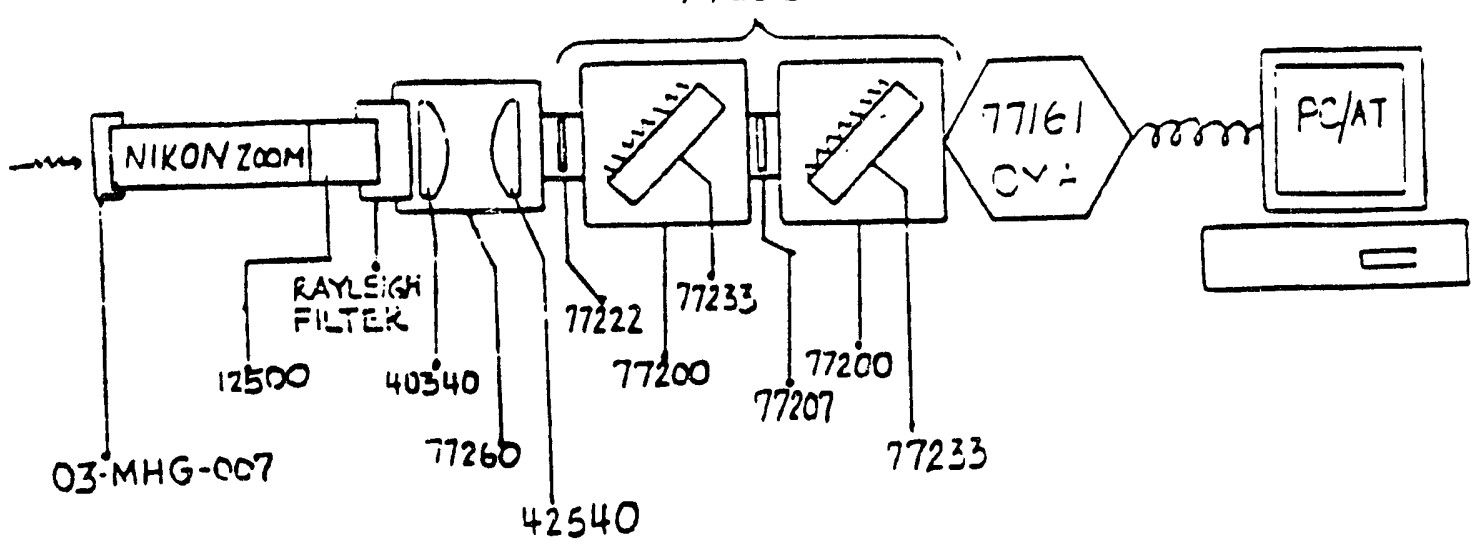

KEY.

-..--

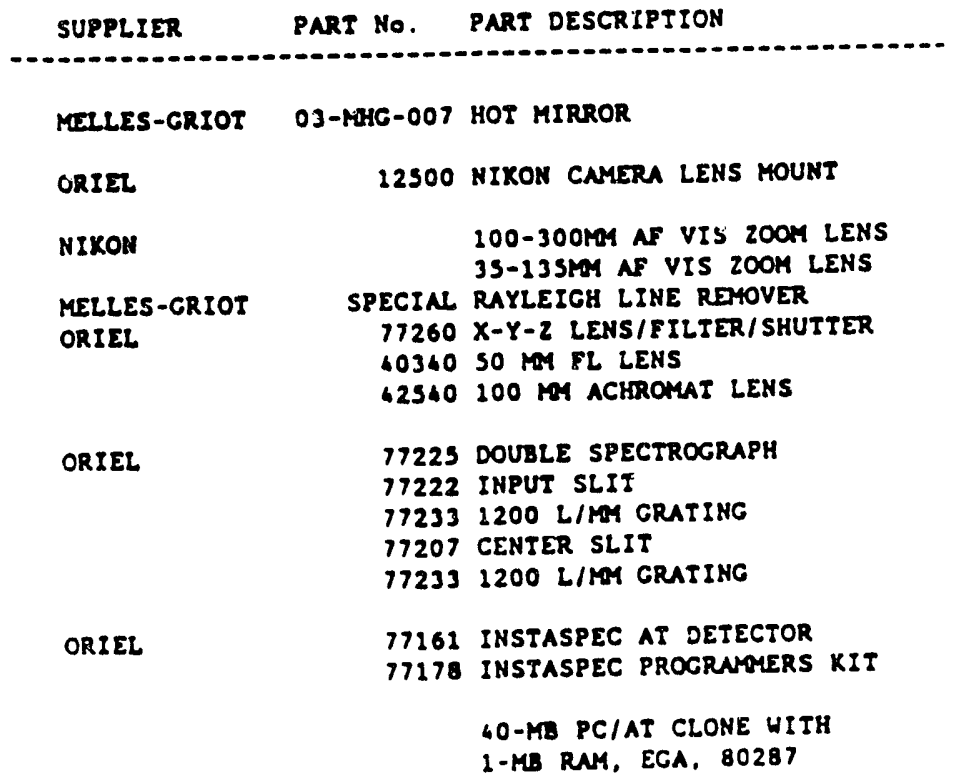

Figure 6-6. Laboratory-scale system layout-Raman signal retrieval and processing camera lens system 


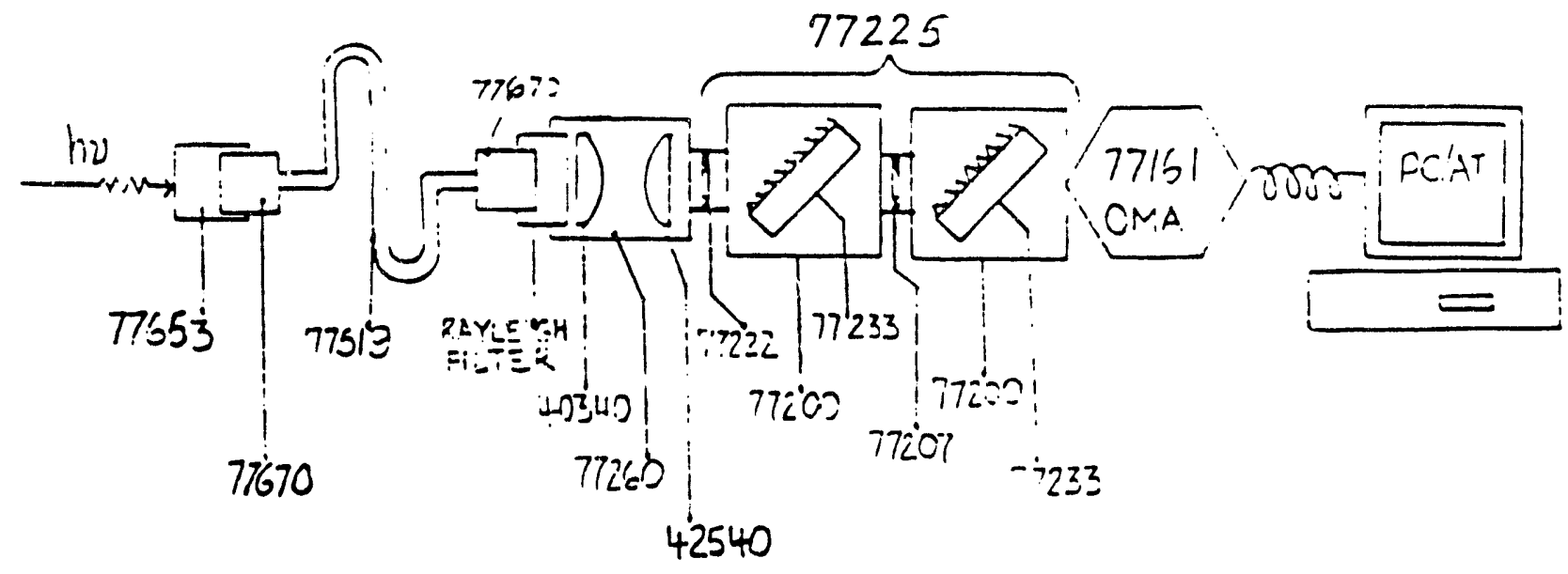

\begin{tabular}{|c|c|c|}
\hline SUPPLIER & PART NO. & PART DESCRIPTION \\
\hline MELLES-GRIOT & $03-$ MHC- 007 & HOT MIRROR \\
\hline ORIEL & 22500 & NIKON CAMERA LENS MOUNT \\
\hline ORIEL & $\begin{array}{l}77633 \\
77670 \\
77319 \\
77670 \\
77357\end{array}$ & $\begin{array}{l}\text { COLLECTOR LENS WITH SBUTTER } \\
\text { FERRULE ADAPTER } \\
\text { I.OOOUM SINGLE FIBER (X 2O) } \\
\text { WITH SMA TERMIMATIONS } \\
\text { FERRULE AOAPTER } \\
\text { FIBER HOLOER W/ EDMLE FLANGE }\end{array}$ \\
\hline $\begin{array}{l}\text { MELLES-GRIOT } \\
\text { ORIEL }\end{array}$ & $\begin{array}{l}\text { SPECIAL } \\
77260 \\
40340 \\
42540\end{array}$ & $\begin{array}{l}\text { RAYLEICH LINE RDHOVER } \\
X-Y-2 \text { LENS/EILIER/SHUITER } \\
\text { SO TM FL LENS } \\
100 \text { M ACHROMT LENS }\end{array}$ \\
\hline ORIEL & $\begin{array}{l}77222 \\
77200\end{array}$ & $\begin{array}{l}\text { INPUT SLIT } \\
\text { SINGLE SPECTROCRAPH }\end{array}$ \\
\hline $\begin{array}{l}77225 \\
\text { DOUBLE SPECTROC }\end{array}$ & $\begin{array}{l}77233 \\
77207 \\
77200 \\
77233\end{array}$ & $\begin{array}{l}\text { CENTER SLIT } \\
\text { SINGLE SPECTROCRAPH } \\
1200 \text { LIMPH GRATING }\end{array}$ \\
\hline ORIEL & 77161 & $\begin{array}{l}\text { INSTASPEC AT DETECTOR } \\
\text { 40-MB PCIAT CLONE WITH } \\
\text { 1-MB RAM. ECA, 80287, AND } \\
\text { LASER PRINTER OR PEN-PLOTTER }\end{array}$ \\
\hline
\end{tabular}

Figure 6-7. Laboratory-scale system layout-Raman signal retrieval and processing fiberoptic system 


\section{Camera Lens Retrieval}

In the lens option, the Raman signal is retrieved via a Nikon zoom lens arrangement with an optional hot mirror (03-MHG-007). It then passes through the Melles Griot Rayleigh-Filter to a condenser/focusing assembly (77260). The focusing assembly (77260) matches the spectrograph's F-number, and focuses the Raman signal through a slit (77222) into the spectrograph assembly (77200 or 77225 ). This focusing assembly is essential to make sure the Raman signal is properly imaged on the spectrograph slit to reduce stray light and signal wastage, and to optimize the throughput in the spectrograph. Both focusing assembly lenses are achromatic, non-aberrant and non-reflecting.

The 77225 double spectrograph consists of two 77200 spectrographs with a coupling slit (77207). The second spectrugraph will only be used if the first unit gives insufficient resolution and noise reduction. The sinectrographs feed into the Optical Multichannel Analyzer (77161), which is connected via its interface card to the personal computer. The system is very modular and conceptually simple. As mentioned earlier, if the Rayleigh line is not successfully atten:ated by the notch filters, a double-spectrometer will be needed in place of the first spectrograph. This double spectrometer will operate in the subtractive mode and will assist the notch filters to attenuate the Rayleigh signal. The double spectrometer will be followed by a spectrograph, which will feed into the Optical Multichannel Analyzer.

\section{Fiberoptic Collection}

If signal is collected by fiberoptics, the zoom lens will be replaced by a fiber capped with a collection lens (77653). The !ens (77653) has a shutter to enable zero checking. The fiber system and ancillary fittings are shown in Figure 6-7. As suggested earlier, both lens and fiber retrieval systems should be evaluated and compared.

\subsubsection{Laboratory-Scale System Costs (Feasibility Evaluation Costs)}

The laboratory-scale system components are called out in Table $6-2$ and $6-3$, and the costs are presented. Note that these costs reflect only a one-of-a-kind laboratory system for evaluating 
Table 6-2. Itemization of system components and costs

INSTRUNENT

GROUP

(2)

PART NO. PART DESCRIPTION

BASIC OPTIONAL

COHPONENTS COMPONENTS

PRICE

PRICE

ALIERNATE

(5)

(6)

VENDOR

(3) (4)

(6)

(7)

A. LASER

A. -

SPEC-PHYS

SPEC-PQYS

CONTINUUY

CONTINUUM

DCR-11 Nd:YAC LASER

BG-2B BARMOHIC GENERATOR

YG660-30 Nd: YAG LASER

DS BARMONIC GENERATOR

$\$ 26,400$

$\$ \$, 800$

$\$ 27,500$

$\$ 4,300$

B. LIGET DELIVERY SYSTEM

ORIEL

79218 MOUNTING ADAPTER

$\$ 35$

77597 FIBER COUPLER

$\$ 225$

773191,000 m SINGLE PIBER (x 10)

773742 SMA FIBER TERUINATIONS

77670 FERRULE ADAPTER

77643 COLLIMATING BENM PROBE

$\$ 189$

$\$ 25$

$\$ 68$

78150 BEAM SPLITTER BOLDER

$\$ 599$

NRC

OQIONC. 1 BEAM SATPLER

ORIEL

77829 PLANGE CONNECTOR RING

77802 CABLE MOUNT

$\$ 210$

$\$ 32$

77670 FERRULE ADAPTER

$\$ 25$
$\$ 25$

$773191,000 \mathrm{um}$ SINGLE FISER (x 2m) $\$ 514$

773742 SMA PIBER IERMINATIONS $\$ 189$

77670 PERRULE ADAPTER

77645 COLLIMATING BENM PROBE

$\$ 25$

$\$ 68$

OUTPUT LIGHT SAMLING

ORIEL

77344 UV-VIS-NIR PMT

70680 PMT BOUSIMG

70705 PHT POUER SUPPLY

70710 PHT CURRENT PREAMP

$\$ 930$

$\$ 378$

$\$ 1,125$

$\$ 475$

70702 READOUT

$\$ 895$ 
Table 6-2. Itemization of system components and costs (continued)

\begin{tabular}{|c|c|c|c|c|c|c|}
\hline $\begin{array}{l}\text { INSTRUREYIT } \\
\text { GROUP } \\
\text { (1) }\end{array}$ & $\begin{array}{l}\text { SUPPLIER } \\
\text { (2) }\end{array}$ & $\begin{array}{l}\text { PART Mo. } \\
\text { (3) }\end{array}$ & $\begin{array}{l}\text { BART DEST,RIPTIOW } \\
\vdots, 1)\end{array}$ & $\begin{array}{l}\text { BASIC } \\
\text { COMPONEETS } \\
\text { PRIEZ } \\
\text { (S) }\end{array}$ & $\begin{array}{l}\text { OPTIONAL } \\
\text { COMPONENIS } \\
\text { PRICE } \\
\text { (6) }\end{array}$ & $\begin{array}{l}\text { NLTERNATE } \\
\text { VENDOR } \\
\text { PRICE } \\
\text { (7) }\end{array}$ \\
\hline \multicolumn{7}{|c|}{ c. RAMN SIGMAL RETRIEVNL SYSTEM } \\
\hline & $\begin{array}{l}\text { METLES-GRIOT } \\
\text { ENLING }\end{array}$ & $\begin{array}{r}03-1096-007 \\
35-6865\end{array}$ & $\begin{array}{l}\text { HOT MIRROR } \\
\text { BOT MIRROR }\end{array}$ & & $\$ \$ 2$ & $\$ 164$ \\
\hline & ORIIL & 12300 & MIKOM CNDTRA LENS MOUNT & $\$ 79$ & & \\
\hline & MIKON & $\begin{array}{l}M-2000 \\
B R 3\end{array}$ & 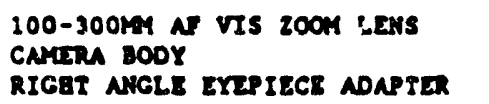 & $\$ 643$ & $\begin{array}{l}\$ 293 \\
\$ 247\end{array}$ & \\
\hline $\begin{array}{l}\text { LENS } \\
\text { SYSTEM }\end{array}$ & QUANTA RAY & & 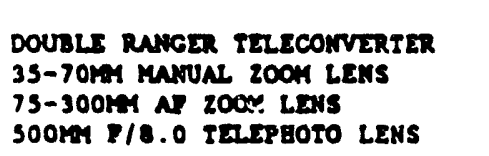 & & sos & $\begin{array}{l}\$ 100 \\
\$ 360 \\
\$ 200\end{array}$ \\
\hline $\begin{array}{l}\text { PIBER } \\
\text { SYSTER }\end{array}$ & ORIEL & $\begin{array}{l}77653 \\
77670 \\
77519 \\
77574 \\
77670 \\
77357\end{array}$ & 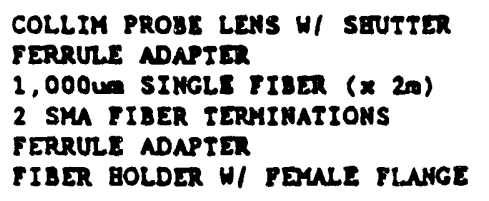 & $\begin{array}{r}\$ 97 \\
\$ 23 \\
\$ 516 \\
\$ 189 \\
\$ 25 \\
\$ 53\end{array}$ & & \\
\hline & $\begin{array}{l}\text { MELLES-GRIOT } \\
\text { ORIER }\end{array}$ & $\begin{array}{r}\text { SPECIAL } \\
77260 \\
40340 \\
42340\end{array}$ & 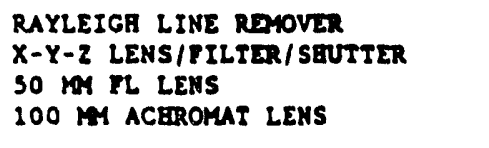 & $\begin{array}{r}\$ 1,200 \\
\$ \$ 87 \\
\$ 50 \\
\$ 85\end{array}$ & & \\
\hline \multicolumn{7}{|c|}{ D. SPECTRAL RESOLUTION OR RUMAN SICNAL } \\
\hline & ORISL & $\begin{array}{l}77200 \\
77222\end{array}$ & $\begin{array}{l}\text { 1/4 H SPECTROGRAPB } \\
\text { INPUT SLIT }\end{array}$ & $\begin{array}{l}\$ 2,783 \\
\$ 238 \\
\$ 289\end{array}$ & & \\
\hline at & $\begin{array}{l}\text { E attached notes } \\
\text { end of Table }\end{array}$ & $\begin{array}{l}77233 \\
77223 \\
77222 \\
77233 \\
77207 \\
77233\end{array}$ & $\begin{array}{l}1200 \text { L/MAY GRATIMG } \\
\text { DOULLE SPECTROCRAPB } \\
\text { INPUT SLII } \\
1200 \text { L/MA GRATING } \\
\text { CENTER SLIT } \\
1200 \text { L/MAM GRATING }\end{array}$ & & $\begin{array}{r}\$ 6,350 \\
\$ 238 \\
\$ 289 \\
\$ 96 \\
\$ 289\end{array}$ & \\
\hline & SPEX & $\begin{array}{r}3405 \\
33519 \\
33519 \\
16798\end{array}$ & 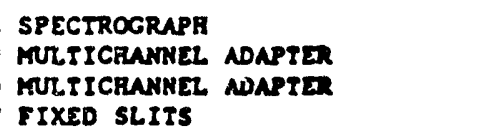 & & & $\begin{array}{l}\$ 3,990 \\
\$ 655 \\
\$ 455 \\
\$ 150\end{array}$ \\
\hline
\end{tabular}


Table 6-2. Itemization of system components and costs (continued)

\begin{tabular}{|c|c|c|c|c|c|c|}
\hline $\begin{array}{l}\text { INSTRURENT } \\
\text { GROUP } \\
\text { (1) }\end{array}$ & $\begin{array}{l}\text { SUPPLIRR } \\
\text { (2) }\end{array}$ & $\begin{array}{l}\text { PART Mo. } \\
\text { (3) }\end{array}$ & $\begin{array}{l}\text { PART DESCRIPIIOW } \\
\text { (4) }\end{array}$ & $\begin{array}{l}\text { BASIC } \\
\text { COAOONENTS } \\
\text { PRICE } \\
\text { (3) }\end{array}$ & $\begin{array}{l}\text { OPTIONAL } \\
\text { COMPONETS } \\
\text { PRICE } \\
\text { (6) }\end{array}$ & $\begin{array}{l}\text { ALTERHATE } \\
\text { VENDOR } \\
\text { PRICE } \\
\text { (7) }\end{array}$ \\
\hline & SPEX & $\begin{array}{r}1800684 \\
1673 C\end{array}$ & $\begin{array}{l}1800 \text { L/MA GRATING } \\
\text { CONIROLLER }\end{array}$ & & & $\begin{array}{l}\$ 600 \\
\$ 980\end{array}$ \\
\hline & EGLG PARC & $\begin{array}{r}1234 \\
3801-0139\end{array}$ & $\begin{array}{l}\text { IRIPLI GRATIMG SPECTROGRAPB } \\
1200 \text { L/MA GRATIHC }\end{array}$ & & & $\$ 4, \$ 10$ \\
\hline
\end{tabular}

E. OPTOELECTROMIC CONVRRSION OP SPECTRAL DATA (OPIICAL MULTICEANIEL AYALYSIS)

\begin{tabular}{|c|c|c|c|c|}
\hline ORIX & 77261 & $\begin{array}{l}\text { INSTASPEC AT DETECTOR } \\
\text { ADDITIONAL COST FOR TES } \\
\text { DIODS ARRAY INTENSIPIER } \\
\text { INSTASPEC PROGRANERS RIT }\end{array}$ & $\begin{array}{r}\$ 10,276 \\
\$ 150\end{array}$ & $\$ 11,500$ \\
\hline EGSG-PARC & $\begin{array}{r}1461 \\
1462 \\
1453 \\
1461 / 88\end{array}$ & $\begin{array}{l}\text { OHA DETECTOR INTERYACE } \\
\text { DETECTOR CONTROLLER MODULE } \\
\text { DETECTOR } \\
\text { PC SOFTHARE } \\
\text { ADDITIONAL COST FOR INTENSIFIED, } \\
\text { GATED, DIODE ARRAY SYSTEM }\end{array}$ & & $\begin{array}{r}\$ 3,990 \\
\$ 90 \$ \\
\$ 6, \$ 65 \\
\$ 1,050 \\
\$ 9,200\end{array}$ \\
\hline
\end{tabular}

P. CORPUTER PROCESSIHG OF SPECTRA

$\begin{array}{ll}\text { AO-MB PC/AT CLONE WITE } & \$ 1,600 \\ \text { 1-ME RAY, EGA, 80287 } & \\ \text { LASER PRINTER OR PEN-PLOTTER } & \$ 1,500\end{array}$

MOTEs:

If the Rayleleh flleer and double spectroszaph fall to reduce etray llghe and Raglelgh algnel suffletently, a double-spectroserer in the subtrative mode plus spectoeraph plus Reyleleh notch flleer vill be tried. The costs appear below: 
Table 6-2. Itemization of system components and costs (concluded)

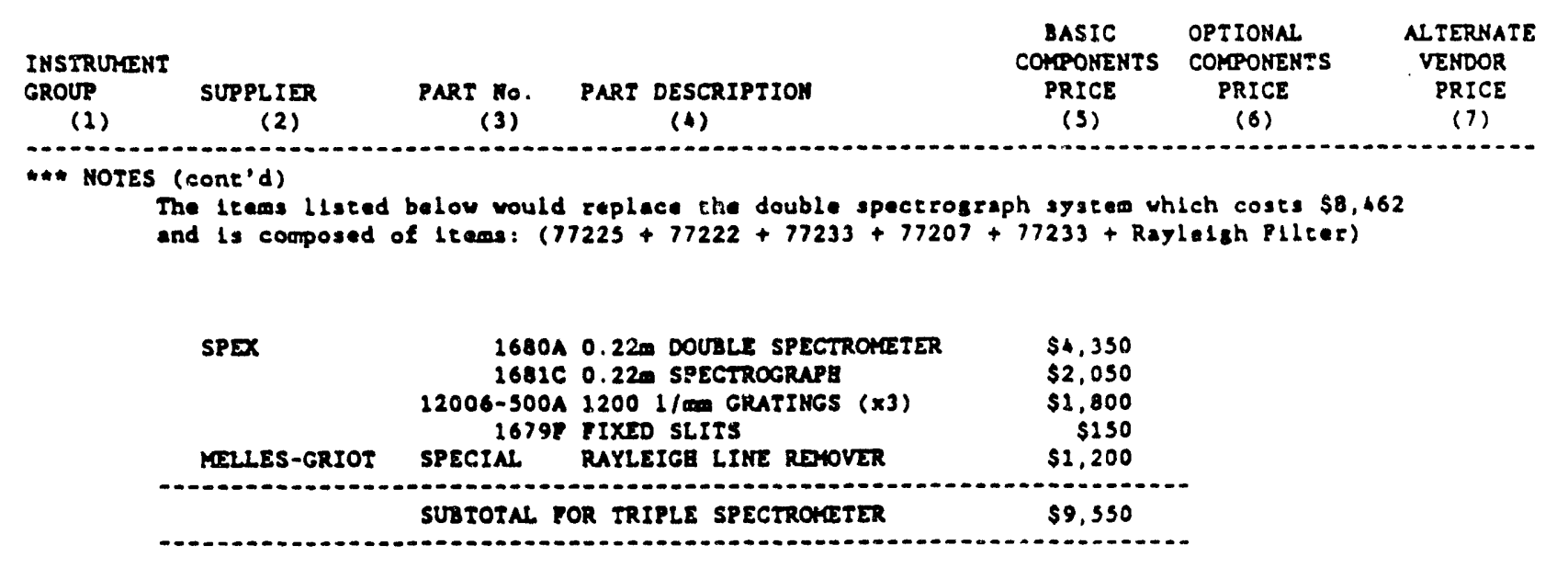


Table 6-3. Miscellaneous experimental apparatus and costs

\begin{tabular}{|c|c|c|c|c|c|c|}
\hline $\begin{array}{l}\text { INSTRUMENT } \\
\text { GROUP } \\
\text { (1) }\end{array}$ & $\begin{array}{l}\text { SUPPLIER } \\
\text { (2) }\end{array}$ & $\begin{array}{l}\text { PART No. } \\
\text { (3) }\end{array}$ & $\begin{array}{l}\text { PART DESCRIPTION } \\
\text { (4) }\end{array}$ & $\begin{array}{c}\text { BASIC } \\
\text { COMPONENTS } \\
\text { PRICE } \\
\text { (S) }\end{array}$ & $\begin{array}{l}\text { OPIIONAL } \\
\text { COMPONENTS } \\
\text { PRICE } \\
\text { (6) }\end{array}$ & $\begin{array}{c}\text { ALTERNATE } \\
\text { VENDOR } \\
\text { PP.:CE } \\
\text { (7) }\end{array}$ \\
\hline \multicolumn{7}{|c|}{ G. MISCELLANEOUS ITEMS } \\
\hline & ORIEL & $\begin{array}{l}10770 \\
44990 \\
7761: \\
14200 \\
17281 \\
12350 \\
13420 \\
14423 \\
77612\end{array}$ & 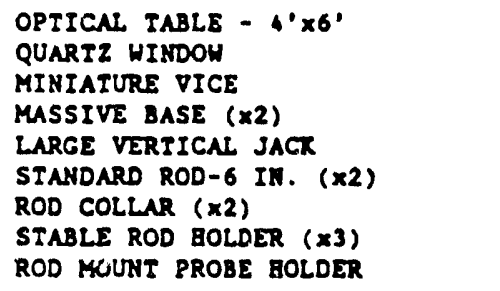 & $\begin{array}{r}\$ 4,040 \\
\$ 248 \\
\$ 32 \\
\$ 306 \\
\\
\$ 30 \\
\$ 48 \\
\$ 90 \\
\$ 75\end{array}$ & 175 & \\
\hline & NELPORT & $\begin{array}{l}\text { G-LGS-NDGA } \\
\text { G-LCS-NDGA }\end{array}$ & $\begin{array}{l}\text { GOGGLES VIS }(\times 2) \\
\text { GOGGLES UV }(\times 2)\end{array}$ & $\begin{array}{l}\$ 336 \\
\$ 336\end{array}$ & & \\
\hline & MIXRON & 370 & $\begin{array}{l}\text { NBS TRACEABLE TUNGSTEN } \\
\text { IDMPERATURE CALIE SOURCE }\end{array}$ & $\$ 11,200$ & & \\
\hline & ORIEL & $\begin{array}{l}63356 \\
68830 \\
63366\end{array}$ & $\begin{array}{l}\text { NBS TRACEABLE 20OW CALIB LANAP } \\
\text { PWR SUPPLY FOR 200W CALIB LAMP } \\
200 W \text { LAMP MOUNT }\end{array}$ & $\begin{array}{r}\$ 865 \\
\$ 1,673 \\
\$ 96\end{array}$ & & \\
\hline & & & $\begin{array}{l}\text { BN, T102, Na2SO4, AND OTBER } \\
\text { WAVELENGTB CALIB. CEREAICALS }\end{array}$ & $\$ 200$ & & \\
\hline & & & FIBER WICXS, CONTAINER, FUELS & $\$ 500$ & & \\
\hline & & SUBTOTAL & & $\$ 20,177$ & $\$ 773$ & \\
\hline
\end{tabular}


the feasibility of Raman Spectroscopy as an Industrial WPTA technology. System cost issues and projections for production-scale cost reductions are discussed in Section 6.3.1.5.

For the laboratory-scale system components in Tables 6-2 and 6-3, the subsystem containing each instrument is listed in column 1 (e.g., Light Delivery System). Vendors are tabulated in column 2, parts numbers in column 3, and parts descriptions in column 4 . The costs for basic system components are tabulated in column 5 , optional items are tabulated in column 6 , and column 7 presents comparative costs for the major items such as the laser and OMA. The total system cost is presented for both the base system and the base system with options. The basic system cost is $\$ 50,541$, while the additional cost of optional equipment is $\$ 24,468$. The three major options are the image intensifier, the second spectrograph and the PMT light sampling assembly. The additional option cost is the total of column 6 less items that would be replaced by the option. Specifically, this equals $\$ 27,778$ less the costs of the single spectrograph:

$$
\$ 27,778-(\$ 2,783+\$ 238+\$ 289)=\$ 24,468
$$

In addition to these Raman system costs, several other items, totalling $\$ 20,177$, are required for experimentation. These items include the Mikron 370 NBS-traceable tungsten lamp temperature calibration source $(\$ 11,300)$, the NBS traceable white light calibration source $(\$ 2,636)$, fiberfrax wicks, and hydrocarbon fuel, all of which are listed in Table 6-3. The Mikron 300 NBS-traceable blackbody temperature calibration source is cheaper, at $\$ 7,400$, than the Mikron 370 , but cannot provide non-unity emissivities or non-gray spectra. The Mikron 370 emissivity varies slightly with temperature and is non-unity $(\sim 0.44)$-a condition more likely to be found in industry than constant, unity emissivity. Thus, the 370 is the preferred unit. The unit will also enable calibration and comparison of the PIC Pyrolaser pyrometer. Equipment specifications are presented in the appendices, and this issue is further discussed in Section 6.3.2.6. 
The Quanta Ray Zoum lenses in Table 6-2 are an after-market brand and are listed as aiternatives because their quality is uncertain. Nonetheless, they cost so much less than name brands such as Nikon and Minolta that they should be evaluated for possible future application.

\section{Contingencies}

The development and final versions of the Raman Spectroscope will have a printer or plotter attached, and will require software for the implementation of controls. The costs for these items are presented in Table 6-3. A good, low-end dot matrix printer currently retails for about $\$ 180$. Plotters cost about $\$ 1,500$ o $\$ 2,000$ for small (8-in by 11 -in units), although a small postscript capable laser printer, such as the HP-IIP with special fontware, retails in the same price range and may be more versatile. Finally, the Mikron 370 is only useful above $800^{\circ} \mathrm{C}$. It will be necessary to buy or lease a Mikron 300 (or Mikron 330) for any calibrations below $200^{\circ} \mathrm{C}$ (or $100^{\circ} \mathrm{C}$ ). The costs for these and other contingencies are estimated at 15 percent of the base, optional and miscellaneous costs from Tables 6-2 and 6-3. This brings total experimentation hardware costs to

$$
115 \% \times(\$ 50,541+\$ 24,668+\$ 20,177)=\$ 109,694
$$

\subsubsection{Production-Level System Cost Issues-Economic Feasibility}

\section{System Costs}

The system presented above for laboratory evalurition costs about $\$ 50,000$ without options and about $\$ 70,000$ with the options considered important. With labor and gross margin added, this would seem to indicate a market price of about $\$ 150,000$ to about $\$ 200,000$ for a high-end Raman thermometry system like the proposed design. The price objective for production-volume Raman systems is about 25 to 30 percent of these levels, and seem unobtainable at first glance. However, Raman system components are currently treated as specialty research items, and there is very much room for prices to come down to the $\$ 40,000$ to $\$ 50,000$ per system range for a high-end system 
comparable to the one detailed in this report. Low-end systems with less laser power requirements, and operating in clean environments at low temperatures (several hundred ${ }^{\circ} \mathrm{C}$ ), are expected to cost about half this range.

\section{Electronics and Electrooptics}

The price reductions will come about because the industrial Raman systems will be multiple replicas of an identifiable OEM unit with volume production savings, rather than collections of specialty items. For example, the price of a 20-MB Winchester hard disk is listed by EG\&G-PARC in their $R \& D$ components price list as $\$ 3,310$. The street price for these items in single quantities is about $\$ 190$ to $\$ 200-$ with controllers. All the computer-related hardware in Raman systems show similar distortions in pricing. These systems are generally sold in packages, allowing 500 percent or more markup in the computer system, interface board anc' related systems prices. The package deals include items such as detector power supplies, software and analog interface boards that are required to make the Raman detectors work, and are not readily available by themselves at lower price. (The researcher is thus compelled to buy the entire package.) The related software is also priced high, and seems to reflect an expectation of low sales volume. (A package of BASIC with manuals is offered at $\$ 525$, while the single quantity street price is about $\$ 200$ for Microsoft Basic or $\$ 70$ for Microsoft Quickbasic.)

The laser and optical components also show prices that reflect both the specialization of the field and manufacturers' expectations of low sales volumes. For example, Oriel sells about 4 OMA Instaspec systems per month. The market assessment performed by Acurex for this project reveals that sales of 0.5 percent of the total unit base per year would double Oriel's OMLA sales volume. A major part of the Instaspec system cost lies in manufacturing setup. Discussions with Oriel, assuming their curre $-t$ cost structure, sales expectations and production setup, indicate discounts of about 20 to 30 percent at a sales volume of 50 to 100 units/yr. The actual discount depends on both volume and timing. If the sales are bunched in time, Oriel need not carry significant stock or incur multiple setup costs, and the discounts will be higher. (Under their current cost structure and 
sales volume, Oriel projects discounts of 25 to 30 percent at 500 units/yr, and 30 to 35 percent at 1000 units/yr.)

Oriel indicates that the base price for the 20 percent discount will also go down as the total sales volume increases. This is partly because, if the development costs have to be recouped in a given time (e.g., 5 years), a higher sales volume indicates a lower required price per unit to recoup the costs. Thus, it is possible that OMAs and other optics will fall by over 30 percent from their current base prices before discount. It is worth noting that these items are not only used for Raman Spectroscopy, but in other spectroscopic and optical fields. As a result, the demand could increase as the prices go down (further introducing economics of scale and lnwering prices). In addition, such items as intensifiers can find application in other consumer products such as telescopes, scanners and consumer imaging systems if they become low enough in price. Thus, supply and variety will also increase.

In summary, the optical and optoelectronics systems costs are expected to decrease significantly if Raman Spectroscopy makes the transition from a specialty post-graduate research technique to a basic form of industrial instrumentation. The exact amount of decrease is difficult to predict since the economics, methods and objectives of production will change significantly. However, discussions with producers indicate that base prices before discounts could fall by up to 30 percent, while the additional volume discounts are projected in the range of 20 to 35 percent. These price changes are projections and assume:

- The same cost structure as currently exists, including high setup costs per unit (few units per setup)

- The same sales volume expectations as currently exist

The computer and peripherals packaged with current Raman systems show clear room for cost decrease. Electronics systems costs are expected to fall by at least 50 to 60 percent with the increased sales discussed above and better packaging. In some electronic units, this price reduction level can already be exceeded by simply repackaging. 


\section{Lasers}

The DCR-11 laser system by Spectra Physics has been ruggedized for several OEMs. This laser has been customized as a maintenance-free blackbox for several uses including helicopter, submarine and desert environment applications. They have also been mounted next to jet engines for resting. The OEM volume discounts depend on several factors including laser specifications such as lineshape and housing, power and computer interface, as well as location of use (application in offshore locations will be more expensive since the corresponding service centers must be paid for warranty service). Spectra Physics provides the following conservative estimates for OEM discounts on the DCR-11 laser:

- Up to 50 units/yr gets 10 to 12 percent discount

- 50 to 100 units/yr gets 15 percent dis zount

- Over 100 units/yr gets 15 to 20 percent discount

It should be noted that these are very conservative estimates, and the company expects actual reductions to be higher. Offshore laser production by Spectra Physics and competing firms will also mean cheaper lasers. Finally, we note here that the DCR-11 is intended for the most difficult applications such as measurement of very high temperature $(\sim 2000 \mathrm{~K})$ parts in very sooty environments. It has far more power ( $135 \mathrm{~mJ} / \mathrm{pulse}$ ) than would be required in the large number of heat treating applications where temperatures are below $\sim 1000 \mathrm{~K}$, and there is little or no soot, laser-induced particulate incandescence or background luminosity. The proposed system, therefore, would be a high-end system in industry. As was demonstrated in Section 6.3.1.2, under the heading, "Optoelectronic Conversion of Resolved Spectra," even a $10 \mathrm{~mJ}$ pulse energy overcomes the workpiece $2,000^{\circ} \mathrm{K}$ blackbody radiation when gating is applied. (This calculation was done assuming no soot.) At these high temperatures, one DCR-11 could be used for simultaneous measurements at 14 points and still overcome the workpiece radiation. Thus, the laser price savings for multiple-measurement systems could be as high as 90 percent since one laser would service 14 measurement stations (i.e., 14 individual Raman systems, each with one laser, would not be 
required). The DCR-11 was chosen for this project to allow evaluation of most ranges of factors likely to be experienced in industry. A smaller laser would be cheaper but could not evaluate thermometry at high dirt/ash/soot loadings and 2,000 $\mathrm{K}$ temperatures.

\section{Operation and Maintenance Issues}

Current Raman equipment is built for R\&D, and typically contains several user-serviceable and user-adjustable parts. Indeed, graduate students, faculty, industrial and post-graduate researchers spend significant amounts of time adjusting and fine tuning their lasers, optics, electronics and computer programs. This is the exact opposite of the intent of the system envisaged for industrial applications. In the industrial unit, the laser will be a black box with a sealed beam output (much like current OEM applications of the DCR-11 laser). The entire optical system will be sealed, as much to exclude stray light as to exclude unauthorized adjustments. The idea is to relegate the operator/system interface to a few innocuous and foolproof touchpads. Required operator training must be kept to a minimum, ideally less than 1 week. The final production system will be self diagnosing, and will generate information that can be accessed by modem from the manufacturer. This way, the manufacturer can execute remote diagnostics tests and keep the operator unencumbered. The laser has proven its worth in existing OEM systems where the only maintenance item is the lamp replacement after 30 million flashes.

The lenses, optics and computer systems are also simple and rugged, and require minimal operator contact (outside of occasional cleaning of the beam delivery and signal retrieval lenses). The laser and most of the Raman system will also be remote so that all the operator sees is the touchpad with simple English instructions, a display screen, and possibly a printer or plotter. Thus, operation and maintenance costs of the system will be minimal, and could be covered in a service contract purchased with the system for a low price.

One of the major operator training issues will be safety around intense laser beams. Besides safety goggles, fire drills and emergency response actions will need to be practiced. In particular, 
the work environs must be made laser-safe, and possibilities for beam reflections toward worker areas removed.

The service contract and required operator training could also be combined with the warranty and service coverage provided by the laser and optical manufacturers. Spectra Physics, for example, provides a 1-yr parts and labor warranty on mechanicals and electronics, and a 90-day warranty on optics and crystals. Travel time is not covered, and their nearest service advisor will respond at a set zone charge. Complete service warranties can be arranged, including items such as training, warranty to cover parts and labor, and service response times of $4,8,12,24 \mathrm{hr}$, etc. The service charges are $\$ 90 / \mathrm{hr}$ plus air fare plus $\$ 200 /$ day per diem for overnight jobs. Training also costs $\$ 90 /$ hr. Spectra Physics has service centers in Mountain View, California; Chicago, Illinois; Albuquerque, New Mexico; New Jersey; and several other urban areas in the United States, Canada, and Europe. They estimate that an average site visit to troubleshoot costs about $\$ 1,000$. The warranties provided by Quantel are similar.

Oriel provides a 1-yr warranty on all products, and free software upgrades for 2 yr. Repairs are done in Connecticut, and repair cycles take about 1 week or more. Most of their optics stock is off-the-shelf and can be shipped within 7 days. They will provide free telephone help on software. (Competing optics manufacturers have similar warranties and services.)

\subsection{LABORATORY-SCALE TEST PLAN}

\subsubsection{Introduction}

The laboratory tests are designed to investigate the suitability of Raman Spectroscopy for workpiece temperature mes:surement. These tests have two major objectives:

- To investigate the impact of noise sources on measurements, and determine $\mathrm{S} / \mathrm{N}$ ratios and accuracies to be expected in Raman WPTA systems

- To identify the design bottlenecks preventing wide application of Raman thermometry in industry. 
The laboratory-scale tests are planned to be divided into the following eight tasks:

- Task 1-Documentation of Useful Raman Lines

- Task 2-Development of Deconvolution Software

- Task 3-5-Factor Noise Tests

- Task 4-General Optics Tests

- Task 5-Identification of Design Bottlenecks

- Task 6-Temperature Calibration

- Task 7-Equipment Calibration Issues and Temperature Calculation

- Task 8-Modeling of and Correction for Anharmonic Effects

Tasks 7 and 8 will be concurrent with Tasks 3, 4, and 6. The tasks are discussed in the subsections that follow.

\subsubsection{Task 1-Documentation of Useful Raman Lines}

This task will involve a literature search for Raman lines that are useful for solid thermometry. The lines will include modes from ceramics and insulating materials, metal crystals, metallic oxides, nitrides, silicides, carbides, sulfates and other salts. The findings will be documented for subsequent tasks. Information on temperature-related anharmonicities will also be documented. This information will include linewidth changes, line frequency shifts and parameters from analytical models of anharmonicity in useful lines.

\subsubsection{Task 2-Development of Deconvolution Software}

A program will be written to interface with the Instaspec II program and to process workpiece Ra:aan spectral data, using the results of Task 1. The program will be able to deconvolve Stokes and Anti-Stokes bancis in various WPTA applications, and will calculate and display the temperatures. The program will also generate control signals for external hardware, based on temperature reading. Programming will be done with the subroutines and programmer package provided with Instaspec II. Because of the substantial capabilities of Instaspec II, the programming effort is not expected to be extensive. 


\subsubsection{Task 3-5-Factor Noise Tests}

This task will study the effects of background luminosity, workpiece radiation, lasermodulated incandescence, window fluorescence, and rejection. The proposed test schedule will involve measuring the temperature of a known solid while it is being viewed through flames of varying optical thicknesses. The test objective will be an electrically heated tungsten filament in a Mikron 370 NBS-traceable temperature calitration source. The flames will be provided by a row of fiberfrax wicks burning liquid hydrocarbon fuels (methanol, iso-octane, cyclohexane, kerosene, toluene). The experimental configuration is shown in Figure 6-8. Background luminosity noise can be varied by changing the fuel and/or number of wicks. The soot content will also allow the effects of laser-modulated incandescence to be evaluated. The third major source of noise, workpiece blackbody radiation, will be varied by changing the current through the tungsten.

The experimental design consists of a two-level, four-factor configuration with the following factors:

- Luminosity (L)

- Workpiece solid radiation (B)

- Laser-modulated incandescence (I)

- Window fluorescence (W)

The fifth factor, Rejection (R), will also be evaluated. The Yates' Algorithm table is presented in Table 6-4, where the response is the temperature difference between the NBS. traceable tungsten temperature and the Raman indicated temperature $\left(T_{N B S}-T_{R}\right)$. The two levels of luminosity could be provided by four wicks burning toluene $(+)$, and no flame/methanol flame $(-)$. The two levels of workpiece radiation will be provided by tungsten at $2000 \mathrm{~K}(+)$ and at $300 \mathrm{~K}$

$(-)$. The two levels of laser-modulated incandescence will be provided by toluene at maximum laser power $(+)$ and at 10 percent laser power. The two levels of window fluorescence will be provided by placing a dirty quartz window between the laser and the first wick $(+)$ and having no window $(-)$. 


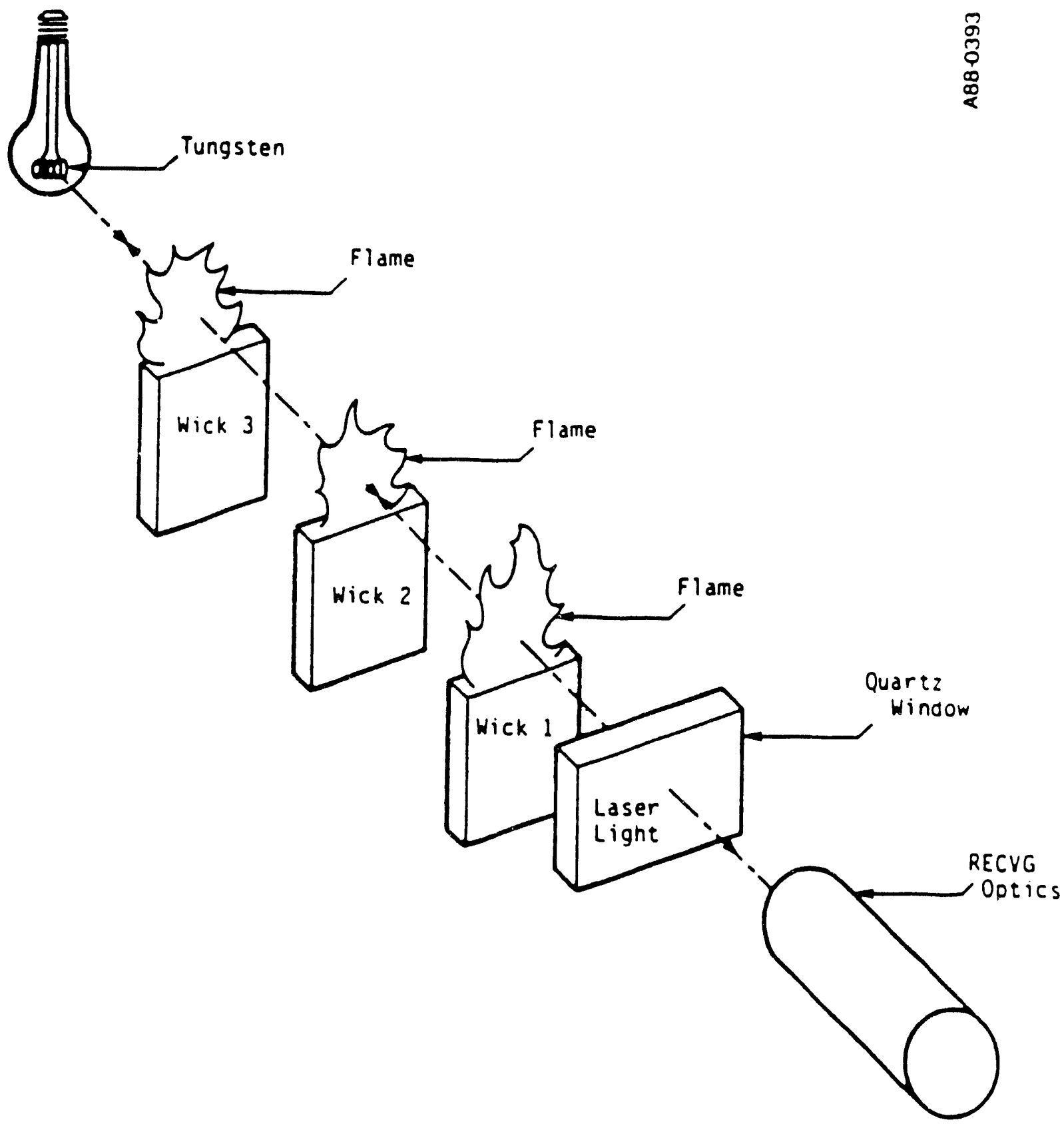

Figure 6-8. Experimental test configuration for studying effects of luminosity, workpiece radiation, laser-modulated incandescence, and window fluorescence 
Table 6-4. Yates' Algorithm

Response $=\left(T_{N B S}-T_{R}\right)=($ NBS-traceable temperature $\cdot$ Raman temperature $)$

\begin{tabular}{|c|c|c|c|c|c|}
\hline \multirow[b]{2}{*}{ Test } & \multirow{2}{*}{$\frac{\begin{array}{c}\text { Input } \\
\text { Variables }\end{array}}{\text { LB I W }}$} & $\begin{array}{c}\text { Yate's Algorithm } \\
\left({ }^{\circ} \mathrm{C}\right)\end{array}$ & \multirow[b]{2}{*}{ Divisor } & \multirow{2}{*}{$\begin{array}{l}\text { Ectimate } \\
\left({ }^{\circ} \mathrm{C}\right)\end{array}$} & \multirow{2}{*}{$\begin{array}{l}\text { Combination } \\
\text { of Factors }\end{array}$} \\
\hline & & $T * \quad(1) \quad(2) \quad(3) \quad(4)$ & & & \\
\hline $\begin{array}{l}1 \\
2 \\
3 \\
4 \\
5 \\
6 \\
7 \\
8 \\
9 \\
10 \\
11 \\
12 \\
13 \\
14 \\
15 \\
16\end{array}$ & 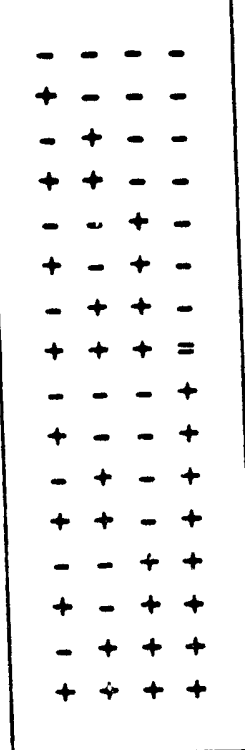 & & $\begin{array}{r}16 \\
8 \\
8 \\
8 \\
8 \\
8 \\
8 \\
8 \\
8 \\
8 \\
8 \\
8 \\
8 \\
8 \\
8 \\
8\end{array}$ & & $\begin{array}{l}\text { Average } \\
L \\
B \\
\text { LB } \\
I \\
\text { LI } \\
B ! \\
\text { LBI } \\
W \\
\text { LW } \\
B W \\
\text { LBW } \\
\text { IW } \\
\text { LIW } \\
\text { BIW } \\
\text { LBIW }\end{array}$ \\
\hline
\end{tabular}


The two levels of rejection ratio will be provided by using two or three filters $(+)$ and one filter (-). These levels are summarized in Table 6-5. The (-) level for workpiece radiation will be changed to the $800^{\circ} \mathrm{C}$ to $1200^{\circ} \mathrm{C}$ range if the other important variables show a need for less contrast in the blackbody radiation $(\cdot)$ and $(+)$ levels. Using this higher range for the $(\cdot)$ level will also allow more accurate evaluation of the breakpoints for employing cheaper lasers.

Other important factors may be identified as the experiment commences, and these will be noted and incorporated into the factorial design if DOE wishes to evaluate their impacts.

Factorial designs at two levels were chosen for the experiments because:

- They require relatively few runs per factor studied; and although they are unable to fully explore a wide range in the factor space, they can indicate major trends and so Jetermine a promising direction for further experimentation

- When a more thorough local exploration is needed, factorial designs can be suitably augmented to form composite designs

- The 2-level factorial designs form the basis for 2-level fractional factorial designs. Fractional factorials allow very efficient evaluation of a large number of factors superficially instead of a large number thoroughly. In this development phase, several factors are expected to impact the Raman system and a fractional factorial design greatly reduces the effort required to assess these factors for importance.

Table 6-5. Variable levels for test matrix (Yates' Algorithm) thermometry tests

\begin{tabular}{|l|l|l|}
\hline \multicolumn{1}{|c|}{ Variable } & \multicolumn{1}{|c|}{$(\cdot)$ Level } & \multicolumn{1}{c|}{$(+)$ Level } \\
\hline Luminosity & No flame & 4 wicks toluene \\
Solid radiation & $300 \mathrm{~K}$ & $2000 \mathrm{~K}$ \\
Incandescence & $10 \%$ laser power & $100 \%$ laser power \\
Window fluorescence & No window & Dirty quartz window \\
Rejection ratio & 1 filter & 2 or 3 filters \\
\hline
\end{tabular}


- Factorial designs and fractional factorial designs may be used as building blocks so that the degree of complexity of the final design can match the sophistication of the problem

- The interpretation of the observations produced by the designs can proceed largely by elementary arithmetic and common sense

The traditional experimental design is the "One-Factor-At-A-Time" (OFAAT) method. In this method, experimental factors are varied one at a time, while the remaining factors are held constant. This was formerly held as the only correct way to conduct research. The OFAAT method provides an estimate of the effect of a single variable (A) at selected fixed conditions of the other variables $\left(\mathrm{X}_{1}, \mathrm{Y}_{1}, \mathrm{Z}_{1}\right)$. For this estimate to be generally relevant, we must assume that the effect of variable $A$ is the same at all settings of the other variables- $\left(X_{2}, Y_{2}, Z_{2}\right),\left(X_{3}, Y_{3}, Z_{3}\right)$, etc. In other wcrds, for the OFAAT estimate to be generally relevant, we must assume that over the ranges of interest, the variables act additively. However, the factorial design is superior to the OFAAT method because:

- If the variables $X, Y, Z$ do act additively, the factorial design provides the estimates of effects with more precision. To obtain estimates of the main effects of $\mathrm{K}$ factors acting additively, the OFAAT method requires at least $(k+1) / 2$ to $k$ times as many runs as the factorial design.

- If the variables do not act additively, the factorial, unlike the OFAAT method, can detect and estimate interactions that measure the nonadditivity

\subsubsection{Task 4-General Optics Tests}

This task will examine the impact of the various subsystems on Raman temperature reading. The components will be shaken, wiggled, turned, saturated, realigned and misaligned to investigate system ruggedness. Fiberoptic connections, lenses and filters, and attenuation and reflection will be examined for their impact on system stability. Gratings will be turned at various angles, and different orientations will be investigated. Spectrographs will be misaligned and placed out of focus to varying degrees, and the diode detector arrays saturated to find recovery times. The Rayleigh 
filter will be removed or turned down to investigate blooming and related effects. All optical components will be wiggled about their aligned positions, room lighting will be changed, and objects repositioned in the room to investigate the impact of stray light and reflections. Both quantitative and qualitative findings will be documented.

Finally, future evaluations should:

- Investigate the UV and IR lines for Signal/Noise performance

- Compare holographic gratings against classically ruled gratings to quantify stray-light performance

- Investigate the impacts of grating line density and slit widths

\subsubsection{Task 5-Identification of Design Bottlenecks}

This task will identify and discuss the engineering issues that must be overcome to make Raman Spectroscopy a competitive WPTA technology. Findings from the earlier tasks will be incorporated. Areas to be investigated include:

- Photon delivery

- Photon collection

- Spectrograph performance: resolution, noise, photoprocessing

- Data acquisition and processing: detectors, $A / D$ boards, computers

- Deconvolution and other software issues

\subsubsection{Task 6-Temperature Calibration}

This task will involve comparison of Raman temperatures against NBS-traceable temperature standards. For this purpose, a Mikron Model 370 Temperature Calibration Sourcc will be used, and the Raman system employed to measure its temperature. The 370 delivers temperatures between $800^{\circ} \mathrm{C}$ and $2300^{\circ} \mathrm{C}$ at $1^{\circ} \mathrm{C}$ resolution. Its specifications are presented in the appendices. By comparison, the Mikron 330 blackbody calibration model delivers temperatures between $100^{\circ} \mathrm{C}$ and $1700^{\circ} \mathrm{C}$ with $1^{\circ} \mathrm{C}$ resolution. This unit costs $\$ 12,400$, and provides optical access to the molybdenum disilicide heating element. The Mikron 330 does not provide the 
emissivity variation and non-gray spectrum of the Mikron 370, but allows calibrations at the lower t:mperatures. The Mikron 300 , at $\$ 7,400$, is also a blackbody calibration source, with a range of $200^{\circ} \mathrm{C}$ to $1200^{\circ} \mathrm{C}$. This model also does not provide emissivity changes and non-gray behavior with temperature. As noted earlier, the Mikron 370 is preferable because its emissivity variations and non-gray spectrum are similar to industrial workpiece behavior. This task will include an effort to lease one of the blackbody calibration units from Mikron for use at lower temperatures. The lease cost is uncertain, and an allowance of 20 percent of purchase price has been included in the 15 percent contingency figure for the costs noted in Section 6.3.1.4.

Raman temperatures will be plotted against NBS-traceable standards for all the 5-factor settings in the Yates' Algorithm of Task 3. Analysis of Variance (ANOVA) techniques will be used to compare the Raman and NBS temperature readings, and to determine the degree of difference between them. The techniques will include 1-way parametric ANOVA (F-tests), prediction intervals, and 1-way non-parametric ANOVA such as the Kruskal-Wallis tests (CHI-squared). If significant differences are found, the noise factor causing the differences will be isolated, and the extent of disagreement documented. Methods will be suggested for addressing significant differences between the Raman temperatures and the NBS standards.

\subsubsection{Task 7-Equipment Calibration Issues and Temperature Calculation}

This task is designed to help obtain quality results from the experiments. Task 7 will run concurrently with Tasks $3,4,6$, and 8 .

\section{Equipment Calibration Issues}

The band frequency and intensity measurements must both be precise to nbtain meaningful temperature measurements from the Raman spectra. In addition, if there are several Raman peaks, as there will be in a practical system, the frequency axis has to be accurate. The remainder of this subsection discusses the important calibration issues that will be addressed in Task 7 . 


\section{Wavelength-Axis Calibration}

In a linear array based system such as the proposed design, the effective slit width varies from pixel to pixel due to the detector array's manufacturing processes which include such effects as imperfect registration of photolithographic masks. The observed spacing between array elements also varies due to field curvature of the optical system. If an intensifier is employed, we must additionally compensate for this component's non-linearity. These factors preclude a simple twopoint, linear calibration of the wavelength axis. The calibration will involve measuring known standard Raman lines from a few solid materials in the same geometry as will be used for the experimental measurements. (Recall that a band of wavelengths is spread across the 1024 detector elements. This band can contain several spectral lines. Since spectral lines have finite widths, each spectral line is spread across a number of detector elements.) A detector element is mapped to each spectral line by assigning the wavelength of the spectral line peak to the element with the highest number of counts within the spectral line. For example, if elements 2 to 10 lie within spectral line W, and element 7 has the highest number of counts in this group, then the wavelength represented by element 7 is identified as the wavelength of the spectral line peak. In other words, the spectral line W peaks at element 7 or the wavelength corresponding to element 7 .

These assignments are precise to within \pm 1 element. A cubic fit is then used with these known spectral lines to calculate wavelengths at other array elements. The uncertainty at any of the other array elements is $z \pm 1$ element, and the magnitude of uncertainty is determined by the number of spectral lines used in the calibration and the choice of curvefit (a cubic fit accounts for system non-linearities better than a linear fit).

Sub-pixel calibrations will be carried out for the OMA. The goodness of fit is expected to hold to within $1 / 5$ th of an element (the repeatability in wavelength assignment is expected to be within $1 / 5$ th of the nominal spectral dispersion per element. For example, $0.016 \mathrm{~nm}$ repeatability is expected for a nominal element resolution of $0.08 \mathrm{~nm}$ ). The method takes each standard spectral line used in the calibration, and calculates the centroid by numerical integration. Only portions of 
spikes above 10 percent of the peak count will be used in the integrations, and the interpolation will use steps of 0.01 element. The centroid is assigned the input wavelength to the nearest 0.01 element. The correction curve for the wavelength axis is then generated via a cubic fit. The standard spectral lines will be identified in Task 1, and these will be chosen to bracket the wavelength range under test around the $532 \mathrm{~nm}$ line. This wavelength range depends on the spectral line chosen for temperature measurement in Task 1. The calibration standard Raman lines will include the Stokes and Anti-Stokes spectra from $\mathrm{BN}$ hexagonal phase, $\mathrm{Na}_{2} \mathrm{SO}_{4}$, and the anatase modification of $\mathrm{TiO}_{2}$.

\section{Intensity Axis Calibration}

Calibration of the intensity axis must compensate for:

- Changes in the effective element width and sensitivity with wavelength

- The intensifier

- The non-uniform spatial response of the array detectors

Since the effective element width varies across the array, the wavelength axis needs to be calibrated first. Knowledge of the wavelength assigned to each element is then used to calibrate the Intensity axis' relative response per element. The uniformity of response varies by as much as \pm 20 percent from one element to another, and the overall system deviation from linearity is about 1 percent. Corrections also need to be made for detector dark count and transmission characteristics of the Rayleigh notch filter. The calibration method involves exposing the detector array to an NBS standard white light source and comparing measured intensities to the known spectral irradiance of the source. A compensation fartor is determined at each of several standard pre-set frequencies (calibration points). By virtue of the wavelength axis calibration, these pre-set frequencies correspond to particular pixels, and linear interpolation is used to assign compensation factors to other pixels. This method compensates for the factors discussed above.

These calibrations will be carried out periodically during the entire laboratory evaluation to assess drift and repeatability. 


\section{Temperature Calculation}

The temperature can then be calculated from the corrected band intensities and band frequencies using

$$
\frac{I_{0}\left(w_{0}+w\right)^{4}}{I_{a}\left(w_{0}-w\right)^{4}}=\exp \left(\frac{h c w}{k T}\right)
$$

where $I_{a}$ and $I_{s}$ and the Anti-Stokes and Stokes band intensities, $w_{0}$ is the pump laser wavelength $(532 \mathrm{~nm}), \mathrm{w}$ is the Raman frequency shift, $\mathrm{h}$ is Planck's Constant, $\mathrm{k}$ is Boltzmann's Constant, and $c$ is the speed of light. In this notation, the quantized energy is $E=$ how.

\section{Application of Different Raman Lines over Different Temperature Ranges}

Task 1 involves searching for Raman lines that can be used for WPTA measurements. The Raman intensities of the lines identified in this search may indicate that it is impossible to apply one line over the entire measurement range. For example, the Anti-Stokes signal may be too weak at low temperatures for a vibrational mode that provides excellent line strengths above $1,000^{\circ} \mathrm{C}$. In such a case, a backup line and a changeover temperature or temperature range specified for switching from one line to the other will be sought.

Another reason for seeking alternative lines is that the workpiece atmosphere might change and render the primary spectral line unusable. For example, if a workpiece is in an oxidizing atmosphere for part of a cycle and in a strongly reducing atmosphere for another part, an oxide spectral line may be suitable in the oxidizing atmosphere but absent in the reducing atmosphere. It will therefore be necessary to use different lines in the different atmospheres.

\subsubsection{Task 8-Modeling of and Correction for Anharmonic Effects}

Mode anharmonicity as related to mode frequency and linewidth variation with temperature will be investigated in this task. Two basic approaches will be adopted: analytical calculation, and experimental measurement plus curvefits. Both approaches are summarized below. 


\section{Analytical Modeling}

The analytical calculations will employ two methods:

- The pseudoharmonic approximation, which accounts for thermal expansion and phononphonon interactions in evaluating the temperature dependence of phonon frequencies and linewidths. A phonon decay model will be employed for linewidth estimation.

- The quasiharmonic approximation, which solely considers lattice thermal expansion in accounting for the temperature dependence of phonon frequencies

Calculations will be performed for each ceramic or metallic compound (i.e., oxides, nitrides, sulfates, metal crystals, carbides, silicides) whose line is being considered for use in WPTA Raman thermometry. The temperature dependent frequency shifts and linewidth changes calculated for each of the metallic comfounds will be compared with experimental observations on spectra from the pure compound. Using these comparisons, the analytical model parameters will be adjusted to obtain the best fits over the measured temperature range $(\sim 300 \mathrm{~K}$ to $200 \mathrm{~K})$.

With the linewidths and line frequencies thus determined, the raw OMA scan data can be corrected and Instaspec can be used for band integration and peak ratioing to find temperature.

\section{Experimental Measurements with Curvefitting}

The second approach will seek to determine if the lineshifts and line broadening can be measured. If the shifted lines can be identified and the lineshapes measured, then 2-parameter Lorentzian curvefits can be combined with Instaspec's capabilities to determine the shifted line frequency and peak height. Knowing these parameters, Stokes/Anti-Stokes ratios can be taken with Instaspec, and temperatures calculated from the corrected band intensities and band frequencies using Equation (6-6).

These temperatures will then be compared with the NBS temperatures and correction curves drawn up. In effect, the mode anharmonicities will be accounted for or bypassed without rigorous calculations. 
This second, non-analytical approach is conceptually simpler and more direct, and would be preferable for the industrial system. For example, some lines, such as the $1366 \mathrm{~cm}^{-1} \mathrm{E}_{\mathrm{g}}$ line of $\mathrm{BN}$, are found to broaden and shift to lower frequencies as temperature increases. The linewidth can triple between $300 \mathrm{~K}$ and $2000 \mathrm{~K}$. The new lineshape at each temperature can be obtained by curvefitting a Lorentzian to obtain the band intensity peak and central frequency. Indeed, the frequency variation of the linepeaks may be useful for independent temperature determination and will be investigated for this purpose. 


\section{SECTION 7}

\section{RECOMMENDED LABORATORY-SCALE TESTS AND SENSOR DEVELOPMENT-PHASE II}

\subsection{INTRODUCTION}

The objective of the project is to develop a commercially viable WPTA for accurate temperature control of loads in industrial furnaces. Successful completion of this program will result in substantial benefits to users. They are:

- Improved quality of products

- Lower cost of production

- Lower use of energy (conservation)

With present technologies, it is not possible to remotely measure temperature accurately unless very special conditions are met. Remote temperature measuring instrumentation needs are only partially met by radiation pyrometers. The critical surface emissivity must be estimated to utilize radiation pyrometers.

Strength and corrosion resistance of materials are often dependent upon precise heat treatment. Chemical reactions in process plants are controlled via process temperatures. Unnecessary exposure to high temperatures often causes a weakening of the material due to undesirable grain growth in the crystallography.

Quality of products is presently often determined by post-treatment destructive or nondestructive testing. The cost of rejection is high, since most heat treatments are the last step prior to completion of parts. Some products discolor if improperly heat treated, lowering the value of the product. 
Lower production costs can be realized. Chemical reactions often have an optimum temperature which provides the highest yield. Lower reject rates result in lower cost to the producer and the consumer. Present accurate measuring techniques require direct contact senscrs. These sensors are difficult to attach, and in some cases it is dangerous to do so. Very high temperature measurements are virtually impossible relying on other indirect means of temperature measurements.

Many heat treatment processes require that a minimum temperature be met. Operators make sure that the temperature of a product gets high enough, wasting valuable resources. Precise knowledge of temperature will allow operators to optimize their processes.

A market assessment was made based on U.S. Industrial Process Heating Energy Consumption Data. Assessment data were:

- Viability of the product

- Applicability of the technology

- Size of the industry

- Need for precise measurements or control

Contacts were made with the various industries to gain direct information.

The result of the market assessment showed that four industries have sufficient resources to allow for early market penetration. They are:

- Metal heat treating facilities

- Glass annealing and forming industries

- Petroleum refining and chemical production industries

- Clean clay firing industries

The initial market size is approximately 5000 units at $\$ 20,000$ each. This is based on expenditures never exceeding 2 percent/yr of revenues. Unit market size increases substantially with lower price. The industry culture will in some cases be difficult for market penetration. Some industry clients understand the benefit accurate temperature measurements can offer whereas much 
education will be required for others. In some industries an attitude prevails that the "good old way" is the best method.

The risk of development for a small company may be quite high if it addresses only a single market. A multipurpose instrument could defray costs over a number of applications. A short-term as well as a long-term development effort is likely to be the best combination to meet the needs of industry. Much effort was expended by Exxon to develop the basic principles of Pyrolaser, and implementation of the Pyrolaser concept was carried out by PIC. It is being recognized, however, that the instrument could be significantly enhanced to offer a broader measurements capability and that this effort would be a relatively short-term effort compared to the Raman Spectroscopy type of instruments.

Support for the project is needed, because it is unlikely that a small company could fund long-term development of the technologies without outside help. The benefits to society would accrue in the form of lower energy use to produce many varieties of products at a lower cost. Lower energy consumption will contribute to lower pollution levels, which is also beneficial. As production of the instrumentation increases, lower instrument costs will be realized leveraging the beneficial effects.

\subsection{RECOMMENDED WPTA DEVELOPMENT PROGRAM-PHASE II}

The short-term project goals recommended are to enhance Pyrolaser to. provide an instrument with enhanced capabilities to industry.

The enhancements recommended for implementation are:

- Improve the performance of the instrument in relation to surface specularity

- Provide the fiberoptics multiplexing capability to lower cost per measurement point

- Extend the measurement range of the instrument for lower temperatures

The long-term development objective recommended is the development of a Raman Spectroscopy technology based WPTA system. This would allow measurements to be made in environments that are presently precluded such as: 
- Atmospheres containing particulate mater

- Surfaces having high specularity

Development of Raman Spectroscopy instrumentation promises a reduction in sensitivity to these temperature measurement interferences. Furthermore, Raman Spectroscopy has multimedia appeal providing for other surface property measurement capabilities.

In summary, the proposed project can achieve the objectives of providing a new high accuracy remote temperature measurement capability in the long-term that does not exist today. Raman Spectroscopy has the potential to make many positive contributions to industry, and, as a result, to society. The state-of-the-art portable Pyrolaser offers a shorter term solution to industry needs, when requirements for proper operation are met. 


\section{REFERENCES}

1. "U.S. Industrial Process Heating Energy Consumption-1985," Report GRI-88/0051, Gas Research Institute, Chicago, Illinois.

2. Census of Manufactures-Industry Series 1982, U.S. Bureau of the Census, U.S. Government Printing Office, Washington, DC.

3. Annual Survey of Manufactures 1980-81, U.S. Bureau of the Census, U.S. Government Printing Office, Washington, DC.

4. Gile, P.E., "Temperature Sensors: How They Work, Where They are Used," Power, August 1986, pp. 91-94.

5. Steam/Its Generation and Use, 39th Edition, Babcock and Wilcox Co., 1978, pp. 33-4 to 33-18.

6. Ely, F. G., "Measurement of Gas Temperature in Boiler Furnaces," Bal 3-555, The Babcock and Wilcox Co. Research Center, Alliance, Ohio, 1969.

7. Mayer, A. M., Phil. Mag., 45, 18, 1973.

8. Green, S. G. and Woodham, A. U., "Rapid Furnace Temperature Distribution Measurement by Sonic Pyrometry," Central Electricity Generating Board, Marchood Engineering Laboratories, Marchood, Southampton, England, 1983.

9. Siegel, R. and Howell, J. R., "Thermal Radiation Heat Transfer," 2nd Ed., Hemisphere Publishing Corp., McGraw-Hill Book Company. 
APPENDIX A

ECONOMIC ANALYSIS

A-1 


\section{CASE SFECIFIC ECONOMIC FAFAMETEFS}

Workpiece Temperature Analyzer by Acurex

Fyrolaser - Petroleum Refining Industry

OIP Improved Combustion Efficiency

Industrial Sector SIC 28 Code per THRESH................

Enter System Type -- Three Choices

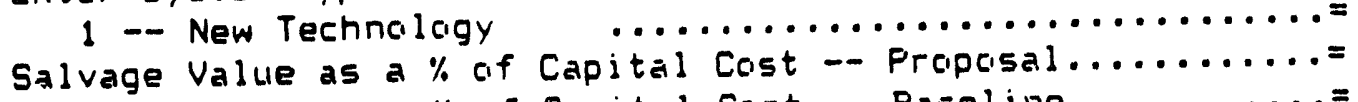

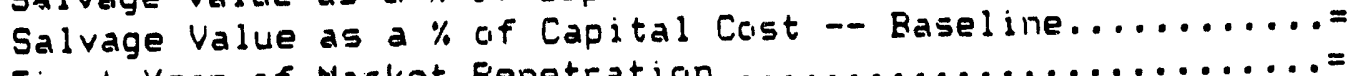

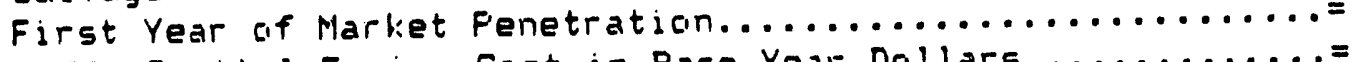

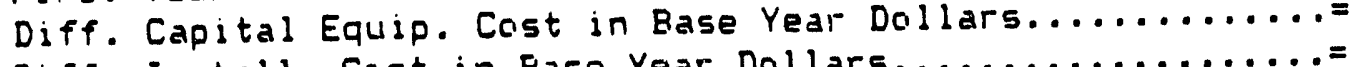

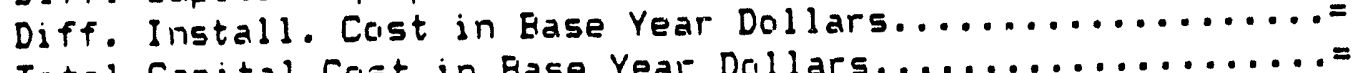

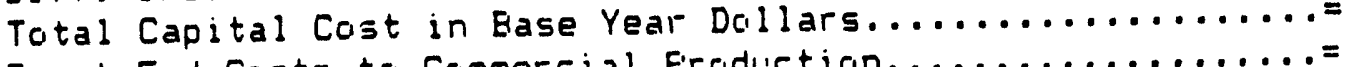

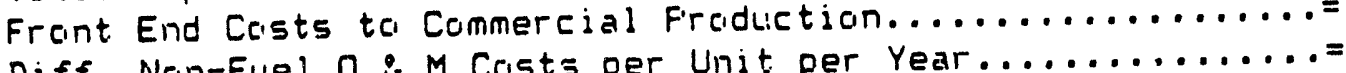

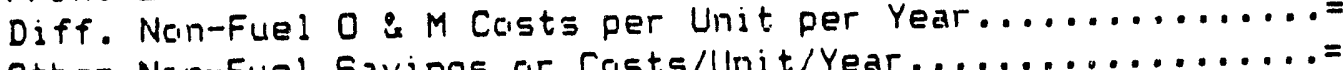

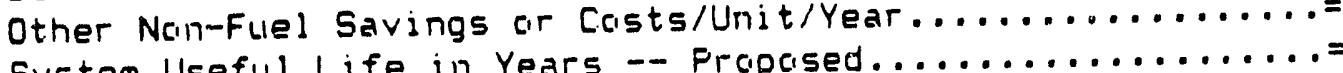

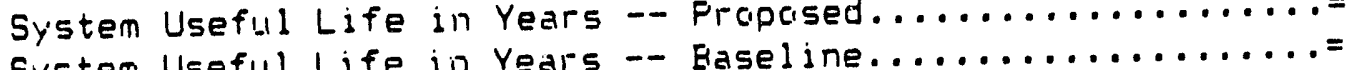

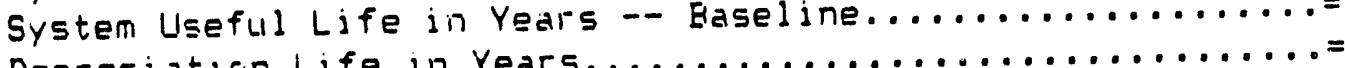

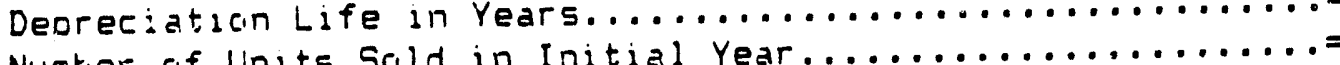

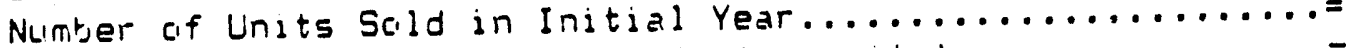

Ma:i imum Market Fatential (cumulative units)..............

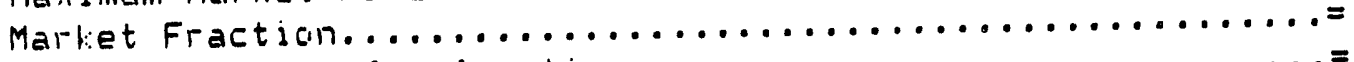

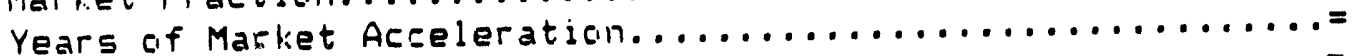

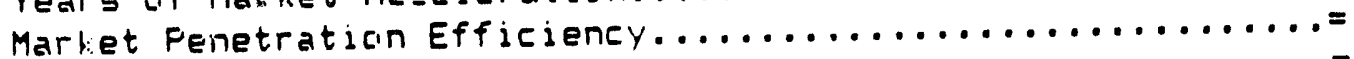

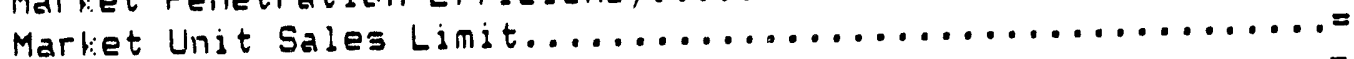

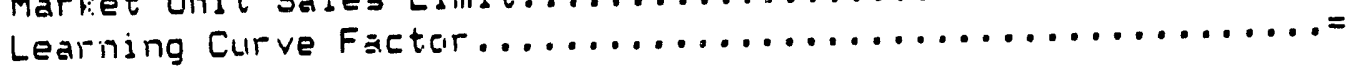

Energy Savings per Unit per Year (Etu)

per Unit per Year (Btu)

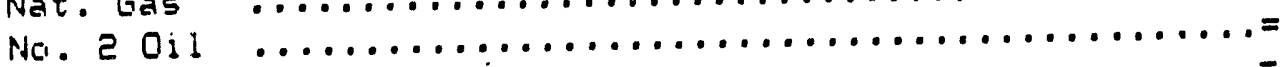

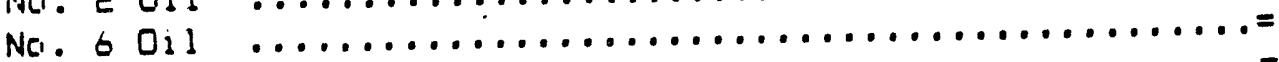

Calal

Electric

Other

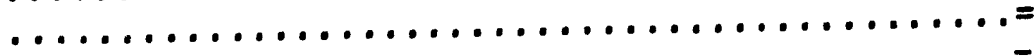

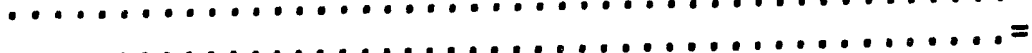

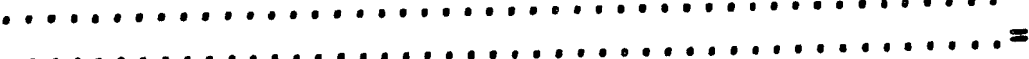

4. OOE+ 09

$0.00 E+100$

$0.00 E+100$

$0.0 \% E+O Q$

$0.00 E+00$

$0.00+0)$

First Year of Federal Investment....................

Federal Investments in Sequence (0001)

Yr 1990

150

First Year of Frivate Investment.....................

$1990^{\circ}$

Private Investments in Sequence (so00)

Yr $1990^{\circ}$

100

February 20, 1990

Fage 2

JWLarson

DOE/OIP 


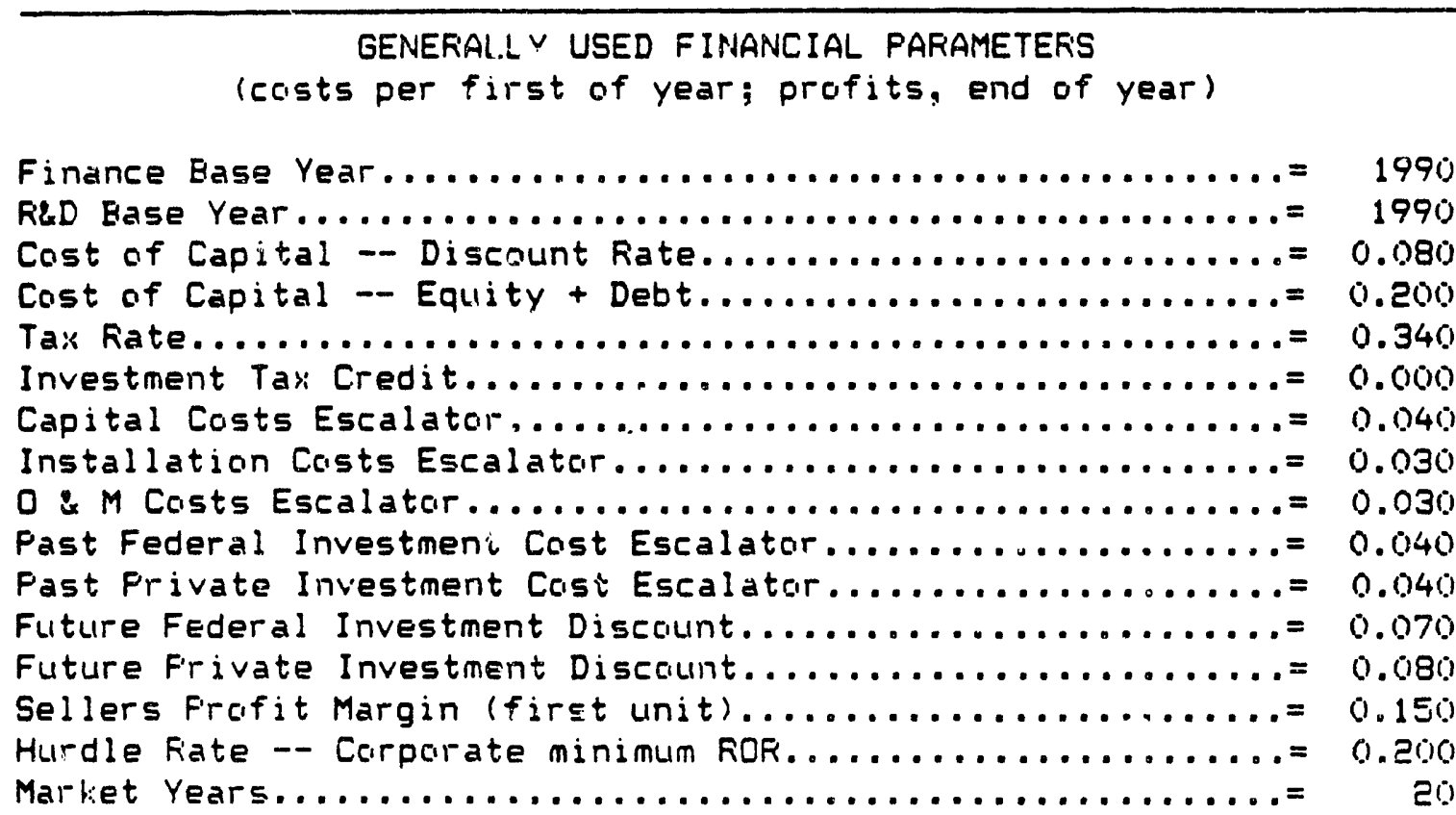

Energy Cast per Milliar. Btus

Nat. Gas

No. 2 Oil

No. 6 Oil

Calal

Electric

Other

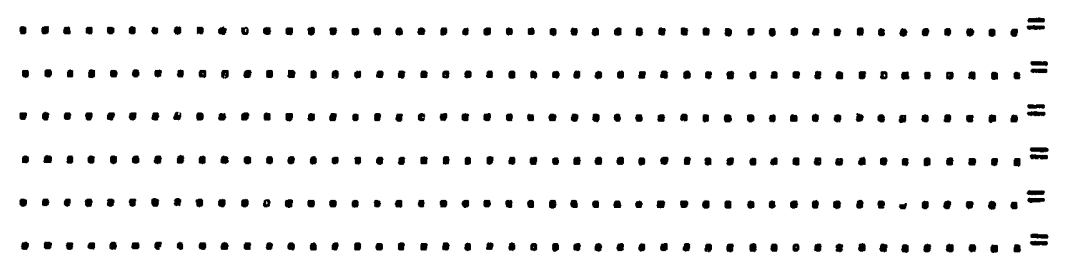

3.630

4.560

3.320

1.880

5.690

1.000

Energy Cost Escalatars

Nat. Gas

$\mathrm{Na} .2 \mathrm{OIl}$

..........

$\mathrm{Na} .6$ Qil

Calal

Electric

Other

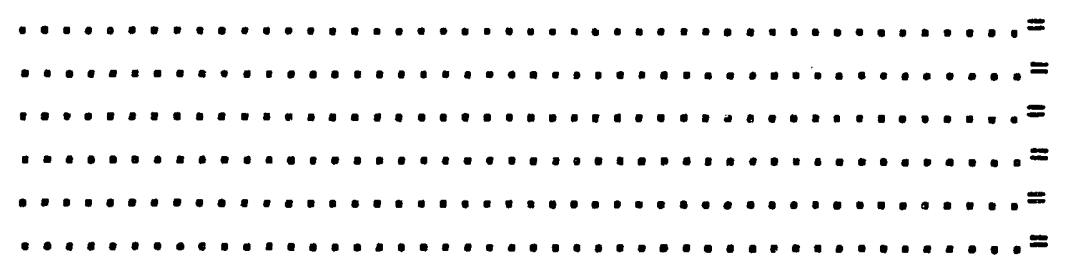

0.070

0.060

0.060

0.060

0.050

0.060

February 20, 1990

Fage 1

JWLarsan

DUะ/OIF 
DOE/DIF THFESHOLD ANALYSIS MODEL -- (ECONOIFE)

Froject Name: Workpiece Temperature Analyzer by Acurex

Deseriptian: Fyralaser - Fetraleum Fefining Industry

ENERGY SAVINGS POTENTIAL (BtU/YR)

\begin{tabular}{lrrrrrr} 
Fuel Type & 1995 & 2000 & 2005 & 2010 & $\begin{array}{r}\text { Cumulative } \\
2010\end{array}$ \\
\hline Nat. Gas & $1.23 E+12$ & $2.00 E+12$ & $3.23 E+12$ & $4.00 E+12$ & $6.23 E+13$ \\
Na. 2 Oil & $0.00 E+00$ & $0.00 E+00$ & $0.00 E+00$ & $0.00 E+00$ & $0.00 E+00$ \\
Na. 6 0il & $0.00 E+00$ & $0.00 E+00$ & $0.00 E-60$ & $0.00 E+00$ & $0.00 E+00$ \\
Caal & $0.00 E+00$ & $0.00 E+00$ & $0.00 E+00$ & $0.00 E+00$ & $0.00 E+00$ \\
Electric & $0.00 E+00$ & $0.00 E+00$ & $0.00 E+00$ & $0.00 E+00$ & $0.00 E+00$ \\
Other & $0.00 E+00$ & $0.00 E+00$ & $0.00 E+00$ & $0.00 E+00$ & $0.00 E+00$ \\
\hline TOTAL & $1.23 E+12$ & $2.00 E+12$ & $3.23 E+12$ & $4.00 E+12$ & $0.23 E+13$ \\
E/DOE* & $5.72 E+02$ & $9.32 E+02$ & $1.50 E+03$ & $1.86 E+03$ &
\end{tabular}

POTENTIAL MONETAFY SAVINGS (\$/YT)

(Discounted to 1990 dollars)

\begin{tabular}{lrrrrrr} 
Fuel Type & 1095 & 2000 & 2005 & 2010 & Cumulative \\
\hline Nat. Gas & $4.63 E+06$ & $7.19 E+00$ & $1.11 E+07$ & $1.31 E+07$ & $2.10 E+08$ \\
Na. 2 0il & $0.00 E+00$ & $0.00 E+00$ & $0.00 E+00$ & $0.00 E+00$ & $0.00 E+00$ \\
Na. 6 0i1 & $0.00 E+00$ & $0.00 E+00$ & $0.00 E+00$ & $0.00 E+00$ & $0.00 E+00$ \\
Coal & $0.00 E+00$ & $0.00 E+00$ & $0.00 E+00$ & $0.00 E+00$ & $0.00 E+00$ \\
Electric & $0.00 E+00$ & $0.00 E+00$ & $0.00 E+00$ & $0.00 E+00$ & $0.00 E+00$ \\
Other & $0.00 E+00$ & $0.00 E+00$ & $0.00 E+00$ & $0.00 E+00$ & $0.00 E+00$ \\
\hline TOTAL & $4.63 E+06$ & $7.19 E+06$ & $1.11 E+07$ & $1.31 E+07$ & $2.10 E+08$
\end{tabular}

ECONOMIC ATTRACTIVEIVESS

$\begin{array}{lc}\text { End User's ROI: } & 1061.7 \% \\ \text { Payback. Fericid: } & 0.1 \text { years } \\ \text { Developer's ROI: } & 309.2 \% \\ & \\ \text { Benefits Rating: } & 0.4\end{array}$

\section{PFIOGFAM EFFICIENCY}

$\begin{array}{lr}\text { ETI: } & 554.8 \\ \text { MEI : } & 314.2 \\ \text { RFD (1995): } & 21.7 \\ \text { RFD (2000): } & 33.7 \\ \text { RFD (2005): } & 51.9 \\ \text { RFD (2010): } & 61.4\end{array}$

* B/DCE = Barrels per Day Oil Equivalent. 
DOE/OIF' THRESHOLD ANALYSIS MODEL -- (ECONOIF'Z)

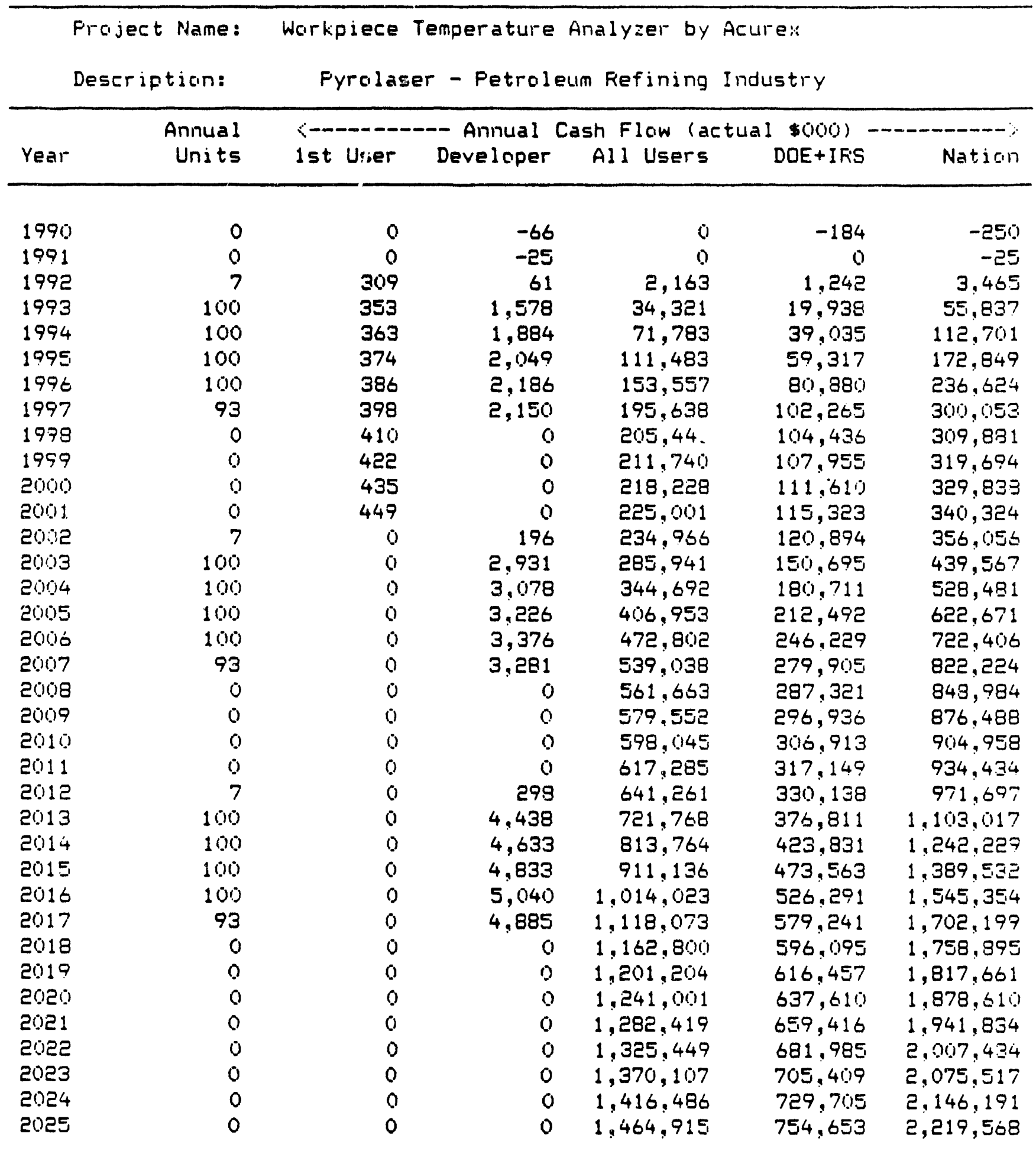

February 20, 1990

Page 5

JWLarson

DOE/OIF 
DOE/OIF THFESHOLD ANALYSIS MODEL -- (ECONOIF'E)

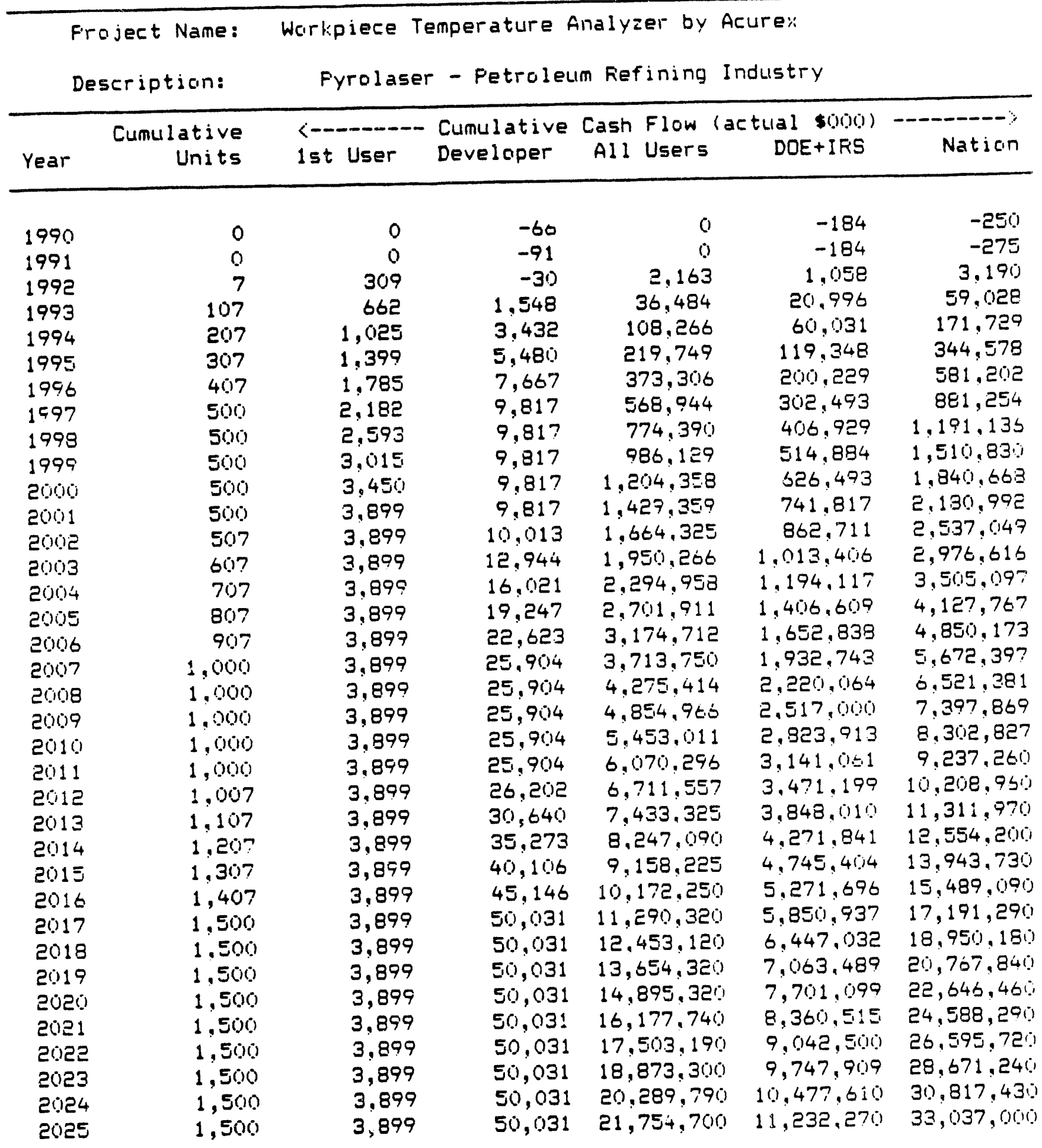

February 20, 1990

Page 6

JWLarson

DOE/OIF 
DOE/OIF THFESHOLD ANALYSIS MODEL -- (ECONOIF'?)

\begin{tabular}{|c|c|c|c|c|c|c|}
\hline & $\begin{array}{l}\text { o ject Name: } \\
\text { scription: }\end{array}$ & $\begin{array}{l}\text { Workpiece } \\
\text { Fyrolas }\end{array}$ & $\begin{array}{l}\text { Temperature } \\
\text { ser - Petrole }\end{array}$ & $\begin{array}{l}\text { Analyzer by } \\
\text { eum Fiefining }\end{array}$ & $\begin{array}{l}\text { Acure\% } \\
\text { Industry }\end{array}$ & \\
\hline Year & $\begin{array}{r}\text { Cumulative } \\
\text { Units }\end{array}$ & $\begin{array}{l}\text { L------- } \\
\text { lst User }\end{array}$ & $\begin{array}{c}\text { Cumulative } \\
\text { Developer }\end{array}$ & $\begin{array}{l}\text { Cash Flow (d } \\
\text { All Users }\end{array}$ & $\begin{array}{c}\text { iscounted } \$ 0001) \\
\text { DOE+IFiS }\end{array}$ & Nation \\
\hline 1990 & 0 & 0 & -61 & 0 & -170 & -231 \\
\hline 1991 & 0 & 0 & -82 & 0 & -170 & -253 \\
\hline 1992 & 7 & 245 & -34 & 1,717 & $8 ! 5$ & 2,498 \\
\hline 1993 & 107 & 505 & 1,126 & 26.944 & 15,471 & 43,540 \\
\hline 1994 & 207 & 752 & 2,4018 & 75,798 & 42,037 & 120.243 \\
\hline 1995 & 307 & 988 & 3,699 & 146.051 & 79,417 & 229,167 \\
\hline 1996 & 407 & 1,213 & 4.974 & 235.650 & 126,610 & 367.235 \\
\hline 1997 & 500 & 1,427 & 6,136 & 341,347 & 181,860 & 529,344 \\
\hline 1998 & 500 & 1,633 & 5,136 & 444,121 & 234,104 & $684,3.51$ \\
\hline 1999 & 500 & 1,828 & 6,135 & 542,197 & 284,108 & 832,442 \\
\hline 200 & 500 & 2,015 & 6,136 & 635,791 & 331.976 & 973,903 \\
\hline $2(0) 1$ & 500 & 2,193 & 6.136 & 725,142 & 377,772 & 1.109 .051 \\
\hline 50.5 & $50 ?$ & 2,193 & 6.208 & 811,537 & 422,224 & 1.239 .972 \\
\hline 200 & 607 & 2,193 & 7,200 & 908,891 & 473,530 & $1,389,627$ \\
\hline 2604 & 707 & 2,193 & 8,176 & $1,017,552$ & 530,498 & 1.556 .226 \\
\hline 20,0 & 807 & 2,193 & 9,118 & $1,136,338$ & 592,522 & $1,737,978$ \\
\hline 2000 & 907 & 2,193 & 10,030 & $1,264,121$ & 659,070 & 1,933, 221 \\
\hline 2007 & 1,000 & 2,193 & 10,851 & $1,399,015$ & 729,116 & $2,138,982$ \\
\hline $50 \%$ & 1.000 & 2,193 & 10,851 & $1,527,159$ & 795,692 & $2,335,702$ \\
\hline 5019 & 1,000 & 2,193 & 10,851 & $1,653,500$ & 859,399 & $2,523,751$ \\
\hline 20110 & 1,000 & 2,193 & 10,851 & $1,772.305$ & 920,369 & $2,703,526$ \\
\hline 2011 & 1,000 & 2,193 & 10,851 & $1,885,849$ & 978,705 & $2,875,406$ \\
\hline $201 \overline{1}$ & 1,007 & 2,173 & 10.902 & $1.995,065$ & $1,034,933$ & $3,040,700$ \\
\hline 2013 & 1,107 & 2,193 & 11,602 & $2,108,888$ & $1,094,355$ & $3,214,845$ \\
\hline 20114 & 1,207 & 2,193 & 12,278 & $2,227,712$ & $1,156,242$ & $3,396,233$ \\
\hline 20,15 & 1,307 & 2,193 & 12,932 & $2,350,899$ & $1,220,269$ & $3,584,100$ \\
\hline $2: 116$ & 1,407 & 2,193 & 13,563 & $2,477,841$ & $1,286,153$ & $3,777,557$ \\
\hline 2017 & 1,500 & 2,193 & 14,129 & $2,607,441$ & $1,353,295$ & $3,974,865$ \\
\hline 20118 & 1.500 & 2,193 & 14,129 & $2,732,241$ & $1,417,273$ & $4,163,643$ \\
\hline 2019 & $1,5,600$ & 2,193 & 14,129 & $2,851,613$ & $1,478,534$ & $4,344,277$ \\
\hline 2020 & 1,560 & 2,193 & 14,129 & $2,965,805$ & $1,537,205$ & $4,517,139$ \\
\hline ટ૭:1 & 1,500 & 2,193 & 14,129 & $3,075,067$ & $1,593,387$ & $4,682,583$ \\
\hline ર૭:ર & 1,500 & 2,193 & 14,129 & $3,179,630$ & $1,647,188$ & 4.840 .947 \\
\hline 2023 & 1,500 & 2,193 & 14.129 & $3,279,710$ & $1,698,714$ & $4,992,554$ \\
\hline 2024 & 1,500 & 2,193 & 14,129 & $3,375,513$ & $1,748,068$ & 5.137 .710 \\
\hline 2025 & 1,500 & 2,193 & 14,129 & $3,467,252$ & $1,795,327$ & $5,276,709$ \\
\hline
\end{tabular}

February 20, 1990

Fage 7

JWLarson

DOE/OIF 
DOE/OIF THFESHOLD ANALYSIS MCIDEL -- (ECONOIF'Z)

Fraject Name: Workpiece Temperature Aralyzer by fcure:

ECONOMIC PEFSFECTIVE OF FIFST USER

\begin{tabular}{|c|c|c|c|c|c|}
\hline \multirow[b]{2}{*}{ Year } & \multirow{2}{*}{ Tax Breal: } & \multirow{2}{*}{$\begin{array}{c}\text { Annual Dollars } \\
\text { Dperations }\end{array}$} & $------->$ & \multicolumn{2}{|c|}{ Cumulative Dollars } \\
\hline & & & Cash Flow & Actual & \\
\hline 1992 & 1,565 & 339,655 & 308,980 & $308,980^{\circ}$ & 245,279 \\
\hline 1993 & 2,685 & 350,299 & 352,984 & 661,964 & 504,732 \\
\hline 1994 & 1,918 & 361,294 & 363,211 & $1,025,175$ & 751.927 \\
\hline 1995 & 1,370 & 372,652 & 374,022 & $1,399,197$ & 987,625 \\
\hline 1996 & 1,141 & 384,388 & 385,527 & $1,784,725$ & $1,212,577$ \\
\hline 1997 & 1,141 & 396,514 & 397,656 & $2,182,382$ & $1,427,418$ \\
\hline 1998 & 1,141 & 409,047 & 410,188 & $2.592,570$ & $1,632,614$ \\
\hline 1959 & 0 & 421,999 & 421,999 & $3,014,569$ & $1,828,081$ \\
\hline 2000 & 0 & 435,388 & 435,388 & $3,449,958$ & 2.014 .812 \\
\hline 2001 & 0 & 449,230 & 449,230 & $3,899,187$ & $2,193,207$ \\
\hline
\end{tabular}

February 20, 1990

Fage 8

JWI. arsoin

DDE/OIF 
DOE/OIF THFESHOLD ANALYSIS MODEL -- (ECONOIFE)

Project Name: Workpiece Temperature Analyzer by Acura:s

ECONOMIC FERSFECTIVE OF DEVELOFER

\begin{tabular}{|c|c|c|c|c|c|}
\hline \multirow[b]{2}{*}{ Year } & \multirow{2}{*}{$\begin{array}{l}\text { Units } \\
\text { Sold }\end{array}$} & \multirow{2}{*}{$\begin{array}{l}\text { Unit } \\
\text { Cost }\end{array}$} & \multirow{2}{*}{$\begin{array}{l}\text { Aninual \$ } \\
\text { Cash Flaw }\end{array}$} & \multicolumn{2}{|c|}{ Cumulative Dollars } \\
\hline & & & & Actual & Discounted \\
\hline $1990^{\circ}$ & 0 & 0 & -66.000 & $-66,000$ & -61.111 \\
\hline 1991 & 0 & 0 & $-24,737$ & $-90,737$ & $-82,319$ \\
\hline 1992 & 7 & 43,057 & 60,551 & $-30,186$ & $-34,252$ \\
\hline 1903 & 100 & 44.673 & $1,578,269$ & $1,548,083$ & $1,125,023$ \\
\hline 1994 & 100 & 46,351 & $1,883,507$ & $3,431,590$ & $2,407,706$ \\
\hline 1975 & 100 & 48,092 & $2,048,723$ & $5,480,314$ & $3,698,749$ \\
\hline 1796 & 100 & 49,900 & $2,186,322$ & $7,666,636$ & $4,974,440$ \\
\hline 1997 & 93 & 51,777 & $2,150,426$ & $9,817,062$ & $0.136,254$ \\
\hline 1993 & 0 & 53,725 & 0 & 9.817 .062 & $6.136,254$ \\
\hline 1999 & 0 & 55,747 & $\dot{0}$ & $9,817,062$ & $6,136,254$ \\
\hline 2000 & 0 & 57.846 & 0 & $9,817,062$ & $6,136,254$ \\
\hline 2001 & 0 & 60,026 & 0 & $9,817,062$ & $6,136,254$ \\
\hline 2002 & 7 & 62,289 & 196.224 & $10,013.290$ & $6,208,405$ \\
\hline 2003 & 100 & 64.638 & $2,930,501$ & $12,943,790$ & $7,206,126$ \\
\hline 2004 & 100 & 67.076 & $3,0.77,629$ & 16.021 .410 & $8,176,321$ \\
\hline 2005 & 100 & 69.6018 & $3,225,582$ & $19,247,000$ & $9,117,837$ \\
\hline 2006 & 100 & 72,235 & $3,375,687$ & 22.622 .690 & $10,030,180$ \\
\hline 2007 & 93 & 74.965 & $3,281,081$ & $25,903,770$ & $10,851.270$ \\
\hline 2008 & 0 & 77,799 & 0 & $25,903,770$ & $10,851,270$ \\
\hline 8009 & 0 & 80,741 & 0 & $25,903,770$ & 10.851 .270 \\
\hline 2010 & 0 & 83,795 & 0 & $25,903,770$ & $10.851,270$ \\
\hline 2011 & 0 & 86,966 & 0 & $25,903,770$ & 10.851 .270 \\
\hline 2012 & 7 & 90,259 & 299,341 & $26,202,110$ & $10,901,080$ \\
\hline 2013 & 100 & 95,677 & $4,438,110$ & $30,640,220$ & $11,601,970$ \\
\hline 2014 & 100 & 97,227 & $4,632,716$ & $35,272,930$ & $12,278,420$ \\
\hline 2015 & 100 & 100,913 & $4,833,165$ & $40,106,090$ & $12,931,830$ \\
\hline 2016 & 100 & 104,740 & $5,039,958$ & $45,146,070$ & $13,562,810$ \\
\hline 2017 & 93 & 108,794 & $4,885,156$ & $50,031,2=0$ & $14,129,070$ \\
\hline 2018 & 0 & 112.840 & 0 & $50,031,220$ & $14,129.070$ \\
\hline 2019 & 0 & 117.125 & 0 & $50,031,220$ & $14,129,070$ \\
\hline 2020 & 0 & 121,574 & 0 & $50,031,220$ & $14,129,070$ \\
\hline 2021 & 0 & 126,195 & 0 & $50,031,220$ & $14,129,070$ \\
\hline 2022 & 0 & 130,993 & 0 & $50,031,220$ & $14,129,070$ \\
\hline 2023 & 0 & 135,975 & 0 & $50,031,220$ & $14,129,070$ \\
\hline 2024 & 0 & 141,148 & 0 & $50,031,220$ & $14,129,070$ \\
\hline 2025 & 0 & 146,521 & 0 & $50,031,220$ & $14,129,070$ \\
\hline
\end{tabular}

February 20,1990

Fage 7

JWLarsan

DOE/QIF 
DOE/OIF THRESHOLD ANALYSIS MODEL -- (ECONOIF'?)

Froject Name: Workpiece Temperature Analyzer by Acure:

ECONOMIC FERSFECTIVE OF FEDERAL SECTOF:

\begin{tabular}{|c|c|c|c|c|c|}
\hline \multirow[b]{2}{*}{ Year } & \multirow{2}{*}{$\begin{array}{l}\text { 1st User } \\
\text { Tay Ereak }\end{array}$} & \multirow{2}{*}{$\begin{array}{l}\text { Developer } \\
\text { Tax Break: }\end{array}$} & \multirow{2}{*}{$\begin{array}{l}\text { Annual } \\
\text { Cash Flaw }\end{array}$} & \multicolumn{2}{|c|}{ Cumulative Dollats } \\
\hline & & & & Actual & Discaunted \\
\hline 1590 & 0 & 34,000 & $-184,000$ & -184.000 & -170.370 \\
\hline$: 991$ & 0 & 1,263 & 0 & -184.000 & -170.370 \\
\hline 1992 & 1.566 & 2,165 & $1,241,769$ & $1,057,769$ & 815,396 \\
\hline 1993 & 2,685 & 1,546 & $19,938,340$ & $20,996,110$ & $15,470,660$ \\
\hline 1994 & 1,918 & 1,105 & $39,035,130$ & $60,031,230$ & $42,037,310$ \\
\hline $199 \Xi$ & 1,370 & 920 & $59,317,070$ & $119,348,300$ & $79,417,110$ \\
\hline 1996 & 1,141 & 920 & $80,880,350$ & $200,228,700$ & $120,610,000$ \\
\hline 1997 & 1,141 & 920 & $102,264,600$ & $302,493,300$ & $181,860,400$ \\
\hline 1998 & 1.141 & 0 & $104,435,900$ & $406,929,000$ & $234,104,300$ \\
\hline 1999 & 0 & 0 & 107.954 .800 & $514,883,800$ & $234,1018,200$ \\
\hline E000 & 0 & 0 & $111,609.600$ & 620.493 .500 & $331,975,600$ \\
\hline 2001 & 0 & 0 & $115,323,300$ & $741,816,700$ & $377,772,000$ \\
\hline Eo02 & 0 & 0 & $120,893,800$ & 962.710 .500 & $422,224,400$ \\
\hline 2003 & 0 & 0 & $150,695,300$ & $1,013,406,000$ & $473,530,200$ \\
\hline 20014 & 0 & 0 & $180,711,000$ & $1,194,117,000$ & $530,497,500$ \\
\hline 2005 & 0 & 0 & $212,492,400$ & $1,406,609,000$ & $592,522,300$ \\
\hline 2006 & 0 & 0 & $246,228,500$ & $1,652,338,000$ & $659,070,100$ \\
\hline 2067 & 0 & 0 & $279,905,500$ & $1,732,743,000$ & $729,116,100$ \\
\hline 2008 & 0 & 0 & $287,320.800$ & $2,220,064,000$ & $795,691,800$ \\
\hline 2009 & 0 & 0 & $296,935,500$ & $2,517,000,000$ & $859,398,600$ \\
\hline 2010 & 9 & 0 & $306,912,900$ & $2,823,913,000$ & $920,368,300$ \\
\hline 2011 & 0 & 0 & $317,148,700$ & $3,141,061,000$ & $978,705.000$ \\
\hline 2012 & 0 & 0 & $330,137,600$ & 3.471 .199 .000 & $1,034,933,0 \%$ \\
\hline 2013 & 0 & 0 & $376,810,700$ & $3,848,010,000$ & $1.094,355.000$ \\
\hline 2014 & 0 & 0 & $423,831,400$ & $4,271,841,000$ & $1,156,242,000$ \\
\hline 2015 & 0 & 0 & $473,563,100$ & $4,745,404,000$ & $1,220,269,000$ \\
\hline 2016 & 0 & 0 & 526.291 .400 & $5,271.695,000$ & $1,286,153,000$ \\
\hline 2017 & 0 & 0 & $579,241,100$ & $5,850,937,000$ & $1,353,295,000$ \\
\hline 2018 & 0 & 0 & $596.095,400$ & $6,447,032,000$ & $1,417,273.000$ \\
\hline 2019 & 0 & 0 & $616,457,100$ & $7,063,489,000$ & $1,478,534,000$ \\
\hline 2020 & 0 & 0 & $637,609,800$ & $7,701,099,000$ & $1,537,205,000$ \\
\hline 2021 & 0 & 0 & $659,415,500$ & $8,360,515,000$ & $1,593,387,000$ \\
\hline 2022 & 0 & 0 & $681,985,400$ & $9,042,499,000$ & $1,647,188,000$ \\
\hline 2023 & 0 & 0 & $705,409,400$ & $9,747,909,000$ & $1,698,714,000$ \\
\hline 2024 & 0 & 0 & $729,704,800$ & $10,477,610,0,00$ & $1,748,068,000$ \\
\hline 2025 & 0 & 0 & $754,653,100$ & $11,232,270,000$ & $1,795,327,000$ \\
\hline
\end{tabular}

February 20,1990

Page 10

JWLarson

DOE;OIF 


\section{CASE SFECIFIC ECONOMIC FARAMETERS}

Workpiece Temperature Analyzer by Acure::

Pyralaser - Metal Heat Treating Industry

OIF Improved Cambusticin Efficiency

Industrial SeEtor SIC 28 Code per THRESH...............

Enter System Type -- Three Chaices

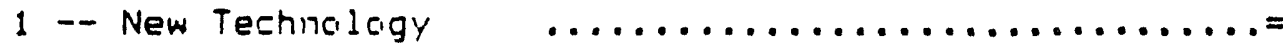

Salvage Value as a $\%$ cif Capital Cost - Froposal...........

Salvage Value as a \% of Capital Cost -- Easeline...........

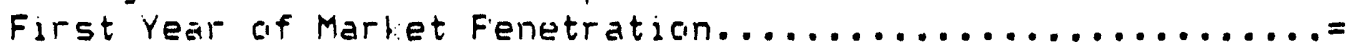

Diff. Capital Equip. Cost in Base Year Dollars............

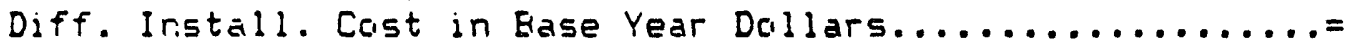

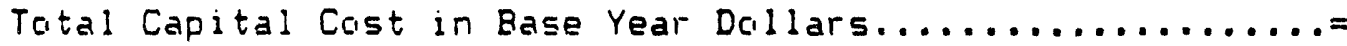

Frant End Cists ta Commercial Freduction...................

Diff. Non-Fuel o \& M Costs per Unit per Year..............

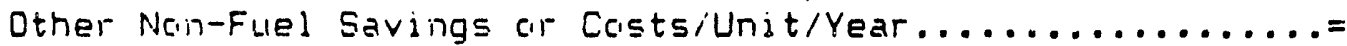

System Useful Life in Years - Fircupcised.................

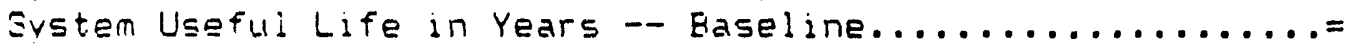

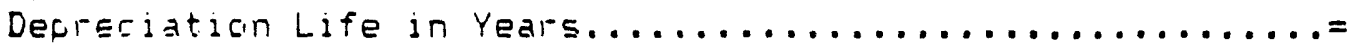

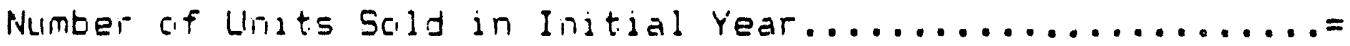

Ma:imım Maillet Fotential (cumulative units)..............

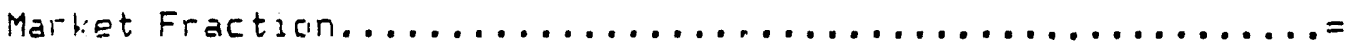

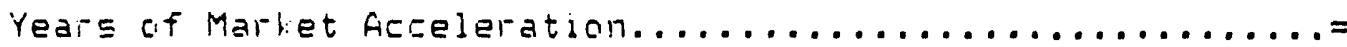

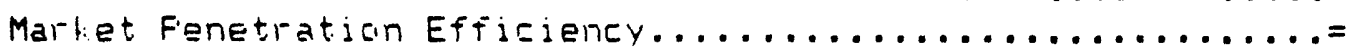

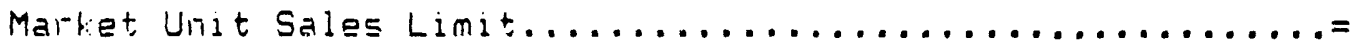

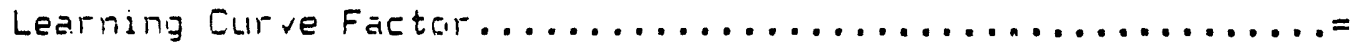

Energy Savings pe! Unit per Year (Etu)

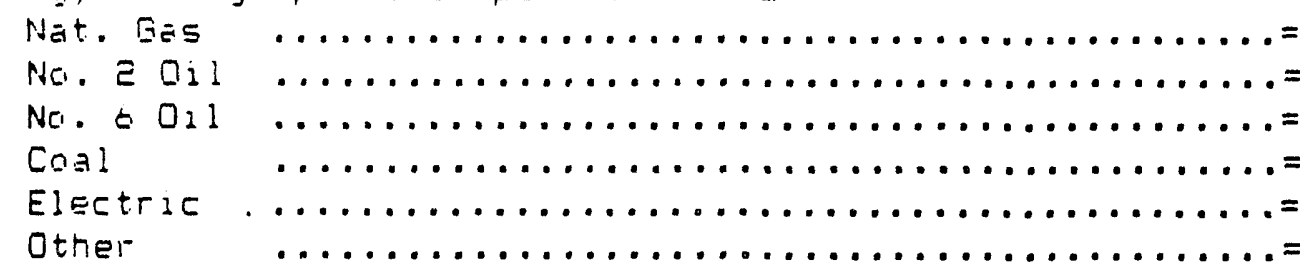

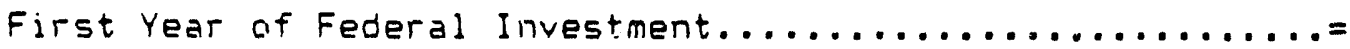
Federa! Investments in Sequence ( $\$ 000)$

Yr $1990 \quad 150$

$$
\begin{array}{r}
14 \\
1 \\
0.00 \\
0.00 \\
1992 \\
\$ 20,000 \\
\$ 10,000 \\
\$ 20 \\
\$ 25,000 \\
\$ 2,000 \\
\$ 182,000 \\
10 \\
10 \\
7 \\
7 \\
10,000 \\
0.05 \\
3 \\
1.000 \\
100 \\
0.90
\end{array}
$$

$3.00 E+09$

$0.00 E+00$

$0.00 \mathrm{E}+00$

$0.00 E+0 O$

$0.00 E+00$

$0.00 E+00$

1990

1990

First Year af Firivate Investment..................... Frivate Investments in Sequence (\$00) Yr 1991) 100

February 20,1990

Page 2

JWLarson

DOE/OIF 


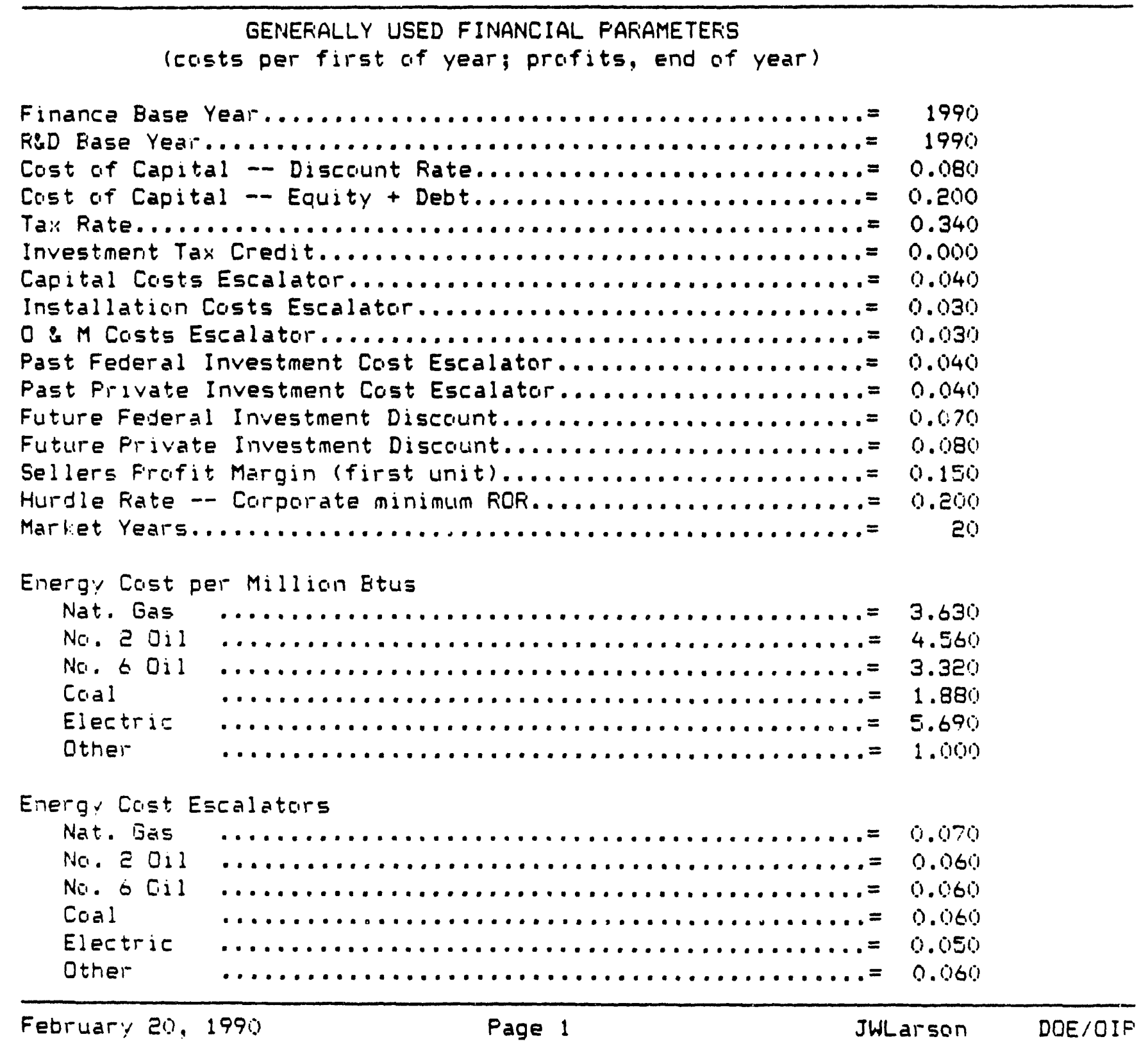


DOE/OIF THFESHOLD ANALYSIS MODEL -- (ECONOIFZ)

Froject Name: Worl:piece Temperature Analyzer by Acure:
Descripticin:

ENERGY SAUINGS FOTENTIAL (BTU/YFi)

\begin{tabular}{|c|c|c|c|c|c|}
\hline Fuel Type & 1995 & 2000 & $\begin{array}{l}\text { inual } 2005 \\
\qquad\end{array}$ & 2010 & $\begin{array}{r}\text { Cumulat a ve } \\
2010\end{array}$ \\
\hline $\begin{array}{l}\text { Nat. Gas } \\
\text { No. } 2 \text { Oil } \\
\text { No. } 6 \text { Oil } \\
\text { Coal } \\
\text { Electric } \\
\text { Other }\end{array}$ & $\begin{array}{l}9.21 E+11 \\
0.00 E+00 \\
0.00 E+00 \\
0.00 E+00 \\
0.00 E+00 \\
0.00 E+00\end{array}$ & $\begin{array}{l}1.50 E+12 \\
0.00 E+00 \\
0.00 E+00 \\
0.00 E+00 \\
0.00 E+00 \\
0.00 E+00\end{array}$ & $\begin{array}{l}2.42 E+12 \\
0.00 E+00 \\
0.00 E+00 \\
0.00 E+00 \\
0.00 E+00 \\
0.00 E+00\end{array}$ & $\begin{array}{l}3.00 E+12 \\
0.00 E+00 \\
0.00 E+00 \\
0.00 E+00 \\
0.00 E+00 \\
0.00 E+00\end{array}$ & $\begin{array}{l}4.67 E+13 \\
0.00 E+00 \\
0.00 E+00 \\
0.00 E+00 \\
0.000+00 \\
0.00 E+00\end{array}$ \\
\hline $\begin{array}{l}\text { TOTAL } \\
\text { E/DOE* }\end{array}$ & $\begin{array}{l}9.21 E+11 \\
4.29 E+0.5\end{array}$ & $\begin{array}{l}1.50 E+12 \\
6.99 E+02\end{array}$ & $\begin{array}{l}2.42 E+12 \\
1.13 E+0.3\end{array}$ & $\begin{array}{l}3.00 E+12 \\
1.40 E+03\end{array}$ & $4.67 E+13$ \\
\hline
\end{tabular}

FOTENTIAL MONETARY SAUINGS (\$/YI)

(Discounted to 1990 dallars)

\begin{tabular}{|c|c|c|c|c|c|}
\hline \multirow[b]{2}{*}{ Flle! Type } & \multicolumn{4}{|c|}{ Annual } & \multirow{2}{*}{$\begin{array}{r}\text { Cumulative } \\
2010\end{array}$} \\
\hline & 1995 & $200^{\circ}$ & 2005 & 2010 & \\
\hline Nat. Gas & $3.47 E+06$ & $5.39 E+06$ & $8.31 E+0.6$ & $9.83 E+06$ & $1.53 E+13$ \\
\hline $\mathrm{Nal} \cdot 2$ Oil & $0.00 E+00$ & $0.00 E+00$ & $0.00 E+00$ & $0.00 E+00$ & $0.00 E-00$ \\
\hline $\mathrm{No}$. \& Dil & $0.00 E+00$ & $0.00 E+00$ & $0.00 E+00$ & $0.00 E+00$ & $0.00 E+00$ \\
\hline$[0 . \approx]$ & $0.00 E+00$ & $0.00 E+00$ & $0.00 E+00$ & $0.00 E+00$ & $0.00 E+00$ \\
\hline Electric & $0.00 E+00$ & $0.00 E+00$ & $0.00 E+00$ & $0.00 E+00$ & $0.00 E+00$ \\
\hline Other & $0.00 E+00$ & $0.00 E+\infty 0$ & $0.00 E+00$ & $0.00 E+00$ & $0.00 E+100$ \\
\hline 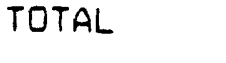 & $3.47 E+06$ & $5.39 E+06$ & $8.31 E+0.6$ & $9.83 E+1.06$ & $1.58 E+08$ \\
\hline
\end{tabular}

ECONOMIC ATTFACTIVENESS

$\begin{array}{lc}\text { End User's ROI: } & 431.8 \% \\ \text { Payback Feriod: } & 0.2 \text { years } \\ \text { Develaper's ROI: } & 309.2 \% \\ \text { Benefits Rating: } & 0.4\end{array}$

\section{FFIOGRAM EFFICIENCY}

$\begin{array}{ll}\text { ETI : } & 416.1 \\ \text { MEI : } & 235.7 \\ \text { RFD (1995): } & 16.3 \\ \text { FFD (2000): } & 25.3 \\ \text { RFD (2005): } & 38.9 \\ \text { FFD (2010): } & 46.0\end{array}$

* B/DOE = Barrels per Day Oil Equivalent.

February 20, $1990^{\circ}$ Fage 4 JWLarson $\cdot$ DOE/OIF


DOE/OIF' THFESHOLD ANALYSIS MODEL -- (ECONOIF'?)

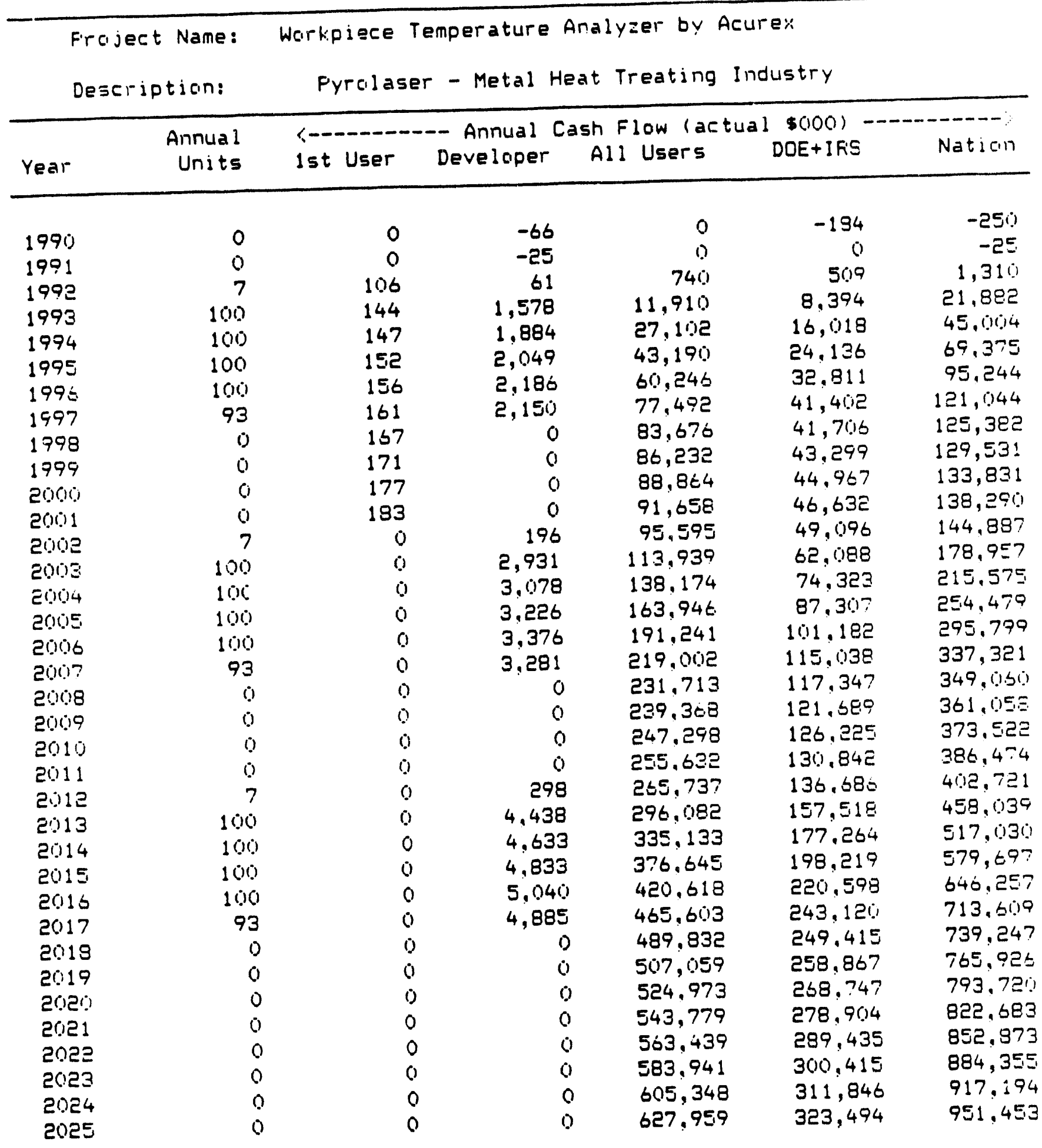

February 20, 1990 
DOE/OIF THRESHOLD ANALYSIS MODEL -- (ECONDIFE)

Froject Name: Workpiece Temperature Analyzer by Acure:

Description: Pyrolaser - Metal Heat Treating Industry

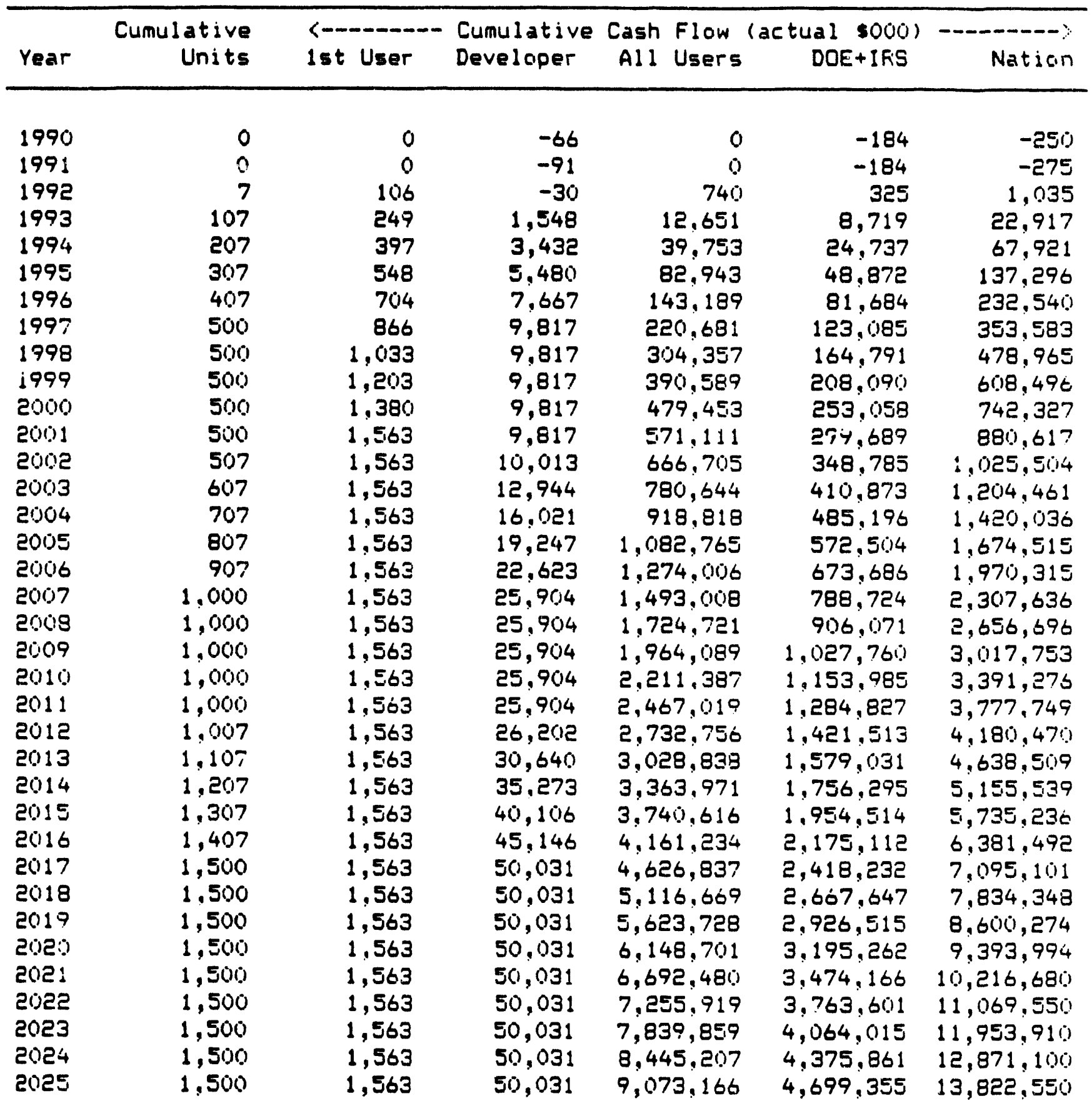

February 20, 1990

Page 6

JWLarsan

DOE/OIF 
DOE/OIF THFESHOLD ANALYSIS MODEL -- (ECONDIFE)

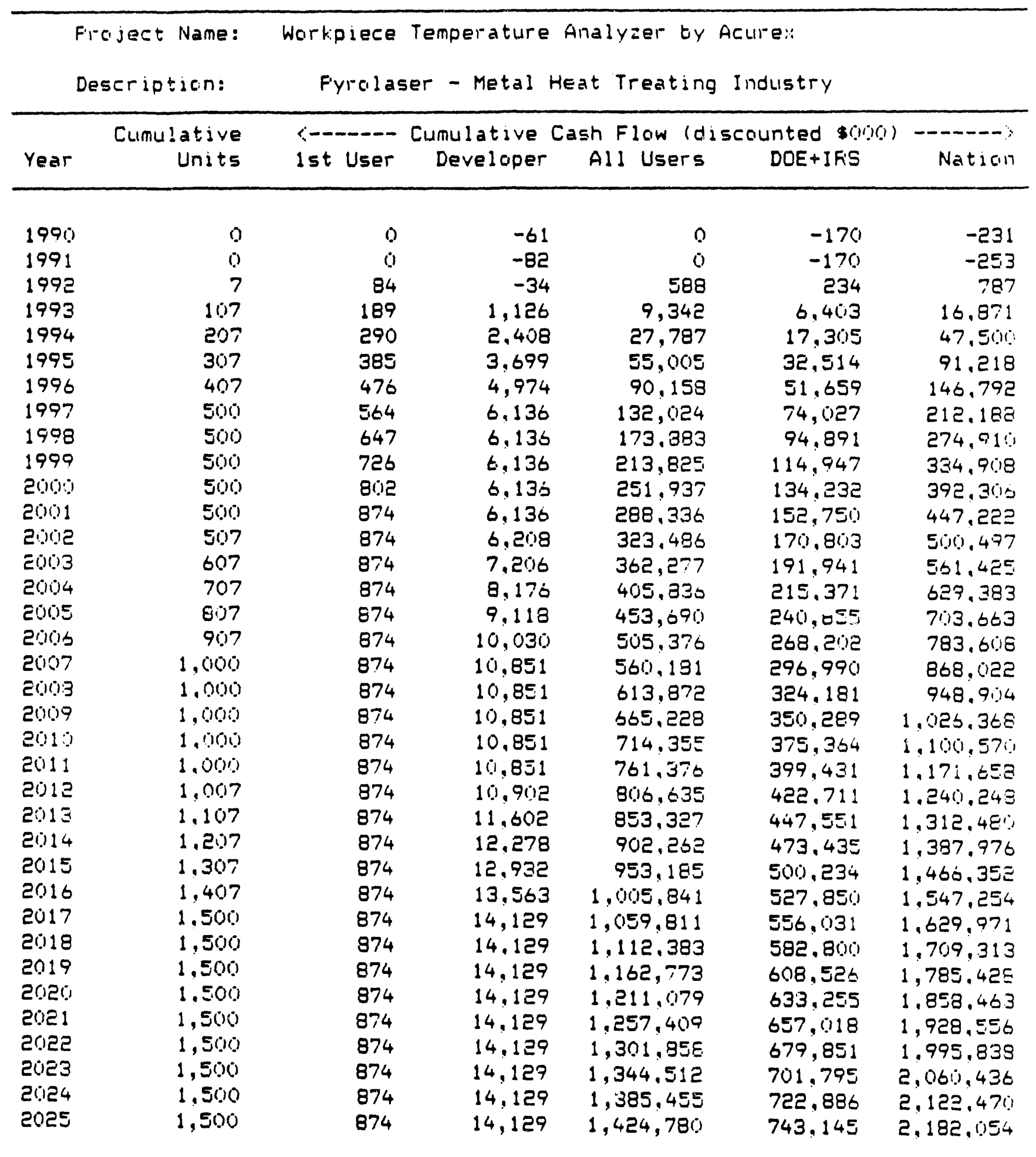

February 20,1990

Page 7

JWLarson

DOE/OIF 
DOE/OIF THFESHOLD ANALYSIS MODEL -- (ECONOIFE)

Fraject Name: Warlipiece Temperature Analyzer by Acurex

ECONOMIC PEFSFECTIVE OF FIRST USER

\begin{tabular}{|c|c|c|c|c|c|}
\hline Year & Ta» Ereak & $\begin{array}{c}\text { Anrual Dollars } \\
\text { Dperations }\end{array}$ & Cash Flow & $\begin{array}{l}\text { Cumul } \\
\text { Actual }\end{array}$ & $\begin{array}{l}\text { e Dallars } \\
\text { Discounted }\end{array}$ \\
\hline $\begin{array}{l}1992 \\
1993 \\
1994 \\
1995 \\
1996 \\
1997 \\
1998 \\
1999 \\
2000 \\
2001\end{array}$ & $\begin{array}{r}1,566 \\
2,685 \\
1,918 \\
1,370 \\
1,141 \\
1,141 \\
1,141 \\
0 \\
0 \\
0\end{array}$ & $\begin{array}{l}136,423 \\
140,857 \\
145,447 \\
150,200 \\
155,123 \\
160,223 \\
165,507 \\
170,983 \\
176,659 \\
182,544\end{array}$ & $\begin{array}{l}105,748 \\
143,541 \\
147,364 \\
151,569 \\
156,264 \\
161,364 \\
166,648 \\
170,983 \\
176,659 \\
182,544\end{array}$ & $\begin{array}{r}105,748 \\
249,290 \\
396,654 \\
548,223 \\
704,483 \\
865,852 \\
1,032,500 \\
1,203,483 \\
1,380,143 \\
1,562,687\end{array}$ & $\begin{array}{r}83,947 \\
189,454 \\
289,747 \\
385,263 \\
476,440 \\
563,620 \\
646,986 \\
726,184 \\
801,950 \\
874,441\end{array}$ \\
\hline
\end{tabular}

February 20, 1990

Fige 8

JWLarsan

DOE/OIF 
DOE/OIP THFESHOLD ANALYSIS MODEL -- (ECONOIFZ)

Froject Name: Workpiece Temperature Analyzer by Acure:

ECONOMIC PERSFECTIVE OF DEVELOIFEF

\begin{tabular}{|c|c|c|c|c|c|}
\hline Year & $\begin{array}{r}\text { Units } \\
\text { sold }\end{array}$ & $\begin{array}{l}\text { Unit } \\
\text { Cast }\end{array}$ & $\begin{array}{l}\text { Annual } \\
\text { Cash Flaw }\end{array}$ & $\begin{array}{l}\text { Cumula } \\
\text { Actual }\end{array}$ & $\begin{array}{l}\text { Dollars } \\
\text { Discounted }\end{array}$ \\
\hline 1990 & 0 & 0 & $-66,000$ & $-66,000$ & $-61,11 !$ \\
\hline 1991 & 0 & 0 & $-24,737$ & $-90,737$ & $-82,319$ \\
\hline 1992 & 7 & 43,057 & 60,551 & $-30,186$ & $-34,252$ \\
\hline 1973 & 100 & 44.673 & $1,578,269$ & $1,548,083$ & $1,125,823$ \\
\hline 1994 & 100 & 46,351 & $1,883,507$ & $3,431,590$ & $2,407,70.5$ \\
\hline 1995 & 100 & 48,092 & $2,048,7 \varepsilon 3$ & $5,480,314$ & $3,698,749$ \\
\hline 1996 & 100 & 49,900 & $2,186,322$ & 7.666 .636 & $4,974,446$ \\
\hline 1997 & 93 & 51,777 & $2,150,426$ & $9,817,062$ & $6,136,254$ \\
\hline 1998 & 0 & 53,725 & 0 & $9,817,062$ & $6,136,254$ \\
\hline 1999 & 0 & 55,747 & 0 & $9,817,062$ & $6,136,254$ \\
\hline 2000 & 0 & 57,845 & 0 & $9.817,052$ & $6,136,25,4$ \\
\hline 2001 & 0 & 60,026 & 0 & $9,817,062$ & $6,136,254$ \\
\hline 2005 & 7 & 62,289 & 196,224 & $10,013,290$ & $6,208,405$ \\
\hline 2003 & 100 & 64,638 & $2,930,501$ & $12,943,790$ & $7,206,126$ \\
\hline 2004 & 100 & $67.07 \mathrm{~b}$ & $3,077,629$ & $16,021,410$ & $8,176,321$ \\
\hline 2005 & 100 & 69.608 & $3,225,582$ & $19,247,000$ & $9,117,837$ \\
\hline 2006 & 100 & 72,236 & $3,375,687$ & $22,622,590$ & $10,030,180$ \\
\hline $200 ?$ & 93 & 74,965 & $3,281,081$ & $25,903,770$ & $10,851,270$ \\
\hline 2003 & 0 & 77,709 & 0 & $25,903,770$ & $10,851,270$ \\
\hline 2009 & 0 & 80,741 & 0 & $25,903,770$ & $10,851,270$ \\
\hline 2010 & 0 & 83,795 & 0 & $25,903,770$ & $10,851,270$ \\
\hline 2011 & 0 & 86,906 & 0 & $25,903,770$ & $10,851,270$ \\
\hline 2012 & 7 & 90,259 & 298,341 & 25, 202,110 & $10,902,080$ \\
\hline 2013 & 100 & 93,677 & $4,438,110$ & $30,640,220$ & $11,601,970$ \\
\hline 2014 & 100 & 97.227 & $4,632,716$ & $35,272,930$ & $12,278,420$ \\
\hline 2015 & 100 & 100,913 & $4,833,165$ & $40,106,090$ & $12,931,880$ \\
\hline 2016 & 100 & 104,740 & $5,039,968$ & $45,146,070$ & $13,562,810$ \\
\hline 2017 & 93 & 108,714 & $4,885,150$ & $50,031,220$ & $14,129,070$ \\
\hline 2018 & 0 & 112,840 & 0 & $50,031,220$ & $14,129,070$ \\
\hline 2019 & 0 & $117,1 \geq 5$ & 0 & $50,031,220$ & $14,129,070$ \\
\hline 2020 & 0 & 121,574 & 0 & $50,031,220$ & $14,129,070$ \\
\hline 2021 & 0 & 126,195 & 0 & $50,031,220$ & $14,129,070$ \\
\hline 2023 & 0 & 130,993 & 0 & $50,031,220$ & $14,129,070$ \\
\hline 2023 & 0 & 135,975 & 1) & $50,031,220$ & $14,129,070$ \\
\hline 2024 & 0 & 141,148 & $\dot{0}$ & $50,031,220$ & $14,129,070$ \\
\hline 2025 & 0 & 146,521 & 0 & $50,031,220$ & $14,129,070$ \\
\hline
\end{tabular}

February 20,1990

Fage ?

JWLarson

DOE/OIF 
DOE/OIF THRESHOLD ANALYSIS MODEL -- (ECONOIPE)

Firoject Name: Warkpiece Temperature Analyzer by Acura:

ECONOMIC FERSPECTIVE OF FEDERIAL SECTCR

\begin{tabular}{|c|c|c|c|c|c|}
\hline Year & $\begin{array}{l}\text { 1st User } \\
\text { Tax Break }\end{array}$ & $\begin{array}{l}\text { Develaper } \\
\text { Tax Break }\end{array}$ & $\begin{array}{l}\text { Annual } \\
\text { Cash Flow }\end{array}$ & $\begin{array}{l}\text { Sumil } \\
\text { Actual }\end{array}$ & $\begin{array}{l}\text { ve Dollars } \\
\text { Discounted }\end{array}$ \\
\hline $1990^{\circ}$ & 0 & 34,000 & -184.000 & -184.000 & $-170,370$ \\
\hline $19 c_{1}$ & 0 & 1,263 & 0 & $-184,000$ & $-170,370$ \\
\hline 1992 & 1,566 & 2,165 & 508,902 & $324,90 \varepsilon$ & 233,613 \\
\hline 1993 & 2,685 & 1,546 & $8,393,623$ & $8,718,525$ & $6,403,175$ \\
\hline 1794 & 1,918 & 1,105 & $16,017,980$ & $24,730,510$ & $17,304,740$ \\
\hline 1995 & 1,370 & 920 & $24,135,890$ & $48,872,400$ & $32,514,450$ \\
\hline 1996 & 1,141 & 920 & $32,811,130$ & $81,583,530$ & $51,659,420$ \\
\hline 1997 & 1,141 & 920 & $41,401,630$ & $123,085,200$ & $74,027.430$ \\
\hline 1998 & 1,141 & 0 & $41,705,880$ & $164,791,000$ & $94,890,740$ \\
\hline 1999 & 0 & 0 & $43,299,170$ & $208,090,200$ & $114,946,600$ \\
\hline 2000 & 0 & 0 & $44,967,370$ & $253,057,600$ & $134,232.300$ \\
\hline 2001 & 0 & 0 & $46,631,550$ & $299,689,100$ & $152,750,300$ \\
\hline 2002 & 0 & 0 & $49,096,330$ & $348,785,500$ & $170,803,000$ \\
\hline 2003 & 0 & 0 & $62,088,010$ & $410,873,500$ & $191,941,500$ \\
\hline 2004 & 0 & 0 & $74,322,910$ & $485,196,400$ & $215,371,100$ \\
\hline 2005 & 0 & 0 & $87,307.220$ & $572,503,600$ & $240,855,300$ \\
\hline 2006 & 0 & 0 & $101,182,400$ & $673,686,000$ & $258,201,700$ \\
\hline 2007 & 0 & 0 & $115,038,400$ & $788,724,400$ & $276,989,900$ \\
\hline 2003 & 0 & 0 & $117,346,500$ & $9010,070,900$ & $324,180,500$ \\
\hline 2007 & 0 & 0 & $121,689,500$ & $1,027,760,000$ & $350,288,700$ \\
\hline 2010 & 0 & 0 & $126,224,300$ & $1,153,985,000$ & $375,364,000$ \\
\hline 2011 & 0 & 0 & $130,842,400$ & $1,284,827,000$ & $399,431,200$ \\
\hline 2012 & 0 & 0 & $136,685.800$ & $1,421,513,000$ & $422,710,800$ \\
\hline 2013 & 0 & 0 & $157,513,000$ & $1,579,031,000$ & $447,551,360$ \\
\hline 2014 & 0 & 0 & $177,263,800$ & $1,756,295,000$ & $473,435,000$ \\
\hline 5015 & 0 & 0 & $198,219,000$ & $1,954,514,000$ & $500,234,500$ \\
\hline 2010 & 0 & 0 & $220,598,100$ & $2,175,112,000$ & $527,850,400$ \\
\hline 2017 & 0 & 0 & $243,120,300$ & $2,418,232,000$ & $556,031,300$ \\
\hline 2018 & 0 & 0 & $249,415,000$ & $2,667,647,000$ & $582,800,400$ \\
\hline 2019 & 0 & 0 & $258,867,200$ & $2,926,515,000$ & $608,525,900$ \\
\hline 2020 & 0 & 0 & $268,747,200$ & $3,195,262,000$ & $633,254,900$ \\
\hline 2021 & 0 & 0 & $278,904,000$ & $3,474,166,000$ & $657,017,500$ \\
\hline ट022 & 0 & 0 & $289,434,700$ & $3,763,601,000$ & $679,850,700$ \\
\hline 2023 & 0 & 0 & $3010,414,500$ & $4,064,015,000$ & $701,794,500$ \\
\hline 2024 & 0 & 0 & $311,845,900$ & $4,375,861,000$ & $722,886,000$ \\
\hline 2025 & 0 & 0 & $323,494,200$ & $4,699,355,000$ & $743,144,600$ \\
\hline
\end{tabular}

February 20, $1990^{\circ}$

Page 10

JWLarsan

DOE/OIF 


\section{CASE SFECIFIC ECONOMIC PARAMETERS}

Workpiece Temperature Analyzer by Acurex.

Ramen Specticascopy Semiconductor Industry

DIF Imoraved Camoustian Efficiency

Industrial Sectar SIC 28 Cade per THFESH.................

Enter System Type -- Three Chaices

1 -- New Technolagy

...........................

Salvage Value as a $\%$ af Capital Cost -- Froposal...........

Salvage Value as a $\%$ of Capital Cost -- Baseline............

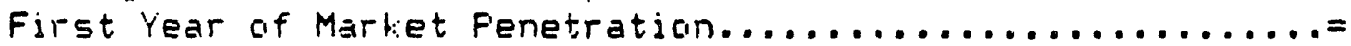

Diff. Capital Equip. Cost in Base Year Dollars...............

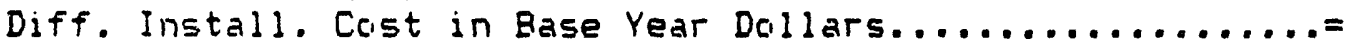

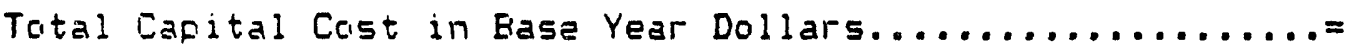

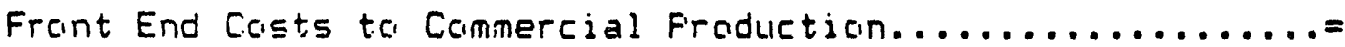

Diff. Non-Fuel 0 \& M Custs per Unit per Year.................

Other Nan-Fuel Savings ar Cests/Unit/Year................

System Lleeful Life in Years -- Frapased.................. =

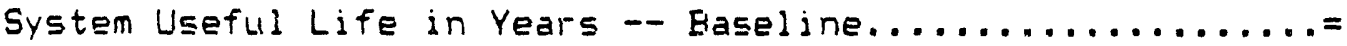

Depreciaticin Life in Years..........................

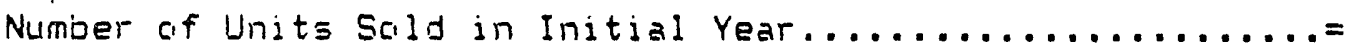

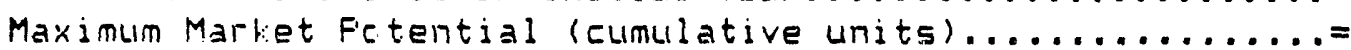

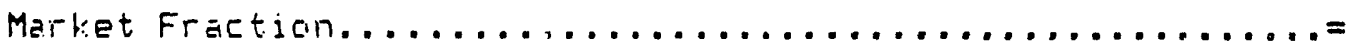

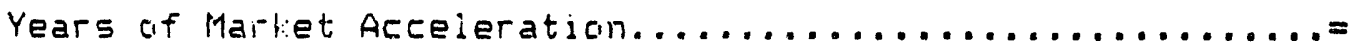

Marlet Fenetraticin Efficiency......................

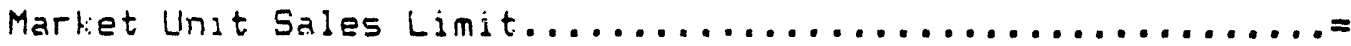

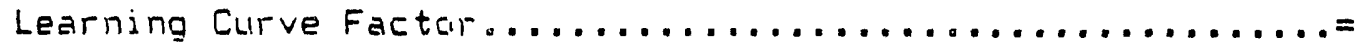

Energy Savings per Unit per Year (Etu)

Nat. Gas

$\mathrm{Na}$. $2 \mathrm{O}$ il

$\mathrm{Na}, 6 \mathrm{Qil}$

[a]

Elettric

other

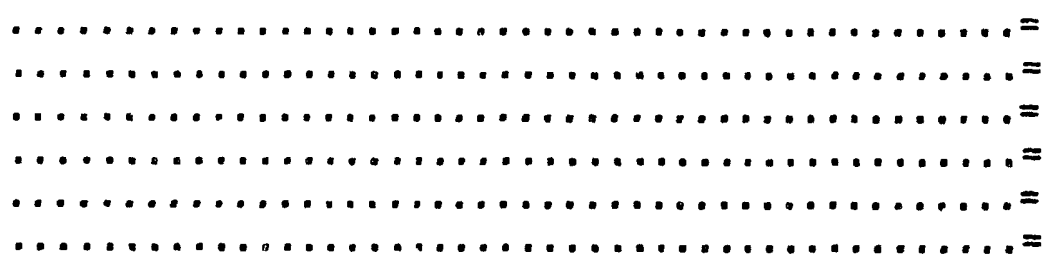

First Year eff Federal Investment..................... Federal Investments in Sequence $(\$ 000)$

Yr $1990^{\circ}$ 390

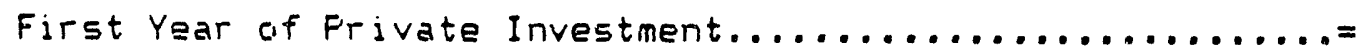
Private Investments in Sequence (\$000) Yr 1970

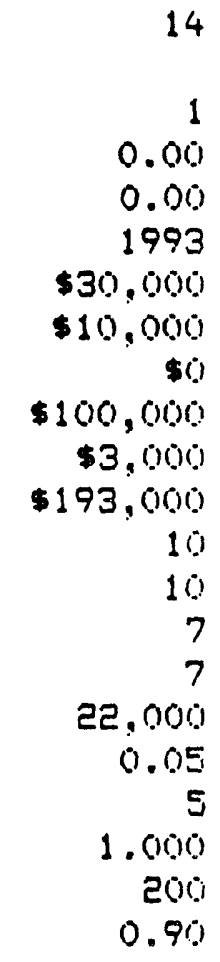

1.00E+09

$0.00 E+00$

0.0 OE +00

$0.00 E+00$

$0.00 E+00$

$0.00 E+00$

1990

$1990^{\circ}$

February 20, 1990

Page 2

JWLarson

DOE/OIF 


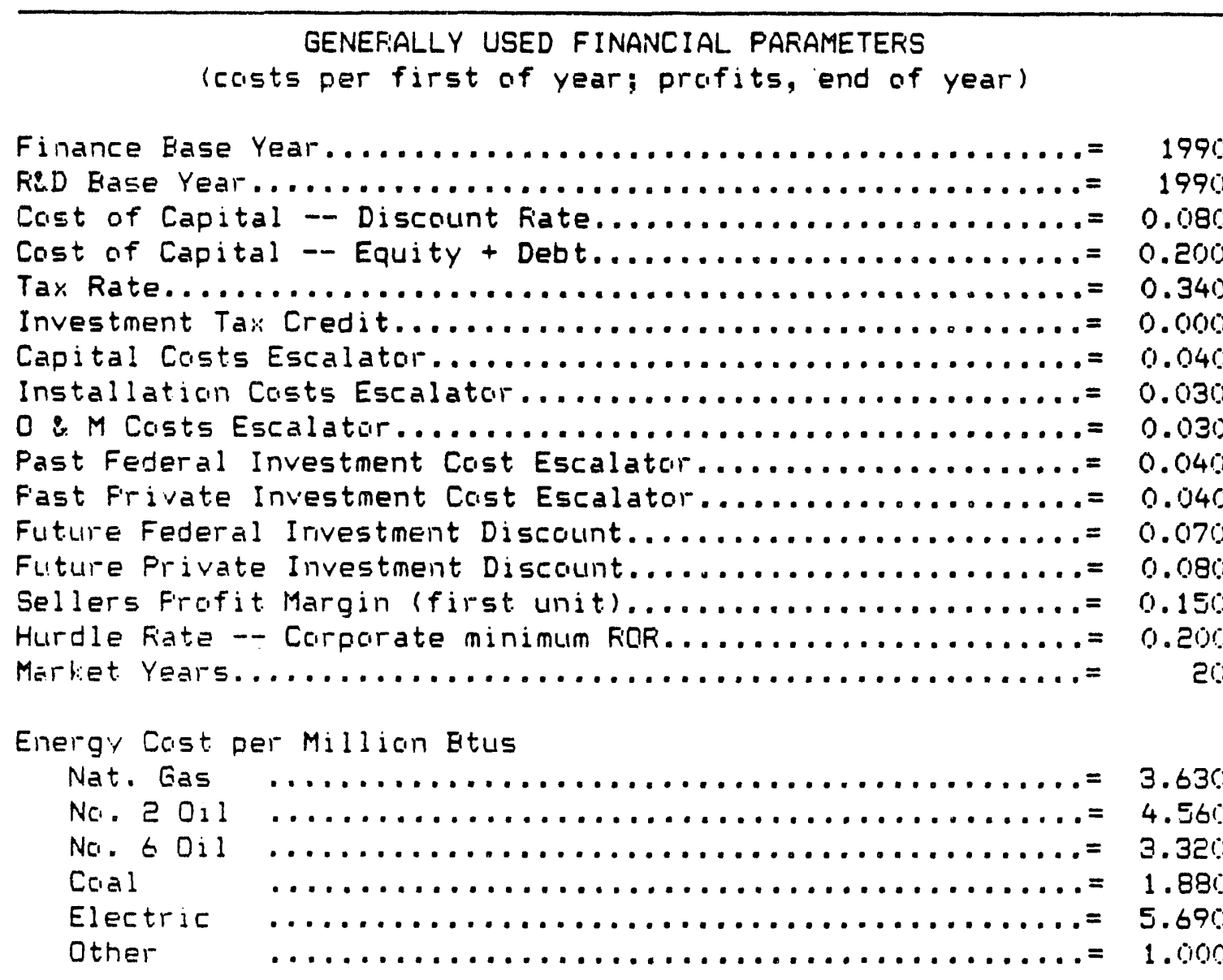
Energy Cast Escalators
Nat. Gas $\ldots \ldots \ldots \ldots \ldots \ldots \ldots \ldots \ldots \ldots \ldots \ldots \ldots \ldots \ldots \ldots=0.070$

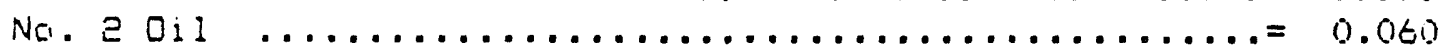

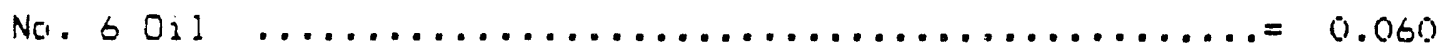

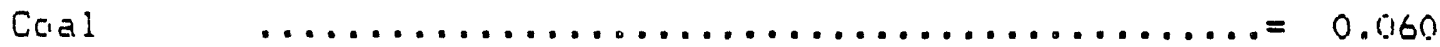

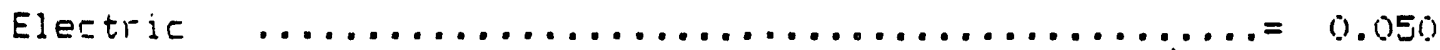

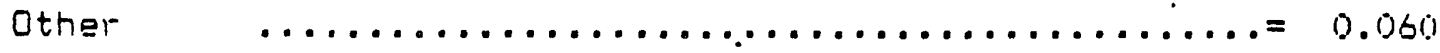

February 20, 1990

Page 1

JWLarson

DOE/OIP 
DOE/OIF THFESHOLD GNALYSIS MODEL -- (ECONOIFE)

Froject Name: Workpiece Temperature Analyzer by Acure:

Descripticn: Raman Spectroscofy Semiconductar Industry

ENERGY SAVINGS FOTENTIAL (BtU/YFi)

\begin{tabular}{lrrrrrr} 
Fuel Type & 1995 & 2000 & 2005 & 2010 & $\begin{array}{r}\text { Aumulative } \\
2010\end{array}$ \\
\hline Nat. Gas & $4.07 E+11$ & $1.10 E+12$ & $1.51 E+12$ & $2.20 E+12$ & $3.25 E+13$ \\
No. 2011 & $0.00 E+00$ & $0.00 E+00$ & $0.00 E+00$ & $0.00 E+00$ & $0.00 E+00$ \\
Na. 6 Oil & $0.00 E+00$ & $0.00 E+00$ & $0.00 E+00$ & $0.00 E+00$ & $0.00 E+00$ \\
Caal & $0.00 E+00$ & $0.00 E+00$ & $0.00 E+00$ & $0.00 E+00$ & $0.00 E+00$ \\
Electric & $0.00 E+00$ & $0.00 E+00$ & $0.00 E+00$ & $0.00 E+00$ & $0.00 E+00$ \\
Other & $0.00 E+00$ & $0.00 E+00$ & $0.00 E+00$ & $0.00 E+00$ & $0.00 E+00$ \\
\hline TOTAL & $4.07 E+11$ & $1.10 E+12$ & $1.51 E+12$ & $2.20 E+12$ & $3.25 E+13$ \\
B/DOE* & $1.90 E+02$ & $5.13 E+02$ & $7.02 E+02$ & $1.03 E+03$ &
\end{tabular}

FCTENTIAL MONETAFYY SAVINGS ( $\$ /$ Y $)$

(Discaunted to 1990 dollars)

\begin{tabular}{lccccc} 
Fuel Type & 1995 & 2000 & 2005 & 2010 & $\begin{array}{r}\text { Cumulative } \\
2010\end{array}$ \\
\hline Nat. Gas & $1.53 E+06$ & $3.96 E+06$ & $5.17 E+06$ & $7.21 E+06$ & $1.09 E+08$ \\
Na. 2 0il & $0.00 E+00$ & $0.00 E+00$ & $0.00 E+00$ & $0.00 E+00$ & $0.00 E+00$ \\
Na. 6 0il & $0.00 E+00$ & $0.00 E+00$ & $0.00 E+00$ & $0.00 E+00$ & $0.00 E+00$ \\
Caal & $0.00 E+00$ & $0.00 E+00$ & $0.00 E+00$ & $0.00 E+00$ & $0.00 E+00$ \\
Electric & $0.00 E+00$ & $0.00 E+00$ & $0.00 E+00$ & $0.00 E+00$ & $0.00 E+00$ \\
Other & $0.00 E+00$ & $0.00 E+00$ & $0.00 E+00$ & $0.00 E+00$ & $0.00 E+00$ \\
\hline TOTAL & $1.53 E+06$ & $3.96 E+06$ & $5.17 E+06$ & $7.21 E+06$ & $1.09 E+08$
\end{tabular}

ECONOMIC ATTRACTIVENESS

$\begin{array}{ll}\text { End User's ROI: } & 326.6 \% \\ \text { Payback Feriad: } & 0.3 \text { years } \\ \text { Neveluper's ROI: } & 268.3 \% \\ & \\ \text { Benefits Rating: } & 0.2\end{array}$

\section{F'ROGRAM EFFICIENCY}

ETI:

MEI:

FFD (1995):

RFD (2000):

RFD (2005):

RFD (2010):
139.1

77.8

2.8

7.1

9.3

13.0

* E/DOE = Barrels per Day Oil Equivalent. 
DOE/OIF' THRESHOLD ANALYSIS MODEL -- (ECONOIFE)

\begin{tabular}{|c|c|c|c|c|c|c|}
\hline \multicolumn{2}{|c|}{$\begin{array}{l}\text { Firoject Name: } \\
\text { Descriptian: }\end{array}$} & \multicolumn{5}{|c|}{$\begin{array}{l}\text { Workpiece Temperature Analyzer by Acure: } \\
\text { Raman Spectroscopy Semicanductor Industiry }\end{array}$} \\
\hline Year & $\begin{array}{l}\text { Annual } \\
\text { Units }\end{array}$ & lst User & $\begin{array}{l}\text { Annual } \\
\text { Develciper }\end{array}$ & $\begin{array}{c}\text { Cash Flaw (ac } \\
\text { All Users }\end{array}$ & $\begin{array}{c}\text { DOI } \$(0)(0)- \\
\text { DOE+IFS }\end{array}$ & Natian \\
\hline 1990 & 0 & 0 & -66 & 0 & -424 & -490 \\
\hline 1991 & 0 & 0 & 0 & 0 & 0 & 0 \\
\hline 1992 & 0 & 0 & -103 & 0 & 0 & -103 \\
\hline 1993 & 7 & 100 & 85 & 697 & 527 & 1,309 \\
\hline 1994 & 200 & 150 & 4,413 & 21,529 & $17,40,8$ & 43,350 \\
\hline 1795 & 200 & 154 & 5,210 & 53,102 & 33,081 & 91,392 \\
\hline 1996 & 200 & 158 & 5,634 & 86,370 & 49,726 & 141,727 \\
\hline 1997 & 200 & 162 & 5,992 & 121,481 & 67.492 & 194,765 \\
\hline 1998 & 200 & 167 & 6,327 & 158,615 & 86,365 & 251,308 \\
\hline 1999 & 93 & 172 & 3,083 & 185,353 & 95,396 & 283,832 \\
\hline 2000 & 0 & 176 & 0 & 196.0135 & 97,146 & 293,181 \\
\hline 20101 & 0 & 181 & 0 & 201,347 & 100,955 & 302,302 \\
\hline $50 \% 5$ & 0 & 187 & 0 & 207,058 & 104,662 & 311,720 \\
\hline 2003 & 7 & 0 & 270 & 214,0105 & 109,172 & 323.447 \\
\hline 2004 & 200 & 0 & 8,063 & 247.791 & 136.811 & 392.665 \\
\hline 2005 & 200 & 0 & 8,450 & 297,191 & 161.577 & 467,218 \\
\hline 2006 & 200 & 0 & 8,843 & 349,333 & 187.885 & 546.061 \\
\hline 2007 & 200 & 0 & 9,243 & 404,423 & 215,737 & 629,403 \\
\hline 2008 & 200 & 0 & 9,654 & 462,544 & 245,267 & 717,405 \\
\hline 2019 & 93 & 0 & 4.679 & 507,317 & 261,311 & 773,307 \\
\hline 2010 & 0 & 0 & 0 & 530,452 & 267,684 & 798,137 \\
\hline 2011 & 0 & 0 & 0 & 546.076 & 277,291 & 823,366 \\
\hline 2012 & 0 & 0 & 0 & 562.551 & 286,889 & $849,44 \%$ \\
\hline 2013 & 7 & 0 & 413 & 580,988 & 297,747 & 879,145 \\
\hline 2014 & 200 & 0 & 12,189 & 635.335 & 340,824 & 988,348 \\
\hline 2015 & 200 & 0 & 12,713 & 712.470 & 379.548 & $1,104.731$ \\
\hline 2016 & 500 & 0 & 13,254 & 793,748 & 420,599 & 1.227.6(1) \\
\hline 2017 & 200 & 0 & 13,814 & 879,480 & 463,985 & $1,357,270$ \\
\hline 2018 & 200 & 0 & 14,393 & 969,8011 & 509,906 & 1.494 .100 \\
\hline 2019 & 93 & 0 & 6,966 & $1,043.016$ & 537,330 & $1,587,313$ \\
\hline 2020 & 0 & 0 & 0 & $1,086,973$ & 551.842 & $1,638,815$ \\
\hline 2021 & 0 & 0 & 0 & $1,120,428$ & 571,342 & 1.691 .770 \\
\hline 20.22 & 0 & 0 & 0 & $1,155,530$ & 591,042 & 1.746 .572 \\
\hline 2023 & 0 & 0 & 0 & $1,192,145$ & 611,153 & $1,8013,298$ \\
\hline 2024 & 0 & 0 & 0 & $1,230,132$ & 631,890 & $1,862,028$ \\
\hline 2025 & 0 & 0 & 0 & $1,269,465$ & 653,378 & $1,922,843$ \\
\hline
\end{tabular}

February 20, 1990

Page 5

JWLarsan

DOE/DIF 
DOE/OIF THFESHOLD ANALYSIS MODEL -- (ECONOIF??

\begin{tabular}{|c|c|c|c|c|c|c|}
\hline & $\begin{array}{l}\text { ject Name: } \\
\text { sciption: }\end{array}$ & $\begin{array}{l}\text { Workpiece Ter } \\
\text { Raman Spe }\end{array}$ & ectroscupy S & $\begin{array}{l}\text { Arialyzer by } A \\
\text { Semiconductor }\end{array}$ & $\begin{array}{l}\text { Acure: } \\
\text { ir Industry }\end{array}$ & \\
\hline Year & $\begin{array}{r}\text { Cumulative } \\
\text { Units }\end{array}$ & ist User & $\begin{array}{l}\text { Cumulative } \\
\text { Develaper }\end{array}$ & $\begin{array}{c}\text { Cash Flaw la } \\
\text { All Users }\end{array}$ & $\begin{array}{c}\text { actual } \$ 000) \\
\text { DOE+IFS }\end{array}$ & Nation \\
\hline 1990 & 0 & 0 & -66 & 0 & -424 & -490 \\
\hline 1991 & 0 & 0 & -66 & 0 & -424 & -490 \\
\hline $\begin{array}{l}1992 \\
1993\end{array}$ & 0 & 0 & -169 & 0 & -424 & -553 \\
\hline 1993 & 7 & 100 & -84 & 697 & 103 & 716 \\
\hline 19 & 207 & 250 & 4,329 & 22,220 & 17.511 & 44,066 \\
\hline 19 & 407 & 403 & 9.538 & 75,328 & 50,592 & 135,458 \\
\hline 19 & 607 & 561 & 15,172 & 161,698 & 100,318 & 277,188 \\
\hline 16 & 807 & 723 & 21,164 & 283,178 & 167,810 & 472,153 \\
\hline 19 & 1,007 & 890 & 27.492 & 441,793 & 254,176 & 723,461 \\
\hline 1990 & 1,100 & 1,062 & 30,574 & 627,147 & 349,573 & $1,007,293$ \\
\hline 200 & 1,100 & 1,8 & 30.574 & 823,182 & 446,718 & $1,300,474$ \\
\hline 2001 & 1,100 & 1,420 & 30,574 & $1,024,5 \approx 7$ & 547.674 & $1,602,777$ \\
\hline 2002 & 1,100 & 1.607 & 30,574 & $1,231,586$ & 652,336 & 1.914 .497 \\
\hline 2013 & 1.107 & 1,6 & 30.845 & $1,445,591$ & 761,508 & $2.237,944$ \\
\hline 2004 & 1,30 & 1.6 & 38,908 & $1.693,382$ & 898,319 & 2.630 .609 \\
\hline 2005 & 1,50 & 1,6 & 47,358 & $1,990,573$ & $1,059,896$ & $3,097,827$ \\
\hline 2006 & 1,70 & 1,6 & 56,201 & $2,339,906$ & $1,247,781$ & $3,643,887$ \\
\hline 2007 & 1 & 1,6 & 65.444 & $2,744,329$ & $1,463,518$ & $4,273,290$ \\
\hline 2000 & 2,107 & 1,607 & 75.097 & $3.206,873$ & 1.708 .794 & 4.990 .755 \\
\hline 2009 & 2,200 & 1.6 & 79.777 & $3,714,190$ & 1.970 .095 & $5,704,062$ \\
\hline 2010 & 2,200 & 1,6 & 79,777 & $4,244,642$ & $2,237,779$ & $6,5.52,193$ \\
\hline 2011 & 2,200 & 1.6 & 79,777 & $4,790,718$ & $2,515,070$ & $7,385,564$ \\
\hline 2013 & 2,200 & 1.6 & 79.777 & 5.353 .267 & $2.801,957$ & $8,235,004$ \\
\hline 2013 & 2,207 & 1,607 & 80.186 & $5,934,257$ & $3,099,706$ & $9,114,1+8$ \\
\hline 201 & 2.407 & 1,607 & 92,375 & $6,569,592$ & $3,440,530$ & $10,102,500$ \\
\hline 2015 & 2,007 & 1,607 & 105,088 & $7,282,062$ & $3.820,078$ & $11,207,230$ \\
\hline 2016 & 2,807 & 1,607 & 118,342 & 8.075 .810 & $4,240,677$ & $12,434,830$ \\
\hline 2017 & 3,007 & 1,607 & 132,156 & $8,955,290$ & $4,70,4,6 \in 2$ & $13,792,110$ \\
\hline 2018 & 3,207 & 1,607 & 146,549 & $9,925,090$ & $5,214,569$ & $15,285,210$ \\
\hline 2019 & 3,300 & 1,607 & 153,515 & $10,968,110$ & $5,751,899$ & $16,873,520$ \\
\hline 2020 & 3,360 & 1,607 & 153,515 & $12,055,080$ & $6,303,742$ & $18,512,340$ \\
\hline 2021 & $\begin{array}{l}3,300 \\
3,300\end{array}$ & 1,607 & 153,515 & $13,175,510$ & $6.875,084$ & $20,204,110$ \\
\hline $\begin{array}{l}2022 \\
2023\end{array}$ & $\begin{array}{l}3,300 \\
3,300\end{array}$ & $\begin{array}{l}1,607 \\
1,607\end{array}$ & 153,515 & $=14,331.040$ & $7,466,125$ & $21,950,68$ \\
\hline 2024 & $\begin{array}{l}3,300 \\
3,300\end{array}$ & $\begin{array}{l}1,607 \\
1,607\end{array}$ & $\begin{array}{l}153,515 \\
153,515\end{array}$ & $\begin{array}{l}15,523,180 \\
16,753,310\end{array}$ & $\begin{array}{l}8,077,278 \\
8,709,174\end{array}$ & $23,753,980$ \\
\hline 2025 & $\begin{array}{l}3,300 \\
3,300\end{array}$ & 1,607 & $\begin{array}{l}153,515 \\
153,515\end{array}$ & $\begin{array}{l}16,753,310 \\
18,022,780\end{array}$ & $\begin{array}{l}8,709,174 \\
9,362,552\end{array}$ & $25,616,010$ \\
\hline
\end{tabular}

February 20, 1990 
DOE/OIF THFESHOLD ANALYSIS MODEL -- (ECONOIFZ)

\begin{tabular}{|c|c|c|c|c|c|c|}
\hline & $\begin{array}{l}\text { o ject Name: } \\
\text { seripticin: }\end{array}$ & $\begin{array}{l}\text { Workpiece } \\
\text { Fiaman } s\end{array}$ & $\begin{array}{l}\text { Temperature } \\
\text { Spectroscopy }\end{array}$ & $\begin{array}{l}\text { Analyzer by } \\
\text { Semicanducta }\end{array}$ & Industry & \\
\hline Year & $\begin{array}{r}\text { Cumulative } \\
\text { Units }\end{array}$ & ist User & $\begin{array}{c}\text { Cumulative } \\
\text { Developer }\end{array}$ & $\begin{array}{c}\text { Cash Flow (di } \\
\text { All Users }\end{array}$ & $\begin{array}{c}\text { counted } \$ 0001 \\
\text { DOE+IRSS }\end{array}$ & Naticin \\
\hline 1990 & 0 & 0 & -61 & 0 & -393 & -454 \\
\hline 1991 & 0 & 0 & $-t 1$ & 0 & -393 & -454 \\
\hline 1992 & 0 & 0 & -143 & 0 & -393 & -535 \\
\hline 1993 & 7 & 73 & -80 & 512 & -5 & 427 \\
\hline 1994 & 207 & 175 & 2,923 & 15,165 & 11,843 & 29.930 \\
\hline 1995 & 407 & 272 & 6,206 & 48,628 & 32,689 & 87,523 \\
\hline 1996 & 607 & 364 & 9,493 & 99,024 & 61.704 & 170,220 \\
\hline 1997 & 807 & 452 & 12,730 & 164,656 & 98,168 & 275,554 \\
\hline 1998 & 1.007 & 535 & 15,896 & 244,003 & 141,372 & 401.271 \\
\hline 1999 & 1,100 & 615 & 17,324 & 329,857 & 185,559 & 532,740 \\
\hline 2000 & $1,: 200$ & 691 & 17,324 & 413,933 & 227,2Е3 & 658,480 \\
\hline 2001 & 1,100 & 763 & 17,324 & 493,891 & 267,314 & 778, E2E \\
\hline 200E & 1,100 & 831 & 17,324 & 570.026 & $30.5,798$ & 893,147 \\
\hline 2013 & 1,107 & 831 & 17,416 & 642,886 & 342,967 & $1,003,268$ \\
\hline 2004 & 1,307 & 831 & 19.957 & 721,000 & 386,095 & $1,127,052$ \\
\hline 2005 & 1,507 & 831 & 22.424 & 807,747 & 433,258 & $1,263,429$ \\
\hline 2006 & 1,707 & 831 & 24,814 & 902,161 & 484.037 & 1.411 .012 \\
\hline 2007 & 1,907 & 831 & 27,127 & $1,003,367$ & 538,025 & $1,568,519$ \\
\hline 5008 & 2,107 & 831 & 29,364 & $1,110,544$ & 594,856 & 1.734 .764 \\
\hline 2009 & 2,200 & 831 & 30,368 & $1,219,398$ & 650,920 & $1,900,676$ \\
\hline 2010 & 2,200 & 831 & 30,368 & $1,324,765$ & 704,097 & 2.059 .230 \\
\hline 2011 & 2,200 & 831 & 30,368 & $1,425,210$ & 755,102 & $2,210,680$ \\
\hline 2012 & 2,200 & 831 & 30,368 & 1.521 .021 & 803,964 & $2,355,353$ \\
\hline 2013 & 2,207 & 831 & 30,432 & $1,612,643$ & 850,918 & 2.493 .993 \\
\hline 2014 & 2,407 & 831 & $3 \approx, 212$ & $1,705,413$ & 900,684 & $2,638,309$ \\
\hline 2015 & 2,607 & 831 & 33,931 & $1,801,740$ & 952,000 & $2,787,671$ \\
\hline 2016 & 2,807 & 831 & 35,590 & $1,901,100$ & 1.004 .053 & $2,941,350$ \\
\hline 2017 & 3,007 & 831 & 37,191 & $2,003,050$ & $1,058,435$ & $3,098,677$ \\
\hline 2018 & 3,207 & 831 & 38,736 & $2,107,136$ & $1,113,162$ & $3.259,035$ \\
\hline 2019 & 3,300 & 831 & 39,428 & $2,210,788$ & $1,166,561$ & $3,416,777$ \\
\hline 2020 & 3,300 & 831 & 39,428 & $2,310,807$ & $1,217,337$ & $3,567,574$ \\
\hline 2021 & 3,300 & 831 & 39,428 & $2,406,267$ & $1,266,017$ & $3,711,713$ \\
\hline 5052 & 3,300 & 831 & $39,4 \overline{8}$ & $2,497,426$ & $1,312,644$ & $3,849,499$ \\
\hline 2023 & 3,300 & 831 & 39,428 & $2,584,506$ & $1,357,286$ & $3,981,220$ \\
\hline 2024 & 3,300 & 831 & 39,428 & $2,667,706$ & $1,400,023$ & $4,107,158$ \\
\hline 2025 & 3,300 & 831 & 39,428 & $2,747,205$ & $1,440,941$ & $4,227,575$ \\
\hline
\end{tabular}

February 20, 1990

Fage 7

JWLarson

DOE/OIF 
DOE/OIF THRESHOLD ANALYSIS MODEL -- (ECONOIF'E)

Project Name: Warkpiece Temperature Analyzer by Acuie:

ECONOMIC FERSFECTIVE OF FIFST USER

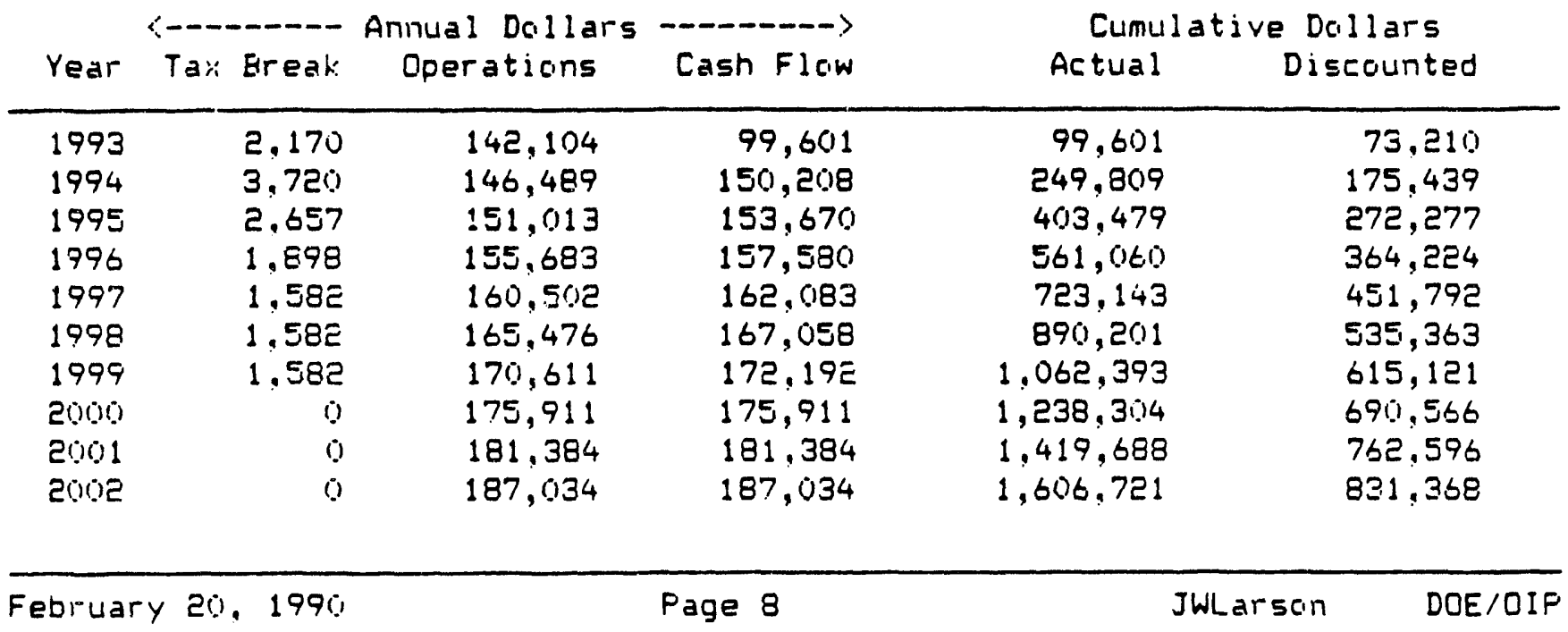


Project Name: Workpiece Temperature Analyzer by Acure:

ECONOMIC PEFSFECTIVE OF DEVELOFEF

\begin{tabular}{|c|c|c|c|c|c|}
\hline \multirow[b]{2}{*}{ Year } & \multirow{2}{*}{$\begin{array}{r}\text { Units } \\
\text { Soldd }\end{array}$} & \multirow{2}{*}{$\begin{array}{l}\text { Unit } \\
\text { Coist }\end{array}$} & \multirow{2}{*}{$\begin{array}{l}\text { Aninual } \\
\text { Cash Flaw }\end{array}$} & \multicolumn{2}{|c|}{ Cumulative Dollars } \\
\hline & & & & Actual & Discounted \\
\hline 1990 & 0 & 0 & $-66,000$ & -66.000 & $-61,111$ \\
\hline 1991 & 0 & 0 & 0 & -66.000 & $-61,111$ \\
\hline 1992 & 0 & 0 & $-102,907$ & $-168,907$ & $-142,802$ \\
\hline 1993 & 7 & 55,922 & 84,837 & $-84,069$ & $-80,444$ \\
\hline 1994 & 2010 & 58,047 & $4.412,770$ & $4,328,700$ & $2,922,813$ \\
\hline 1995 & 200 & 60,255 & $5.209,525$ & $9,538,224$ & $6,205,696$ \\
\hline 1996 & 200 & 62,553 & $5,633,790$ & $15,172,020$ & $9,492,957$ \\
\hline 1997 & 200 & 64.930 & $5,992,348$ & $21,164,370$ & $12,730,430$ \\
\hline 1998 & 200 & 67,410 & 6.327 .224 & 27.491 .590 & $15,895,620$ \\
\hline 1999 & 93 & 69.980 & $3,082,701$ & $30,574,290$ & $17,323,510$ \\
\hline 2000 & 0 & 72.649 & 0 & $30,574,290$ & $17,323,510$ \\
\hline 2001 & 0 & 75.420 & (i) & $30,574,590$ & $17,323,510$ \\
\hline 2002 & 0 & 78,299 & 0 & $30,574.290$ & $17,323,510$ \\
\hline 2003 & 7 & 81,288 & 270,327 & $30,844,620$ & $17,415,540$ \\
\hline 20014 & 200 & 84,393 & 8.063 .144 & $38,907,760$ & $19,957,380$ \\
\hline 2005 & 200 & 87.617 & $8,450,160$ & $47,357,920$ & $22,423,900$ \\
\hline 2006 & 200 & 90.966 & 8.842 .624 & $56,200,550$ & $24,813,790$ \\
\hline 2007 & $200^{\circ}$ & 94,444 & $9,243,173$ & $65,443,720$ & $27,126,880$ \\
\hline 2008 & 500 & 98,057 & 9.653 .754 & $75,097.480$ & $29,363,770$ \\
\hline 2007 & 93 & 101,809 & $4,679,079$ & $79,776,550$ & $30,367,650$ \\
\hline 2010 & 0 & 105.706 & 0 & $79,776,550$ & $30,367,650$ \\
\hline 2011 & 0 & 109,754 & 0 & $79,776,550$ & $30,367,650$ \\
\hline 2012 & 0 & 113,958 & 0 & $79,776,550$ & $30,367.350$ \\
\hline 2013 & 7 & 118,324 & 409,338 & $80,186,380$ & $30,432,290$ \\
\hline 2014 & 200 & $122,860^{\circ}$ & $12,188,700$ & $92,375,080$ & $32,212,050$ \\
\hline 2015 & 200 & 127,571 & $12,712,770$ & $105,087,900$ & $33,930,840$ \\
\hline 2016 & 200 & 132,465 & $13,254,110$ & $118,342,000$ & $35,590,070$ \\
\hline 2017 & 200 & 137,548 & $13,813,900$ & $132,155,900$ & $37,191,290$ \\
\hline 2018 & 200 & 142.827 & $14,393,230$ & $146,549,100$ & $38,736,080$ \\
\hline 2019 & 93 & 148,312 & $6,966,171$ & $153,515,300$ & $39,428,360$ \\
\hline 2020 & 0 & 154,008 & 0 & $153,515,300$ & $39,428,360$ \\
\hline 2021 & 0 & 159,926 & 0 & $153,515,300$ & $39,428,360$ \\
\hline 2022 & 0 & 166,073 & 0 & $153,515,300$ & $39,428,360$ \\
\hline 20123 & 0 & 172,458 & 0 & $153,515,300$ & $39,428,360$ \\
\hline 2024 & 0 & 179,0192 & 0 & $153,515,300$ & $39,428,360$ \\
\hline 2025 & 0 & 185,982 & 0 & $153,515,300$ & $39,428,360$ \\
\hline
\end{tabular}

February 20,1990

Page 9

JWLarson

DOE/OIF 
DOE/OIF THRESHOLD ANALYSIS MODEL -- (ECONOIFE)

Praject Name: Workpiece Temperature Analyzer by Acure:

ECONOMIC PEFSFECTIVE OF FEDEFAL SECTOF:

\begin{tabular}{|c|c|c|c|c|c|}
\hline Year & $\begin{array}{l}\text { 1st User } \\
\text { Tax Ereak }\end{array}$ & $\begin{array}{l}\text { Developer } \\
\text { Tax Break }\end{array}$ & $\begin{array}{l}\text { Annual } \$ \\
\text { Cash Fleiw }\end{array}$ & $\begin{array}{l}\text { Cumula } \\
\text { Actual }\end{array}$ & $\begin{array}{l}\text { Ive Dallars } \\
\text { Disccunted }\end{array}$ \\
\hline 1990 & 0 & 34,000 & $-424,000$ & -424.000 & -392.593 \\
\hline $\begin{array}{l}1991 \\
1992\end{array}$ & $\begin{array}{l}0 \\
0\end{array}$ & 0 & 0 & $-424,000$ & $-392,593$ \\
\hline $\begin{array}{l}1992 \\
1993\end{array}$ & $\begin{array}{r}0 \\
2,170^{\circ}\end{array}$ & 5,253 & 0 & $-424,000$ & $-392,593$ \\
\hline $\begin{array}{l}1993 \\
1994\end{array}$ & $\begin{array}{l}2,170 \\
3,720\end{array}$ & 9,006 & 527,306 & 103,306 & -5.007 \\
\hline $\begin{array}{l}1944 \\
1995\end{array}$ & $\begin{array}{l}3,720 \\
2,657\end{array}$ & 6,433 & $17,408,000$ & $17,511,310$ & $11,842,580$ \\
\hline 1956 & $\begin{array}{l}2,657 \\
1,893\end{array}$ & 4,595 & $33,080,710$ & $50,592,010$ & $32,687,030$ \\
\hline 1977 & $\begin{array}{l}1,893 \\
1,582\end{array}$ & 3,829 & $49,725,990$ & $100,318,000$ & $61,703,560$ \\
\hline 1998 & $\begin{array}{l}1,582 \\
1,582\end{array}$ & 3,829 & $67,492,430$ & $167,810,400$ & $98,167,690$ \\
\hline 1999 & $\begin{array}{l}1,582 \\
1,582\end{array}$ & 3,829 & $\begin{array}{l}86,365.850 \\
95,395.260\end{array}$ & $254,176,300$ & $141,372,100$ \\
\hline 2000 & $\begin{array}{r}1,582 \\
0\end{array}$ & 0 & $\begin{array}{l}95,395,260 \\
97,145,830\end{array}$ & $349,572,600$ & $185,559,000$ \\
\hline 2001 & 0 & $\begin{array}{l}0 \\
0\end{array}$ & $\begin{array}{r}97,145,830 \\
100,955,300\end{array}$ & $446,718,400$ & $227,223,200$ \\
\hline 2002 & 0 & $\begin{array}{l}0 \\
0\end{array}$ & $100,955,300$ & $547,673,800$ & $267,313,900$ \\
\hline 2003 & 0 & $\begin{array}{l}0 \\
0\end{array}$ & $104,662,500$ & $652,336,300$ & $305,798,000$ \\
\hline 2004 & 0 & $\begin{array}{l}0 \\
0\end{array}$ & $109,171,900$ & $761,508,100$ & $342,960,800$ \\
\hline 2005 & 0 & 0 & $136,810,800$ & $898,318,900$ & $386,095,200$ \\
\hline 2006 & 0 & $\begin{array}{l}0 \\
0\end{array}$ & $161,577,200$ & $1,057,896,000$ & $433,253,000$ \\
\hline 20007 & 0 & $\begin{array}{l}0 \\
0\end{array}$ & $187,885,000$ & $1,247,781,000$ & $484,037,400$ \\
\hline 2008 & 0 & $\begin{array}{l}0 \\
0\end{array}$ & $215,736,800$ & $1,463,518,000$ & $538,025,200$ \\
\hline 2009 & 0 & $\begin{array}{l}0 \\
0\end{array}$ & $245,266,600$ & $1,708,784,000$ & $594,856,500$ \\
\hline 2010 & 0 & $\begin{array}{l}0 \\
0\end{array}$ & $261,310,500$ & $1,970,095,000$ & $650,920,100$ \\
\hline 2011 & 0 & $\begin{array}{l}0 \\
0\end{array}$ & $267,684,300$ & $2,237,779,000$ & 704.097 .000 \\
\hline 2012 & 0 & $\begin{array}{l}0 \\
0\end{array}$ & $277,290,600$ & $2,515,070,000$ & $755,10,000$ \\
\hline 2013 & 0 & $\begin{array}{l}0 \\
0\end{array}$ & $286,88^{\circ}, 300$ & $2,801,959,000$ & \\
\hline 2014 & 0 & $\begin{array}{l}1 \\
0\end{array}$ & $297,746,600$ & $3,099,705,000$ & $850,917,900$ \\
\hline 2015 & 0 & $\begin{array}{l}0 \\
0\end{array}$ & $340,824,100$ & $3,440,530,000$ & $900,684,300$ \\
\hline 2016 & 0 & $\begin{array}{l}0 \\
0\end{array}$ & $379,548,200$ & $3,820,078,000$ & $951,999,800$ \\
\hline 2017 & 0 & $\begin{array}{l}0 \\
0\end{array}$ & $420,599,200$ & $4,240,677,000$ & \\
\hline 2018 & 0 & $\begin{array}{l}0 \\
0\end{array}$ & $463,985,000$ & $4,701,662,000$ & $\begin{array}{l}1,058,435,000 \\
1,113,162,000\end{array}$ \\
\hline 2019 & 0 & $\begin{array}{l}0 \\
0\end{array}$ & $509,906,300$ & $5,214,569,000$ & \\
\hline 2020 & 0 & $\begin{array}{l}0 \\
0\end{array}$ & $537,330,400$ & $5,751,899,000$ & $\begin{array}{l}1,166,561,000 \\
1,217,339,000\end{array}$ \\
\hline 2021 & 0 & $\begin{array}{l}0 \\
0\end{array}$ & $551,842,500$ & & $1,266,017,000$ \\
\hline 2022 & 0 & $\begin{array}{l}0 \\
0\end{array}$ & $571,342,100$ & & $1,312,644,000$ \\
\hline 2023 & 0 & $\begin{array}{l}0 \\
0\end{array}$ & $591,041,600$ & $\begin{array}{l}7,466,125,000 \\
8,077,278,000\end{array}$ & $1,357,286,000$ \\
\hline 2024 & $\dot{0}$ & $\begin{array}{l}0 \\
0\end{array}$ & $611,152,800$ & & $1,400,023,000$ \\
\hline 2025 & 0 & $\begin{array}{l}0 \\
0\end{array}$ & $\begin{array}{l}631,896,000 \\
653,378,000\end{array}$ & & $1,440,941,000$ \\
\hline
\end{tabular}

February 20, 1990

Fage 10

JWLarson

DOE/OIF 


$$
\text { A }-30
$$




\section{APPENDIX B}

IMPROVED INFRARED TEMPERATURE MEASUREMENT BY UTILIZATION OF LASER TECHNOLOGY

B-1 


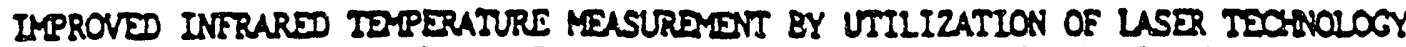

U. Baustian, E.K. Matthews, Pyrometer Instrument Co., Northvale, NU U.S.A.

Ifrrocuction -- Radietion pyrowetars are widely used for mensuring temperatures in ucientific and industrial applicatione thare it is inconvenient or impractical to utilize direct contacting sensors. Product contemination, operator safety and sensor durability justify non-contact techniques. Inis paper discusses an iaproved measurewent technique using a pulsed laser to determine enissivity. (E), a critical variable for accurale temperature determination.

TILRMAL RADIATION -- All bodles above absolute zero radiate thermal energy. The SLefun-Boltemann law describes the rate at which a black surface emits this energy per unit ares over all possible wavelengths, $W_{b}=\sigma T^{4}$ where (Wb) is the total emissive power, and $(r)$ the Stefan-Boltzmann, constant and $(T)$ the teaperature of the surface. No perfectly black body exists in nature; nosi-black surfaces endt radiant energy at a lesser rate, $W=G W$ where $(E)$ is the total henispherical enissivtty of the surfece. Duissivity is a function of tenperature and various surface charecteristica of the watcrial; it is the average endssivity over all wavelengthe and directions of the anitted radiant energy. Planck's diatribution Law describes the zadiant energy eniftad by monocluromatic black aurface around the wavelength $\omega$.

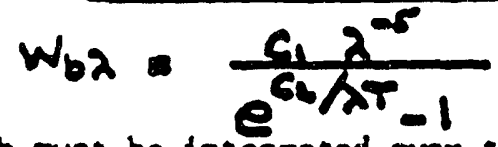

which must be integrated over the range $\lambda_{1}$ to $\lambda_{2}$ to obtain the caitted radiant energy, which for a non-black body is

$$
w=\int_{\lambda_{1}}^{\lambda_{2}} \varepsilon_{2} w_{b 2} d \lambda \quad \text { where } c 1 \text { and } c 2 \text { are consuntes. }
$$

1KE LMISSIVITY PROBLDM - Unile pyraneters can detect the energy enitted from a radiating surface, the determination of surface temperature requires also a knowledge of the endsaivity (E). Unfortunately, missivity varies widely for different anteriuls, and for the eane material at different temperateres and arface conditions, such as roughness. See LABLE I

\begin{tabular}{|c|c|c|c|}
\hline IASLE I EXAMPLES & TEPERATURE "E & MISSIVITY (E) & DISSIVITY (E) \\
\hline Aluninum & 338 & 0.05 pulished & 0.49 oxidized \\
\hline $160 n$ & 302 & 0.16 polished & 0.98 oxidized \\
\hline
\end{tabular}


Lisissivity changes with te. Fature; for metals it gerierally xreases and for nonaxclals it decreases with incronsing temperature.

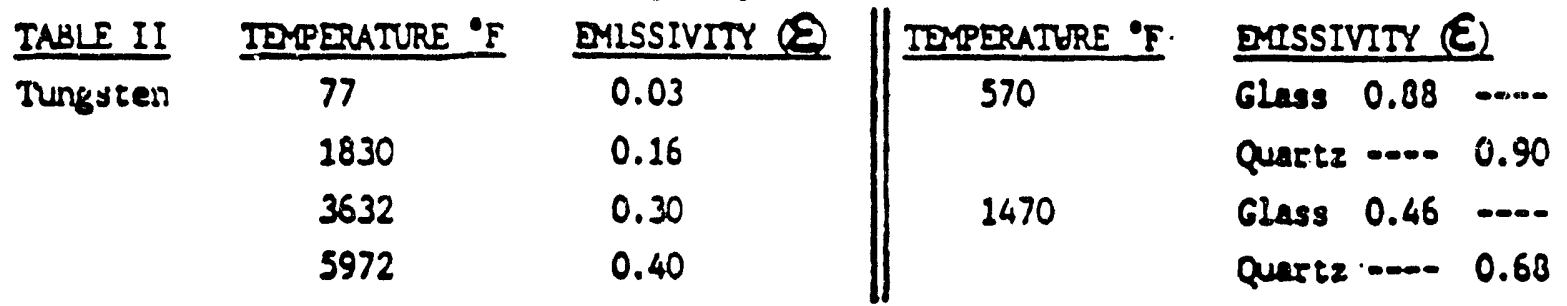

It is clear that to measure surfare comperature it is vital to have direct knowledge of the conissivity. Directlonally, the higher the teuperature and the lower the coissivity, the greater the error in temperature geasurement.

THE IRRADLANCE PROBLEY -- In many applications the teoperature of a material withill a furnace is required whore the walls of thr furnace are hotter than the target. If the enissivity of the target is less than unity, then somi energy from the walls will be reflected by the target to the measuring pyrometer. The pyrometer will rcceive more radiance than that entited soley by the target. The temperature readings will be incorrect due to this 1rradiance as well as due to the surface emissivity. The error increases with temperature difference (wall minus target temperature) and with decreasing enissivity.

TABLE III Calculated Temperature Error "F Due to. Irradiance and Indssivity DMISSIVITY WNUL TPMPRATURE MINUS TARGET IDMPERATURE 'F

$\begin{array}{lllll}0.75 & \frac{200}{71} & \frac{400}{176} & \frac{600}{300} & \\ 0.85 & 45 & 120 & 219 & \text { These Ertors Are For Target } \\ 0.95 & 16 & 46 & 97 & \text { Temperature of } 18000^{\circ} \mathrm{F} \\ 0.98 & 6 & 30 & 44 & \end{array}$

The above errors are too large to be jamored in most applications and the need for an instrument to measure directiy emisaivity is evident.

INSTRUMDT DESCRIPTIEN -. The pyroweter (PYROLASER) is a 6.5 lb. battery poweied (or on-litie) instrurient contaluing all couponents - Laser, electronics, opties, and data loger.

OPIICAI SYSTPY -- The optical systen is of single axds configuration with the viewing, focusing, (dlstance measuring) lasar tranerall, laser recelve and radsance receive, all being colxcident through objective lens. The Laset eransmit energy is introduced via a bean splleter and filtars protect the operator frow any-laser energy. The field of view is $7^{\circ}$; the measuring cone $1 / 3^{\circ}$ with measuring range 6 to $30 \mathrm{ft}$. For snall targets add-on lenses are used. 
USER -. The measuring instoment uses a solid state CaAs if a stack Laser with peak power of $25 \mathrm{~W}$. The laser is pulsed to distinguish between reflected laser (AC-signal) and enilted radiance (DC-signal) from the target. Tha exrorwous changes of radiant laser power with ablent temperatune 1s roughly compensated for by changins the supply voltage of the storage capactlor. The finul precision is achieved by referring the laser return signal to the monttored laser output signal.

The wavelength of 865rm according to tests done by Exxon 1s a goid endindow through cumbustion gases, However, for pyrometry this short wavelength 1 ind the lowest masurable temperature to about $600^{\circ} \mathrm{C}$. It $1 \mathrm{~s}$ desirable to extend the range of the instrument to lewer tenperatures. Hindows are avallable at $2.25 \mathrm{im}, 2.2 \mathrm{~m}$ and $3.7 \mathrm{~m}$. Currently, there 1s a lack of coild state lasers at these anclengths. FuECRONICS -- Besides comminicating with the operator via keyped, LOD-display, Inview-finder LED-display, and/Or RS232 conmunication line, the electronics messure the distance to the target by detecting the lens position after focussing manully, to power and file the laser, to monitor the outgoing signal, and to detect the retuming laser signal and the radiance enitted fran the target, tinally; to calculate from lhese raw data the tomperature and enissivity and to store the results. Flgure 1 is a block diagran of the eloctronics.

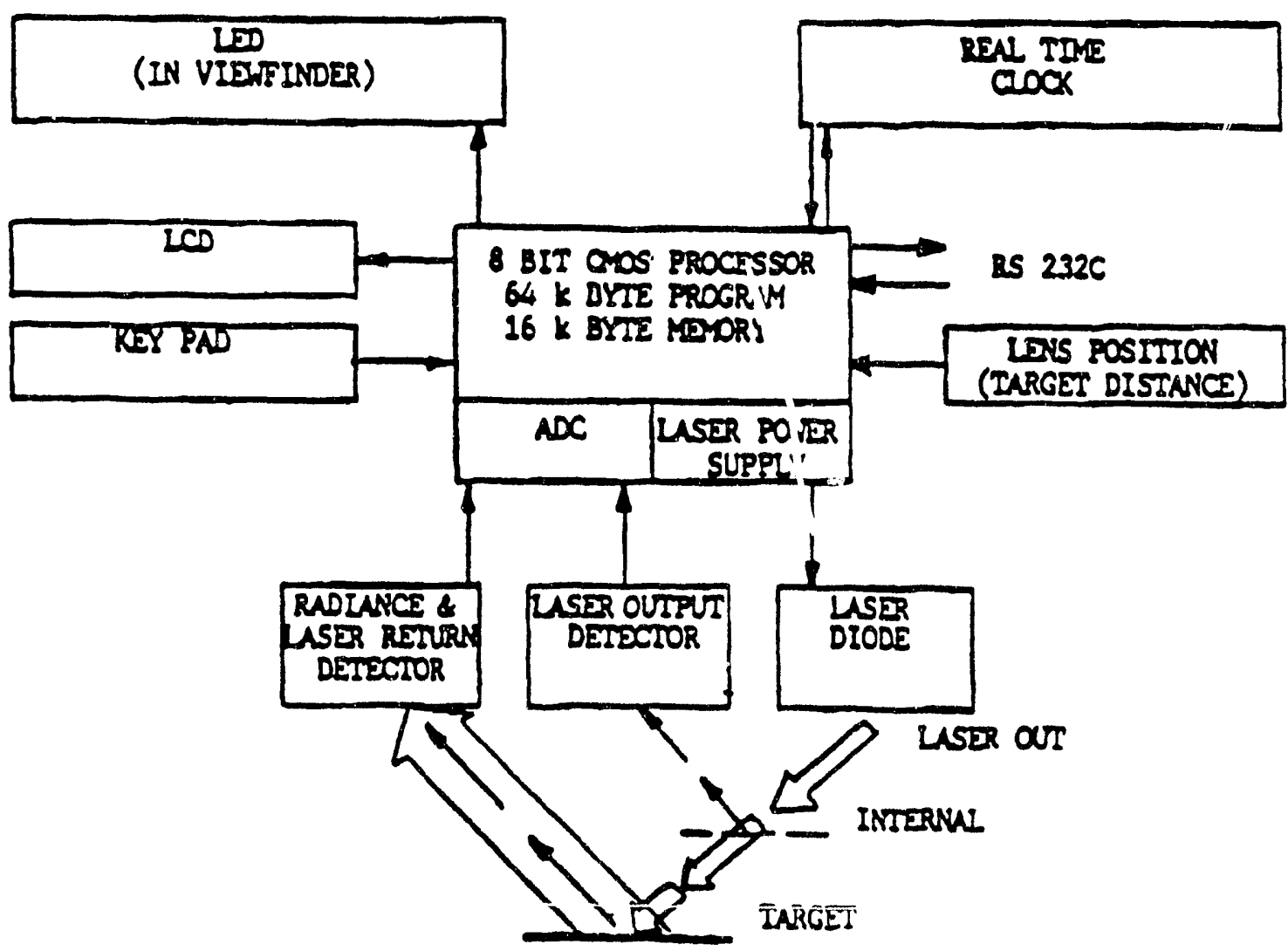




\section{APPENDIX C EQUIPMENT SPECIFICATIONS}

- LASER SPECIFICATIONS

- Spectra Physics DCR-11 Nd:YAG lasers

- Continuum YG-600 Nd:YAG lasers

- OPTOELECTRONICS

- Diode Array Detectors

- 77200 1/4 m Spectrographs, Slits and Gratings

- 77225 1/4 m Double Spectrographs

- Data Acquisition Systems: INSTASPEC II-AT/XT

- EG\&G OMA III System

- NBS TRACEABLE TEMPERATURE CALIBRATION SOURCES 


\title{
LASER SPECIFICATIONS
}

\author{
Spectra Physics DCR-11 Nd:YAG lasers
}



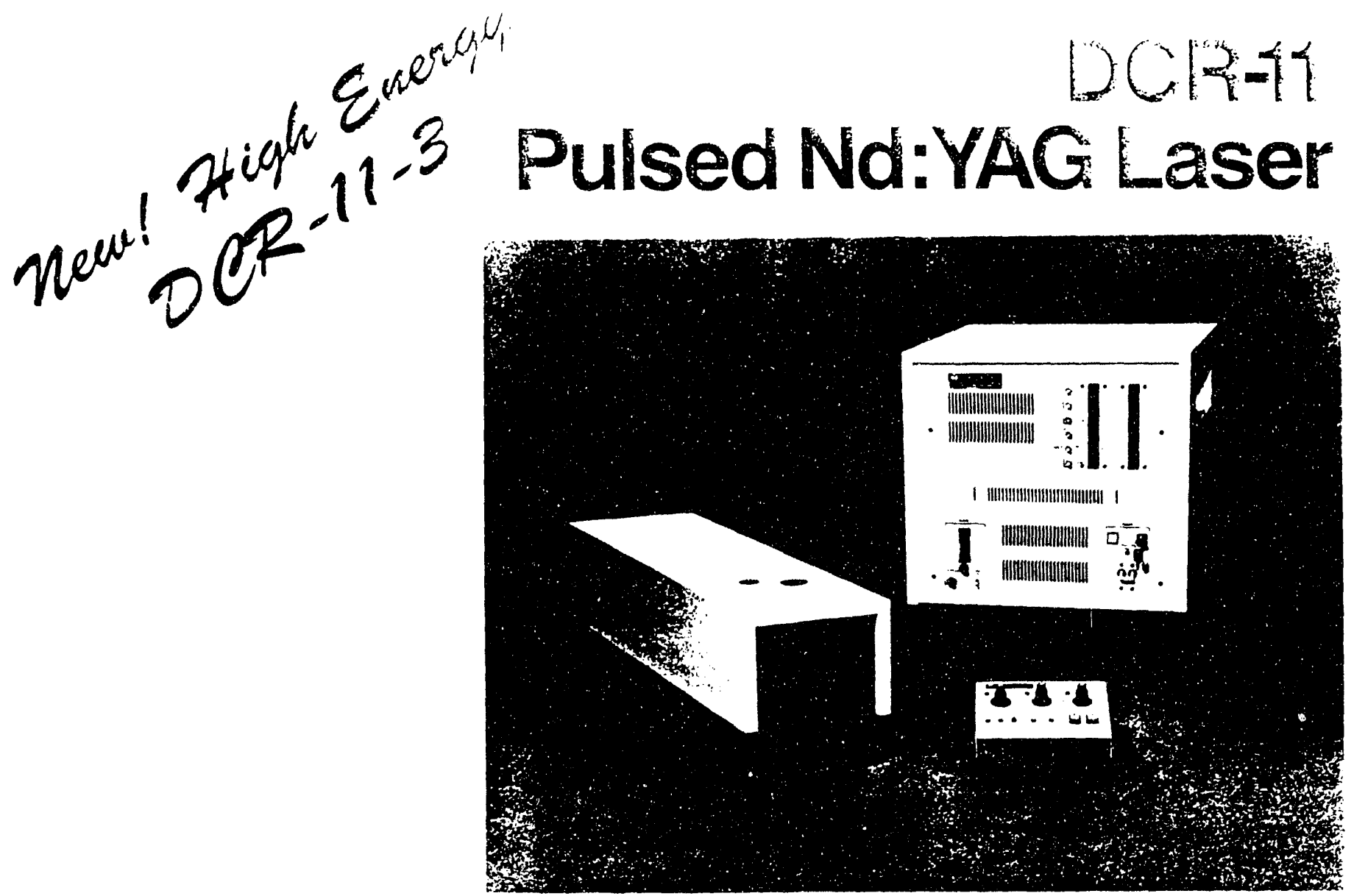

\section{An Economical and Transportable Pulsed Laser}

\section{Features:}

- High Energy, High Quality Output

- Compact

- Self-contained Cooling

- Computer Controllable

- Rugged
The Quanta-Ray DCR-11 is a unique combination of performance, convenience, and economy. It has the high energy, stability, and beam quality that are typical of the diffraction coupled resonator. It comprises three small packages designed for maximum convenience: a remote control that places all operating controls at your fingertips, a power supply so small it can be put where it beiongsout of the way, and a laser head that can be mounted wherever you need it. A computer interface links the laser with automated laboratory or factory environments, and because its cooling and cavity purge systems are self-contained, the
DCR-11 adapts easily to flying, floating, or rolling laboratories.

The DCR-11 was designed for total economy. Its utility requirements are minimal: single phase $208 \mathrm{~V}$ service. The stability of the diffraction coupled resonator makes it virtually maintenance free, and a conservative electronic design insures a long operating life.

The DCR-11 continues the Spectra-Physics Quanta-Play tradition of design excellence and high performance. Indeed, it is the standard bearer for the next generation of pulsed Nd:YAG lasers. 


\section{DCR-11 System Description}

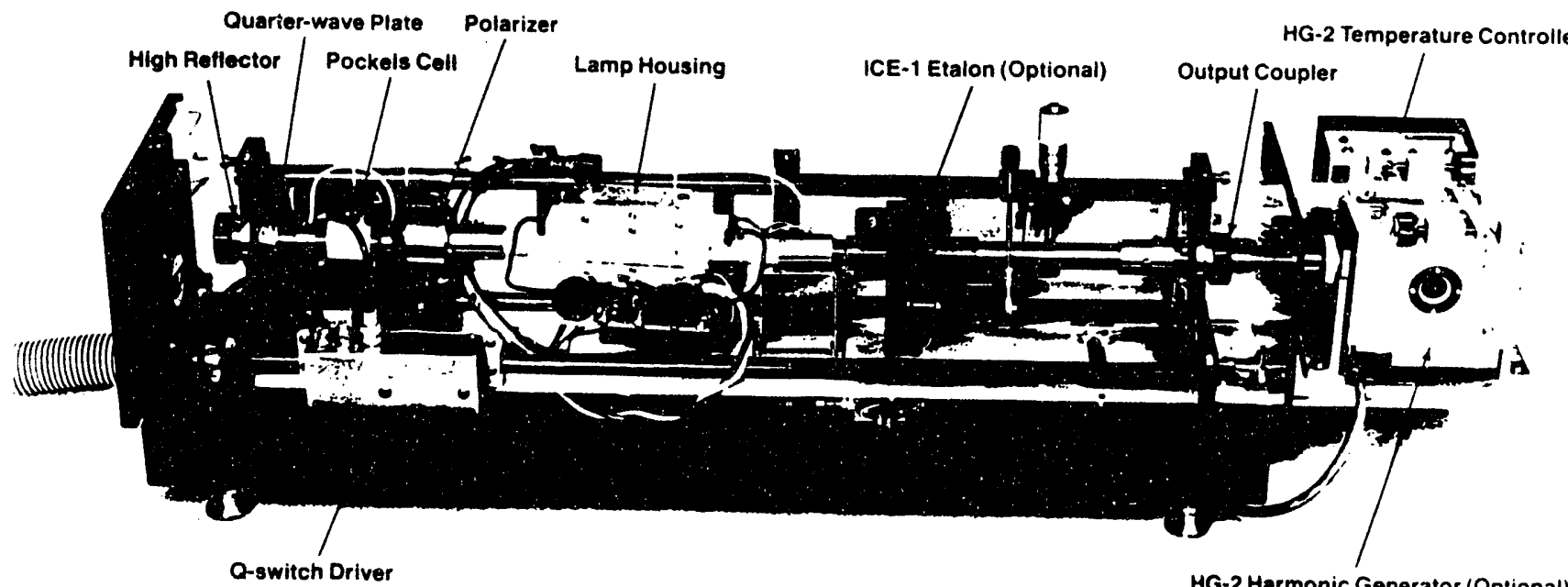

Figure 1: In-line optical layout of the DCR-11 results in high performance and high reliability.

DCR-11 Uses the Diffraction

\section{Coupled Resonator}

The Nd:YAG laser primary wavelength of $1064 \mathrm{~nm}$ is well placed in the optical spectrum for nonlinear conversion to both longer and shorter wavelengths. If the commonly used nonlinear processes (harmonic generation, frequency mixing, and Raman scattering) are to produce coherent outputs efficiently, the input beam must have a high degree of spatial coherence as well as high peak power.

The diffraction-coupled resonator (DCR) provides the best means of delivering these essential qualities. Herbst, Komine and Byer' first adapted Siegman's unstable resonator concept to the large volume, high gain Nd:YAG medium. In 1978 Quanta-Ray brought the first commercial laser based on this concept to market. The DCR-11 is the third generation of Quanta-Ray lasers to utilize this conve nient, reliable, and cost effective desian.

Figure 2 is a schematic of the DCR. The output coupler has a high reflectivity dot in the center of a convex substrate. The laser beam diverges as it is reflected off the dot, and as it builds in intensity, it effectively sweeps the gain from the $\mathrm{Nd}$ :YAG medium. The concave high reflector collimates the beam and compen. sates for thermal lensing of the Nd:YAG rod. As the beam exits the resonator, the light diffracts around the edge of the dot. creating the characteristic "donut" spatial profile

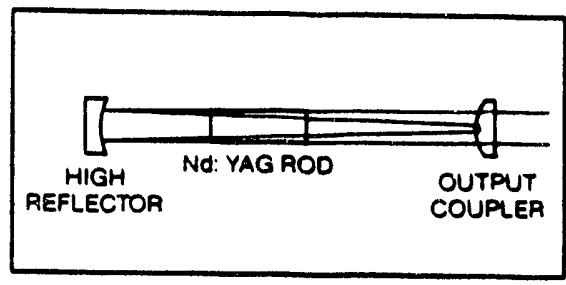

Figure 2: Diftraction Coupled Resonator

The DCR-11 is an oscillator only, designed as a compact laser that produces high power at a nominal $10 \mathrm{~Hz}$ repetition rate with no need for external cooling water. The system comprises three major components: the laser head, its power supply. and a control module. A flexible ten-foot umbilical, which contains all cooling, purge, and power lines connects the power sup. ply and laser head.

\section{Compact Laser Head}

Saves Valuable Space

Because the DCR-11 laser head contains only the optical resonator, Q-switch driver electronics, and lamp start circuit, it occupies but two square feet of valuable optical benchtop. More space is available for your experiment. Figure 1 shows the laser head interior, with the optional HG-2 harmonic generator attached. This simple, in-line optical layout results in high performance and high reliability.

Unique Q-Switch Provides

a Choice of Pulse Widths

The Q-switch has two pulse widths: 8 and $2.5 \mathrm{nsec}$ (nominal). Changing pulse widths is as simple as changing a single BNC cable connection on the Q-switch driver.

A Marx bank drives the Q-switch efficiently and with minimal time jitter. The DCR-11 uses a combination of a polarizer, quarter-wave plate, and Pockels cell to regulate the loss in the cavity. No voltage is applied to the Pockels cell during the build-up of the population inversion; holdoff is provided by the quarter-wave plate/ polarizer combination. To form the light pulse, a high speed, high voltage waveform is applied to the Pockels cell, cancelling the effect of the quarter-wave plate. Since the Pockels cell is only biased when the Q-switch is turned on, the DCR-11 is immune to $Q$-switch leakage caused by changes in ambient temperature; therefore, the Q-switch voltage rarely needs adjustment. Additionally, the short duty cycle of the Pockels cell prolongs the life of this critical component.

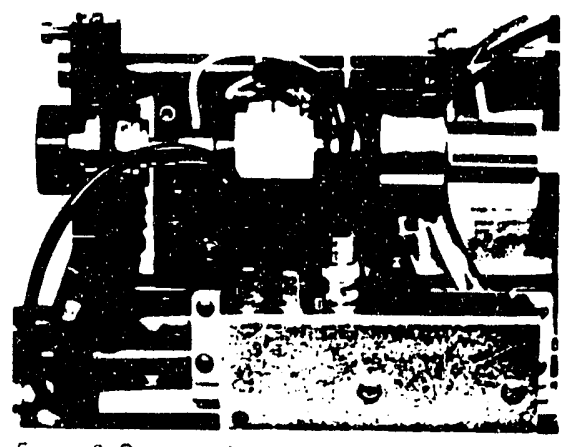


Pump Chamber Design Provides Excellent Spatial Coherence The Nd:YAG rod is optically pumped by one flash lamp in a close-coupled chamber, whose geometry produces excellent beam quality. The mechanical design of its housing makes lamp replacement quick and simple. without disturbing the optical alignment. Because the DCR-11 uses only one flash lamp. which is simmered for maximum stability and lifetime. the operating cost is greatly reduced

\section{Self-contained Air Purge}

Assures Clean Optical Path

The entire optical path is enclosed with stainless steel dust tubes. sealed with $O$ rings, and purged with filtered and dried air. This prevents contamination, eliminates the need for cleaning, and substantially increases the lifetime of the optics. The air purge system is sufficient for most environments, but connections are provided so bottled nitrogen can be used under harsh conditions

Proven Mechanical and Optical Design for Reliable, Stable Output

The reliability and high performance of the DCR-11 are due to its diftraction coupled resonator, careful mechanical design, and execution using the highest sign, and materials. The diffraction coupled resonator extracts maximum energy from the Nd:YAG rod. By virtue of this optical design, the mode quality and energy of the output are insensitive to ordinary perturbations of the optical cavity. The superior mode quality is demonstrated by the highest harmonic conversion efficiencies in the industry.

Use of composite graphite rods for resonator construction results in unsurpassed temperature stability; therefore, no optical adjustments are necessary during normal operation. Kinematic decoupling of the optical rail from the cover of the laser head assures mechanical stability.

Quanta-Ray DCR lasers have been installed and operate reliably in numerous applications, both mobile and stationary.

\section{A Power Supply That Fits}

Under The Table

Because the power sumpiy is only bi cm (22.5 in.) high, it fits ther mast uplical lables, or it can be sunied in a sandard 19-inch electronks atonet

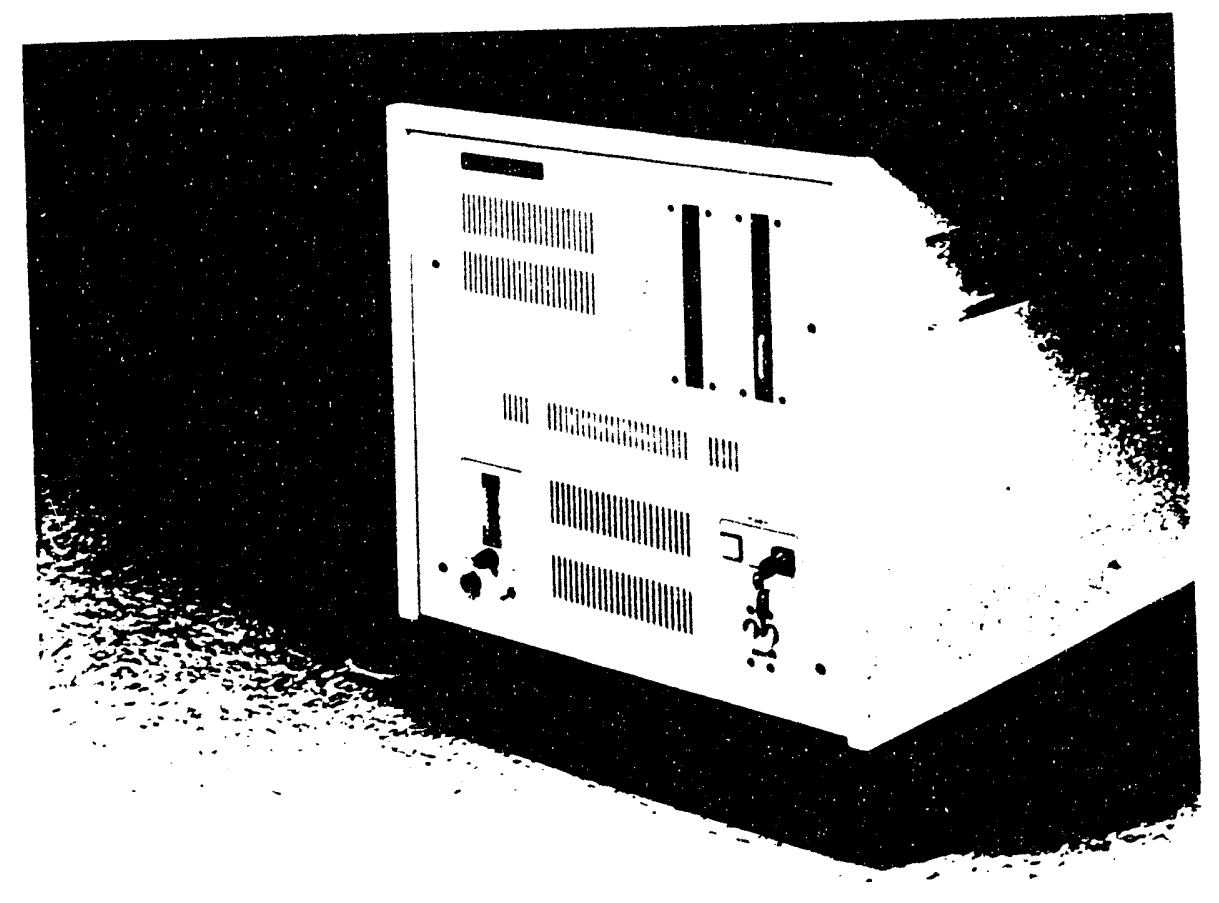

Figure 4: Compact Power Supply Fits Under Most Oplical Tabies

The power supply is not only compact, it is also self-contained, except for electrical service. It contains a closed cycle cooling system, which dissipates heat without an external water supply. The filtered-air purge system. also housed in the power supply. keeps optics clean under normal operating conditions, eliminating the need for external nitrogen. Both features increase laboratory flexibility, reduce operating costs, and lower system weight. which simplities installation of the DCR. 11 both in the laboratory and in the field

The electrical efticiency and well regulated output of the high frequency switch. ing power supply are evidence of its careful design. Because it is well regulated. the stored energy delivered to the flashlamp is stable to $0.25 \%$

A single control board drives the supply and monitors its performance. Control circuitry employs a ground plane to minimize inductive effects arid sectromagnelic in.

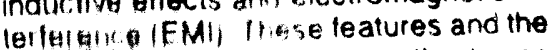

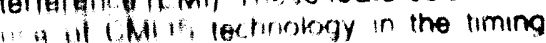

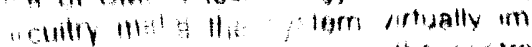

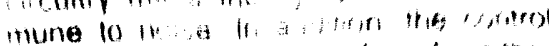

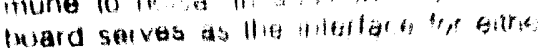

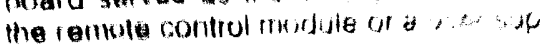
phed cominiter
The main circuit breaker and master key switch are the only controls located on the power supply; the rest are on the control module. The tront panel of the power sup. ply also has the computer interface connector and BNC connectors for all synchronization signals. This keeps most signal cables uff the optical table and out of the way.

The power supply is completely protected against inadvertent power fallures. If une occurs, the system automatically shuts down, preventing damage to the laser.

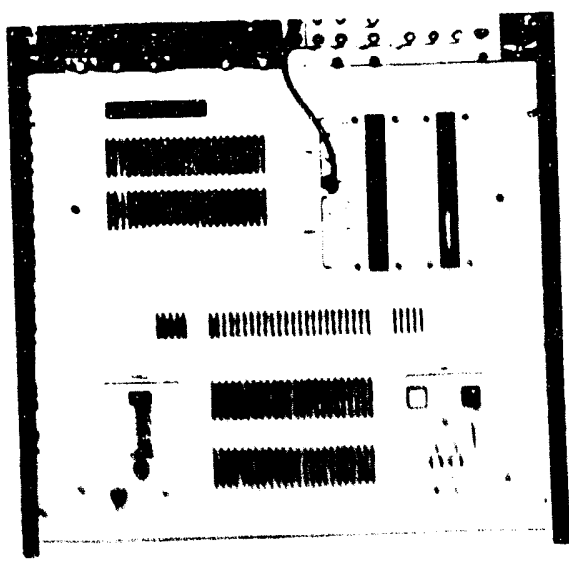

f jures Power Supditis Hack Murtatio

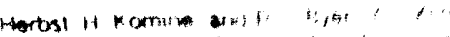

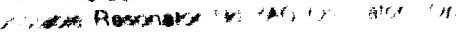

min $y$ 


\section{Remote Control}

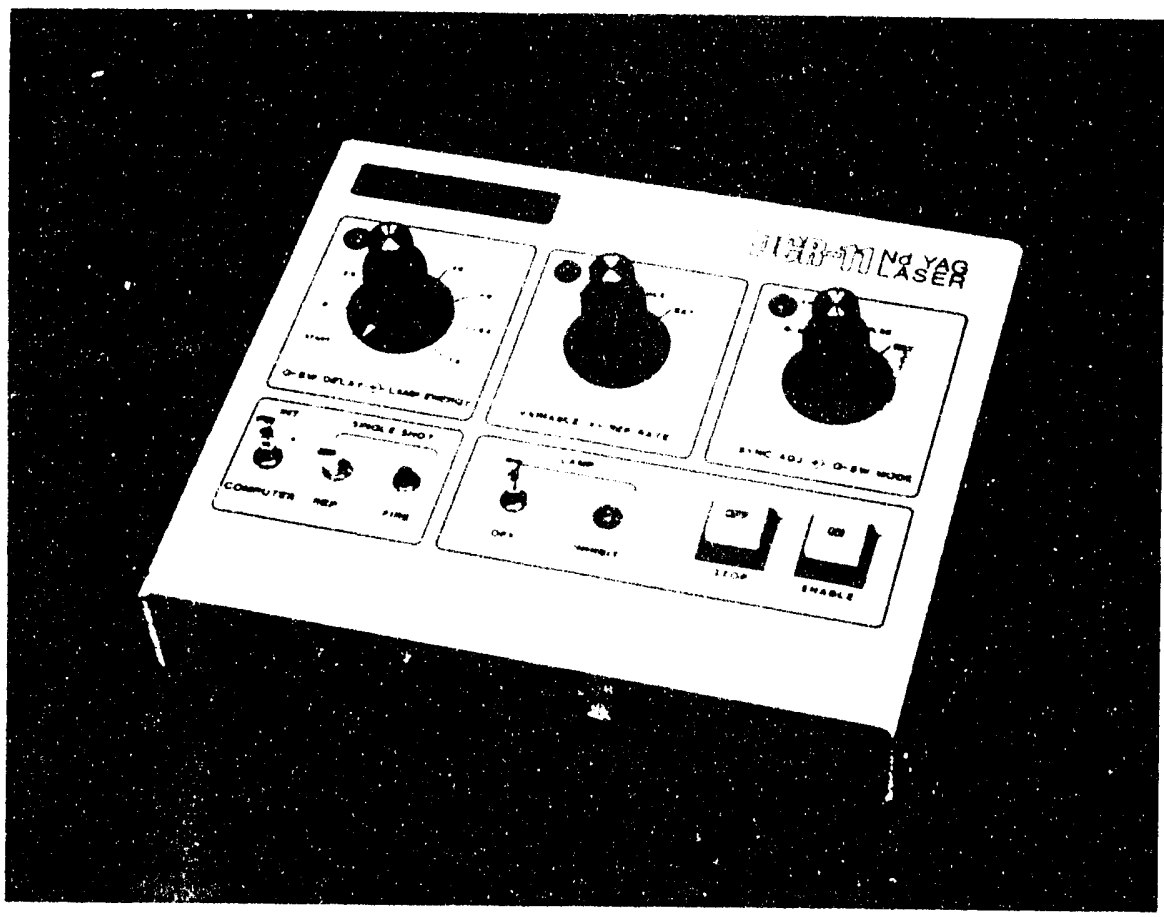

Sigure 6 Rerricti :oniol of All Funcuons

Conirols at Your Fingertips for Maximum Convenience

A handy romote module controls all func. thors, so once the main circuit breaker is closed. you can tum your attention to the exprerment A ten-loot cable connects the module to the power supply, keeping con. rot of lamn nnergy. pulse repetition rate. and 0 -swith firing at your fingertips

The DCR-: : ets you match the pulse width and timing to rour experimental needs its controls allow you to choose the Q-switch mode, repetitun rate, and whether or not to synchrorlze tiring with external events. Th, Q-swith mode cortrol allows $Q$. switched operation. long pulse operation withoutc switch or externaitriggeting spctronim with external events The r.ot. et"un ratw s.lector permits operat or d atz, syacmionous with the vrltace or uraiow electronic futer The variatite arettom ate sters accurate triggench

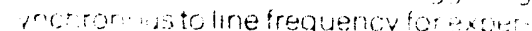
w...ts a . ng measurement of low - . . n
The connectors for external triggering are tocated on the power supply cabinet. Digtal mput circuls require standard TTL compatiole pulses and are overload protacted The high quality of synchronizaton outputs assure accurate triggering of externa! devices. System logic prevents problems caused by an improper turn on sequence

A toggle swith on the remote control module swiches the system between witch formans active under computer contor, woran inmediately restore man-

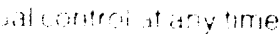
manual and computer control. Since the
The DCR-11 Can be Completely Computer Controlled

Complete automatıon of youi experıment or process is now available. Once the DCR. 11 is turned on, a toggle switch on the remote control module transfers control to your laboratory computer, which can then control and monitor all laser functions.

The system tests computer input for valid commands. An inadvertent computer program error will not harm the laser. If a control command is invalid. the DCR-11 sends an error message to the computer and halts optical output. Digital control commands are latched prior to lamp firing. which ensures that control parameters do not change during the firing sequence. All digital communications utilize standard TTL compatible signals and are transmitted via a parallel port for high speed data transter. All digital input circuits are optoisolated.

Analog strobing provides the option to sample analog control data during perı. ods of low electrical noise and hold it for subsequent firıng of the laser. Arialog input circuits employ differential amplifier signal processing to suppress noise pickup 


\section{DCR-11 System Accessories}

HG-2 Harmonic Generator

The HG-2 provides exceptionally efficient nonlinear wavelength conversion of the uniphase, diffraction-limited output beam of the DCR-11. The high energy output generates harmonics efficiently without the aid of beam focusing optics. Consequently, it is ideally suited for many research applications, particularly for pumping tunable dye lasers. In fact, it has ample pump energy to drive multiple dye cells, with sufficient fundamental and har. monic energy remaining for other experimental uses.

$K D^{*} P$ is the material of choice for harmonic gerieration because of its durability. The crystals in the HG-2, each cut to the proper phase-matching angle, are mounted in a temperature stabilized environment to prevent drifting of the output power. Simple mechanical translation of the crystals changes the wavelength of the output. A single knob adjusts the phasematching angle for maximum power at each stage of harmonic generation. (The fourth harmonic crystal is not temperature-controlled because it is operated close to its 90 phase matching angle.)

Output beam polarization can be conveniently rotated to any desired orientation. For maximum durability and performance, the HG-2 uses no index-matching fluids. Mechanical crystal mounts prevent contamination problems. Other important HG-2 features include: hermetically sealed optics, a purge port, a dessicant chamber. controlled back reflections.

Performance specifications of the HG-2 are shown in the table on page 7 .

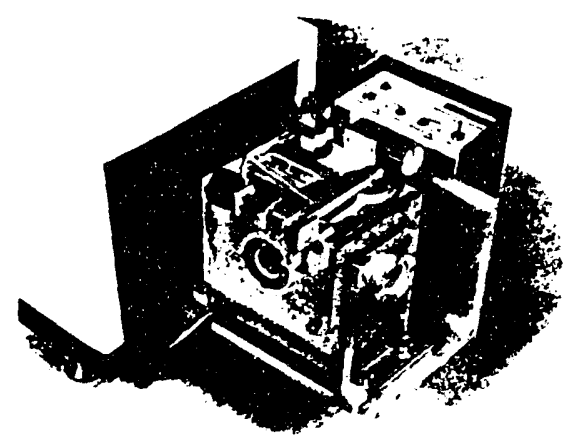

Figure 7: HG-2 Harmonic Generator
ELH-2 Electronic Line

Narrowing Accessory

The ELN-2, which is used in conjunction with the ICE-1, further reduces the linewidth of the fundamental to less than 0.02 $\mathrm{cm}^{-1}$. This exceptional performance is achieved through a novel method of electro-optic control of the pre-Q-switched gain of the DCR oscillator. The result is laser oscillation confined to a spectral linewidth less than $1 / 50$ of that of the DCR-11 alone. When the ELN-2 is used, the loss in output energy is less than $20 \%$.

Our tests have shown that more than $50 \%$ of the output pulses from the DCR are transform limited, i.e., they have a linewidth narrower than $0.002 \mathrm{~cm}^{-1}(60 \mathrm{MHz})$. Figure 9 shows both the time and frequency spectra of such a pulse. Those puises that are not single axial mode in character have higher frequency components that arise from intermode modulation of adjacent $\mathrm{c} / 2 \mathrm{~L}$ resonator modes. Consequently, the temporal pulse shape is structured, but even these pulses are contained in the overall multiple-pulse linewidth of less than $0.02 \mathrm{~cm}^{-1}$

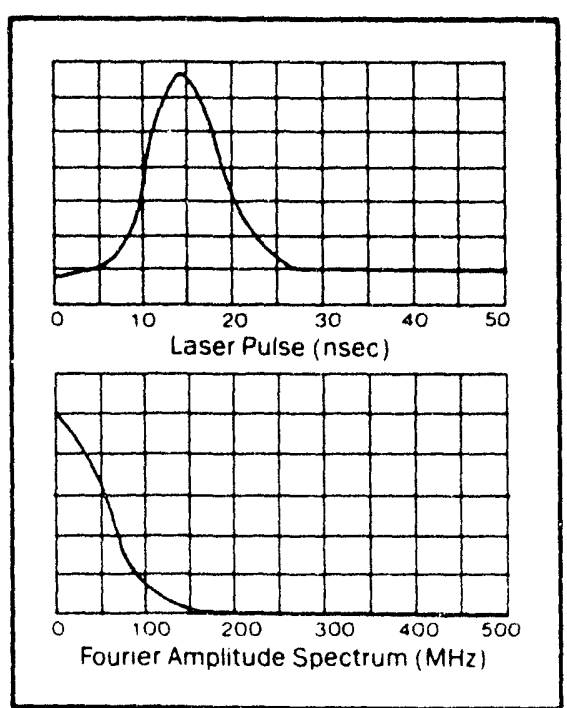

Figure 8: Time and Frequency Spectra of a Transform-limited Pulse
ICE-; Temperature Controlied

Intracavity Etalon

The ICE-1 reduces the linewidth of the DCR fundamental to less than $0.2 \mathrm{~cm}^{-1}$ Other etalons that narrow the linewidth even further are available by special or. der. While the insertion loss of the etalon is less than $10 \%$, a provision is made for easy removal from the intracavity space when your experiment requires maximum power instead of narrow linewidth.

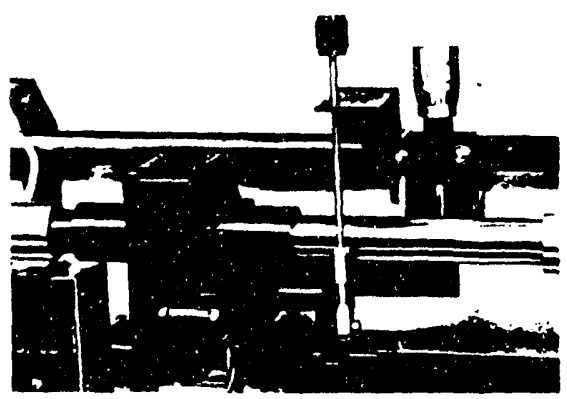

Figure 9: ICE-1 Intracavity Etalon

Additional Quanta-Ray " Accessories The DCR-11 is a compatible pump source for the PDL-2 pulsed dye laser, PDA-1 pulsed dye amplifier, RS-1 Raman shifter. and the WEX-1 wavelength extender. For more information about these products. contact your Spectra-Physics sales engineer. 


\section{DCR-11 System Performance}

Pulse Energy Stability

The histogram in Figure 10 demonstrates the pulse energy stability of the DCR-11 at $1064 \mathrm{~nm}$. Sample data was acquired at 10 Hz over 1.5 hours. More than 58,000 pulses were measured and sorted by a gated integrator/multichannel analyzer apparatus. Over $90 \%$ of the pulses were within $\pm 1 \%$ of the mean energy, and every pulse was within $\pm 2.3 \%$ of the mean.

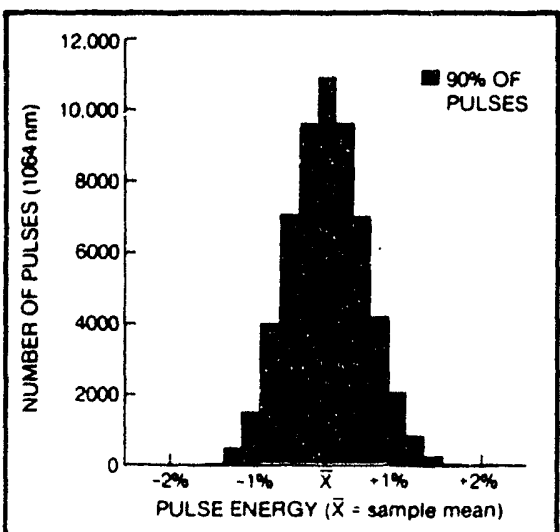

Figure 10: Histogram of Pulse Energy Stability

\section{Variable Pulse Width}

Figures 11 and 12 show the temporal waveforms of the $1064 \mathrm{~nm}$ laser puises measured by a fast photodiode. The hor:zontal scale is 5 nsec per large division for both photos. Figure 11 depicts the output when the DCR-11 is in the normal Qswitched mode, 8 nsec (nominal) pulse width, giving a peak power of $30 \mathrm{MW}$. Figure 12 shows the output in the fast $Q$. switch mode. Its 2.5 nsec (nominal) pulse width yields peak powers that approach $100 \mathrm{MW}$. The fast mode is useful in timeresolved spectroscopy, and is recommended for picosecond pulse amplification.

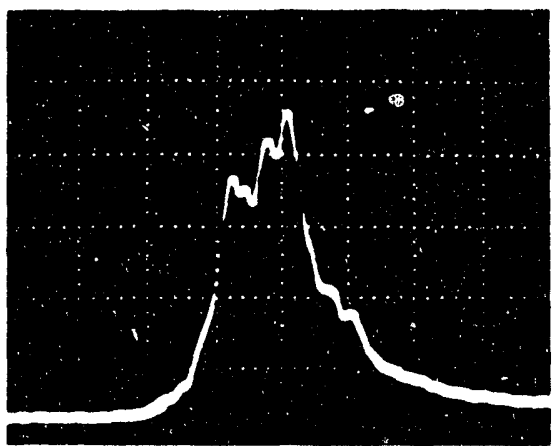

Figure 11: Temporal Protile of Output Pulse in Normal Q-switch Mode

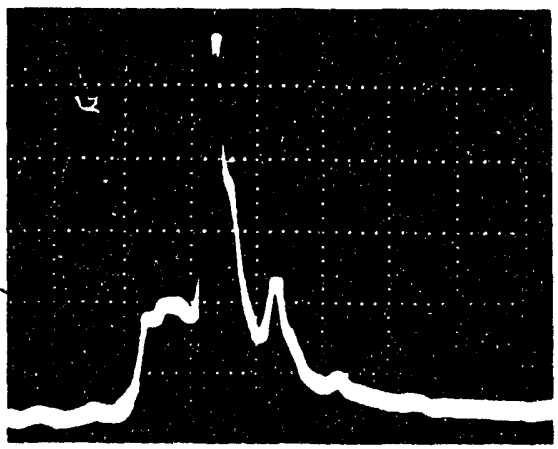

Figure 12: Temporal Proflie of Output Putse in Fast Q-switch Mode
Spatial Mode Pattern

Figure 13 shows the beam intensity pattern of the DCR-11 with its standard op tics. The inset is a two-dimensional spatial profile of a typical pulse. The remainder of the figure is an intensity distribution of a single laser pulse. For the latter a linear diode array was precisely placed in the center of the beam one meter from the output coupler. This cross section dem. onstrates the smooth intensity contour produced by the Quanta-Ray " diffraction coupled resonator.

Filled-in-beam (FIB) optics are avallable for applications requiring energy in the center of the beam. Quanta-Ray' holds the patent for use of unstable resonator optics in solid-state lasers (U.S. patent number $4,310,808$ ).

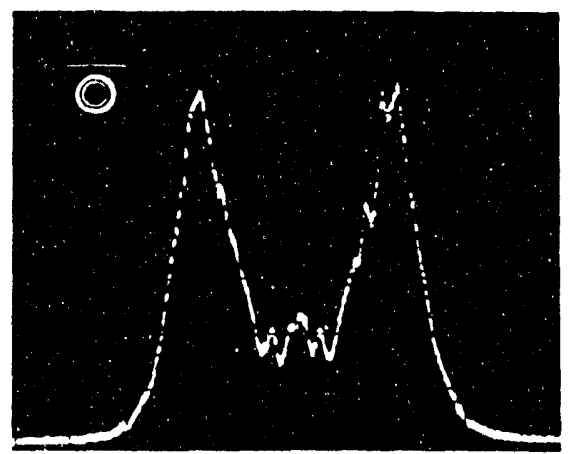

Figure 13: Spatial Characteristics of a Typical Pulse 


\section{Specifications}

\begin{tabular}{|c|c|c|c|c|}
\hline & $1064 \mathrm{~nm}$ & $532 \mathrm{~nm}$ & $355 \mathrm{~nm}$ & $266 \mathrm{~nm}$ \\
\hline $\begin{array}{l}\text { Pulse Width } 2 \text { (nsec) } \\
\text { Pulse Energy (mJ) }\end{array}$ & 8.9 & $6-7$ & $5-6$ & 4.5 \\
\hline DCR-11-2 & 275 & 135 & 60 & 30 \\
\hline DCR $-11-3$ & 320 & 155 & 70 & 35 \\
\hline Puise Energy Stability & $\pm 4 \%$ & $\pm 7 \%$ & $\pm 10 \%$ & $\pm 15 \%$ \\
\hline Pulse Repetition Rate & \multicolumn{4}{|c|}{$10 \mathrm{~Hz}$ optimum, $1-14 \mathrm{~Hz}$ range } \\
\hline Output Pulse Jitter & \multicolumn{4}{|c|}{$<0.5$ nsec (rms) from sync pulse } \\
\hline Spatial Mode & \multicolumn{4}{|c|}{$\begin{array}{l}\text { Diffraction coupled, uniphase, nearly } \\
\text { diffraction limited, } 6.4 \mathrm{~mm} \text { diameter }\end{array}$} \\
\hline Linewidth & \multicolumn{4}{|c|}{$\begin{array}{l}<1.0 \mathrm{~cm}^{-1} \text { at } 1064 \mathrm{~nm} \\
<0.2 \mathrm{~cm}^{-1} \text { at } 1064 \mathrm{~nm} \text { with optional ICE-1 } \\
<0.02 \mathrm{~cm}^{-1} \text { at } 1064 \mathrm{~nm} \text { with optional ELN-2 }\end{array}$} \\
\hline Flashlamp Lifetime & \multicolumn{4}{|c|}{$>10^{7}$ pulses } \\
\hline $\begin{array}{l}\text { Linear Polarization } \\
\text { DCR-11-2 } \\
\text { DCR-11-3 }\end{array}$ & \multicolumn{4}{|c|}{$\begin{array}{l}>96 \% \text { at } 1064 \mathrm{~nm} \\
>92 \% \text { at } 1064 \mathrm{~nm}\end{array}$} \\
\hline Average Power Stability & \multicolumn{4}{|c|}{$\begin{array}{l}5 \% \text { per } 10 \mathrm{hr} \text { at } 1064 \mathrm{~nm}, 532 \mathrm{~nm} \text {, } \\
\text { or } 355 \mathrm{~nm} \text { with optional } \mathrm{HG}-2\end{array}$} \\
\hline Beam Divergence & \multicolumn{4}{|c|}{$<0.5 \mathrm{mrad}$} \\
\hline Beam Pointing Stability & \multicolumn{4}{|c|}{$<0.5 \mathrm{mrad}$} \\
\hline Electrical Requirements ${ }^{3}$ & \multicolumn{4}{|c|}{$\begin{array}{l}208 \text { or } 220 \mathrm{~V} \text { (nominal), } \\
\text { single phase } 10 \mathrm{~A}, 50 / 60 \mathrm{~Hz}\end{array}$} \\
\hline $\begin{array}{l}\text { Dimensions: } \\
\text { Laser Head } \\
\text { Laser Head with } H G-2^{4} \\
\text { Power Supply }\end{array}$ & \multicolumn{4}{|c|}{$\begin{array}{l}83.8 \times 22.9 \times 26.7 \mathrm{~cm}(33.00 \times 9.00 \times 10.51 \mathrm{in} .) \\
102.2 \times 22.9 \times 26.7 \mathrm{~cm}(40.25 \times 9.00 \times 10.51 \mathrm{in.}) \\
49.5 \times 59.1 \times 55.8 \mathrm{~cm}(19.50 \times 23.25 \times 21.98 \mathrm{in} .)\end{array}$} \\
\hline $\begin{array}{l}\text { Weight: } \\
\text { Laser Head } \\
\text { Power Supply }\end{array}$ & \multicolumn{4}{|c|}{$\begin{array}{l}25 \mathrm{~kg}(55 \mathrm{lb}) \\
68 \mathrm{~kg}(150 \mathrm{lb})\end{array}$} \\
\hline Umbilical Length & \multicolumn{4}{|c|}{$305 \mathrm{~cm}(10 \mathrm{ft})$} \\
\hline
\end{tabular}

1 Specifications sublect to change without nolice. Uniess stated olnerwise, specilicalions apply to both versions.

2. Short pulse mode. included at 10 extra cost, ceduces out ie width by a factor of about three (10 $2.5 \mathrm{nsec}$ at $1064 \mathrm{~nm}$ ) and recfuces puise energy approximately $10 \%$.

3 Input transformer has taps at 190. 209. 220. and $240 \mathrm{~V}$ Once a tap is chosen, actual input voltage diflering oy mote than $+5 \%$ trom norninal vollage may affecl operation of the laser

4 Hergh of lasel head given with adjustable teet at the middle of their range $1+0.5 \mathrm{~cm}$. $020 \mathrm{in}$,

\section{Warranty}

Spectra-Physics products are protected by a one-year warranty. All mechanical. electronic, and optical parts and assem. blies are unconditionally warranted to be free of defects in workmanship and mate. rial for the first year following delivery. This warranty is in lieu of all other warranties. express or implied. and does not cover inc Jental or consequential loss.

\section{Laser Safety}

Spectra-Physics has worked closely with federal agencies to promote the safe use of lasers and has designed this product to comply with the Center for Devices and Radiological Health (CDRH) standards now in effect in the United States.

A CORH warning logotype, similar to that shown here, appears on each laser to indicate the CDPH classification and to certify that the output power of the laser will not exceed the power level printed on the logotype.
DANGES

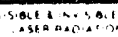

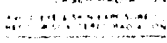
$\because \ldots$ 

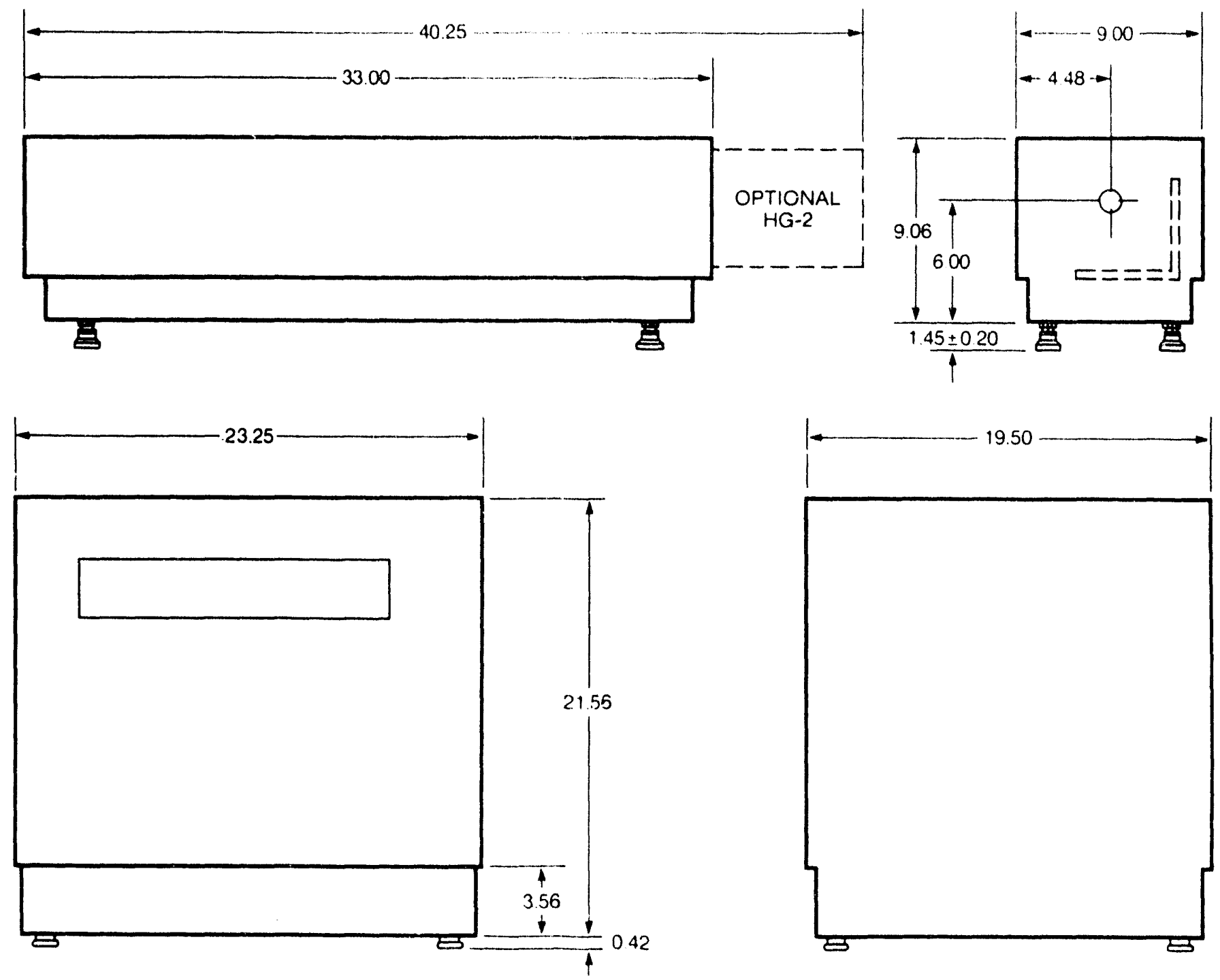

\begin{tabular}{|c|c|c|c|c|}
\hline \multirow{4}{*}{$\begin{array}{l}\text { Laser Products Division } \\
\text { Customer Service } \\
1250 \text { W. Middiefield Rd } \\
\text { P.O. Box } 7013 \\
\text { Mountain View, CA } 94039-7013 \\
\text { Telephone (toll free): } \\
\text { (800) } 227-8054 \\
\text { Telex: } 348-488 \\
\text { Fax: (415) } 969-4084\end{array}$} & \multirow{3}{*}{$\begin{array}{l}\text { Reglonal Sales and } \\
\text { Service Centers } \\
\text { Eastern Uniled States } \\
366 \text { S. Randoiphville Rd } \\
\text { Piscataway. NJ 08854-4175 } \\
\text { Telephone (NJ). } \\
\text { (201) } 981-0390 \\
\text { (Outside NJ) } \\
\text { (800) } 531-5693 \\
\text { Fax: (201) } 981-0029\end{array}$} & $\begin{array}{l}\text { Spectra-Physlcs B.V.B.A. } \\
\text { North Trade Building } \\
\text { Noorderlaan } 133 \\
2030 \text { Aniwerp } \\
\text { Belgium } \\
\text { Telephone (03) } 542-6203 \\
\text { Telex } 34467\end{array}$ & $\begin{array}{l}\text { Spectra-Physics S.R.L. } \\
\text { Via Derna } 1 \\
\text { 1-20132 Milano } \\
\text { traly } \\
\text { Telephone }(02) 2853665 \\
\text { or (02)2841568 } \\
\text { Telex } 351483\end{array}$ & \multirow[t]{2}{*}{$\begin{array}{l}\text { Spectra-Physics AG } \\
\text { Schweizergasse } 39 \\
4054 \text { Basel } \\
\text { Switzerland } \\
\text { Telephone } 061,541154 \\
\text { Telex } 64335 \\
\text { Canada, Latin America, } \\
\text { Pacilic Areas }\end{array}$} \\
\hline & & Spectra-Physics, Lid. & Spectra-Physics K.K. & \\
\hline & & & $\begin{array}{l}\text { 15-8 Nanpeidal-cho } \\
\text { Shibuya-ku } \\
\text { Tokyo } 150\end{array}$ & $\begin{array}{l}\text { Spectra-Physics International } \\
1250 \mathrm{~W} \text { Middlefield } \mathrm{Rd} \\
\mathrm{P}\end{array}$ \\
\hline & $\begin{array}{l}\text { Spectra-Physics Pty. Lid. } \\
826 \text { Mountain Highway } \\
\text { Bayswater. Victoria } 3153 \\
\text { Australia }\end{array}$ & $\begin{array}{l}\text { England } \\
\text { Telephone }(0442) 232322 \\
\text { Telex } 826411 \\
\text { Fax }(0442) 68538\end{array}$ & $\begin{array}{l}\text { Japan } \\
\text { Teiephone } 103,770-5411 \\
\text { Telex } 2466976 \\
\text { Fax (03) } 770-4197\end{array}$ & $\begin{array}{l}\text { Mountain View CA } 94039.7013 \\
\text { Teleonone (A15) } 961.2550 \\
\text { Telex } 348-488 \\
\text { Fax } 415,969.4084\end{array}$ \\
\hline $\begin{array}{l}\text { Spectra-Physics GmbH } \\
\text { Siemensstrasse } 20 \\
\text { D-6100 Darmstadt } \\
\text { F.R. Germany } \\
\text { Telephone: }(06151) 708-0 \\
\text { Telex: } 419471 \\
\text { Fax: }(06151) 708-232\end{array}$ & $\begin{array}{l}\text { Telephone (61) } 3-7295155 \\
\text { Telex AA } 33498 \\
\text { Fax }(61,3-7204256\end{array}$ & $\begin{array}{l}\text { Spectra-Physics S.A. } \\
\text { Avenue de Scandinavie } \\
\text { ZA de Courtaboeut } \\
\text { BP } 28 \\
91941 \text { LES IIt.1S Cedex } \\
\text { France } \\
\text { Telephone } 169079956 \\
\text { Telex } 691183 \\
\text { Fax } 6907 \text { b0 } 93\end{array}$ & $\begin{array}{l}\text { Spectra-Physics B.V. } \\
\text { Prot Dr Dorgelotaan } 20 \\
\text { PO Box } 2264 \\
5600 \text { CG Eindnoven } \\
\text { The Netherlands } \\
\text { Telephone } 10401451855 \\
\text { Telex } 51668\end{array}$ & \\
\hline
\end{tabular}

- 1988 Specira-Physics Inc 


\section{LASER SPECIFICATIONS}

Continuum YG-600 Nd:YAG lasers

C. 13 


\section{Quantel International \\ YG660 Series Datasheet}

(All specifications at $1064 \mathrm{~nm}$ unless otherwise noted)

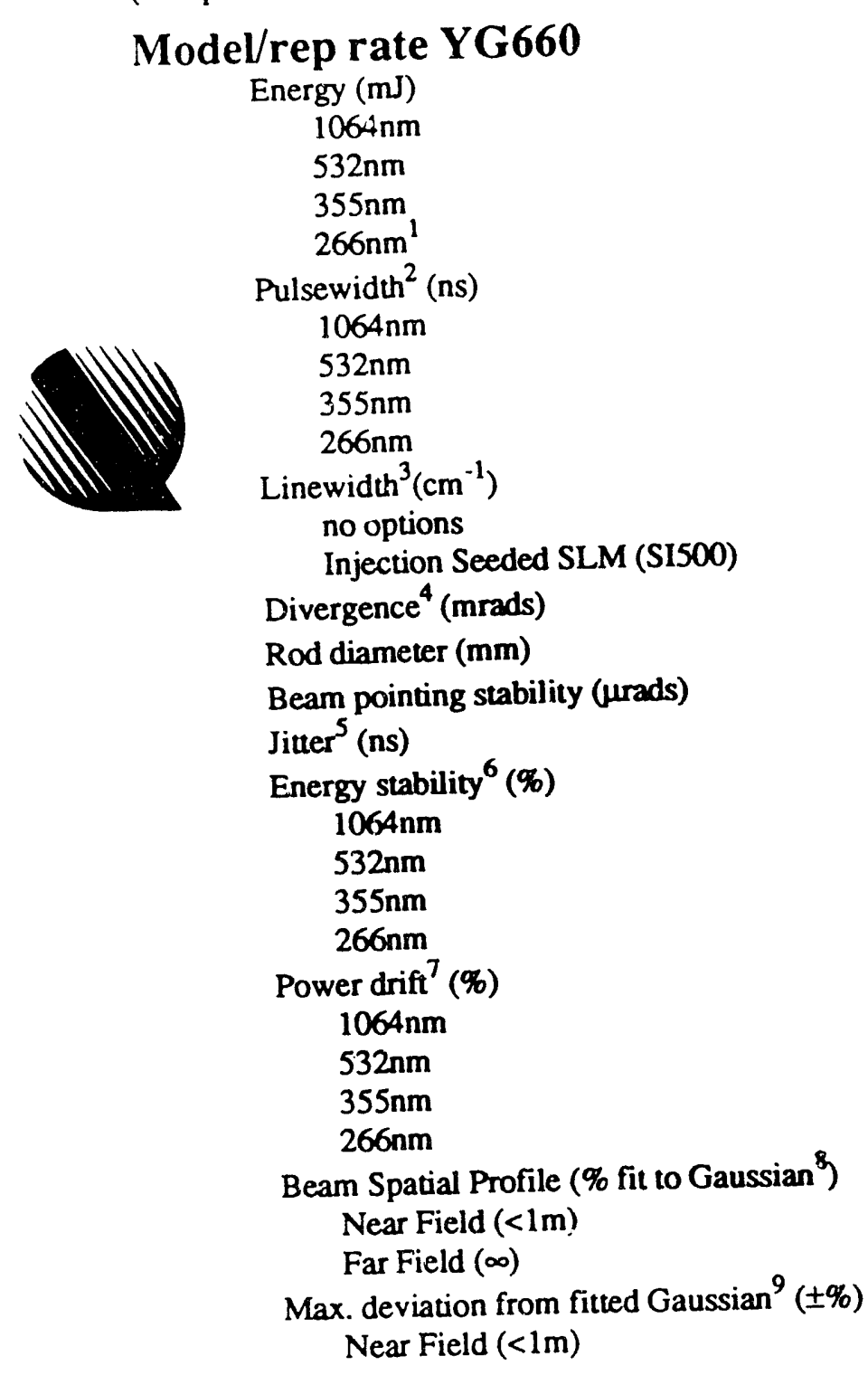

\begin{tabular}{|c|c|c|c|}
\hline$-10 \mathrm{~Hz}$ & $-20 \mathrm{~Hz}$ & $-30 \mathrm{~Hz}$ & $-50 \mathrm{~Hz}$ \\
\hline 250 & 225 & 210 & 200 \\
\hline 100 & 80 & 65 & 60 \\
\hline 45 & 35 & 25 & 20 \\
\hline 15 & 10 & 8 & 6 \\
\hline $5-7$ & $5-7$ & $6-8$ & $6-8$ \\
\hline $4-6$ & $4-6$ & $5-7$ & $5-7$ \\
\hline $4-6$ & $4-6$ & $5-7$ & $5-7$ \\
\hline $3-5$ & $3-5$ & $4-6$ & $4-6$ \\
\hline 1.0 & 1.0 & 1.0 & 1.0 \\
\hline 0.006 & 0.006 & 0.005 & $0.00 \mathrm{~s}$ \\
\hline 0.5 & 0.5 & 0.5 & 0.6 \\
\hline 6 & 6 & 6 & 6 \\
\hline 250 & 250 & 350 & 400 \\
\hline 0.5 & 0.5 & 0.6 & 0.6 \\
\hline 2.5 & 2.5 & 3.0 & 3.0 \\
\hline 3.5 & 3.5 & 4.5 & 4.5 \\
\hline 4.0 & 4.0 & 5.0 & 5.0 \\
\hline 10 & 10 & 12 & 12 \\
\hline 3.0 & 3.0 & 3.0 & 3.0 \\
\hline 5.0 & 5.0 & 6.0 & 6.0 \\
\hline 5.0 & 5.0 & 6.0 & 6.0 \\
\hline N/A & N/A & N/A & N/A \\
\hline 0.70 & 0.70 & 0.70 & 0.70 \\
\hline 0.95 & 0.95 & 0.90 & 0.90 \\
\hline 30 & 30 & 35 & 35 \\
\hline
\end{tabular}

With temperature phase matched quadrupling.

Full Width Half Maximum.

FWHM $1 \mathrm{~cm}^{-1}=30 \mathrm{GHz}$.

Full angle for $86 \%$ energy.

With respect to external trigger \pm ins with SI 500 option.

\pm shot-to-shot for $99.9 \%$ of pulses.

\pm from average for 8 hours.

A least squares fit to a Gaussian profile. A perfect fit would have a coefficient of 1 .

At beam center. 


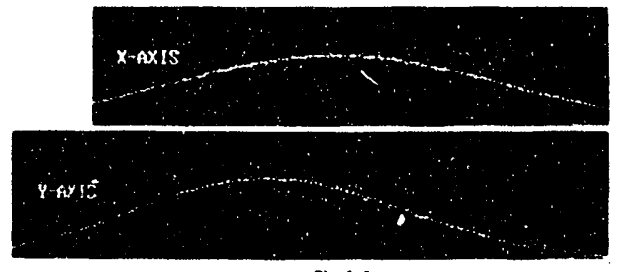

near field

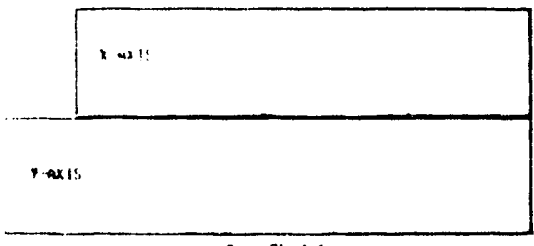

far ficld

Beam Temporal Profile

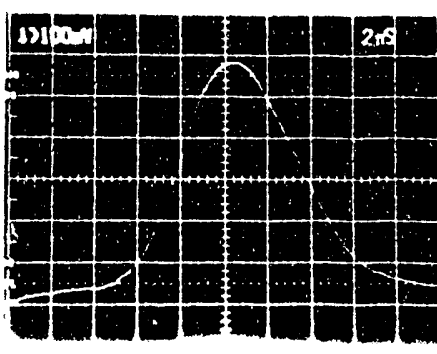

seeded

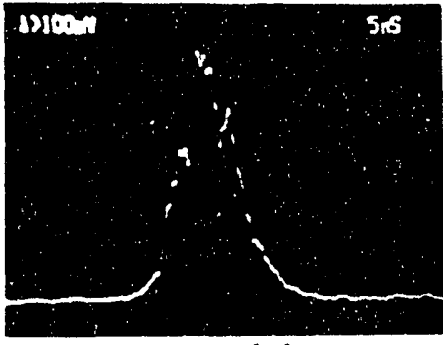

unsceded

Optical Layout

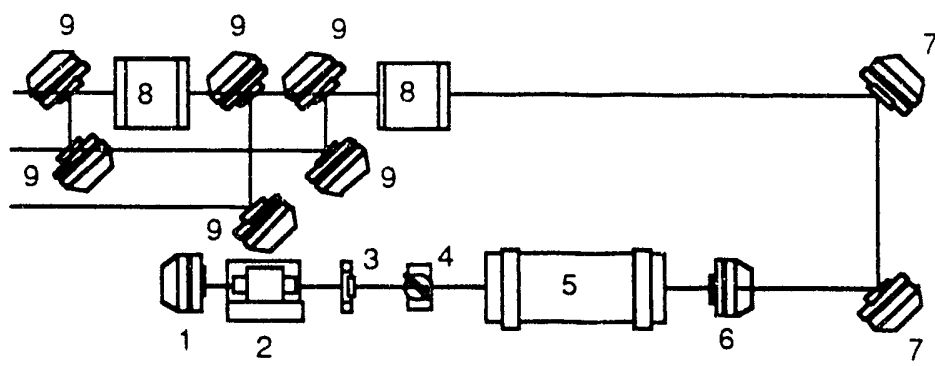

\author{
1) Rear mirror \\ 2) Pockels cell Q-switch \\ 3) Quarter-wave plate \\ 4) Polarizer \\ 5) $6 \mathrm{~mm} \mathrm{Nd:YAG}$ \\ 6) Gaussian m uror output coupler \\ 7) Tuming mirrors \\ 8) Hamonic generators \\ 9) Dichroic separation
}

\title{
Physical Layout
}
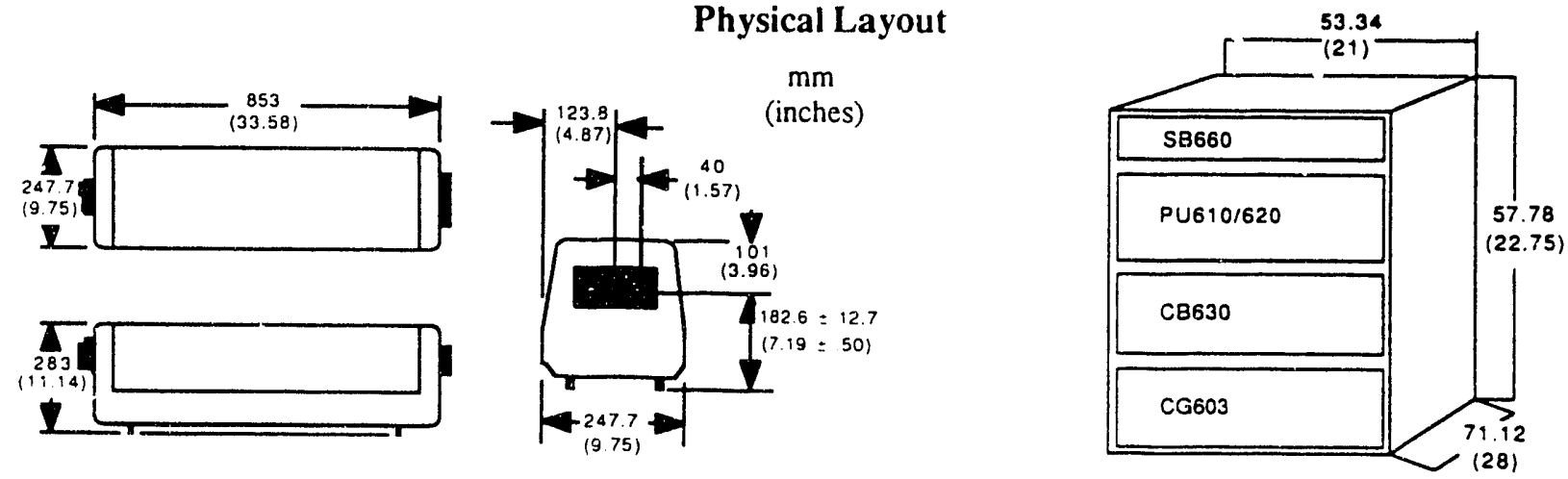

Quantel International 3150 Central Expressway Santa Clara, CA 95051

Phone: 408-727-3240

FAX: 408-727-3550
Scrvice Requirements

Power: 208V, 3 phase, 12A/phase; 220V/20A single phase Water: 3-4GPM@ @0-60 PSI 


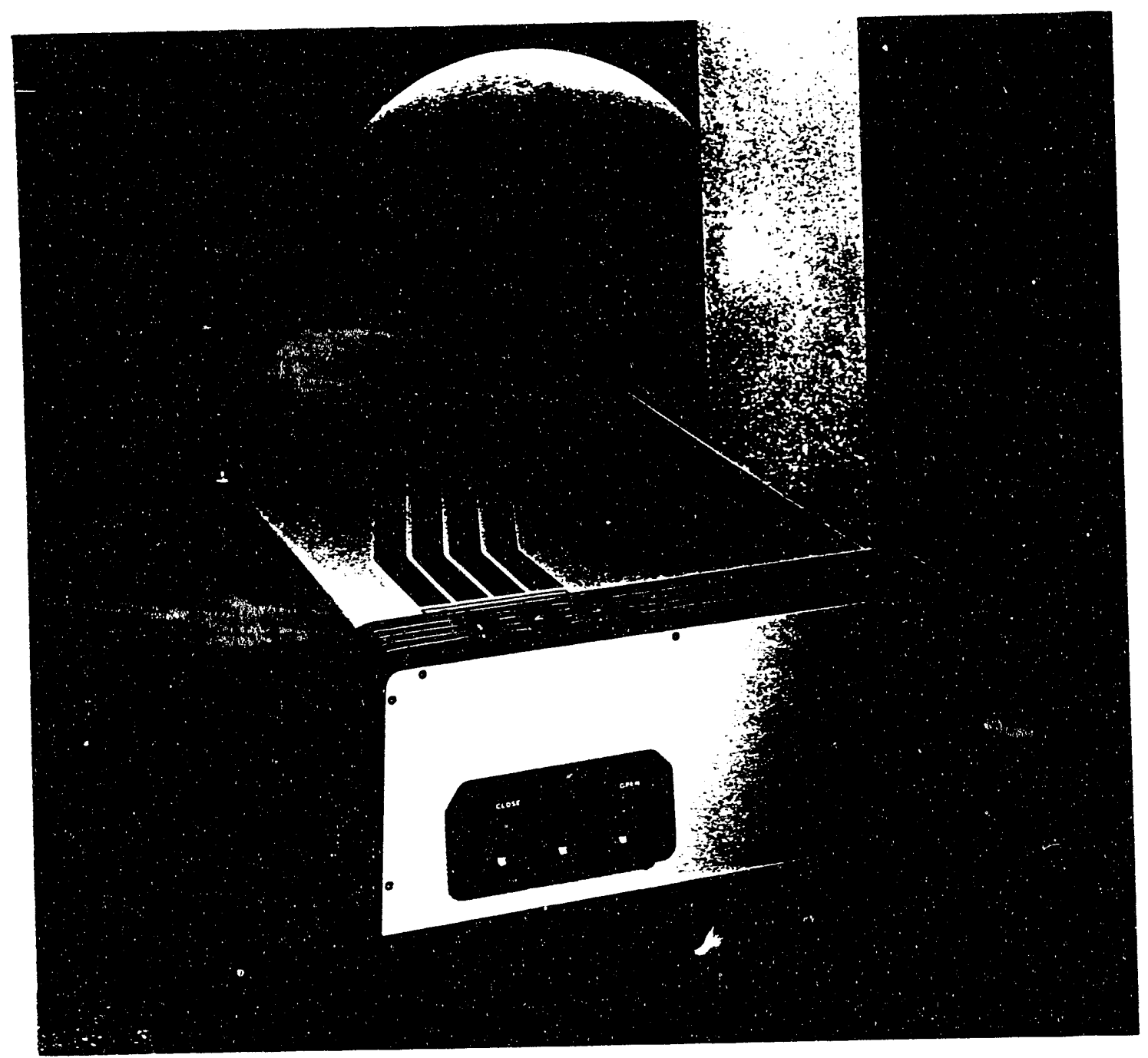

e Continuun

THE YG 600 SERIES.

HIGH PERFORMANCE

ND:YAG LASERS. 


\section{Presenting the YG 600 Series:}

our third generation of Nd:YAG lasers.

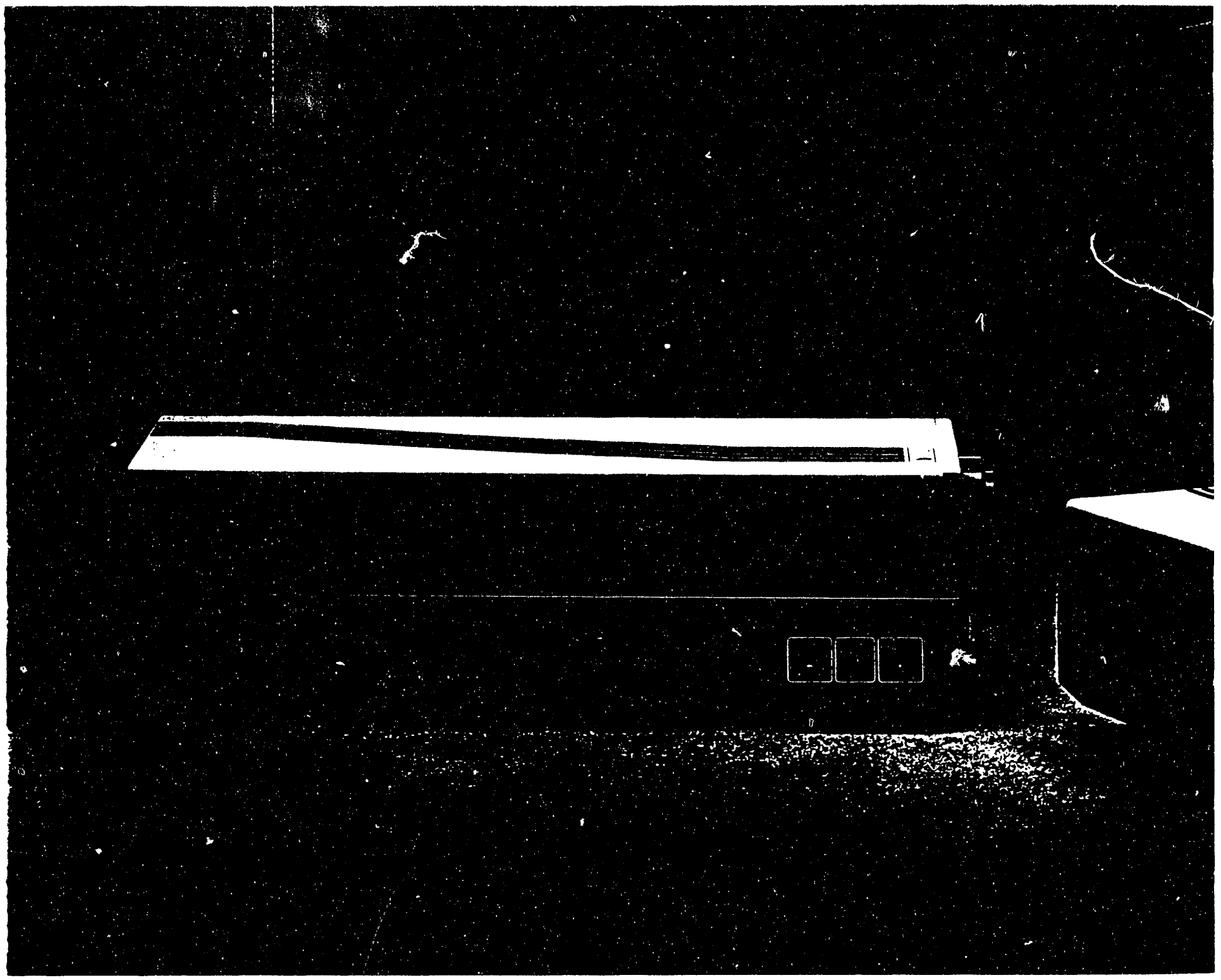




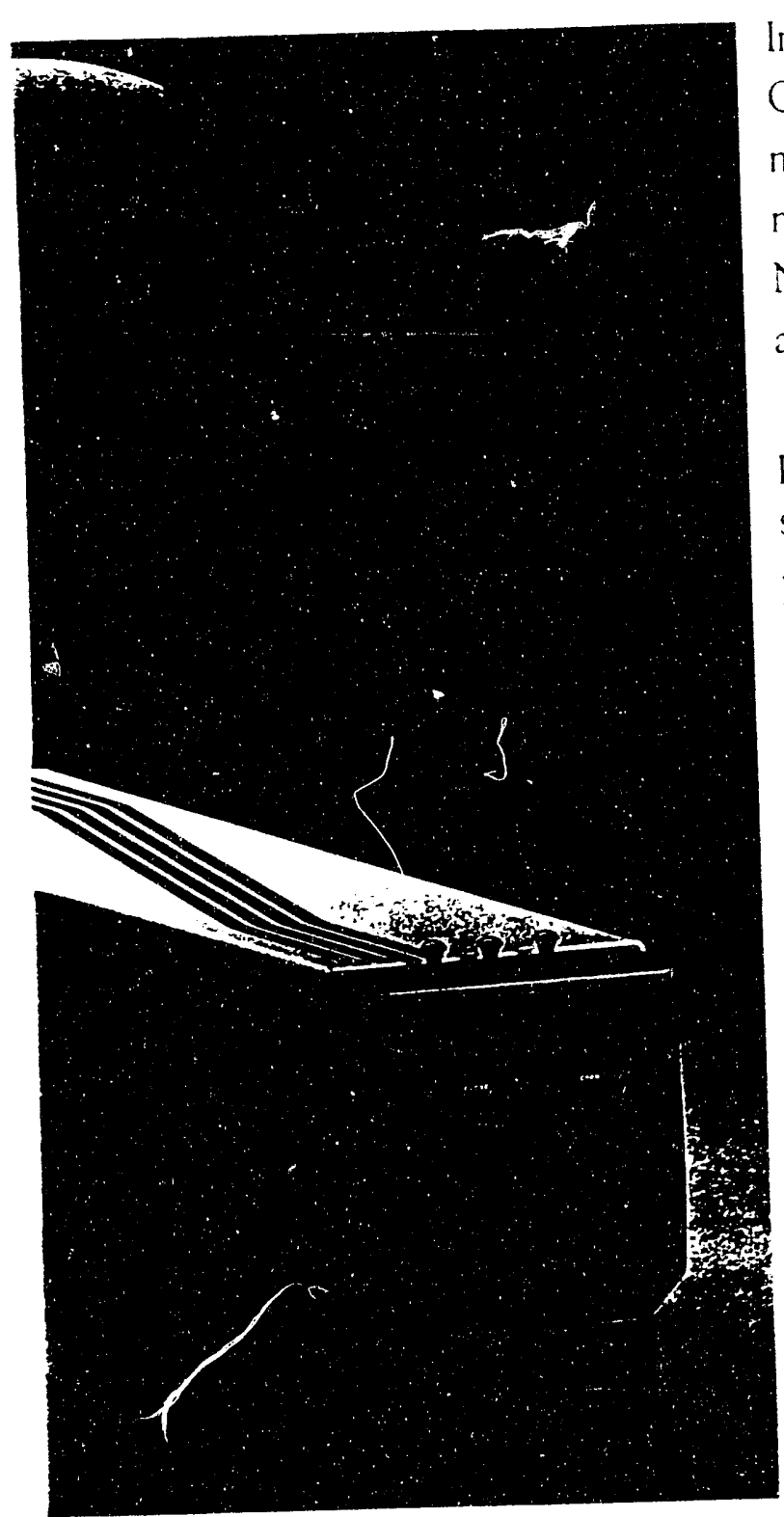

In succeeding the $Y G 400$ and $Y G 500$, Quantel's YG600 series draws on more than a dozen years in designing, manufacturing and supporting pulsed Nd:YAG lasers for a host of high power applications.

As the world's only established company dedicated to pulsed solid-state systems, we stand uniquely suited to provide a global customer base with products and service unexcelled. - Across the board-the highest performance specifications of any commercial Nd:YAG products - The industry's best warranty and warranty renewal plan -Revolutionary packaging requiring half the space of competitive products Standard systems include oscillator only, oscillator/amplifier, and oscillator/ dual amplifier systems.

Custom Nd:YAG laser systems are available: Quantel remains the most diversely capable provider of pulsed solid-state lasers in the world. 


\section{We designed the YG 600 Series with the laser end user in mind.}

The first thing you'll notice about the YG600 series lasers is their size; they are $50 \%$ smaller than competing designs. This tangible difference gives the first indication of a product line completely re-engineered to keep pace with today's changing laboratory environment.

\section{OPTICAL ASSEMBLY}

When you remove the top cover and the sealed internal covers you'll notice the absence of steel from the resonator assembly-in its place graphite-stiffer and more stable than Invar assuring unsurpassed long term stability.

The laser heads offer easy accessa quick lock releases the heads from their kinematic mounts for convenient lamp replacement with no realignment recyuired.

The high efficiency evidenced in our SF600 series heads allows operation at roughly half the pump level of compering prociucts. Reducing the thermal loading on the rods promotes optimum beam cuality and harmonic conversion efficiency by minimizing the thermally-induced birefringence-this at repetition rates to $50 \mathrm{~Hz}$.

The flashlamps are simmered ensuring
The YG600 design reflects our customers' concern for ease of operation. Easy accessibility within a modular framework re. sults in minimal downtime for both occasionat and routine maintenanra

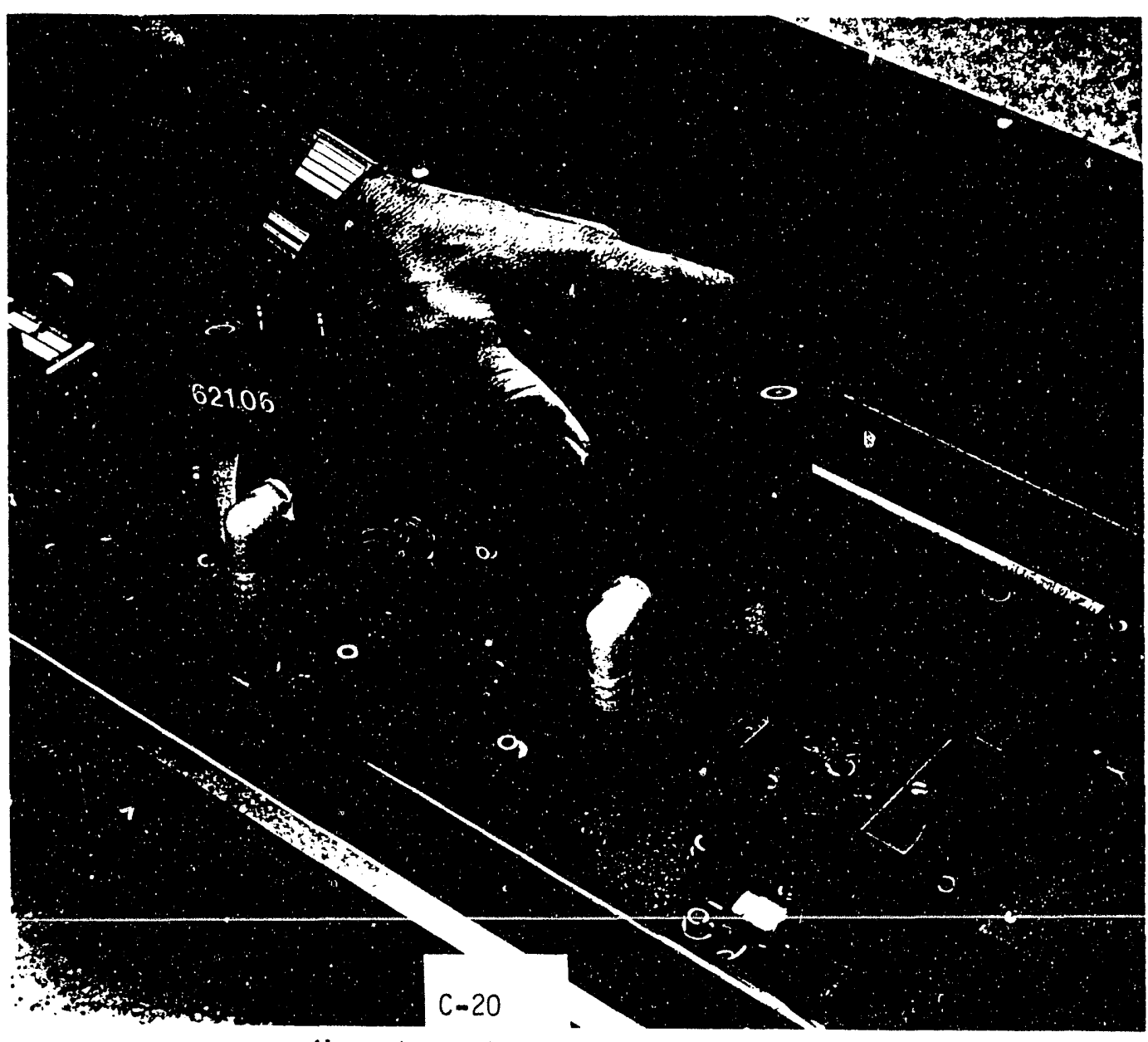

Beam spatlal p'rolile 
quiet, reproducible pumpung with lifetmes rated at 30 million shots. It is noteworthy that our largest standard sistem (YG682) contains but (3) linear flashlamps while the YG661 generates more than 18 watts at $1064 \mathrm{~nm}$ from a single xenon lamp.

Rod diameters from $6 \mathrm{~mm}$ to $9.51 \mathrm{~mm}$ are standard within the $Y G 61)($ ) series and Quantel offers the option of $12.7 \mathrm{~mm}$ Nd:YAG amplifiers on a custom basis.

\section{POWER SUPPLY}

Notice how the power supply is sized to allow convenient storage beneath a standard optical bench, thus minimizing its encroachment on the laboratory.

The redesigned PFN fearures fastswitching capacitor charging units designed around industrial grade MOSFETs for high efficiency and uncompromised reliability:

Two control units are offered: one featuring microprocessor logic is fully $\mathrm{PC}$ compatible. The optional RB02 remote unit allows user control of all laser parameters including:

\section{- Start/Stop}

- Program number of shors in a scan

- Change laser repetition rate

- alter pulse-width

- Tune harmonic generators

These same parameters can be controlled from any PC comparible computer through the RS3232 interface.

For the high energy sistems YCG YG682) an electronic power attenuator

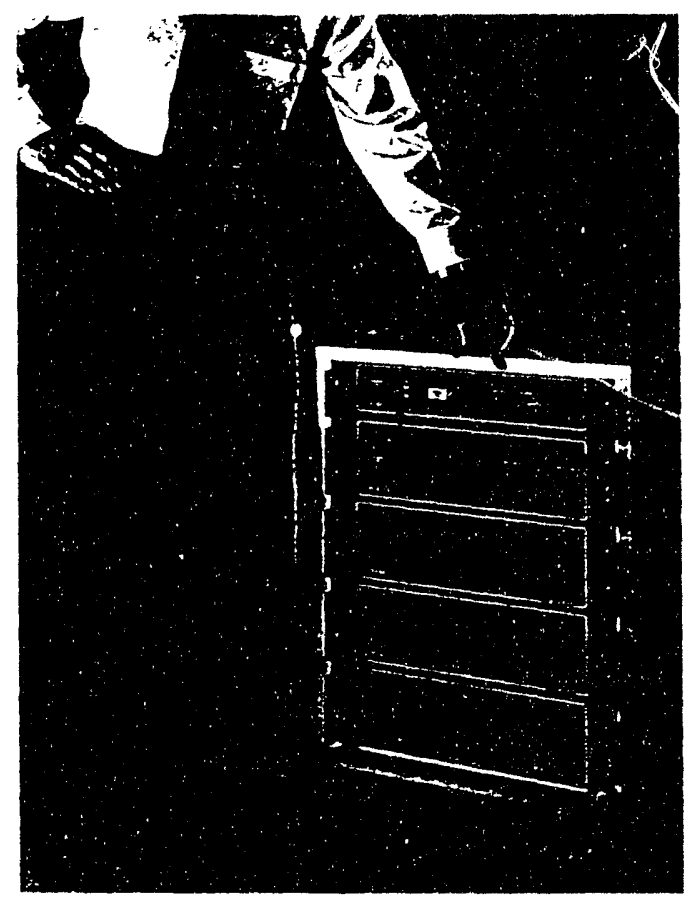

allows the user conventent adiustment of the laser outpur with minmal effect on other laser parameters.

In designing and engineerment the $Y(, 6)(x)$ series we have relicd heavily on input from the laser user communiry. Judge tor wourself and see if you don tomeur that user orientation results in a superior product.
The poner sisipl, picturea: is that of the :ardiest lay... whin the YGGootamil. Control power energy sturage and cooling are functions of rach mounted subassemblies peemit. ting great fexbrility in system design.
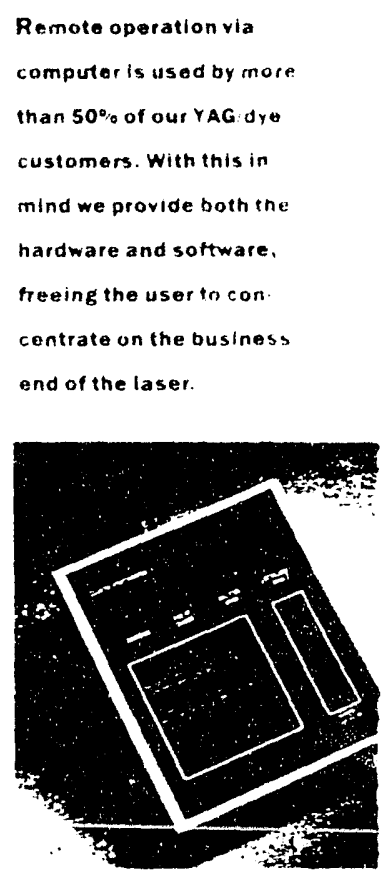


\section{From the performance leader, Q-switched lasers which clearly set the standards.}

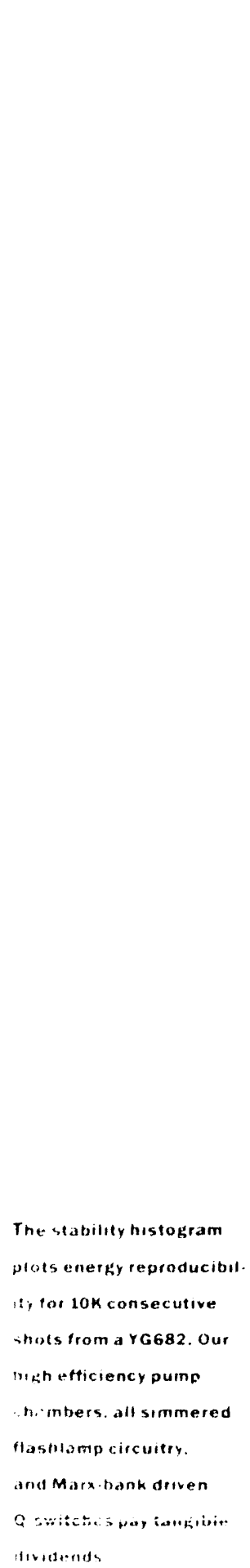

ONERGENCESPOIMUMG STABILTY

Thus same diagnowas package allow's us to roution lv measure the intrinsk divergence which we will guarantere at less than 2 mmes the diffraction limit for all models) and the beam pointung stability as - $250 \mathrm{p}$ rads.

It is notcworthy that our divergence speccification is tor a gaussian beam rather than an airy disc. In comparing Quantels beam divergence with those from diffraction coupled resonators, note that the minimum spot size achievable with our systems is smaller by nearly a factor two.

\section{ENERGY}

The YG682 delivers more than 140() $\mathrm{mJ}$ at $1064 \mathrm{~nm}$, more than $750 \mathrm{~mJ}$ at $5.32 \mathrm{~nm}$ for 10 Hzoperation. The short pulse-widths, low divergence and unitorm near field energy distribution enable us to guarantec more than $280 \mathrm{~mJ}$ at $35.5 \mathrm{~nm}$ using standard KD P crystals in temperamure stabilized housings. All YGG(0) series lasers ordered with fourth harmonic generators come equipped with temperature phasematching.

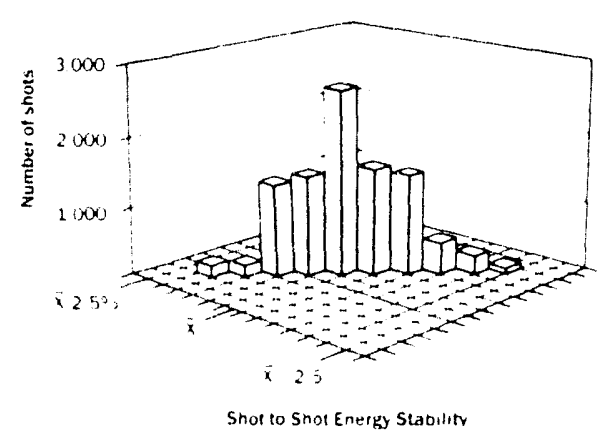

The resomator employed in all YCigo() series stesems produces hole-tree unitorm

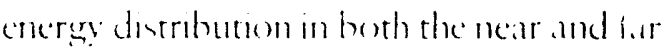
field. Fis. I shows a i Dimensomal portrat ot the YCigho at a range of imeters usme Beameode: Amplified ystems will exhohit

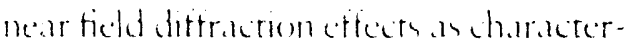

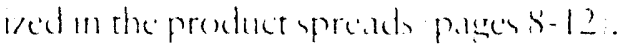

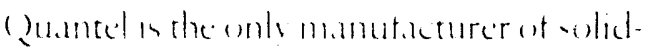

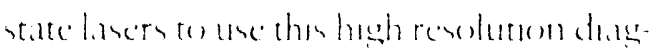

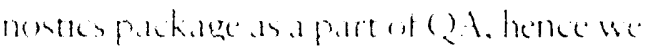

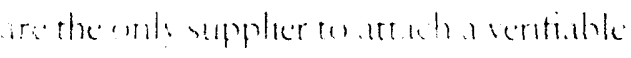

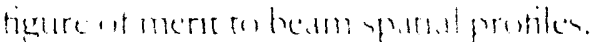




\section{STABILIT}

The histogram of Fig. 2 shows the reprosdecibilies for formen shete to be less than

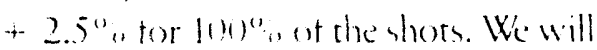
guarantee this level of pertormance for all YGhon arenesistems.
Our speciticatom on drotes lese than $+4 " \%$ for the tund.ument.1 output, less th.m1 + 5" therd harmomss.

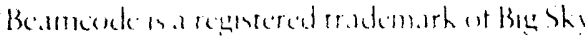
soliware.
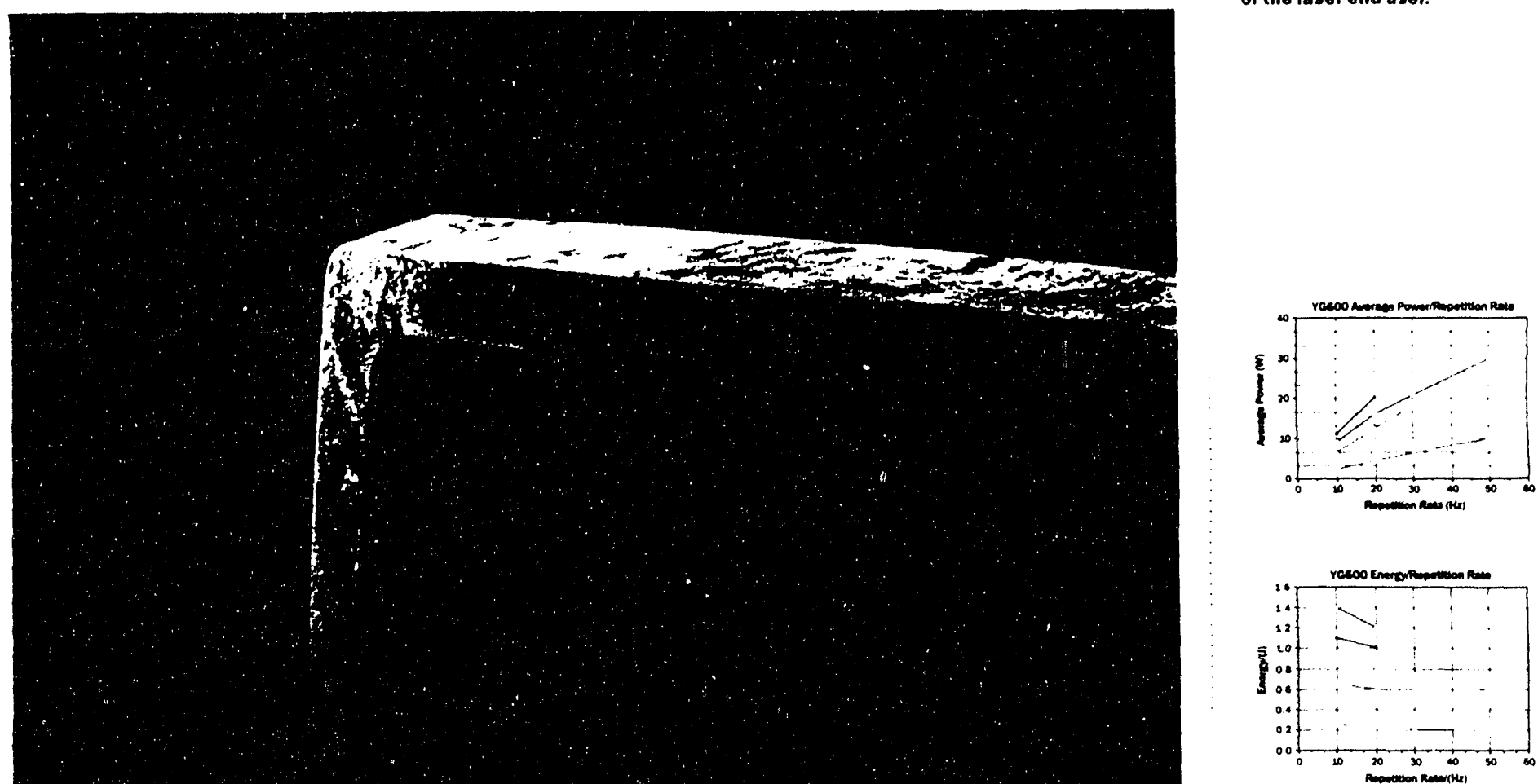

Fig. 1 


\section{Quantel International's unique Gaussian-coupled resonator: The no-compromise solid state solution.}

The heart of any high powered Nd:YAG laser is the oscillaror. Developed specifically for injection seeding and now offered as standard on all Y $G 600)$ series, Quantel's V-ROC resonator has in the short time since its introduction become the standard by which all others must be compared. framework has tor the Y'C GSOI) series been upgraded by subsntuning graphite for Invar. This design allows tor thermal expansion without applying me thanical constraints to the graphite rods whoh ofter increased rigidity over their Invira counterparts.

A Marx bank drives the Pockets cell

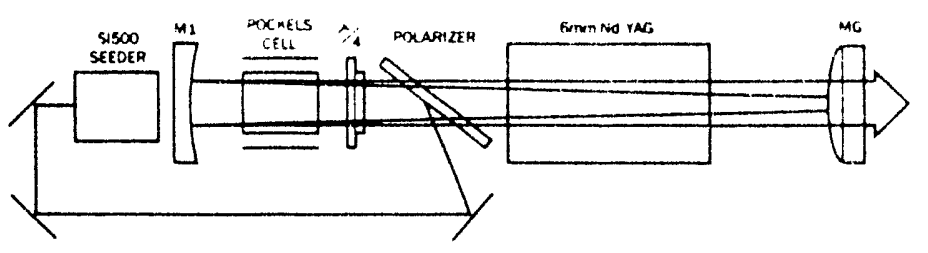

Quantels V.ROC Resonator shown wtth injection Seeding

(Q-switch on all YG600) veres models. This is a 7.ro Volt DC bias trigger which assures long lifetime and crisp operation with $<5())$ ps jitter for

unseeded lasers, < lns

This unique design, 2 years in development utilizes a varrable reflective output coupler-the Galussian mirror-to provide no-compromise pertormance:

- High energy/ Hich peak power

- Near diffraction limited focusability

- Uniform spatial profile near and far field -Available with 3 linewidth options including SL.M on all models

The V-ROC oscilliator though geometrically unstable is made optically stable by the unique properties of the Gaussian mirror." As the intra-cavity beam encounters $\mathrm{Mg}$ ir is trianstormed upon reflection into a beam with the same TE.Moo spatial characteristics bur wirh reduced size. This enables large intra-ioniry mode volume therefore efficient enerere extracton from what is phr sicalls a serv shore resemater $1<50 \mathrm{~cm})$. The omall a aze promotes short pulsewidths and excellent day to day stability.

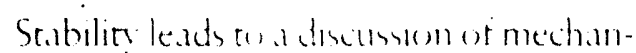
ics where our "rionome" $i$ bar reson.tor jitter when injecton seeded. Hold-olf against free-runnung conventonal mode lasing) is provided lyy a cuarter-wave plate in series with high contriast pollarizers.

Compare ours ro nether dengens delivering low order beams at the expense of beam spatial uniformiry or uniform beams which are in fact mulcimode. See if you don't agree-there's no comparison to the no compromise solution. V-ROC...only from Quantel where a strong commitment to R\&D combuned with the compuny's

Fr..: :

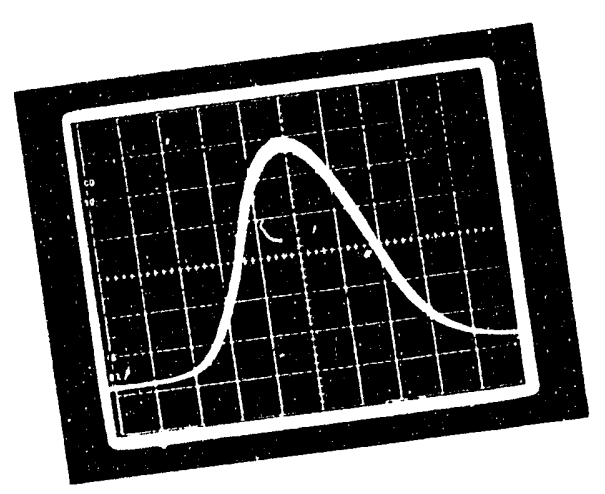


clear focus on solid-state lasers gives us a decisive lead in Nd: YAG laser design.

With evermore Q-switched applications requiring narrow bandwidth and/or bearfree temporal profile, we have seen a steady increase in the percentage of lasers ordered with our $\$ 500$ injection seeding system. Quantel is by far the leading supplier of injection seeded $\mathrm{Nd}$ : YAGs and here our system engineering concept is clearly in evidence. The diode pumped seeder(" 3 ) is built into the optical head assembly on all YG600 models-not tacked on as an afterthought. The user has the option of operating SLM or nimitimode with the flip of a switch; when seeded the CW output is coupled into the Q-switched resonator via the polarizer protected from feedback by a permanent magnet Faraday isolator integral to the unit. With the SI500 option Quantel guarantees greater than $99.9 \%$ of shots to be single longitudinal mode. Compare this to performance levels obtained through other electronic line narrowing techniques and you'll understand why we regard "seeding" as breakthrough technology.

- 1 A. E. Scomm Lascrepp. $836-837$

"2 A. Caprara, S. Busober, R. Aubert "Inkcotion seceding of

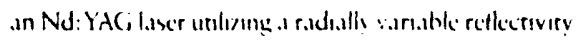
output coupier."

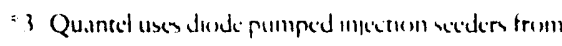
Lightuanc Belectrontis.

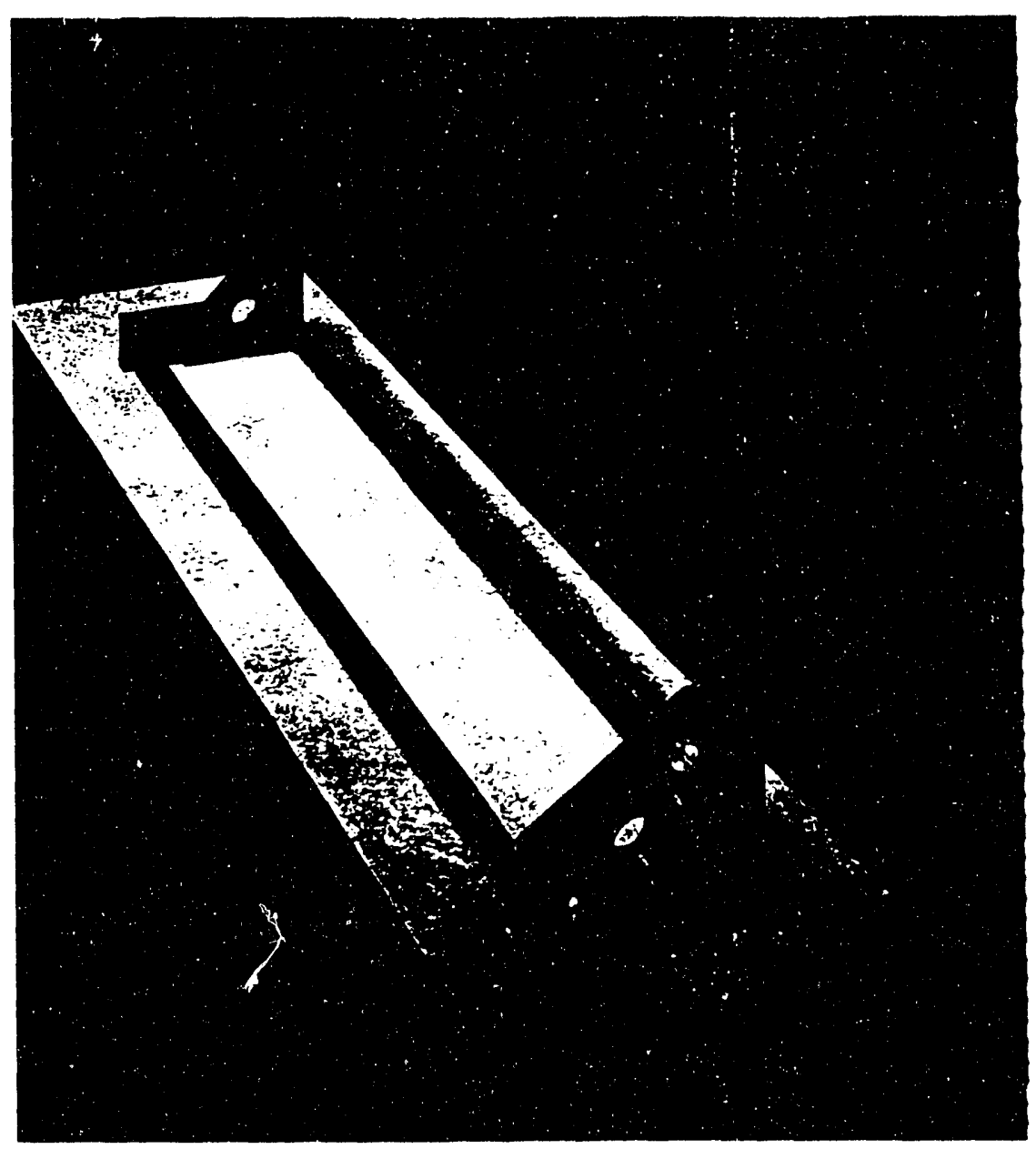

Mroughout the yG600

series we have bulll on our considerable experience. Where new designs and/or new materials were cho. sen the selectlon foltows extensive testing under varied operating canditions. 


\section{The YG 680 Series delivers the highest performance of any commercially available Nd:YAG laser.}

To fully appreciate the $Y(6,80$ performance, consider the following:

-For the last 10 years we have offered $20 \%$ more energy than the nearent mial. With the advent of the YG680 scres our lead increases to nearly $50 \%$-we guarantee $\mathrm{E}>750 \mathrm{~mJ}$ at $532 \mathrm{~nm}$ for the $Y G 682$ at $10 \mathrm{~Hz}$.

-The YG682 at $20 \mathrm{~Hz}$ delivers more than $12 \mathrm{~W}$ at $532 \mathrm{~nm}$-again $50 \%$ more than the closest competitor.
-..... Injecuon seed d single longitudinal mode operatmen is an option on every laser in the í (inso) ecries with no derating m beam partal pusile or energy.

\section{STANDARD FEATURES}

-Quantel's exclusive V-ROC." " resonator delivering high peak power, superior beam yuality and ne.ar ditfraction-limited divergence.

-Quantel's SF 60) series laser headsthe industry's most efficient allowing low
Pictured is a YG682 with the $\$ 1500$ injection seed. ing option. For applica. tions requiring oven higher energy we offer LOHz Q-switched lasers on a custom basis with guar. anteed Is at $532 \mathrm{~nm}$ : $400 \mathrm{~mJ}$ at $355 \mathrm{~nm}$. For higher average power systems ask your Quantel sales engineer for information on our YG1000 series of Q.switched Nd:YAGs daltuering up to $30 \mathrm{~W}$ at $\$ 32 \mathrm{~nm}$ at repetition rates from 540-1080Hz.

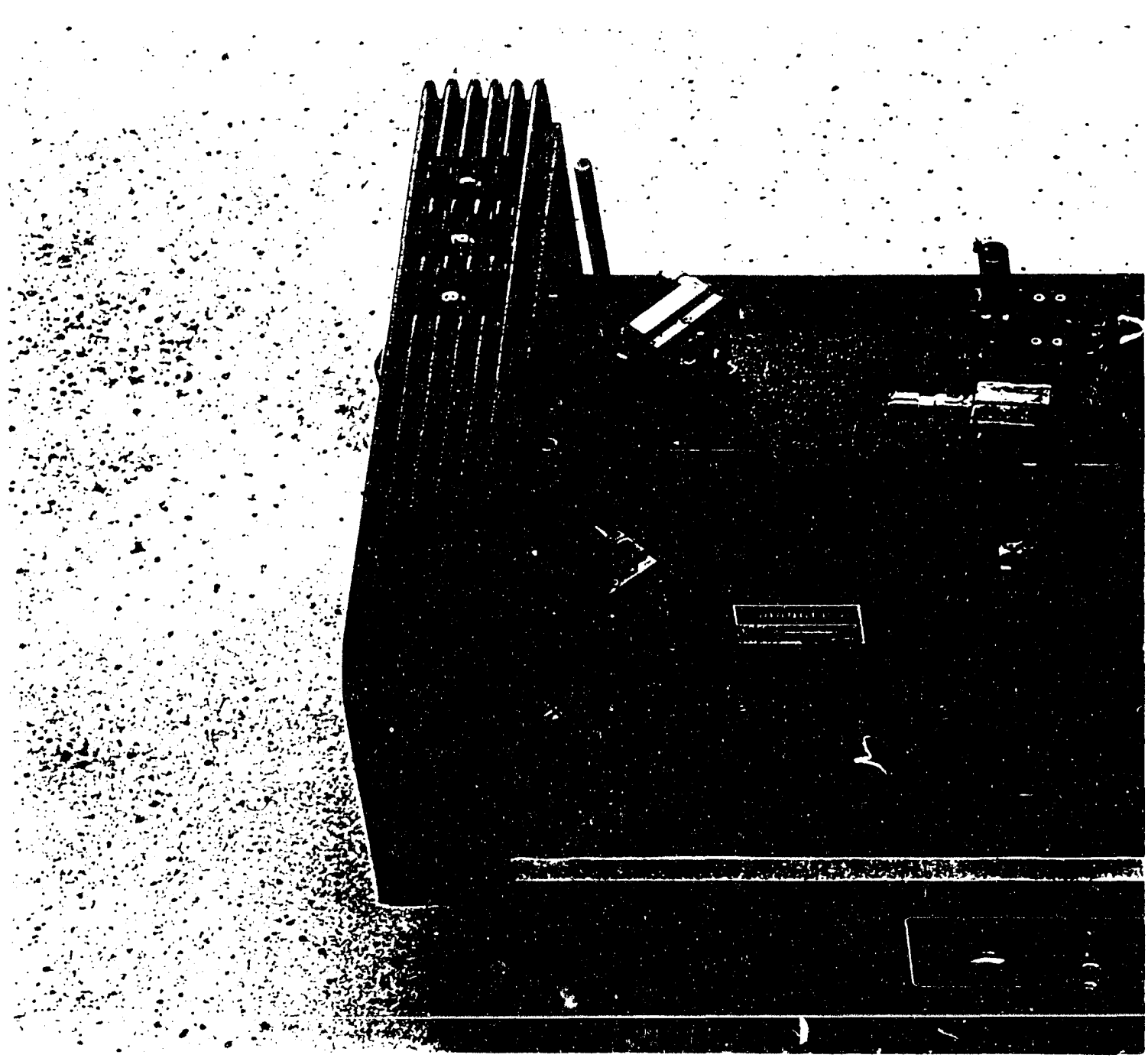




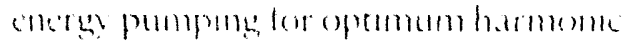
combersion

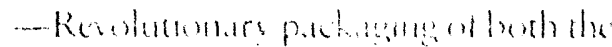
optical he ded and pouces supply are roughts

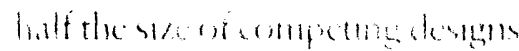

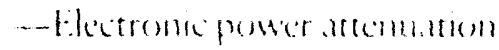

-Sealed moner conere wheth avold the use of beam culles

\section{OPVIOHAL ACCESSORIFS}

- Temperature stabilized secend and third harmonic generaless with temperanure phase-matched trepuency quadrupling

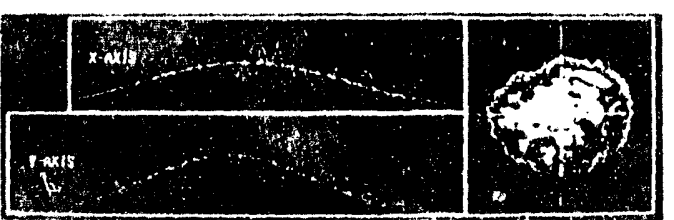

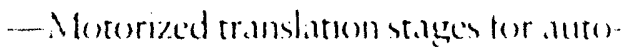
macrs wirdength selection -Beam access packages availing multiple die laster pumping schemes - Parallel inode-locted operation offering paik powers > 1 Cigamatt
The profise shows the fre quency doubled output of a rG682 at a iange of 1 moter. Sucti a veam becomes purely Gaussian in the far-field.

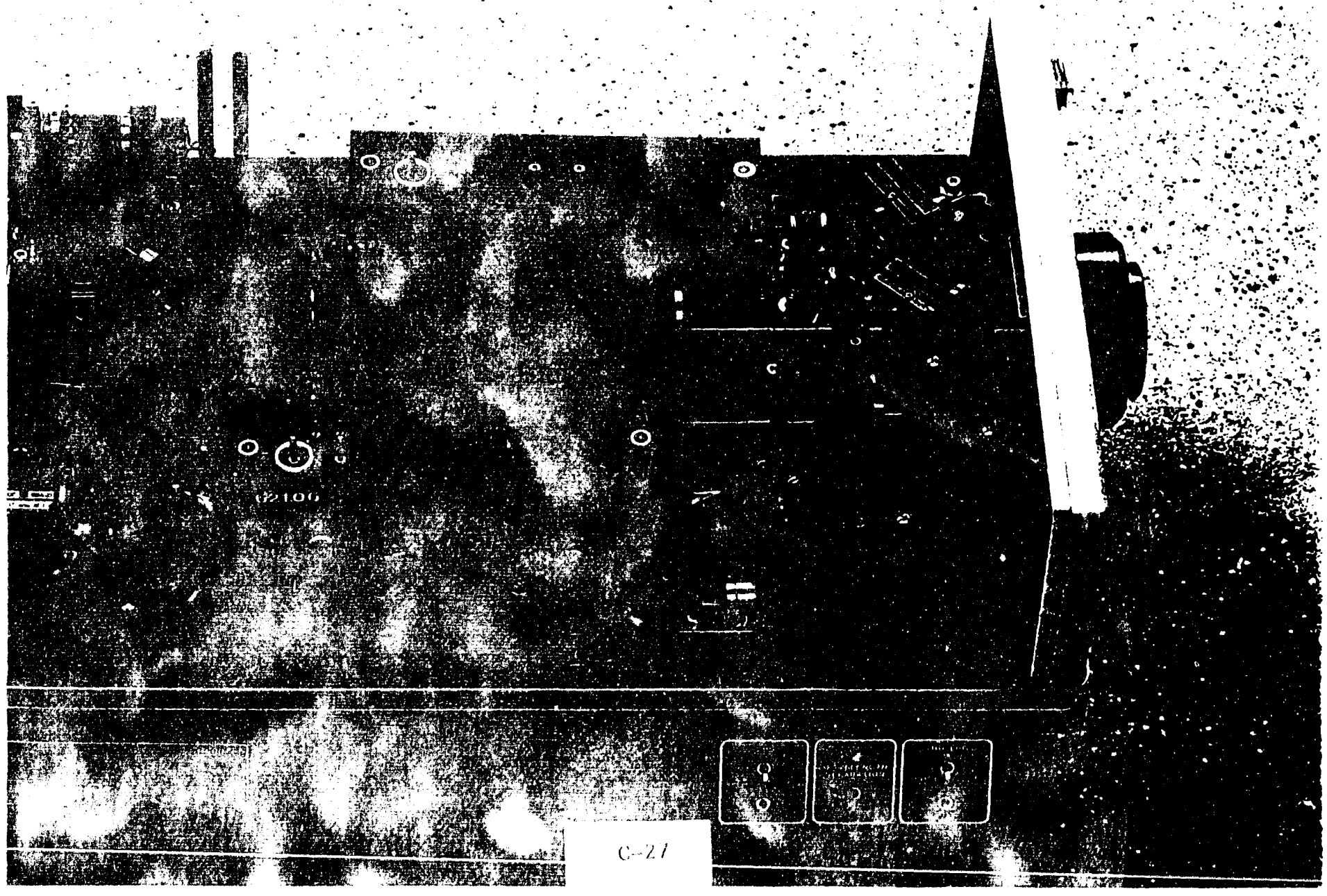




\section{The YG 660 Series guarantees big laser performance at a small laser price.}

The YG660 series represents a new dimension in high powered $\mathrm{Nd}$ : YAG design: single head, single flashlamp lasers with performance and features which belie their compact size and price. The optical head measures less than 34 " in length and weighs less than $35 \mathrm{lbs}$. The power supply which has the option of air conling can operate from a standard 110 volt source making the YG660-10 ideal for OEM applications. All YG660 models are single flashlamp designs minimizing the cost of extensive operation. The YG660 series feature a new mechanical design concept wherein stabilization is maintained by the optical bench assembly: honeycomb aluminum with a graphite skin. A positive airflow is maintained keeping the optical surfaces clean even outside the laboratory environment. For performance start with:

-Guaranteed energy $>300 \mathrm{~mJ}$ at $532 \mathrm{~nm}$ for $10 \mathrm{~Hz}$ operation

-Guaranteed average power of nearly 6 Watts at $532 \mathrm{~nm}$ for $30 \mathrm{~Hz}$ operation
Due to its small size. frucal power consump. tion and the excellont tow Irequency demping ehar. ectoriatics exhiblted by the Eraphite bench. the yeseo is ideally sulted for industrial. moblle or airborne environments.

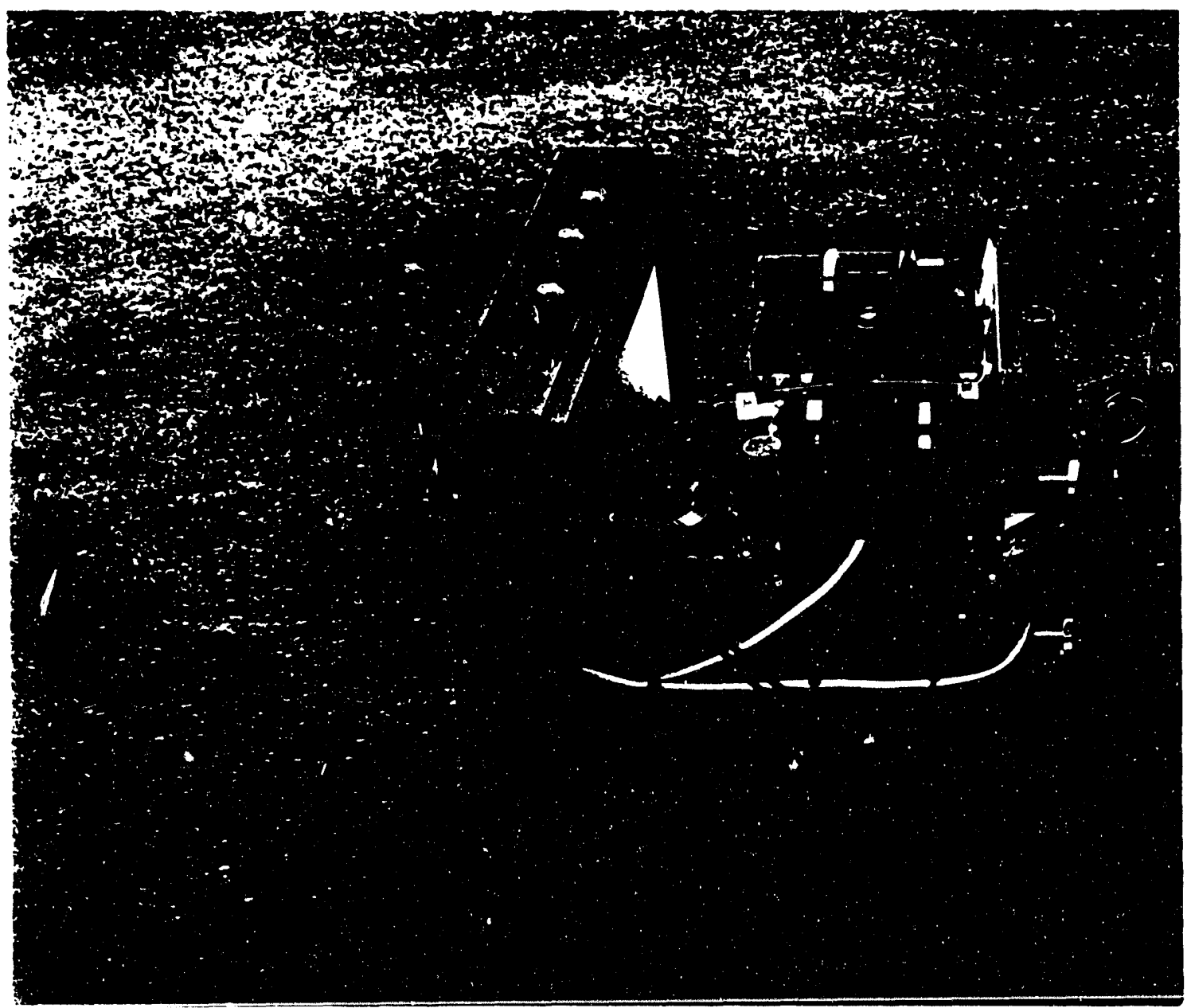


- Injection seeded SLM performance available on all models

-Quantel's V-ROC'" resonator providing uniform uniphase beam

The YG661 guarantees the lowest cost per photon of any pulsed Nd:YAG laser available. When coupled with our TDL line of tunable dye lasers we offer to the scientific community a high power runable package with a twist: economy.

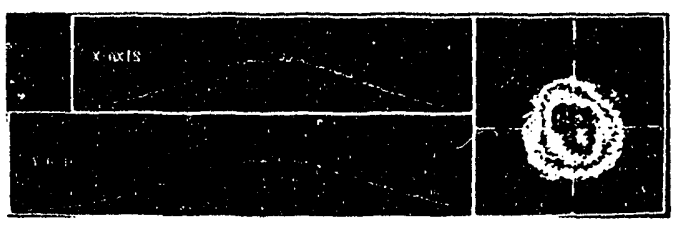

The bear: profile is of a rG660 at a rarige of five meters.

\section{OPTIONAL ACCESSORIES}

- Temperature stabilized second and third harmonic generators with temperature phase-matched frequency quadrupling - High contrast dichroic separation packages

- RB02 Remote Box plus RS2.32 interface.

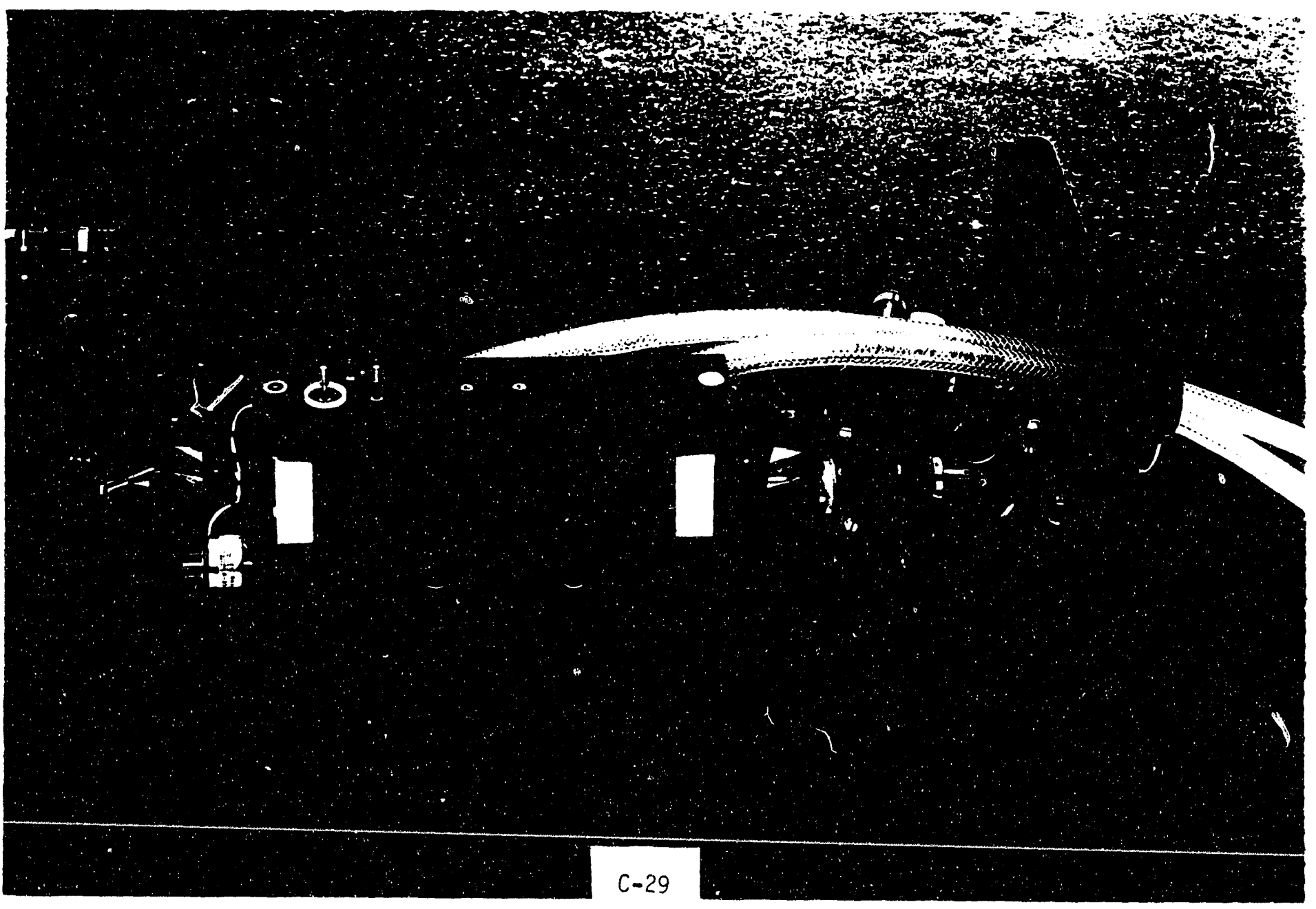




\section{Industry leading lasers from a company known for its after-sales support.}

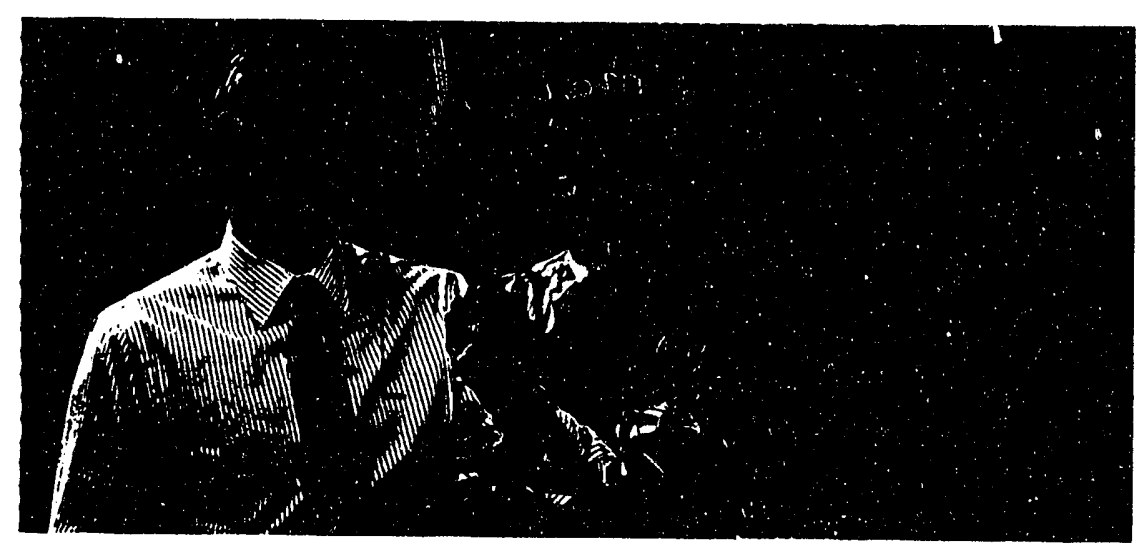

In an industry where large faceless corporations are becoming the rule, our people keep Quantel the exception.

With any $Y(660)$ series system comes Quantel's (o),nmitment to customer sattisfaction: a commitment to go the extra mile to insure a product which, beyond meering specifications, genuinely satisfies the customer recuirements.

Our team of engincers and rechnicians has the expertise to design, manufacture and service Nd: YAC i lasers which take complete advantage of current advances in orystal growth, laser diode, electro-optic and optical coatung technologies. This ahility to respond quickly to the marketplace, maintaining at all sme's a tamily of produces which is contemper ary with the support industries is what maties ( )uantel unicuse.

From our t5. (3)(n) sepuare foces Santal

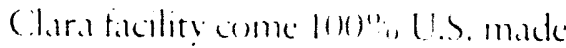
produces issembled, reseded (2) Hd, and decumented hy our teament m-herase laser

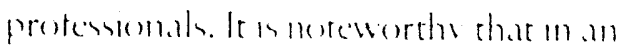
indusery often plagued hy lachlunter

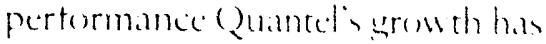

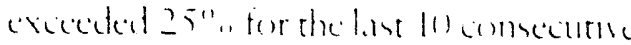

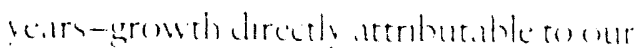

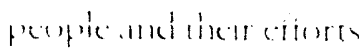

Whether you're a first time laser user or a seasoned laser jock, our sales engineers and product managers will work closely with you in defining the YG600 series model plus options which, while tailored to your present application, retains the flexibility to address quite different needs of research to come.

A key element to Quantel's continued success is our service commitmenta commitment which begins with the installiation and continues through the lifetime of the laser-often through several generations of operattors. All of our highly trained service technicians are specialists in solid-state lasers-their attention is not divided between ion or excimer technologies.

All Quantel Y 6600$)$ series lasers come backed by the industry's best warranty: I ye. Ir on the optical head assembly and 18 menths on the power supply.

At Quantel we have spent 12 years developing a reputation for leading edge performance. We firmly believe the $Y(i 61)()$ series to be the tinest line of high power Nd: YAC; lasers available and we invite comparisons with any commercially available products. To learn more ahoue the $Y(j 6)(0)$ fiamily or to learn how a (2-switched Nd:YAC; addresses your laser requirements, call us todaly. See why weve become the \# provider of high power pulsed lasers mall the world. 


\section{UNTED STATES}

Maln Orfice

Quantel International, Inc. 3150 Cencrill Expresswas Santa Clara, CA 95051

Tel: (408) 727.3240

Tix: 628807.36

\section{East Coast}

Quantet International, Inc. 152 Dartmouth Strcer

Marlboro, MA 01752

Tel: $(508) 624.4454$

\section{Southwestom}

Quantel international, inc. 13101 Washington Blvd.

Suite 216

Los Angeles, CA 90066

Tel: (213) 306-6757

\section{Mldwest}

Quantel International, Inc.

919 Golf Road

No. 5

Arlington Heights, IL 600005

Tel: (312) 228-6685

\section{JAPAN}

Quantel K.K.

Shinjuku R Bldg.

15-6 Wakamasucho Shınıuku-ku

Tokyo 162 Japan

Tel: 03-208-1064
INTERNATIONAL

REPRESENTATVES:

Bonelux

Opulas B.V.

P.O. Bor 222

24(1) AE Alphen ad R R In

T.1: ()1720.31234

Th: $39-33$

\section{Gormany}

Oprilas GimbH

Boschstrasse 12

D.8039 Puchheim

TCl: (0 89) 80 10.35

Tlx: 5213927 opeld

\section{Japan}

Autex, Inc.

Matsumoto Bldg.

2-14 Tomibisacho

Shmouku-ku, Tokvo 162.

Tel: $03.226-6.321$

TW $x: 232.4958$

Swltzerland

(iMPSA

Electro-eptic/Laser

19. Avenue des Baumertes

CH 1020 Renens 1/Lususanne

Switzerland

Tel: $021 / 3+8181$

Tix: $24+2.3$

\section{United Kingdom}

cohereme (h) I lat

Combridge Solence Parh

Niftom Rorid

C.mbralige $(B+1+R$

Tol: (1)223) 4205001

rla: 81 the

Spain

fortontict

Pinar, 6-Bis

28006 Madrid

Tol: 2627-63.2618145

Tlx: 27488

\section{Israel}

Newtec, L.td.

H.lamed-Heh 19

Givatayim 53105

lsracl

Til: (1)3.324|8|

TIx: 371707

\section{PrC}

Ciloh.l Technolugs, Inc:

Beypng ()ficic

Xivuan Hotel, Room 919

Erligon Xiflas

Bciling, (hina

Tel: 890.721 .91

\section{Tolwan}

Superbin Co., Led.

$5 F-3,792$, Tun Hua South Road P.O. Bux 59555

Taipci, Taiwan 116, R.O.C.

Tel: 0)2-705.4205

TIx: 21206 SUPERBIN 


\section{OPTOELECTRONICS SYSTEMS}

- OPTOEIECTRONICS

- Diode Array Detectors

- 77200 1/4 m Spectrographs, Slits and Gratings

- 77225 1/4 m Double Spectrographs

- Data Acquisition Systems: INSTASPEC II-AT/XT

- EG\&G OMA III System 


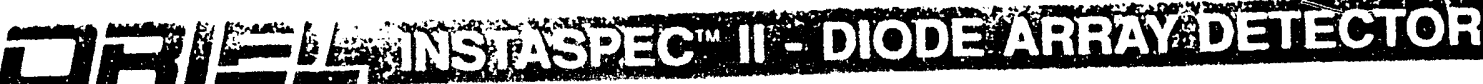

\section{FEATURES}

- Arrays with 512 or 1024 detector elements

- Fast 5 millisecond scan time

- Captures pulsed light exposures

- Calibratable for absolute energy radiometry

- Detector attaches to a modified Nikon camera

- Full graphics capabilities

\section{ADVANTAGES}

- A day's research done in minutes

- Friendly complete software for instant use

- No problems from mechanical scanning

- Total control using standard computers

- Versatile and adaptable to many applications

- Data files compatible with Lotus 1-2-3

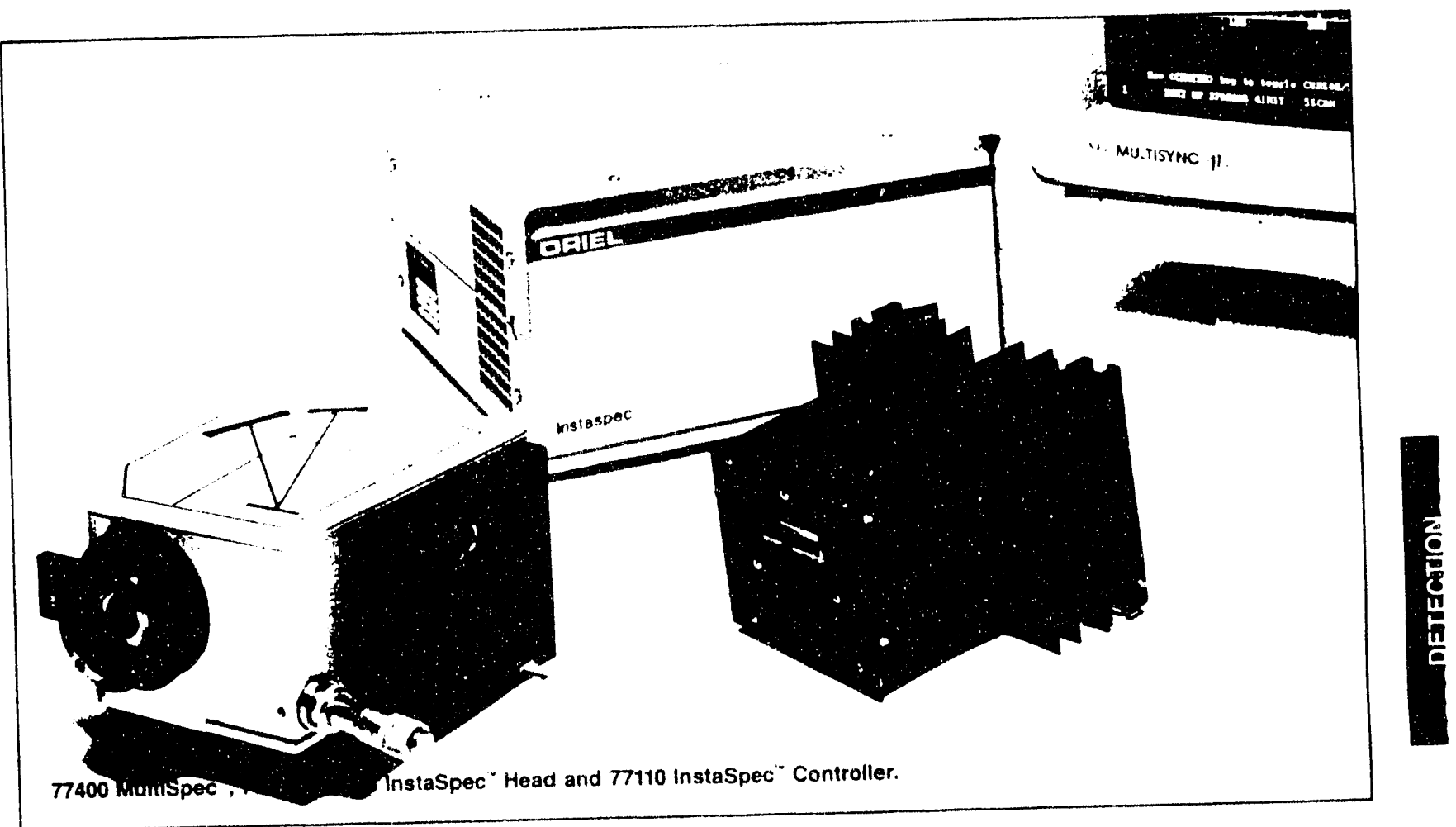

Photodiode arrays are versatile and powertul detectors for many applications. Though the arrays are simple in concept, extensive engineering of support hardware and software is required to get the best results from these detectors. Our new instaSpec" II System provides both the hardware and soth. ware that's easy-to-use and adaptable, in a single economic package.

InstaSpec ' is a multi-element detector for use in spectro. scopy and image analysis. InstaSpec" simplifies many experiments and monitoring processes.

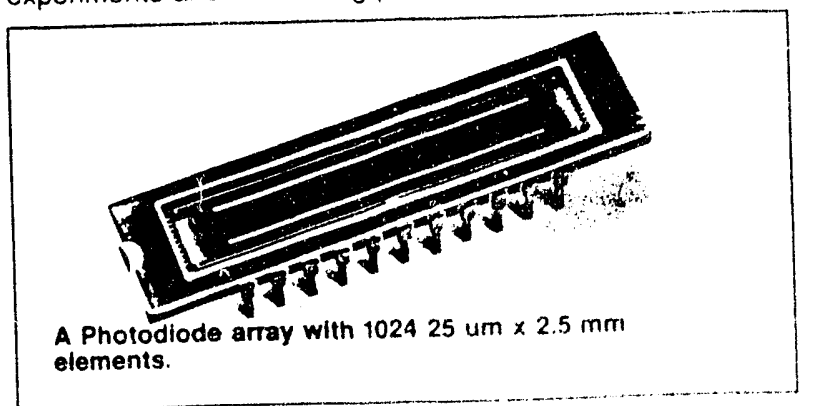

\section{APPLICATIONS}

- Spectroradiometry, and fluorescence

- Beam protiling of pulsed or continuous sources

- Light source analysis

- Detection of ultrashort flashes

- Time resolved spectroscopy

- Interference fringe measurements

- Tracking of position, alignment and focus

- Spectrophotometric process contro!

A complete InstaSpec" system consists of:

- Diode Array Detector Head

- Controller

- Optional Spectrograph (for spectroscopy)

- Interface Card

- Computer

- Graphics Card and Monitor

- Software

- Printer and Plotter

- Mounting Flange 


\section{DRIEI INSTASPEC "II - DIODE ARRAYS}

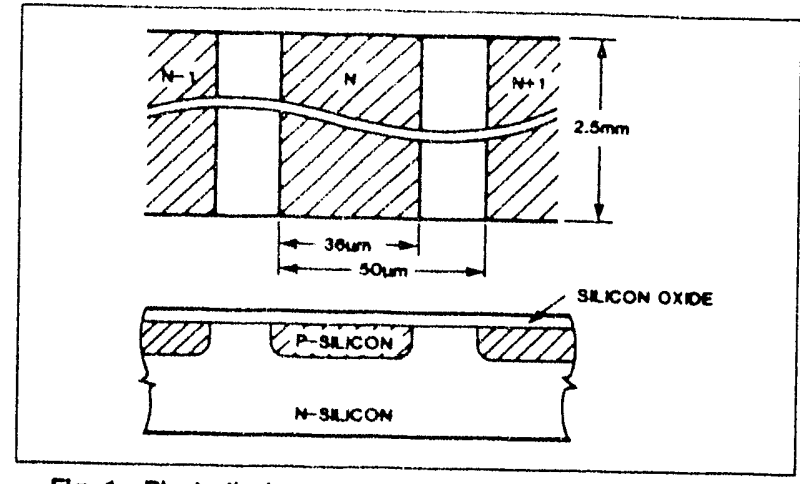

Fig. 1 Photodlode array construction.

A photodiode array is a line of silicon detectors constructed as an integrated circuit. Light generates a photocurrent and causes a charge to accumulate in the series of diodes. Switching transistors sequentially read and reset the charge from each diode element, and direct the output to a single output line. The output charges are converted to a voltage, amplified, and converted by an analog to digital converter into a series of digitized readings for computer processing. The cycle time for the scan of the diodes, along with the light intensity, governs the charge stored before it is read. The scan rate is determined by clock pulses which are fod to the array circuit by an external controller. Scan rates for spectroscopic applications are typically $5 \mathrm{~ms}$ to $100 \mathrm{~ms}$ to read an entire array.

\section{MUL.TICHANNEL DEVICES}

The most important advantage of diode arrays over other detectors such as photomultiplier tubes is the multichannel nature of the arrays. Many hundreds of data points (channels, wavelengths) can be recorded in one single reading. As a consequence, diode arrays are excellent for taking a series of scans of a changing optical source. A good practical example of this is in spectrophotometry. where a spectrograph/diode array combination can replace a motor-driven scanning monochromator and photomultiplier tube, and take entire spectra in a few milliseconds.

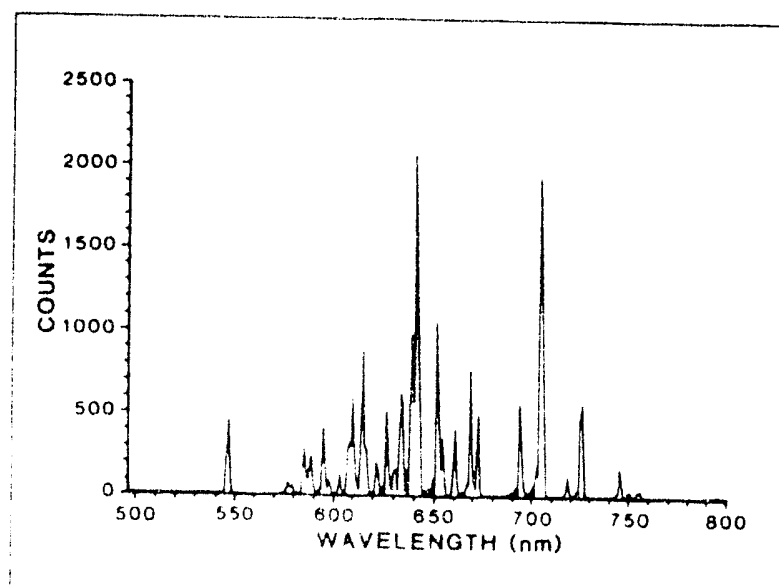

Fig. 2 Spectrum of Hellum Neon plasma.

\section{EXPOSURE TIMES}

Diode arrays and photomultiplier tubes are fundamentally different in their method of light measurement. Photomultiplier tubes measure radiant flux (power), i.e. watts, while diode arrays measure radiant energy, i.e. joules. The diode elements accumulate charge generated by the arrival of photons, and the charge is proportional to the total radiant energy. For constant light sources, this is the product of the radiant flux and exposure time. In essence a diode array acts as an electronic photographic film, and the exposure time is adjusted to obtain the best signal.

\section{SPECTRAL RESPONSE}

The spectral response of a silicon diode array is that of silicon, and is from about $180 \mathrm{~nm}$ to $1100 \mathrm{~nm}$, which is better than the majority of photomultiplier tubes. The sensitivity at $200 \mathrm{~nm}$ can be about $20 \%$ of the peak response, between 600 and $800 \mathrm{~nm}$.

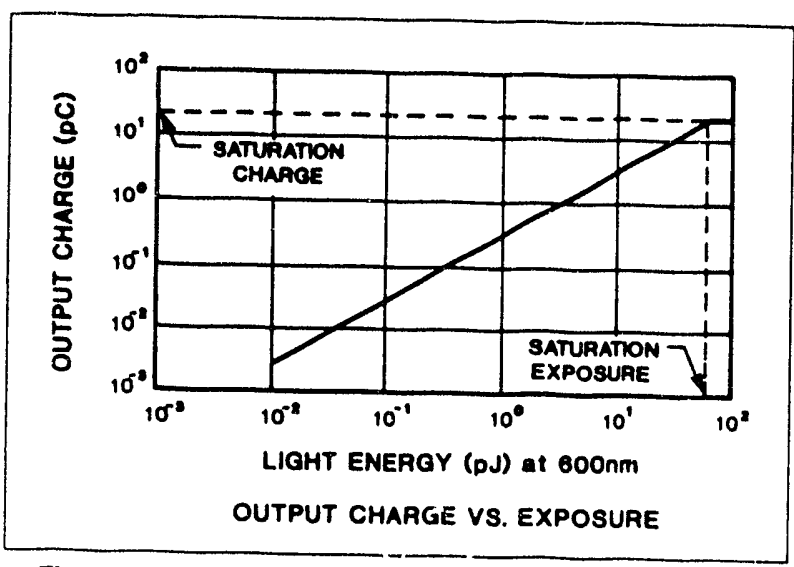

Fig. 3 Diode output charge vs. Ilght energy.

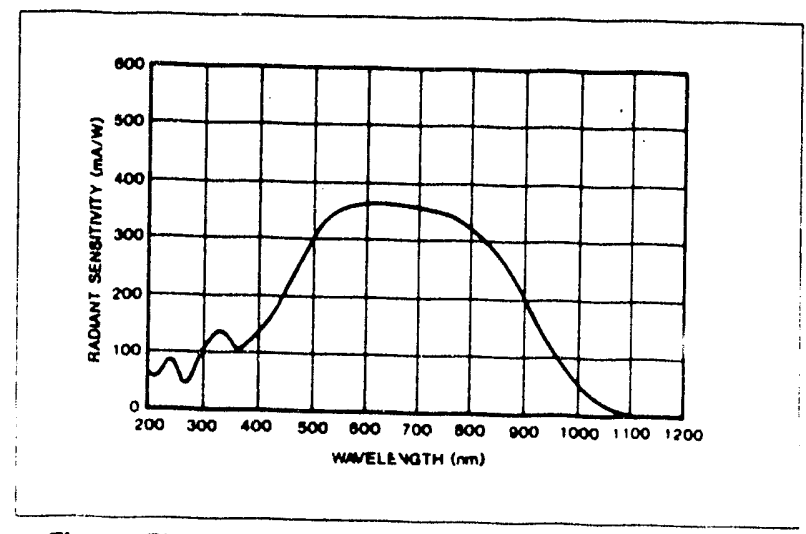

Fig. 4 Pholodiode array spectral response. 


\section{$\square \vec{f}=1,1 / 4$ METER MÓNOCHROMATOR/SPECTROGRAPH}

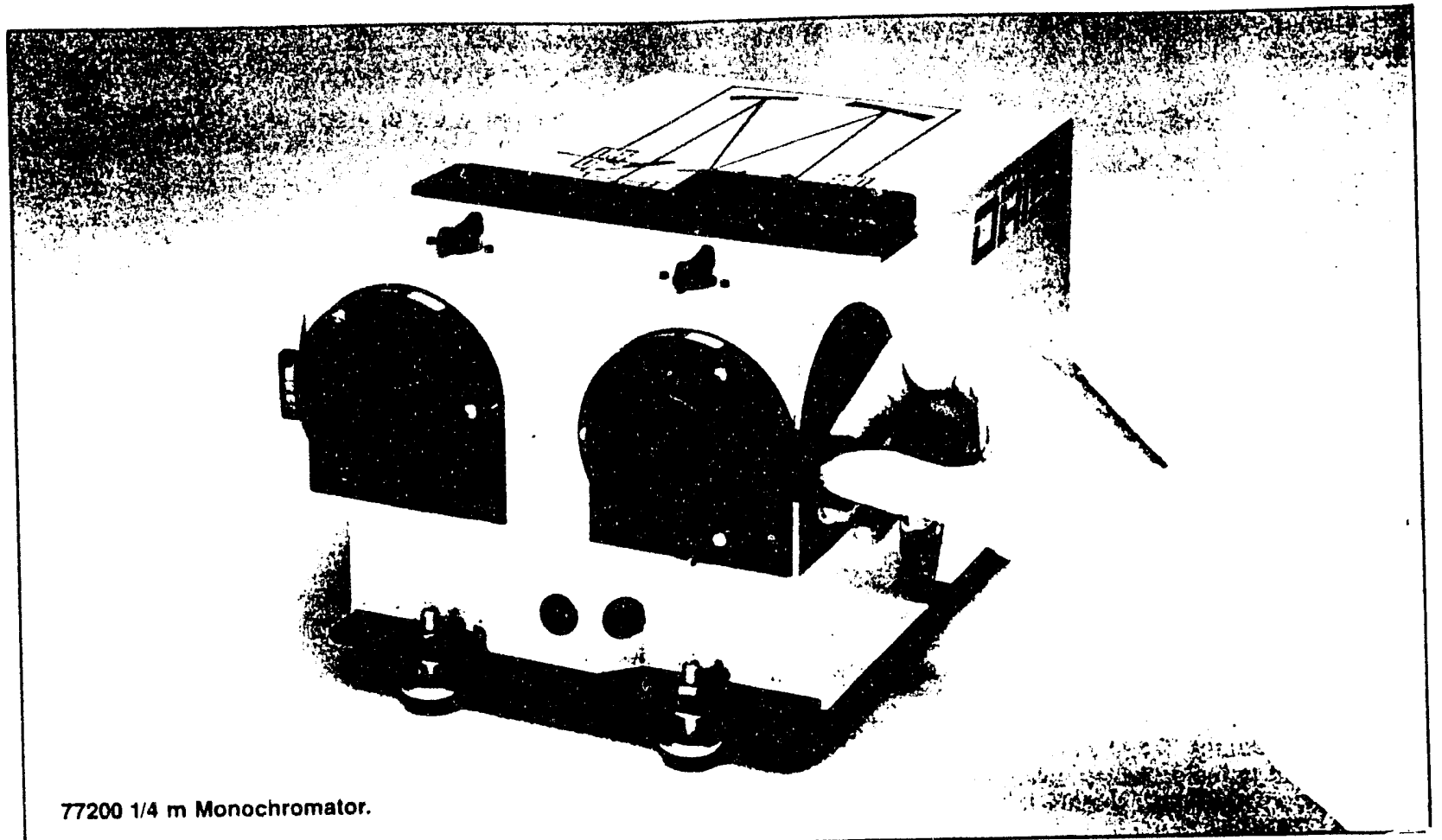

$772001 / 4 \mathrm{~m}$ Monochromator.

\section{- Operates as a monochromator or spectrograph}

- $0.1 \mathrm{~nm}$ resolution with a $1200 \mathrm{l} / \mathrm{mm}$ grating

- Wide spectral range - $200 \mathrm{~nm}$ to $24 \mathrm{um}$ with interchangeable gratings

- Fast F/4.4 optics

- Selectable lateral or paraliel slit configurations

- Low stray light

- Fully supported stepper drive and data acquisition options

- Low cost scanning drives

- Sturdy monolithic construction

Performance and versatility make this $1 / 4$ meter Monochromator/Spectrograph an excellent choice for moderate resolution spectroscopy. Use it as a traditional monochromator with input and output slits, or as a spectrograph. It has a flat output plane for instruments such as instaSpec". Our diode array detector

Fiesolution in the visible is $0.1 \mathrm{~nm}$ with a 1200 line $/ \mathrm{mm}$ grating. The spectral range is $200 \mathrm{~nm}$ 10 24 microns with interchangeable gratıngs.

The flanged input and output shits accept any of our 1.5 Inch Series of Accessories. This provides the 77200 with a family of detector, source and beam handling accessories. Use the 77200 with our Light Sources or Universal Mono chromator Illuminator for monochromatic tllumination Choose from a range of optics, including fiber optics. io best transfer the light between the source. the 77200 . and your sample. Mount the InstaSpec on the output and select trom an array of gratings to capture spectra very quickly
APPLICATIONS

- Monochromatic irradiation or illumination

- Spectroscopic studies

- Radiometry and photometry

- Transmission, reflection, and absorption

- Emission and fluorescence

- Lasers and fiber optic studies

We offer a comprehensive range of optical, mechanical. and motorized accessories to simplify the use of the 77200 . In the next several pages we describe:

Single 77200 Monochromator 213

Gratıngs

Slits

Single Monochromator Mountıng

Double Monochromator

Double Monochromator Mounting

Ordering Information

Selected Related Products:

Universal Monochrmator llluminator

Input Accessories

Focusing Lens Assemblies.

Fiber Optic Accessories

Monochromator Reflectors

Filters for Monochromators.

Stepper Wavelength Drives

Synchronous Wavelength Drives

Wavelength Re.ddc'st

213
215
216
218
219
221
22




67
243
244
248
251
252
281
283
283




\section{LATERAL OR PARALLEL. CONFIGURATIONS}

The 77200's design allows the input and output ports 10 be changed from a lateral (in-line) to a paraliel (side by side) configuration. Fig. 2 shows the two configurations. Simply rotate the pair of folding mirrors (M3 and M4), and block the unused ports with the light tight caps. The two mirror pos:tions are precisely preset. The parallel configuration can save space because input and output accessories mount side by side.

For some applications, you may wish to combine the two configurations by using a parallel port and a lateral port

\section{FLAT FIELD FOR ARRAYS OR CAMERAS}

The 77200 functions both as a monochromator and spectrograph. As with our MultiSpec", the optical arrangement produces a flat output field. Remove the exit slit and you have a 1.0 inch $(25.4 \mathrm{~mm})$ flat output plane for diode arrays, film cameras, vidicons, and IR converters.

InstaSpec", our diode array detector described on pages 347 to 359 , fits on the parallel output port to record and display spectra in the 200 to $1100 \mathrm{~nm}$ range. See Fig. 1 below. for a typical wavelength scan taken in 5 milliseconds.

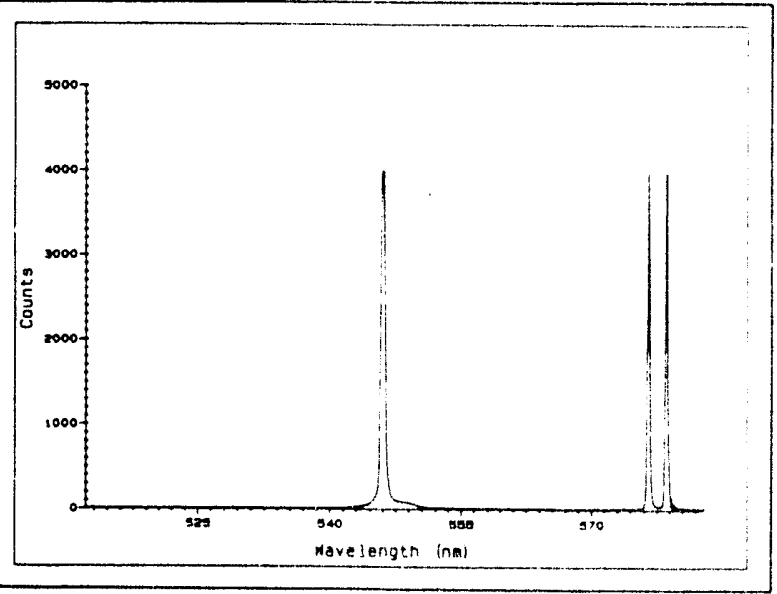

Fig. 1 Scan of $6035 \mathrm{Hg}(\mathrm{Ar})$ Lamp taken with InstaSpec and 77200 Spectrograph. A 1200 $1 / \pi . m, 500 \mathrm{~nm}$ Blaze Grating was used.

\section{OPTICAL CONFIGURATION}

The 77200 utilizes an in-plane asymmetrical Czerny. Turner configuration, illustrated in Fig. 2. Placing the entrance and exit slits asymmetrically, with respect to the grating, allows the zero coma point to be located within the working wavelength range. This results in minımal aberration throughout the range

A batfle is supplied to mask off the center of the grating to block re-entrant spectra

\section{HIGH EFFICIENCY}

The dispersion is iwice that of our $772501 / 8$ meter Mono chromator. For any slitgrating combination in the 1.8 meter the $1 / 4$ meter uses a slit twice as wide to achieve the same bandpass. The fixed slits in the $1 / 4$ meter are $18 \mathrm{~mm}$ high This large slit area results in better throughput

See pages 230 to 233 for comments on throughput and pertormance data.

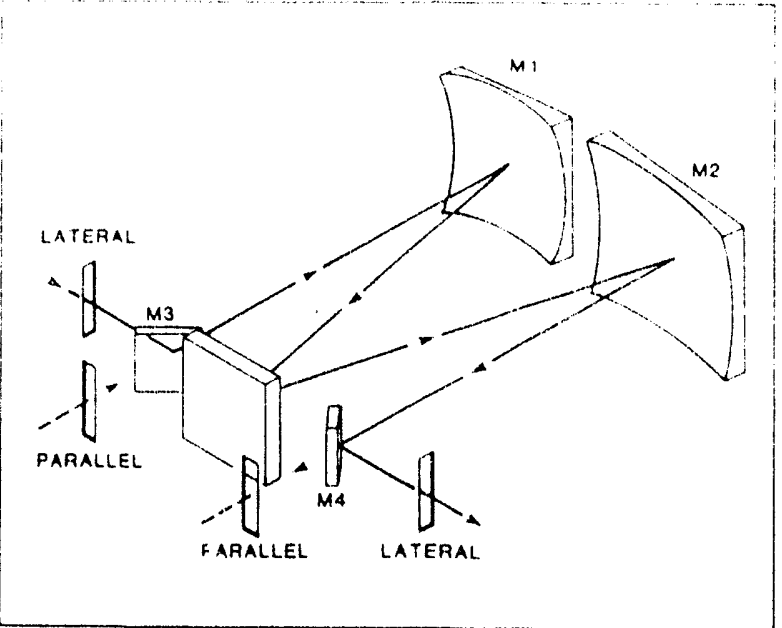

Fig. 2 Lateral and parallel conflgurations of the 77200 .

\section{STRAY LIGHT}

Many factors influence the stray light at the output. The grating used, the operating wavelength and the scattering of light inside the monochromator are usually the most important. The stray light signal also depends strongly on such external factors as the intensity and spectral distribution of the input source and the detector's spectral response. The superb stray light rejection of the 77200 is shown for two modes where stray light can be a significant problem: UV measurements, and close to an intense monochromatic line.

- With a 60055 Deuterium Source, a 77345 Photomultiplier (S-5 response) and a 77231 Holographic Grating blazed at $200 \mathrm{~nm}$, measurements were made with and without a glass plate in the bealn. The glass blocks all radiation below $320 \mathrm{~nm}$. At $25 \mathrm{u} \mathrm{nm}$, the stray light signal was only $0.14 \%$ of the unblocked signal.

- With a Helium Neon laser at $632.8 \mathrm{~nm}$ focused on the slit in an $F / 5$ cone. the average of the stray radiation mea. surements at $612.8 \mathrm{~nm}$ and $652.8 \mathrm{~nm}$ was $0.0012 \%$ of the 632.8 reading, when using the 77231 Grating

\section{WAVELENGTH DRIVE AND READOUT}

We use a sirie bar linkage to drive the gratıng. The sine drive provides a linear dependence of wavelength on lead screw advance. This lead screw can be manually driven by an external hand crank, or by optional stepper motors. The hand crank is outside the path of the beam, regardless of the configuration of the slits. A convenient, five digit wavelength counter on top of the instrument displays the wavelength in nanometers when a $1200 \mathrm{l} / \mathrm{mm}$ grating is used. The first counter is marked with $0.02 \mathrm{~nm}$ graduations to let you read the wavelength $100.01 \mathrm{~nm}$. For gratıngs with different groove density multiply the reading by the appropriate wavelength dial factor tound in Table 1 on page 215.

\section{INERT GAS PURGE}

These monochromators have a hose fitting to allow you to purge the housing with dry nitrogen and obtain transmission down to $175 \mathrm{~mm}$ See the atmospheric transmittance curve on page 164 


\section{DRIEI, SPECIFICATIONS}

\section{For $1 / 4 \mathrm{~m}$ Monochromator/Spectrograph}

\section{SPECIFICATIONS \\ Range: \\ Minimum bandpass: (10 um slit - 1st order) \\ Reciprocal Dispersion: \\ Focal Length: \\ Effective Aperture \\ Wavelength Readout: \\ Wavelength Dial Range: \\ Wavelength Dial Accuracy: \\ Wavelength Precision: \\ Re-entrant Spectra: \\ Dimensions: \\ Weight: \\ $200 \mathrm{~nm}$ to $24 \mathrm{um}$ with interchangeable gratings $175 \mathrm{~nm}$ with dry nitrogen purge \\ $0.1 \mathrm{~nm}$ with $1200 \mathrm{l} / \mathrm{mm}$ grating \\ $1.6 \mathrm{~nm} / \mathrm{mm}$ for $2400 \mathrm{l} / \mathrm{mm}$ grating $3.2 \mathrm{rm} / \mathrm{mm}$ for $1200 \mathrm{l} / \mathrm{mm}$ grating at $500 \mathrm{~nm}$ \\ $250 \mathrm{~mm}$ \\ $\mathrm{F} / 4.4$ \\ 5 digit counter with index marks every $0.02 \mathrm{~nm}$ \\ $0.1200 \mathrm{~nm}$ with $1200 \mathrm{l} / \mathrm{mm}$ grating \\ $1 \mathrm{~nm}$ with $1200 \mathrm{Vmm}$ grating \\ The wavelength is resertable to $0.1 \mathrm{~nm}$ from either direction \\ None when used with supplied baftle \\ $7.3 \times 10.75 \times 5.75$ inches $(185 \times 273 \times 146 \mathrm{~mm})$ \\ $12 \mathrm{lb}(5.5 \mathrm{~kg})$}

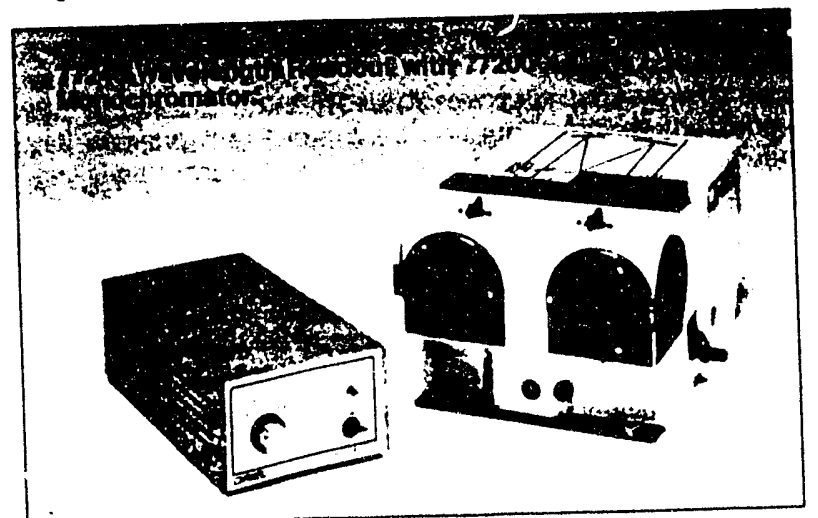

MOTORIZED WAVELENGTH DRIVES AND ACCESSORIES

\section{Digital Stepper Motor Drives}

Two internally mounted stepper motor drives are available for bidirectional scanning or wavelength selection. See page 281 for complete details. See pages 285 to 288 for information on the 78200 Drive Controller, and pages 289 to 293 for computer intertacing.

\section{Fixed Speed Scanning Drives}

For fixed speed and unidirectional scanning, our more economical synchronous motors are an excellent chorce. See page 283 for information.

\section{Analog Wavelength Readout}

The 77246 Wavelength Readout can be used with both types of wavelength drives. It puts out a precise DC signal. proportioral to wavelength setting. See page 283 for detalls

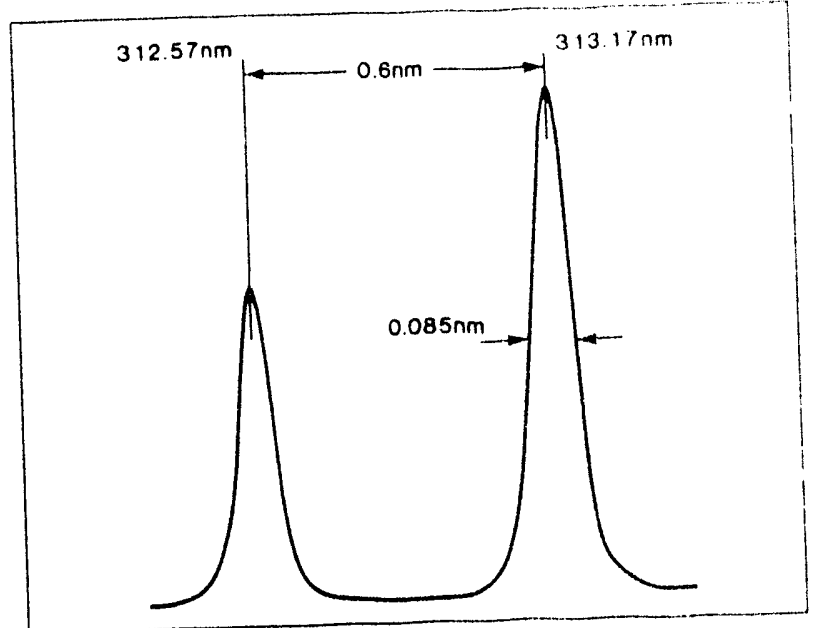

Fig. 3 Wavelength scan.

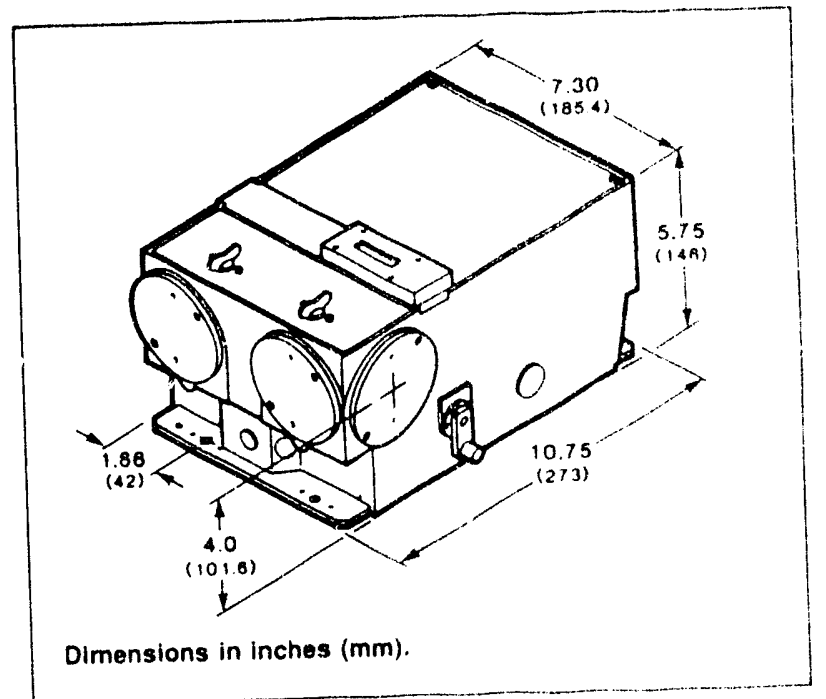

Fig. $4772001 / 4 \mathrm{~m}$ Monochromator. 


\section{DREELGGATINGS}

\section{For $1 / 4 \mathrm{~m}$ Monochromator/Spectrograph}

The combination of grating and slits define the bandpass spectral range, and power throughput of a monochromator. The input slit and grating are the major factors in determining the resolution of the 77200 in the spectrograph mode. An attractive feature of the 77200 is the ease with which you can insert and remove these components.

These $50 \times 50 \mathrm{~mm}$ replicated gratings corne prealigned in a protective frame. The frame has a tab so you can hold the grating without touching its surface. Simply remove the lid of the monochromator, and slip the grating into place.

Fig. 1 shows the relative efficiency of our 77232 and 77233 gratings for unpolarized light. Choose the holographic gratings for lowest stray light and where spectral ghosts could be mistaken for results!

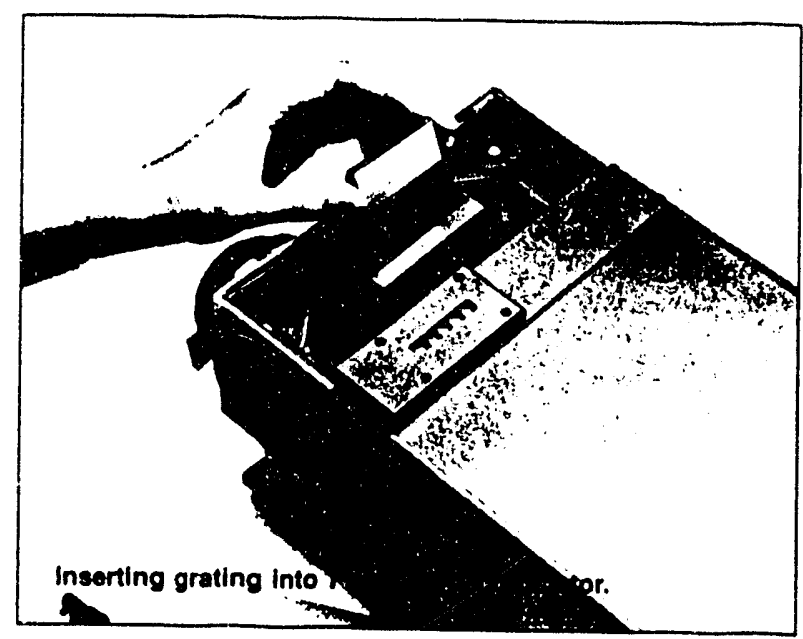

Table 1 Grating Specifications

\begin{tabular}{|c|c|c|c|c|c|c|c|c|}
\hline \multirow{2}{*}{$\begin{array}{c}\text { Model } \\
\text { No. }\end{array}$} & \multirow{2}{*}{$\begin{array}{c}\text { Blaze } \\
\text { Wavolength }\end{array}$} & \multirow[b]{2}{*}{ Type } & \multirow{2}{*}{$\begin{array}{l}\text { Groove } \\
\text { Spacing } \\
(1 / \mathrm{mm})\end{array}$} & \multirow{2}{*}{$\begin{array}{l}\text { Wavelength } \\
\text { Dlal and } \\
\text { Bandwidth } \\
\text { Factor }\end{array}$} & \multirow{2}{*}{$\begin{array}{l}\text { Reciprocal } \\
\text { Dispersion } \\
\text { (nm/mm) }\end{array}$} & \multicolumn{2}{|c|}{ Wavelength Region } & \multirow{2}{*}{$\begin{array}{l}\text { Wavelength Span } \\
\text { at } 500 \mathrm{~nm} \\
\text { when } 77200 \text { is } \\
\text { used as a } \\
\text { spectrograph }\end{array}$} \\
\hline & & & & & & Primary & Usable & \\
\hline 77230 & $270 \mathrm{~nm}$ & Holographic & 2400 & $x 0.5$ & 1.6 & $175.500 \mathrm{~nm}$ & $150-600 \mathrm{~nm}$ & $41 \mathrm{~nm}$ \\
\hline 77231 & $200 \mathrm{~nm}$ & Holographic & 1200 & $x_{1}$ & 3.2 & $180-700 \mathrm{~nm}$ & $180-700 \mathrm{~nm}$ & $82 \mathrm{~nm}$ \\
\hline 77232 & $280 \mathrm{~nm}$ & Fuled & 1200 & $x_{1}$ & 3.2 & $200.375 \mathrm{~nm}$ & $175.700 \mathrm{~nm}$ & $82 \mathrm{~nm}$ \\
\hline 77233 & $500 \mathrm{~nm}$ & Ruled & 1200 & $x_{1}$ & 3.2 & $330-750 \mathrm{~nm}$ & $300-1000 \mathrm{~nm}$ & $82 \mathrm{~nm}$ \\
\hline$\pi 7234$ & $1.0 \mathrm{um}$ & Ruled & 600 & $\times 2$ & 6.4 & $0.67 \cdot 1.5 \mathrm{um}$ & $0.6-2.0 \mathrm{um}$ & $164 \mathrm{~nm}$ \\
\hline 77235 & $2.0 \mathrm{um}$ & Ruled & 300 & $x 4$ & 12.8 & $1.33-3.0 \mathrm{um}$ & $1.2 \cdot 4.0 \mathrm{um}$ & N/A \\
\hline 77236 & $4.0 \mathrm{um}$ & Ruled & 150 & $x 8$ & 25.6 & $2.67-6.0$ um & $2.4-8.0$ um & $N / A$ \\
\hline 77237 & 8.0 um & Ruled & 75 & $x_{16}$ & 51.2 & $5.33-12.0 u m$ & $4.8-16 u m$ & $N / A$ \\
\hline 77238 & $12.0 \mathrm{um}$ & Ruled & 50 & $\times 24$ & 76.8 & $3.0-18.0 \mathrm{um}$ & $7.2-24$ um & $N / A$ \\
\hline 77239 & $200 \mathrm{~nm}$ & Ruled & 600 & $\times 2$ & 6.4 & $180.300 \mathrm{~nm}$ & $175.500 \mathrm{~nm}$ & $164 \mathrm{~nm}$ \\
\hline 77240 & $550 \mathrm{~nm}$ & Ruled & 400 & $x_{3}$ & 9.6 & $360.600 \mathrm{~nm}$ & $300-900 \mathrm{~nm}$ & $246 \mathrm{~nm}$ \\
\hline 77241 & $730 \mathrm{~nm}$ & Ruled & 200 & $x_{6}$ & 19.2 & $485.1100 \mathrm{~nm}$ & $400-1200 \mathrm{~nm}$ & $492 \mathrm{~nm}$ \\
\hline 77242 & $800 \mathrm{~nm}$ & Ruled & 50 & $x 8$ & 25.6 & $530-1200 \mathrm{~nm}$ & $450 \cdot 1300 \mathrm{~nm}$ & $655 \mathrm{~nm}$ \\
\hline 77243 & $750 \mathrm{~nm}$ & Ruled & 600 & $x 2$ & 6.4 & $500-1125 \mathrm{~nm}$ & $400.1500 \mathrm{~nm}$ & $164 \mathrm{~nm}$ \\
\hline
\end{tabular}

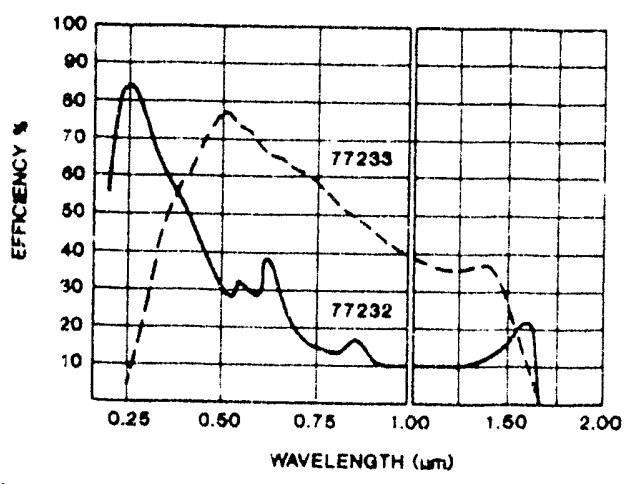

Fiq. 1 Efflclency of $1200 \mathrm{t} / \mathrm{mm}$ grating relative to aluminum coating. 


\section{$\square F I E I, 1 / 4 \mathrm{M}$ MONOCHROMATOR/SPECTROGRAPH SLITS}

We offer three types of slit assemblies:

- Variable Slits-continuously adjustable slit width.

- Multiple Fixed Slit Wheel with 8 slit widths.

- Single Fixed Slit Assembly with choice of 8 slit widths.

Each slit type has 1.5 Irich Series flanges to support our range of 1.5 inch Series accessories, sources, and detectors.

\section{CHOOSING A SLIT}

The entrance and exit slits of a monochromator determine the throughput and bandpass. For convenience we list here the major considerations in choosing a slit.

Three of the most common applications of the 77200 are:

\section{As a source monochromator.}

The desired bandpass often determines the slit width. The bandpass of the transmitted light is approximated by:

Slit width $X$ Reciprocal dispersion fer an input with a continuous spectrum such as light from a xenon or QTH lamp.

Closing the slits reduces the bandpass and the power through the monochromator.

2. A detector monochromator for spectral analysis.

The most important step is deciding the largest bandpass which gives the spectral information required. Refer to Fig. 1. Work with the largest bandpass you can get away with for maximum signal. A wide slit means a large bandpass, which has the additional benefit of simpler coupling of a source into the monochromator.

3. With instaspec or other array detector.

System resolution is best with a smaller slit width, down to about twice the element width.

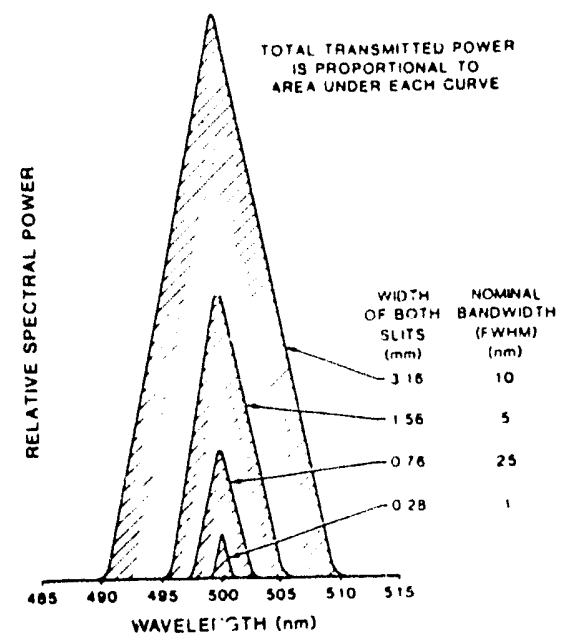

Fig. 1 Transmitted power for broadband and uniform source which overtills the $3.16 \mathrm{~mm}$ slits varies as the square of the slit width.

\section{VARIABLE SLIT ASSEMBLY}

The 77248 Variable Slit Assembly offers the most flexibility. Slit width is continuously adjustable from 20 um to $3.2 \mathrm{~mm}$. The corresponding bandpass ranges from $0.13 \mathrm{~nm}$ to $10 \mathrm{~nm}$ when used with a $1200 \mathrm{l} / \mathrm{mm}$ grating. Multiply by the Grating Factor for other gratings. The adjustment wheel has index markings every $0.1 \mathrm{~mm}$. The slit height is also adjustable. A sliding wedge aperture varies the height from $1 \mathrm{~mm}$ to $12 \mathrm{~mm}$.

A flange on the outside of this slit assembly lets you mount any of the Oriel 1.5 inch Series accessories described on pages 155 to 157 on Oriel Detectors.

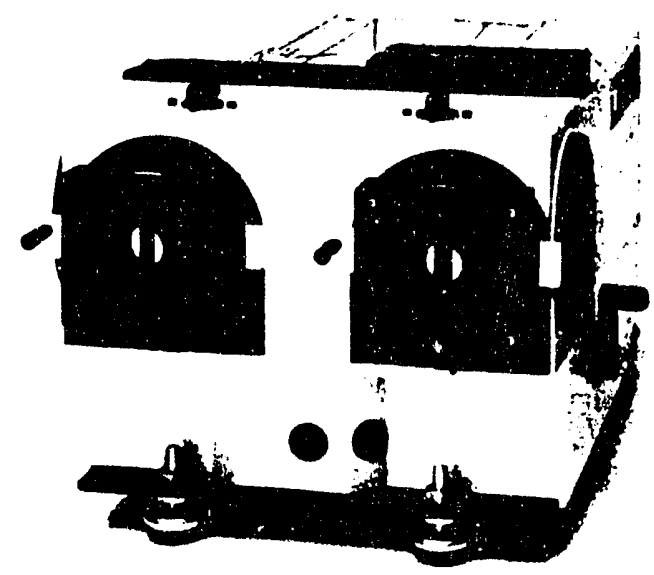

77200 Monochromator with 77248 variable slits.

\section{C -41}




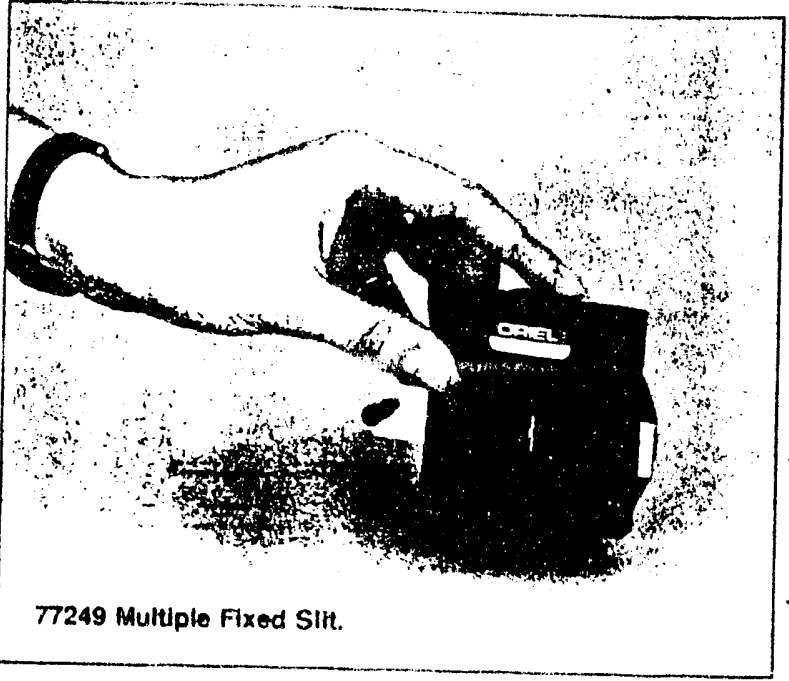

MULTIPLE FIXED SLIT

The 77249 consists of 8 fixed slits on a wheel. The slit wiaths are listed below. The wheel has a positive detent for exact repeatability of slt position. A sliding wedge adjusts the slit height from $11012 \mathrm{~mm}$.

The table below lists the approximate bandpass of these slits when used with a $1200 \mathrm{l} / \mathrm{mm}$ grating. Multiply by the Grating Factor for other gratings

The 77249 has a llange 10 support any of our 1.5 Inch Series Accessories described on pages 155 to 157

Approximate Bandpass of Multiple Fixed Slits when used with a $1200 \mathrm{l} / \mathrm{mm}$ grating.

\begin{tabular}{|c|c|c|}
\hline Slit Position & Width (um) & $\begin{array}{c}\text { Bandpass } \\
\text { (nm) }\end{array}$ \\
\hline 1 & 50 & 0.25 \\
2 & 120 & 0.5 \\
3 & 280 & 1 \\
4 & 600 & 2 \\
5 & 1240 & 4 \\
6 & 760 & 25 \\
7 & 1560 & 5 \\
8 & 3160 & 10 \\
\hline
\end{tabular}

\section{FIBER OPTIC SLIT REPLACEMENTS}

We offer single fibers and fibet optic bundles with rec tangular outputs that can act as Monochromator Slits. See page 248 for details

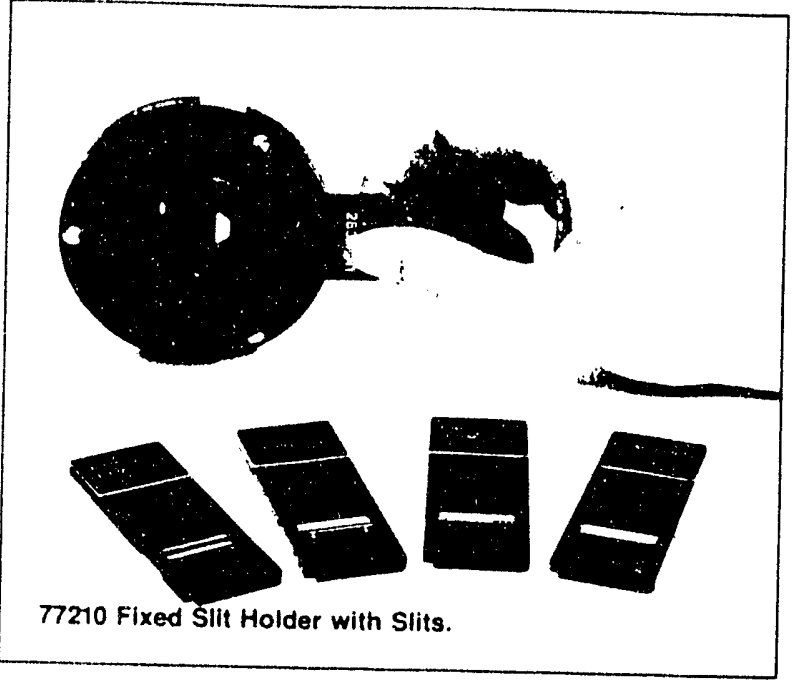

\section{FIXED SLITS}

Fixed slits are a good choice when only one or two widths are required. Eleven different precision slits, each separately mounted in a machined slide, are available for quick and repeatable insertion into the 77210 Fixed Slit Holder.

These slits cover a range from $10 \mathrm{um}$ to $6.32 \mathrm{~mm}$ in width. The table below lists the approximate bandpass of these slits when used with a $1200 \mathrm{l} / \mathrm{mrn}$ gratıng.

The 77210 Fixed Slit Holder accepts 1.5 Inch Series Accessories.

Approximate Bandpass of Multiple Fixed Slits when used with a $1200 \mathrm{l} / \mathrm{mm}$ grating.

\begin{tabular}{|c|c|c|c|}
\hline $\begin{array}{c}\text { Model } \\
\text { No. }\end{array}$ & $\begin{array}{c}\text { Width } \\
\text { (um) }\end{array}$ & $\begin{array}{c}\text { Height } \\
\text { (mm) }\end{array}$ & $\begin{array}{c}\text { Bandpass (nm) } \\
\text { (at 500 nm) }\end{array}$ \\
\hline 77222 & 10 & 2 & 0.1 \\
77220 & 25 & 3 & 0.15 \\
77219 & 50 & 6 & 0.25 \\
77218 & 120 & $18^{\circ}$ & 0.5 \\
77217 & 280 & $18^{\circ}$ & 1 \\
77216 & 600 & $18^{*}$ & 2 \\
77215 & 760 & $18^{\circ}$ & 2.5 \\
77214 & 1240 & $18^{\circ}$ & 4 \\
77213 & 1560 & $18^{\circ}$ & 5 \\
77212 & 3160 & $18^{\circ}$ & 10 \\
77211 & 6320 & $18^{\circ}$ & 20 \\
\hline
\end{tabular}

- Since these slits are $18 \mathrm{~mm}$ high, more throughput is available trom extended sources and Photoilax'm with
higher power lamps.

\section{INPUT SLIT FOR 77200 USED AS A SPECTROGRAPH}

When using the 77200 as a spectrograph only one slit assembly is needed Choose the type of slit assembly. Variable. Multiple Fixed. or Fixed for your application. 


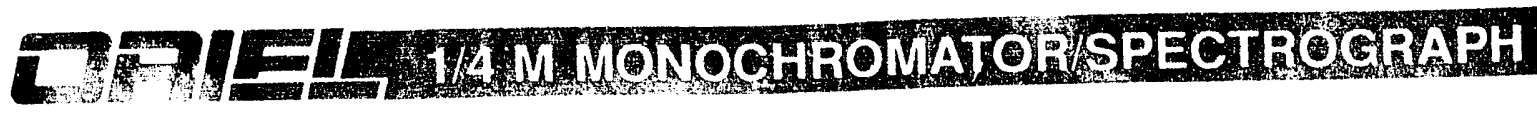

\section{Mounting Information}

The 77200 weighs 12 lbs. ( $5.5 \mathrm{~kg}$ ). For some applications, par icularly those where the critical optical components are supported off the 77200 , no fastening is necessary. We supply four instrument feet with the 77200 . These are for leveling and provide 0.63 inch (16 mimi height nejustment.

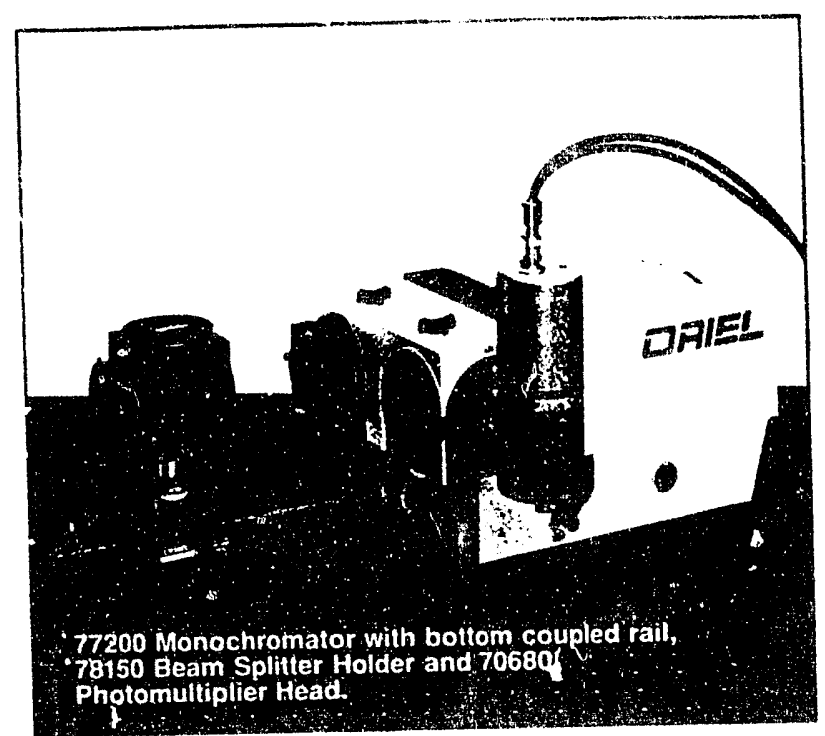

\section{BOTTOM-COUPLED RAIL.}

The 77252 Special Table Rail may be bolted to the bottom of the monochromator to facilitate bringing light to or from the instrument. It is very convenient when the 77200 is used on a desktop oi standard wooden lab bench.

The center of the rail lies under either one parallel port or the two lateral ports. Use two rails to mount accessories at both parallel ports.

The 77252 is 24.0 inches $(610 \mathrm{~mm})$ long. It extends out. ward from the monochromator so carriers can be placed on it ts nold optical components in line with the corts. Order car. riers and optical mounts from Volume 1.

\section{MOUNTING TO A RAIL OR BENCH}

The Bottom Coupled Rail duscribed above attaches directiy to the monochromator in a fixed position. and components translate along it. To transinte the monochromator along a table rail or optical bench order the 77292 Set of Adapter Bars and four 11641 Narrow Carriers. You will need two rails separated by 8 inches when using the lateral ports and 4 inches when using the parallel ports. Order carriers and raits trom volume!.

\section{MOUMTING TO AN OPTICAL. TABLE}

Fixing the 77200 in place can save a lot of trustration when working with exterded opticel arrangements. Use the mounting holes on the monoctromator base 10 bolt it directly 10 optical tables with enther 10 inch or $25 \mathrm{~mm}$ hote spacing. The optical height is 40 inches $(102 \mathrm{~mm})$. For wher optical heights use the precision spacers on pege 241

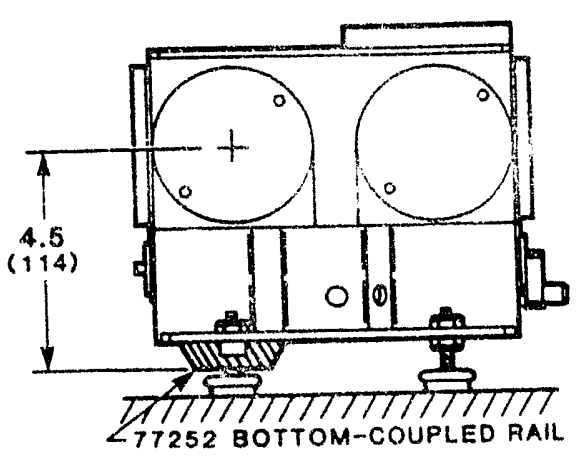

Dimension in inches $(\mathrm{mm})$.

Flg. 1 Monochromator with 77252 Table Rall mounted along parallel port.

\section{ROD MOUNTING}

Four tapped holes in the underside of the 77200 accept Oriel Bench Rods. You should use four rods if you wish to rod mount this device. The minimum practical optical height will be about 7.0 inchas $(178 \mathrm{~mm}$ ). (See Fig. 2.)

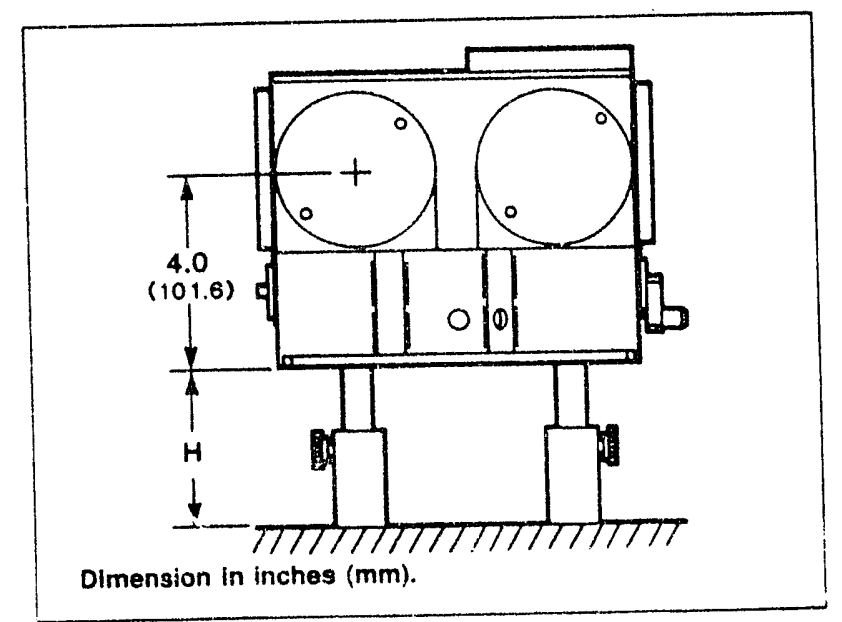

Fig. 2 Monochromator rod mounted to optical table.

\section{MOUNTING WITH THE MONOCHROMATOR \\ ILLUMINATOR}

The 7345 Monochromator Illuminaiur on page 167 is a dual source illuminator. Using two sourres is otten necessary to extend the usable spectral range. The 77475 Mounting Kit mounts the 7345 and 77200 together. The llluminator is matched to the 77200 .

\section{MOUNTING WITH PHOTOMAX}

See pages 234-241 for performance and hardware for use of the 77200 with the efficient Photomax Lamp Housing. 


\section{UFHEI $1 / 4 \mathrm{M}$ DOUBLE MONOGHROMATOR}

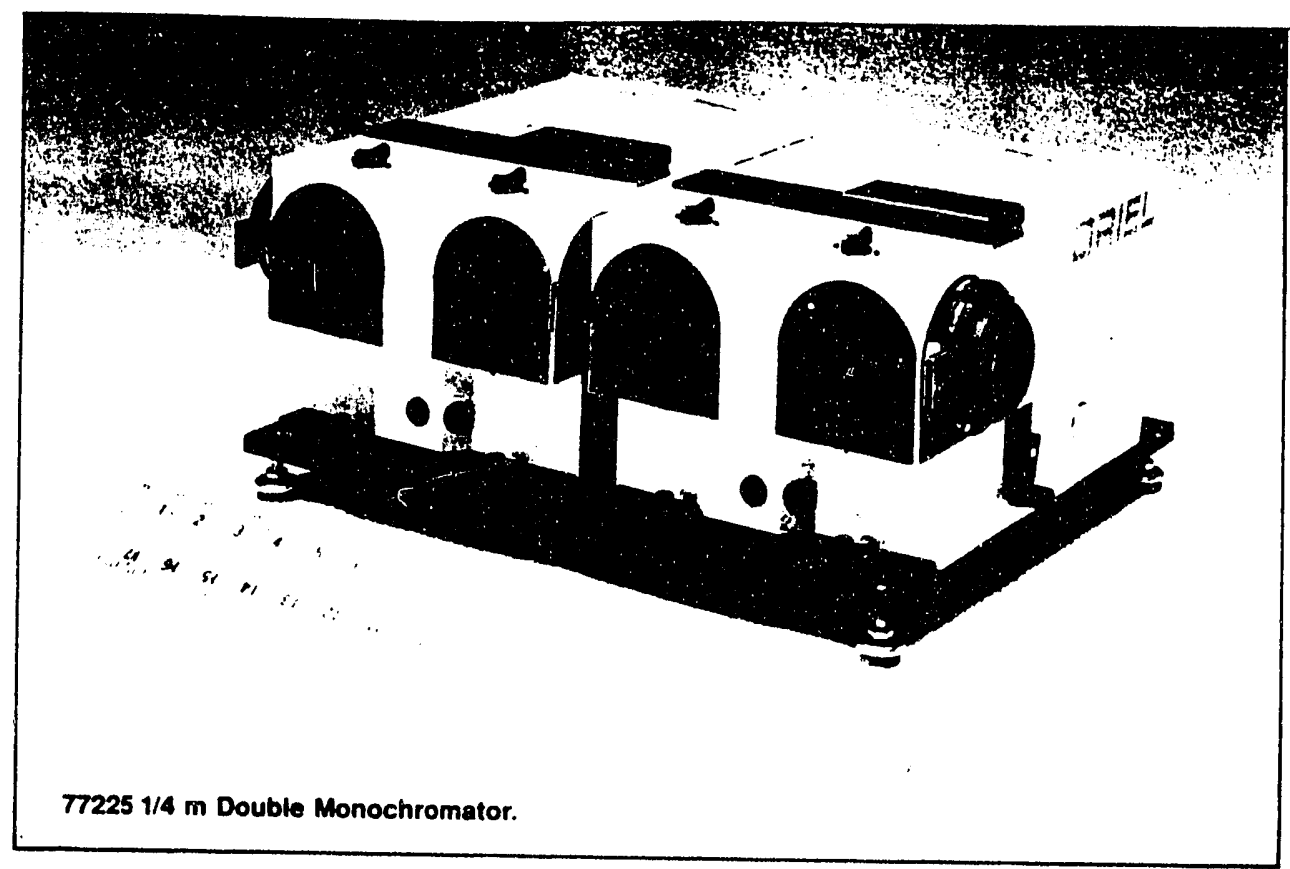

The outstanding resolution and the low stray light of the $1 / 4$ $m$ monochromator are further enhanced by combining two 77200 Monochromators into a double monochromator. The stray light of the combination is negligible while the bandwidth is halved. (See Fig. 1.) For a given slit width the throughput is, of course, reduced. Usually the stray light performance is the motivation for going to the double monochromator. In this case it is often possible to compensate for the reduced throughput by increasing the slit width to admit more of the source image. Opening the slits also transmits more radiation for a source with a bandwidth wider than the instrument bandpass.

\section{THE 77225 DOUBLE MONOCHROMATOR}

The 77225 Double Monochromator consists of two 77200 Monochromators in optical tandem. A single center slit serves as the lateral exit slit of one and the lateral entrance slit of the other. The dispersions of the two monochromators are added. A mechanical assembly couples the two units without light leakage, and holds the common center slit. The wavelength drive shafts are coupled together so a single crank or motor drives both units. A common base plate holds the monochromators in alignment.

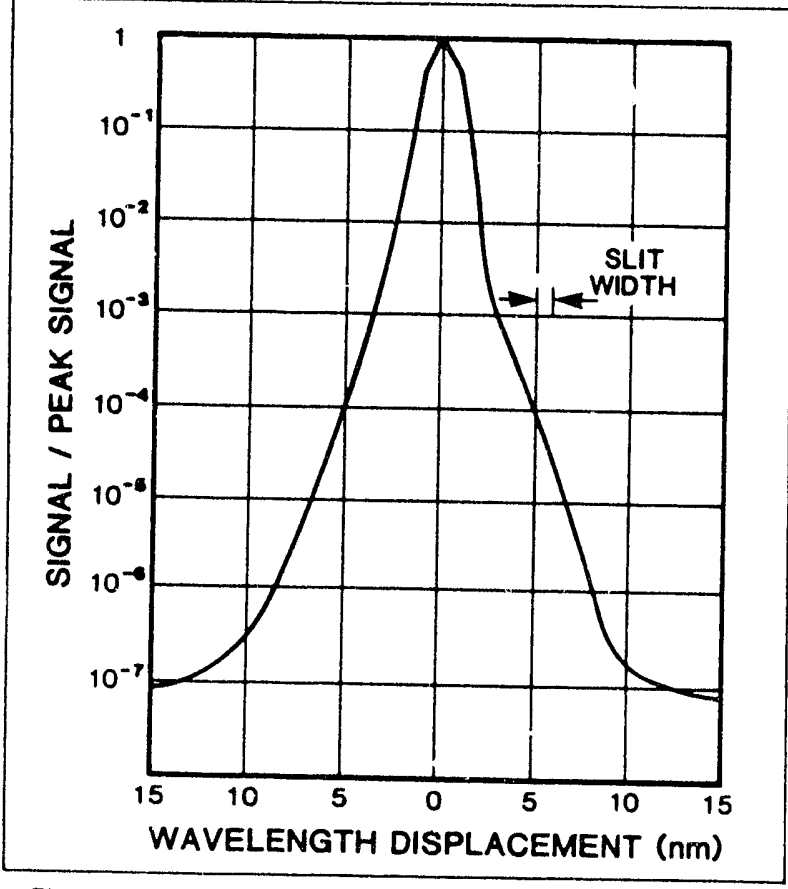

Fig. 1 Ratio of measured output signal to the peak signal as the wavelength of the 77225 Double Monochromator was changed from 617 to $648 \mathrm{~nm}$ with a HeNe laser at $632.8 \mathrm{~nm}$ focused into the monochromator at F/5. Both monochromators were fitted with 772331200 $1 / \mathrm{mm}$ gratings blazed at $500 \mathrm{~nm}$. The performance is even better with 77231 holographic gratings. 


\section{$\square F=1,1 / 4$ M DOUBLE MONOCHROMATOR MOUNTING}

\section{PRODUCT NUMBERS AND WHAT YOU SHOULD ORDER}

The 77225 Double Monochromator consists of two 77200 $1 / 4$ Meter Monochromators aligned on a base plate with a center slit assembly. In addition to the 77225 you should order two identical gratings, two slit assemblies for the entrance and exit ports and a fixed slit for the center port. Select holographic gratings for the very best stray light performance. The center slit should be at least $0.5 \mathrm{~mm}$ wider than the entrance and exit slits; if you choose variable or multiple slit assemblies for the input and output, then order several fixed slits for the center.

If you already have one or two 77200 s and want to set up the double monochromator, order the 77226 Conversion Kit. This has all that is required to convert two single 77200 s (with identical gratings) to the 77225 except for the center slit. Order a center slit appropriate to your input and output slits.

\section{STRAY LIGHT}

The second m mochromator accepts the total output of the first, including the stray light. It then passes the desired waveband and rejects the input stray light component. Any light which enters the second monochromator can, of course, be scattered and become stray light. Restrict the width of the center slit to no more than $0.5 \mathrm{~mm}$ larger than the other slits to minimize unwanted radiation passing into the second monochromator.

We have measured the stray light of the 77225 Double Monochromator for the two meaningful conditions described on page 213 for the 77200 Single Monochromator.

- Using 77232 Holographic Gratings, $1 \mathrm{~nm}$ bandpass, a 6312 Deuterium Lamp, the 77345 Photomultiplier, and a glass filter, the stray light was $5 \times 10^{.5 \%}$ of the signa! for the 77225 . This contrasts with the $0.14 \%$ for the single 77200 .

- Using 77233 Holographic Gratings, and a : HeNe laser at $632.8 \mathrm{~nm}$, the stray light at 622.8 and $642.8 \mathrm{~nm}$ was $2 \times 10^{-5 \%}$ of the signal.

\section{DOUBLE MONOCHROMATOR WITH INSTASPEC}

The 77225 Double Monochromator can be used with InstaSpec', our diode array, with significant reduction of stray light. Since the dispersion is doubled, the spectral range covered is only half that obtained with a single mono. chromator using the same grating.

When using the 77225 with InstaSpec', a special center slit is required. The 77207 slit is 0.6 inches $(15 \mathrm{~mm})$ wide by 0.15 inches $(4 \mathrm{~mm})$ high.
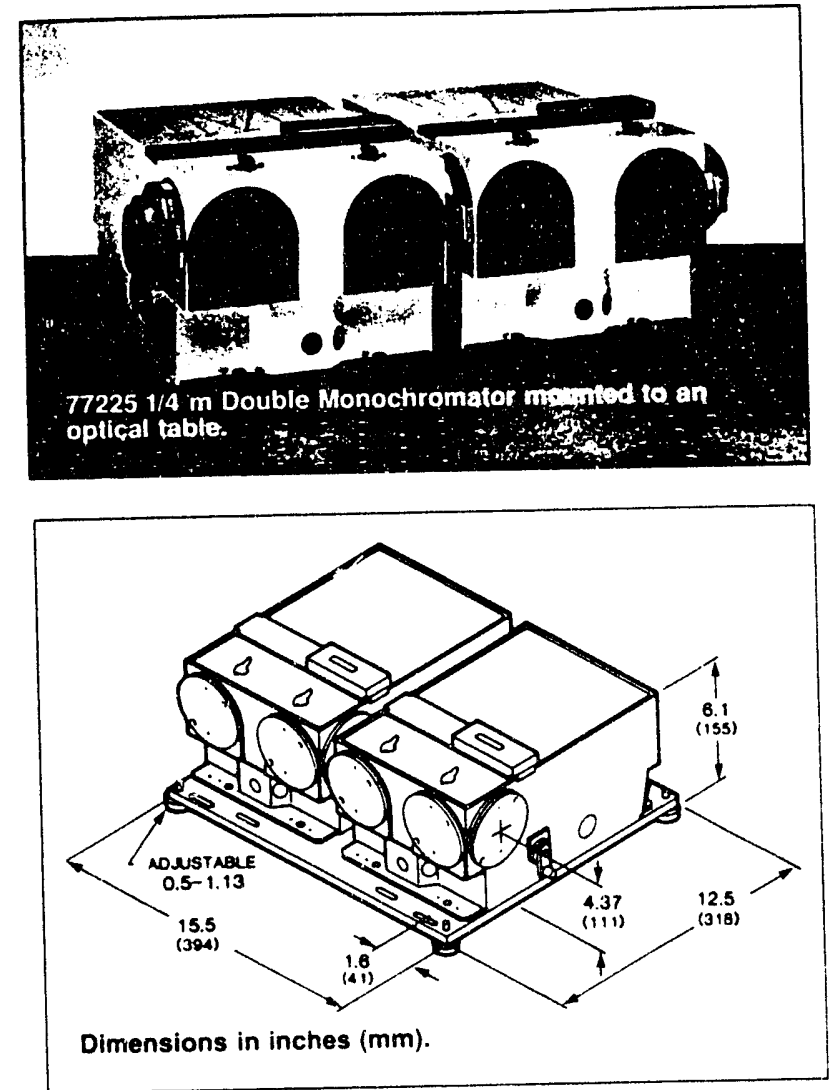

Fig. $2772251 / 4 \mathrm{~m}$ Double Monochromator. 
You can use the model $7.2251 .4 \mathrm{~m}$ Double Monochroma tor as a stand-alone unit. The four instrument feet allow the optical height to be adjusted trom 05 to 1.13 inches (13 to 29 $\mathrm{mm})$ Or, mount the 77225 directly to optical tables. Tech Bases. or carriers in a fixed height position

\section{FIXED HEIGHT MOUNTING}

\section{To Optical Table or TechBase}

You can fix the 77225 to optical tables with holes on 1.0 inch or $25 \mathrm{~mm}$ centers. The base plate has separate slots for inch and metric hole patterns. The slots allow 1.0 inch 125 $\mathrm{mm}$ ) adjustment along the parallel ports. The optical height is 4.4 inches $(112 \mathrm{~mm})$ above the table surface. Use spacers from page 211 to raise the height. (See Fig. 1 below.)

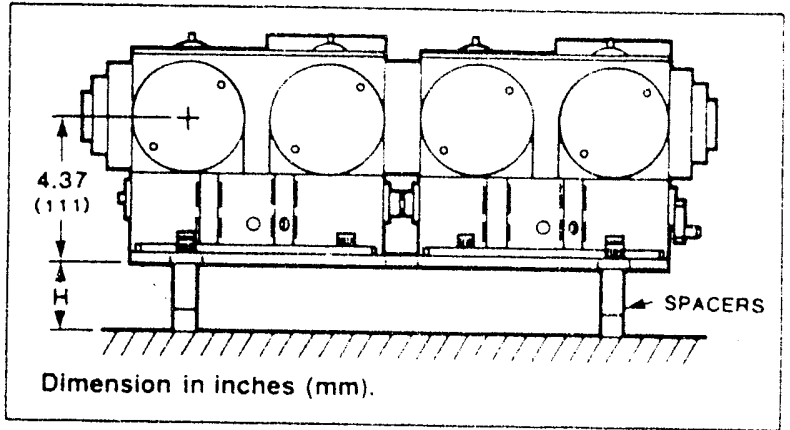

Fig. i 77225 Double Monochromator shown in lateral (in-line) configuration mounfed to table with spacers.

\section{To Optical Benches or Rails}

To mount the 77225 Double Monochromator io benches or rails order the 77293 Set of Adapter Bars. iwo standard benches or rails $(24.0$ inches $(610 \mathrm{~mm})$ in length or longer) and four 11641 Narrow Carriers.

The two adapter bars mount to the bottom of the Double Monochromator base plate and to the carriers. They lie perpendicular to the ralls. providing a sturdy square frame on which the monochromator system rests. See Fig. 2 below and photo on right.

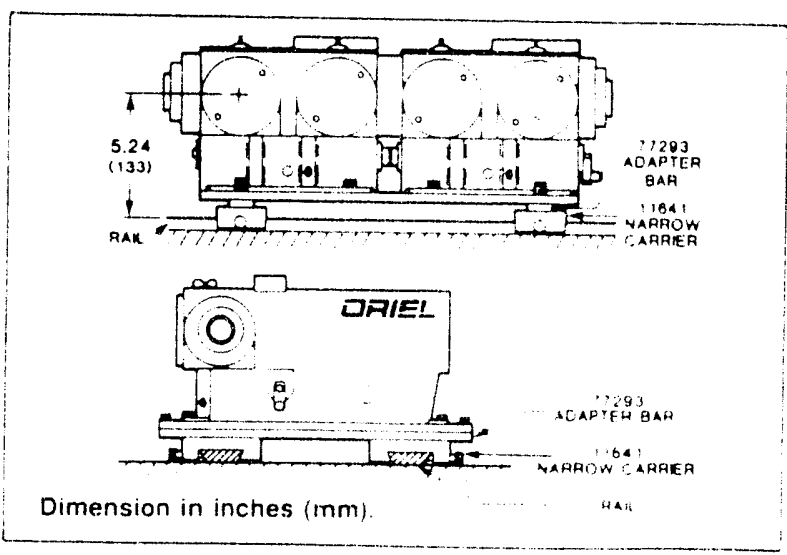

Fig. 2 Front and side view of 77225 Double

Monochromator mounted to 11522 Table

Rails using the 77293 Adapter Bars and

11641 Narrow Carriers Lateral (in-lirie)

configuration snown
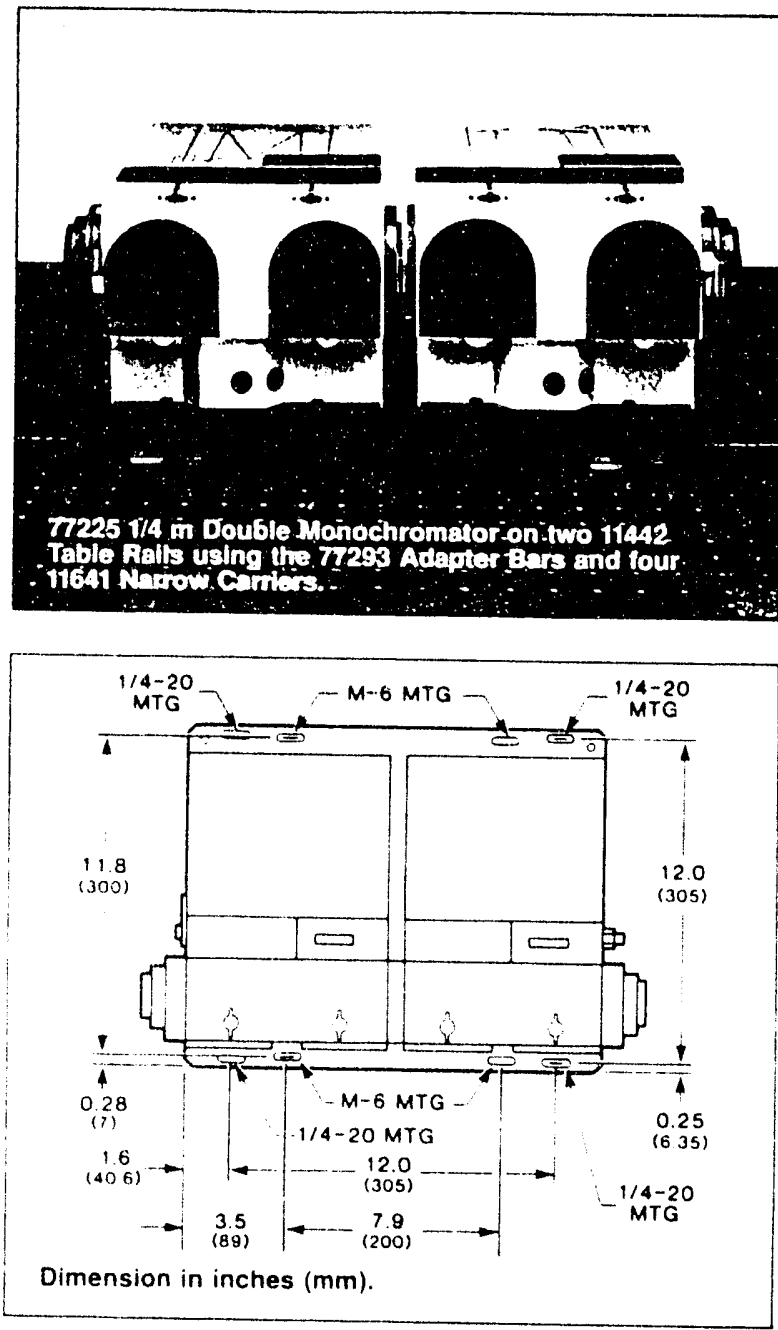

Fig. 3 Dimensions and mounting hole locations for 77225. Top view of lateral (in-line) configuration. 


\section{DRIEI ORDERING INFORMATION}

\section{For $1 / 4 \mathrm{~m}$ Monochromator/Spectrograph}

\footnotetext{
MONOCHPOMATORS SPECTROGRAPHS

77200 MONOCHROMATOR/...................... 2783.00 SPECTROGRAPH HOUSING

$\$ 3450.00$

77201 VIS.NIR MONOCHROMATOR Includes 77233 Grating, and two 77217 Slits with Fixed Slit Holders. (Range: $300-1000 \mathrm{~nm}$ )

77202 VIS-NIR MONOCHROMATOR $\$ 3970.00$ Includes 77233 Grating, and two 77248 Variable Slit Assemblies. (Range: $300-1000 \mathrm{~nm}$ )

77203 VIS.NIR MONOCHROMATOR ...............\$4044.00 Includes 77233 Grating, and two 77249 Multiple Fixed Slit assemblies. (Range: $300 \cdot 1000 \mathrm{~nm}$ )

77225 DOUBLE MONOCHROMATOR/ SPECTROGRAPH Includes two 77200 monochromator housings, com. mon base, wavelength drive adapter, center fixed stit holder, and factory assembly and alignment. Order gratings, input and output slit assemblies, and center fixed slit separately.

For Double Monochromator

(a) Choose two identical grating assemblies.

(b) Choose inputoutput stit assemblies:

two variable slits

- two multiple fixed slit wheels

- two interchangeable fixed slit holders and two fixed slits

(c) Order a center fixed slit. The fixed slit width should be larger than the inputoutput slit widths, and at least $0.5 \mathrm{~mm}$ wide.

For Double Spectrograph.

(a) Choose two identical grating assemblies

(b) Choose input slit assembly.

(c) Order 77207 Center Slit.

77226 Double Monochromator Conversion Kit s... 5446.00 Includes common base. wavelength drive adapler, and center fixed slit holder. Order center fixed slit separately.
}

\section{SLIT ASSEMBLIES AND SLITS}

77248 Variable Slit 20 um to $3.2 \mathrm{~mm}$ variable. width. 1 to 12 $\mathrm{mm}$ variable height

77249 Multiple Fixed Slit Wheel Eight Slits, 1 to $12 \mathrm{~mm}$ variable height

77210 Interchangeable Fixed Slit Holder 77211 Fixed Slit. $6.32 \mathrm{~mm} .18 \mathrm{~mm}$ high 77212 Fixed Slit. $316 \mathrm{~mm}, 18 \mathrm{~mm}$ high 77213 Fixed Slit. $1.56 \mathrm{~mm}, 18 \mathrm{~mm}$ high 77214 Fixed Slit. $124 \mathrm{~mm} .18 \mathrm{~mm}$ high 77215 Fixed Slit. $760 \mathrm{um}, 18 \mathrm{~mm}$ high 77216 Fixed Slit, $600 \mathrm{um}, 18 \mathrm{~mm}$ high 77217 Fixed Sitt, $280 \mathrm{um} .18 \mathrm{~mm}$ high 77218 Fixed Slit. $120 \mathrm{um}, 18 \mathrm{~mm}$ high 77219 Fixed Slit. 50 um. $6 \mathrm{~mm}$ high 77220 Fixes Slit. 25 um. $3 \mathrm{~mm}$ high 77222 Fixec Slit. 10 um, $2 \mathrm{~mm}$ high

77207 Center Slit for Double Spectrograph with InstaSpec: $06 \times 0.15$ inches
GRATING ASSEMBLIES

All gratings are mounted in quick interchange holders.

\begin{tabular}{|c|c|c|}
\hline 77230 & $\begin{array}{l}\text { Holographic Grating } \\
175.500 \mathrm{~nm}, 2400 \mathrm{l} / \mathrm{mm}\end{array}$ & $\$ 415.00$ \\
\hline 77231 & $\begin{array}{l}\text { Holographic Grating } \\
180-700 \mathrm{~nm}, 1200 \mathrm{l} / \mathrm{mm}\end{array}$ & $\$ 415.00$ \\
\hline 7232 & $\begin{array}{l}\text { Grating, } 280 \mathrm{~nm} \text { Blaze } \\
175.700 \mathrm{~nm}, 1200 \mathrm{l} / \mathrm{mm}\end{array}$ & $\$ 289.00$ \\
\hline 77233 & $\begin{array}{l}\text { Grating, } 500 \mathrm{~nm} \text { Blaze } \\
300-1000 \mathrm{~nm}, 1200 \mathrm{l} / \mathrm{mm}\end{array}$ & \$ 289.00 \\
\hline 77234 & $\begin{array}{l}\text { Grating. } 1.0 \text { um Blaze } \\
0.6-2.0 \mathrm{um}, 600 \mathrm{l} / \mathrm{mm}\end{array}$ & \$ 289.00 \\
\hline 77235 & $\begin{array}{l}\text { Grating. } 2.0 \mathrm{um} \text { Blaze } \\
1.2-4.0 \mathrm{um}, 300 \mathrm{Vmm}\end{array}$ & $\$ 289.00$ \\
\hline 7236 & $\begin{array}{l}\text { Grating, } 4.0 \text { um Blaze } \ldots . . \\
2.4-8.0 \mathrm{um}, 150 \mathrm{l} / \mathrm{mm}\end{array}$ & \$ 289.00 \\
\hline 237 & $\begin{array}{l}\text { Grating, } 8.0 \text { um Blaze } \cdots \\
4.8 \cdot 16.0 \mathrm{um}, 75 \mathrm{imm}\end{array}$ & S 289.00 \\
\hline 7238 & $\begin{array}{l}\text { Grating, } 12.0 \mathrm{um} \text { Blaze } \\
7.2-24 \mathrm{um} .50 \mathrm{l} / \mathrm{mm}\end{array}$ & $\$ 289.00$ \\
\hline 7239 & $\begin{array}{l}\text { Grating, } 200 \mathrm{~nm} \text { Blaze } \\
175-500 \mathrm{~nm}, 600 \mathrm{~V} / \mathrm{mm}\end{array}$ & $\$ 289.00$ \\
\hline 7240 & $\begin{array}{l}\text { Grating, } 550 \mathrm{~nm} \text { Blaze } \\
300-900 \mathrm{~nm}, 400 \mathrm{~V} / \mathrm{mm}\end{array}$ & \$ 289.0 \\
\hline 77241 & $\begin{array}{l}\text { Grating, } 730 \mathrm{~nm} \text { Blaze } \ldots . . \\
400-1200 \mathrm{~nm}, 200 \mathrm{l} / \mathrm{mm}\end{array}$ & $\$ 289.0$ \\
\hline 77242 & $\begin{array}{l}\text { Grating, } 800 \mathrm{~nm} \text { Blaze } \cdots \\
450.1300 \mathrm{~nm}, 150 \mathrm{~V} / \mathrm{mm}\end{array}$ & \$ $289 . C$ \\
\hline 7243 & $\begin{array}{l}\text { Grating. } 750 \mathrm{~nm} \text { Blaze... } \\
400.1500 \mathrm{~nm}, 600 \mathrm{l} / \mathrm{mm}\end{array}$ & 9.0 \\
\hline
\end{tabular}

\section{MOUNTING ACCESSORIES}

77252 Monochromator Table Rail

$\$ 155.00$

24 inches long. Attaches to tortom of 77200 .

77292 Set of Adapter Bars (For bench or rail mounting 77200.)

77293 Set of Adapter Bars (For bench or rail mounting 77225 .)

$\$ 139.00$

$\$ 139.00$ See page 211 for Precision Spacer Sets and Fods and Rod Holders. 


\section{$\square=2$, INSTASPEC'" II - SPECIFICATIONS}

\section{THE INSTASPEC" " I SYSTEM}

Individual specifications of the components available from Oriel are detailed below. Some suggested completely integrated systems are listed on page 358, and itemized components on page 359.

A complete Basic InstaSpec " II System consists of:

- Uncooled Diode Array Detector Head

- Controller

- Optional Spectrograph (for spectroscopy)

- Low Speed Interface Card

- XT Type Computer

- Hercules Graphics Card and Monitor

- Software

- Printer

\section{A complete Advanced InstaSpec' "I System} consists of:

- Thermoelectrically Cooled Diode Array Detector Head

- Controller

- Thermoelectric Cooler Control Cara

- InstaCool" Refrigerated Recirculator

- InstaDry" Purging Unit

- Optional Spectrugraith (fer spectroscopy)

- High Speed Interface Card

- AT or 386 Type Computer

- EGA or VGA Color Graphics Card and Monitor

- Software

- Printer

- Plotter

A complete Diode Array Camera System consists of:

- Uncooled Camera Diode Array Detector Head

- Controller

- Camera, Mount and Lens

- Low or High Speed Interface Card

- XT, AT or 386 Type Computer

- Hercules, EGA or VGA Graphics Card and Monitor

- Software

- Printer and/or Plotter

\section{DETECTOR HEADS}

Three types of detector heads are available:

- Uncooled Deiector

- Thermoelectrically Cooled Detector

- Camera Detector Head

All three types are available with either 512 or 1024 ele. ment diode arrays.

\section{SPECIFICATIONS}

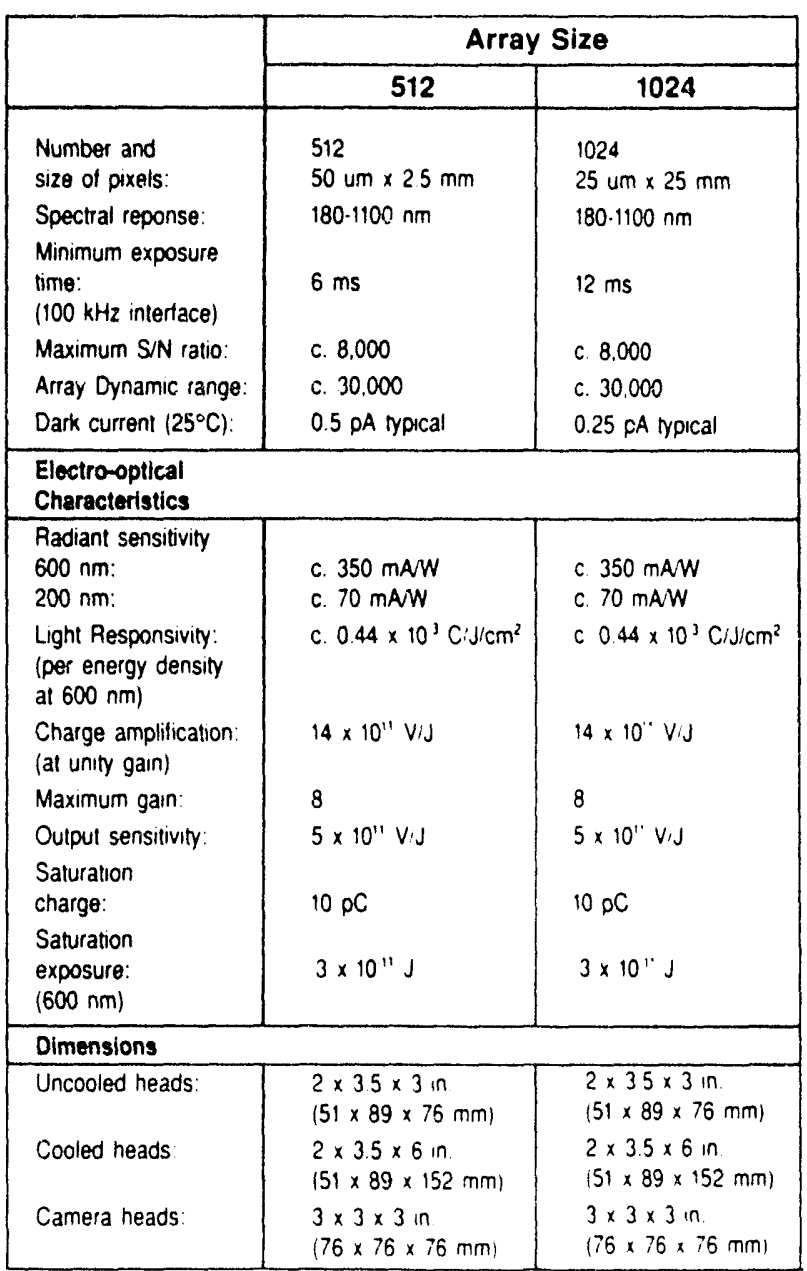


THEFIAOELECTRIC COCLER

Cooled detector heads only. Requires the thermoelectric cooler control card for the controller.

\section{Thermostated temperature}

Under normal ambient

Minimum with InstaCool

$5^{\circ} \mathrm{C}$

Temperature Stability

Fluctuations:

Dritt:

$\pm 0.1^{\circ} \mathrm{C}$

$\pm 0.5^{\circ} \mathrm{C} /{ }^{\circ} \mathrm{C}$

INSTACOOL REFRIGERATED RECIRCULATOR

This unit is used to pump refrigerated liquid through the detector head to lower the temperature of the diode array to as low as $-20^{\circ} \mathrm{C}$. Provision is also made for cooling the purging gas from InstaDry", or some other source of dried gas.

$\begin{array}{ll}\text { Temperature range: } & 50^{\circ} \mathrm{C} 10 \cdot 15^{\circ} \mathrm{C} \\ \text { Temperature stability: } & \pm 0.1^{\circ} \mathrm{C} \\ \text { Maximum pumping height: } & 10 \mathrm{tt} .(3 \mathrm{~m})\end{array}$

\section{CONTROLLER}

The controller provides power and timing signals to the detector head. It also sets the exposure time and coordinates the synchronizing signals to and from other instruments. The thermoelectric cooler control card is required for cooled detector heads.

Exposure time range:

$6 \mathrm{~ms} 1010 \mathrm{~min}$, and

line synchronized

Diode array read rate:

Dynamic range

12.5, 25, 50 and $100 \mathrm{kHz}$

BNC (TTL) Outputs

External synch:

12 bit

Video signal

Video trigger

Gate/Camera trigger

BNC (TTL) Inputs

Trigger Input:

Remote trigger

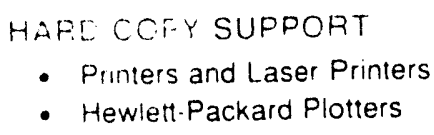

- Printers and Laser Printers

- Hewlett-Packard Plotters

\section{INTERFACES}

$\begin{array}{ll}\text { Low speed } & 25 \mathrm{kHz} 12 \text { bit AD board } \\ & \text { (XT computers only) } \\ \text { Medium speed. } & 50 \mathrm{kHz} 12 \text { bit ADD board } \\ & \text { (AT \& } 386 \text { computers only) } \\ & 50 \mathrm{k} 4 \mathrm{z} 12 \text { bit ADD board } \\ & \text { (PS/2 computers only) } \\ \text { High speed } & 100 \mathrm{kHz} 12 \text { bit AD board } \\ & \text { (AT \& } 386 \text { computers only) }\end{array}$

Other interface cards will be available at a later date.

\section{SOFTWARE}

- Instaspec "Program

Included with InstaSpec" system.

Stand alone executable program

Not copy protected

Operating manual included

- Programmer's Kit

Interfacing manual

Array drivers, subprograms and source code

\section{CAMERA SHUTTER}

This is a modified Nikon camera body for use as a fast mechanical shutter, and for imaging light sources onto a diode array detector. This permits the use of a wide variety of high quality $35 \mathrm{~mm}$ Nikon lenses. Only uncooled camera detector heads can be attached to the camera body. The InstaSpec ${ }^{2}$ Mounting Adapter, model 77150 , is required to accurately attach these heads to the camera body.

Camera type

Lens mount:

Lenses:

Shutter speeds
Nikon, $35 \mathrm{~mm}$ single-lens reflex Nikon bayonet mount

More than 70 Nikkor" and Nikon series $E$ lenses

Stepless from $1 \mathrm{~s}$ to $0.5 \mathrm{~ms}$ Manual and electronic ( $B$ setting)

\section{COMPUTER AND MONITOR SPECIFICATIONS}

Computer:

- XT (8086) compatible, with 8087 coprocessor

- AT (80286) compatible, with 80287 coprocessor

- 386 (80386) compatible, with 80387 coprocessor

- IBM PS/2 computer with appropriate coprocessor

640 kbytes of memory

Hard disk recommended

Other computers will be supported at a later date.

\section{Graphics Cards and Monitors:}

- Hercules card and monochrome $720 \times 348$ resolution monitor

- Enhanced Graphics Adapter (EGA) with color $640 \times$ 350 monitor

- Video Graphics Adapter (VGA) with color $640 \times 480$ monitor 


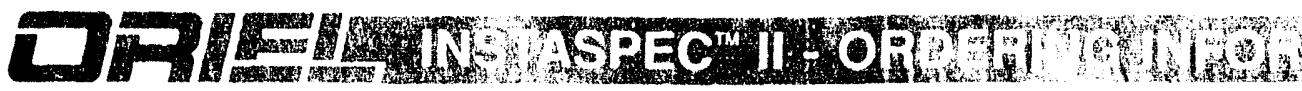

\section{COMPLETE INSTASPEC" SYSTEWIS}

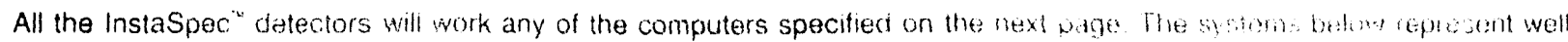

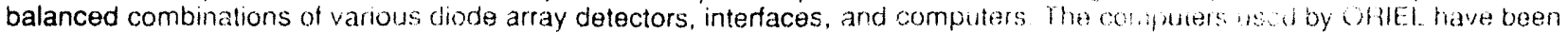
carefully evaluated for their supermor performance and quality.

Detectors can be purchased separately by those who already possoss a commuter system, andicu the combunalions can merely be considered as a guide for ordering individual components from the beriazed list at the end of this section

\section{THE INSTASPEC" XT SYSTEM}

This is the basic low cos! InstaSpec "system for imaging or spectroscopy. An additional spectrograph is required for spec. troscopic measurements

77160 InstaSpec" Xr Defector

- Uncooled 51 ? Gement Diode Array Detector Head

- Controtler

- InstaSpec "Software and Manual

- Low Speed interface Card

- Instaspec* Mouning flange

77170 XY 11 MHz Computor

- 640 kbyte RAM

- 8087 Coprocessor

- $51 / 4$ inch 360 kbyte Floppy Disí Orive

- 20 Mbyte Hard Disk

- Hercules Monochrorne Graphics Card and Monitor

- Parallel and Serial Ports.

- 9 Pin printer

\section{THE INSTASHEO" "Y SYSPIN}

This is the high sctiat, high resolution InstaSpec" system for imaging or specirsscopy $A$ additional spectrograph is required for spectioscoptc neasurements.

77161 InstaSpec Ar Detector

- Uncooled 1024 Element Diode Array Detector Head

- Controlier

- Instaspec "Soltware and Manua

- Medium Sotiod intertace Card

- Instaspec Ma zithing Flargge

\section{AT/286 $10 \mathrm{MHz}$ Computer}

- 1 Mbyte RAM

- 80287 Coprocessor

- 5 1/4 inch 12 Mbyte Floppy Disk Drive

- 40 Mbyte Hard Oisk

- EGA Graphics Ciard and Momior

- Parallel and Sermal Ports

- 24 Pin Printe

- Hewlett Packard Color Pro Plotler

\section{THE INSTASPEC ET SYSTEM}

This combines righ speed and long ofegration times using a cooled Instaspec system for unaging or spectroscopy. An additional spectrographis is required for spectroscopic mea surements.

77162 InstaSper ET Detector

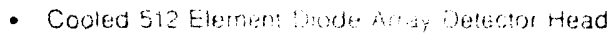

- Controller

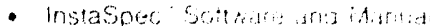

- Cooler coneros find

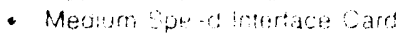

- Inetasuer Mourtina flanges

- Instadry Pugma Jom

77171 AT/236 $10 \mathrm{Mr}+2$ Computer

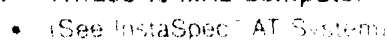

\section{THE INSTASPEC GT SYSTEM}

This is the top pertorring Instaspec "systen tt comblies very high acquisition speed, high resolution. and long integra. ton tumes, with excellent graphics cisplay Thus uses a conled instaspec "system for maging or spiertroscopy An additional spectrograph is tequmed for spectroscopic measurements.

77163 Insiaspec Gr Deteutor

- Cooled 1024 Elemer + Diode Array Detector Head

- Controller

- Instasper "Sormare and Manual

- Cooler Control Card

- High Speed Intellace Card

- InstaSpec Mouriting Flange

- InstaCool Fiecircutato

- Instabry Ptirging lint

$7717228020 \mathrm{MHx}$ Computer:

- Mbyte RaM

- B0287 Coprótessor

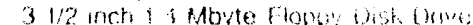

do Movts lard Disk

CoA Graphics Gard and hombor

Parallel and Seral Forts

- Cia Pir Prinar

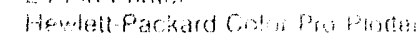

\section{THE INSTASPEC" IT SYSTEM}

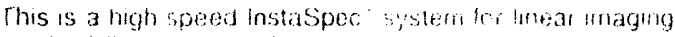
using the Nikon owmera shutter and thon ienses

77164 instesper, if Detector

* Uncooled 5 te Elemean Cadmata loode Array Detector Head

- Controller

- Instasper 'soityaro and Manual

- Meduin Suees tnlertace Card Camera Stumtter

- Instaspec Mounting Accessony

$105 \mathrm{~mm}$ VIS Lens Kil

77171 A $28610 \mathrm{MHz}$ Computer

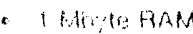

- gomir Coprocessor

5 1.4 weth 12 Muve Thopy Uist Dris 40 Mlyte Hard Dist

- ECin Graptucs Carro and limurar

- Paraliel and janal fors

$\therefore 2.4$ Pul Printer

Hewteil Packard Color Pro plomer 


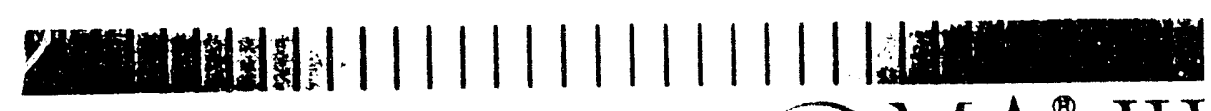 \\ OMA III}

\section{The Total Solution For All Your Spectroscopy Investigations}

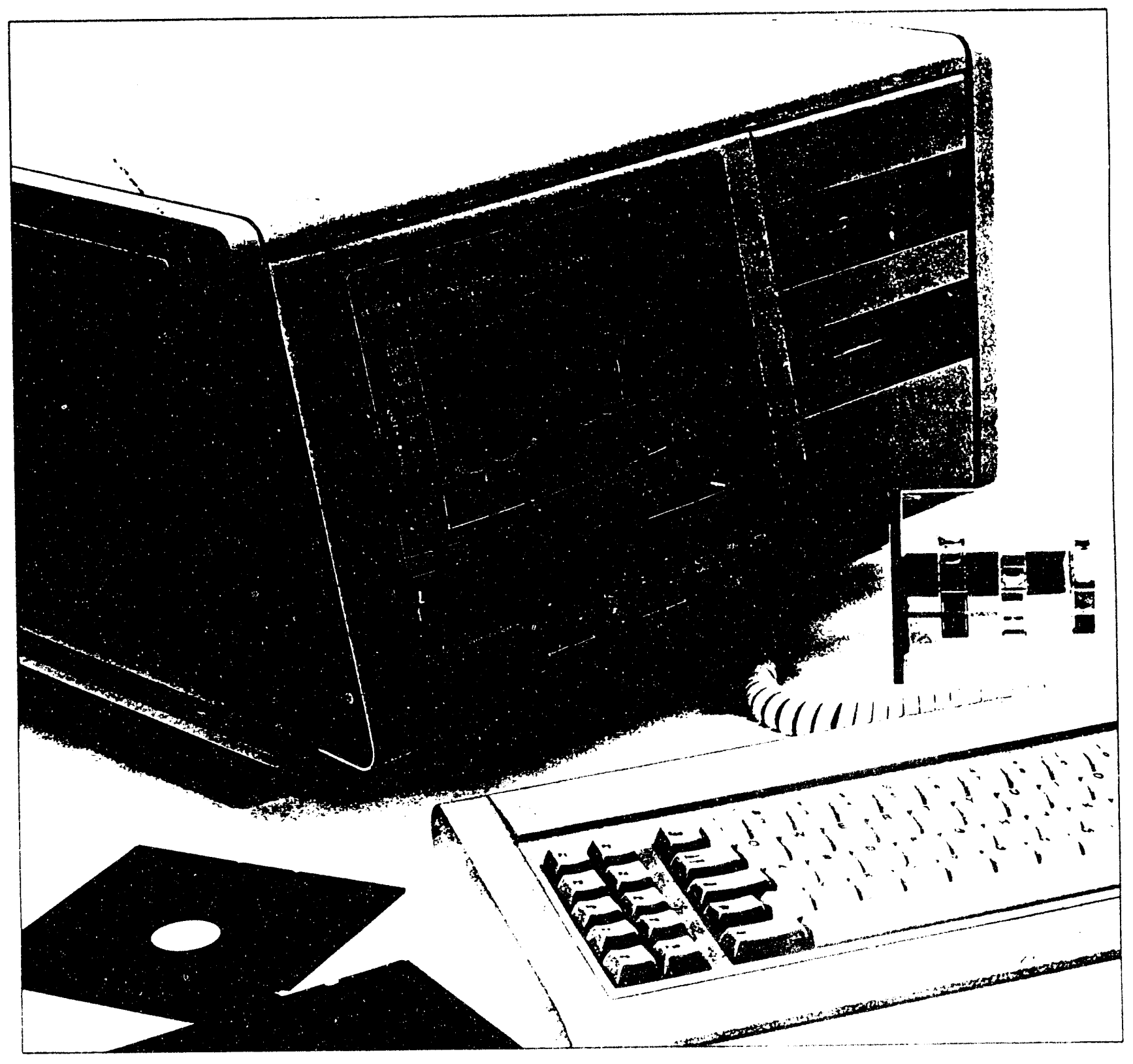

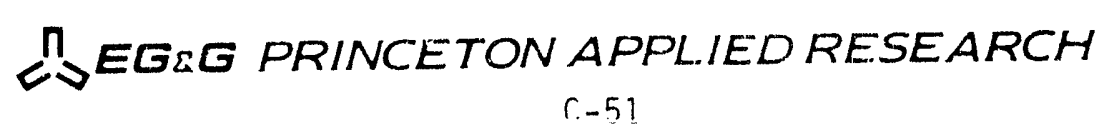


- Measure Multiple Wavelengths from the Near-Intrared to the $X$-Ray Region

OMA III, the state-of-the-art Optical Multichannel Analyzer system from EG\&G Princeton Applied Research Corporation, consists of an integrated family of multiple element ight detectors and signal processing equipment The OMA III can rapidly collect and analyze full spectrum data containing wavelengths from the near-infrared to the $x$-ray region

The basic OMA III system consists of a Model 1460 System Processor or a Model 1461 Detector Interface, alony with a diode array or Vidicon Detector and a Detector Controller module. The detector at the frunt end of most OMA systems is attached to a spectrograph. The OMA detector can be considered to operate like "electronic film" that replaces the single element detector of preOMA systems.

The Model 1461 OMA system requires an external computer. It should be your choice if you need to attach an OMA to an existing lab computer without sacrificing essential OMA power. The Model 1461 brochure describes that system more fully.
The Model 1460 OMA described in this brochure is a self-contaned system that you can literally unpack, set up, and run. It requires neither programming knowledge, nor external hardware or software to be able to acquire and fully process spectral data. The desktop-sized Model 1460 System Processor is the most prominent component of the system. It features Motorola 58000-based high speed signal processing. two double-sided. double-density floppy disk drives lone of which can be replaced by a 20 Mbyte hard disk). as well as a high resolution, touch-sensitive screen, an external keyboard, and front panel buttons for flexibility of control. All OMA III systems include schematic diagrams and a comprehensive operating manual.

With the OMA III, you won't have to compromise your experiment to match the requirements of our instruments. Through the 1460's friendly system of menus, you can easily change the system's setup and data acquisition parameters to meet your needs. In fact, it is so easy to learn to use our 1460-based OMA that you should find few occasions when you will find it necessary to refer to the manuai before running experiments.

-OMA is a registered irademark of Princeton Applied Research Corporation

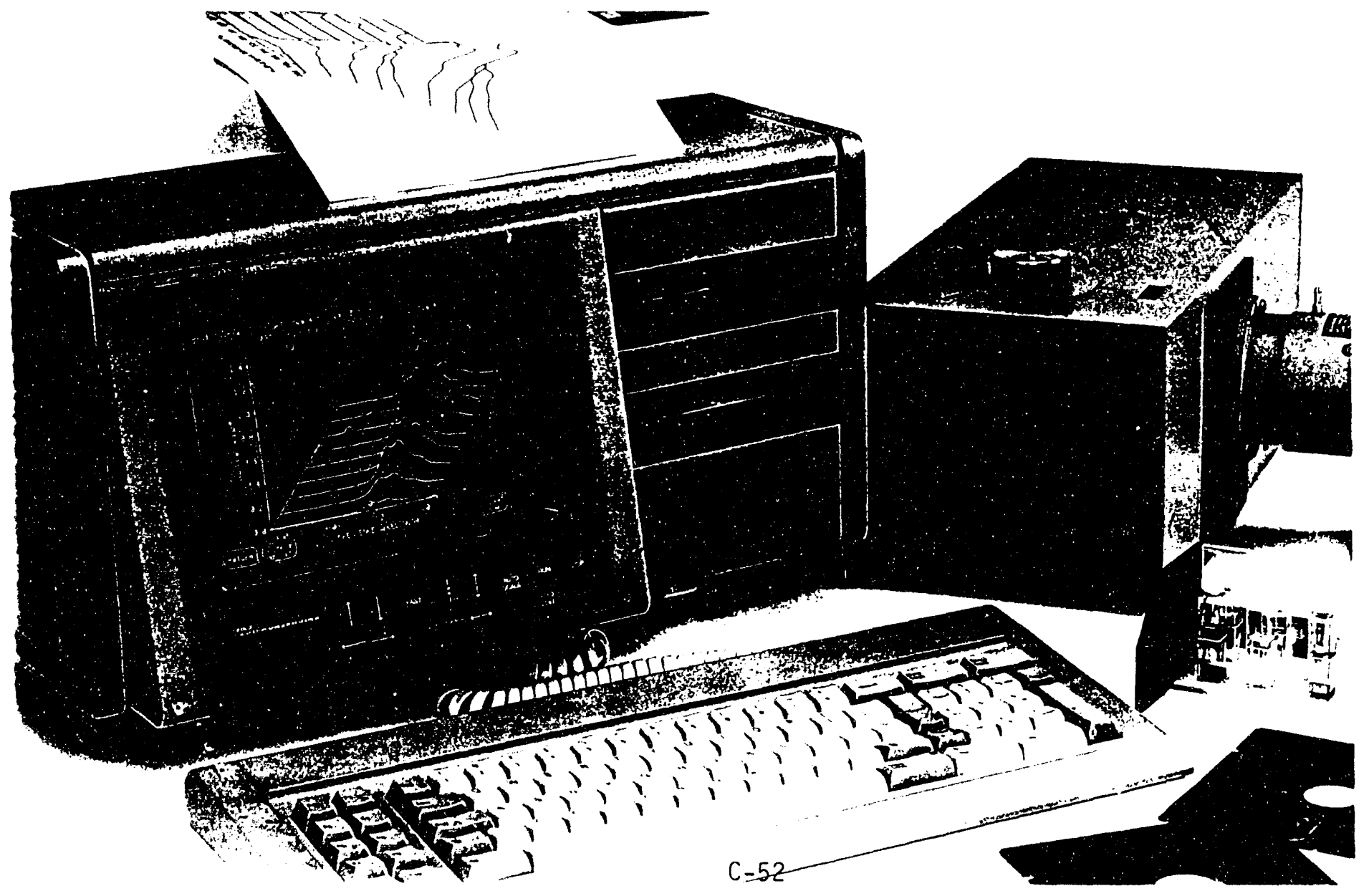




\section{What Are The Benefits Of Using An OMA?}

- Acquire a Full Spectrum from a Single Pulsed Event

The abuity of the detector's dode array co store signals until sampled alows the OMA 10 capture a full soectrum of data trom a single event The duration of sucri everts can ange from CW to Dulses in the temtosucond range. The OMA is therefore the deal instiument for experments involving pulsed lasers, flash lamps, explosives, Tokamaks, etc

Compared to systems that requrre a light pulse for each wavelength of data to be collected, the OMA lowers the consumption of sample mater!als and it also lessens sample degradation due to exposure 10 high intensity light sources, both of which can save researchers both ume and money in the same way, the OMA also overcomes problems such as Shot-10-Shot Variance. which makes it difficult to exactly correlate separate waveiengths in mechanically scanned systems

\section{- Rapid Scanning Yields Kinetic Information}

Since OMA detectors are electronically scanned. they can collec: a spectrum much faster than most mechanically scanned systems Depending on experimental conditions, such as speciral resoluton and the number of data points. a continuously scanning OMA III can acquire a 75 point spectrum in as little as $2 \mathrm{~ms}$

its large memory capacity. along with its powerful post processing sottware, makes the ONiA ideal for stopped-flow, liquid chromatography, and other time-varying experiments.

\section{- Optical Shuttering for Time Resolution and Background Rejection}

OMA detectors with gated intensifiers capable of being snuttered at nanosecond speeds are ideaily suited for investigations such as time resolved fluorescence or absorbance. Such intensitiers are able to extiact very narrow "ume sices" of the !lime-varyingl spectra associated with such experiments

During data acquisition, hign speed gating can aiso be used to reject background signals. This is accomplished by controlling the detector so that it only collects data during the time pulses are being received With this feature. it is possible to carry out investigations that would otherwise prove 10 be very diticult, such as analyzing the Raman spectra of particles or gases in flames and studying water pollution via pulsed fluorescence experiments conducted in daylight.

- Rapid Collection of Weak Signal Spectra Researchers conducting low light level exper ments wovng Raman scattenng. Fluores cence. Phosphorescence Lummescence etc

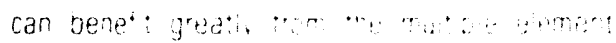

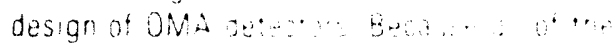

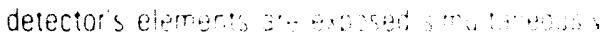

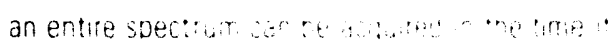

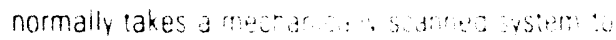

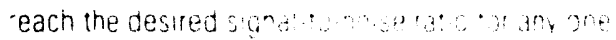

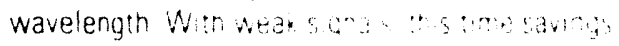

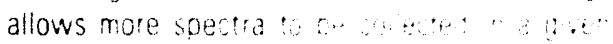

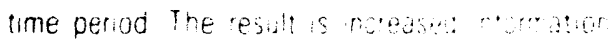

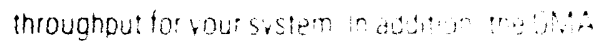

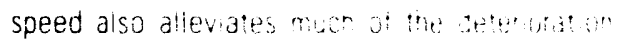

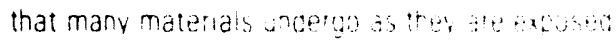
to light sources with net exclutur powers of long exposure times

\section{- Greater Signal-To-Noise Ratio During Fixed-Time Experiments}

Unlike a single element deterso wh ch can obtan data from a single wavelength noevas ot the desired spectrum Jurng my a teution of the

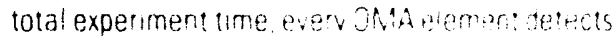
light during the enture time an expetments berng run Therefore for a given ime deroc ONiAs wili have beller delectivity as weit so notedsen tull spectruml S N ratto These OMA advontages ate effective over the complew range of no nst? ment, which covers data acauston tmes "ort $\mathrm{CW}$ to nanoseconds

- Rapid, Reproducible Data Acquisition in Industrial Applications

Mar y industrial processes inviving lignt require very rapid testing. The OMA It is the ideal tool for this work since it oniv takes seconds for an OMA to measure a coating thickess or to verty the performance of such devices as filters, light sources, and mirrors the high reguouc bitity of OMA Ill data allows test esults to oe expressed in calibrated radiomernc unts fillaily the $1460 \mathrm{~s}$ multple wavelength canabutin along wit is speed and powerful Y T soltware makes the OMA the perfect chorce to morior ine drnames of the semiconductor industi, s plasma etching chambers.

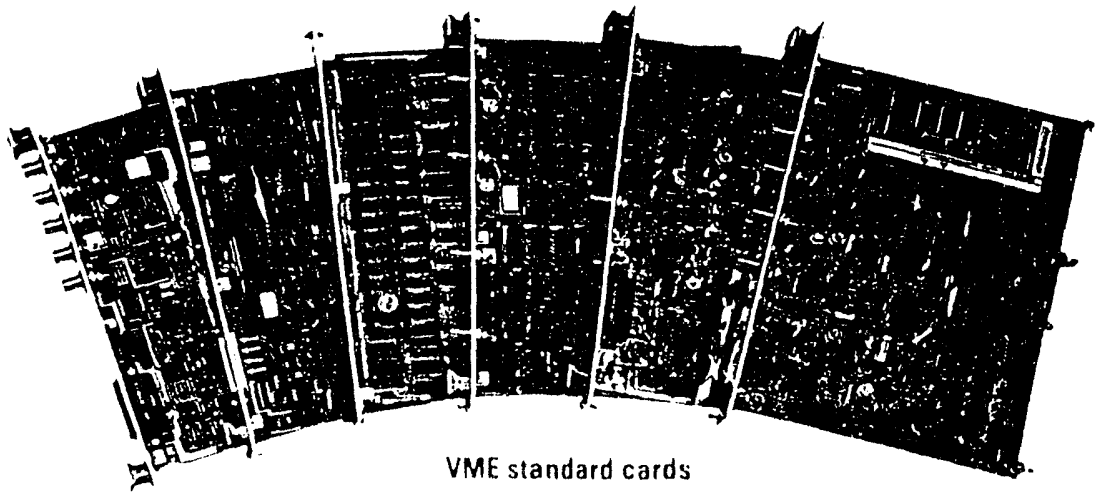

$C-53$ 


\section{$4 . \quad H o w$ Does The OMA III Make Your Work Easier?}

\section{- Flexible And Easy To Learn}

Based on state-of-the-art signal acquisition techniques, the heart of ine OMA III is really its menudriven software. The 1460's menus are very easy to use because they are designed to present only pertinent choices at each stage of your experi. ment. In addition, the flexibility of being able to operate the instrument under programmed control. as well to control it manually through either the touchscreen or the keyboard, makes the OMA III easily adaptable to all experiments.

\section{OPTIMIZE THE DATA ACQUISITION PROCESS TO YOUR EXPERIMENT}

\section{- Control Detector Scanning to Increase Sensitivity and/or Speed}

OMA III systems that include the Model 1463 Detector Controller module allow you to mix normal scanning with "grouped" and/or "fast" scan patterns (Fig. 1). During grouped scanning, the OMA combines the uutputs of contiguous elements of the detector's diode array in order to improve sensitivity and memory utilization. Fast scanning, on the other hand, allows you to decrease the total scanning time of the instrument by selec. tively ignoring data from portions of the array that are not expected to collect useful information. It does this while retainirig wavelength calibration

Besides being able to select from a broad range of detectors with various sensitivities, you can also change an OMA's sensitivity by setting exposure times ranging from milli-seconds to hours. In addition, our gated detectors allow you to time resolve high speed events with gate times as fast as $5 \mathrm{~ns}$

\section{- Collect Data in Hostile Environments}

If you plan to collect data in a hostile environment or an inaccessible location. you can set up the 1460 to remotely control an optional Model 1461 Detector Interlace land its accompanying detec. torl. at distances up to 100 feet from the OMA's System Processor

\section{- Optional Programmable Pulser for Full} Control

The Model 1303 Gate Pulse Interface option is a programmable TTL pulse generator whose delay can be automatically incremented during data acquisition When the Model 1304 Pulse Ariplifier option is included with the system, you can also set the width of the gate pulse. The combinaton of the 1303 and a pulve yenerator allows wo 0

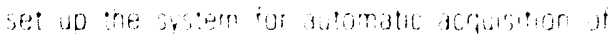

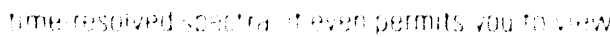

changing intensities of stopped flow. plasma chemistries, and fluorescence in real tıme

\section{POWERFUL DATA ACQUISITION MODES}

\section{- Display Spectra in Real Time or Select from 17 Preprogrammed Data Acquisition Modes}

The OMA III includes 17 preprogrammed Dita Acquisition Modes that have proven valuable to researchers over the years. These flexible modes allow you to meet the requirements of nearly every experiment by selecting data acquisition operations (fig. 2) ranging from simple averaging to complex kinetics routines and multimemory sequences

Several Data Acquisition Modes even allow you to automatica!ly subtract data pairs and/or ignore a number of scans between each data acquisition In addition, many modes allow you to select trig. ger inputs and outputs to best match your experi. ment.

\section{Data Acquisition Mode Examples:}

The following functional descriptions of Data Acquisition Modes 2, 7, and 12 illustrate some of the flexibility and power of OMA III data acquis.tion. In these examples, the user specifies integer values for ' $\mathrm{J}$ '. ' $I$ ', and ' $\mathrm{K}$ '. The variable, ' $\mathrm{J}$ ', is the number of separate memory buffers into which data will be stored. while ' $l$ ' is the number of scans per data acquisition, and ' $K$ ' is the number of scans to be ignored during each data acquisition

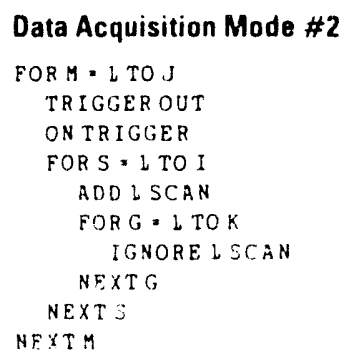

Explanation: ' $J$ ' sets of scans take place. with ' 1 ' scans summed into each set Each set of scans is preceded by a TRIGGER DUT The system then scans, waiting to recelve an ON TRIGGER' instead of instantly proceeding Immediately after each ON TRIGGER', a complete set of ' 1 ' scans is accumulated and the results from each set are ADDED into separate memones This mode allows YOu to IGNORE $K$ scans ater each added scan iK con equal ol In Mone \#2 al wata ADDEO with se bet orecison
Figure 2. Data Acquisition Mode Setup Screen

$$
\text { C }-54
$$


Note that Data Acquisition . Vlode \# is nearly dentical to Mode \#2. with the only difference being that Mode \#! does not walt :0 receive an ON TRIGGER pulse before taking data

Comment: With 'J' set to : and ' $K$ ' set :00. Mode $\# 2$ is a very trequently used data acquisition mode if ' $J$ ' is set 10 an integer greater than 1. a series of experiments can be run Setting ' $K$ ' $>0$ allows the system to walt a predetermined interval for each event such as the recharging of a laser's power supply.

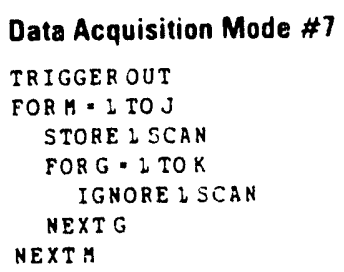

Explanation: Following a single TRIGGER OUT pulse, ' $J$ ' scans occur. The result of each is STORED in a different memory. This mode aliows you the option to IGNORE ' $K$ ' scans after each STORED scan.

Comment: In this Kinetics mode, the STORE command uses two bytes to store each data point, thus allowing twice as many curves to be stored. The instrument's sampling rate can be slowed down by setting ' $K$ ' $>0$.

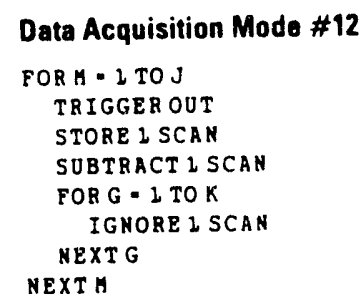

Explanation: This mode STORES ' $J$ ' scan pairs, with each pair occupying a unique memory. Fol. lowing a TRIGGER OUT, the first scan of each pair Is STORED in a memory and the second scan is then SUBTRACTED from the one just stored. This process is repeated for each of ' $J$ ' memories Mode \#12 allows you to IGNORE ' $K$ ' scans after each subtracted scan

Comment: Mode \#12 is ideal for applications involving pulsed experiments with dynamic optical backgrounds. The subtraction of the scan that follows the "hot" scan allows the most accurate background correction possible. It also combines into a single run what used to require two sepa. rate experiments.

Setting ' $K$ ' $>0$ allows you to prevent detector saturation by performing low duty cycle experiments with short exposure times. This minimizes the need to water-cool the detector to reduce 'dark current."

\section{CUSTOM DESIGN YOUR OWN DATA ACQUISITION MODES}

Users with unusuai data acquisition requirements can custom design their own Data Acquisition Modes, using our unique DAD (Data Acquisition Design) software

DAD allows you to design data acquisition modes in which you can mix the ACD. SUBTRACT, IGNORE, STORE, TRIGGER OUT, and ON TRIGGER commands in virtually limitless combınatıons, using a range of memories that you specify. DAD will control TL outputs with logical tests conducted on a scan-by-scan basis / such as IF. THEN ELSE. .). It even reads and interprets TTL inputs.

The total flexibility provided by DAD will maximize OMA performance for experiments not covered by the standard set of data acquisition modes. Thus, your OMA III system will grow to run experiments that have yet to be defined. There is not enough room in this brochure to describe the full potential of our DAD software. Please feel free to ask your EG\&G PARC representative for more complete information on this unique OMA III feature.

\section{DATA MANIPULATION AND DISPLAY FEATURES To Mest the Requirements of Virtually Every Experiment}

\section{- Calibrate Both Spectral Axes}

With a standard spectral line source, you can quickly calibrate the OMA's $X$-axis in units of wavelength $(\mathrm{nm})$ or wavenumbers $\left(\mathrm{cm}^{-1}\right)$, using a linear or third order polynomial fit. In addition, you can calibrate the amplitude of the curve data in terms of radiometric units (Fig. 3).

You can even select from three automatic scaling options for data displays, as well as expand displays horizontally or vertically by oressing the appropriate front panel keys

\section{- Process Spectral Data with an Extensive Set of Math Functions}

The OMA's built-in full curve computation capabilities include such functions as logarithms, square roots, and inany other features found in advanced scientific calculators. The 1460 allows you to solve equations that operate on real numbers, as well as on user-defined variables. One of the most convenient math features in the OMA allows you to solve equations using enture files in a single entry, as in

$$
F q=F 7 \cdot F 2
$$

This adds the contents of each data point in file F7 to the corresponding points in file F2. The results are stored in file F9. Each of these files can contain thousands of data points! No more do you have to manipulate files with clumsy techniques. such as FORI = 1 TO 1024 ... NEXTI

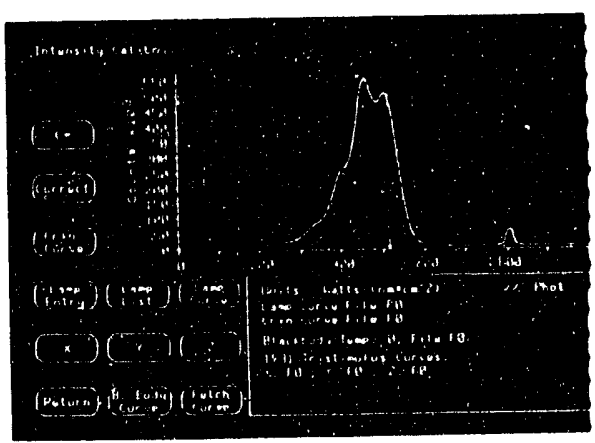

Figure 3. Radiometric Calibration Screen 


\section{6}

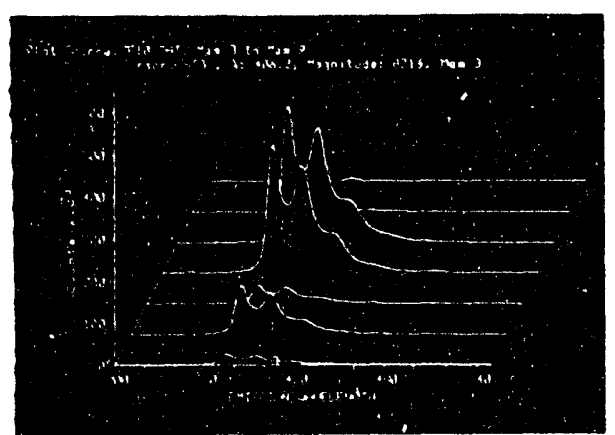

Figure 4.

A Multimemory $X: Y$

Plot With "Hidden"

Lines Removed

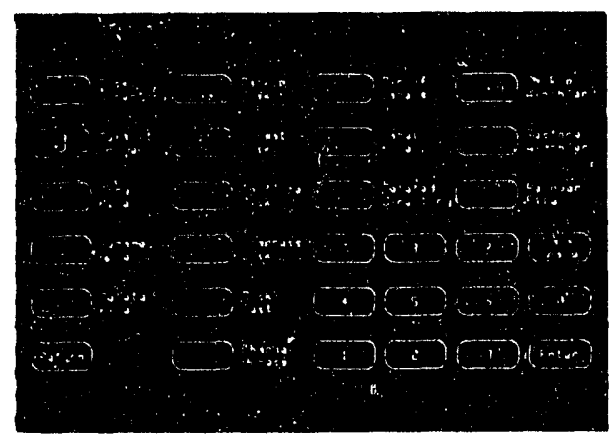

Figure 5. Disk

Operating System

Control Screen
The data being manipulated can be located in Live memory, in disk files, or in "RAM buffers", which are special sections of memory that are used as high speed virtual disks. In addition, the 1460 allows you to smooth data curves, as well as to display their first five derivatives using a SavitzkyGolay algorithm.

\section{- Display Multiple Curves and Multiple Memories}

The 1460 System Processor allows you to simultaneously display up to four curves on the same set of axes. These curves can include real-time data, as well as information stored in disk files. When data is stored in sequential memories, the OMA III can display the data in a "waterfall" format (Fig. 4), or ii can graph all the memories on a single axis. With the waterfall format, you have the option to display the memories in forward or reverse order. You can elect to "hide" overlapping portions of the curves and you can vary the angle of the " 2 " axis to improve readability.

\section{- Choose from a Variety of Powerful Background Subtraction Methods to Meet YOUR Experimental Requirements}

The spectral data collected by the detector is normally mixed with unwanted background data resulting from dark current in the detector and from ambient light in the laboratory. The OMA offers several methods which you can use to display and store data that has been compensated for such background effects.

- Automatic Source Compensation Modes Excitation energy variations during data acquisition can often affect experimental results. The

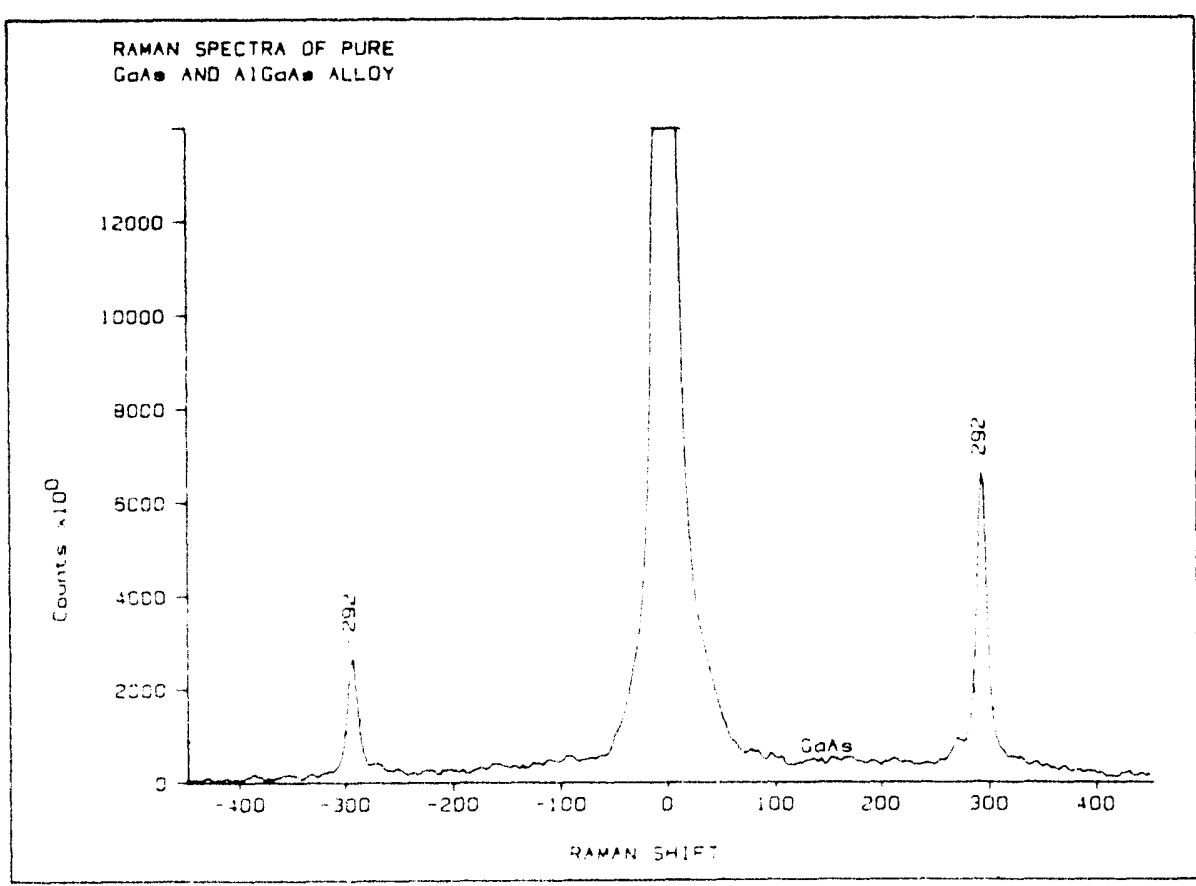

Figure 6. Sample Plotter Output
OMA's source compensation hardware and software allow you to correct data being stored for variations in the intensity of experimental light sources.

\section{PRODUCE \\ PUBLICATION-QUALITY HARDCOPY With Powerful Plotting and Printing Software}

The OMA III is easily interfaced to a wide selec. tion of plotters and printers. Our powerful plotting software allows you to manip!slate data sets by selecting not only the source of the data, but also the range and order of the memories to be plotted and the ranges of their $X$ and $Y$ axes. Before plotting, you can set up all parameters and observe the results on the screen. The plotting software supports multiple character sizes, plot sizes, line types, plotting speeds and pen colors. It even allows you to place comments or labels anywhere on the paper. This results in publication quality hardcopy that is very clear and easy to interpret (Fig. 6).

The OMA allows you to print data stored in memory. including curve values stored in user-accessible memory registers. You can even print OMA graphICs displays, including data curves and entire system screens on an Epson FX-80, FX-85, or FX-100 dot matrix printer

\section{POWERFUL DISK OPERATING SYSTEM SOFTWARE \\ For Easy Manipulation of OMA files}

In addition to allowing you to label, store and retrieve data files at will, the OMA III's custom disk operating system software (Fig. 5) automatically stores all instrument parameters to disk. You can then use a single command to reset the system to the stored settings. This feature allows you to rapidly change from one experimental setup to another while saving you the pain of having to repeat an experiment if you forget to record a parameter

The key element to the 1460 's DOS, as with all OMA III features, is flexibility. You decide what you want to do and the system makes it easy for you to do it You will find that the OMA III Imposes very few constraints on your experıments

\section{ADVANCED TIME RESOLVED SPECTROSCOPY}

\section{- Compare How Spectral Regions Change} with Time

\section{- Control External Devices Through " $Y: T$ "} Analysis

Another powerfut OMA teature is its ability to dispia; the relationshio of spectral areas to time 
The 1460's advanced "Y T sutware alons ow to see how uo $t 08$ areas lor 8 ser.ce reo ecuellons bajed on up to 24 spectral regrors crange with respect to time The OMA can simultaneously plot up to eight of inese unciors white data is being acquired (Fic 7) in act you can se: up the OMA to continuousiy tes: mese innctions and : use the system's $T L$ poris io switch exiernal equipment $O N$ or OFF baseo on ine resuits of these tesis One very useful Y T operation alows you to use complex mathematicai operations to posi-process multumemory date that is already stored on disk. These are only some of the features of our $Y$ : T scftware that make the OMA III unique in the field.

\section{EASILY PROGRAMMABLE FOR UNATTENDED OPERATION}

\section{-...Through Keystroke Programming}

There are three ways to set up the OMA to automatically collect data. The first is to enter a "Keystroke Program" in memory !n much the same manner as vou would enter a series of keystrokes into a programinable calcuiator (Fig. 8). Even thougn it doesn't require elaborate computer program. ming. this feature allows you to automatically execute frequently used data acouisition and processing sequences. as well as make decisions that cause automatic branching. (for more detais. please request our Keystroke Programming Applis. cation Note.

\section{- ... Through Rear Panel Control}

The second method that allows unattended operation is to control data acquisition by means of an external computer connected to the standard RS232C or GPIB interfaces on the 1460's rear panel. Data from the OMA can then be sent to or from another computer, where it can be further analyzed and stored.

\section{- ... Through BASIC}

BASIC Language Option Adds the Capabilities of a Powerful Microcomputer to the OMA'S Instrumentation

The thro way 10 automaticaliy run the $1460: \%$ program the system in EASIC, uSIng out ootore Hemerway Operating System solware Frugr a BASiC program runarig on the 1460 , you car se: the OMA's data acousition parameiers. collec: anc analyze data, and gisplay the resuling curves. never leavrig the BASIC program you can ever design your own touch scieens as a inal iouch io customize your experiment

A sysiem that ncludes our BASIC soitware gives your OMA IIl the unmatched power and "exibul, of a high-speed BASIC computer and the incus. in's most powerful data acquistion system, a: combinec into one convenien: package

\section{A VARIETY OF INTERFACES Increases the Number of Potential OMA III Applicatioris}

The flexibility of the OMA III is entianced bi :s RS232C and GPIB interfaces. Each of these nie: faces can be assigned as a Rear Panel Contro: port for an exiernal computer, or as a plotter of printer port or an $1 / 0$ link. Note that the optiona $1 / C-B$ module includes a second PS232C intertace and a Centronics" port that can be used io dive a parallel printer.

\section{RELIABILITY AND REPRODUCIBILITY}

The solid construction of all OMA III components. combined with the rigid quality conirol anc inspection procedures at EG\&G PARC, makes this system by far the mori ieliable optical analyzer in today's marketplace All OMA III systems inolude software updates and a two year waranty

\section{OMA III Hardware Options}

- Choose from a Growing Family of System Options, Including More than 19 Diode Array Detectors

EG\&G PARC offers a wide selection of toth standard and high performance jetectcis The : 412.1420 . 1421, and 1422 series of hign performance detectors is designed for the Mode: $: 463$ Detertor Controller. while the $1452: 45 j$ and 1454 serres of detectors are used wit tre lioce "462 cor. troller. The following pacges describe tre OMA lli's required components. as well as severa optona accessories

\section{DETECTOR CONTROLLER MODULES}

- Model 1463 Detection Systems-The Ultimate for Performance and Control

The Mode! 1463 Detector Controlier is a wre card module based on a 4 -bi: Ararg-to-Ogg:a: converter I supports nomal scanring as NE! as fas: access. grouded al c mixes toce ser secuences the 1463 noludes Trgget rou and

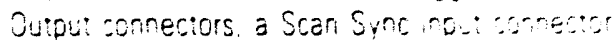
$x$. Y anc 2 outputs for monitor scopes escra a aja adustmer:s and avided outout bo" - acator

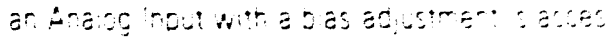

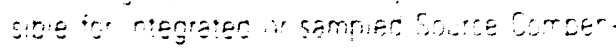

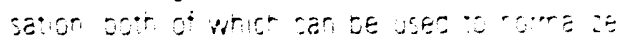

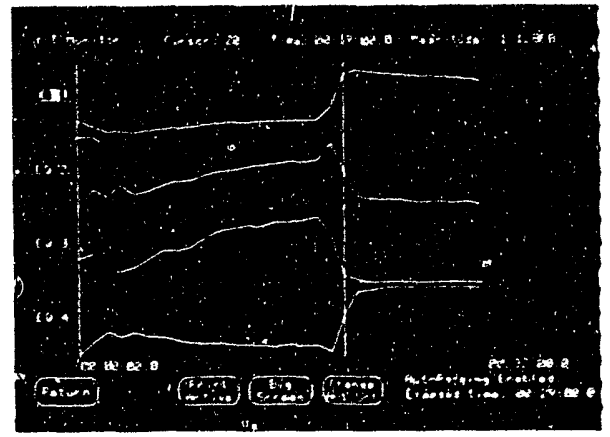

Figure 7. Y:T Plot of Four Equations

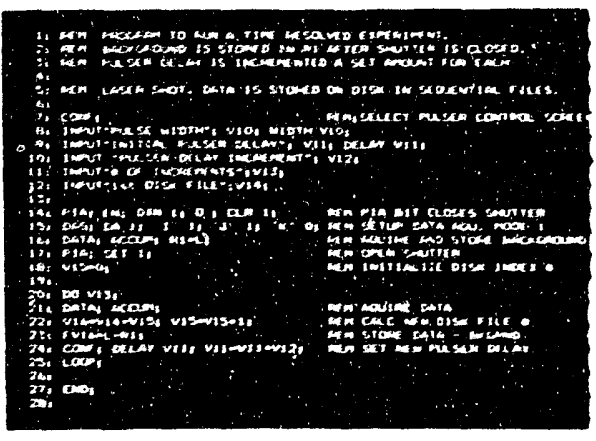

Fiqure 8. Sample Keystroke Program 
spectral curves for the effects of fluctuations in exciting light sources. Detectors using the 1463 controller have their Exposure Times and Peltier Coolers adjusted through software.

\section{- Model 1462 Detection Systems-For Cost Effective, Reliable and Accurate Data Acquisition}

The Model 1462 Detector Controller resides on a single VME card. It includes a 12-bit Analog-toDigital converter, and it has the Model 1462/99 14-bit A/D converter card available as an option. The Model 1462 can acquire a spectrum of 512 elements in $15 \mathrm{~ms}$, or one with 1024 elements in $30 \mathrm{~ms}$. The 14-bit A/D option decreases the scan time to 10 and $20 \mathrm{~ms}$, respectively. The 14 -bit A/ $D$ option also increases the detector's dynamic range four times (from 4095 to 16383)

In addition, the Model 1462 has a $0-10 \mathrm{~V}$ video output port available for a real-time display on an oscilloscope. The 1462 provides BNC connectors for Trigger Input and Trigger Output signals and it also includes a Source Compensation input connector. The 1462 Detector Controller does not support mixed-mode scanning, but it does allow you to adjust the temperature by means of an easily accessible trimpot.

\section{- Model 1216 Vidicon Detection Systems-} For Two-Dimensional Data Acquisition

The 1460-based Vidicon system is a two dimensional data acquisition system with excellent sensitivity and a high dynamic range. It allows you to specify the detector's scan pattern in single or multiple tracks. Thus the detector can be adjusted for optimum data collection.

The Model 1216 Detector Controller services the scanning, power and signal processing requirements for all EG\&G PARC OMA III Vidicon-based detectors. The Model 1216 may be operated with the Model 1460 System Processor via the High Speed Serial port on the 1460's DMA card. Note

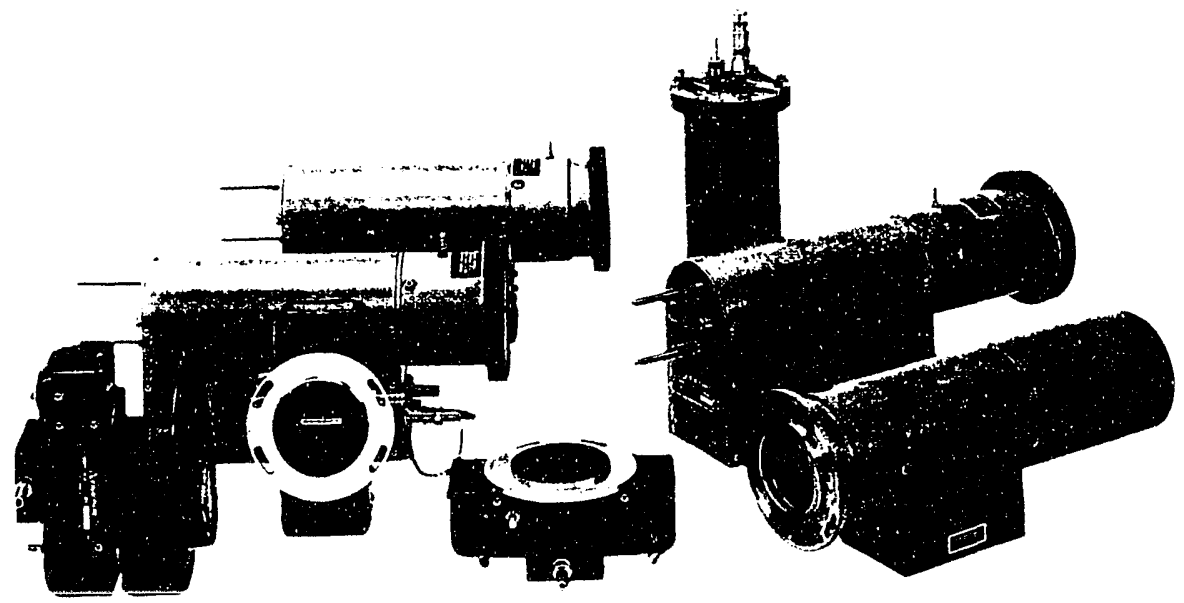

OMA * III Detectors $C-58$ that the 1216 can also be operated as a computer peripheral through its own 16-bit Parallel Interface.

\section{HIGH PERFORMANCE DETECTORS (for the 1463 Controller)}

The high performance detectors described in the following paragraphs offer fast readout time combined with sophisticated scan patterns.

The Model 1412 is a 1024-element silicon photodiode array detector that has the highest sensitivity of our unintensified detectors. The 1412 incorporates a Peltier cooler for normal operation at $-20^{\circ} \mathrm{C}$. (This temperature can be brought even lower with supplemental cooling.) Such low temperatures make possible extended integration directly on the photodiodes. The spectral response of the 1412 is from below $200 \mathrm{~nm}$ to $1100 \mathrm{~nm}$.

The Model 1412F detector is identical to the Model 1412, with the exception that it has been designed for direct coupling to fiber optic bundles. such as those at the end of special image intensifiers. It therefore has a fiber optic faceplate in place of the quartz window. It can be used with experiments that employ specially designed intensifiers or other fiber optic inputs. Since the $1412 \mathrm{~F}$ can be evacuated, it is ideal for $x$-ray and VUV measurements when coated with appropriate scintillators.

The Model 1412XR is an X-ray sensitive version of the Model 1412 detector. This detector is the ideal instrument for the detection of pulsed or CW $x$-rays in the $1.20 \mathrm{keV}$ range. Based on a diode array, the M1412XR features $950.2 \mathrm{~mm} \times 25 \mathrm{um}$ elements, each of which has a sensitivity of approximately 0.8 count per $8 \mathrm{keV}$-photon.

The Model 142:0/1421 series of detectors consists of a set of 12 intensified diode array detectors based on a proximity- focused microchannel plate (MCP) intensifier. These detectors offer a sensitivity of one AVD converter count per detected photon. The individual detectors in the 1420/1421 series differ with respect to their cathode types. the numbe: of detector elements, and their gating abilities. All 1420/1421 detectors feature low geometric distortion and the ability to cool the diode array to $35^{\circ} \mathrm{C}$ so that long integration times can be used

The Model 1422 is an intensified, low cost detector based on an electrostatically focused MCP intensifier. It features 1000 elements and one count per detected photon. This detector is ideal for applications that do not require gating or UV sensitivity. Although the Model 1422 has some

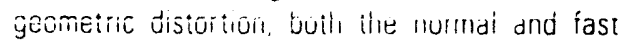
phosphor versions have excellent line spread /resolutionl and they can be cooled $10 \cdot 35^{\circ} \mathrm{C}$ 


\section{STANDARD DETECTORS (for the 1462 Controller)}

The Models 1452A and 1453A are 512 and 1024 element versions, respectively, of the same detector. Both are unintensified detectors based on a Reticon linear photodiode array. Each has a broad wavelength response of 180 to $1100 \mathrm{~nm}$. These detectors include Peltier coolers to maintain a normal operating temperature of $-5^{\circ} \mathrm{C}$, although they can be set as low as $-35^{\circ} \mathrm{C}$.

The Model 1454A is the most sensitive of the $145 x$ series of detectors. It features an electrostatically focused intensifier in front of a 512 element diode array and it provides detection levels of approximately 100 photons per AVD converter count. The detector's temperature is normally maintained at $-5^{\circ} \mathrm{C}$ by a Peltier cooler, although it can be set as low as $-35^{\circ}$. Like the other $145 x$ series detectors, the $1454 \mathrm{~A}$ is capable of low temperature operation using a water flow block to assist the Peltier cooler. The wavelength response of this detector is limited to approximately 365 to $900 \mathrm{~nm}$ by the glass input of the intensifier and by its cathode, respectively. An optional UV scintillator extends the blue response to below $200 \mathrm{~nm}$.

\section{VIDICON DETECTORS (for the 1216 Controller)}

Vidicon Detectors provide two-dimensional light sensing capabilities with a virtually limitless number of possible scan patterns

The Model 1252 series of Vidicon detectors are optimized for various spectral ranges by controlling the target thickness and by the proper selection of window materials. Anti-reflective coatings reduce spurious (moire) effects at wavelengths longer than $800 \mathrm{~nm}$, which is where silicon target materials begin to become transmissive

The Model 1254 and 1254E Vidicon Detectors have peak sensitivities of 14 photons per count. and they can be gated by the Model 1211 Gate Pulse Generator to provide time iesolution down to $40 \mathrm{~ns}$. The Model 1254E is the same as the 1254, with the exception that it has an extended red photocathode response.

\section{SPECTROGRAPHS}

EG\&G PARC has a large selection of gratings available for the Models 1231, 1232, and 1234 spectrographs. These gratings allow you to optimize your spectrograph to the wavelength and dis. persion ranges required for your experiment. (The gratings are fully described in the specification sheets for the individual spectrographs.)

We also have three lengths of quartz bundles available for our spectrographs. The $1.0 \mathrm{~m}, 1.9 \mathrm{~m}$, and $2.9 \mathrm{~m}$ kits for the Model 1232, and 1234 spectrographs are Fiber Optic Kit Models K0219. $\mathrm{K} 0218$, and K0217, respectively. The corresponding kits for the Model 1231 spectrograph are Models K0222, K0221, and K0220.

The Model 1231 is a $32.0 \mathrm{~cm}$ focal length ( $f$ ) 5.4). low stray light Czerny-Turner spectrograph designed to accommodate all OMA detectors Because of its vertically and horizontally flat focal plane, the Model 1231 is particularly well suited for area detectors including Vidicons

The Model 1232 is a $15.6 \mathrm{~cm}$ focal length (f) 3.8), compact cross-beam Czerny-Turner spectrograph with a $90^{\circ}$ exit/entrance relationship. It is designed specifically for linear focal plane array detectors.

The Model 1234 is a $27.5 \mathrm{~cm}$ ( $\$ / 3.8)$, cross-beam Czerny-Turner spectrograph designed to be used with all diode-array detectors from EG\&G PARC. This spectrograph features a turret mo!nnt that can hold up to three gratings, each of which can have unique blaze and groove frequencies

\section{PULSE GENERATORS}

\section{- Control Gated Detectors with EG\&G PARC Puise Generators}

The Model 1303 Gate Pulse Interface resides on a single VME card. It generates pulses with delays that can be auto-incremented through software. The Model 1303 can increment delays up to $13 \mathrm{~ms}$ in $1 \mathrm{~ns}$ steps and it includes on-board optical and electrical trigger inputs. The 1303 also provides a software-controlled pulse width. When its output is amplified by the Model 1304 Pulse Amplifier, the pulse width can be varied from 100 ns to $10 \mathrm{~ms}$

The Model 1304 Pulse Amplifier, combined with the Model 1303 puiser or a user-supplied pulse generator, is designed to turn gated detectors $\mathrm{ON}$ and $\mathrm{OFF}$ by supplying high voltage gate

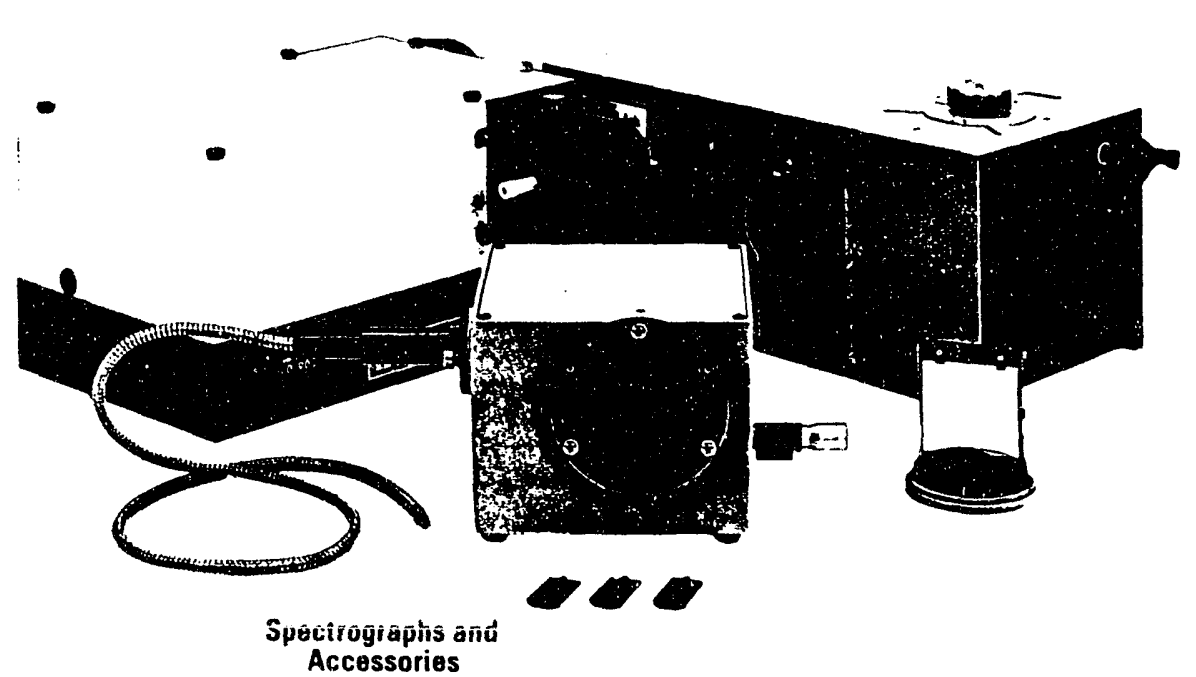

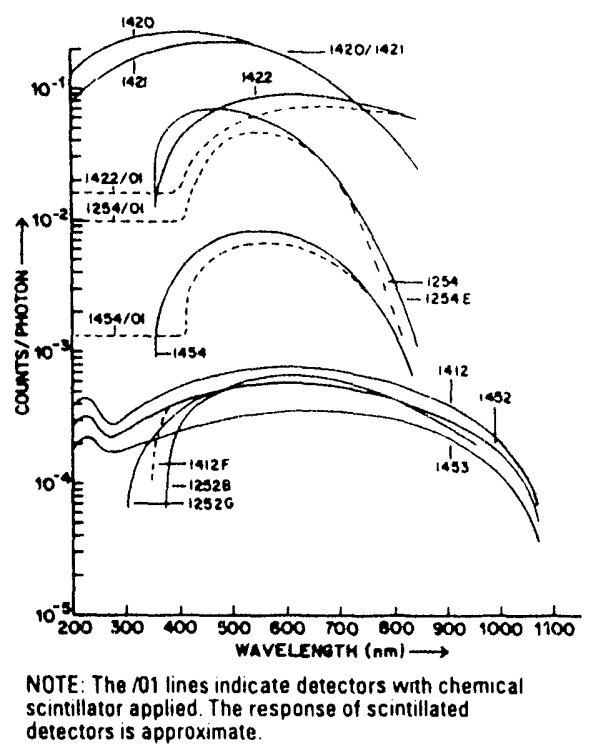

Figure 9. Typical Detector Response Curves 
pulses in the $100 \mathrm{~ns}$ to $10 \mathrm{~ms}$ range. The Model 1304 also includes monitor outputs that can prove very useful while an experıment is being set up and tested.

The Model 1302 High Speed Gate Pulse Generator has an adjustable delay. This triggered pulser is used to supply gate pulses of 5 . 10 , or $20 \mathrm{~ns}$ width to gated 1420 series detectors Its delay time is adjustable from 0 to $256 \mathrm{~ns}$ with a propagation delay $\geq 40 \mathrm{~ns}$. Like the Model 1304. it also includes monitor outputs that can be very useful while an experiment is being set up

The Model 1211 Gate Pulse Generator is used to gate the Model 1254 series of SIT Vidicon detectors. The Model 1211 has an adjustable Pulse Width of 40 ns to $999 \mu s$ and a adjustable Delay Time of 100 ns to $999 \mathrm{~ms}$. The pulse amplitude is adjustable from $-500 \mathrm{~V} 10-1500 \mathrm{~V}$, with a Repetition Rate of $10 \mathrm{kHz}$ continuous $(100$ $\mathrm{kHz}$ burst). The 1211 is remotely programmable with a Model 1211/99 interface. If the 1211/80 Terminator Box is used, the 1211 will also work with 1420/21 detectors

The Model i, "1 Optical Trigger Detector uses a fiber optic input to an avalanche photodiode to produce a 100 us TTL pulse from a 20 ns light pulse as small as $3 p \mathrm{~J}$ (at $650 \mathrm{~nm}$ ). During data acquisition, the Model 1301 can be used to optically trigger a pulse generator or the system's detector controller.

\section{ADDITIONAL OPTIONS}

- The 1/0-B Module - an Extremely Useful, Cost-Effective Option

The V/O-B Module (Model 1008/92 to 1008/99) is a VME plug-in card that includes a real-time clock with battery backup that is used to stamp

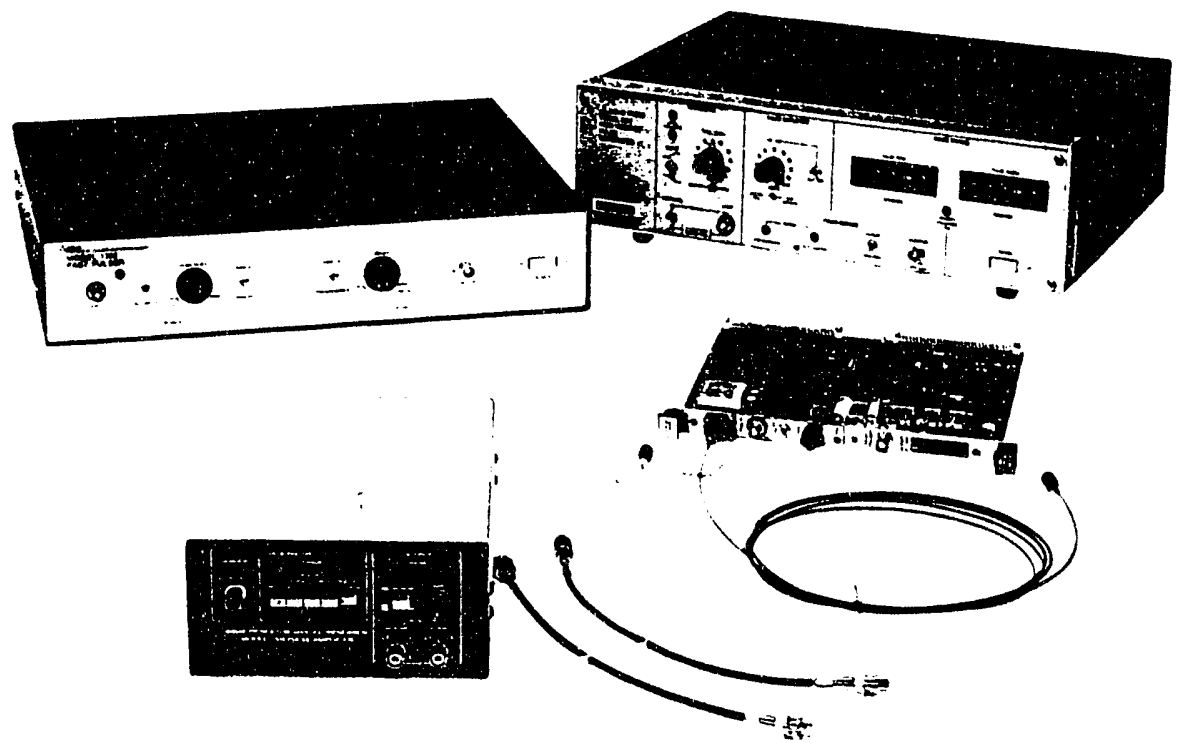

OMA - III Pulsers data files with the date and time they were saved to disk. The $1 / 0-8$ also includes a Centronics printer port, a second RS232C serial port, analog recorder outputs, a.l 8-bit programmable bidirectional 1/0 port (usable by BASIC), and an optional $512 \mathrm{~K}$ bytes of additional memory

The CE0091 Extended Memory VME board adds 256K bytes per card to the OMA's memory.

The CE0113 Extended Memory VME board adds 2 Mbytes of extra memory to the OMA III

\section{- Hemenway BASIC-A Major Increase in OMA Power for a Modest Investment}

The Model 1460/89 Hemenway BASIC software option turns your OMA into an integrated system consisting of the best light detection and analysis system in today's marketplace, combined with a powerful BASIC microcomputer. The instrument and computer software work together to acquire and analyze data without user intervention. The main features of the BASIC software are:

- Complete software control of all instrumentation parameters

- Support of all OMA interfaces (with redirect. able $1 / 0$ ports)

- Versatile set of powerful math functions

- Graphics support including scaling, axes, etc.

- Touch Screen Design

- Multitasking operation with touchscreen or keyboard control

The Model 1460/98, 20 Mbyte Hard Disk option replaces the lower floppy disk drive in the Model 1460. The hard disk is an ideal OMA III accessory if you are storing a large number of data files or if you plan to do much BASIC or Keystroke Programming.

Digital Plotters supplied by EG\&G PARC Include the following the Houston Instrumenis. Inc. DMP 40 (the RS232C version is PARC Model RE0093 and the GPIB version is Model REO100) and the DMP 29 (PARC Model REO 146), and the Hewlett Packard, Inc. Model HP7440A GPIB plotter (PARC Model Number RE0144) (The OMA il! software also supports the HP7470. HP7472. HP7475, and HP7550 plotters.)

The Model RD0033 Dot Matrix Printer, which is the senal version of the Eoson FX.85 printer is fully graphics-compatible with the OMA III The printer can be driven oy the CPU or $1 / 0 . B$ serial port

The Model C0217 Extender Cable, zllows you io place a $14: 2$ s: $1: 2 x$ seres deteror wo to 25 feet rom the wore! labs Uetecto Controller cand ilf you wisn to sog....e the 25 toot cable 
for the standard cable normally shipped with a new system, order the Model No. 1463/99 cable. Note that the extended cable resulis in a slight signal-10-noise ratio degradation wher, compared to the standard 6 foot cable

- Collect Data in Hostile Environments by Using the OMA to Remotely Control an Optional Model 1461 Detector Interface

The Model 1461 Detector Interface, when combined with the Model SC0071 Extender

Cable, allows you to remotely collect spectra in hosule (or inaccessible) environments up to 100 teet from the 1460 System Processor After you connect a Model 1461 to your 1460 system, you will be able to control the OMA just as you always did the 1461 is virtually "invisible" to the user The Model 1461 can also be used without a Model 1460 if it is properly interfaced to an external computer

\section{Specifications For The Model 1460 System Processor}

Soft-Touch Screen: 9 inch diagonal, high resolution, raster scan $(656 \times 356$ pixels), with 60 active touch-sensitive regions $(10 \times 6)$. Screen has adjustable tilt $+15^{\circ}$ to $-10^{\circ}$, and brightness is software controlled

Disk Drives: Two 5-1/4 inch double-sided, double-density floppy drives are standard. Each stores $385 \mathrm{~K}$ bytes of data under the control of file management software.

Front Panel Keys: Thirteen keys on the front of the System Processor perform such operations as moving the cursor, expanding, contracting, and autoscaling displays. as well as stopping and resuming the drawing of curves

External Keyboard: Containing a numeric keypad, as well as cursor control and function keys the keyboard is used as an alternate means of command entry. It is also used to enter k'eystroke and BASIC programs into the OMA

CPU: VME card with 68000 microprocessor, $512 \mathrm{~K}$ bytes of RAM, an RS232C port, and access to a RESET switch for rebooting. (RAM is expandable with additional memory boards.)

I/0-A: VME card with IEEE-488 GPIB port and EG\&G PARC parallel interface
CRT Controller: VME card with BNC connectors for a monochrome video output signal, for horizontal, vertical, and composite sync signals, as well as for the blanking pulse.

1460 DMA: Intelligent Direct Memory Access VME card with 68000 microprocessor that can perform extremely sophisticated data acquisitions, including asynchronous accumulation using both addition and subtraction of data. The 1460 DMA also includes a 16-bit programmable 1/0, a reset switch, and a proprietary High Speed Seria Interface to communicate with a Model $14 b^{\circ} 1$ Detector Interface or a Model 1216 Detector Controller.

\section{Power Requirements:}

\begin{tabular}{|c|c|c|}
\hline Selected Voltage & Range (V rms) & Fuse Rating \\
\hline 115 & $100-130$ & $3.0 \mathrm{~A}$ \\
& S.B. \\
\hline 230 & $200-260$ & $1.5 \mathrm{~A}$ \\
& S.B \\
\hline $48-62 \mathrm{~Hz}$ & $250 \mathrm{~V}$ \\
\hline 260 VA Maximum & S. B. \\
\hline
\end{tabular}

Dimensions: $11-1 / 4^{\prime \prime}$ High $\times 18-1 / 2^{\prime \prime}$ Wide $\times$ $20^{\prime \prime}$ Deep $(28.6 \mathrm{~cm} \times 47 \mathrm{~cm} \times 50.8 \mathrm{~cm})$

Weight: $65 \mathrm{lbs}(30 \mathrm{~kg})$ 
The innovative engineerng behind the ONA III system has produced a Model 1460 System Processor that is iruly the OM:A console of the future The Model 1460 has been designed to control all present and tuture EG\&G PARC detectors in fac:. Model 1215 OMA II system processors now in the field can already be replaced oy the much more powerfur Model 1460 . Very soon. a single 1460 System Processor wil be able to control several detectors simultaneously, with each detector connected to its own Model 1461 Detector Interface

- Diskette-Based Software and Modular Design Provide for Easy Upgrading and Expansion Because the 1460 is a disk-based system. software improvements are easily integrated into existing instruments in addition, since the system was designed with the universally accepted VME-bus configuratıon, hardware enhancements usually require little more than simply adding one or more VME cards. Because the OMA III is so easily upgraded, Ii can never become obsolete

\section{- Software Updates}

Our policy of assuring that our customers always have the latest version of the OMA's software means that the system's performance will grow during the life of the instrument. Indeed, many user-suggested improvements are included in the current release of the software.

\section{Warranty}

\section{- 2 Year Warranty}

We back up the OMA III with a 24 month warranty on all hardware components except detectors. For a small additional charge, detectors can also be warranted for 24 months. Prompt and cour teous service is avallable at EG\&G PARC facilities around the world

\section{A Final Word}

\section{- Enjoy Easy Access to Our Professional Cus:umer Support Staff}

At EG\&G PARC, we have earned our reputatior not only by supplying the scientific community with instruments of unsurpassed quality since 196', but also by our readiness to stand behind our products with a : uly professional and accessible cus'umer support staff. Please feel free to contact the factory or your local representative if you have anv questions about the OMA III system, its accessories, or any of our other products.

\section{¿ EGEG PRINCETON APPLIED RESEARCH Scientific Instruments Division}

P.O. BOX 2565 • PRINCETON. NJ 08543.2565. USA - 609/452.2111 - TELEX: 843409 

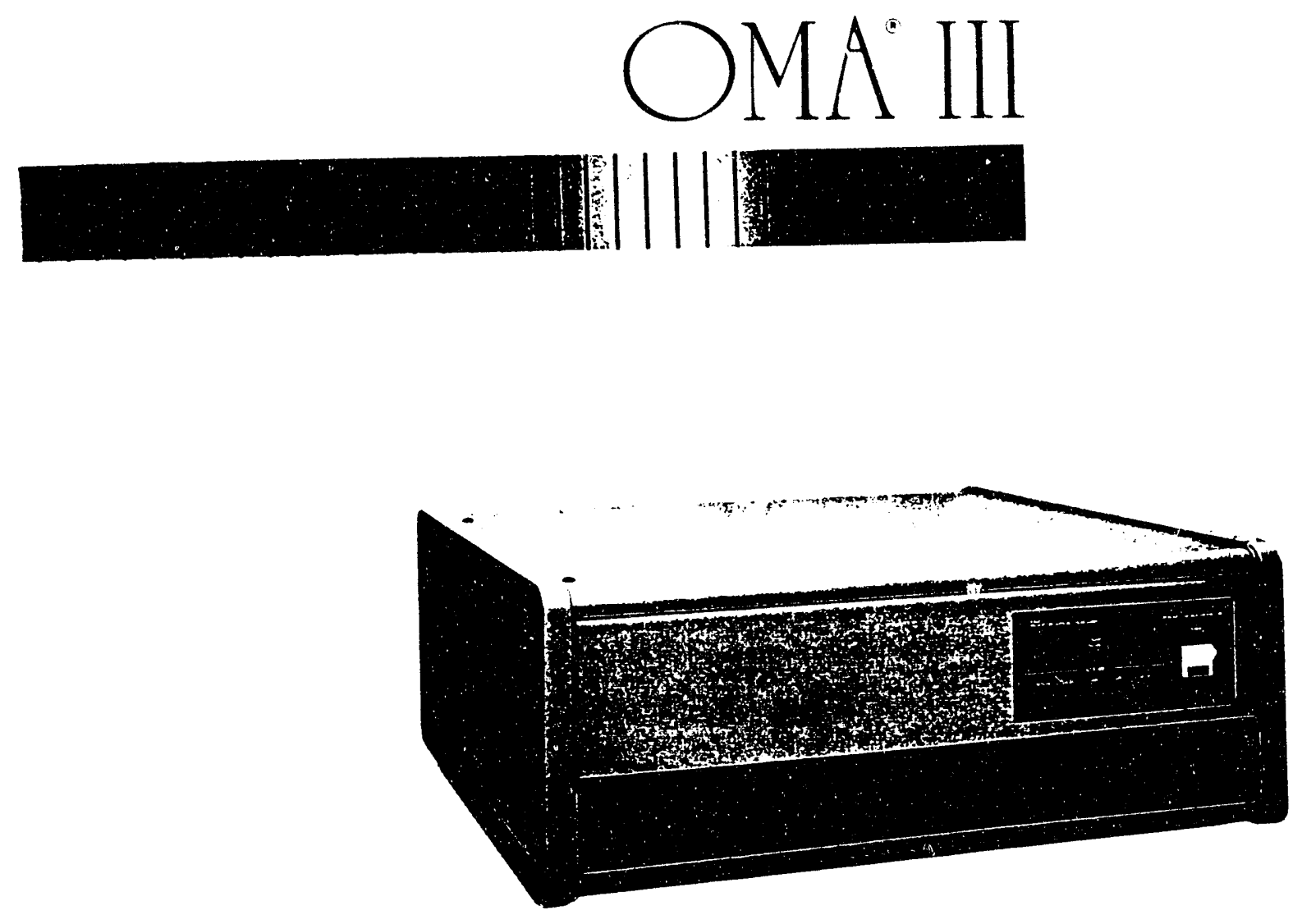

MODEL 1461

\section{DETECTOR INTERFACE}

$\stackrel{n}{\cap} E G \pi G$ PRINCETON APPLIED RESEARCH 
$\Pi$ he OMA III family of instruments is designed to do simultaneous, multiple resolution element spectroscopy. The Model 1460 System Processor and the Model 1461 Buffered Detector Controller are the major computer options in the family. If you need a state-ofthe-art OMA system with full software and hardware that you unpack and use, the Model 1460 is your choice. The Model 1460 brochure describes this flexible system more fully.

The Model 1461 is your choice if you:

- already have a computer and need a cost effective OMA without sacrificing any essential OMA power;

- have a large amount of hardware and software invested in a computer controlled experiment that needs an OMA;

- require multiple OMA's connected to a central computer;

- need an OMA but have unique software requirements or computing power not supplied by the $M 1460$.
OMA technology has been evolving at EG\&G Princeton Applied

Research since 1972. The M1461 is a superior instrument that reflects all of the lessons of past experience. Some of the major features of this instrument are:

- control of any detector from the growing family of more than 17 linear diode array based detectors:

- acquisition of data using one of more than 16 preprogrammed Data Acquisition Modes;

- a non-standard data acquisition mode can be designed for the few cases where your experiment doesn't match the preprogrammed modes (this OMA will never limit your future experiments);

- storage of data until transmission to a host computer:

- preprocessing of the data, such as background subtraction which lessens the time it takes to transmit an experiment result to the host computer;
- interaction with an experiment through programmable. TTL I/O bits, input triggers, and output triggers:

- modular design allows easy upgrades or changes as new experimental requirements turn up;

- standard RS232 and IEEE interface communication links loptional high speed DMA transfer to DEC computers):

- 2-year warranty;

- no charge software update policy.
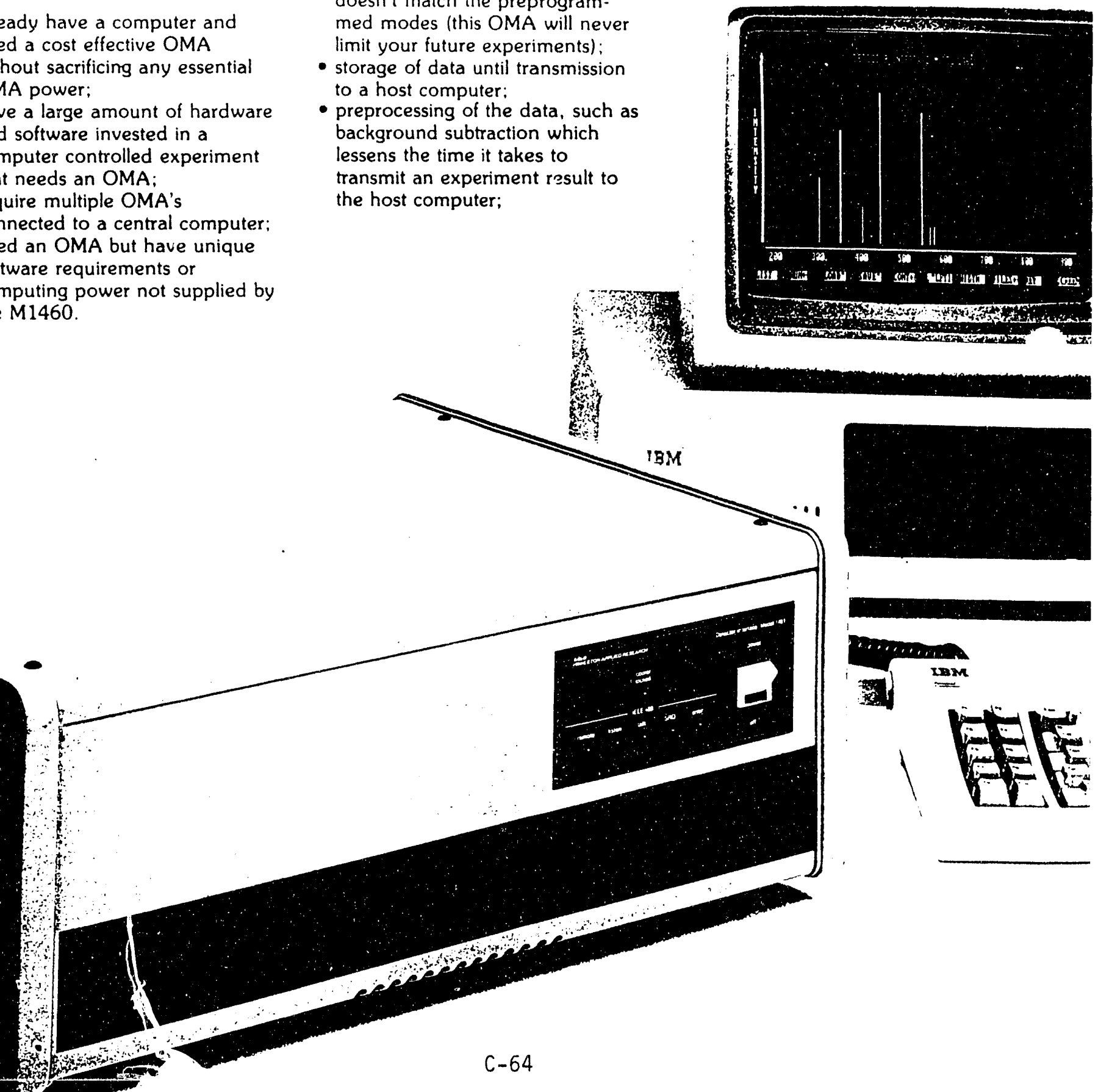
1

he Model 1461 Software

has been designed to

provide most of the common data acquisition modes of

optical multichannel analyzers and also to permit user programming for special requirements. For example. setting the exposure time (the time the light is allowed to integrate on the detector elements) is as simple as sending the command ET and the desired value over the computer interface. Other commands such as a Total Scans.

Trigger Out. Trigger In and Store in a Memory have similar command mnemonics. Once the setup commands have been sent. the

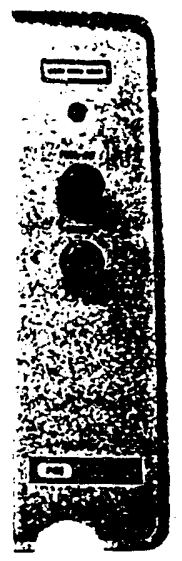

RUN command tells the Detector Interface to acquire the spectrum
Several different data acquisition modes are preprogrammed and others may be created with the user programming mode. Normal scan reads and digitizes each detector element and stores the data in a memory. Fast scan skips over individual elements in $.5 \mu \mathrm{s}$ and allows the user to improve the time resolution by only storing the elements of interest. Grouping combines adjacent pixels into one data point. giving the advantages of improved sensitivity and faster data collection. The mixed mode permits all of the above scan modes to be combined in one scan of the detector. For instance, you can skip the first 100 channels. group the next 100 into 50 data points, and scan the rest in normal mode. This complex scan pattern will be executed every time the RUN command is sent from th.e host computer.
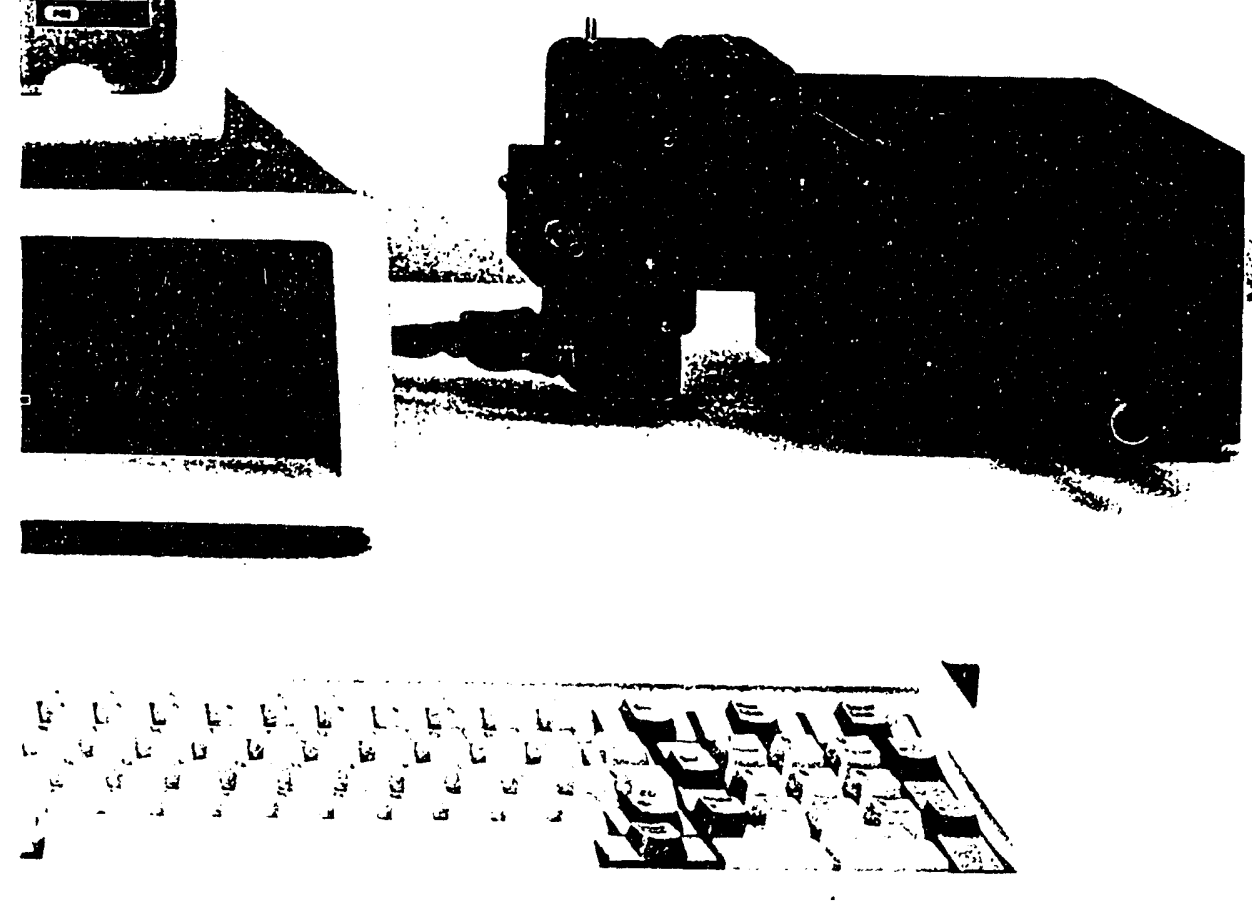
In addition, an output trigger can be sent before each scan or only at the beginning of the first scan. Likewise, an input trigger can be required before each scan or only at the beginning of the first scan. It is also possible to interleave the input and output triggers such that an output trigger is sent at the beginning and an input trigger is required for each scan. Any memory can be designated as a background that can be subtracted from the accumulated data before the spectrum is transmitted to the host computer.

The second major group of data acquisition modes are concerned with storing one scan or summed si:ans into sequential memories. Here the experimenter can sum into one memory a number of double-precision curves before automatically moving to the next memory and repeating the data accumulation. The built-in routines allow trigger outputs to be sent and input triggers to be required. Background subtraction of each of the accumulated spectra is easily performed.

These two major groups of data acquisition modes were designed to provide common methods of data collection. Realizing that unique measurement requirements arise, a high level language of over twenty commands has been included. It gives absolute control over the sequence of data collection. including output trigger, input trigger, memory used, and number of scans taken. Any number of data acquisition modes may be created for the Model 1461 and loaded from the host computer

The Model 1461 Detector Interface can be equipped with a High Speed Serial/Parallel Card. which allows it to be connected to the Model 1460 System Processor. This configuration allows the detector to operate remote (up to 100 feet) from the Model 1460 System Processor and still have all the advantages of our exclusive OMA III software. Realtime spectra are displayed on the Model 1460 Soft-touch screen and later stored on the floppy disk. This card can also be used to transfer data to another computer. using 16-bit parallel transmission
$\mathrm{M}$

odel 1461 Hardware. The Model 1461 Detector interface is based on a sophisticated Motorola 68000 microprocessor. The VME standard bus structure is used for all expansion modules. This basic system consists of the CPU card with $128 \mathrm{~K}$ of ROM and $32 \mathrm{~K}$ of RAM storage. Also included on the CPU board are the two computer interfaces. IEEE-488 GPIB and RS232C, and a PIA parallel interface adapter. This configuration will allow six double precision (32 bits/point) 1024-element curves to be stored or as many as 24 single. precision 512 -element curves. The standard memory is expandable with the addition of optional 256K byte or $2 \mathrm{MEG}$ byte memory cards

The Detector Interface requires one detector controller module to complete a basic system. The Model 1462 Detector Module is a single-card module designed to control any of the $145 X$ series detectors. It has a 12-bit ADC and can acquire a spectrum of 512 elements in $15 \mathrm{~ms}$. A 1024-element detector can be read in $30 \mathrm{~ms}$ and stored in memory. In addition, the Model 1462 has a video output for a real-time display on any oscilloscope and both Trigger Out and Trigger In. A Source Compensation input is provided to normalize the spectrum against the fluctuations of a light source. An optional 14-bit ADC is available as a plug-in card and decreases the scan time to $20 \mathrm{~ms}$ per 1024 . element detector and $10 \mathrm{~ms}$ per 512 -element detector.

The Model 1463 Detector Module is a three-card module designed to control Models 1412, 1412F. and 1420 Detectors. Based on a 14.bit ADC, it can digitize data at $16 \mu \mathrm{s} /$ channel. It supports fast access. grouping. and mixed mode scan patterns. Trigger Input and two Trigger Outputs are provided, as well as $X, Y, Z$ outputs for monitor scopes. In addition. an Analog input with a bias adjustment is accessible from the rear panel for Source Compensation

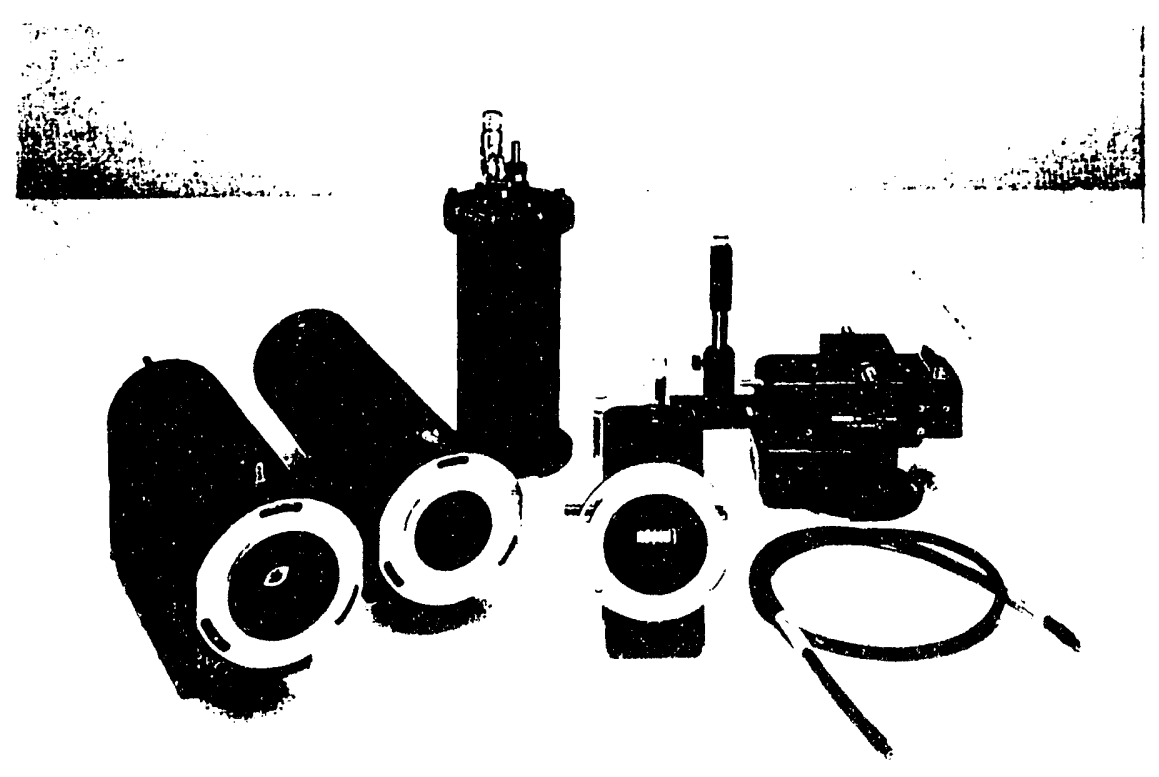


1111<smiles>C1=CCCCCCCCC1</smiles>
omputer Interfacing. The Model 1461 Detector Interface comes with both RS232C and IEEE.488 GPIB as standard. A high speed serial port (HSS) for connection to the Model 1460 System Processor and a DEC 16-bit parallel DRV 11-B interface are available as a separate card.

The RS232C interface can be set from 150 baud up to $19.2 \mathrm{~K}$ baud It supports 7 or 8 data bits, 1 or 2 stop bits, odd, even or no parity checking, hardware handshaking and XON-XOFF software handshaking. The software can detect and configure the interface to accept carriage returns or carriage return-line feeds as a terminator. The RS232C offers one advantage over other computer interfaces available; it can be used where a long distance between the host computer and the Detector Interface is necessary.

The IEEE-488 GPIB also has some distinct advantages over the older methods of transmitting data and commands. The GPIB can provide data at $-12 \mu \mathrm{s} /$ byte in Binary Dump Mode. Thus a full 1024 point curve can be output in $60 \mathrm{~ms}$ (start overhead time included). It can also be used in a star configuration or a daisy-chain configuration. This means one host computer can be connected to more than one Detector Interface or, alternatively, one Detector Interface and several other GPIB compatible instruments, such as plotters, printers and motor-driven spectrographs, could be connected.

The Model 1461 is a truly intelligent Detector Interface. It is the ideal solution to low cost, high speed parallel detection of optical spectra and yet, can be expanded to meet the most demanding of future needs.

$11 \mid 1$

1

etectors. Several inferent photodiode arrav detectors. each with its own unicule advantages. are avalable

The individual detectors in the OMA III family are explained more fully in their specification sheets.

Models 1452 and 1453 Detectors The Model 1452 is a 512 element unintensified detector based on a Reticon linear photodiode arrac The Model 1453 is a 1024 element version of the same detector Each has a broad wavelength response of $200 \mathrm{~nm}$ to $1100 \mathrm{~nm}$ individuai photodiodes are $25 \mu \mathrm{m}$ wide by 2.5 $\mathrm{mm}$ high and the length is

$12.5 \mathrm{~mm}$ for the 512 array and $25 \mathrm{~mm}$ for the 1024 array They include a Peltier cooler to maintain a normal operating temperature of $+5^{\circ} \mathrm{C}$ and can be set to a user selectable temperature $1-19^{\circ} \mathrm{C}$ limit) under software control $A$ water flow block to remove heat at the lower setting and a $N$, purge port to prevent moisture build up are provided

Model 1454 Detector. The most sensitive of the $145 \mathrm{X}$ series of detectors is the Model 1454-a 512-element intensified diode array providing detection levels of approximately 100 photons per $A D C$ count. The array dimerisions are $25 \mu \mathrm{m}$ by $2.5 \mathrm{~mm}$ by $12.5 \mathrm{~mm}$ long and temperature is maintained at $+5^{\circ} \mathrm{C}$ by a Peltier cooler l.ike the other detectors of this series. low temperature operation. $\mathrm{N}_{2}$ purge, and water flow block are standard. The wavelength response of the 1454 is limited by the intensifier to the range of $365 \mathrm{~nm}$ to $800 \mathrm{~nm}$. An optional UV scintillator extends the blue response to $200 \mathrm{~nm}$.

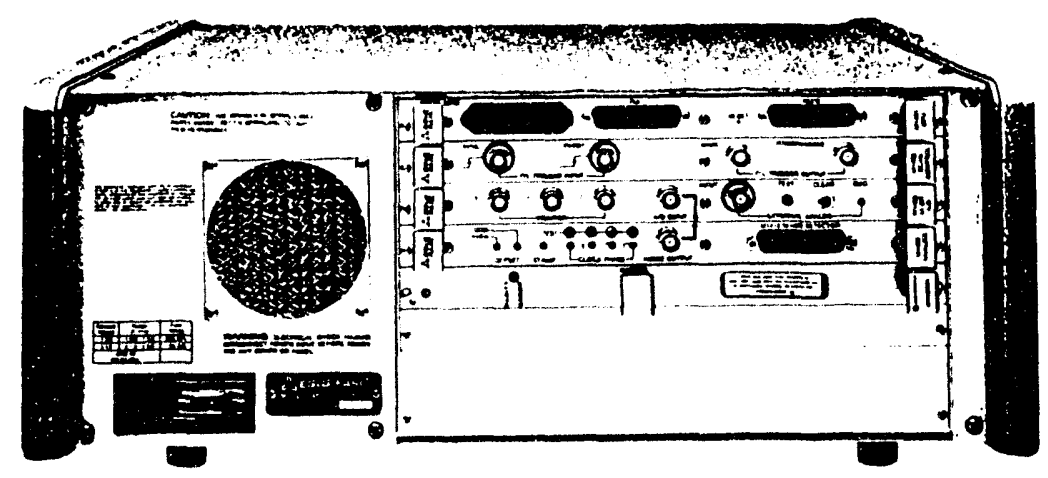

The rear panel of the Model 1461 shows the plug.in VME bus modules. The top module is the CPU with RS232C. GPIB and PIA. Next down is the Model 1463 Detector Module (3.card set) with connectors for Triggers and other control signais. Last is a $256 \mathrm{~K}$ byte RAM module. There are three empty slots behind the bottom blank panels

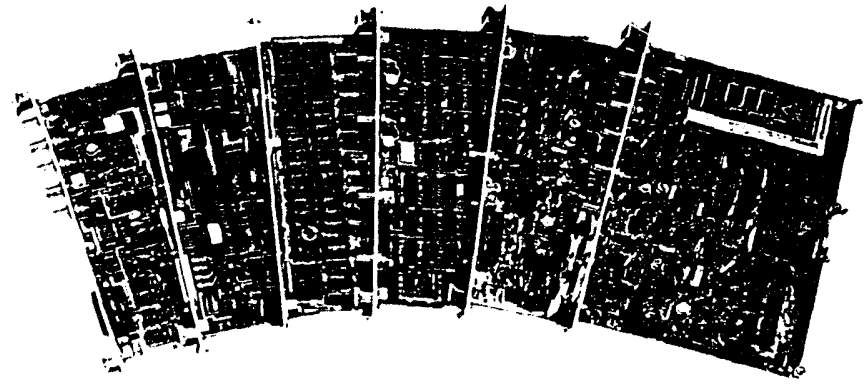


$\mathrm{H}$

igh Performance

Detectors.

Model 1412 and $1412 \%$

Detectors The Model 1412

is a 1024 element silicon photodiode array detector that incorporates a Peltier cooler for normal operation down to $-20^{\circ} \mathrm{C}$ and even lower with supplemental hquad cooling Extended integration directly on the photodindes is therefore posinle The spectral response is from 200 io $1100 \mathrm{~nm}$ and it has the highest sensitivity of anv unintensified detector The Model $1412 \mathrm{~F}$ detector has been designed for direct coupling to fiber optic outputs and has a fiber optic faceplate in place of the quartz window It can be used wherever the experimenter requires a special design intensifier or other input optics

Model 1420 1421 Detectors. This familu of 12 miensified diode array detectors offers a sentillutu of one ADC count per defected photon Selecoun of a cathode tupe. number of detecom elements and gating abilitu allows the leser cost. effective motchma of the detector io the experment The whole familu features low geometric distortion and the dihte we cont the arrav io

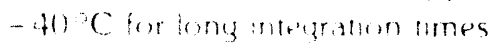

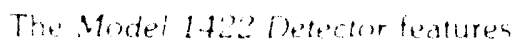
linale elements and orie? count per devected phomon performance at a low crest The deperor is teteal for

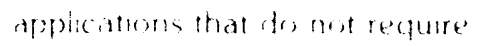

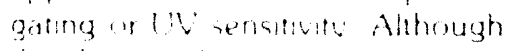

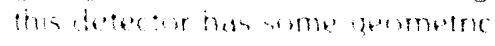
dinforton thas exertlent ine

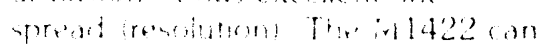

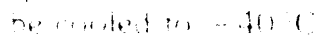

D ata Acquisition Mode Power. The following three Data Acquisition Modes are listed to present typical examples of the Acquisition Power of the M1461

\section{ACQUISITION MODE $* 2$}

FOR $M=M E M$ TO MEM $+J$

TRIGGER OUT

ON TRIGGER

FOR $S=1$ TO 1

ADD

FOR $G=1$ TO $K(K$ can equal 0$)$

IGNORE

NEXT G

NEXT S

NEXTM

EXPLANATION: 'J' sets of scans occur with ' $I$ ' scans in each set. Each set of scans is preceded by a TRIGGER OUT and an ON TRIGGER. A complete set of ' $T$ scans is taken after each ON TRIGGER and the results from each set are ADDED into separate memories. There is provision for ignoring ' $K$ ' scans after each ADDED scan

Mode (2) is identical to Mode (1). except that the instrument must wait for an incoming ON TRIGGER signal before beginning each set of scans

COMMENT DA2 with $\mathrm{J}=1$ and $\mathrm{K}=0$ ) is a classic data acquisition mode With $J>1$. a series of experiments can be run. Setting $K>0$ can be used for such timing convenience as allowing a laser's supply to recharge

\section{ACQUISITION MODE $* 7$ \\ TRIGGER OUT \\ FOR $M=$ MEM TO MEM + J \\ STORE \\ FOR $G=1$ TO $K$ ( $K$ can equal 0 ) \\ IGNORE \\ NEXT G \\ NEXT M}

EXPLANATION Following a single TRIGGER OUT. 'I' scans occur The result of each is STORED in a different mernory There is provision for gnormy $K$ ' scans after each STORED scan

COMMENT In DA7 the STORE command uses 2 bytes to store a data point allowing better utitization of memory in this kinetics mode?
$K>0$ can be used to slow down the sampling rate in the basic time units of detector scans for a kinetics experiment

ACQUISITION MODE "12

FOR MEM = MEM TO MEM + J

TRIGGER OUT

STORE

SUBTRACT

FOR $G=1$ TO $K(K$ can equal 0$)$

IGNORE

NEXT G

NEXT M

EXPLANATION: There are ' $J$ ' scan pairs. with each pair using a different memory. Each is preceded by a TRIGGER OUT. The first scan of each pair is STORED in memory. The second scan of each pair is SUBTRACTED from the one just STORED. There is provision for ignoring ' $K$ ' scans after each SUBTRACTED scan

COMMENT: Mode DA12 is ideal

for application to pulsed experiments that are taken in dynamic optical backgrounds. The subtraction of the scan immediately after the "hot" scan allows the most accurate possible background correction. It also combines what used to be two experiments into one.

The IGNORE feature of this mode allows the user to do low duty cycle experiments with short detector exposure times. Thus minimizing dark current or the need to add water cooling to the peltier

DA $X$ : The ability to mix ADD. SUB. IGNORE. STORE. TRIG OUT. ON TRIG. PIA commands etc in virtually limitless combinations allows total flexibility to maximize OMA performance for experiments not covered by the standard set of DA modes This feature means that the M1461 will be able to grow into as yet undefined experiments

Ail DA modes have corresponding modes with no output triggers This feature allows the user complete freedom to take experimental back grounds without the need is disconnect BNC cables idust one example of the attention to expermental detal gamed through 14 years of OMA design । 


\section{lialifin}

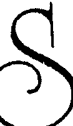

ample Commands for

M1461. To help

understand the ease of programming a M1461, a a small sample of the high level commands is listed below.

A ":" is the command delimiter, an " $n$ " indicates a numerical input, and a " $d$ " indicates a default condition An " $r / s$ " denotes a command that functions as an input when an " $n$ " is present or a status poll when no " $n$ " is present. The large number of " $\mathrm{r} / \mathrm{s}$ " commands are especially useful during program design. Also a string of commands may be stored and executed by a single command.

\section{STATUS COMMANDS}

CL: $\quad$ Reply is a 1 if peltier cooler is temperature-locked at set point.

Reply is 0 if peltier cooler is still moving toward lock

DLEN

Reads the detector length (512 or 1024

ERR: Responds with enor codes

MIN ET

Tells programmer the minimum allowed exposure time based upon the current detector setup and size

MAX.MEM: Tells programmer the maximum number of available memories.

\section{DETECTOR CONTROLLER SETUP COMMANDS \\ DT $n: r / S$ Detector temperature in ${ }^{\circ} \mathrm{C}$ \\ ET $n: r / s \quad$ Exposure time in seconds (i.e. 3. 02) \\ TRIG ON: Turns main trigger on \\ TRIG OFF : $d$ Turns main trigger off \\ LS: Sets the detector controller to line-synchronized scans \\ DDRA $n: \quad$ Sets the direction of dala register $A$}

PORT $A \cap r / s$ Sets or reads the data register $A$

DATA ACQUISITION COMMANDS

DA $n$ is Selects one of the preprogrammed data acquisition modes

In t s Selects the number of detector scans added into a memory during a data acquisition

$J n$ is Selects the number of memories io be lilled during a data acquisition

$K \mathrm{n}$. Selects the number of detector scans that are ignored during a data acquisition

RUN

Begins dala acquisition All memories set to recelve data will be cleared before operation

\section{CURVE CALCULATION COMMANDS \\ CLR $n$ : Sets memory, $n$, to zero \\ CLR ALL. Sets all memories to zero \\ MEM $n \mathrm{r} / \mathrm{s}$ Sets current memory to. $n$. or tells program the current memory numbers \\ SUB n $1, n 2$ Subtracts the contents of mernory. $n 1$. from memory, $n 2$. leaving the result in memory. $\mathrm{n} 2$ \\ DP

$$
\begin{aligned}
& \text { preciston of currently. } \\
& \text { selected Data Acquistion }
\end{aligned}
$$$$
\text { Responds with data }
$$$$
\text { Mode }
$$

\section{SAMPLE PROGRAM}

The following string of commands are all that is needed to expcute an externally triggered

\begin{tabular}{|c|c|}
\hline CL: & Is the cooler locked? \\
\hline ET 1 : & $\begin{array}{l}\text { Sel exposur time to } 100 \\
\mathrm{~ms}\end{array}$ \\
\hline DA 2: & $\begin{array}{l}\text { Select one of the externally } \\
\text { triggered acquisition } \\
\text { modes }\end{array}$ \\
\hline 11: & $\begin{array}{l}\text { One detector scan will be } \\
\text { stored }\end{array}$ \\
\hline J1 & $\begin{array}{l}\text { One trigger out/in } \\
\text { sequence will be stored }\end{array}$ \\
\hline K O: & $\begin{array}{l}\text { There will be no ignored } \\
\text { scans }\end{array}$ \\
\hline RUN: & $\begin{array}{l}\text { The experiment is } \\
\text { executed }\end{array}$ \\
\hline
\end{tabular}
experiment.

BD 1,1,1024. Data is sent to the host computer
(B)

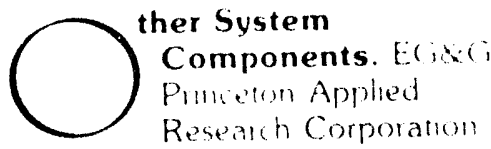

offers manu other instruments in complement the OMA. III famili. Individual specification sheets are available on the Model 1228 Model 1229. and Model 12:33 Spectrogtaphs

The Model 1.303 Gate Pulse Interface is a VME card that provides soffware controlled delave for all pulses and software controlled width for the Model

1.304. Major features are the abilitu to increment delaus up to $1: 3 \mathrm{~ms}$ in 1 ns steps. an electrical trigger. and an on-board optical trigger

There are two gate pulse generators used to gate detectors on and off The Model 1304 Pulse Amplifier combined with the Model 1.303 or a user-supplied pulse generator supplies gate pulses in the 100 $\mathrm{ns}-10 \mathrm{~ms}$ range. The Model 1302 supplies gate pulses in the $5-20 \mathrm{~ns}$ range

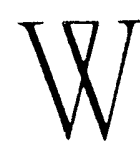

arranty. All hardware carries a 24-month warranty. For a small added charge, all detectors can be warranted for 24 months. 


\section{Model 1461 Specifications}

\section{FRONT PANEL LEDS:}

Cooler Lock

Interface Status

Remote

Talk

Listen

Service Request

Error

REAR PANEL: 8 VME Standard Card Slots

INCLUDED CARDS: CPU -1 slot

CHOICE OF DETECTOR MODULES

1462 Detector Module (145X series) - 1 slot

1463 Detector Module (1412 and 1420) -3 slots

OPTIONAL CARDS

1461/98 HSS/PAR - 1 slot

$1462 / 99$ 14-bit ADC -1 slot

2000-0091 Extended Memory. 256K byte -1 slot each

2000-0113 Extended Memory, 2Meg byte -1 slot

1303 Gate Pulse Interface - 1 slot

\section{CPU Module Specifications}

MICROPROCESSOR: Motorola 68000. 16 bits

MEMORY: 12ठK ROM. 32K RAM (expandable with VME bus RAM Cards)

MEMORY CAPACITY (STANDARD): 6 double precision 132 bits 1024-element curves: 24 single-precision 512 -element curves

\section{COMPUTER INTERFACE:}

RS232C 25-pin (DB-25S) connector

IEEE-488 GPIB connector

PIA 25-pin (DB-25S). 16-bit user-programmable 1/O port Reset Switch

DIMENSIONS: $18.75^{\prime \prime}(47 \mathrm{~cm})$ wide $\times 7.5^{\prime \prime}(19 \mathrm{~cm})$ high $\times 15^{\prime \prime}$ $(38 \mathrm{~cm})$ deep

WEIGHT: $37.5 \mathrm{lbs}(17 \mathrm{~kg})$

SHIPPING WEIGHT: 45 lbs $(20.5 \mathrm{~kg})$

POWER: $120 / 240 \mathrm{~V}, 50 / 60 \mathrm{~Hz}$

ACCESSORIES: Rack Mount Ears. Cables (depending on configuration) 


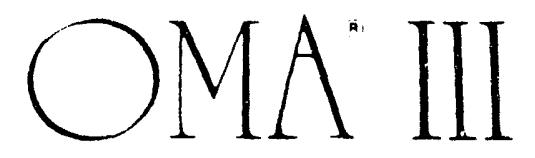

MODEL 1422

INTENSIFIED DIODE ARRAY DETECTORS

DESCRIPTION
The 1422R-1024-N.F and the

M1422-1024-N utilize an image inverting, electrostatically focused im. age intensifier fiber optically coupled to a diode array. The difference between the two detectors indicated by the - $F$ (Fast) designation is the speed of the phosphor in the intensifier. This high gain detector is an excellent choice for experiments in the 350 to $900 \mathrm{~nm}$ wavelength region that do not require gating. Although there is a small amount of geometric distortion due to the electrostatic image section. the line spread of this detector is ex. cellent when compared to a proximity focused MCP intensified detector.

The M1422 uses an S-20R photocathiude behind a glass fiber optic input. The sensitivity is very high in the visible and red with the characteristic glass cut off around $350 \mathrm{~nm}$. UV sensitivity can be gained with tire deposition of a chemical scintillator (M1422/01 option) onto the fiber optic input of the detector. As shown by the typical curve, the scintillator does degrade performance in the visible. Therefore. the scintillator should be selected only if absolutely required.

These detectors are controlled by the M1463 detector controller, a VME caro set that is fully compatible with erther the $M 1460$ or M1461. Some features of the M1463 are mixed scan of the diode array, digital control of temperature and exposure time. source comper. sation, and full compatibility with al! DA modes.

Some applications of the M1422 are:

Raman

Fluorescence

Phosphorescence

Plasma Monitoring

Emission Spectroscopy

Low Level Absorbance or Transmittanc's

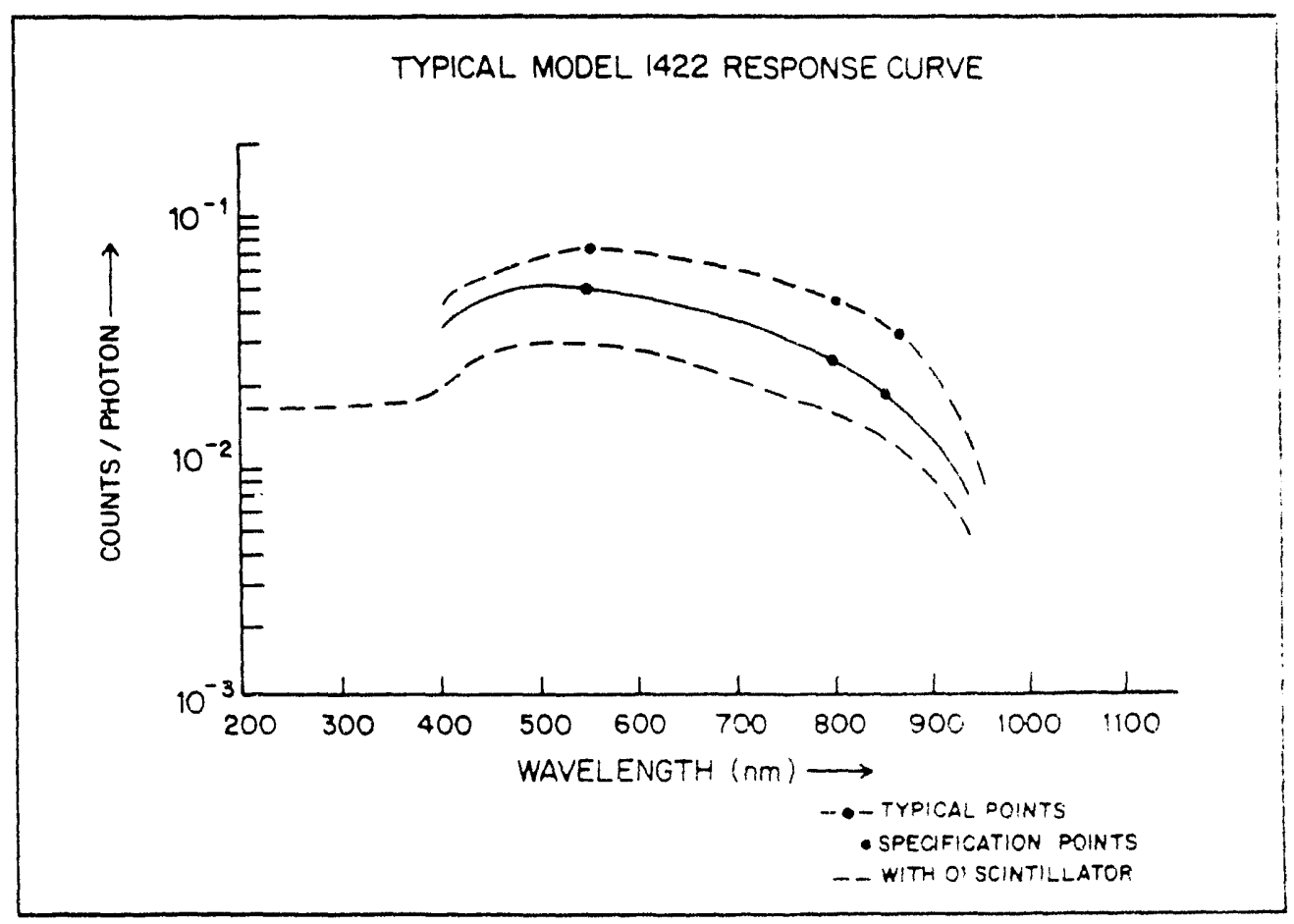




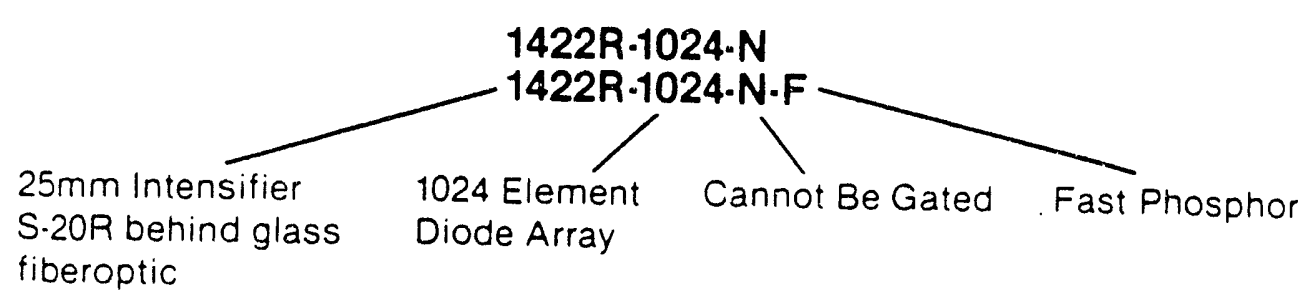

DETECTOR TYPE: Inverting, elec-

trostatically focused, MCP intensified, Diode Array

DEVIATION FROM LINEAR

PHOTOSENSITIVE MATEF'AL: S2OR behind glass fiberoptic

WAVELENGTH RANGE (NM): 350.900

(<200.900 with/01 scintillator)

\begin{tabular}{llll}
\multicolumn{4}{c}{ QUANTUM EFFICIENCY: } \\
\multicolumn{5}{c}{$550 \mathrm{~nm}$} & $\mathbf{8 0 0} \mathbf{n m}$ & $\mathbf{8 5 0} \mathbf{n m}$ \\
\hline Minimum & .05 & .023 & .015 \\
Typical & .07 & .05 & .038
\end{tabular}

RESPONSE: $<1 \%$

UNIFORMITY OF RESPONSE

ACROSS DETECTOR:

$\pm 10 \%$ Typical $\pm 20 \%$ Maximum

GEOMETRIC DISTORTION: $5 \%$.

\# OF ACTIVE ELEMENTS: Size of

Elements 1000 Typical 990 Minimum $25 \mathrm{um} \times 2.5 \mathrm{~mm}$

SYSTEM NOISE (COUNTS/ $\sqrt{\text { SCAN }): ~}$

(a) $20 \mathrm{~ms}, 5^{\circ} \mathrm{C} \leq 1$

SENSITIVITY (PHOTON/COUNT): $550 \mathrm{~nm} 800 \mathrm{~nm} 850 \mathrm{~nm}$

DARK CURRENT: $1 \mathrm{sec} @ 5^{\circ} \mathrm{C}$, typical $1000 \mathrm{cts}$.

$\begin{array}{llll} & & & \\ \text { Minimum } & 20 & 43 & 67 \\ \text { Typical } & 15 & 20 & 27\end{array}$

LINE WIDTH\# of Channels FWHM: 3 PHOSPHOR PERSISTENCE: ( $\mathrm{msec}$ )

GAIN (COUNT/PHOTOELECTRON): $>1$

DYNAMIC RANGE W/M1463 CONTROLER: 16383

\begin{tabular}{crr} 
Detector & $10 \%$ & $1 \%$ \\
\hline$-N$ & 200 & 1000 \\
.$N \cdot F$ & 3 & 25
\end{tabular}

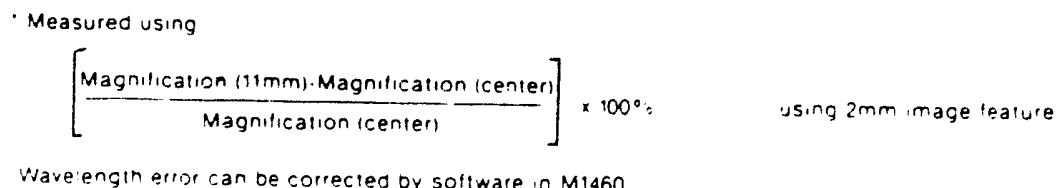




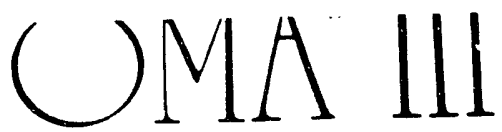

MODEL 1420, 1421

INTENSIFIED DIODE ARRAY DETECTORS

Fast Gate (G) and High Quantum EHticiency (HO) Options

DESCRIPTION
The 1420/21 detector family features a proximity focused, microchannel plate (MCP), image intensifier coupled via fiber optic bundles to a linear diode array. Delector electronics have been carefully optimized to assure optimum exposure time, sensitivity, and intensifier life. These detectors, controlled by the M1463 detector controller (NME card set), are fully compatible with all the data acquisition power of the 1460 or 1461. A major $1420 / 21-1463$ system feature is the ability 10 "mix mode scan". "Fast Accessed" pixels can be rapidly scanned in order to lessen the number of data points and increase the scan rate. Contiguous pixels can be "Grouped" into single data points to increase detectivity, in. crease scan rate, and lessen the number of data points. Fast Accessed and Grouped pixels can then be combined with Normally scanned pixels in virtually limitless combinations.

Some important detector features are:

- High Sensitivity-MCP amplification generates more than one ADC count for each detected photon. Slandard gain is 1.3 counts/photo-electron to ensure a true 10,000:1 dynamic range. If needed, gain can be adjusted up or down.

- Low Noise

- Low Distortion-Proximity focusing causes minimal image distortion. especially when compared to electrostatically locused intensifiers.

\section{- Broad Wavelength Coverage}

- Large ON/OFF Ratio-When the intensifier is off, light leakage through the intensifiers is so low as to be virtually immeasurable.

The M1420 and M1421 delectors use $18 \mathrm{~mm}$ and $25 \mathrm{~mm}$ diameter intensifiers respectively. Photocathode response is specified as bive (B) or red (R) en. hanced. The detectors may be ordered in a fast gate $(G)$ or high quantum etfi. ciency (HO) configuration. The number of elements in the diode array is either 512 or 1024. The above options are combined into " "14208-512-G" format (18 mm, Red enhanced, 512 element. Fast Gated).

The M1420 and M1421 are used in any application that requires high sensitivity over the whole UV.VIS range, tasi lime resolution, or rejection of background light. A partial list of applications are:

- RAMAN

- Fluorescence, Luminescence

- Phosphorescence

- Puised Laser Spectroscopy

- Picosecond Spectroscopy

- Laser Diagnostics

Special order, non-standard versions of the 1420 and 1421 are available. Examples are Solar blind intensifiers (Cs.Te), BR intensifiers, and intet,sifiers with lower priced, sub-spec cathodes for high light, time-resolved applications.

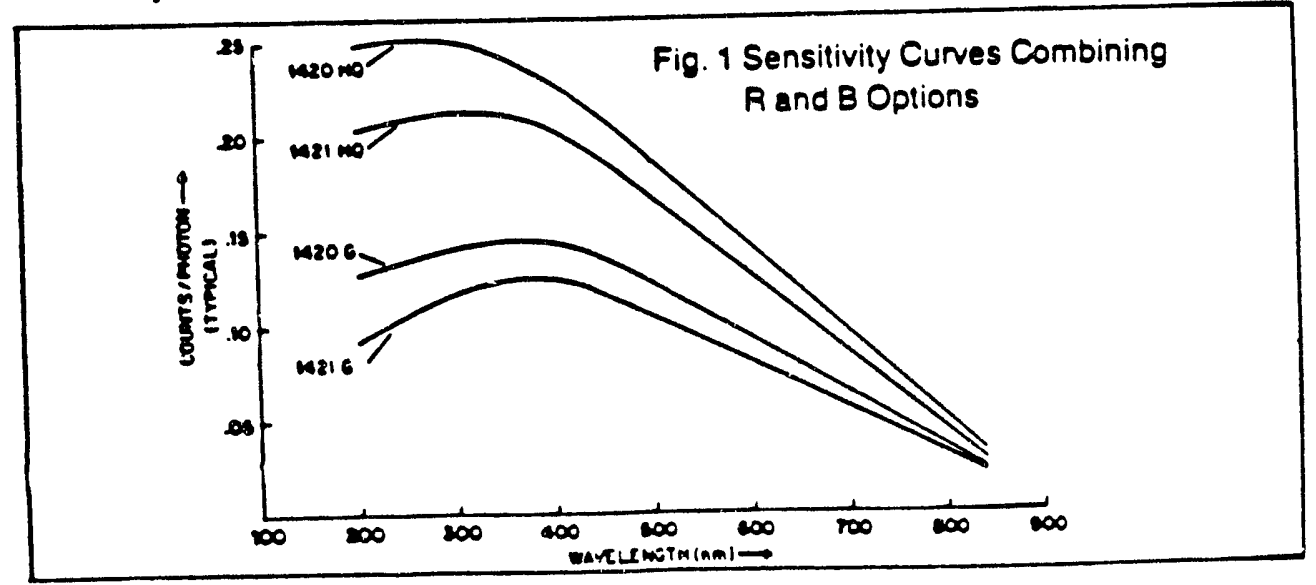

\section{ONEGEG PRINCETON APPLIED RESEARCH}

P.O. BOX 2565 - PRINCETON, NEW JERSEY 08543 - 2565 U.S.A.
(609) $530-1000$ - TELEX: 843409 - FAX: (609) 883-7259 - CABLE: PARCO

$$
C-73
$$


DETECTOR TYPE: Proximity focused $M C P$ intensified diode array

PHOTOCATHODE: Multi-alkali on S1.UV-A fused silica faceplate

INTENSIFIER DIAMETER: $M 1420-18 \mathrm{~mm}$ $M 1421.25 \mathrm{~mm}$

SIZE OF DETECTOR ELEMENTS:

$25 \operatorname{um}(x), 2.5 \mathrm{~mm}(y)$

* Ot Active Elements: 1420_ 512, 512

Minimum

$1420-1024,700$

1421-1024, 890

WAVELENGTH RANGE: $180-800 \mathrm{~nm}$

GAIN (counts/photoelectron)2: $>1$

DEVIATION FROM LINEAR

RESPONSE: $<1 \%$

DYNAMIC RANGE W/1463: 16383

UNIFORMITY OF GAIN ACROSS FACE

D? DETECTOR3: $\pm 25 \%$, $\pm 10 \%$ typical

GEOMETRICDISTORTION: < 1 channel
LINE WIDTH4: 3 rhannels FWHM

DARK CURRENT's (counts):

1024512

element element

.8 sec. + $5^{\circ} \mathrm{C}$ Max. $2970 \quad 1980$

.8 sec, $+5^{\circ} \mathrm{C}$ Typical $350 \quad 560$

$1.0 \mathrm{sec},+5^{\circ} \mathrm{C}$ Typical 440700

1.0 sec, $-20^{\circ} \mathrm{C}$ Typical 3560

TEMPERATURE RANGE W/M1463:

$5^{\circ}$ to $-40^{\circ} \mathrm{C}$

EBI5: $3 \times 10^{-11} \mathrm{LM}^{\mathrm{C}} \mathrm{CM} \mathrm{M}^{2}$

SYSTEM NOISE?: $<1$

counts/(scans) $1 / 2$

ON/OFF RATIO: > 10

GATE WIDTH\& Minimum:

$1420 \ldots$. G. $1421 \ldots$ G 5 ns 1420R....HO 50 ns $1420 B \ldots . . . H Q, 1421 R \ldots . . . H Q 100 \mathrm{~ns}$ $1421 B \ldots . . . H Q \quad 1421 A \ldots$....HQ 150 ns

QUANTUM EFFICIENCY: listed in \% and (mAWatt)':

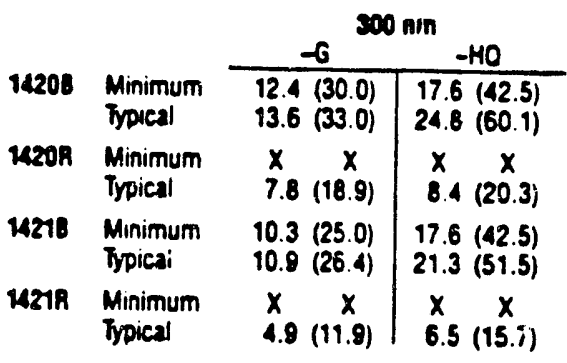

\begin{tabular}{cc|c}
\multicolumn{3}{c}{60 am } \\
\hline 6 & HO \\
\hline $6.76(30.0)$ & $11.3(50.0)$ \\
$10.2(45.3)$ & $15.0(66.2)$ \\
$6.76(30.0)$ & $11.3(50.0)$ \\
10.5 & $(46.4)$ & $15.7(69.7)$ \\
$6.76(30.0)$ & $11.3(50.0)$ \\
$0.1(40.3)$ & $13.7(60.8)$ \\
$6.76(30.0)$ & $11.3(50.0)$ \\
$0.4(41.5)$ & $14.4(64.0)$
\end{tabular}

\begin{tabular}{|c|c|c|c|}
\hline \multicolumn{4}{|c|}{$230 \mathrm{~nm}$} \\
\hline & $-G$ & & -40 \\
\hline $\begin{array}{r}x \\
1.0\end{array}$ & $\begin{array}{c}x \\
(7.0)\end{array}$ & $\begin{array}{r}x \\
1.2\end{array}$ & $\begin{array}{c}x \\
\text { (7.9) }\end{array}$ \\
\hline $\begin{array}{l}1.5 \\
2.5\end{array}$ & $\begin{array}{l}(10.0) \\
(16.7)\end{array}$ & $\begin{array}{l}2.65 \\
3.3\end{array}$ & $\begin{array}{l}(17.5) \\
(21.9)\end{array}$ \\
\hline & $\begin{array}{c}x \\
(5.9)\end{array}$ & $\begin{array}{c}x \\
1.34\end{array}$ & $\begin{array}{c}x \\
(9.0)\end{array}$ \\
\hline $\begin{array}{l}1.5 \\
1.8\end{array}$ & $\begin{array}{l}(10.0) \\
(12.8)\end{array}$ & $\begin{array}{l}2.65 \\
3.8\end{array}$ & $\begin{array}{l}(17.5) \\
(25.3)\end{array}$ \\
\hline
\end{tabular}

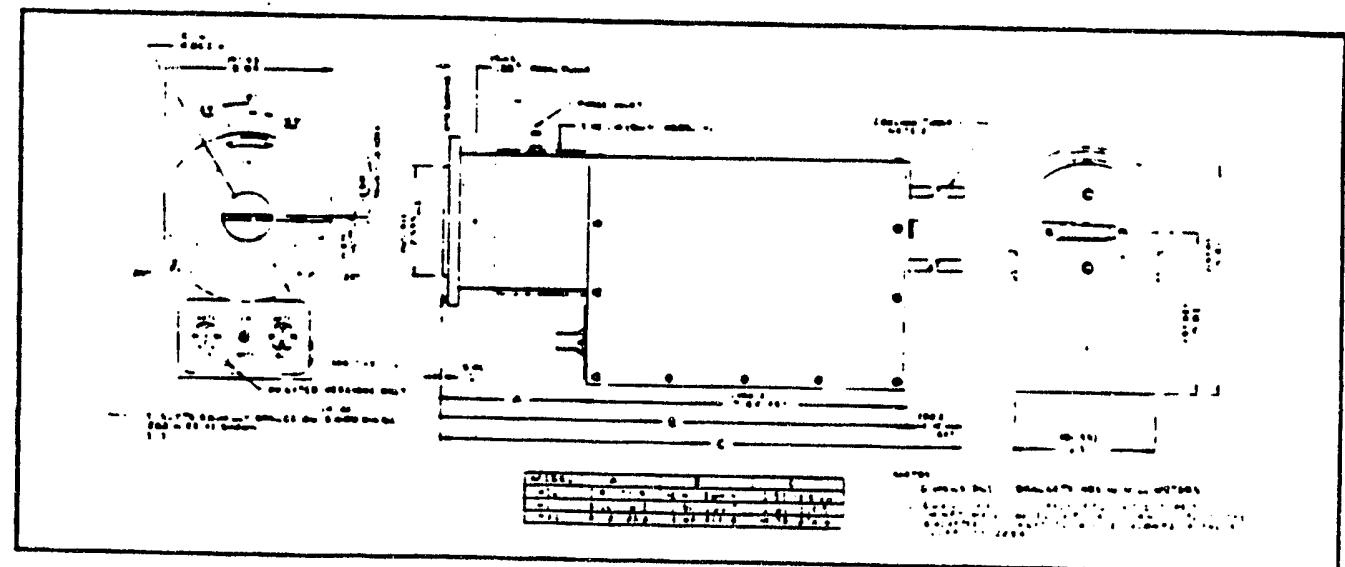

Fig. 2 Outline Drawing of M1420/21 Detector

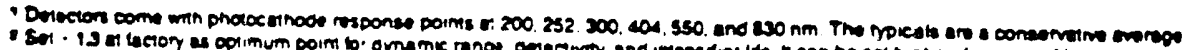

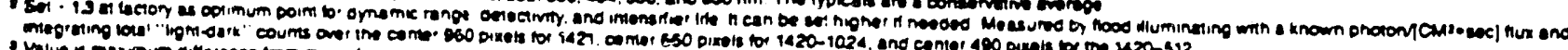

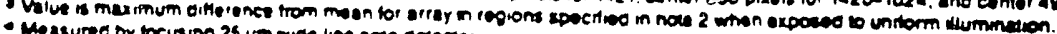

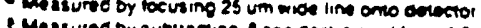

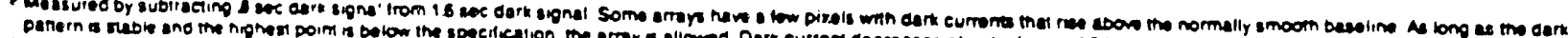

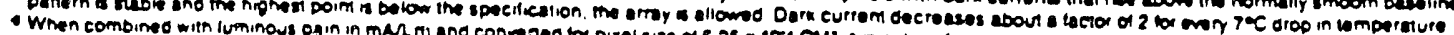

(a)

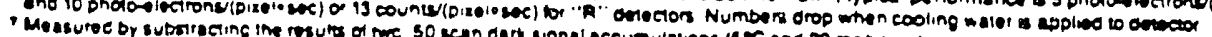

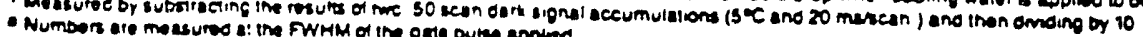




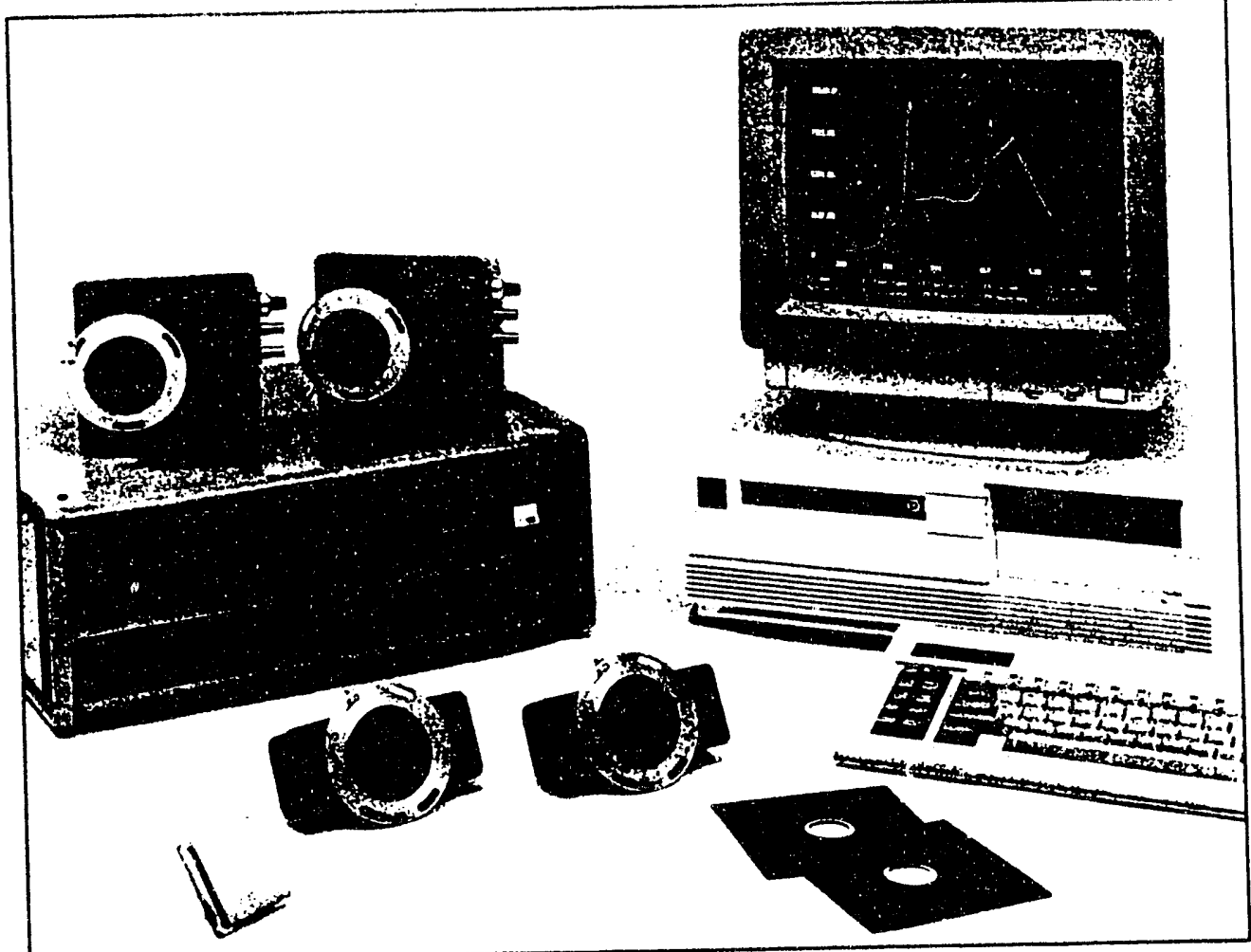

$1452 \mathrm{~A}$ and $1453 \mathrm{~A}$

\section{FEATURES}

- Compact Size

- High Reliability

15 Bit Dynamic Range

- Optimized Mechanical Design

- Single Window Design
APPLICATIONS

- Plasma Monitoring

- Radiometry and Colorimetry

- Light Source Diagnostics

- Absorbance and Transmittance Measurements

- Optical Component Testing

- Laser Scattering

$\begin{array}{ll}\text { 1455A and 1456A } & \text { FEATURES } \\ & =\text { High Sensitivity } \\ & =\text { Improved Minimum Detectable Flux } \\ & \text { Low Distortion } \\ & =\text { Broad Wavelength Coverage } \\ & \text { Large ON/OFF Ratio } \\ & =15 \text { Large Choice of Intensifiers } \\ & \end{array}$

\section{APPLICATIONS}

- Raman

- Fluorescence

- Phosphorescence

- Luminescence

- Pulsed Laser Spectroscopy

- Picosecond Spectroscopy

- Laser Diagnostics 
The M145XA series is a family of cost effective linear diode array based detectors for the M1471 A and M1461 detector interfaces and the M1470A and M1460 detector consoles. These high-performance detectors are designed to cover the entire experimental range of time resolutions (pico-seconds to hours) and light levels. These detectors provide 15 bits of dynamic range when used with the M1470A or M 1471 A. Detector control when used with the M1460 or M1461 is supported via the M1462 detector controller interface (VME card set) which has a standard 12 bit ADC. A 14 bit ADC UPGRADE is available as the M1462/99 option.

All four M145XA detectors are fully compatible with the NEW DAD (Data Acquisition Design) software and the present data acquisition power of any of the controllers.

The M145X series detectors are divided into two SENSITIVITY groups: non-intensified $(1452 \mathrm{~A}, 1453 \mathrm{~A})$ and microchannel plate (MCP) intensified (1455A,1456A).

\section{$1452 \mathrm{~A}$ and $1453 \mathrm{~A}$}

\section{A and 1456A}

These detectors are variable gain gatable (nanoseconds) proximity focused, microchannel plate (MCP), image intensifier coupled via fiber optic bundles to a linear diode array. They differ only in respect to the overall diameter of the intensifiersM1455A $18 \mathrm{~mm}$ or M1456A 25mm. Both are ideal detectors for applications that require high sensitivity over the entire UV-VIS range, fast time resoultion or rejection of ambient background light.

Some important features:

High Sensitivity- MCP amplification generates more than one ADC count for each detected photon. In standard units, the gain is adjusted to 1.3 counts/photo-electron to ensure a true 10,000:1 dynamic range. If needed, gain can be adjusted up or down through a Precision MCP Variable Gain Control. Reproducibility for the different gain settings are maintained through a precision counter-dial.

Improved Minimum Detectable Flux (MDF)' - The M1455A and $M 1456 \mathrm{~A}$ cmploy a new exclusive PARC feature that optimizes cooling of the MCP intensifier's pho-

$$
\text { C-76 }
$$




\section{$1455 \mathrm{~A}$ and $1+56 \mathrm{~A}$ (continued)}

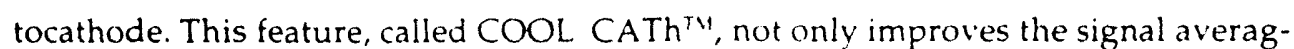
ing of weak signals but also eliminates any condensation build-up on the intensifier's faceplate.

Low Distortion- Proximity focussing causes minimal image distortion, especially when compared to electrostatically focussed intensifiers.

Broad Wavelength Coverage- Multi-alkali photocathodes behind S1-UVA grade Fused Silica face plates yield maximum coverage.

Large ON/OFF Ratio- Gating the intensifiers allows time resolved measurements of low level signals that are buried in an intense background.

Large choice of intensifiers- Eight different intensifiers, each with its own unique advantages, are available for the M1455A and the M1456A. Although not listed in the tables two "BR" enhanced intensifiers are also available.

The M1455A can be supplied with either a 512 element or a 1024 element silicon diode array. The M1456A is supplied with a 1024 element array. Photocathode response is specified as blue enhanced (B) or red enhanced (R). Overall intensifier sensitivity are designated by $(G)$ for fast GATE version or (HQ) for high quantum efficiency. The above options are combined into a "1455R-512-G" format (18 mm, Red photocathode enhanced, 512 element, Gated).

\section{DETECTOR SENSITIVITY}

Typical Sensitivity curves are presented in Fig 1.

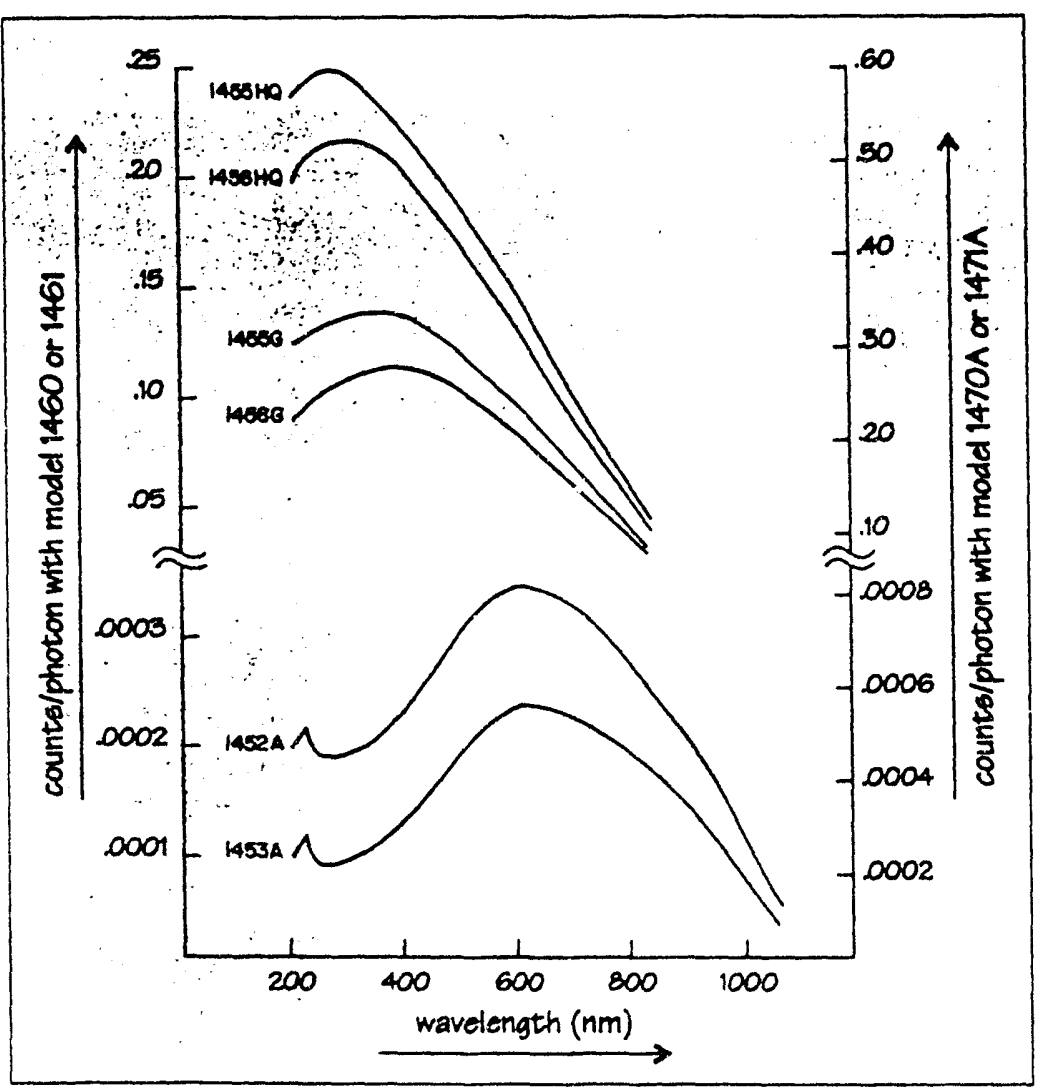

Figure 1. Serisilivily Curies 


\section{TABLE 1}

Quantum Efficiency: listed in \% and ( $\mathrm{mA} / \mathrm{Watt})^{2}$

\begin{tabular}{|c|c|c|c|c|c|c|}
\hline & \multicolumn{2}{|c|}{$300 \mathrm{~nm}$} & \multicolumn{2}{|c|}{$550 \mathrm{~nm}$} & \multicolumn{2}{|c|}{$830 \mathrm{~nm}$} \\
\hline & G & HQ & $G$ & $H Q$ & G & HO \\
\hline \multicolumn{7}{|l|}{14558} \\
\hline minimum & $12.4(30)$ & $17.6(42.5)$ & $6.76(30)$ & $11.3(50)$ & $x$ & $x$ \\
\hline typical & $13.6(33.0)$ & $24.8(60.1)$ & $10.2(45.3)$ & $15.0(66.2)$ & $1.0(7.0)$ & $1.2(7.9)$ \\
\hline \multicolumn{7}{|l|}{$1455 R$} \\
\hline minimum & $x$ & $x$ & $6.76(30)$ & $11.3(50)$ & $1.5(10)$ & $2.65(17.5)$ \\
\hline typical & $7.8(18.9)$ & $8.4(20.3)$ & $10.5(46.4)$ & $15.7(69.7)$ & $2.5(1 €\urcorner)$ & $3.2(21)$ \\
\hline \multicolumn{7}{|l|}{14568} \\
\hline minimum & $10.3(25)$ & $17.6(42.5)$ & $6.76(30)$ & $11.3(50)$ & $x$ & $x$ \\
\hline typical & $10.9(26.4)$ & $21.3(51.5)$ & $9.1(40.3)$ & $13.7(60.8)$ & $.88(5.9)$ & $1.34(9.0)$ \\
\hline \multicolumn{7}{|l|}{ 1456R } \\
\hline minimum & $x$ & & $6.76(30)$ & $11.3(50)$ & $1.5(10)$ & $2.65(17.5)$ \\
\hline typical & $4.9(11.9)$ & $6.5(15.7)$ & $9.4(41.5)$ & $14.4(64.0)$ & $1.9(12.8)$ & $3.2(21)$ \\
\hline
\end{tabular}

TABLE 2

Typical photons/count: G/HQ detector

With Model 1470A and 1471A:

\begin{tabular}{|c|c|c|c|c|c|c|}
\hline $\mathrm{nm}$ & 200 & 252 & 300 & 404 & 550 & 830 \\
\hline $\begin{array}{l}1455 B \\
\text { GHO }\end{array}$ & $2.9 / 2.0$ & $3.0 / 1.6$ & $3.1 / 1.7$ & $2.8 / 1.8$ & $4.1 / 2.8$ & 41.434 .5 \\
\hline $\begin{array}{l}1455 \mathrm{R} \\
\mathrm{G} / \mathrm{HO}\end{array}$ & $x x$ & $5.2 / 4.5$ & $5.3 / 4.9$ & $4.8 / 5.3$ & $3.9 / 2.7$ & $16.6 / 13.0$ \\
\hline $\begin{array}{l}14568 \\
\text { G/MQ }\end{array}$ & $2.4 / 1.9$ & 4.22 .3 & 3.82 .0 & 3.222 .0 & $4.6 / 3.0$ & $46.8 / 30.9$ \\
\hline $\begin{array}{l}1456 R \\
\text { G/HQ }\end{array}$ & $x / x$ & $11.5 / 6.0$ & $8.4 / 6.4$ & $7.8 / 5.6$ & $4.4 / 2.9$ & $21.7 / 13.0$ \\
\hline
\end{tabular}

With Model 1460 and 1461:

$\begin{array}{lllllll}\mathrm{nm} & 200 & 252 & 300 & 404 & 550 & 830 \\ \begin{array}{l}14558 \\ \mathrm{G} / \mathrm{HQ}\end{array} & 6.9 / 4.8 & 7.3 / 3.9 & 7.4 / 4.0 & 6.8 / 4.3 & 9.8 / 6.7 & 100.0 / 83.3 \\ \begin{array}{l}1455 \mathrm{R} \\ \mathrm{G} / \mathrm{HQ}\end{array} & \mathrm{X} X \mathrm{X} & 12.5 / 10.8 & 12.8 / 11.9 & 11.7 / 12.7 & 9.5 / 6.4 & 40.0 / 31.3 \\ \begin{array}{l}14568 \\ \mathrm{G} / \mathrm{HQ}\end{array} & 5.7 / 4.6 & 10.1 / 5.6 & 9.2 / 4.7 & 7.8 / 4.7 & 11.077 .3 & 113.0 / 74.6 \\ \begin{array}{l}1456 \mathrm{R} \\ \mathrm{G} / \mathrm{HO}\end{array} & \mathrm{XX} & 27.8 / 14.5 & 20.3 / 15.4 & 18.8 / 13.6 & 10.6 / 6.9 & 52.3 / 31.3\end{array}$




\section{X SPECIFICATIONS}

\begin{tabular}{|c|c|c|}
\hline & M1452A & M1453A \\
\hline Detector typo & Silicon Diode Array & Silicon Diode Array \\
\hline Photosensitive material & $\begin{array}{l}\text { Silicon behind fused } \\
\text { silica face plate }\end{array}$ & $\begin{array}{l}\text { Silicon behind fused } \\
\text { silica face plate }\end{array}$ \\
\hline Intensifier Diamoter & NA & NA \\
\hline $\begin{array}{l}\text { Ot Active Elements: } \\
\text { all } 25 \mu \mathrm{m} \times 2.5 \mathrm{~mm}\end{array}$ & 512 & 1024 \\
\hline Wavelength Range (nm) & $180 \cdot 1100$ & $180 \cdot 1100$ \\
\hline Quantum Efficiency & $.7 @ 650$ nm & $7 @ 650$ nm \\
\hline \multicolumn{3}{|l|}{$\begin{array}{l}\text { Typical Sensitivity @ } 550 \mathrm{~nm} \\
\text { (photoncount) }\end{array}$} \\
\hline $\begin{array}{l}\text { GAIN(photoelectrons/count) } \\
\text { w/1470A-1471A } \\
\text { w/1460-1461 }\end{array}$ & $\begin{array}{r}830 \\
2000\end{array}$ & $\begin{array}{l}1350 \\
3100\end{array}$ \\
\hline Veriable Gain & NA & NA \\
\hline Deviation from Linear response & $<1 \%$ & $<1 \%$ \\
\hline $\begin{array}{l}\text { Dynamic Range w/1470A-1471A } \\
w / 1462 \\
w / 146299\end{array}$ & $\begin{array}{r}32768 \\
4095 \\
16383\end{array}$ & $\begin{array}{r}32768 \\
4095 \\
16383\end{array}$ \\
\hline $\begin{array}{l}\text { Uniformity of response } \\
\text { across delector }\end{array}$ & $5 \%$ & $5 \%$ \\
\hline Goometric Distortion & $<1$ channel & $<1$ channel \\
\hline Line Width & 2 channels FWHM's & 2 channels FWHMs \\
\hline $800 \mathrm{~ms} @ 5^{\circ} \mathrm{C} \quad \begin{array}{l}\text { Maximum } \\
\text { Typical }\end{array}$ & $\begin{array}{l}2850 \\
1160\end{array}$ & $\begin{array}{r}2500 \\
910\end{array}$ \\
\hline $1 \sec @ 5^{\circ} \mathrm{C}$ & 1430 & 1120 \\
\hline $1 \sec @-20^{\circ} \mathrm{C}$ Trpical & 120 & 100 \\
\hline Temperature Range & $-40^{\circ} \mathrm{C} 1018^{\circ} \mathrm{C}$ & $-40^{\circ} \mathrm{C} 1018^{\circ} \mathrm{C}$ \\
\hline EBP & NA & NA \\
\hline System Noiso(counts $\sqrt{\operatorname{scan}})^{s}$ & $<1.5$ & $<1.5$ \\
\hline OnOH Ratio & NA & NA \\
\hline Gate Width', Minimum & NA & NA \\
\hline
\end{tabular}

M1455AM1456A

Proximity locussed MCP intensified diode array

Multi-alkali photocathode on S1.UV.A fused silica faceplates M1455.18 mm: $1456.25 \mathrm{~mm}$

1455.512512

$1455.700,700$

1456-990: 990

180.900

.12

see table 1 lor detals

see table 2

8

see table 2 for detalls

NA

NA

$.1 \mathrm{ctpe} 104 \mathrm{ctpe}$

$<1 \%$

32768

4095

16383

$\pm 25 \% \pm 10 \%$ typical

$<1$ channel

3 channels FWHM'

$\begin{array}{cc}512 \text { etement } & 1024 \text { otement } \\ 2850 & 2500 \\ 1160 & 910 \\ 1430 & 1120 \\ 120 & 100\end{array}$

$-40^{\circ} \mathrm{C} 1018^{\circ} \mathrm{C}$

$3 \times 10^{\prime \prime} \mathrm{LM} / \mathrm{CM}^{2}$

$<1.5$

$>10^{6}$

1455G, 1456G 5 กs

1455R.HO $50 \mathrm{~ns}$

$14558 \cdot H O$

1456R.HO $\quad 100 \mathrm{~ns}$

1456B-HQ 150 ns

1 Minimum Detectable Flux (MDF) is the amount of light signal (photon/sec) required by a detection element to produce an $A / D$ count that is iwice the system $r$. ise level. Thus, a signal equal to the MDF would provide a signal-to-noise ratio of two

2 Detectors are delivered with actual QE data at 10 wavelengths between 200 and $900 \mathrm{~nm}$. The typical numbers above are an average of 15 detectors received just before this table was constructed. Because photocathode manufacture is still not a science. the typical values can change up or down. The minimum "s at the three specified wavelengths are always guaranted. The red response $9830 \mathrm{~nm}$ can vary greatly because of the sharpness of the drop on the red side of the response curve.

3 Set to 1.3 counts/photoelectron at factory as optimum point for dynamic range, detectivity, and intensifier life. It can be set higher if needed. Measured by flood illuminating with a known photon. $\left(\mathrm{CM}^{2}\right.$ * SEC) flux and integrating total "light-dark" counts over the center 960 pixels for 1456 , center 660 pixels for 1455.700 . and center 490 pixels for the 1455.512

4 Value is maximum difference from mean for array in regions specified in note 2 when exposed to uniform illumination.

\author{
5 Measured by focussing $25 \mu \mathrm{m}$ wide line onto detector
}

6 Measured by subtracting 8 sec dark signal from in $x^{2} \mathrm{C}$ Jark signal. Some arrays have a few pixels with dark currents that rise above the normally smooth baseline. As long as the dark pattern is stable and the highest point is below the specification, the arras. is allowed. Dark current decreases about a tactor of 2 for enerv $7^{\circ} \mathrm{C}$ drop in temperature

7 When combined with luminous gain in $\mathrm{mA} / \mathrm{Lm}$ and cinverted for pixel size of $6.25 \times 10^{4} \mathrm{CM}^{2}$, typical performance is 5 photo eletrons/(plxel * sec) or 6.5 counts/(pixel * sec) for " B" Jetecturs and 10 photo-elextrons/ pixel - sec) or 13 iounts/(pixel - sec) for " $R$ " detectors. Performance improves when couling water and cooled drv nitrogen gas is supplied to the detector

8 Measured by subtraceng the results of two, 50 wan dark sanal arcumulations $15^{\circ}$ \% and $20 \mathrm{~ms} / \mathrm{scan}, 1$ and then dwiding ov 10

9 vumbers are measured at the FWHM of the gate pulse applied 


\section{DETECTOR OUTILINE DRANINGS}

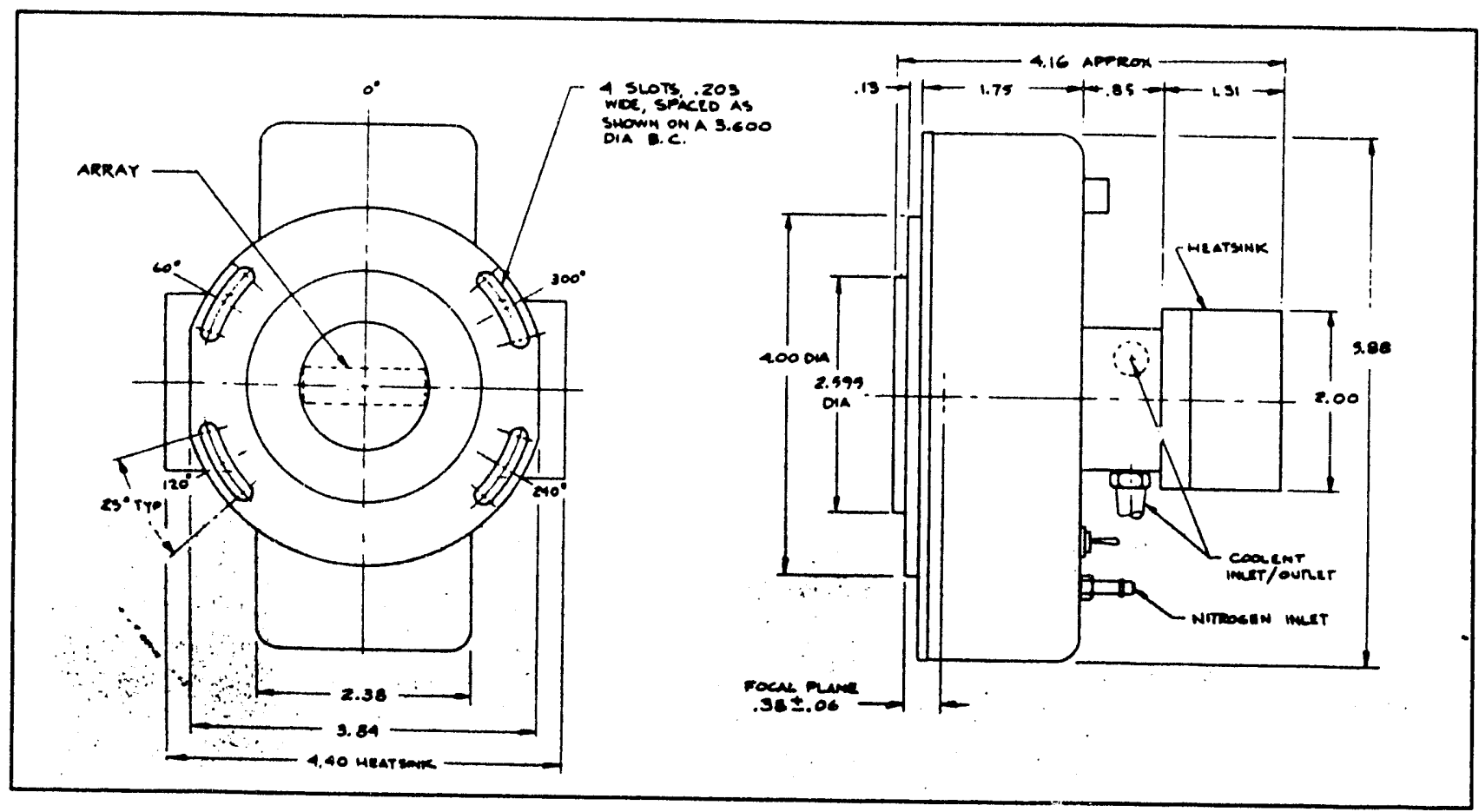

Figure 2. Outline Drawing of $1452 A$ and $1453 A$

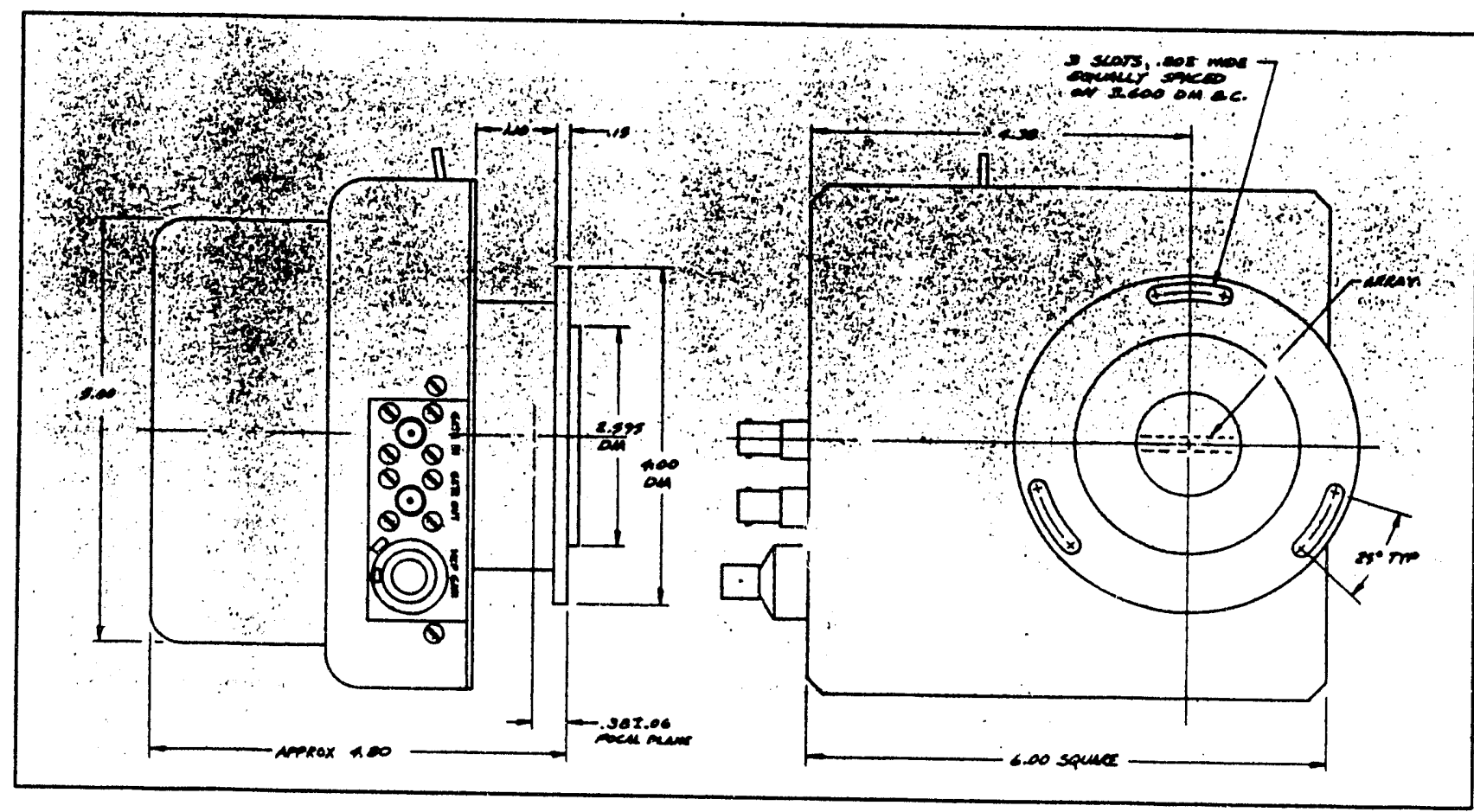

Figure 3. Outline Drawing of $1455 \mathrm{~A}$ and $1456 \mathrm{~A}$

\section{\& EGIG PRINCETON APPLIED RESEARCH}

P.O. BOX 2565 • PRINCETON, NJ 08543-2565 • (609) 530-1000 • TELEX:843409 • FAX:(609) 883-7255

UNITED KINGDOM 0734/773003 • CANADA (416) 475-8420 - NETHERLANDS 03088 7520 • ITALY 02/7386294 • GERMANY 089/926920 FRANCE 1/60/779366 - jAAPÁ̃ 0́3-638-150 
OMP

Preliminary
Data Sheet

\section{Features}

- Supports all PARC solid state detectors via the Model 1461, including CCD, NIR, Diode Array, Intensified Diode Array

- Large data storage capacity for CCDs (32K spectra at $64 \mathrm{~K}$ points per spectrum)

- Automated data acquisition modes

- Method storage

- Eight curve windows

- Context-sensitive Help

- 3-D plots with variable offset angles and hidden line removal

- Selectable IEEE address for easy peripheral control

- Near-real-time screen updates

- File conversion utilities

- Live DA mode operation

- Spectrometer control

- Macro capability

- Intensity-versus-time processing

- Multiple detector support

\section{$20000^{O M A^{\circledR} \text { SPEC }}$ \\ General Purpose OMA Spectroscopy Software}

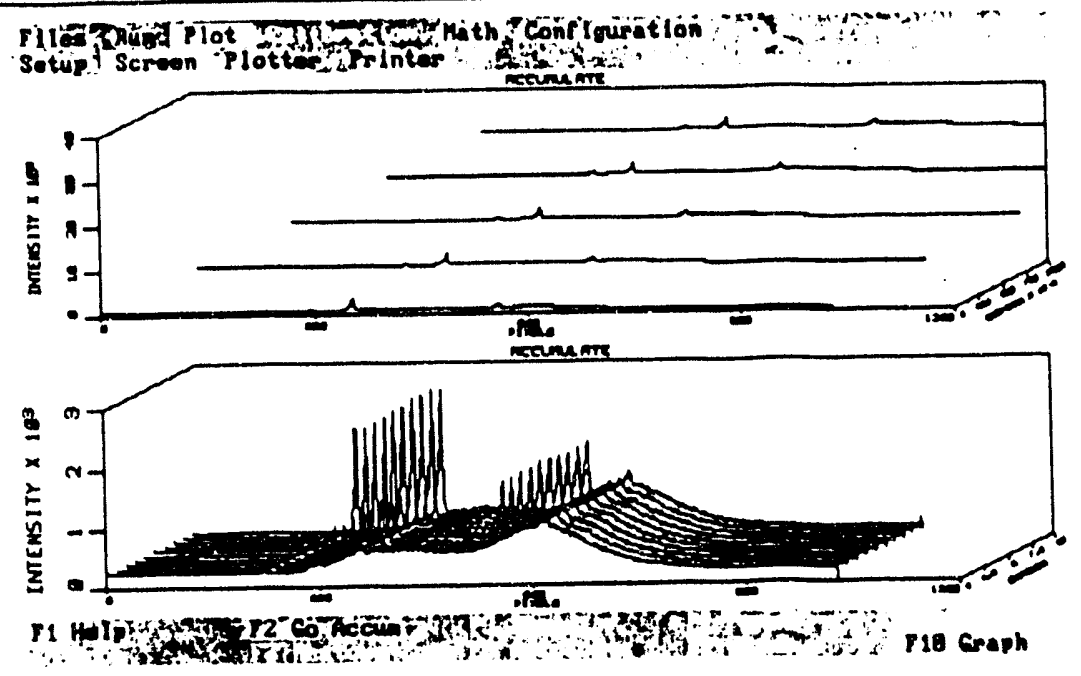

\section{Description}

$T$

he OMA SPEC 2000 from Princeton Applied Research represents a complete redesign of our OMA software, both technically and in look-and-feel. This new package, written in Microsoft C, is equipped to run on all IBM ATs, IBM PS/2s and $100 \%$ IBM-compatibles with a 80286,80386 , or 80486 processor.

The software operates with all PARC solid state detectors, including our new CCD and NIR detectors and our wide range of intensified and unintensified diode array detectors. And it supports our exclusive Data Acquisition Modes for both Diode Arrays and CCDs. We've reworked the screens to make it easier than ever for you to set up and run experiments and perform related tasks like retrieving data or making calculations.

What does this redesign mean to you? For one thing, it gives you the best available OMA spectroscopy software in the world. For another, it gives you a solid foundation for future growth. The OMA SPEC 2000's comprehensive detector support lets you take advaritage of PARC's full line of detectors, which in turn gives you the applications flexibility you need for future expansion.

\section{Future Enhancements}

Our development efforts don't end with the rich set of features already installed.

Here's a list of features on the drawing board:
- Foreground / Background data acquisition mode

- Auto autoscale!

- Auto exposure control
- Auto calibration

- Y-axis calibration

- Curve separation

- Applications packages 


\section{PC Based}

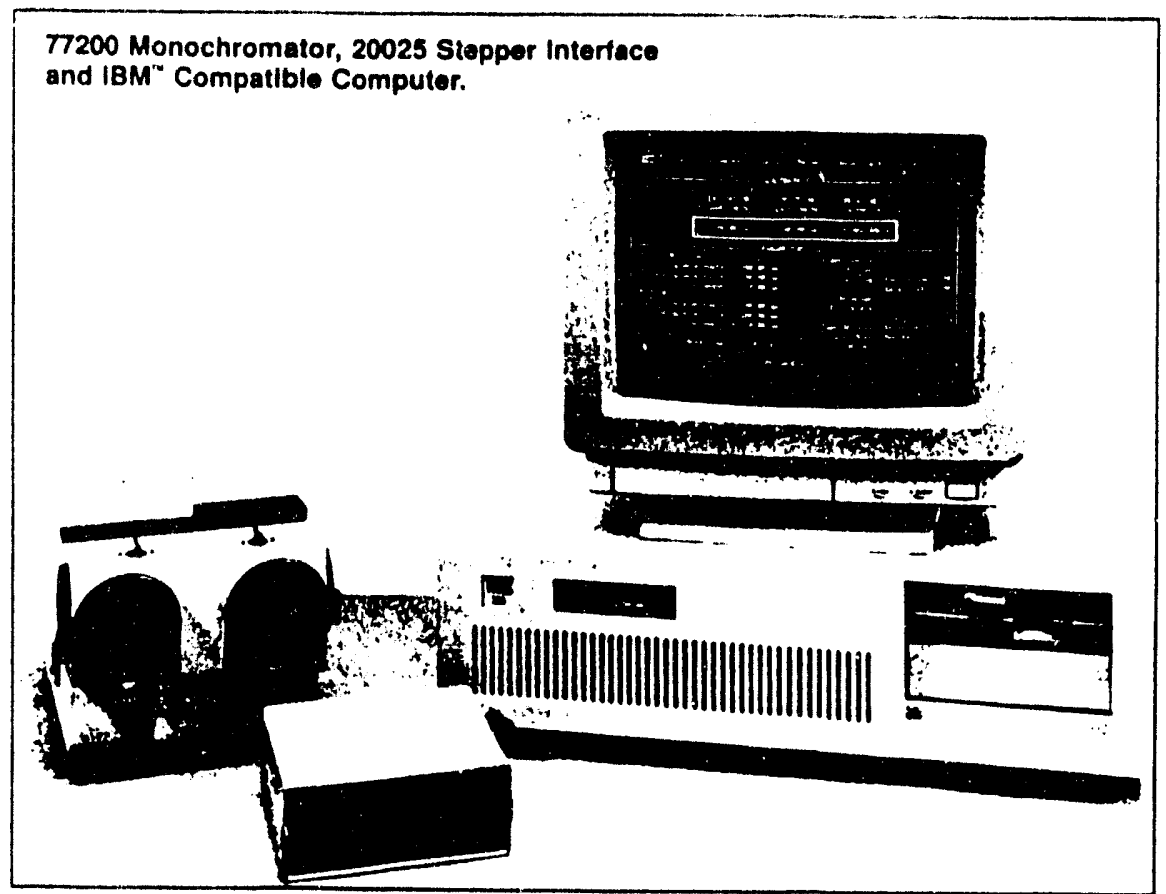

- Designed for IBM PCs and compatibles

- Complete scan control - customize your own scan

- Complete hardware and sottware

- Support many types of detector

- Software for radiometery, absorption, fluorescence

- Single or double beam

If you are considering setting up spectroscopy equipment which involves scanning a monochromator and taking data, then the hardware and software described on the next few pages can save you a lot of time and effort. You can quickly put together a versatile and powerful system for spectroscopy based on an IBM PC compatible: computer; spectroscopy anywhere from the ultraviolet to the infrared. You can choose scan parameters to suit your application.

We describe two boards which plug into the slots inside the computer. Both boards are supported by software to operate our monochromators (with appropriate drive hardware) and take signals from detectors.

- The 78350 Autoranging Radiometry Board is for detectors which behave like current sources; photomultipliers and photodiodes. This board has built-in autoranging for very wide dynamic range without operator intervention.

- The 78250 Voltage Radiometry Board is for any detection system where the final output is in volts proportional to signal. This includes many infrared detection systems employing beam chopping where the signal is recovered by our 70707 Lock-in amplifier. The 7070 Photomultiplier Detector System and 70701 Readout also have suitable outputs.

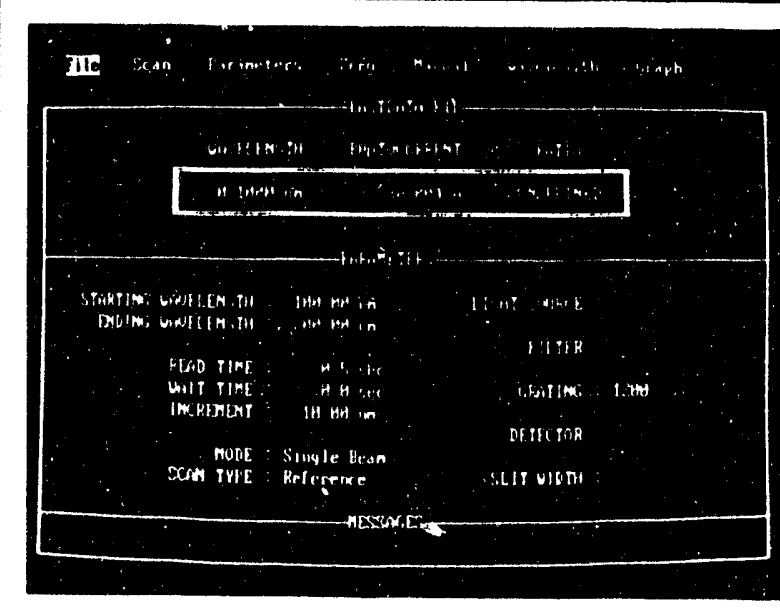

78350 Menu Screen. 


\section{$\square=\mid \square$ SPECTRAL DATA ACQUISITION SYSTEMS}

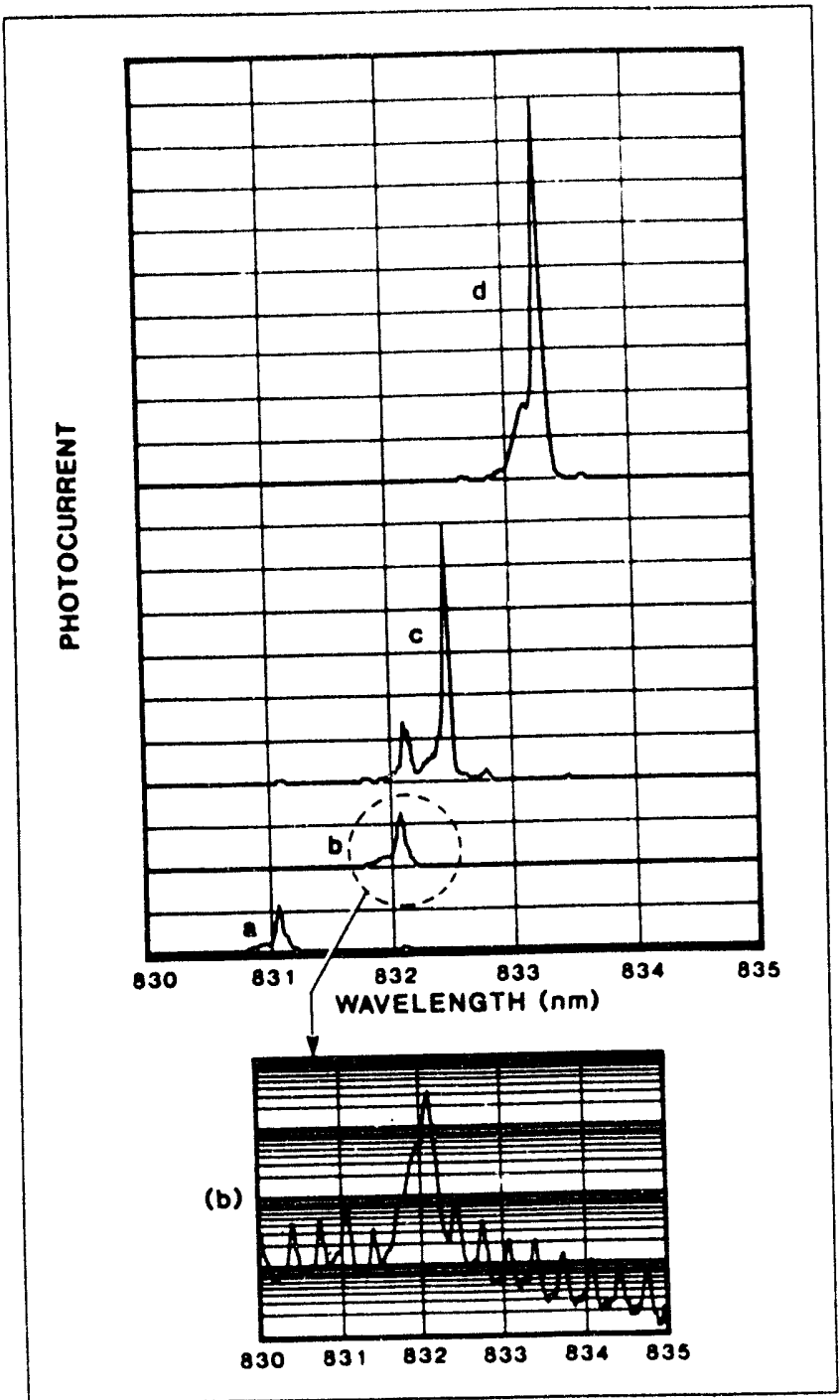

Fig. 1 (a) to (d) show the spectral distribution of a semiconductor diode laser as the current is increased. The spectrum shifts to longer

wavelengths as different modes compete for gain. Even at high current, (c), low level spectral features are apparent. You can examine these using the different plot scaling capability. The spectra were recorded using 77344 Photomultiplier, the 78350 Autoranging Fadiometer Board, $772001 / 4 \mathrm{~m}$

Monochromator with 77233 grating and 10 um slits. The 78350 commanded the 20025 Stepper Interface to operate the 77245 Dual Ratio Wavelength Drive in the high resolution mode $(0.01 \mathrm{~nm}$ steps). This took full advantage of the high resolution of the 77200 . The resolution is shown clearly in the 77200 . The resolution is shown clearly in the
expanded view of spectrum (b). The log plot of the expanded view also shows the plotting capability of the 78350 .

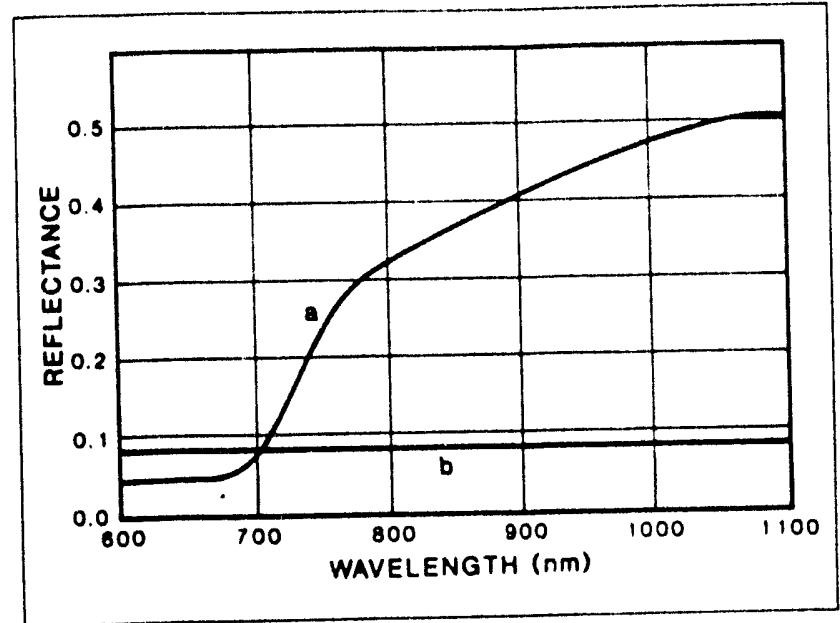

Fig. 2 (a) Near Intrared Hemispherical Tolal Reflectance $\left(8^{\circ}\right)$ of an anodized aluminum surface. (Total reflectence is specular plus diffuse). The data was recorded and ratioed with the 78350 . We used a 7182 sllicon Photodiode in the 71920 Detector Head on the 70491 Reflectance/ Transmittance Sphere. on the 70491 Reflectance/ $772501,8 \mathrm{~m}$

The input beam was from a $772501 / 8 \mathrm{~m}$. Series $\mathrm{C}$ Monochromator illuminated by the 60065 Series Source and a 6199 Secondary Focusing Lens (150 mm F.L.). A 51520 Long Pass Filler remot the beam second order radiation. We recollim with a $100 \mathrm{~mm}$ F.L lens and apertured in diameter before entering the sphere. The reflectance value was derived by ratioing the data file for the anodized sample in the sample holder to the file recorded with the Oriel Certified

Standards of Diffuse Reflectance (page 366). (b) shows the total reflectance of a glass plate for comparison. 


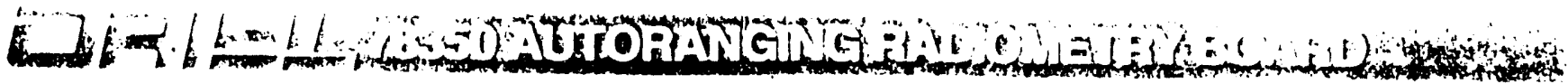

- Integrates Detector Input and Monochromator stepper motor driver into one package

W Seven decades of autoranging and 12-bit A/D converter allow nine decades of dynamic range

- Includes software

- Operation of up to two Monochromator Stepper Motors

- Supports two photocurrent inputs (picoamps to milliamps) for double beam mode or matrix scans

- Occupies single slot of IBM PC bus

The 78350 Autoranging Radiometry Board is a hybrid analog/digital card that plugs directly into the IBM PC Bus, to provide photodetector input and monochromator control. It is designed for, and supported by, spectrophotometry and spectroscopy software. The 78350 records photocurrent from photomultipliers and photodiodes. The 78250 is the version for input voltage

\section{PLUG-IN CARD}

The physical card occupies a single slot in a PC-XT. It draws approximately 5 watts of power and has two BNC connectors and one DB-15 connector at the rear of the com. puter. The calibrated. high-gain analog circuitry is mounted in a shielded can off the surface of the mothercard for optimum electrical isolation. Shielded coaxial cable, isolated from the main mothercard. runs the signal from the BNC connectors into the analog front end (shielded can).
The 78350 card has a transimpedance amplifier input with software switched gain, a fixed gain stage, and a 12 bit $A / D$ converter Input bandwidth is $35 \mathrm{~Hz}$. Maximum resolution is 0.24 picoamperes and maximum photocurrent is 1 milliam. pere. No single photodetector can use the full range but you can cover the linear range of different detectors. See the following page for practical resolution and range with our photodetectors.

\section{INPUTS}

The two inputs are protected to 2000 volts DC across the input and current limited with an input impedance of 2 megohms. The amplifier is based around an ultralow noise FET precision op amp with switchable ranges of amplification. Each individual range is factory calibrate $d$ and directly controlled by software. The output from the analog circuitry is routed into a 12-bit AD converter and ported through the PC Bus. The 78300 software controls the electronics, pertorming autoranging and signal processing of the input.

\section{OUTPUTS}

Two 1/O output ports are for monochromator control. The output is routed through the DB-15: onnector for interface to an Oriel 20030 or 20025 Stepper Intertacs (The 20025 Stepper Interface is for a single monochromator.) See Fig. 1.

The TTL outputs are decoded through address ports on the PC Bus and drive the 20030 (or 20025), capable of driving monochromators at step rates of 4000 steps per minute. (With a 1200 line grating this is $400 \mathrm{~nm} / \mathrm{min}$.)

Often a single monochromator is adequate. Both ports are used with dual monochromator arrangements for performing matrix fluorescence scans where both excitation and emis. sion measurements are required.

Our Double Monochromator Systems (coupled mechanically) use a single Stepper Drive and therefore count as one monochromator.

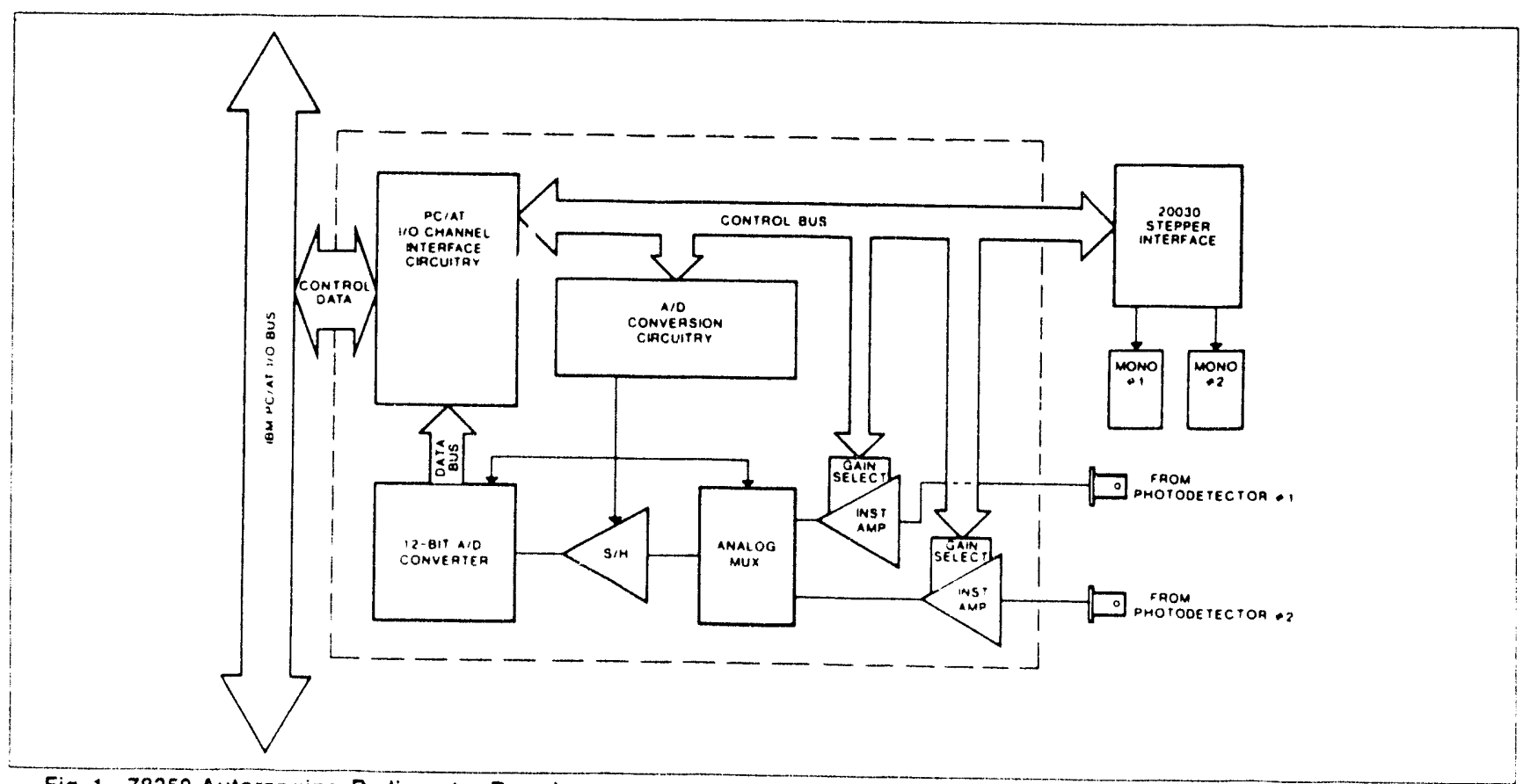

Fig. 178350 Autoranging Radiometry Board

$\mathrm{C}-84$ 


\section{DAIEI, 78350 AUTORANGING RADIOMETRY BOARD}

PHOTODETECTORS USED WITH THE 78350

Oriel carries a complete line of photodetectors which produce a photocurrent proportional to incident light intensity, with spectral sensitivities from the UV to the IR.

Silicon photodiodes come in a variety of sizes and packages, depending on the application, and offer high sensitivities, especially in the near IR. Germanium and Indium Arsenide photodiodes extend the range into the infrared. Photomultipliers have the greatest sensitivity in the visible and ultraviolet, (usually 2 orders of magnitude greater than silicon photodiodes) and produce a photocurrent that is proportional to light intensity over 6 to 8 orders of magnitude. However, they require a separate high voltage power supply (such as the 70705) to operate. Fig. 1 shows the computer reading against photocurrent into the 78350 board over more than 8 orders of magritude. (Photodetector linearity may not match this range.)

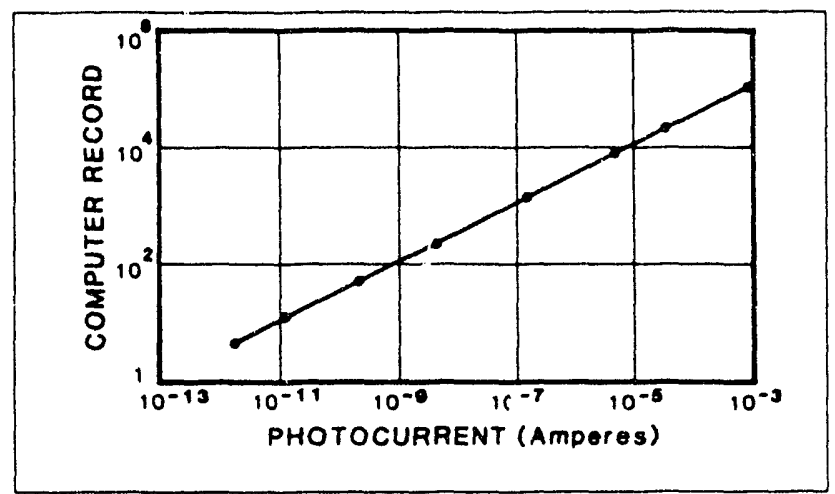

Fig. 1 The computer reading against photocurrent over more than $\mathbf{8}$ orders of magnitude. (Photodetector linearity and stray light usually limit the useful range.)

\section{Dark Current}

All photodetectors produce a small amount of quiescent current in the absence of light, commonly refered to as ddark current. The 78350 Software allows you to take a dark current reading which is then subtracted from all subsequent signal measurements.

\section{REAL PERFORMANCE WITH PHOTODETECTORS}

The principal detectors used with the 78350 are photomultipliers and photodir tes without bias.

\section{Photomultipliers}

These detectors are linear over a wide range if the dynodes are properly supplied and when the output is into a transimpedance amplifier. (The 78350 input is designed in this way). The maximum photocurrent is specified on page 218. For precision radiometry we recommend that the anode current be 10-100 imes less than specified maximum. Avoid using currents of more than $1 \mu \mathrm{A}$. Do not focus light on the photocathode as this will lead to local saturation. And in order to compare signals accurately they must be distriouted equivalently over the sensitive area.

Dark currents can be $10-500$ pA depending on tube voltage and recent history. (Tubes exposed to high light levels have temporarily high dark currents). Dark current is not a tundamenta! !mitation $¥ \$$ it is subtracted out but dark current noise may limit the detectable signal level.
Fig. 2 shows a scan of a steeply rising spectral feature and demonstrates the wide dynamic range of the 78350 . Tr: scan was taken with a 77257 Double Monochromator with a 77345 photomultiplier tube, operated at 600 volts. The 78350 subtracted out the $10 \mathrm{pA}$ dark current. Averaging time was $0.5 \mathrm{~s}$. The low level signal below $610 \mathrm{~nm}$ is due to photomultiplier dark current noise on a stray light background

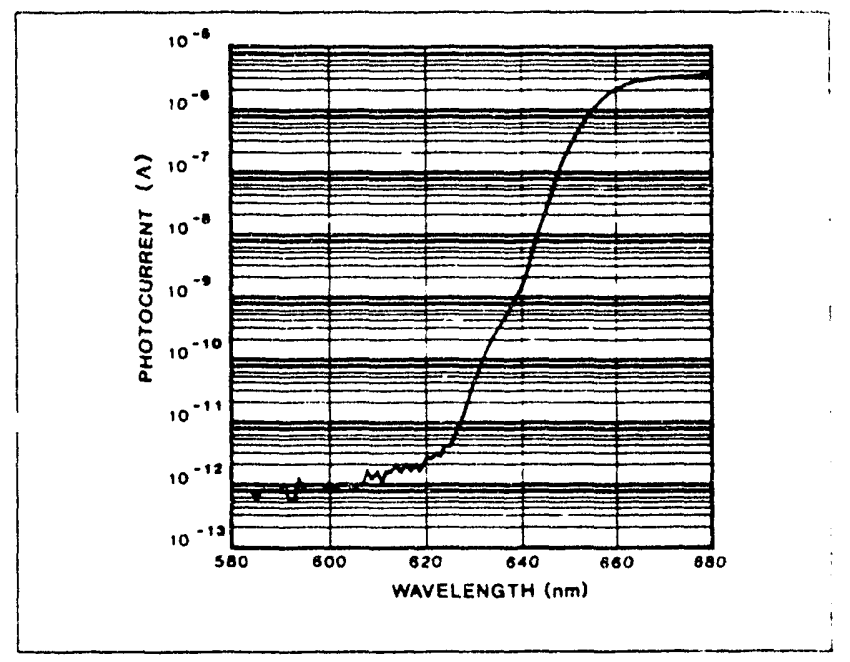

Fig. 2 Spectral scan of a steeply rising feature taken with a 77345 Photomultiplier and 77257 Double Monochromator.

\section{Photodiodes}

Photodiodes have wider spectral range of response inan most photomultipliers and have sensitivity and linear behavior over many decades. Our larger area diodes have linear response over as many as 8 decades.

Unbiased photodiodes have low dark current and dark current noise and are preferred for dynamic range over biased versions. The larger diodes such as the 7182 have higher maximum linear currents (ca.1 mA) and the large area captures much of the output from a monochromator wittioul the necessity for auxiliary optics

Fig. 3 is similar to Fig. 2 but shows the wide rangrig performance with the 7182 Silicon Photodiode.

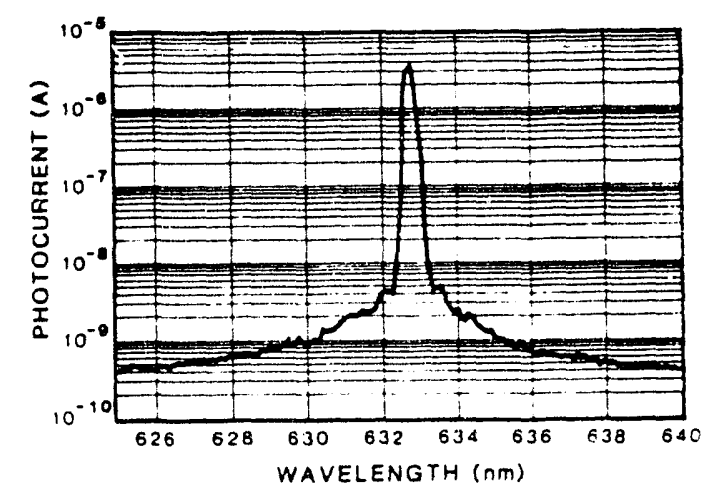

Fig. 3 A scan of a narrow laser line recorded with the 7162 Silicon Photedicde on the ?725? Double Monochromator with two 77298 gratings. 


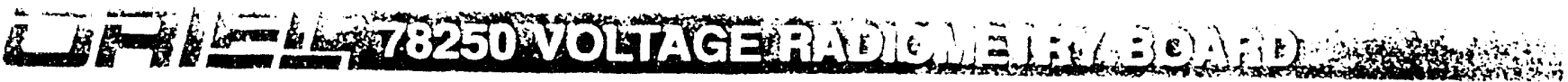

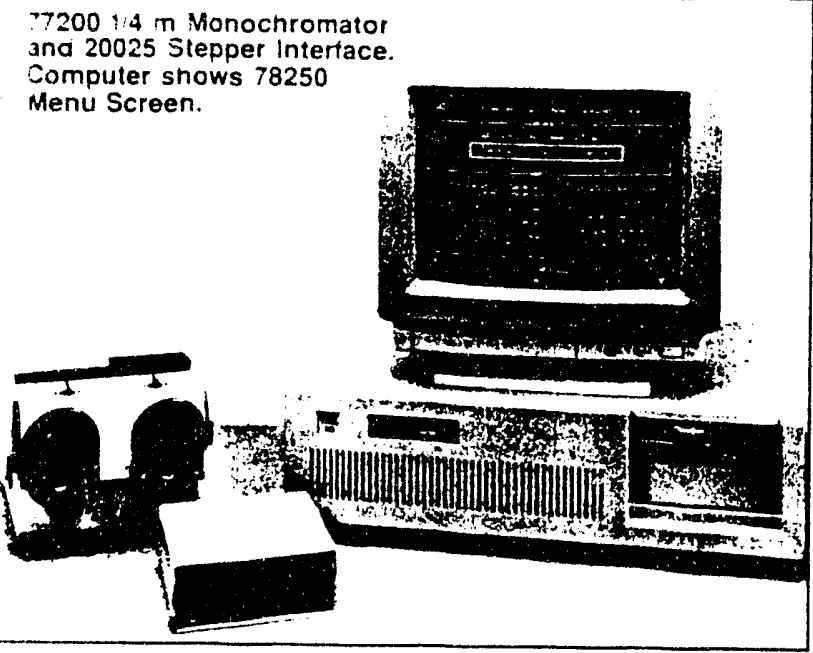

- For detectors, Lock-in Amplifiers or Readouts which produce a voltage signal proportional to radiant flux.

- Designed to interface IBM PC's and light detecition equipment

- Comprehensive software

- Integration of Voltage $A / D$ converter and monochromator control into one package

- Operation of one or two monochromators

- Supports two voltage inputs with jumper selectable gains $(0-100 \mathrm{mV}, 0-1 \mathrm{~V}, 0-10 \mathrm{~V})$

- 2-bit $A / D$ converter allows three decades of dynamic range with selectable voltage range

- Voltage Radiometry Board occupies only a single slot of any IBM PC/XT/AT or Compatible
The 78250 Voltage Radiometry Board is a hybrid analog digital board that plugs directly into the IBM PC Bus. It has full software support for radiometry, fluorescence or absorbance measurements. The hardware and software provide monochromator control and measure voltage signals.

\section{PLUG-IN EOARD}

The physical board occupies a single slot in a PC.XT or AT draws approximately 5 watts of power and presents two BNC connectors and one DB-15 connector to the rear of the computer. The calibrated. selectable-gain analog circuitry is mounted to the rear of the board for noise isolation and is protected from overvoltage input. Shielded BNC connectors. isolated from the main trace layout. connect directly into the analog front end. A grounded plane serves to isolate transients in the computer switching power supply from the detector inputs.

\section{INPUT RANGES}

The 78250 Board has three jumper pın selectable ranges

$\begin{array}{cc}\begin{array}{c}\text { Range } \\ \text { (V) }\end{array} & \begin{array}{c}\text { Resolution } \\ \text { (mV) }\end{array} \\ 0-0.1 & 0.025 \\ 0-1 & 0.25 \\ 0-10 & 2.5\end{array}$

The two channels can be set to different ranges. The two inputs are over-voltage protected to \pm 100 volts $D C$ across the input to ground and current limited with an input impedance of $200 \mathrm{k}$ ohms.

The input amplifier is based around a bipolar ultralow oftset op-amp. The jumper pins select the ranges of amplification. Each individual range is factory calibrated. You select the range to match the voltage source before inserting the board into the computer.

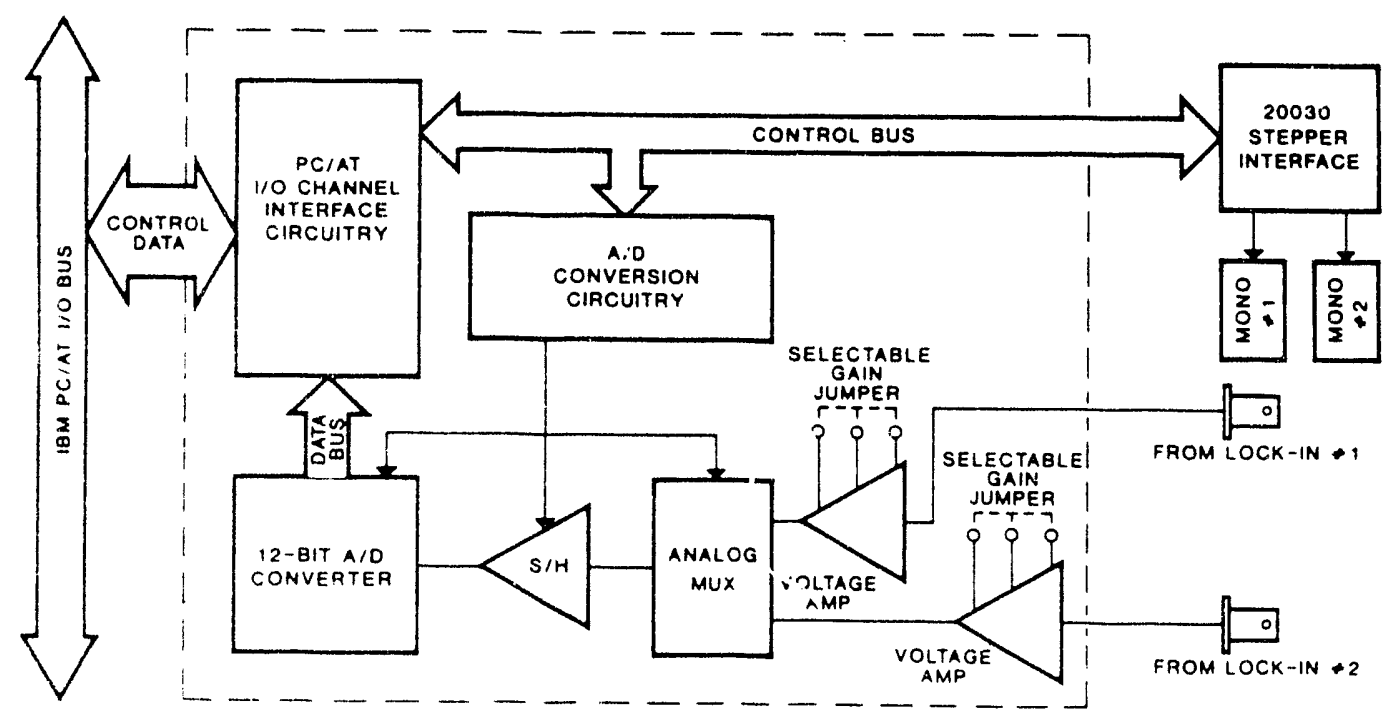

Fig. : 78250 Voltage Radiometry Board. 


\section{$\square F \mid=I, 78250$ VOLTAGE RADIOMETRY BOARD}

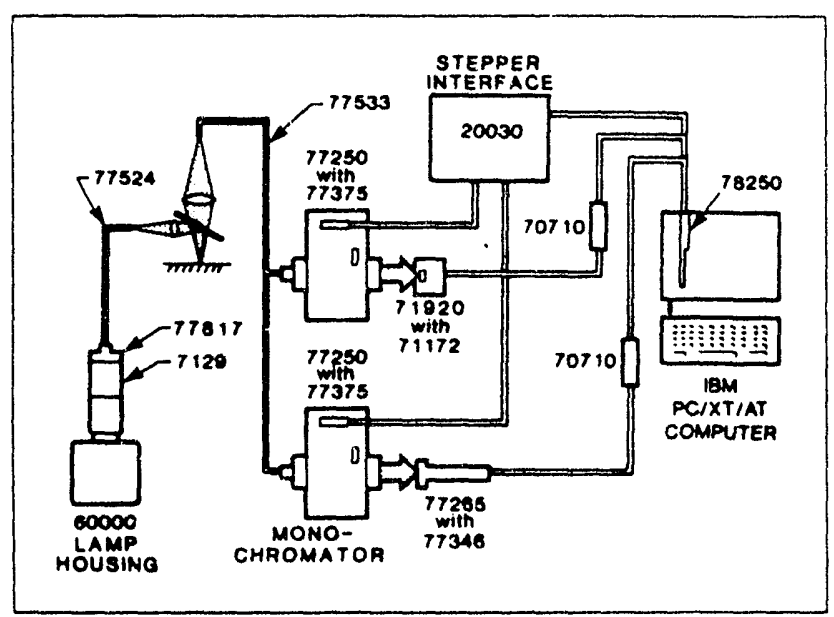

Fig. 2 Arrangement for infrared fluorescence measurements on crystals. The 78250 is used in a dual beam mode. A biased photodlode monitors the source and acts as reference, while the chopper, Lock-in Amplifler and PbS detector monitors the infrared fluorescence.

\section{BIT ANALOG TO DIGITAL CONVERTER}

The output from the analog pre-amp and surge suppresser circuitry is routed into a 12-bit $A / D$ converter and ported through the PC-Bus Interface. The 78250 Software controls the electronics, and signal processing of the digitized signal.

\section{Outputs}

The 78250 controls one or two monochromators through two l/O outputs (DB-15 connector). The output connects to a 20030 Stepper Interface. (The 20025 Stepper Interface will run one monochromator.) The TTL outputs are decoded through address ports on the PC-Bus Interface and drive the 20030 . The 20030 provides the pulses for monochromators at step rates of 4000 steps per minute. This is $400 \mathrm{~nm}$ per minute for a 1200 line $/ \mathrm{mm}$ grating. The software drives two monochromators for matrix fluorescence scans where both excitation and emission wavelengths are scanned.

\section{COMPATIBLE DETECTION EQUIPMENT}

Any of our detectors or detection systems with a voltage output are compatible with the 78250 . The signal source may be as simple as a biased photodiode in our 71925 Detector Housing, or as complex as two 70707 Lock-in Amplifiers which recover signal by phase sensitive detection of chopper modulated radiation. You can use the 70710 Current Pre-amplifier to convert current from photorr. Iltipliers or unbiased photodiodes, to voltage signals for the 78250 . (If these are the only detectors you intend to use. you should consider the 78350 Autoranging Radiometry System described on page 373 .)

Using one of our Readouts to accept the signal from the detector and provide output to the 78250 has advantages.

- You can see the signal level and optimize alignment etc.

- You can condition the signal for best match to the 78250. This involves setting the range on Readouts such as the 7070 . or 7080 . or adjusting the gain and ofiset on the 70701 . You cain also set the time constant on several of these instruments for best SN pertormance.
THE 78250 AND 70707 LOCK-IN AMPLIFIER

Pyroelectric Detectors respond only to chopped light, and other detectors (such as $\mathrm{PbS}$ or $\mathrm{PbSe}$ ) benefit from operation at higher frequencies. You can use these devices with our choppers and the 70707 Lock-in Amplifier and take the output of the Lock-in to the 78250 . This combines the advantages of phase sensitive detection with those of the computer; control, data storage and processing.
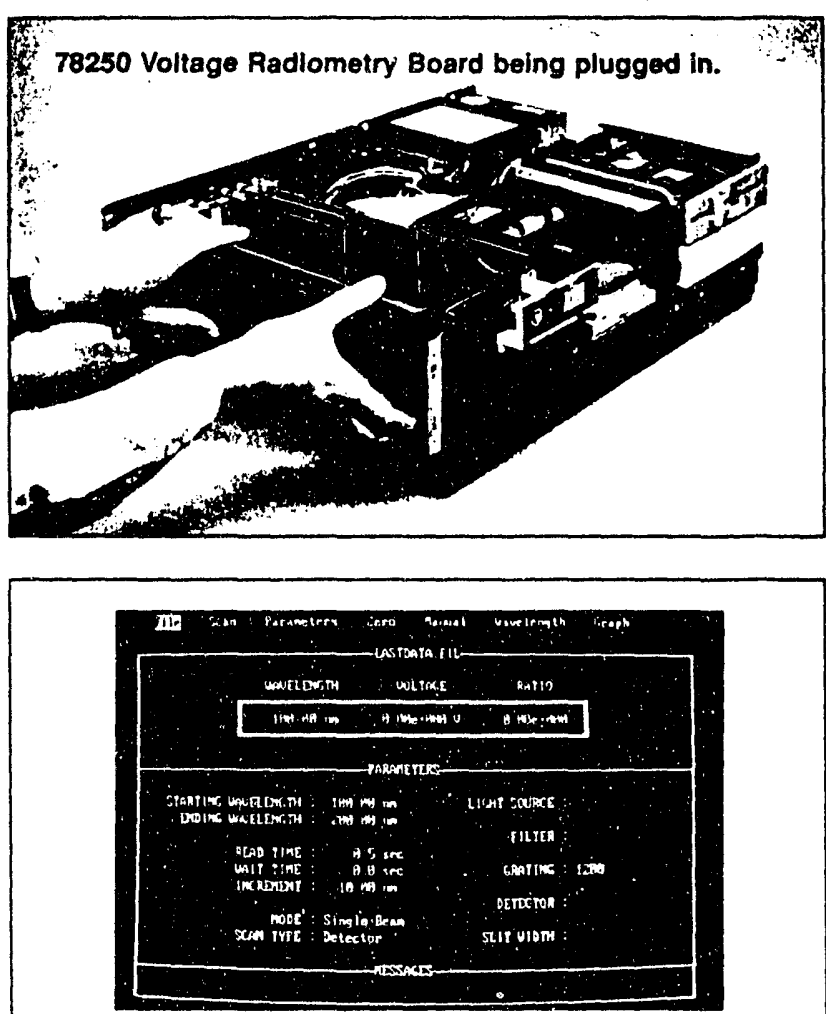

78250 Menu Screen.

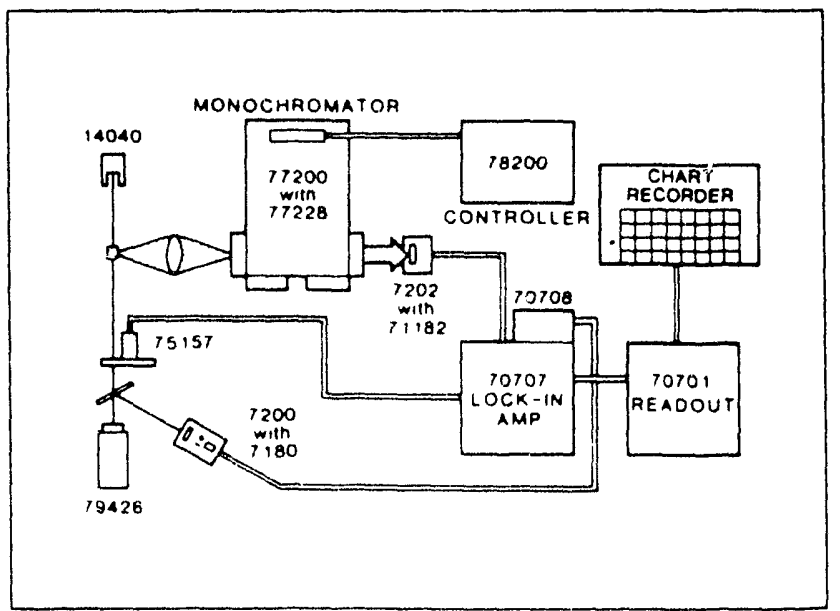

Fig. 3 The 78250 used with a photomultiplier and biased indium arsenide photodiode. With the optional 70701 Readout (not shown) you can easily 'condition' the photodiode voltage for best utilization of the range of the 78250

C-87 


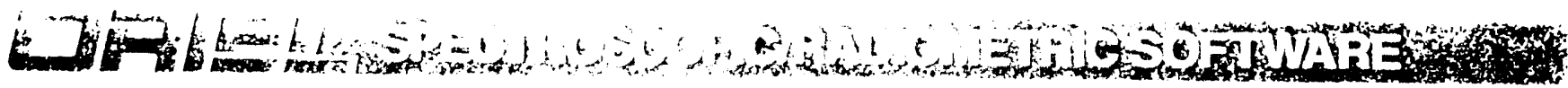

- Controls monochromator and measurement of photocurrent

E Stores, processes, and plots data

a Completely menu driven - No programming experience required

- Presents data in standard Absorbance. Fluorescence, or Radiometric format

- Supports single and dual ratioed beam modes

- Controls up to two monochromators for emission, excitation, and synchronous wavelength scans for fluorescence measurements

- Linear or Log-Linear Plotting of data to Screen, Printer, or Hewlett Packard Pen Plotter

This software consists of three separate programs atiored for specific applications. absorbance, fluorescence. and spectroradiometry. All programs are written for the IBM PC. XT/AT as part of the 78350 Auto ranging Radiometry Board and 78250 Voltage Radiometry Board

There are two slightly different versions of the soltware. one for the 78350 and one for the 78250 . The description which follows covers both versions

The software is written in etticient fast $\mathrm{C}$ (Turbo $\mathrm{C}$ ) and each program is about $200 \mathrm{kB}$. The three programs are variations on a common base. Radiometry has functions specifically for absolute radiometric measurements. Absorbance has explicit emphasis on ratioed measurements and fluorescence has provision for excitation and emission mono chromators.

$$
\text { EFHAPERARE }
$$

The whot is shipped on 525 " 360 kilobyte and 3.5 " - 44 iscanyte media. A monimum of 512 kilobytes RAM is requirec and graphic display adapters supported by the pro. gram or MCGA, The system can work with either a hard disk or a lopir baseo system. A numencal coprocessor is utilized if one s present

\section{$\because$ G.MAIN MENUS}

There are wo operational information screens: the Scan Screen displays wavelength and photocurrent readings as well as operat!onal parameters. the Graphing Screen has graph set.up information and information on dumping graphs to piotters or pninters.

\section{SCAN SCREEN}

In this screen, shown above, a horizontal menu of sub. menus runs across the top of the screen. The remainder of the screen displays key intormation on the scan, wavelength and signal level

You activate any submenu by using either the key corresponding to the first letter of the ttem or using the left or right cursor heys Every submenu of the top horizontal menu brings a Dop-up menu onto the screen You can select the pop up mend tems with either the items first letter or by using the up and down cursor keys. The escape key returns you to the :op horizontal menu or selects default items.

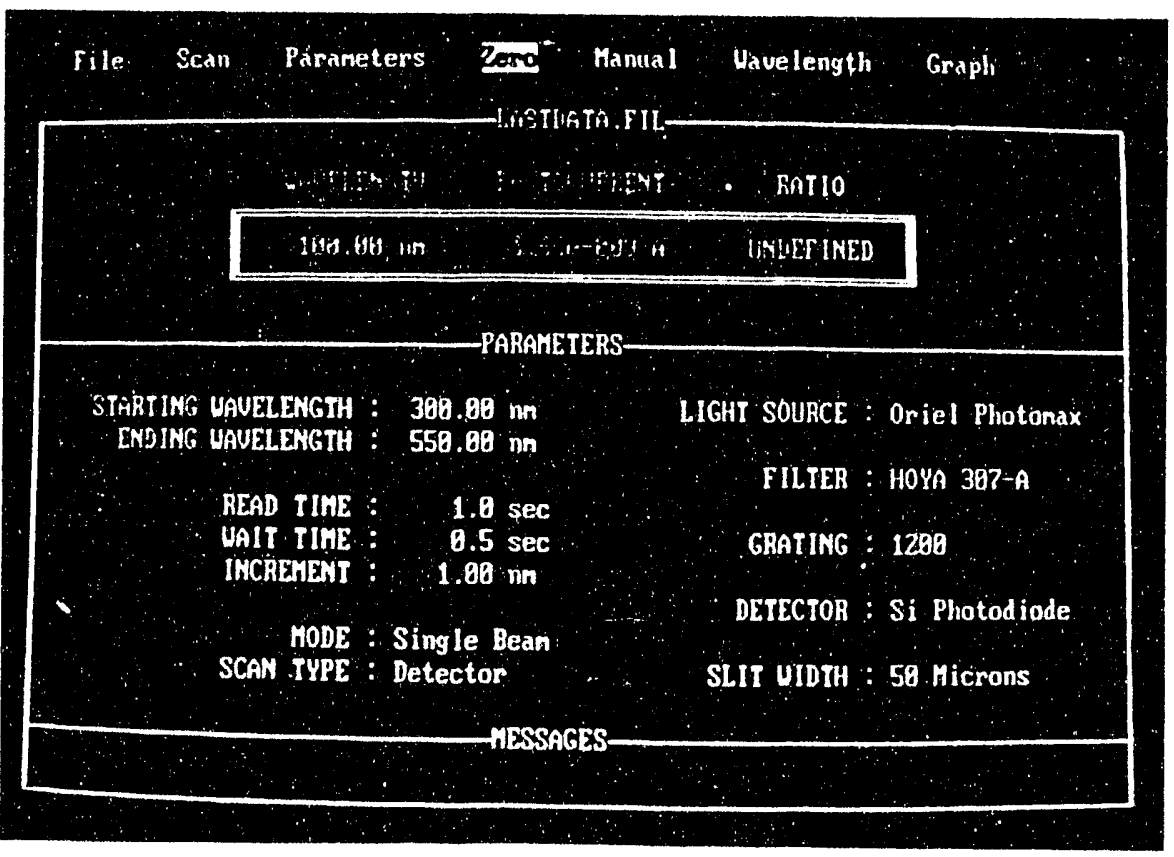

Scan Screen of the 78350 Software. 


\section{DFIEI, SPECTROSCOPIC/RADIOMETRIC SOFTWARE}

\section{File}

This allows you to list the files on the various computer drives and to exit the program, automatically saving the parameters set you have been using, including the last wave. length.

\section{Scan Sub Menu}

This menu allows you to start a scan, save or recall a scan from disk, and display the scan which you have just completed or one you recalled to memory, as a plot. You can also display the scan values to screen and quickly move through to the specific screen of readings around the one of interest Or you can send the list of values to your printer.

The radiometery program includes a 'Type' option in this submenu. This allows you to choose between scans recording the photocurrent, standard lamp scans, and radiometric scans of the unknown.

\section{Parameters Sub Menu}

You select your operating and scan parameters from this submenu. These include grating density (lines $/ \mathrm{mm}$ ), wavelength increment, beginning and ending wavelengths of a scan, and read time. The scanning parameters have error checking routines built in and incorrect parameters are required to be re-entered. The computer uses the grating density entered to check the validity of the scan data.

You can set the read time in increments of 0.1 second. Readings are taken at a rate of about 100 per second (depending on processor speed), and averaged. As you increase read time, the signal to noise ratio improves, but the scan takes longer. For many scans using a photomultiplier detector we use a read time of 0.3 seconds.

If you are using the 78250 Voltage Radiometer System. you should set the 'Input Voltage Range'. 10 match the jumper selectable range on the board.

\section{Zero Routine}

This option prompts you to shutter the beam so the computer records the dark current. Dark current measurements are then automatically subtracted (in software) from each reading.

\section{Wavelength Entry}

You must enter the wavelength setting of the monochromator. The program then keeps track of the wavelength. On exiting. the wavelength setting is stored for automatic recall.

\section{Manual Mode}

Selecting this allows you to toggle or slew the monochromator from the keyboard. Manual mode simplifies peak finding for monochromator calibration or spectral analysis You also have the option to slew to a specific wavelength This. like all the wavelength changes controlled by the program includes an anti-backlash routine.

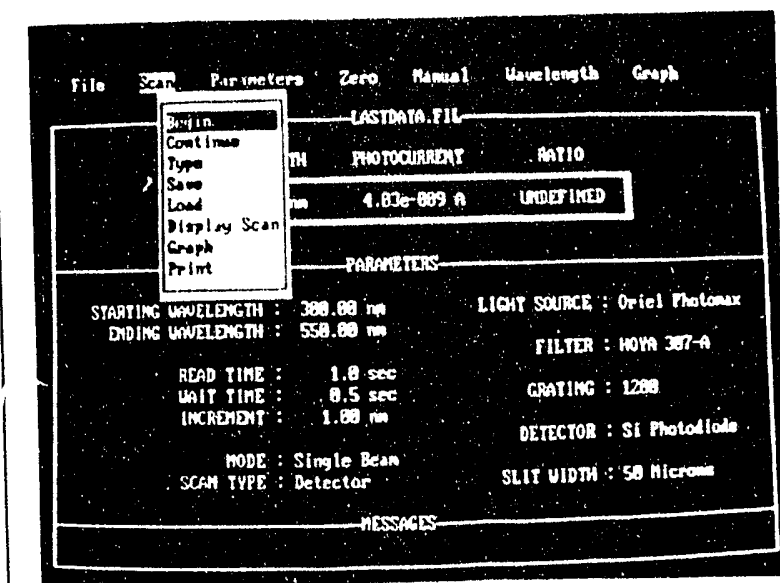

Scan Sub-menu screen.

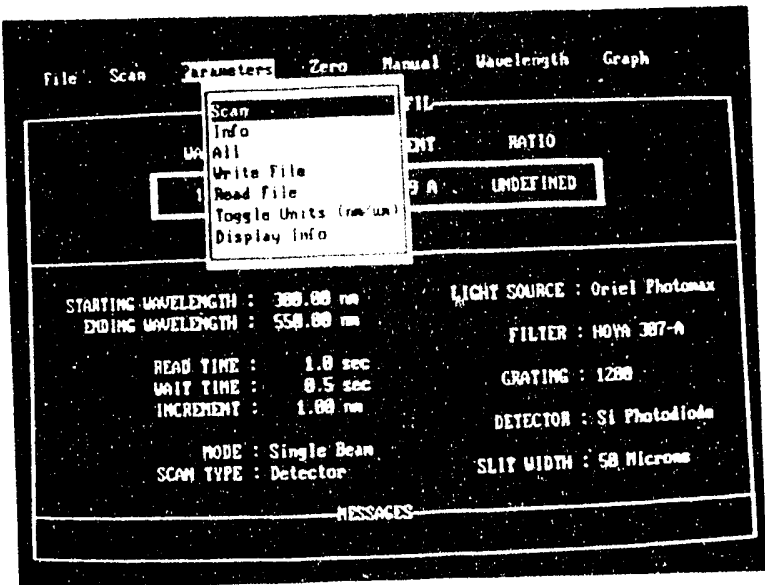

Parameters Sub-menu Screen

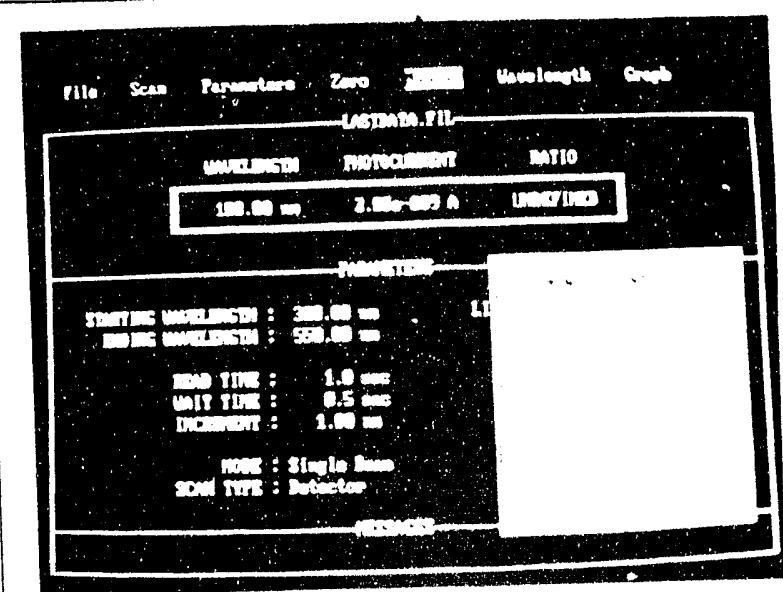

Manual Sub-menu Screen. 
The second screen controls the graphical display of wavelength/photocurrent data taken with the system.

\section{Define Plot}

Here you enter the file you want to plot and how you want it plotted. The sophisticated graphing routine allows arithmetic operations on files. You can multiply or divide a file by a constant, or add. subiract. multiply or divide matching files. (You cannot multiply or divide files with different spectral ranges or increments. The utility program allows you to interpolate files with the same spectral range so that you can operate on them.)

You can then store the result as a new file and perform further operations on it. You can use this technique to conver radiometric data to photometric. (See page 16 for procedure.) To do this you can create a file of the $V(\lambda)$ values using your wordprocessor or the utility program. Similarly you can create files for optical filters and multiply these by light source spectra.

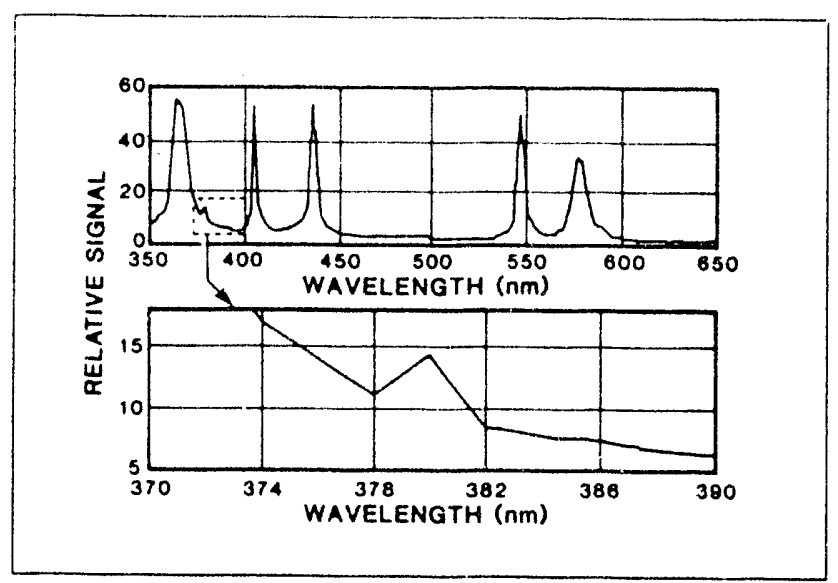

Fig. 1 You can add a wavelength offset to a file should you discover that you had not callbrated the monochromator accurately. You can graph the data using linear-linear format, or for data with no zero or negative values, log-linear format. The horizontal and vertical axis can each be automatically scaled to fit the data or you can choose your own scale ranges. Defined scaling allows you to plot small regions of the scan as shown.

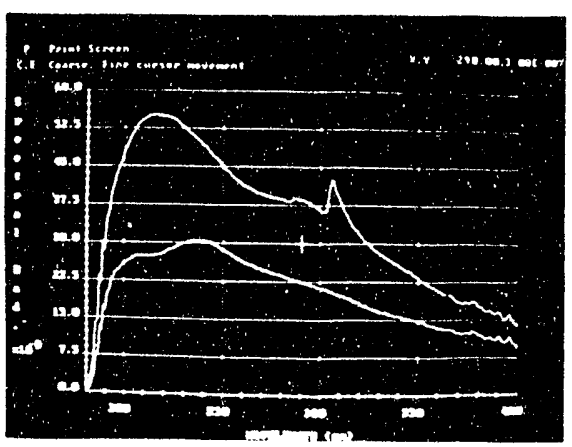

Screen display of two overlaid scans showing raw spectrum and spectrum of radiation transmitted through a sample.

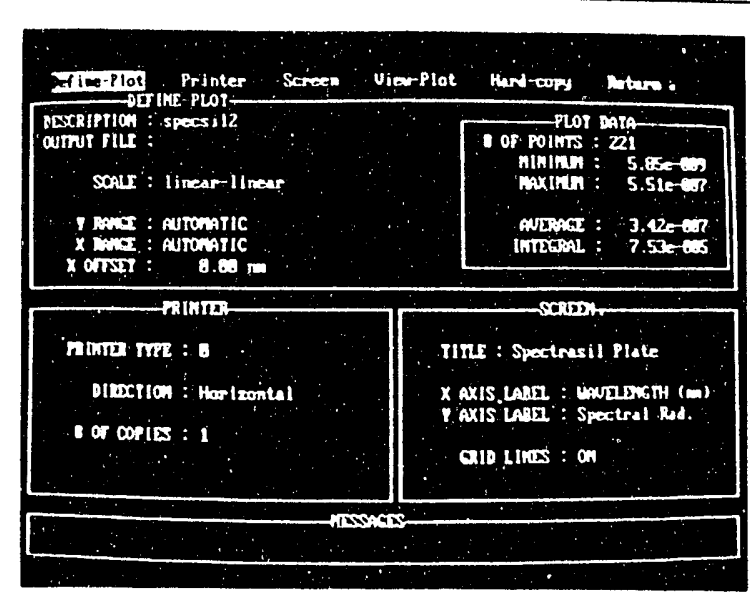

Graphing Screen.

The graphing screen displays the value of the integrated signal over the graphing range. By choosing the range, you can find the integral over any spectral region of interest.

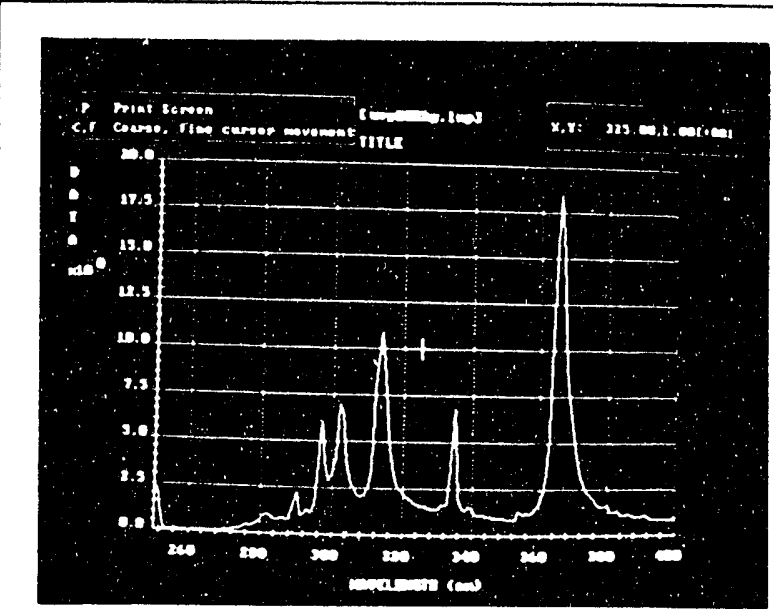

Section of a mercury lamp spectrum.

Data can be plotted on a linear-linear or log-linear plotting scale. A crosshair controlled by the cursor keys can be positioned anywhere on the graph for accurate determination of spectral features or lines. 


\section{$\square F \mid=I$ SPECTROSCOPIC/RADIOMETRIC SOFTWARE}

\section{Printer}

This submenu allows you to select a printer. Over a hundred printers are supported for graphical plotting, including a number of laser printers for high resolution plots, although the greatest resolution is displayed with the HP Pen Plotter.

\section{Screen}

Here you can name the plot, label the axes, and choose whether you want a grid.

\section{Vlew Plot}

You can overlay multiple plots on a single graph for comparison and contrast. The graph which quickly appears on the monitor, can also be dumped to a printer or to a HewlettPackard Pen Plotter (or any pen plotter supporting HPGL commands).

\section{Hard Copy}

If you want the file values or information file printed out you use this submenu.

\section{UTILITIES}

We supply two useful programs for use with the software: the first allows you to create a file from wavelength and value list. When using the Radiometry Software, you must use this to enter the calibration data supplied with your standard lamp. You can also create a file of transmittance for a filter, or the $V(\lambda)$ curve on page 18.

The second program uses a polynomial interpolation routine to match scan increments. This allows you to giznerate a file without entering many points. When entering data for a cut-on filter for example, you neod only enter closely spaced points at the knee of the curve. This program will interpolate between widely spaced points of almost constant transmittance above the cut-on.

\section{SCAN AND OVERLAY CAPABILITY}

Memory limitations and the program structure limit the maximum scan to 2000 points. The overlay capability in the graphing routine is also limited to a total of 2000 points. You can overlay 3 scans of 600 points or two scans of 800 points, but not two scans of 1200 points. You can subdivide large scans for multiple overlay.

\section{FILE EXPORT}

The files are in standard ASCII format. You can export a file to programs such as Lotus $1-2-3^{\circ}$. Asyst ${ }^{\circ}$, or Labtech Notebook ${ }^{\oplus}$ for display, further processing, or inclusion in a report.

\section{COMPUTER COMPATIBILITY}

Idiosyncrasies in IBM compatibles sometimes prevent the proper operation of programs or plug-in boards. If a computer is fully IBM compatible, then our program will work. (We cannot predict compatibility with other plug-in hardware.) We have tested this program on the following computers:

- IBM PC XT (4 MHz), IBM PC AT (8 MHz)

- Compaq DeskPro (XT equivalent, 8MHz)

- Leading Edge Model D (XT equivalent, $8 \mathrm{MHz}$ )

- AST Premium (AT equivalent, $10 \mathrm{MHz}$ )

- Micro Express (AT equivalent, $12 \mathrm{MHz}$ )

The graphics routine will not work with original IBM PC monochrome cards (pre-1983).

The sampling time for a reading depends on the processor speed. For the slowest processor found in these computers (4 MHz) the rate is 80 samples/s. 


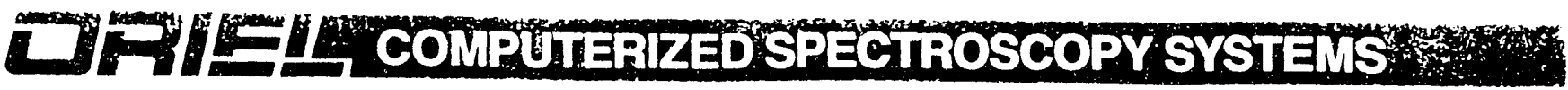

\section{SYSTEM EXAMPLES}

Versatility is a major advantage of Oriel Spectroscopy Sys. tems. You can select a system for a particular application and later change the configuration or add pieces for other applications. On these two pages we illustrate some configurations.

\section{SINGLE OR DOUBLE BEAM?}

Many spectroscopic determinations involve two scans and simultaneous or subsequent comparison of the data sets. If the overall system is stable and repeatable to the required degree you can take one scan at a time and compare (ratio) the files afterwards. The single beam approach is particularly attractive when the alternative is two complex and expensive detection systems. The 68850 Photofeedback System can greatly improve the performance of some single beam arrangements

For highest precision you can take the two scans simultaneously with the 78350 or 78250 in dual beam mode. (Fig. 1) You must pay considerable attention that the signal and reference optical paths react in the same fashion over the wavelength range of the scan to any spatial or polarization changes in the source. Calibrating with absorbance standards helps establish confidence.

The Absorbance program displays and stores the ratio of the two inputs as you scan.

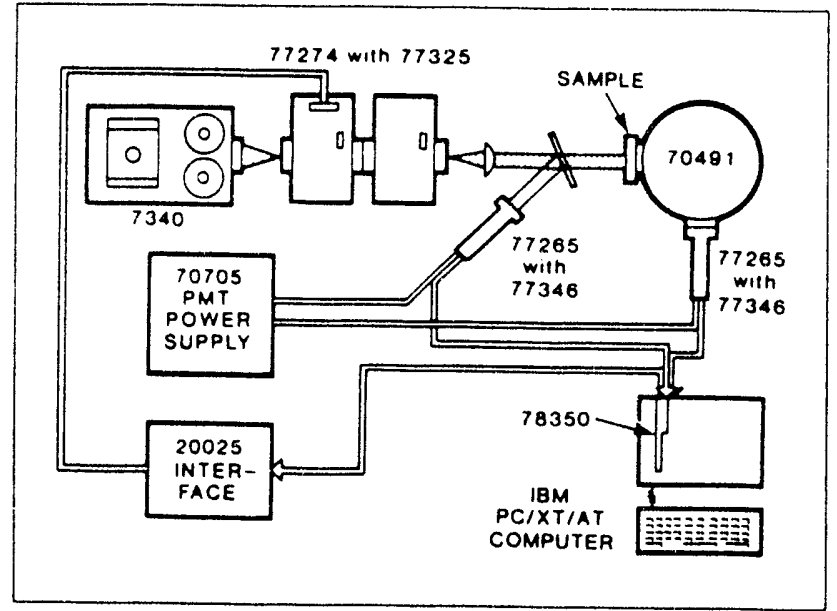

Fig. 1 The components of a double beam system for absorbance measurements. For absorbances above -4 , we recommend that you use a double monochromator, and take particular care with the source spectrum and detector spectral response, to reduce error due to stray light.

\section{Ratioing with the 70707 Lock-in Amplifier}

If chopping and phase sensitive detection has an advan. tage. as it frequently does for intrared detection. then you can ratio the signal from iwo optical detectors with a single 70707 Lock-in Amplifier and the optional Ratio Unit described on page 344. (The signal from the reference detector must be unmodulated ) The output of the Lock-in is a measure of the ratio. Fig. 2 shows one arrangement.

The type of detection arrangement shown in Fig. 2 is very useful to remove the effects of source variation. but does not remove the effects of ambient light or background radiation For this you need to modulate both light paths. Fig. 3 shows a powerful set-up using a chopper and the 78250 to ratio the two channels

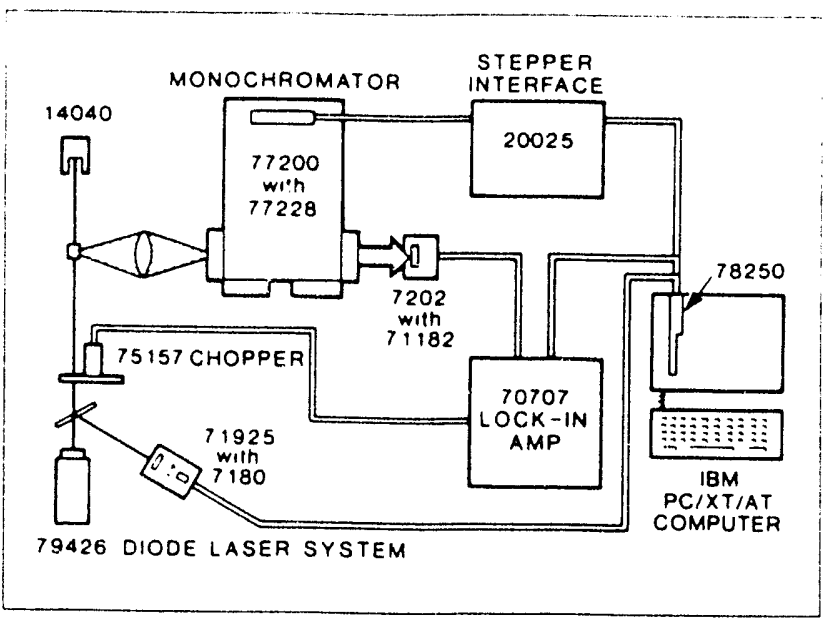

Fig. 2 Measuring near infrared fluorescence using the 79426 Diode Laser System as source. and ratioing the fluorescence signal to the excitation intensity.

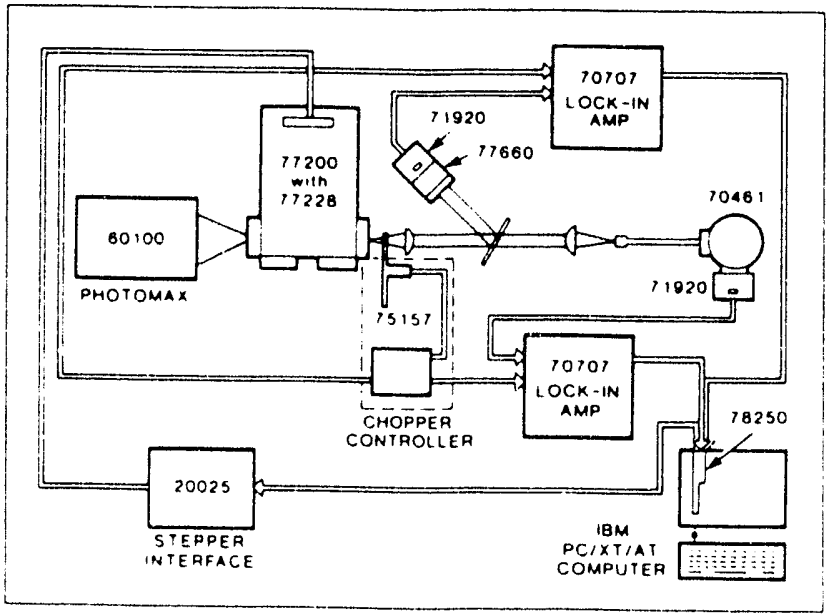

Fig. 3 Computer controlled spectral measurement of optical fiber transmission. Two 70707 Lock-in Amplifiers, one for the signal path and one for the reference beam, remove ambient background. 


\section{$\square \boldsymbol{A} \mid$ EI, COMPUTERIZED SPECTROSCOPY SYSTEMS}

\section{RADIOMETRIC SYSTEM}

Fig. 4 shows a simple but effective radiometer system. The diffuser input to the monochromator is chosen for the particu. lar application.

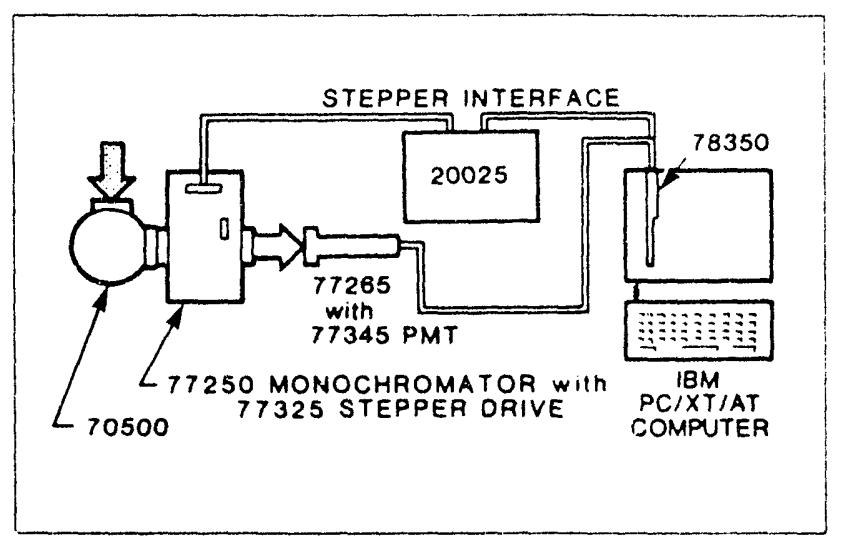

Fig. 4 A radiometer based on the 78350 system uses a single 77250 Monochromator and photomultiplier detector for high sensitivity in the ultraviolet.
In radiometry or photomeiry of light sources, the first step is to record a reference or calibration scan. This measures the system response against a known light source. (See page 62 for suitable standard sources). A scan of the unknown light source follows. Both sources should produce similar values of detector signal to remove any uncertainty about system linearity over a wide dynamic range.

Our radiometry program is designed so you do not have to run scans and divide them afterwards. The program allows you to run a 'Standard' scan of the calibrated lamp. You must supply a file of the calibration values for this lamp. Then by running subsequent scans as Radiometric, the program displays the name of the calibrated lamp file and the number of spectral points which match scan points. Calibration values are interpolated for other points. (If you have too few matching points, then the basis of the radiometric values may be suspect.) Data are recorded and plotted as radiometric, as distinct from detector signal, values. 


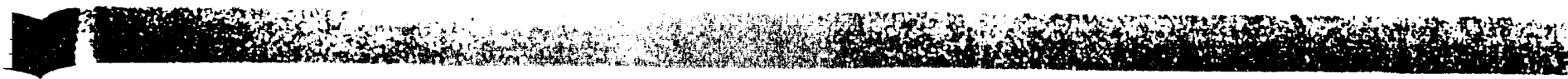

A comple: $;, \cdots, \ldots, \ldots$ ponents

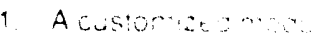

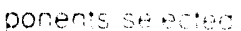

include

- Ligni Source

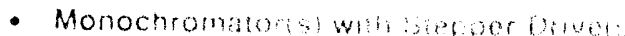
Stepper lilterface

- Detectoris

Contact Oriel Sales Engmeters ${ }^{4}$ in components

2 A 78250 votage Raten: : : : :

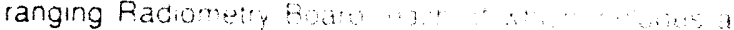
plug-in cara soltwa an at:

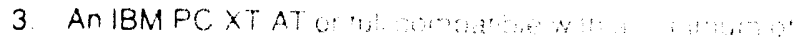

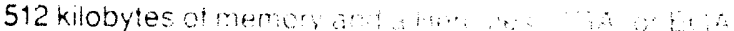

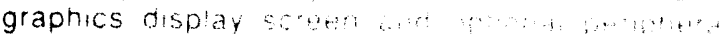

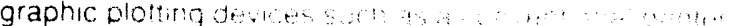
or Hewlett Pacharo

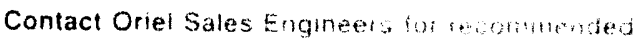

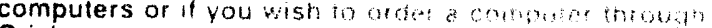
Oriel.

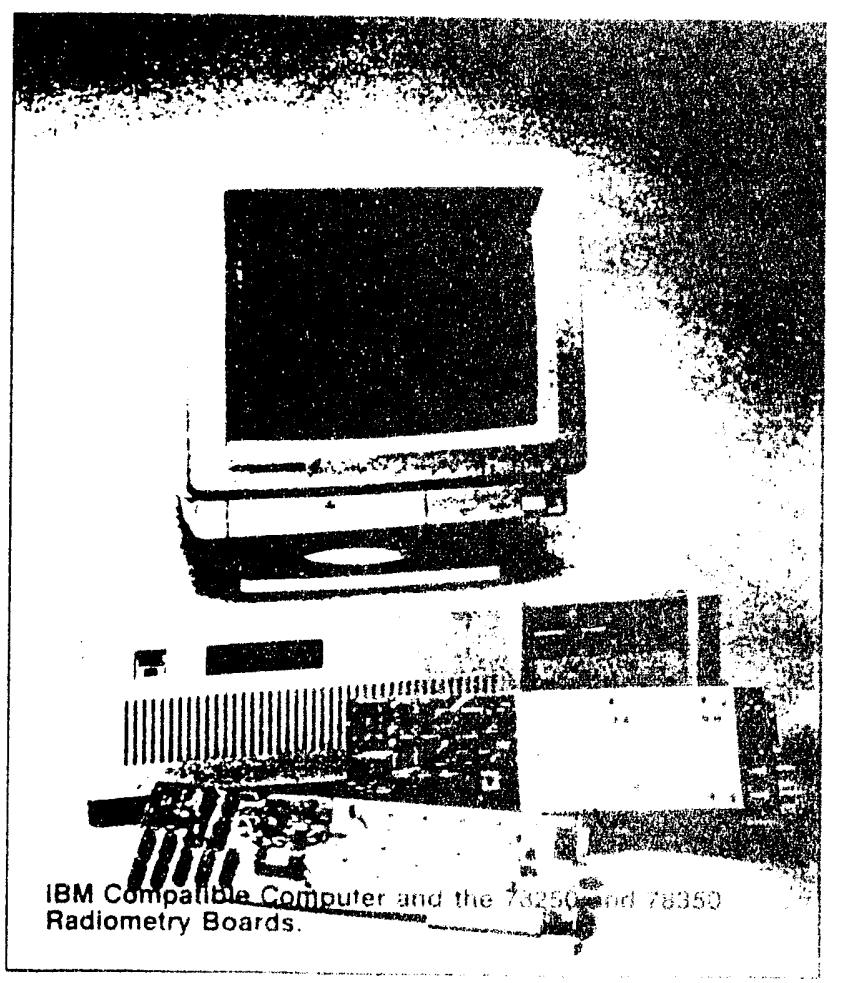

row and now agrams of several systems on pages $\therefore$ ty these do no: show delals of light sources.

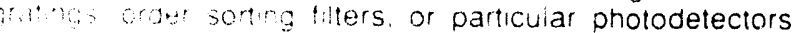

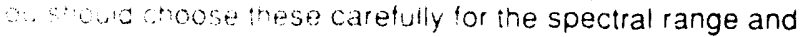

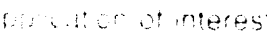

Contaci our Sales Engineers for advice.

\section{OROERING INFORMATION}

$$
\begin{aligned}
& 78350 \text { A woraging Radometry Board } \\
& \text { Montors photocurrents from } \mathrm{pA} \text { to } \mathrm{mA} \text {. } \\
& \text { nudes plug in board. sottware for } \\
& \text { adrometry thorescence and absorbance. } \\
& \text { and cabling to Stepper Interlace }
\end{aligned}
$$

73250 volage Radiometry Board

Monitors voliages from 0 to $10 \mathrm{~V}$. includes plug.in board sotware for radiometery. fluorescence and absorbance, and cabing to Stepper intertace

\section{$\$ 2895.00$}

0




\section{DFIEL, FIBER OPIICS}

Fiber optics add a new dimension to Light Researcu. Their flexibility lets you bend and carry light to inaccessible places Special configurations allow you to reshape beams 10 match monochromator slits and samples. Multi branch models serve as beam splitters or combiners, or as dual source illuminators.

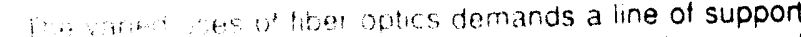
a. andition positioners and 0.1 The buries, hqud lighi guides and

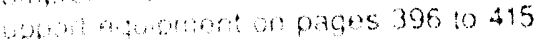

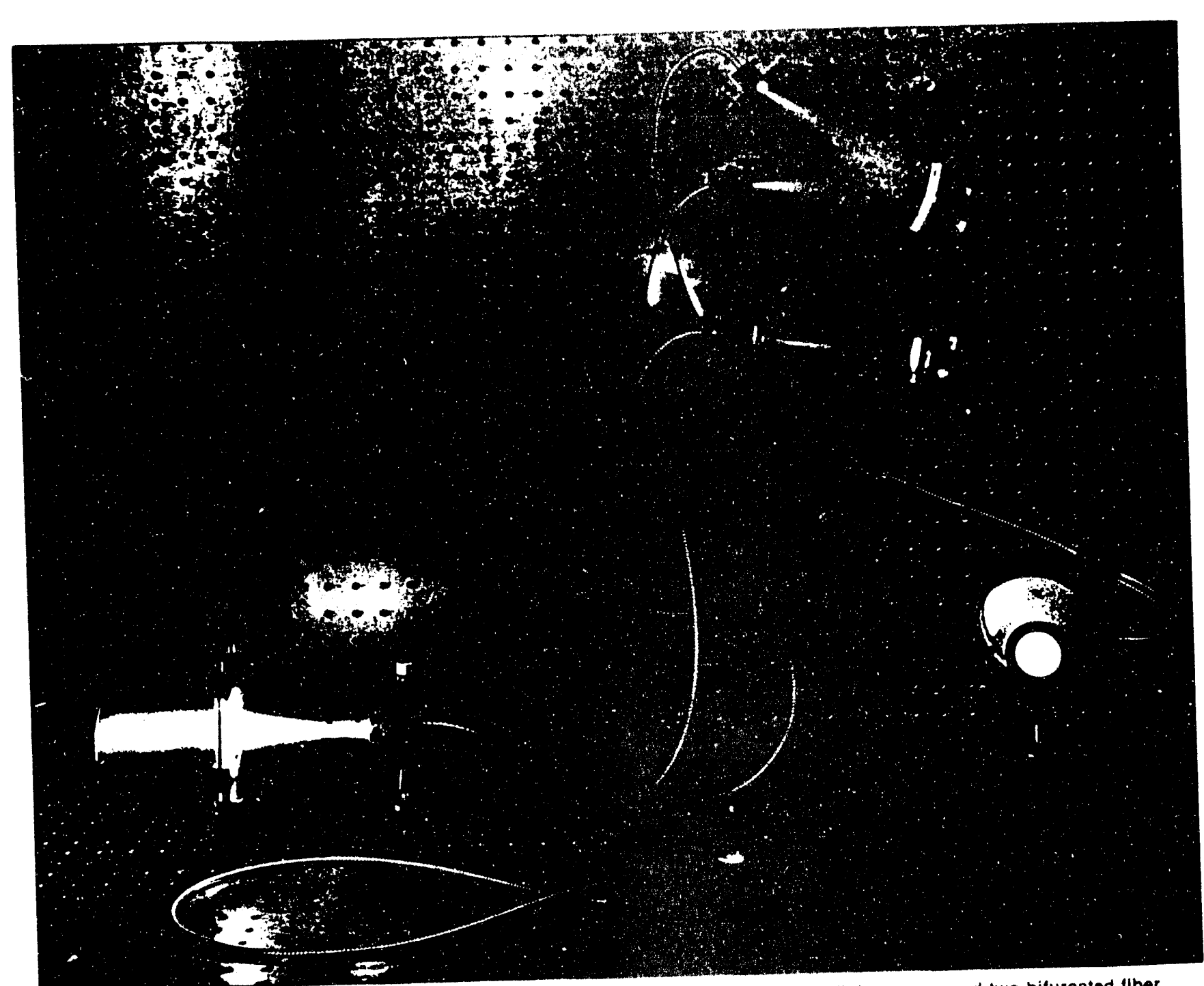

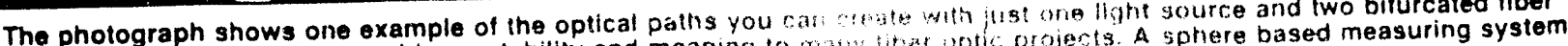
is insensitive to flber output pattern. 


\section{PC Based}

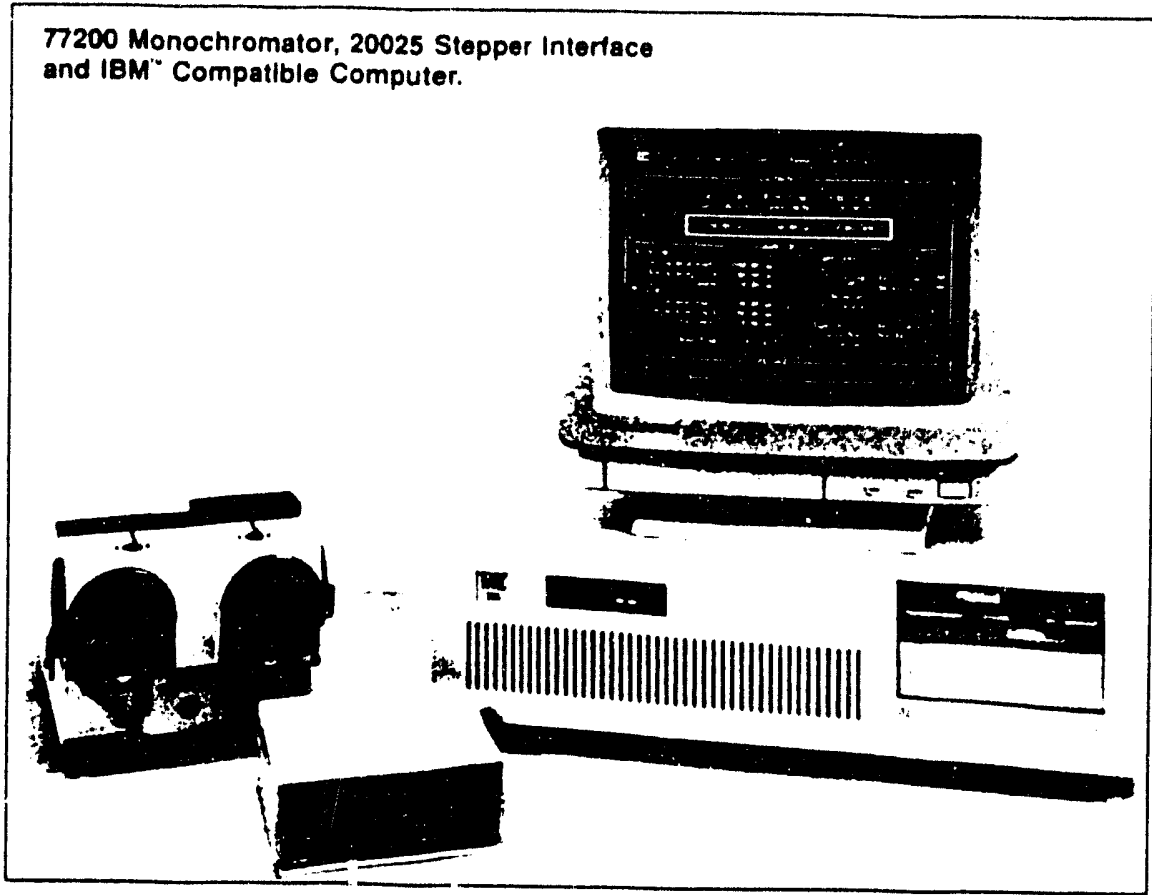

- Designed for IBM PCs and compatibles

- Complete scan control - customize your own scan

- Complete hardware and sottware

- Support many types of detector

- Software for radiometery, absorption, fluorescence

- Single or double beam

If you are considering setting up spectroscopy equipment which involves scanning a monochromator and laking data. then the hardware and software described on the next few pages can save you a lot of time and effort. You can quickly put together a versatile and powerful system for spectro. scopy based on an IBM PC compatible computer; spectroscopy anywhere from the ultraviolet to the infrared. You can choose scan parameters to suit your application.

We describe wo boards which plug into the slots inside the computer. Both boards are supported by software to operate our monochromators (with appropriate drive hardware) and take signals from detectors

- The 78350 Autoranging Radiometry Board is for detectors which behave like current sources; photomultipliers and photodiodes. This board has built-in autoranging for very wide dynamic range without oper. ator intervention.

- The $\mathbf{7 8 2 5 0}$ Voltage Fadiometry Board is for any detection system where the final output is in volts pro. portional to signal. This includes many infrared detec tion systems employing beam chopping where the signal is recovered by our 70707 Lock-in amplifier. The 7070 Photomultiplier Detector System and 70701 Readout also have suitable outputs.

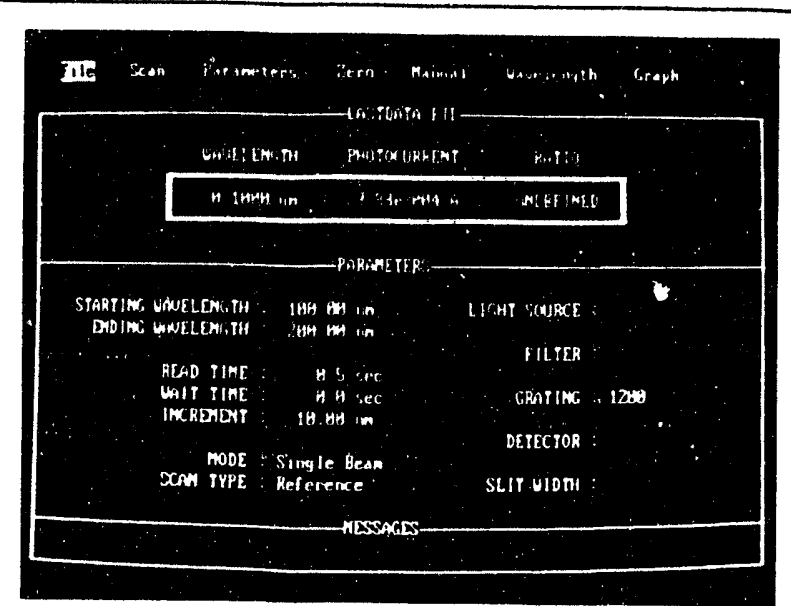

78350 Menu Screen. 


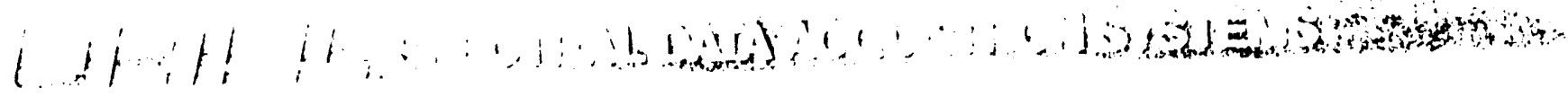

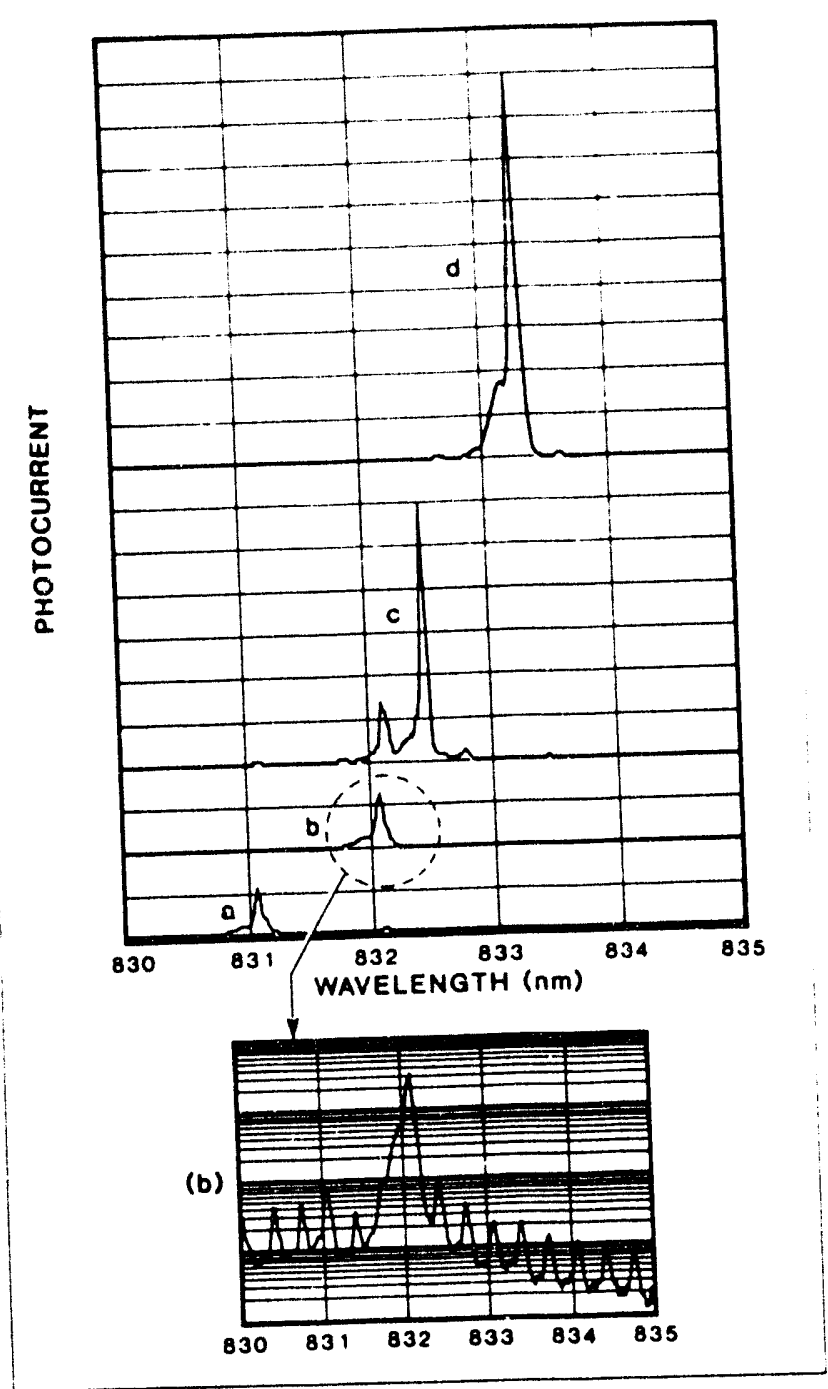

Fig. 1 (a) to (d) show the spectral distribution of a semiconductor diode laser as the current is increased. The spectrum shifts to longer wavelengths as different modes compete for gain. Even at high current, (c), low level spectral features Eve apparent. You can examine these using the are apparent. You can capability. The spectra were different plot scaling capability. The spectra wore recorded using a 77344 Photomultiplier, the Autoranging Padiometer Board, $772001 / 4 \mathrm{~m}$ slits. The 78350 commanded the 20025 Stepper Interface The in in the high resolution advantage of the high resolution of the took full advantage of the high resolution of the
77200 . The resolution is shown clearly in the expanded view of spectrum (b). The log plot of the expanded view also shows the plotting capability of the 78350 .

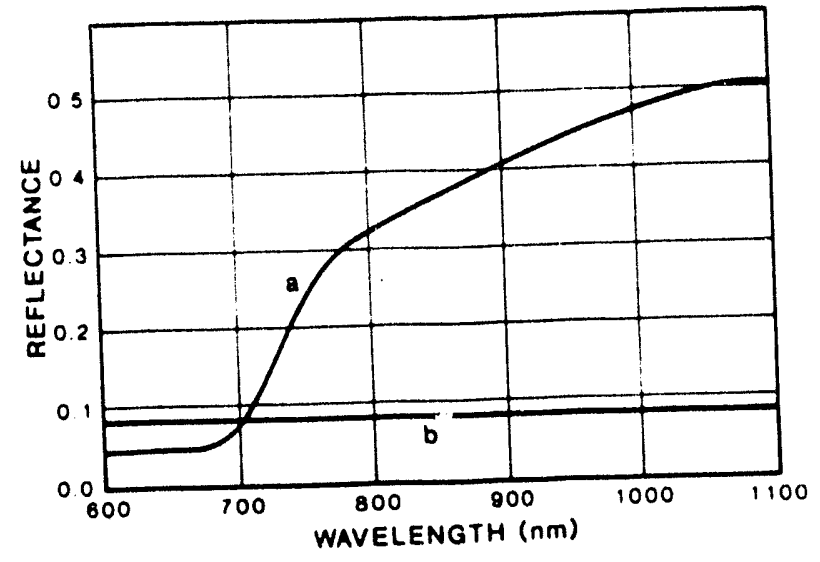

Fig. 2 (a) Near Intrared Hemispherical Tolal Reflectance (8) an anodized aluminum surface. (Tota (8) of an anodizedalur olus diffuse). The data was reflectance is specular with the 78350. We used a recorded and ratioed wit the 71920 Detector Head 7182 Silicon Photodiode in the 71920 Dettance Sphere. on the 70491 Reflectance/ Transmittance The input beam was from a $772501 / 8 \mathrm{~m}$. Monochromator illuminated by the 60065 Series $O$ Source and a 6199 Secondary Focusing Lens (150 $\mathrm{mm}$ F.L.). A 51520 Long Pass Filter remoted the beam second order radiation. We recollimated the beam with a $100 \mathrm{~mm}$ F.L. lens and apertured it to diameter before entering the sphere. The reflectance value was derived by ratioing the data file for the anodized sample in the sample

to the file recorded with the Oriel Certified

Standards of Diffuse Reflectance (page 366 ). (b) shows the to comparison. 
Integrates Detector Input and Monochromator stepper motor driver into one package

Seven decades of autoranging and 12-bit A/D converter allow nine decades of dynamic range Includes software

Operation of up to two Monochromator Stepper Motors

Supports two photocurrent inputs (picoamps to milliamps) for double beam mode or matrix scans

1 Occupies single slot of IBM PC bus

The 78350 Autoranging Radiometry Board is a hybrid analog/digital card that plugs directly into the IBM PC Bus, 10 provide photodetector input and monochromator control. It is designed for, and supported by, spectrophotometry and spectroscopy software. The 78350 records photocurrent from photomultipliers and photodiodes. The 78250 is the version for input voltage.

\section{PLUG-IN CARD}

The physical card occupies a single slot in a PC-XT. It draws approximately 5 watts of power and has two BNC connectors and one DB-15 connector at the rear of the com. puter. The calibrated, high-gain analog circuitry is mounted in a shielded can oft the surtace of the mothercard for optimum electrical isolation. Shieided coaxial cable, isolated from the main mothercard. runs the sigrial from the BNC connectors into the analog front end (shielded can).
The 78350 card has a transimpedance amplifier input with software switched gain. a lixed gain stage. and a 12 bit A.D converter. Input bandwidih is $35 \mathrm{~Hz}$. Maximum resolution is 0.24 picoamperes and maximum photocurrent is 1 milliam. pere. No single chotodetector can use the full range but you can cover the linear range of different detectors. See the following page for practical resolution and range with our photodetectors.

The iwo inputs are protected to 2000 volts DC across the input and current limited with an input impedance of 2 megohms. The amplifier is based around an ultralow noise FET precision op amp with switchable ranges of amplifica. tion. Each individual range is factory calibrated and directly controlled by soltware. The output from the analog circuitry is routed into a 12.bit $A / D$ converter and ported through the PC Bus. The 78300 sottware controls the electronics, perform ig autoranging and signal processing of the input.

\section{OUTPUTS}

Two 1/O output ports are for monochromator control. The output is routed through the DB.15 connector for interface to an Oriel 20030 or 20025 Stepper Interface. (The 20025 Stepper Interface is for a single monochromator.) See Fig. 1.

The TL outputs are decoded through address ports on the PC Bus and drive the 20030 (or 20025), capable of driving monochromators at step rates of 4000 steps per minute. (With a 1200 line grating this is $400 \mathrm{~nm} / \mathrm{min}$.)

Often a single monochromator is adequate. Both ports are used with dual monochromator arrangements for pertorming matrix fluorescence scans where both excitation and emission measurements are required.

Our Double Monochromator Systems (coupled mechanically) use a single Stepper Drive and therefore count as one monochromator

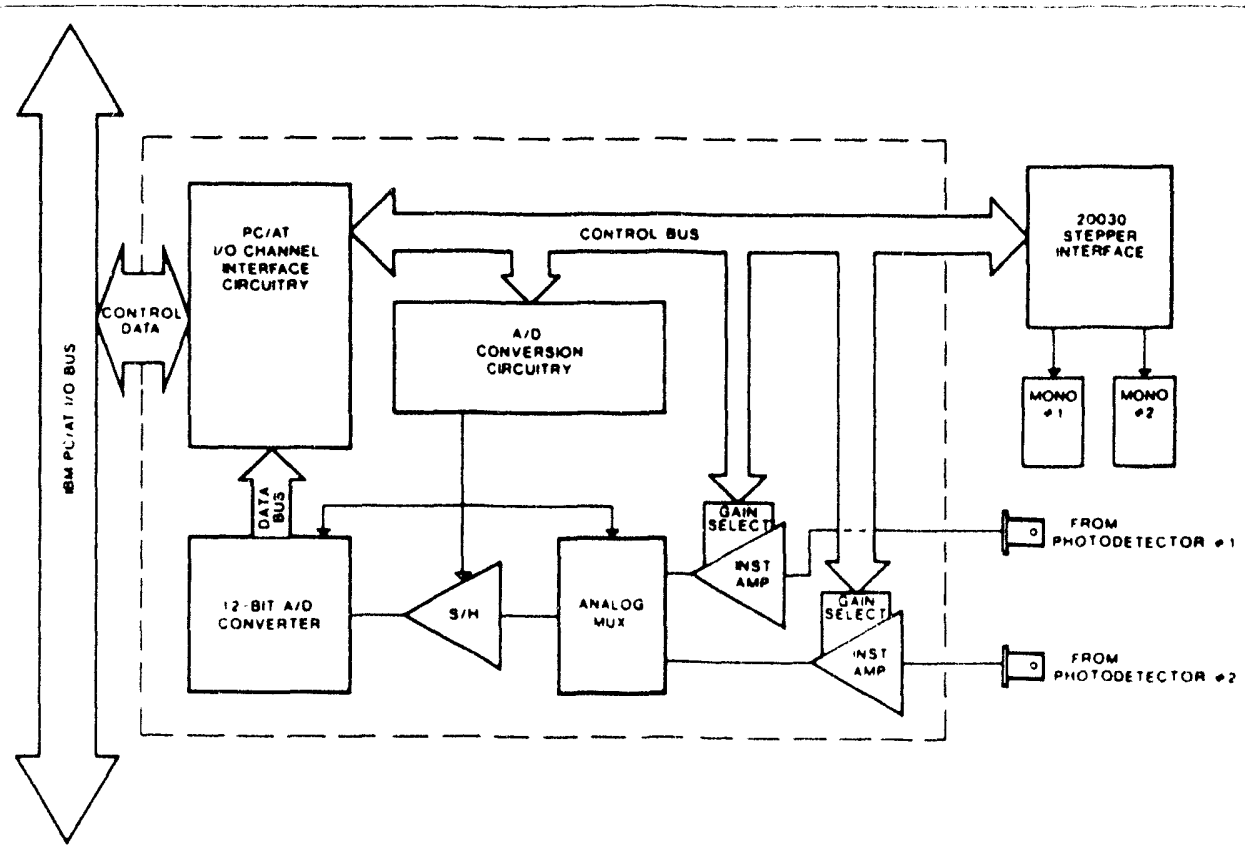

Fig. 178350 Autoranging Radiometry Board 
Oriel carries a complete line of photodetectors which produce a photocurrent proportional to incident light intensity. with spectral sensitivities from the UV to the IR.

Silicon photodiodes come in a variety of sizes and packages, depending on the application, and offer high sensitivities. especially in the near IR. Germanium and Indium Arsenide photodiodes extend the range into the intrared. Photomultipliers have the greatest sensitivity in the visible and ultraviolet. (usually 2 orders of magnitude greater than silicon photodiodes) and produce a photocurrent that is proportional to light intensity over 6 to 8 orders of magnitude. However. they require a separate high voltage power supply (such as the 70705) to operate. Fig. 1 shows the computer reading against photocurrent into the 78350 board over more than 8 orders of magnitude. (Photodetector linearity may not match this range.)

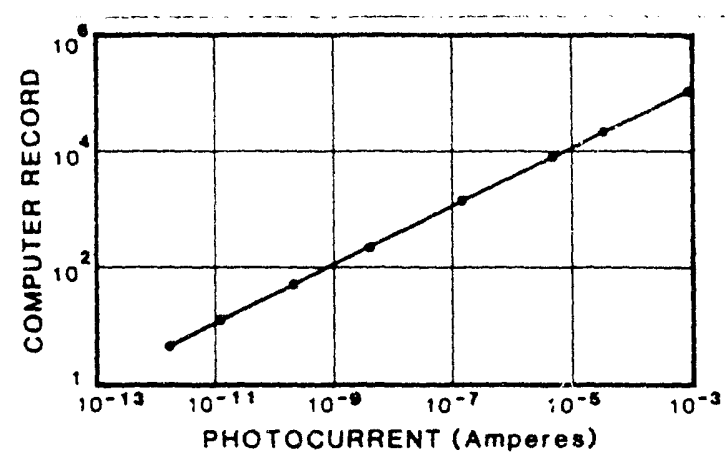

Fig. 1 The computer reading against photocurrent over more than 8 orders of magnitude. (Photodetector linearity and stray ligint usually limit the useful range.)

\section{Dark Current}

All photodetectors produce a small amount of quiescent current in the absence of light, commonly refered to as 'dark current: The 78350 Sottware allows you to take a dark current reading which is then subtracted from all subsequent signal measurements.

\section{REAL PERFORMANCE WITH PHOTODETECTORS}

The principal detectors used with the 78350 are photomultipliers and photodiodes without bias.

\section{Photomultipliers}

These detectors are linear over a wide range if the dynodes are properly supplied and when the output is into a transimpedance amplifier. (The 78350 input is designed in this way). The maximum photocurrent is specified on page 218. For precision radiometry we recommend that the anode current be 10-100 times less than specified maximum. Avoid using currents of more than $1 \mu \mathrm{A}$. Do not focus light on the photocathode as this will lead to local saturation. And in order to compare signals accurately they must be distributed equiv. aleritly cver the sensitive area.

Dark currents can be $10-500 \mathrm{pA}$ depending on tube. voltage and recent history. (Tubes exposed to high light levels have temporarily high dark currents). Dark current is not a iundamenta! timitatinn as it is subtracted out but dark current noise may limit the detectable signal level.
Fig. 2 shows a scan of a steeply rising spectral feature and demonstrates the wide dynamic range of the 78350 . The scan was taken with a 77257 Double Monochromator with a 77345 photomultiplier tube. operated at 600 volts. The 78350 subtracted out the $10 \mathrm{pA}$ dark current. Averaging time was $0.5 \mathrm{~s}$. The low level signal below $610 \mathrm{~nm}$ is due to photomultiplier dark current noise on a stray light background.

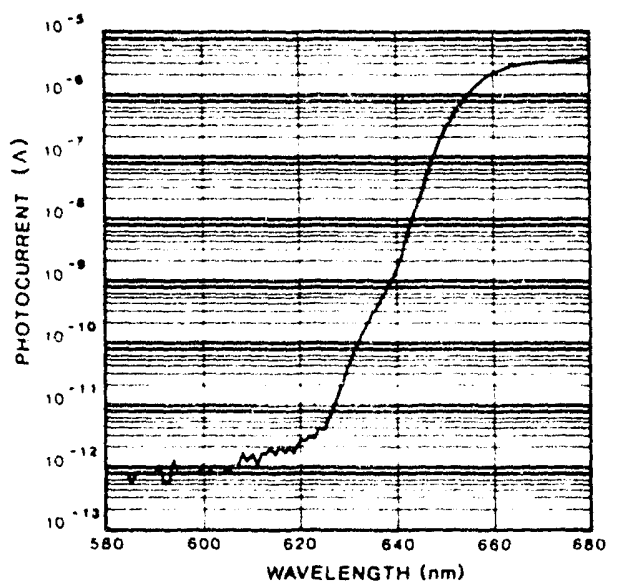

Fig. 2 Spectral scan of a steeply rising feature taken with a 77345 Photomultiplier and 77257 Double Monochromator.

\section{Photodiodes}

Photodiodes have wider spectral range of response than most phoiomultipliers and have sensitivity and linear behavior over many decades. Our larger area diodes have linear response over as many as 8 decades.

Unbiased photodiodes have low dark current and dark current noise and are preferred for dynamic range over biased versions. The larger diodes such as the 7182 have higher maximumi linear currents (ca.1 $\mathrm{mA}$ ) and the large area captures much of the output from a monochromator without the necessity for auxiliary optics.

Fig. 3 is similar to Fig. 2 but shows the wide ranging performance with the 7182 Silicon Photodiode.

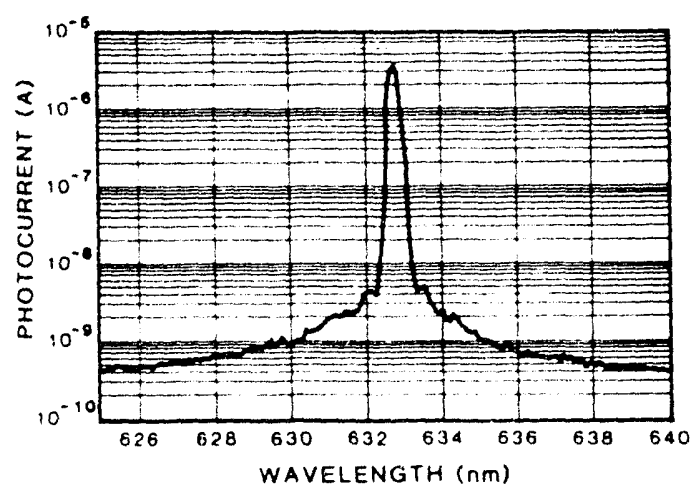

Fig. 3 A scan of a narrow laser line recorded with the 7182 Silicon Photodiode on the 77257 Double Monochromator with iwo ??238 gratings 


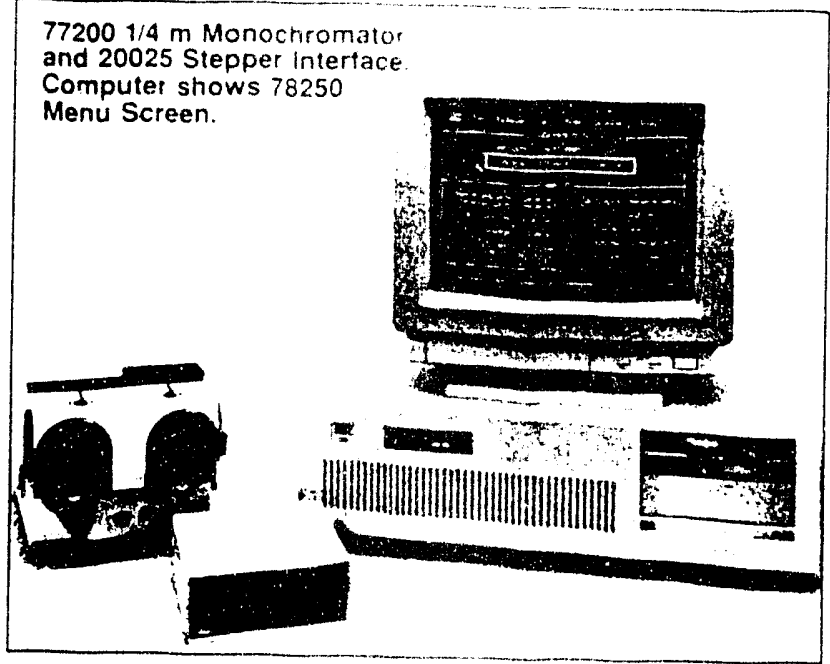

For detectors. Lock-in Amplifiers or Readouts which produce a voltage signal proportional to radiant flux.

- Designed to interface IBM PC's and light detection equipment

- Comprehensive soltware

- Integration of Voltage A D converter and monochromator control into one package

- Operation of one or two monochromators

- Supports two voltage inputs with jumper selectable gains $(0-100 \mathrm{mV}, 0-1 \mathrm{~V}, 0-10 \mathrm{~V})$

- 12-bit A/D converter allows three decades of dynamic range with selectable voltage range

- Voltage Radiometry Boerd occupies only a single slot of any IBM PCXT. AT or Compatible
The 78250 Voliage Radiometry Board is a hybrid analog digital board that plugs directly into the IBM PC Bus. It has futi software support for radiometry. fluorescence or absorbance measurements. The hardware and software provide mono. chromator control and measure voltage signals

The physical board occupies a single slot in a PC.XT or AT draws approximately 5 watts of power and presents iwo BNC connectors and one DB-15 connector to the rear of the crm puter. The calibrated. seisctable-gain analog circuitry is mounted to the rear of the foard for noise isolation and is protected from overvoltage input. Shielded BNC connectors. isolated from the main trace layout, connect directly into the analog front end. A grounded plane serves to isolate transients in the computer switching power supply from the detector inputs

$\therefore \therefore \quad \because \therefore \therefore$

The 78250 Board has three jumper pin selectable ranges

$\begin{gathered}\text { Range } \\ \text { (V) }\end{gathered}$
$0-0.1$
$0-1$
$0 \cdot 10$

$\begin{gathered}\text { Resolution } \\ \text { (mV) }\end{gathered}$
0.025
0.25
2.5

The two channels can be set to different ranges. The two inputs are over-voltage protected to \pm 100 volts $D C$ across the input to ground and current limited with an input imped. ance of $200 \mathrm{k}$ ohms

The input amplifier is based around a bipolar ultralow offset op-amp. The jumper pins select the ranges of amplification. Each individual range is factory calibrated. You select the range to match the voltage source before inserting the board into the computer.

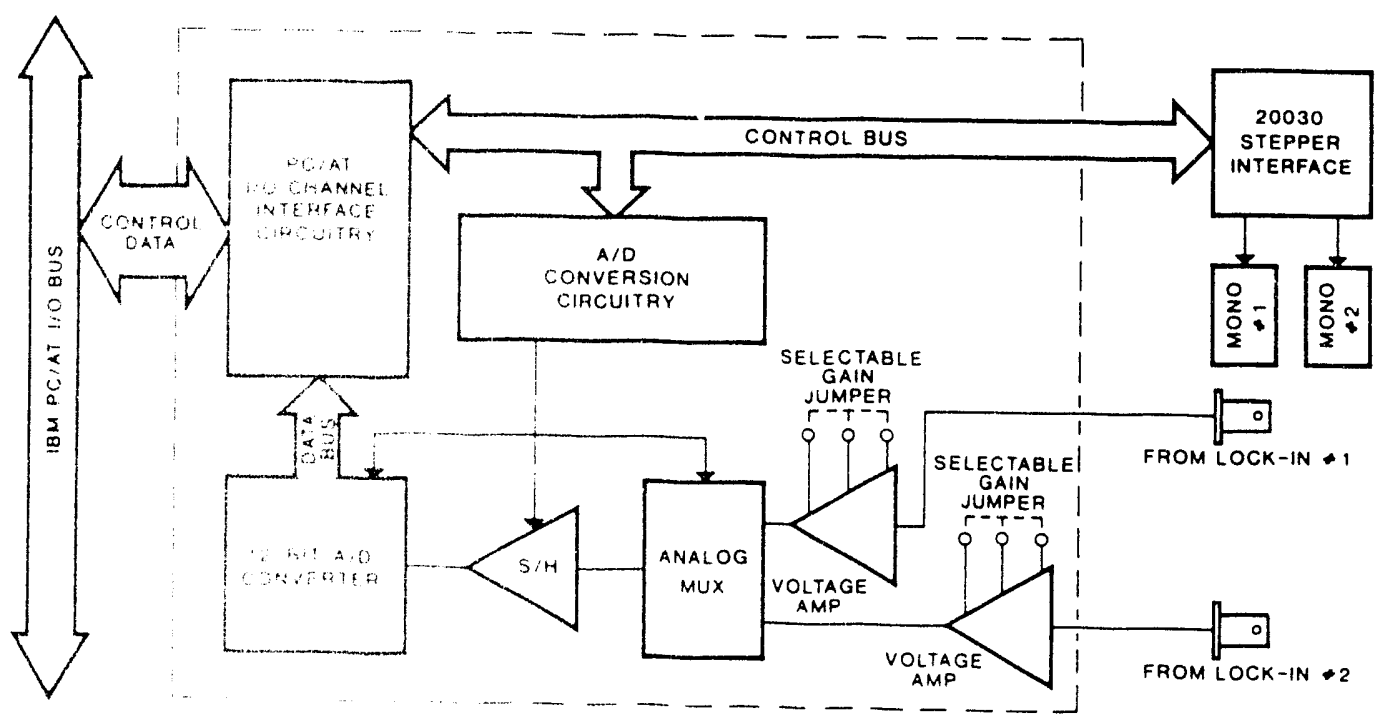

Fig. 178250 Voltage Fadometr eoard 


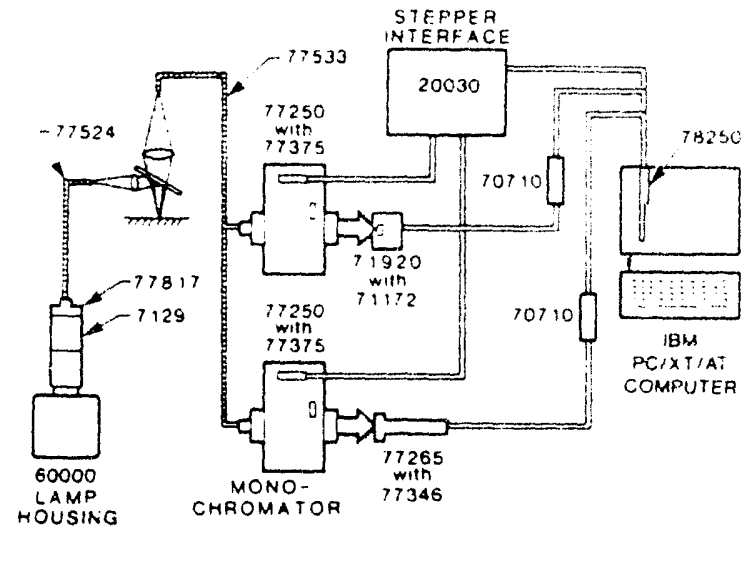

Fig. 2 Arrangement for infrared fluorescence measurements on crystals. The 78250 is used in a dual beam mode. A biased photodiode monitors the source and acts as reference, while the chopper, Lock-in Amplifier and $\mathrm{PbS}$ detector monitors the infrared fluorescence.

\section{i2 3 IT ANALOG TO DIGITAL CONVERTER}

The output from the analog pre-amp and surge suppresser circuitry is routed into a 12 -bit $A / D$ converter and ported through the PC-Bus Interface. The 78250 Software controls the electronics. and signal processing of the digitized signal.

\section{Outputs}

The 78250 controls one or two monochromators through two 1:O outputs (DB.15 connector). The output connects to a 20030 Stepper Interface. (The 20025 Stepper Interface will run one monochromator.) The TTL outputs are decoded through address ports on the PC-Bus Interface and drive the 20030. The 20030 provides the pulses for monochromators at step rates of 4000 steps per minute. This is $400 \mathrm{rim}$ per minute for a 1200 line $/ \mathrm{mm}$ grating. The software drives two monochromators for matrix fluorescence scans where both excitation and emission wavelengths are scanned.

\section{COMPATIBLE DETECTION EQUIPMENT}

Any of our detectors or detection systems with a voltage output are compatible with the 78250 . The signal source may be as simple as a biased photodiode in our 71925 Detector Housing. or as complex as two $70707 \mathrm{~L}$ Jck-in Amplifiers which recover signal by phase sensitive de! iction of chopper modulated radiation. You can use the $70 ;: 11 \mathrm{C}$. Ir rent Pre-amplifier to convert current from photomultiplit is or unbiased photodiodes, to voltage signals for the 78250 . II these are the only detectors you intend to use, you shouid consider the 78350 Autoranging Radiometry System described on page 373 .)

Using one of our Readouts to accept the signal from the detector and provide output to the 78250 has advantages

- You can see the signal level and optimize alignment etc.

- You can condition the signal for besi match to the 78250. This involves setting the range on Readouts such as the 7070, or 7080. or adjusting the gain and oftset on the 70701. You car: also set the rime constant on several of these insirumenis fui besi SAl portor mance.
Pyrce $=\cdots$ Detectors respond ont io chopped light. ano other de:-u:ors Isuch as PoS or PUSe, oeneft from operation ai higher requencles You can use these devices with ou choppers and the 70707 Lock in Amplfier and take the out pul of ir $=$ lock -17 to the -8250 This combines the advantages $C^{\circ}$ onase sensitive detection with those of the compute control data storage and processing.
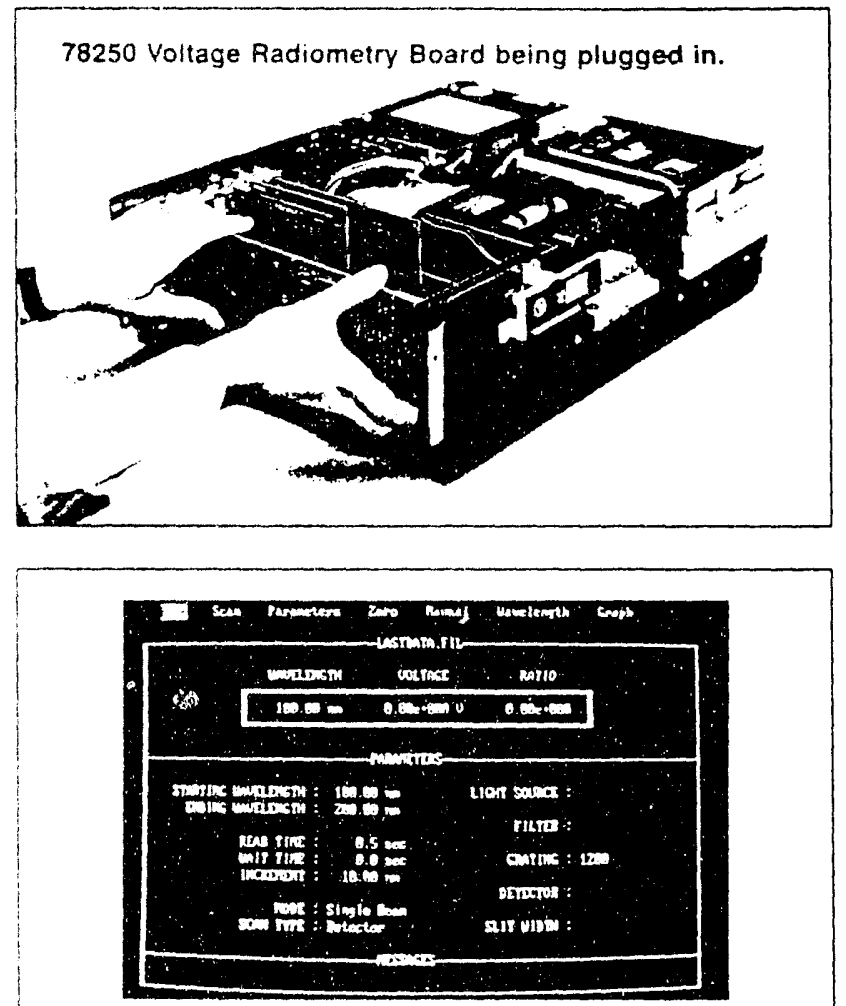

78250 Menu Screen.

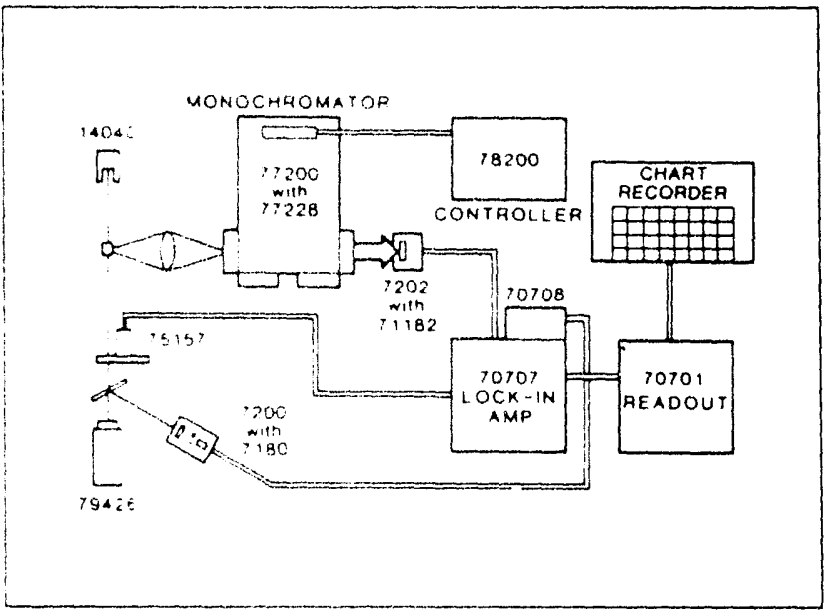

Fig. 3 The 78250 used with a photomultiplier and biased indium arsenide photodiode. With the optional 70701 Readout (not shown) you can easily condition the photodiode voltage for best utitization of the range of the 78250 . 
Controls monochromator and measurement of photocurrent

Stores, processes, and plots data

Completely menu driven - No programming experience required

Presents data in standard Absorbance, Fluorescence, or Radiometric format

Supports single and dual/ratioed beam modes Controls up to two monochromators for emission, excitation, and synchronous wavelength scans for fluorescence measurements

Linear or Log-Linear Plotting of data to Screen, Printer, or Hewlett Packard Pen Plotter

This software consists of three separate programs tailored for specific applications: absorbance. fluorescence. and spectroradiometry. All programs are written for the IBM PC, $\mathrm{XT}$ /AT as part of the 78350 Auto ranging Radiometry Board and 78250 Voltage Radiometry Board

There are two slightly different versions of the software. one for the 78350 and one for the 78250. The description which follows covers both versions

The software is written in efficient last $C$ (Turbo $C$ ) and each program is about $200 \mathrm{kB}$. The three programs are varlations on a common base. Radiometry has funciions specifically for absolute radiometric measurements. Absorbance has explicit emphasis on ratioed measurements and fluorescence has provision for excitation and emission monochromators
The soltware is shipped on 5.25" 360 kilobyte and 35 " 1.44 Megabyte media. A minımum of 512 kilobytes RAM is required and graphic display adapters supported by the program include EGA CGA and Hercules Graphics Card HGC or MCGA). The system can work with either a hard disk or a floppy based system. A numerical coprocessor is utilized if one is present

There are iwo operational intormation screens: the Scan Screen displays wavelength and photocurrent readings as well as operational parameters: the Graphing Screen has graph set-up information and information on dumping graphs to plotters or printers.

$$
\text { D.N SCFEE! }
$$

In this screen. shown above, a horizontal menu of submenus runs across the top of the screen. The remainder of the screen displays key information on the scan. wavelength and signal level.

You activate any submenu by using either the key corresponding to the first letter of the item or using the left or right cursor keys. Every submenu of the top horizontal menu brings a pop-up menu onio the screen. You can select the pop-up menu items with either the item's first letter or by using the up and down cursor keys. The escape key returns you to the top horizontal menu or selects default items.

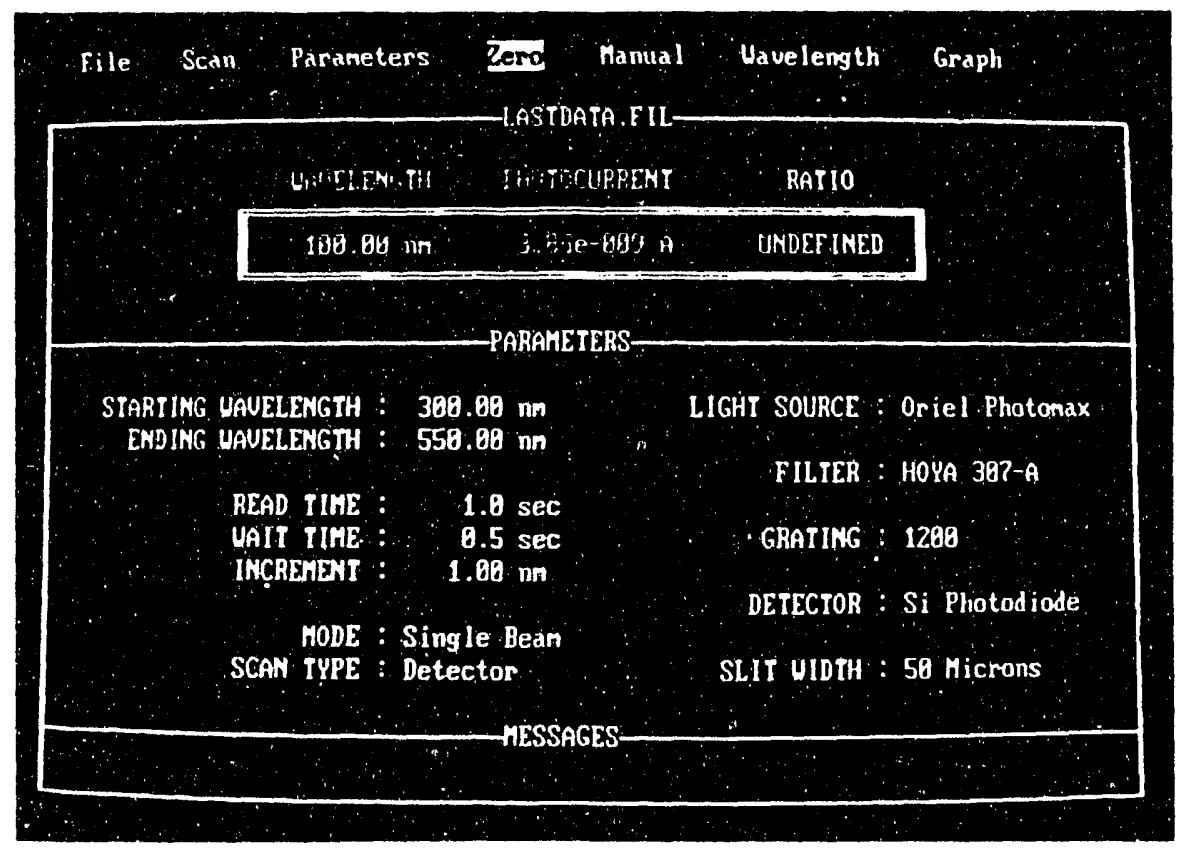

Scan Screen of the 78350 Software 
$i j i_{i=\ldots}^{j} i j$,

File

This allows you to list the flles on the various computer drives and to exit the program, automatically saving the parameters set you have been using, including the last wavelength.

\section{Scan Sub Menu}

This menu allows you to start a scan, save or recall a scan from disk, and display the scan which you have just completed or one you recalled to memory, as a plot. You can also display the scan values to screen and quickly move through to the specific screen of readings around the one of interest Or you can send the list of values to your printer.

The radiometery program includes a 'Type' option in this submenu. This allows you to choose between scans recording the photocurrent, standard lamp scans, and radiometric scans of the unknown.

\section{Parameters Sub Menu}

You select your operating and scan parameters from this submenu. These include grating density (lines $/ \mathrm{mm}$ ), wave length increment, beginning and ending wavelengths of a scan, and read time. The scanning parameters have error checking routines built in and incorrect parameters are required to be re-entered. The computer uses the grating density entered to check the validity of the scan data.

You can set the read time in increments of 0.1 second. Readings are taken at a rate of about 100 per second (depending on processor speed), and averaged. As you increase read time, the signal to noise ratio improves, but the scan takes longer. For many scans using a photomultiplier detector we use a read time of 0.3 seconds.

If you are using the 78250 Voltage Radiometer System. you should set the 'Input Voltage Range', to match the jumper selectable range on the board.

\section{Zero Routine}

This option prompts you to shutter the bearn so the computer records the dark current. Dark current measurements are then automatically subtracted (in software) from each reading.

\section{Wavelength Entry}

You must enter the wavelength setting of the monochromator. The program then keeps track of the wavelength. On exiting, the wavelength setting is stored for automatic recall.

\section{Manual Mode}

Selecting this allows you to toggle or slew the monochromator from the keyboard. Manual mode simplifies peak finding for monochromator calibration or spectral analysis. You also have the option to slew to a specific wavelength. This, like all the wavelength changes controlled by the program includes an anti-backlash routine.

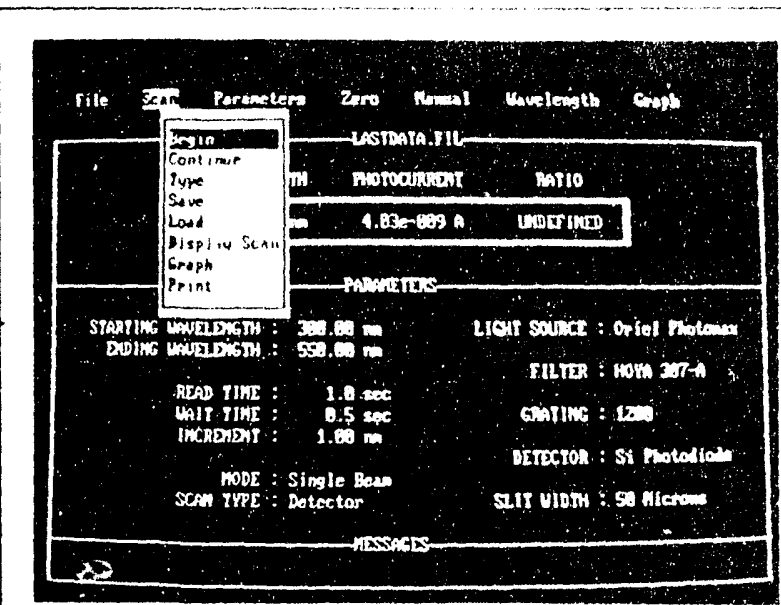

Scan Sub-menu screen.

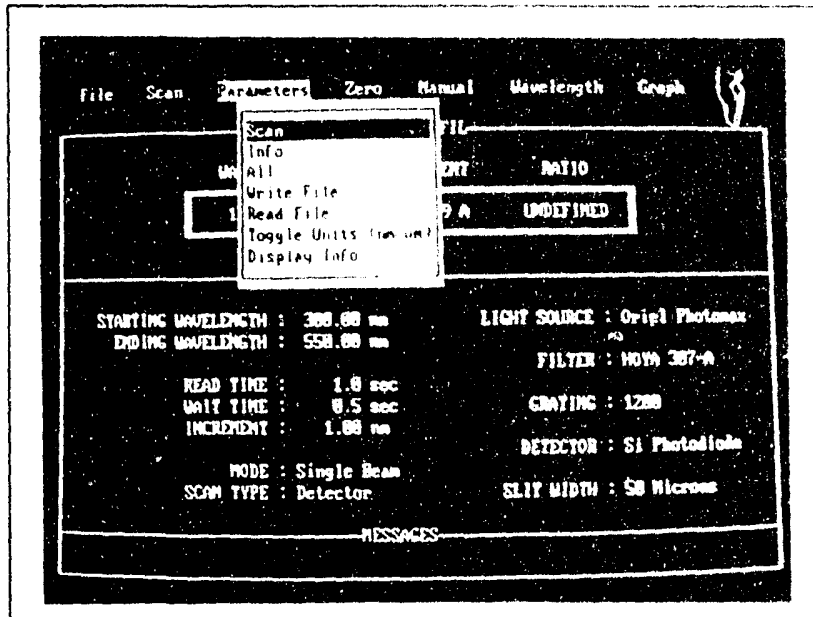

Parameters Sub-menu Screen.

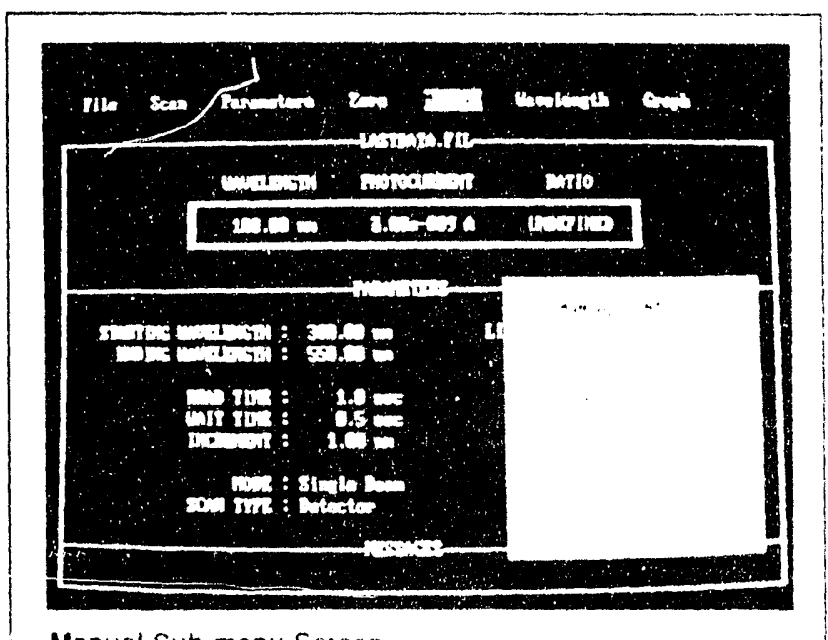

Manual Sub-menu Screen. 
The second screen controls the graphical display of wave length/photocurrent data laken with the sysiern.

\section{Define Plot}

Here you enter the file you want to plot and how you want it plotted. The sophisticated graphing routine allows arithmetic operations on files. You can multiply or divide a file by a constant. or add, subtract, multiply or divide matching files (You cannot multiply or divide files with different spectral ranges or increments. The utlity program allows you to inter polate files with the same spectral range so that you can operate on them.)

You can then store the result as a new file and pertorm further operations on it. You can use this technique to convert radiometric data to photometric. (See page 16 for procedure.) To do this you can create a file of the $V(i)$ values using your wordprocessor or the utility program. Similarly you can create tiles for optical filters and multiply these by light source spectra.

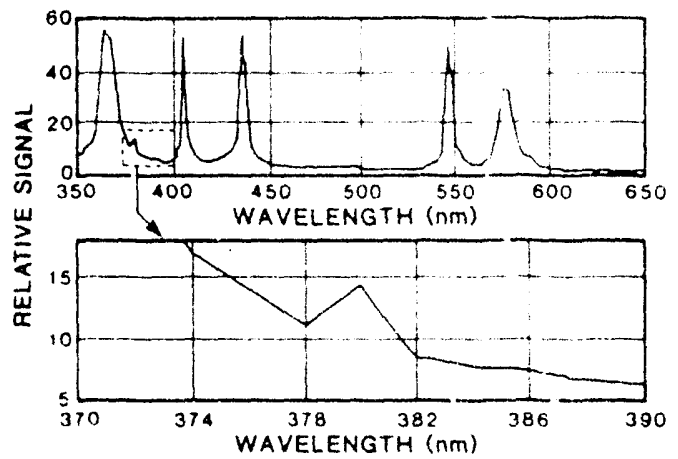

Fig. 1 You can add a wavelength offset to a file should you discover that you had not calibrated the monochromator accurately. You can graph the data using linear-linear format, or for data with no zero or negative values, log-linear format. The horizontal and vertical axis can each be automatically scaled to fit the data or you can choose your own scale ranges. Defined scaling allows you to plot small regions of the scan as shown.

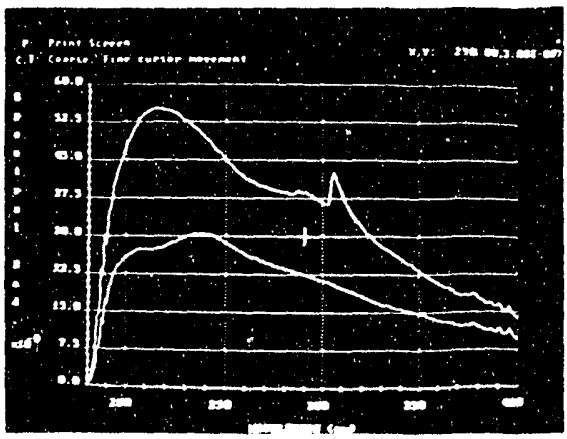

Screen display of two overlaid scans showing raw spectrum and spectrum of radiation transmitted through a sample.

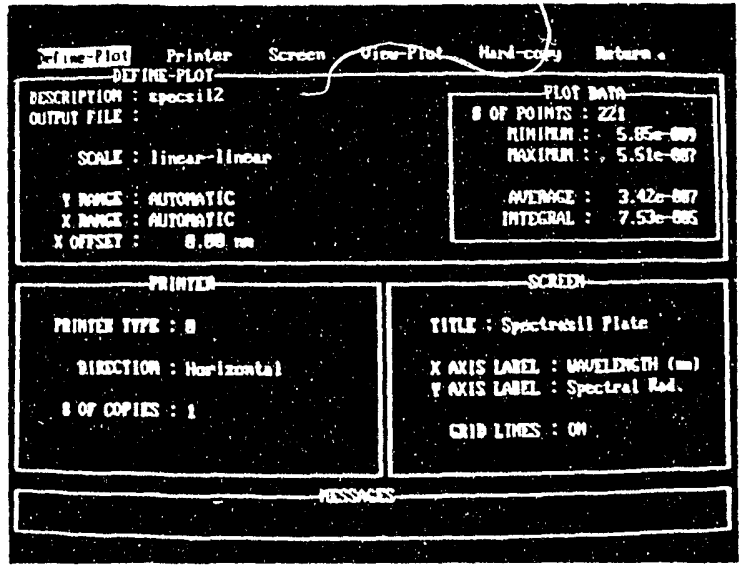

Graphing Screen

The graphing screen displays the value of the inte. grated signal over the graphing range. By choosing the range, you can find the integral over any spectral region of interest.

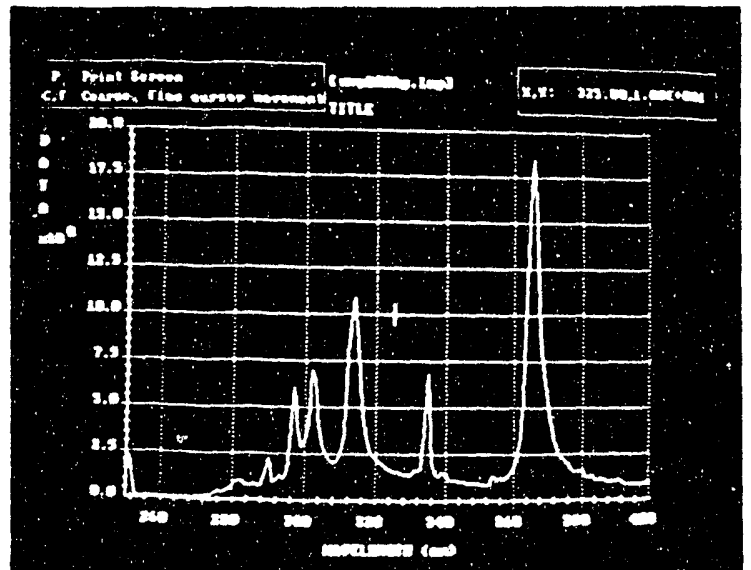

Section of a mercury lamp spectrum.

Data can be plotted on a linear-linear or log-linear plotting scale. A crosshair controlled by the cursor keys can be positioned anywhere on the graph for accurate determination of spectral features or lines. 


\section{Printer}

This submenu allows you to select a printer. Over a hundred printers are supported for graphical plotting, including a number of laser printers for high resolution plots, although the greatest resolution is displayed with the HP Pen Plotter.

\section{Screen}

Here you can name the plot, label the axes, and choose whether you want a grid.

\section{View Plot}

You can overlay multiple plots on a single graph for comparison and contrast. The graph which quickly appears on the monitor, can also be dumped to a printer or to a HewlettPackard Pen Plotter (or any pen plotter supporting HPGL commands).

\section{Hard Copy}

If you want the file values or information file printed out you use this submenu.

\section{UTILITIES}

We supply two useful programs for use with the software: the first allows you to create a file from wavelength and value list. When using the Radiometry Software, you must use this to enter the calibration data supplied with your standard lamp. You can also create a file of transmittance for a filter, or the $V(\lambda)$ curve on page 18 .

The second program uses a polynomial interpolation routine to match scan increments. This allows you to generate a file without entering many points. When entering data for a cut-on filter for example, you need only enter closely spaced points at the knee of the curve. This program will interpolate between widely spaced points of almost constant transmittance above the cut-on.

\section{SCAN AND OVERLAY CAPABILITY}

Memory limitations and the program structure limit the maximum scan to 2000 points. The overlay capability in the graphing routine is also limited to a total of 2000 points. You can overlay 3 scans of 600 points or two scans of 800 points, but not two scans of 1200 points. You can subdivide large scans for multiple overlay.
The files are in standard ASCII format. You can export a file to programs such as Lotus $1-2-3^{*}$. Asyst", or Labtech Notebook" for display, further processing, or inclusion in a report

Idiosyncrasies in IBM compatibles sometimes prevent the proper operation of programs or plug-in boards. If a computer is fully IBM compatible, then our program will work. (We cannot predict compatibility with other plug-in hardware.) We have tested this program on the following computers:

IBM PC XT (4 MHz), IBM PC AT (8 MHz)

Compaq DeskPro (XT equivalent, $8 \mathrm{MHz}$ )

- Leading Edge Model D (XT equivalent, $8 \mathrm{MHz}$ )

- AST Premium (AT equivalent, $10 \mathrm{MHz}$ )

Micro Express (AT equivalent, $12 \mathrm{MHz}$ )

The graphics routine will not work with original IBM PC monochrome cards (pre-1983).

The sampling time for a reading depends on the processor speed. For the slowest processor found in these computers $(4 \mathrm{MHz})$ the rate is 80 samples/s. 


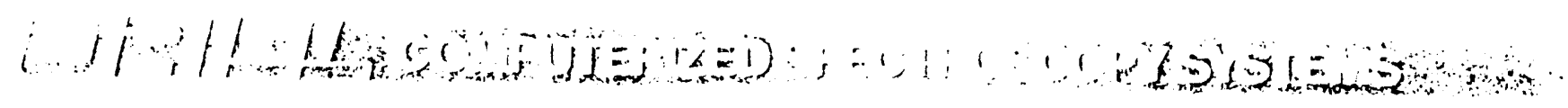

Versatility is a major advantage of Oriel Spectroscopy Systems. You can select a system for a particular application and later change the configuration or add pieces for other applications. On these two pages we illustrate some config. urations.

\section{SINGLE CP, DOUBIE EEAM?}

Many spectroscopic determinations involve two scans and simultaneous or subsequent comparison of the data sets. If the overall system is stable and repeatable to the required degree you can take one scan at a time and compare (ratio) the files afterwards. The single beam approach is particularly attractive when the alternative is two complex and expensive detection systems. The 68850 Photofeedback System can greatly improve the performance of some single beam arrangements.

For highest precision you can take the two scans simultaneously with the 78350 or 78250 in dual beam mode. (Fig. 1) You must pay considerable attention that the signal and reference optical paths react in the same fashion over the wavelength range of the scan to any spatial or polarization changes in the source. Calibrating with absorbance standards helps establish confidence.

The Absorbance program displays and stores the ratio of the two inputs as you scan.

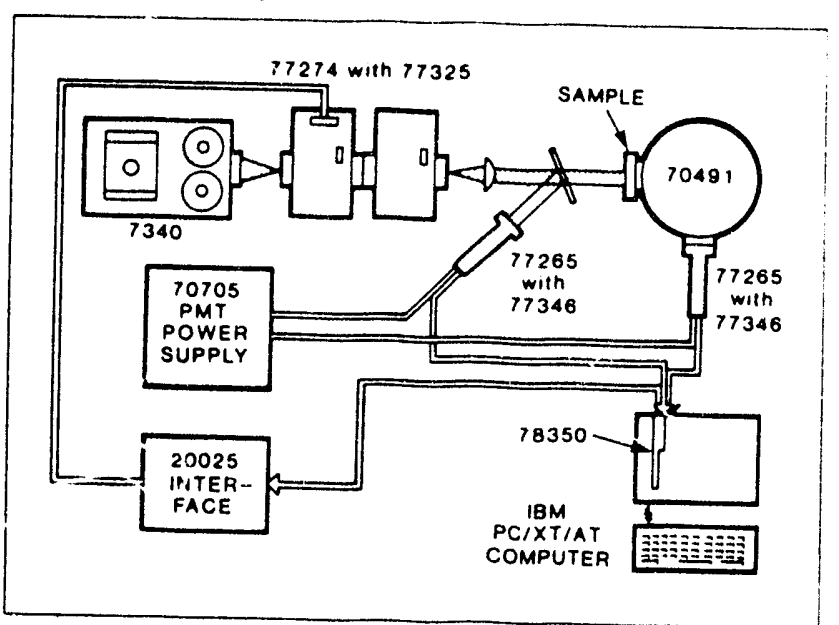

Fig. 1 The components of a double beam system for absorbance measurements. For absorbances above -4 , we recommend that you use a double monochromator, and take particular care with the source spectrum and detector spectral response, to reduce error due to stray light.

\section{Ratioing with the 70707 Lock-in Amplifier}

If chopping and phase sensitive detection has an advantage, as it frequently does for infrared detection, then you can ratio the signal from two optical detectors with a single 70707 Lock-in Amplifier and the optional Ratio Unit described on page 344 . (The signal from the reference detector must be unmodulated.) The output of the Lock-in is a measure of the ratio. Fig. 2 shows one arrangement.

The type of detection arrangement shown in Fig. 2 is very useful to remove the effects of source variation, but does not remove the effects of ambient light or background radiation. For this you need to modulate both light paths. Fig. 3 shows a powerful set-up using a chopper and the 78250 to ratio the two channels.

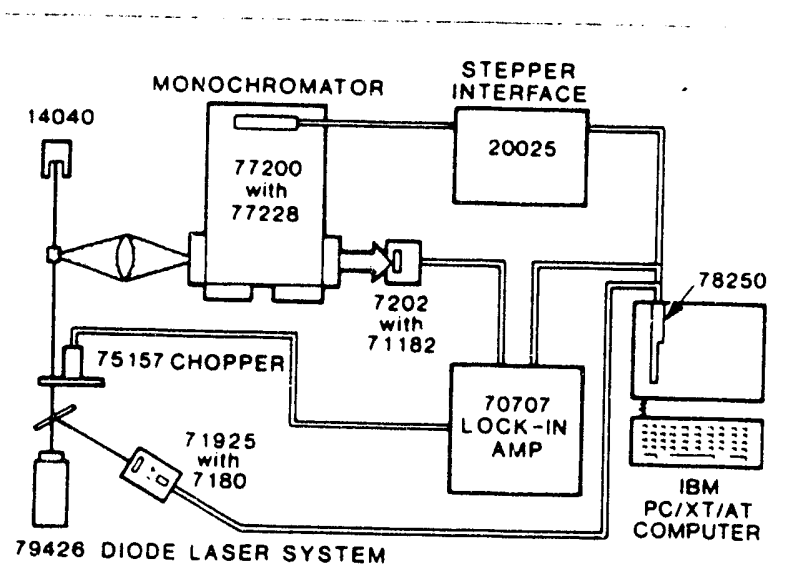

Fig. 2 Measuring near infrared fluorescence using the 79426 Diode Laser System as source, and ratioing the fiuorescence signal to the excitation intensity.

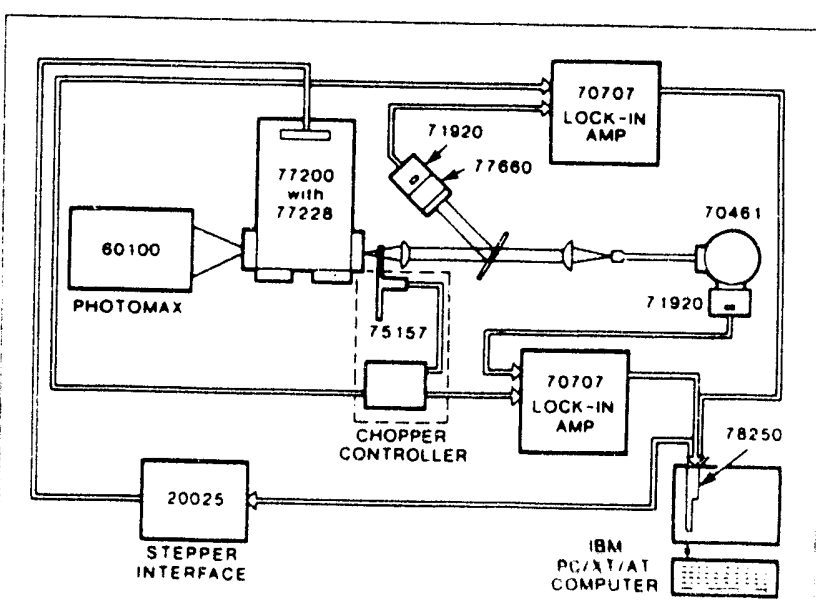

fig. 3 Computer controlled spectral measurement of optical fiber transmission. Two 70707 Lock-in Amplitiers, one for the signal path and oric bor the reference beam, remllus ambient background. 


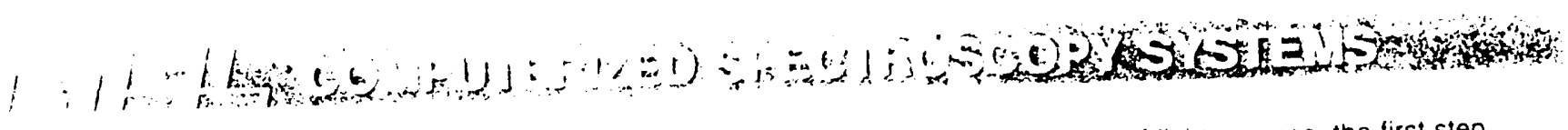

Fig 4 shows a simple but effective radiometer system. The diffuser input to the monochromator is chosen for the particu. lar application.

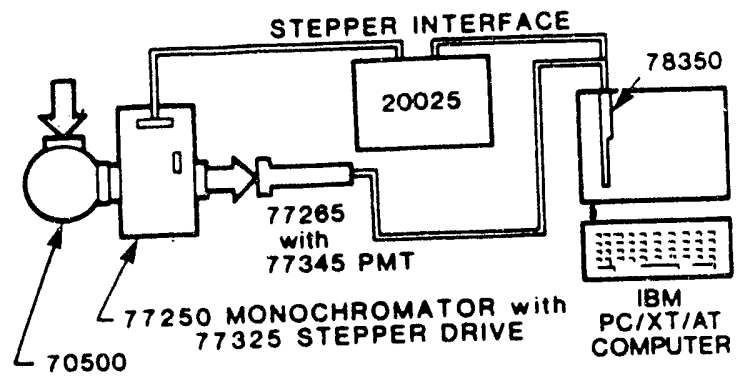

In radiometry or photometry of light sources, the first step is to record a reference or calibration scan. This measures the system iesponse against a known light source. (See page 62 for suitable standard sources). A scan of the unknown light source follows. Both sources should produce similar values of detector signal to remove any uncertainty about system linearity over a wide dynamic range

Our radiometry program is designed so you do not have to scans and divide them afterwards. The program allows you to run a 'Standard' scan of the calibrated lamp. You must supply a file of the calibration values for this lamp. Then by subsequent scans as Radiorietric, the program displays the name of the calibrated lamp file and the number of spectral points which match scan points. Calibration values are interpolated for other points. (If you have too few match. ing points, then the basis of the radiometric values may be suspect.) Data are recorded and plotted as radiometric. as distinct from detector signal, values.

Fig. 4 A radiometer based on the 78350 system uses a single 77250 Monochromator and uses a single multior detector for high sensitivity photomultraviolet. 


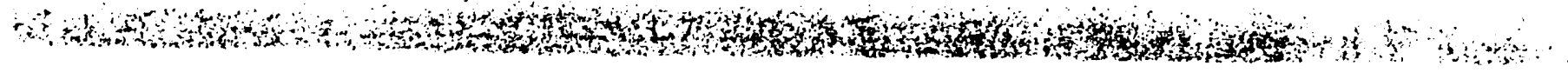

A complete scanning system consists of three main com. ponents:

1. A customized modular spectroscopy system with com ponents selected for the application. Key components include

- Lighi Source (found on pages 14-i05)

- Monochromator(s) with Stepper Drive(s) flound on pages 186-282)

- Stepper Interface (found on page 293)

- Detector(s) (found on pages 296-346)

Contact Oriel Sales Engineers for help in selecting the components.

2. A 78250 Voltage Radiometry Board or 78350 Autoranging Radiometry Board. each of which includes a plug-in card. Software and cables.

3. An IBM PC XXT AT or full compatible with a minimum of 512 kilobytes of memory and a Hercules, CGA, or EGA graphics display screen and optional peripheral graphic plotting devices such as a conventional printer or Hewlett Packard Pen Plotter.

Contact Oriel Sales Engineers for recommended computers or if you wish to order a computer through

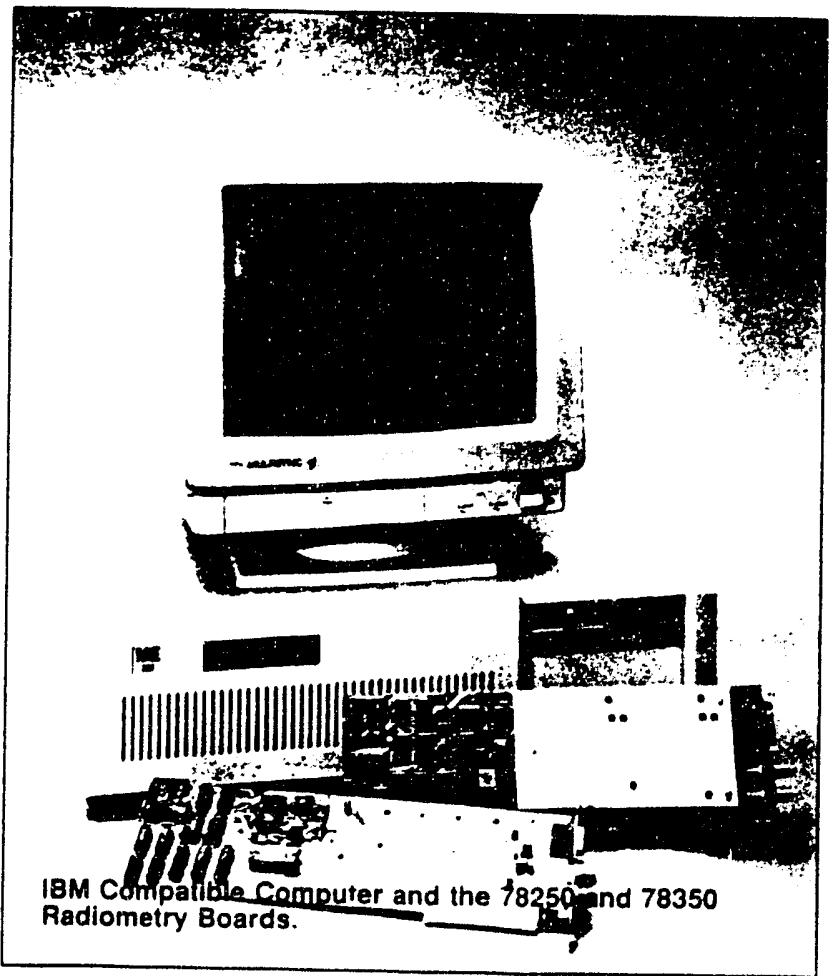

You can find block diagrams of several systems on pages 373 10 382. These do not show detals of light sources. gratings, order sorting filters, or particular photodetectors You should choose these carefully for the spectral range and application of interest.

Contact our Sales Engineers for advice.

\section{CADERING INFORIVILTICIN}

78350 Autoranging Radiometry Board Monitors pholocurrents from pA to mA. includes plug. in board, software for radiometry, fluorescence and absorbance. and cabling to Stepper Interface

78250 Voltage Radiometry Board

Monitors voltages from 0 to $10 \mathrm{~V}$. includes plug-in board. software for radiometery, fluorescence and absorbance. and cabling to Stepper Intertace.
$\$ 2895.00$

.


Fiber optics add a new dimension to Light Research. Their flexibility lets you bend and carry light to inaccessible places Special configurations allow you to reshape beams to match monochromator slits and samples. Mult branch models serve as beam splitters or combiners, or as dual source illuminators.
The varled uses of ther oplics demands a tine of suppont equipment from simple hoiders to precision positioners and mult element imaging lens probes you will find the most comprehensive line of tiber bundles, liquid light guides and support equipment on pages 39610415
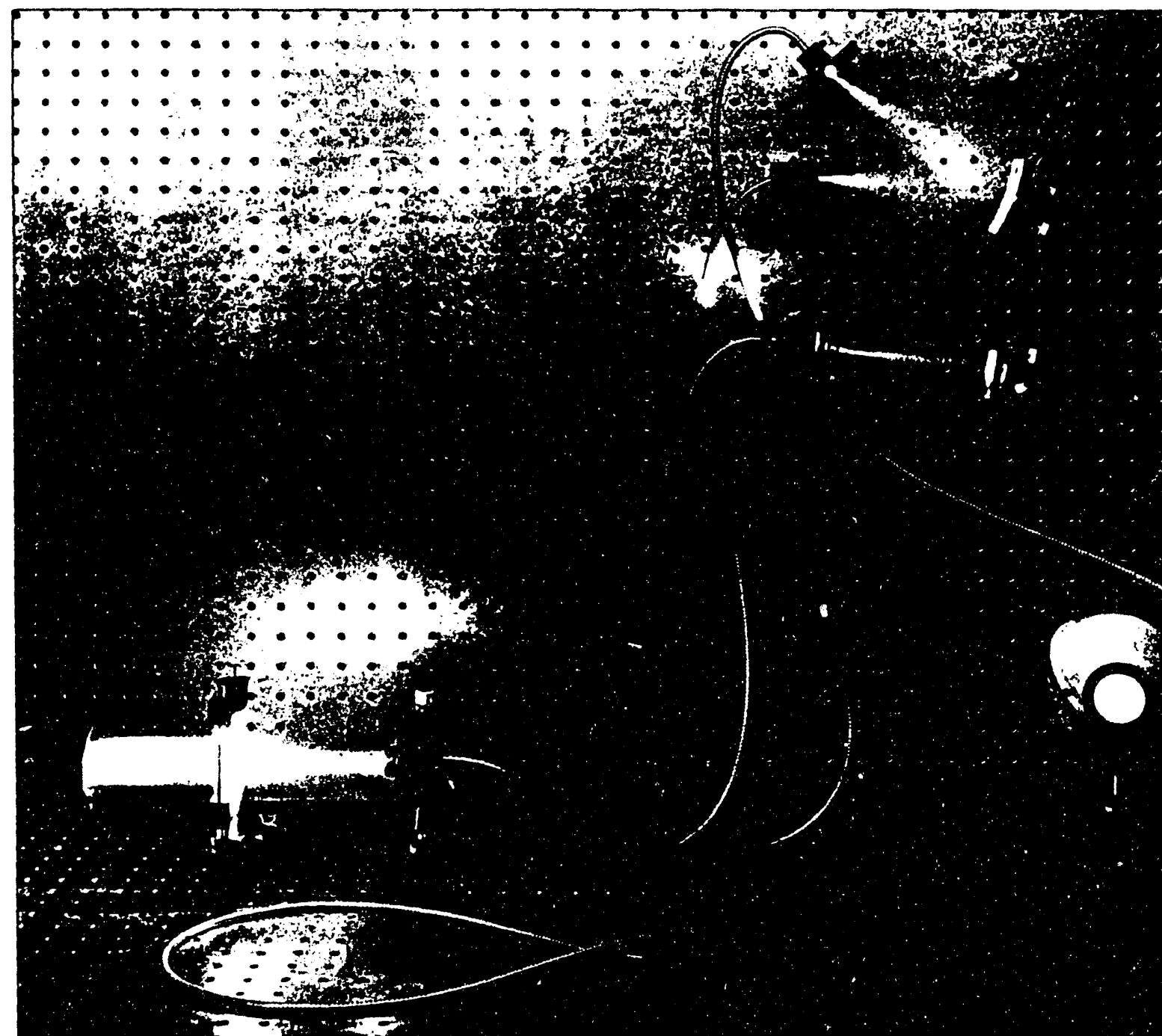

The photograph shows one example of the oplical paths you can create with just orie light source and two bifurcated flber bundles. Integrating spheres add repeatability and meaning to many fiber optic projects. A sphere based measuring system is insensitive to fiber output pattern. 
$C-11 C$ 
NBS TRACEABLE TEMPERATURE CALIBRATION SOURCES

C. 111 


\section{MIKRON 300 SERIES Blackbody Radiation Calibration Sources}

From $-20^{\circ} \mathrm{C}$ to $3000^{\circ} \mathrm{C}$ traceable to NIST

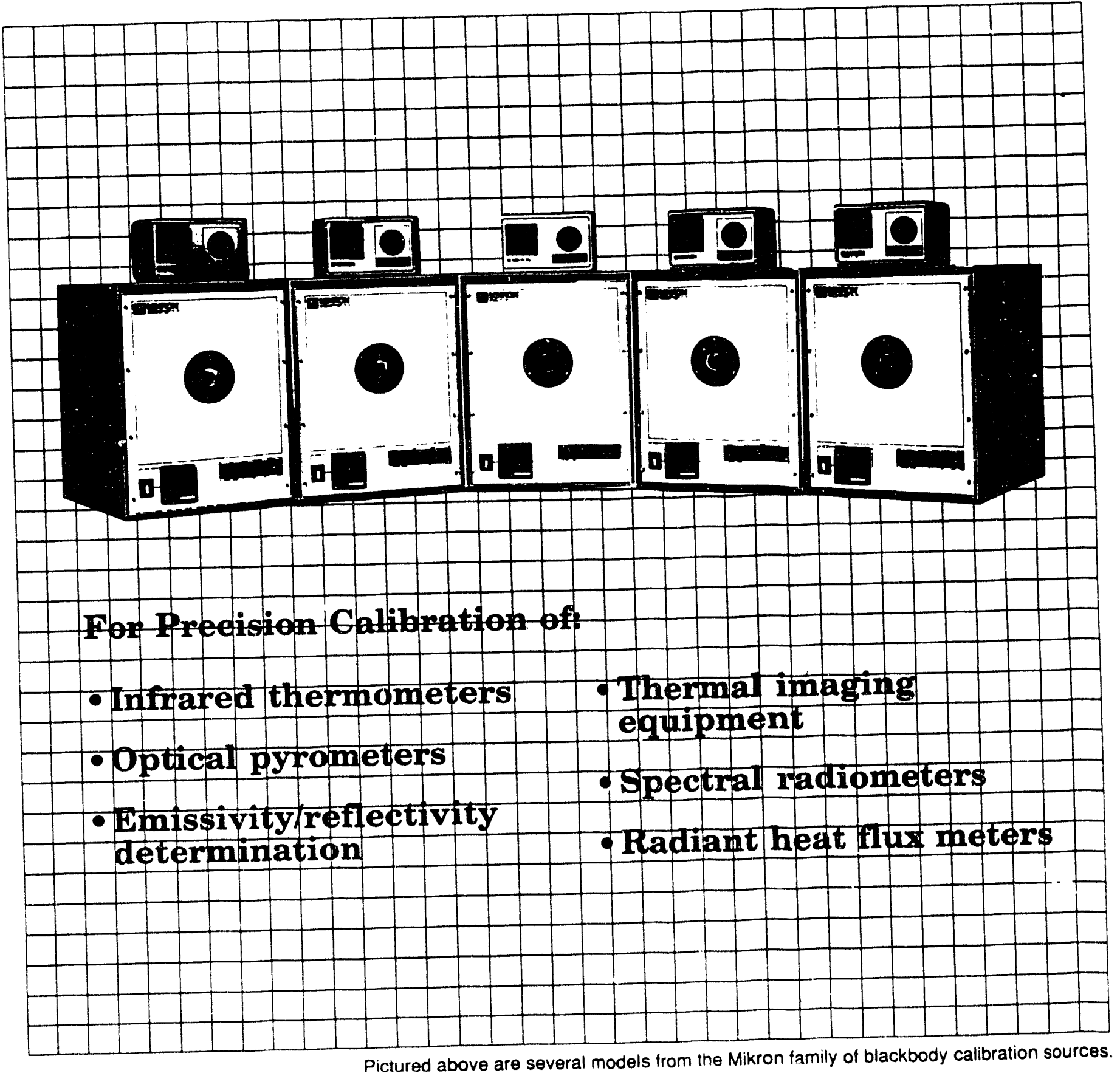




\section{Mikron Blackbody Radiation Calibration Sources}

Mikron has been making blackbody calibration sources since 1970. A tradition of innovation and a wealth of engineering know-how have helped to make Mikron a distinguished name in the field.

The blackbody sources described in this brochure were designed to meet the most demanding calibration standards. They are ideal for checking the accuracy of infrared temperature sensors, spe:trai radiometers, infrared thermal imaging equipment, heat flux meters, etc. These units cover temperature ranges from sub-zero to $3000^{\circ} \mathrm{C}$ and are suitable for calibration requirements in such industries as: ceramic, chemical, petrochemical, environmental control, food, glass, metals, plastics, semiconductor, textile, pharmaceutical, medical, biological and aerospace.

\section{Quality Assurance:}

Reliability is never taken for granted at Mikron. After final assembly, every blackbody source is tested and burned-in for a period of several days and rigorously subjected to thermal cycling and vibration to verify calibration stability before shipment. Every blackbody source has a history file that includes calibration data, production and service information.

\section{MIKRON 340}

The M340 is a portable blackbody calibration source covering the range from sub-zero to $100^{\circ} \mathrm{C}$. The thermoelectric heating/cooling mechanism is utilized to achieve a compact and easy-to-use blackbody source. The M340 has unusually high temperature stability and a stabilization time of only 10 minutes. Source temperature is closely controlled by a selftuning PID controller which displays temperature in a digital readout.

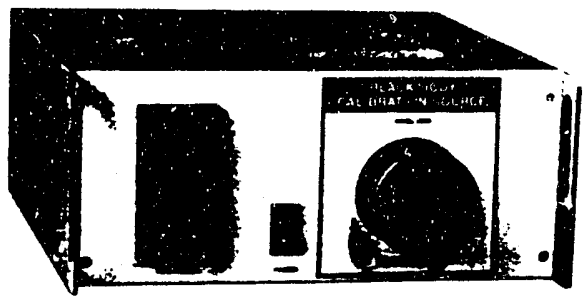

\section{Specifications:}

Temperature Range: -20 to $100^{\circ} \mathrm{C}$ and -14.0 to $199.9^{\circ} \mathrm{F}$

Accuracy: $\pm 0.2^{\circ} \mathrm{C}$

Resolution: $0.1^{\circ} \mathrm{C}$

Stability: $0.1^{\circ} \mathrm{C}$ per 8 hour period Aperture Diameter: $51 \mathrm{~mm}$ (2.0",

Source Non-uniformity: $\pm 0.1^{\circ} \mathrm{C}$

Emissivity: $0.99+.005-0.000$

Temperature Sensor: Platinum RTD
Method of Control: Digital self-tuning PID controller

Stabilization Time: 10 minutes

Operating Ambient Temperature: 5 to $40^{\circ} \mathrm{C}$ ( 40 to $104^{\circ} \mathrm{F}$ )

Power Requirements: $11.5 \mathrm{VAC} \pm 10 \% 50 / 60 \mathrm{~Hz}$ 300w max. (220VAC optional)

Dimensions: $519 \mathrm{~mm} \mathrm{H}$ x $305 \mathrm{~mm} \mathrm{~W}$ x $336 \mathrm{~mm} \mathrm{D}$

Weight: $6.5 \mathrm{~kg}$ (14.5 lbs.)

\section{Optional Features:}

Built-in platinum resistance thermometer standard: Resistance: $100 \mathrm{ohms}$

Accuracy: $\pm 0.1 \%$

RS485 serial communication output

\section{MIKRON 310}

The M310 is a highly compact portable blac.....dy calibration source with a built-in digital indicating controller that can be set at any temperature between ambient and $300^{\circ} \mathrm{C}$. Once set, the source temperature is controlled to within $\pm 0.3^{\circ} \mathrm{C}$ by an internal RTD sensor. The unit has an emissivity of +0.99 .

The M310 is ideal for field maintenance applications since it consumes little power and can be operated from an automotive battery inverter or $\mathrm{AC}$ line voltage.

For applications requiring higher accuracy, the M310 can be supplied with a separate platinum RTD assembly with calibration certificate traceable to NIST.

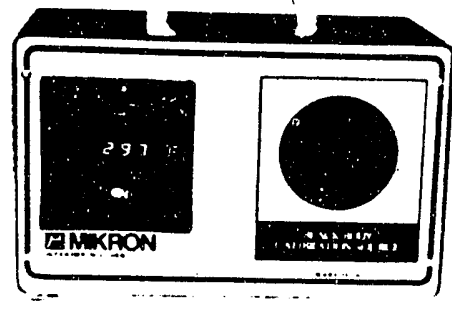

\section{Specifications:}

Temperature Range: (Ambient $+15^{\circ} \mathrm{C}$ ) to $300^{\circ} \mathrm{C}$ or $570^{\circ} \mathrm{F}$

Accuracy: $0.25 \%$ of reading \pm 1 digit

Stability: $0.3^{\circ} \mathrm{C}$ per 8 hour period

Aperture Diameter: $76 \mathrm{~mm}$ (3.0")

Emissivity: $0.99+.005-0.000$

Temperature Sensor: Platinum RTD

Method of Control: Digital PID controller

Warm-up Time: 30 minutes

Operating Ambient Temperature: 0 to $44^{\circ} \mathrm{C}$ (30 to $110^{\circ} \mathrm{F}$ )

Power Requirements: $115 \mathrm{VAC} \perp 10 \%$ 50/60hz 150w max. (220VAC optional)

Dimensions: $178 \mathrm{~mm} \mathrm{H} \times 276 \mathrm{~mm} \mathrm{~W} \times 178 \mathrm{~mm}$ D

Weight: $4.3 \mathrm{~kg}$ ( $9.5 \mathrm{lbs}$.)

Optional Accessories:

Platinum resistance thermometer standard ${ }_{2} \mathrm{C}-114$ 


\section{MIKRON 300}

This blackbody calibration source features a unique uniformly heated spherical cavity with a near ideal emissivity of 0.999 or better. The M300 will deliver any temperature between $100^{\circ} \mathrm{C}$ and $1200^{\circ} \mathrm{C}$. A convenient microprocessorbased, self-tuning digital PID controller holds the selected temperature to within $1^{\circ} \mathrm{C}$ assuring high accuracy calibration of infrared thermometers, thermal imaging equipment, etc. The controller has dual 4-digit display with the lower display indicating the desired set point and the upper display indicating the actual blackbody source temperature.

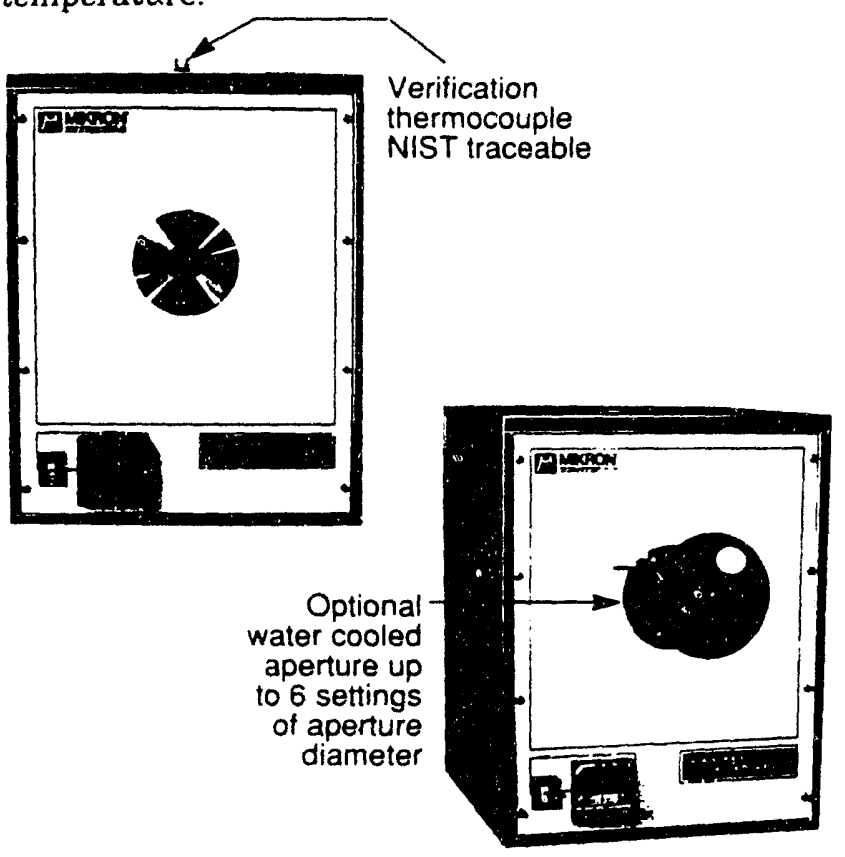

Cavity Heater Life:

Under average usage normally encountered in industry or in the laboratory, cavity heater life is measured in years. A replacement spherical cavity, which is available from stock, can be installed in less than 2 hours. No need to disturb the insulation material since the spherical cavity is pre-assembled inside a stainless enclosure. Supplied complete and ready to operate, the M300 table-top units are easy and convenient to operate. An internal fan keeps the cabinet surfaces at a safe, comfortable temperature.

\section{Specifications:}

Temperature Range: 100 to $1200^{\circ} \mathrm{C}$ and 210 to $2190^{\circ} \mathrm{F}$

Accuracy: $\pm 0.25 \%$ of reading \pm 1 digit

Resolution: $1^{\circ} \mathrm{C}$ or $1^{\circ} \mathrm{F}$

Stability: $0.5^{\circ} \mathrm{C}$ per 8 hour period

Heated Cavity Shape: Spherical

Aperture Diameter: $51 \mathrm{~mm}$ (2.0")

Emissivity: $0.999 \pm .0005$

Method of Control: Digital self-tuning PID controller

Warm-up Time: 1 hour

Operating Ambient Temperature: 0 to $44^{\circ} \mathrm{C}$ (32 to $110^{\circ} \mathrm{F}$
Cooling: Fan cooled, rip inlet on back panel

Power Requirements: 220VAC $\pm 10 \% \quad 50 / 60 \mathrm{~Hz}$ $1.5 \mathrm{kw}$ max. (115VAC optional)

Dimensions: $69 \mathrm{~cm} \mathrm{H}$ x $53 \mathrm{~cm} \mathrm{~W} \times 58 \mathrm{~cm} \mathrm{D}$

Weight: $80 \mathrm{~kg}$ ( 175 lbs.)

\section{Optional Features:}

RS422 serial communication output

Remote analog set point control: 0 to 5 VDC input

\section{Optional Accessories:}

Platinum thermocouple standard - type PT-10

Universal mounting flange

Cold aperture wheel assembly

\section{MIKRON 305}

The M305 blackbody calibration source design achieves significant weight and size reduction over the M300 with only minor sacrifices in specification and performance, making it an ideal unit where portability is required or space is limited. The spherical cavity yields an emissiv:ty of 0.995 over the temperature range of 100 to $1000^{\circ} \mathrm{C}$ with an aperture of $25 \mathrm{~mm}$. An integrally mounted PID controller completes this versatile calibrator.

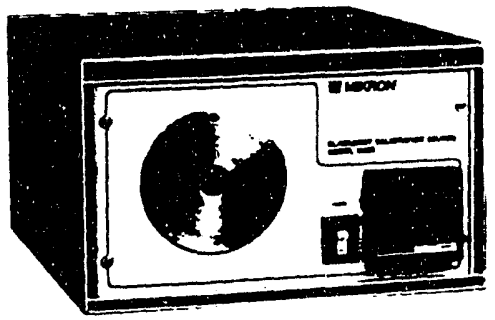

\section{Specifications:}

Temperatire Range: 100 to $1000^{\circ} \mathrm{C}$ and 210 to $1830^{\circ} \mathrm{F}$

Accuracy: $\pm 0.25 \%$ of reading \pm 1 digit

Resolution: $1^{\circ} \mathrm{C}$ or $1^{\circ} \mathrm{F}$

Stability: $1^{\circ} \mathrm{C}$ per 8 hour period

Aperture Diameter: $25 \mathrm{~mm}$ (1.0")

Heated Cavity Shape: Spherical.

Emissivity: $0.995+.0005-.0000$

Sensor: Precision platinum thermocouple

Method of Control: Digital self-tuning

PID controller

Warm-up Time: 15 minutes

Operating Ambient Temperature: 0 to $44^{\circ} \mathrm{C}$ ( 32 to $110^{\circ} \mathrm{F}$ )

Cooling: Fan cooled, air inlet on back panel

Power Requirements: $115 \mathrm{VAC} \pm 10 \% \quad 50 / 60 \mathrm{~Hz}$ $1.0 \mathrm{kw}$ max. (220VAC optional)

Dimensions: $270 \mathrm{~mm} \mathrm{H} \mathrm{x} 430 \mathrm{~mm} \mathrm{~W} \times 370 \mathrm{~mm} \mathrm{D}$

Weight: $25 \mathrm{~kg}$ ( $55 \mathrm{lbs}$.)

\section{Optional Features:}

RS422 serial rommunication output

Remote analog set point control: 0 to 5VDC input

\section{Optional Accessories:}

Platinum thermocouple standard - type PT-10 C -115
Universal mounting flange 


\section{MIKRON 360}

The M360 blackbody calibration source uniquely combines portability with wide temperature range, high emissivity and remarkable resolution. The source and the controller are housed in separate modules which allows the source to be positioned in a location remote from the controller such as in an environmental test chamber, or to be used in tests which involve long path lengths. Each module is fitted with a carrying handle an. can be comfortably carried to manufacturing plant or field research locations.

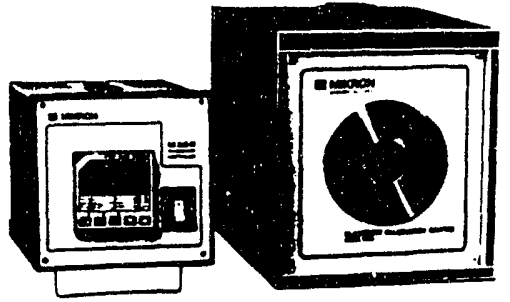

The source is a spherical cavity with a $25 \mathrm{~mm}$ (1.0") dia. aperture. It operates over the 50 to $1100^{\circ} \mathrm{C}$ range with an emissivity of $0.999 \pm 0.0005$ and resolution of $0.1^{\circ}$. The controller is an advanced design with automatic tuning to minimize source stabilization time. It has an optional RS422 communication port for data acquisition and automatic programming of source temperatures by a computer.

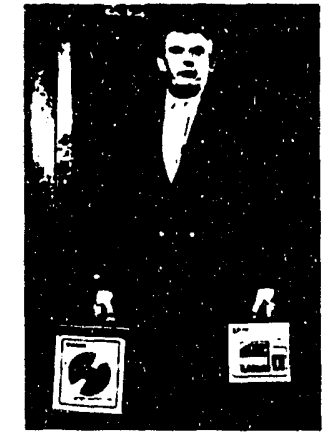

\section{Specifications:}

Temperature Range: Model M360: 50 to $1100^{\circ} \mathrm{C}$ and 200 to $2000^{\circ} \mathrm{F}$; Model M360A: 50 to $750^{\circ} \mathrm{C}$ and 120 to $1400^{\circ} \mathrm{F}$

Accuracy: Model M360: $\pm 0.2 \%$ of reading \pm 1 digit; Model M360A: $\pm 0.05 \%$ of reading $\pm 0.1^{\circ} \mathrm{C}$

Resolution: Model M360: $1^{\circ} \mathrm{C}$ or $1^{\circ} \mathrm{F}$; Model M360A: $0.1^{\circ} \mathrm{C}$ or $0.1^{\circ} \mathrm{F}$

Stability: Model M360: $0.5^{\circ} \mathrm{C}$ per 8 hour period; Model M360A: $0.1^{\circ} \mathrm{C}$ per 8 hour period

Heated Cavity Shape: Spherical

Aperture Diameter: $25 \mathrm{~mm}$ (1.0")

Aperture Solid Angle: $20^{\circ}$

Emissivity: $0.999 \pm 0.0005$

Uniformity of Temperature: To within $\pm 0.1 \%$ of controller setting

Temperature Sensor: Model M360: Thermocouple type S, NIST traceable; Model M360A: Platinum RTD, NIST traceable

Method of Control: Digital self-tuning PID controller

Slew Rate: $10^{\circ} \mathrm{C} /$ minute; Cooling: Fan cooled

Stabilization Time: 10 minutes to within rated accuracy

Operating Ambient Temperature: 0 to $44^{\circ} \mathrm{C}$ (32 tó $110^{\prime} \mathrm{F}$ )

Power Requirements: 115VAC $50 / 60 \mathrm{~Hz}$ $1.0 \mathrm{kw}$ max. (220VAC optional)

Dimensions: Blackbody source: $305 \mathrm{~mm} \mathrm{H} \mathrm{x}$ $273 \mathrm{~mm} \mathrm{~W}$ x $368 \mathrm{~mm}$ D; Controller: $210 \mathrm{~mm} \mathrm{H} \mathrm{x}$
$210 \mathrm{~mm} \mathrm{~W} \times 280 \mathrm{~mm} \mathrm{D}$

Weight: Blackbody source: $15 \mathrm{~kg}$ (33 lbs.); Controller: $5.0 \mathrm{~kg}$ ( $11 \mathrm{lbs}$.)

\section{Optional Features:}

RS422 serial communication output

Remote analog set point control: 0 to 5 VDC input

Optional Accessories:

Platinum thermocouple standard - type PT-10 for M360

Platinum resistance thermometer standard for M360A

Universal mounting flange

Cold aperture wheel assembly

\section{MIKRON 330}

The M330 blackbody calibration source can deliver any temperature between 100 and $1700^{\circ} \mathrm{C}$. A closed end tube with a $25 \mathrm{~mm}$ aperture diameter is heated by Molybdenum Disilicide elements which provide excellent uniformity and a quick heat-up time of only 50 minutes to reach $1700^{\circ} \mathrm{C}$. A self-tuning digital PID controller with adjustable set point holds the temperature to within $1^{\circ} \mathrm{C}$ at $1700^{\circ} \mathrm{C}$, assuring high accuracy calibration. An independent over temperature alarm and cutout system prevents heating element burnout. An internal fan keeps the cabinet surface at a safe, comfortable temperature.

\section{Specifications:}

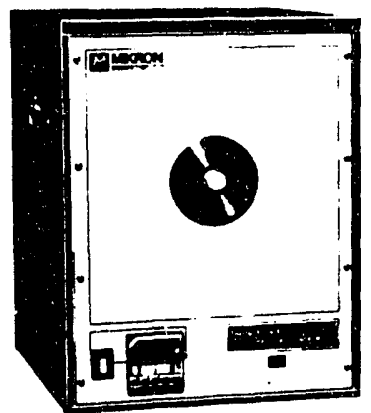

Temperature Range: 300 to $1700^{\circ} \mathrm{C}$ and 572 to $3100^{\circ} \mathrm{F}$

Accuracy: $\pm 0.25 \%$ of reading \pm 1 digit (for temperatures above $600^{\circ} \mathrm{C}$ )

Resolution: $1^{\circ} \mathrm{C}$ or $1^{\circ} \mathrm{F}$

Stability: $1^{\circ} \mathrm{C}$ per 8 hour period

Aperture Diameter: $25 \mathrm{~mm}$ (1.0")

Emissivity: $0.99 \pm .005$

Cavity: Closed end tube $25 \mathrm{~mm}$ ID x $300 \mathrm{~mm}$ long with $125 \mathrm{~mm}$ heated length

Sensor: Platinum thermocouple - type B

Method of Control: Digital self-tuning PID controller

Warm-up Time: To $1700^{\circ} \mathrm{C}$ approx. $50 \mathrm{~min}$.

Operating Ambient Temperature: 0 to $44^{\circ} \mathrm{C}$ $\left(32\right.$ to $110^{\circ} \mathrm{F}$ )

Power Requirements: 220VAC $\pm 10 \%$ $50 / 60 \mathrm{~Hz} 2.0 \mathrm{kw}$ max. (115VAC optional)

Cooling: Fan cooled, air inlet on back panel

Dimensions: $69 \mathrm{~cm} \mathrm{H} \mathrm{x} 53 \mathrm{~cm} \mathrm{~W} \times 58 \mathrm{~cm} \mathrm{D}$

Weight: $80 \mathrm{~kg}$ (175 lbs.)

\section{Optional Features:}

RS422 serial communication output.

Remote analog set point control: 0 t0 $5 \mathrm{VDC}$ input.

\section{Optional Accessories:}

Platinum thermocouple standard - type PT-10

Universal mounting flange

Cold aperture wheel assembly 


\section{MIKRON 370}

The M370 tungsten lamp calibration source features an NIST traceable pyrex enveloped strip lamp and precision DC current source with rate of change limiting controller to protect filament life. This source will deliver any temperature from $800^{\circ} \mathrm{C}$ to $2300^{\circ} \mathrm{C}$ in $1^{\circ} \mathrm{C}$ steps. Pre-aligned apertures provide effortless aiming at the $3 \times 3 \mathrm{~mm}$ active filament area. A microprocessor-based electronic module has memorized the relationship between current and temperature. The emitted radiance intensity of the filament is compensated for the emissivity of the tungsten filament and lamp envelope. This feature eliminates the need for a conversion table. A digital display indicates the lamp absolute temperature.

This convenient source is useful for calibrating two-color infrared thermometers and other single-color thermometers or pyrometers that require small target sizes and high temperatures. The lamp is replaceable in minutes. An internal fan keeps the cabinet surfaces at a safe, comfortable temperature.

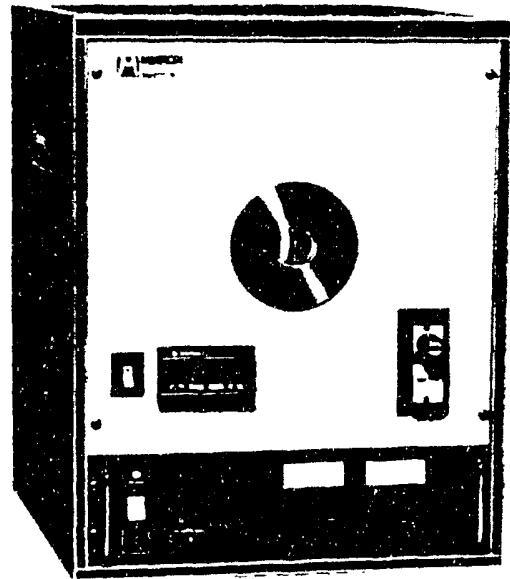

\section{Specifications:}

Temperature Range: 800 to $2300^{\circ} \mathrm{C}$ and 1420 to $4170^{\circ} \mathrm{F}$

Accuracy: $\pm 4^{\circ} \mathrm{C}$ at $2300^{\circ} \mathrm{C}, \pm 2^{\circ} \mathrm{C}$ at $800^{\circ} \mathrm{C}$

Resolution: $1^{\circ} \mathrm{C}$

Stability: $1^{\circ} \mathrm{C}$ per 8 hour period

Source Type: Tungsten filament approximately $33 \mathrm{~mm}$ long and $3 \mathrm{~mm}$ wide with small notch in side of filament

Method of Control: 4 1/2 digit PID controller

Operating Ambient Tenıperature: 0 to $44^{\circ} \mathrm{C}$ (32 to $110^{\circ} \mathrm{F}$ )

Power Requirements: 115VAC $\pm 10 \%$ $50 / 60 \mathrm{~Hz}$ (1200w) max. (220VAC optional)

Dimensions: $69 \mathrm{~cm} \mathrm{H} \times 5.3 \mathrm{~cm}$ W $\times 5.8 \mathrm{~cm} \mathrm{D}$

Weight: $86 \mathrm{~kg}$ ( $190 \mathrm{lbs}$ )

\section{MIKRON:390}

The M390 high temperature blackbody calibrator is without parallel in its capability to produce very high temperature, high emissivity targets and at the same time stabilize at the required temperature within a few minutes of switch-on. The graphite tube target has a $16 \mathrm{~mm}$ diameter. optionally $25 \mathrm{~mm}\left(1.00^{\prime}\right)$ aperture and an emissivity of 0.995 . Target temperature is sensed by a rapid response Mikron infrared fiber optic thermometer which drives a PID controller to regulate the target temperature precisely to the desired value. The controller can: 'ocated up to $7.5 \mathrm{~m}$ from the calibration source $v$ the connecting cable supplied and remote set point setting is achieved via an RS422 communication port.

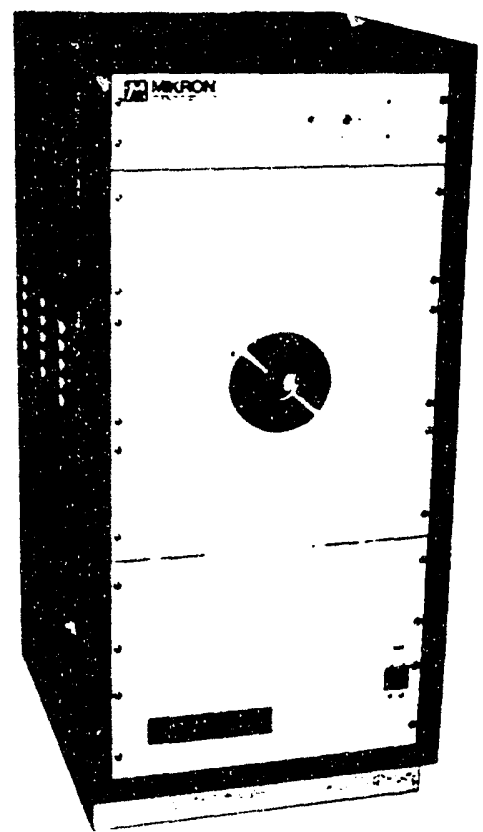

Specifications:

Temperature Range: 600 to $3000^{\circ} \mathrm{C}$ and 1110 to $5430^{\circ} \mathrm{F}$

Accuracy: $0.25 \%$ of reading \pm 1 digit

Cavity. Closed end graphite tube $150 \mathrm{~mm}$ (6.0") long with $64 \mathrm{~mm}\left(2.50^{\prime \prime}\right)$ heated length

Source Diameter: $16 \mathrm{~mm}$ (.625") dia.; $25 \mathrm{~mm}\left(1.0 n^{\prime}\right)$ optional

Emissivity: $0.995 \pm .003$

Cooling: Water cooled, hose connections on rear, $12 \mathrm{lpm}+3 \mathrm{gpm}$ !

Heating Element Type: Graphite tube nitrogen gas purge. $80 \mathrm{lph}(3 \mathrm{cth})$

Temperature Sensor: Mikron "Infraducer"

Method of Control: Digital PID controller

Remote Set Point: RS422 serial communication output

Warm-up Time: Room to $2500^{\circ} \mathrm{C}$ approx. 5 minutes

Interconnecting Cable: $7.5 \mathrm{~m}(25)$ ) long

Operating Ambient Temperature: 0 to $44^{\circ} \mathrm{C}$ i32 to $110 \mathrm{~F}$

Power Requirements: 240VAC, $12 \mathrm{kw}$

Dimensions: $11.3 \mathrm{~mm} \mathrm{H} \times 559 \mathrm{~mm}$ W $\times 622 \mathrm{~mm} \mathrm{D}$

Weight: Approx $182 \mathrm{~kg} 400 \mathrm{lbs} .1$ 
Description of Gptional Acemsories:

Placinum Thermocouple Standard: The Mikron verification thermocouplo standard is a platinum vs. platinum 10 ; rodian ifr-io: thermocouple conforming dosely to 16 [ RPlowe. This thermocouple assembly an hated anto the spherical cavity through a special ofermme at the top of the M300 or thromgh onenine of uher models it contains excep tional measurng accurey. folluwing the published IPIS 68 curve to whthe 0 ? of reading. In addi. tion, an indidual calibration certificate with $100^{\circ} \mathrm{C}$ incremental datia trateable No NIST is supplied. The thermocouple assembly is approximately $33 \mathrm{~cm}$ (13") long with an inmersin lerigth of $25 \mathrm{~cm}\left(10^{\circ}\right)$. For storage, an attractive vet sturdy wooden box with a thinged cover and foam packmg will pro tect the thermocuuple from demage and con tamination. To order specify PN 12341

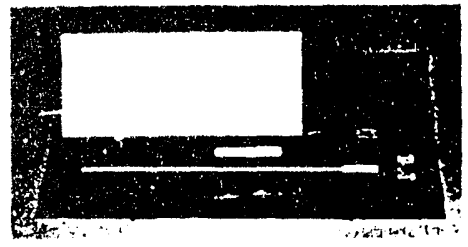

Kesistance Thermometer Standard: The Mikron resistance thermometer is a PT.100 conforming to NIs' and DIV 43760 . It has exceptional accuracy $0.2^{\circ} \mathrm{C}$ and stability. The four internal leads are fine goid and the protectue tube is nickel. The four external lead wires are

hermeticalls saled

from the inot

chamber of the

thermometer. To

order specify

PN 1419 :

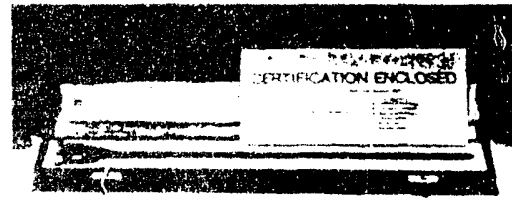

Cold Aperture Whe Assembly: Frequently used in application requining, smaler radiating apertures or verifying lleld of view of infrared thermometers, radioneters or infrared imaging equipment.

Watey or gas cooling capainh. ties of this assernbly ensure minimum contribution of back ground radiation. Precision machining of aperture wheed allows perfect optical itignment.

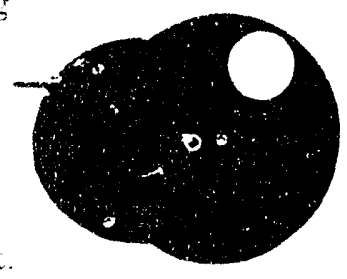
Turdes specty
PNianog?
Aperture Size
$P N: 11+\cdots 1$
$5 . \mathrm{mm} .25 \mathrm{~nm} .13 \mathrm{~mm} .6 \mathrm{~mm}$, 3inm and $2 \mathrm{~mm}$
L6mm 13rm. $10 \mathrm{~mm}, 8 \mathrm{~mm}$ inim and $3 \mathrm{~mm}$

Universal Mounting flange: Thus nange has been machined anth numerum mounting holes to accept

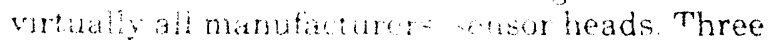
stand-offs provide a ale ance between the sensor

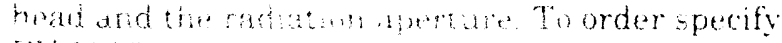
2.: 1. 16rik

\section{CLSTONI MODELS}

The blackbody calibrator specifications in this catalog describe standard, production instruments used routinely in industrial process, medical and research environments. However, with the increasing application of infrared measurement technology in the electronics, aerospace and other demanding fields, the need for special blackbody sources has grown commensurately. Mikron has been able to respond to even the most esoteric requirements, including airborne systems, large area sources, ultra-high resolution calibrators and systems to operate in a vacuum. A selection of these non-standard instruments is illustrated here and we will be pleased to receive your specifications with a view to offering a proposal to meet your special requirements.

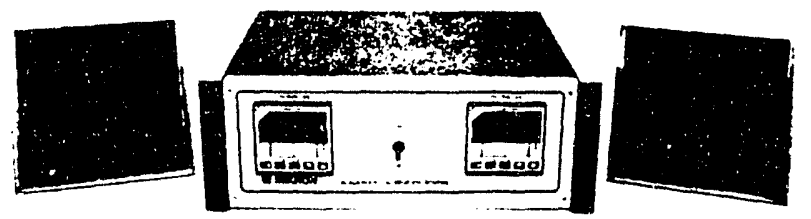

Dual large area low temperature blackbody source

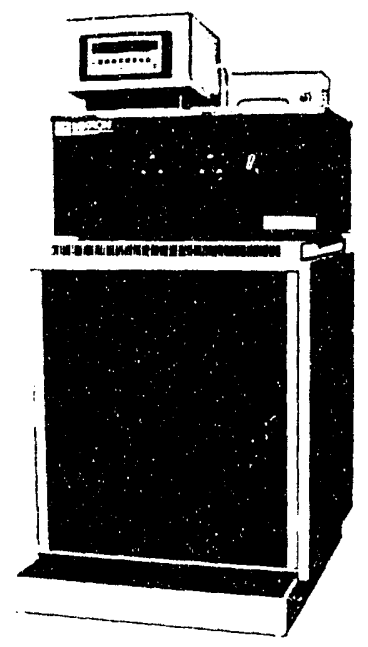

Ultra precision dual independent cavity blackbody source: $0.01^{\circ} \mathrm{C}$ resolution and stability, $0.02^{\circ} \mathrm{C}$ absolute accuracy; temperature range: 0 to $100^{\circ} \mathrm{C}$

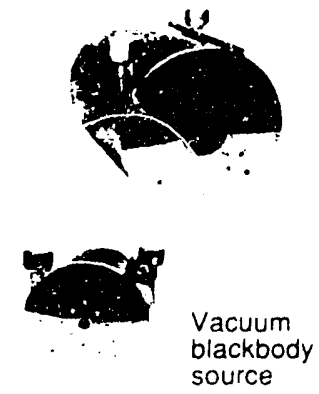

Warranty:

Every blackbody source is covered for all defective material and workmanship for one full year after shipment. Heating elements are excluded from this warranty.

\section{Made in C.S.A.}

The 300 Series is designed and built by Mikron, the leading innovator in infrared thermometry. Manufac. turing facility is located in Wyckoff, New Jersey.

\section{EI MIKRON}

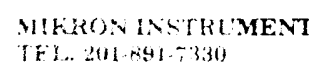

COMPANY, INC., 445 W. Main St., Wyckoff. New Jersey 07481 U.S.A. TELEX: 361870 FAX: 201.891 .1205 

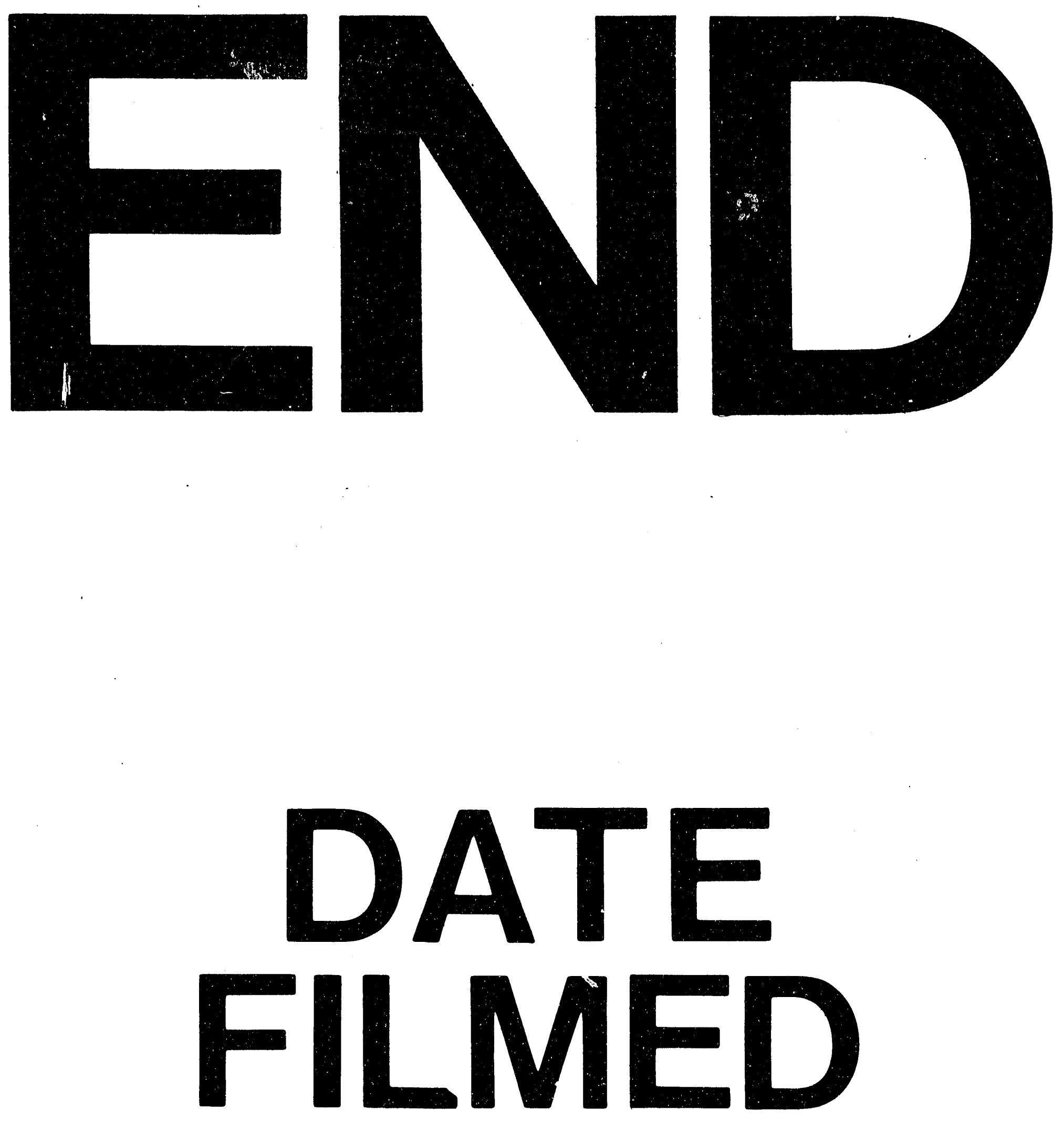

7

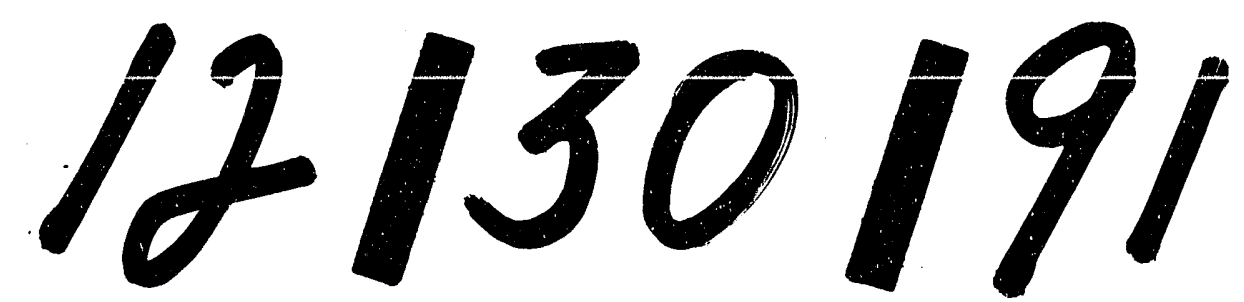


$\overline{\bar{E}}$ $\underline{\underline{z}}$ 